\title{
Aspects of the petrology and geochemistry of the Huckleberry Ridge Tuff, Yellowstone
}

\author{
Elliot James Swallow
}

A thesis submitted to Victoria University of Wellington in partial fulfilment of the requirements for the degree of Doctor of Philosophy in Geology

Victoria University of Wellington,

School of Geography, Environment and Earth Sciences

Wellington, New Zealand

June 2018

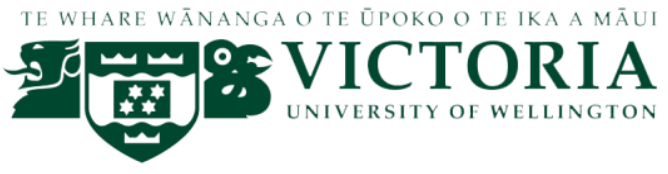




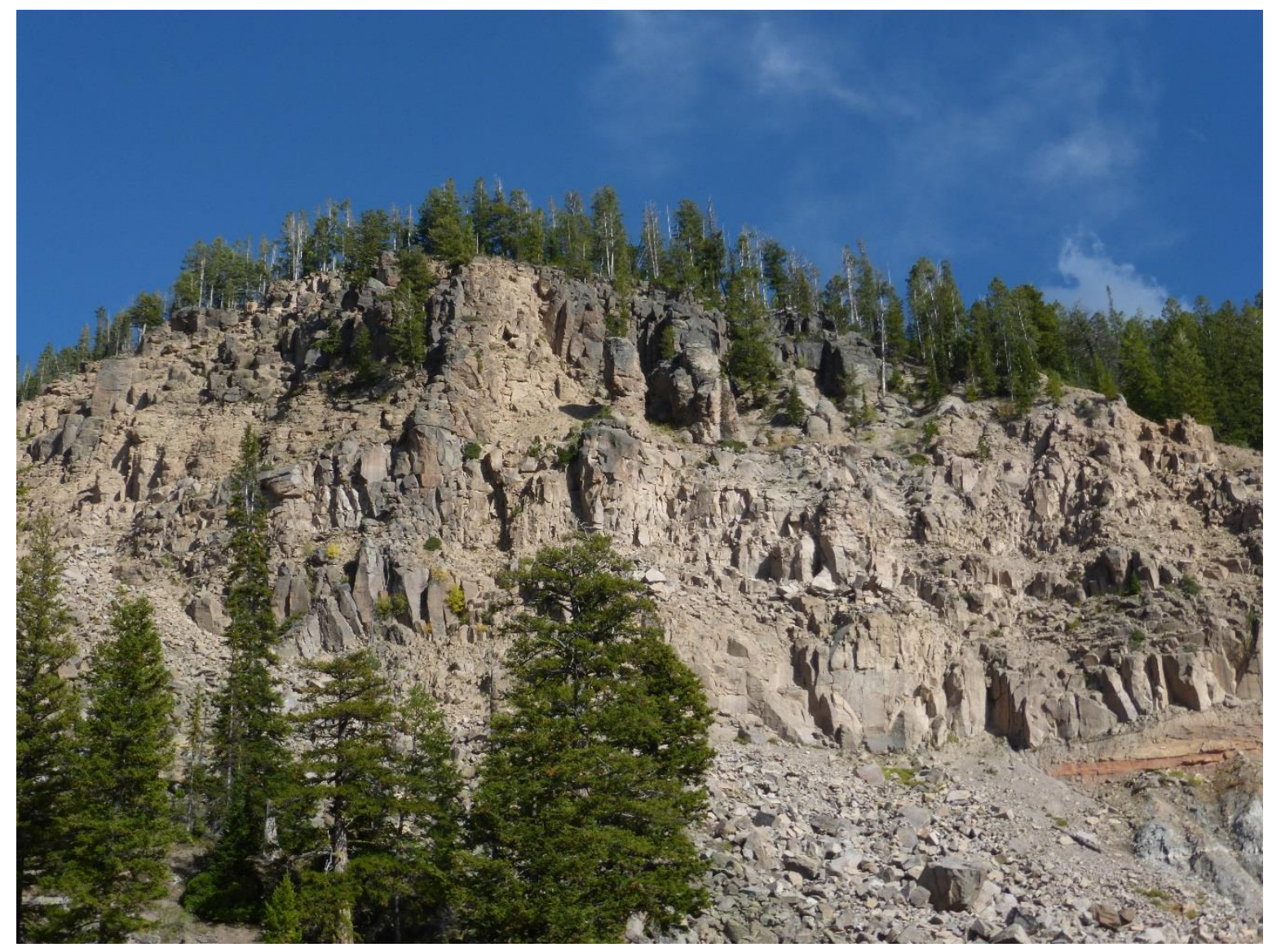

Frontispiece: Photography of Huckleberry Ridge, Wyoming, U.S.A, the type locality of the Huckleberry Ridge Tuff. 
To Edwin, my alter ego

and constant companion 


\section{Abstract}

Silicic (i.e. dacitic-rhyolitic) magmatic systems have the potential to generate large, explosive caldera-forming eruptions which have global effects and consequences. How, and over what timescale, magma accumulates and is stored in the upper crust are key aspects in understanding such systems and their associated hazards. The absence of such eruptions in the historical record, however, has forced understanding of these systems to be developed through numerical models or the study of the deposits in the geological record. Numerical models primarily focus on the long-term generation but instantaneous eruption of single magma (i.e. melt-dominant) bodies. In contrast, the stratigraphic and geochemical nature of eruption deposits often show features more consistent with complex magmatic systems comprising multiple melt-dominant bodies that may have formed rapidly but erupted episodically. Further studies of past eruption deposits are valuable, therefore, in reconstructing silicic magmatic systems and highlighting the nature of melt-dominant body generation and storage.

To this end, this thesis examines the $2.08 \mathrm{Ma}, \sim 2,500 \mathrm{~km}^{3}$ Huckleberry Ridge Tuff (HRT), Yellowstone Plateau volcanic field (YPVF), U.S.A, the deposit of the first and largest of three caldera-forming eruptions in the YPVF. The HRT comprises an initial fall deposit followed by three ignimbrite members ( $A, B$ and $C$ ) with a second fall deposit between members $B$ and $C$. Despite emanating from an archetypal silicic volcanic field, minimal previous work has been undertaken on the geochemical nature of the HRT but it is thought to conform to traditional, unitary magma body ideas. A revised stratigraphic framework, detailing an episodic and prolonged initial fall deposit, identification of a weeks-months time gap between members $A$ and $B$, and a similar but longer years-decades hiatus in activity between members $B$ and $C$ provides the context for this geochemical investigation. A large sample suite representative of the diverse range of physical characteristics of clasts and material found in the HRT was analysed. In situ micro-analysis of matrix glass (major and trace elements) and crystals (major elements) in the initial fall deposit are coupled with major and trace element, and isotopic compositions of single silicic clasts (i.e. pumice/fiamme) from all three ignimbrite members, supplemented by in situ analysis of their crystals and groundmass glass. These data are used to reconstruct the silicic magmatic system. Furthermore, major and trace element, and 
isotopic compositions of rare mafic (i.e. basaltic to andesitic) material found in members $A$ and B provide an insight into the thermal and chemical drivers of HRT silicic volcanism.

This macro- and micro-analytical investigation using multiple techniques reveals remarkable complexity within the large-scale HRT magmatic complex. Four geochemically distinct magmatic systems are differentiated on single clast elemental and isotopic characteristics that are further reflected in crystal and glass compositions. Two of these systems ( 1 and 2 ) were active in the initial fall deposit and member A. Magmatic system 1 is volumetrically dominant in the HRT and is characterised by moderate-high Ba single clast (450-3540 ppm) and glass (100-3360 ppm) compositions, in contrast to the distinctly low-Ba ( $\leq 250$ ppm single clast, $<65$ ppm glass Ba contents) magmatic system 2 . Both these magmatic systems exhibit clustered glass compositions, indicating multiple, laterally-adjacent meltdominant bodies were present, and shared moderate isotopic compositions (e.g. ${ }^{87} \mathrm{Sr}^{86} \mathrm{Sr}_{\mathrm{AC}}=$ 0.70950-0.71191) are explicable by a multi-stage partial melting-fractional crystallisation petrogenesis. The time break between members $A$ and $B$ is associated with mixing and mingling within magmatic system 1 , related to a renewed influx of mafic material, and a cessation of activity of system 2 , which is absent from member $B$. The time break between members $B$ and $C$ reflects significant changes within the magmatic complex. Magmatic system 2 is rejuvenated and melt-dominant bodies associated with two new magmatic systems (3 and 4) are formed, with at least system 3 comprising multiple bodies. These latter two magmatic systems strongly differ in their elemental characteristics (system 3: high $\mathrm{SiO}_{2}[75-$ $78 \mathrm{wt} \% \mathrm{SiO}_{2}$ ]; system 4: dacite-rhyolite [66-75 wt\% $\left.\left.\mathrm{SiO}_{2}\right]\right)$. Despite this, they have similar and highly radiogenic (e.g. ${ }^{87} \mathrm{Sr} /{ }^{86} \mathrm{Sr}_{\mathrm{AC}}=0.72462-0.72962$ ) isotopic compositions indicating shared extensive incorporation of Archean crust. They also contrast in their relation to mafic compositions, with system 4 associated with olivine tholeiitic compositions erupted prior to and following the HRT in the YPVF. In contrast, system 3, like systems 1 and 2, is associated with high-Ba, high-Zr mafic compositions found co-erupted in HRT members A and B. These compositions are similar to lava flows erupted further west at the Craters of the Moon field, and are interpreted as representing partial melts from regions in the lithospheric mantle enriched by high-T, P fluids emanating from the subducted Farallon slab.

Overall, the HRT magmatic complex was remarkably heterogeneous. Two contemporaneous mafic root zones drove four silicic magmatic systems, episodically active throughout the eruption. At least three of these systems comprised multiple laterally- 
adjacent melt-dominant bodies. Intra-eruption time breaks are associated with broad-scale reorganisation of the magmatic complex. This complexity highlights the utility of a detailed, systematic, multi-technique geochemical investigation, within a stratigraphic framework, of the deposits of large silicic caldera-forming eruptions, and breaks new ground in the understanding of such systems. 


\section{Acknowledgements}

Many others have contributed to and enriched my experience during my PhD. Firstly, I extend sincere thanks to my supervisors. Colin, it has been an honour working under and with you for the past few years. Your enthusiasm, dedication and passion know no bounds and have continually driven me on. Thank you for your continued support, providing numerous opportunities for me to travel and develop, trusting in me as a student and giving me the responsibility to tackle such an amazing topic. I hope I have repaid that faith. John, your continued support and words of encouragement have been greatly appreciated and I look back fondly on moments sharing beer, coffee or a rugby discussion with you.

My academic development would not have been as varied and as rigorous without the notable contributions of several colleagues. Bruce Charlier taught me the wondrous world of isotopes with an unparalleled care and enthusiasm. I would also like to thank lan Schipper, Dan Sinclair and Monica Handler for their time and efforts introducing me to the analytical methods and equipment that form the basis of this thesis. Also deserving of thanks are Julie Vry for thesis-changing discussions and Patricia Stein for helping me through my tenure. A Commonwealth Scholarship and VUW FSRG provided financial support for this project.

My post-graduate colleagues have made this an incredibly enjoyable experience. Firstly to my american PhD half-sister Madison. Thank you for showing me the delights of Oregon, being a sounding board for ideas (often over a beer) and a friend throughout this project. I hope our paths cross again soon. Closer to home, there are lots of SGEES students, past and present, who I am very grateful to for their friendship and guidance. Namely, but not limited to: Ben, Celine, Chris (Condor), Chris (Kraus), Fran, Hannah, Jenni, Jürgen, Kate, Katie, Katy, Leo, Loretta, Marcel, Matt, Melissa, Sam, Sandra, Shane (the Boy), Shaun, Simon, Tom and Valerie. It has been a pleasure spending the last few years with you. I also want to thank the Technical Team, particularly Jane, Kosta and Luisa, for not only ensuring lab work ran as smoothly as possible but also for welcoming me into the fold and your friendship.

Finally I want to thank my wonderful family (Mum, Dad, Guy, Ben, Claire and Bessie) for their amazing support and love throughout. But special thanks go to my best friend, Lou. Your constant love, support and encouragment, from near or from afar, has been a great source of strength. I am delighted we are in the same place as this chapter ends. I am so excited for the next adventure to begin. 


\section{Table of Contents}

Title page.

Frontispiece ii

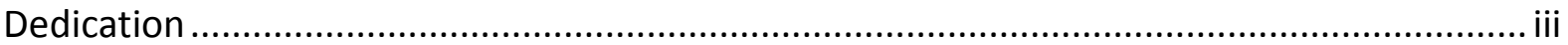

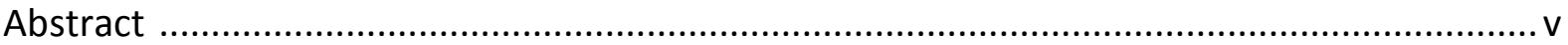

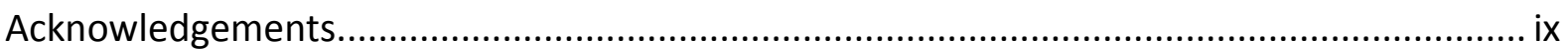

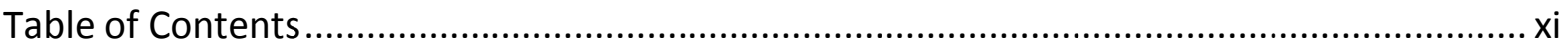

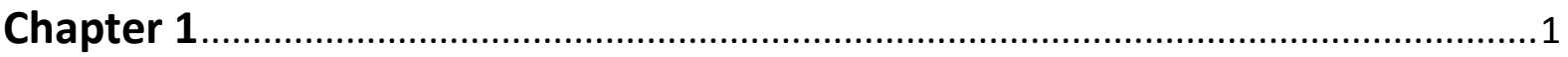

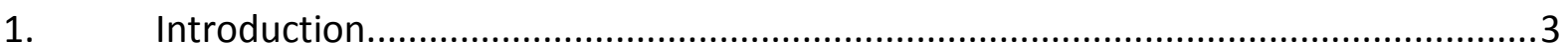

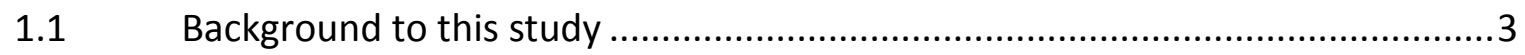

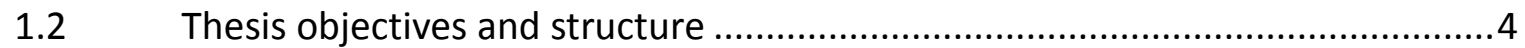

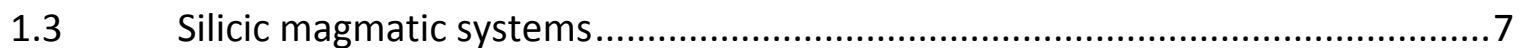

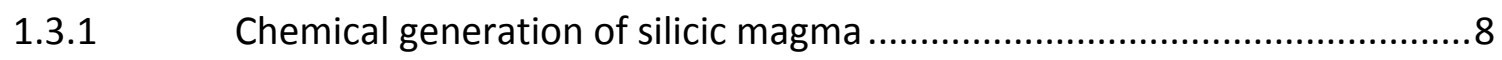

1.3.2 Physical generation of a melt-dominant magma body .............................

1.3.3 Growth of large eruptible magma bodies and eruption triggering............11

1.3.4 The diversity of natural systems from eruption deposits ........................13

1.3.5 The role of mafic magma in silicic magmatism .........................................17

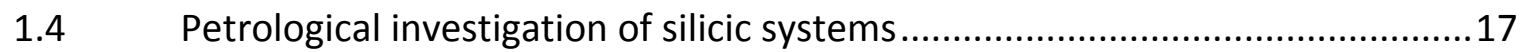

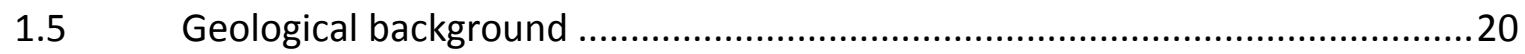

1.5.1 Yellowstone Plateau volcanic field .......................................................20

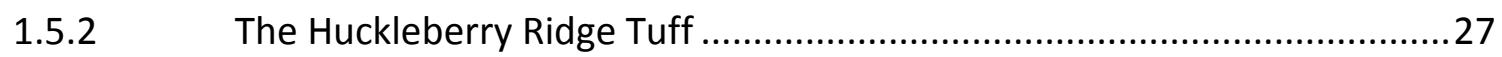

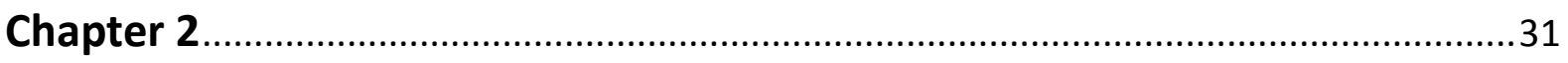

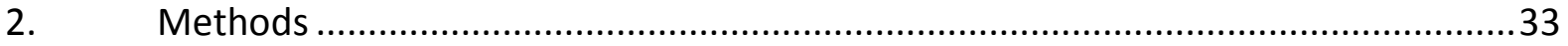

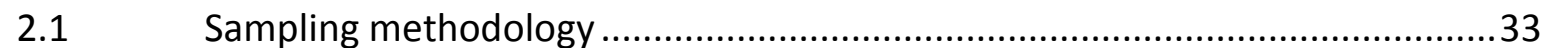

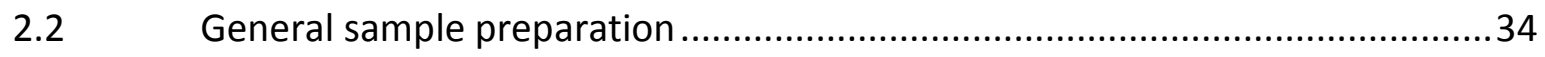

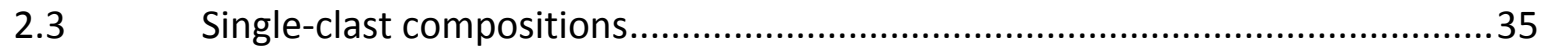

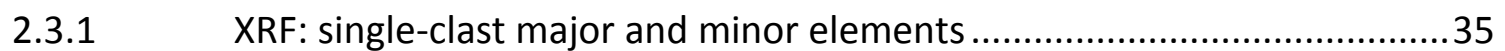

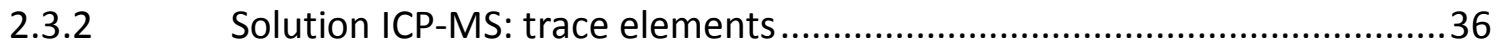




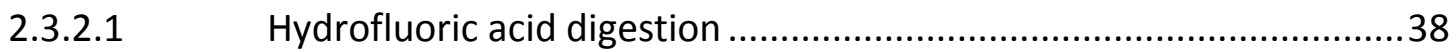

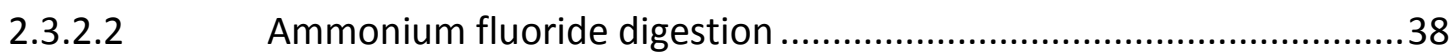

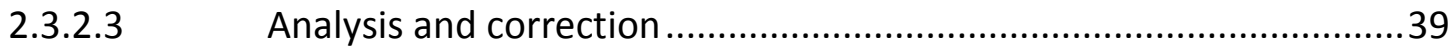

2.3.3 Sample preparation for isotope ratio measurements..............................43

2.3.4 Isotope ratio mass spectrometry ….........................................................46

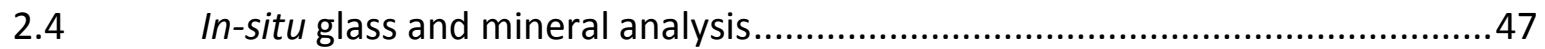

2.4.1 Electron Probe Micro-analysis (EPMA): major and minor elements .........47

2.4.2 Laser ablation (LA-ICP-MS): trace elements ......................................... 48

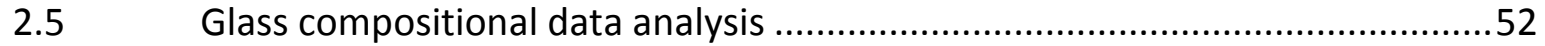

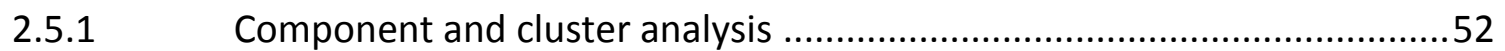

2.5.2 Estimation of analytical uncertainties ................................................... 53

Chapter 3

3. Evacuation of multiple magma bodies and the onset of caldera collapse in a supereruption, captured in glass and mineral compositions ...................................57

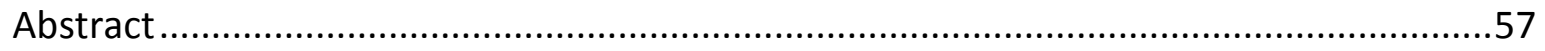

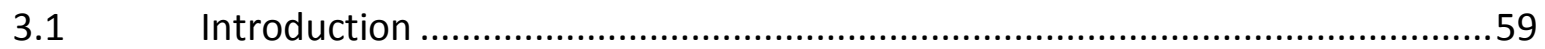

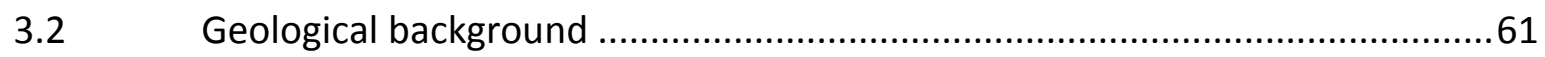

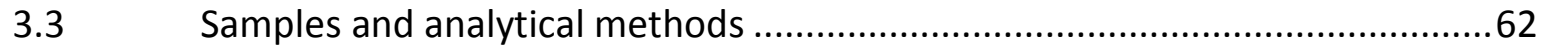

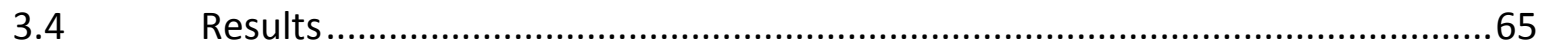

3.4.1 Major element compositions of glasses and feldspar.............................65

3.4.2 Trace element compositions of glassy materials ...................................66

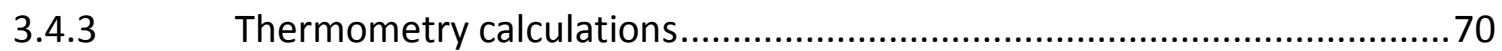

3.4.4 Plagioclase-melt hygrometer............................................................. 71

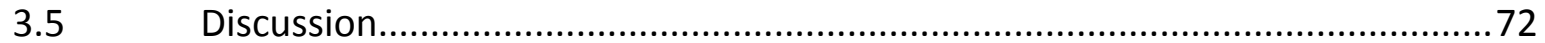

3.5.1 Clustering of melt compositions: controls and significance........................72

3.5.2 Modelling of compositional trends ..................................................... 76

3.5.3 Pre-eruptive state of the Huckleberry Ridge magmatic system ................77

3.5.4 The HRT magma body: configuration and early evacuation ......................79

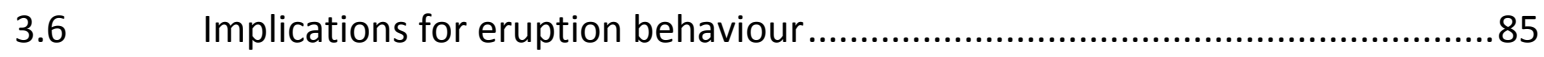

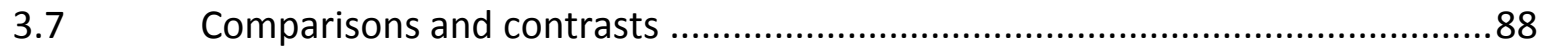


Chapter 4

4. Mafic inputs into the rhyolitic magmatic system of the 2.08 Ma Huckleberry Ridge

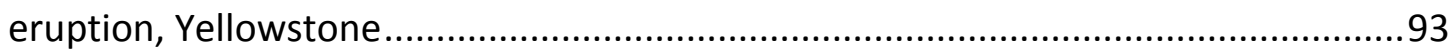

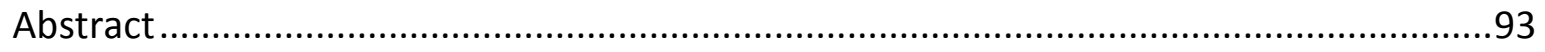

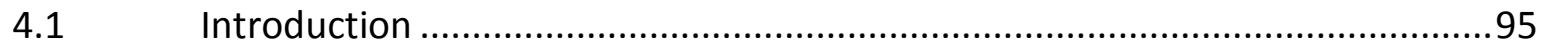

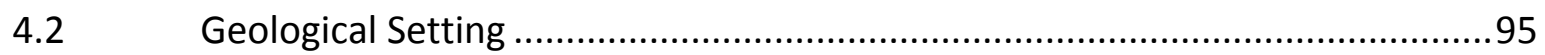

4.2.1 Yellowstone and the Snake River Plain ...................................................95

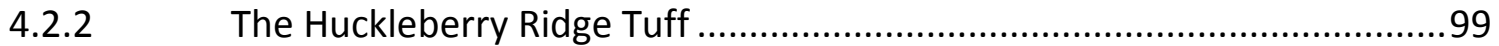

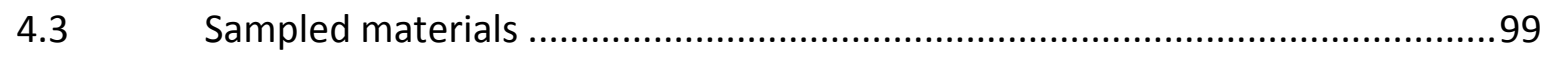

4.3.1 Suite 1: HRT mafic materials...............................................................

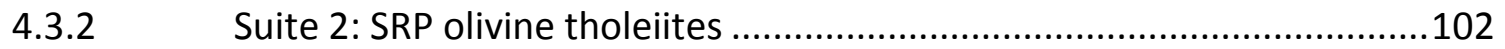

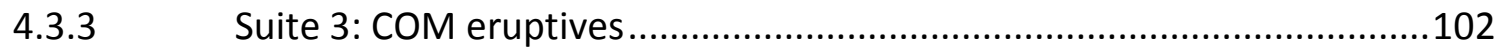

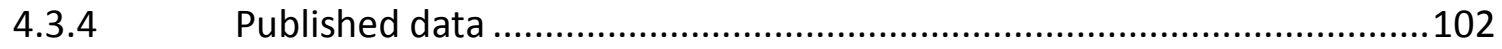

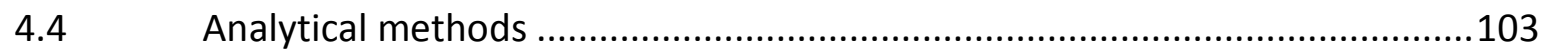

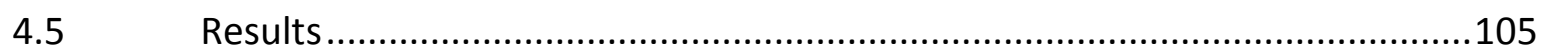

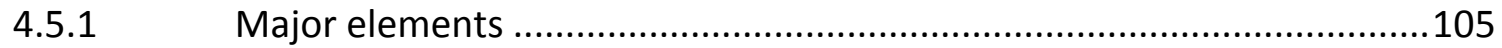

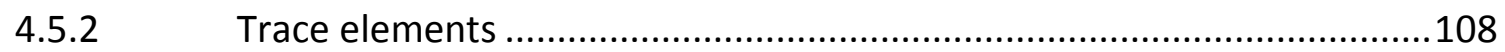

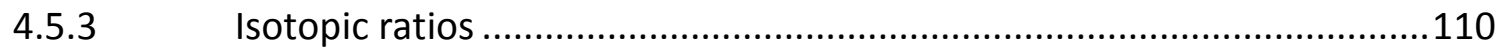

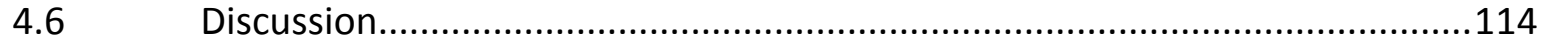

4.6.1 The context of the HRT mafic magmas ...................................................114

4.6.2 Generation of the parental magma for the Suite 1 HRT mafic compositions

4.6.2.1 Fractional crystallisation ...............................................................116

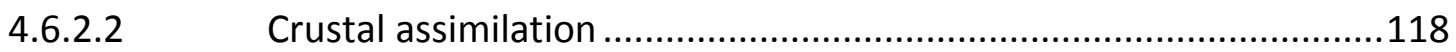

4.6.2.3 Depth/degree of partial melting ...................................................121

4.6.2.4 Enrichment of the mantle source ................................................... 123

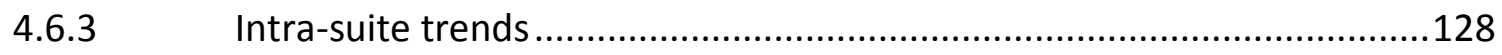

4.6.4 Comparisons and contrasts with the Craters of the Moon lava field ......130 
Chapter 5 .

5. The Huckleberry Ridge Tuff, Yellowstone: evacuation of multiple magmatic systems in a complex episodic eruption

Abstract........

$5.1 \quad$ Introduction 139

$5.2 \quad$ Geological background 142

5.2.1 Yellowstone Plateau Volcanic Field . .142

5.2 .2 Huckleberry Ridge Tuff . .145

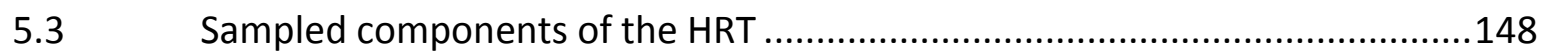

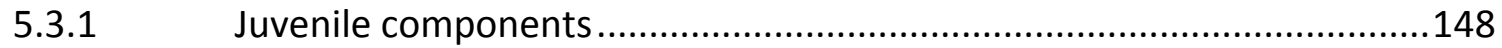

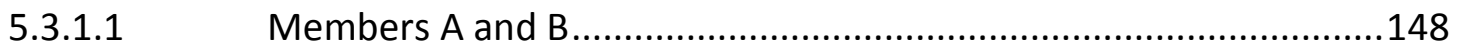

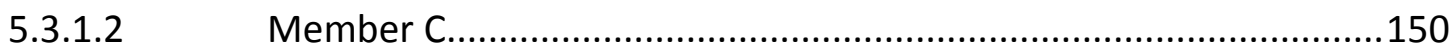

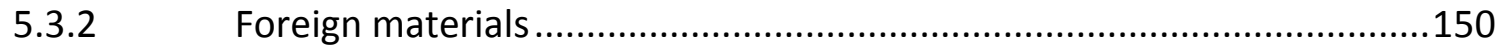

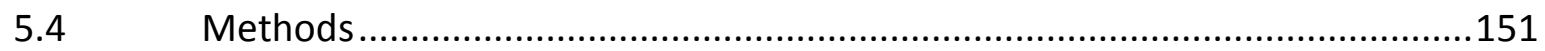

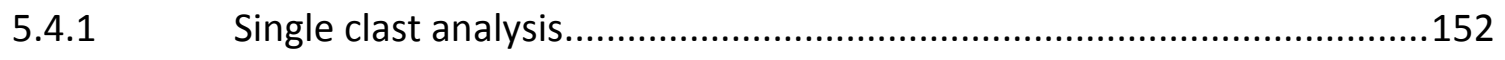

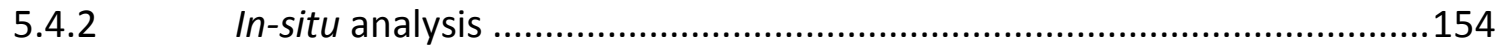

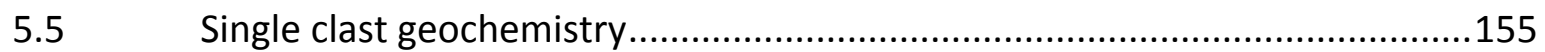

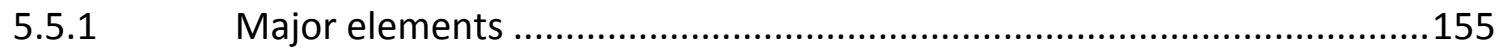

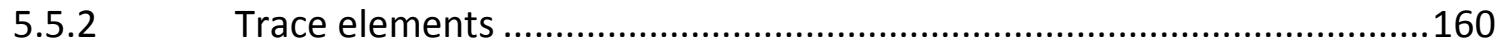

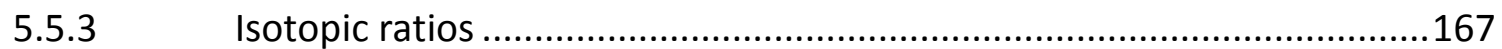

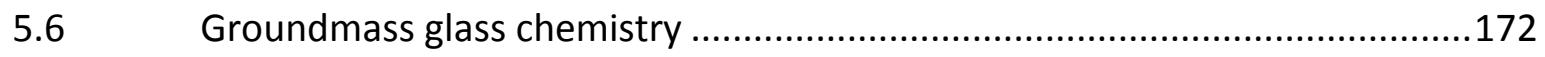

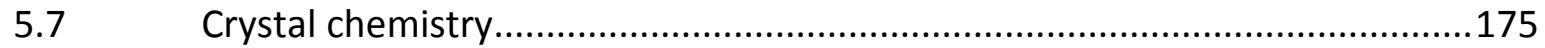

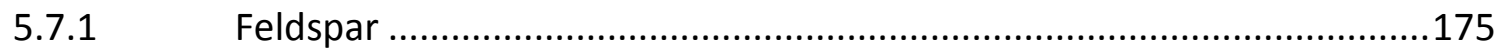

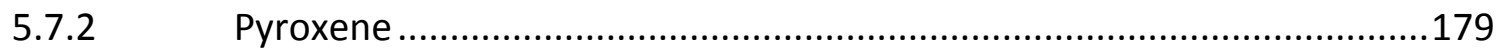

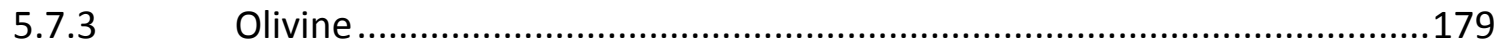

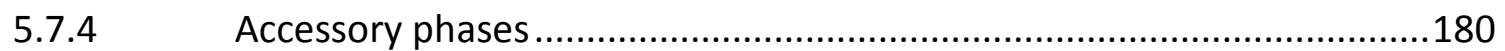

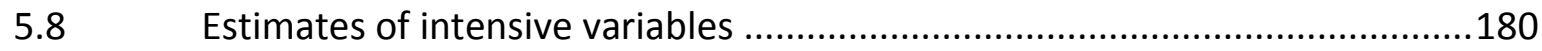

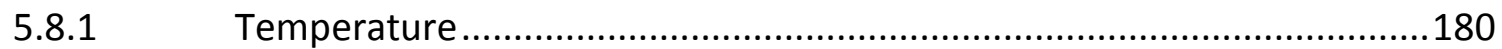




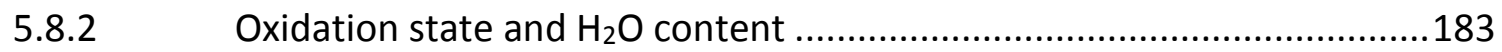

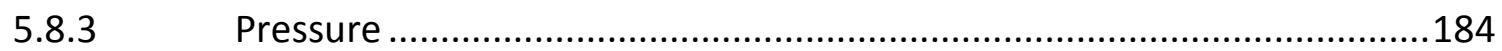

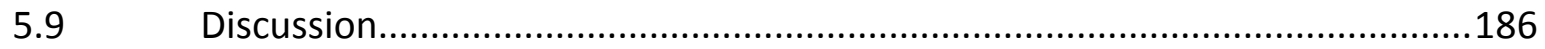

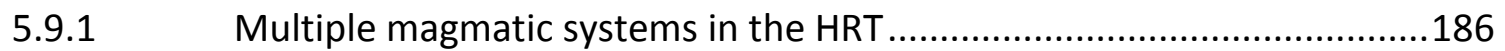

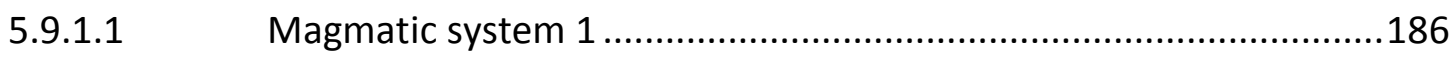

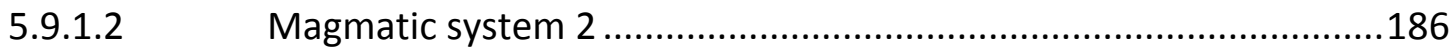

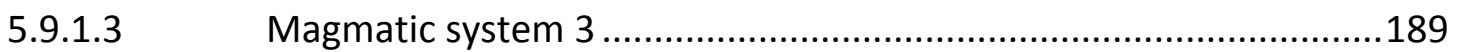

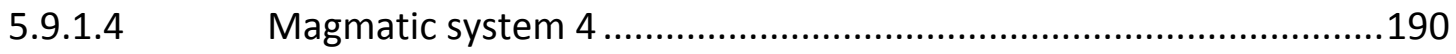

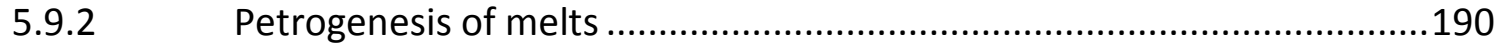

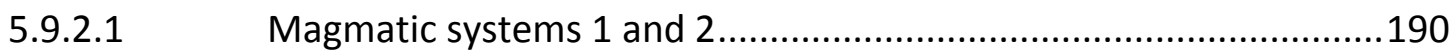

5.9.2.2 Magmatic systems 3 and 4........................................................200

5.9.3 Pre-eruptive intensive variables of the HRT magmatic systems.............203

5.9.4 Configuration of the HRT magmatic complex .......................................206

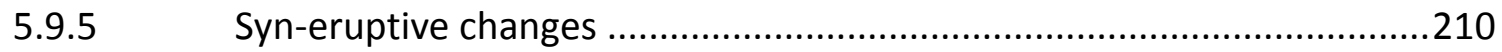

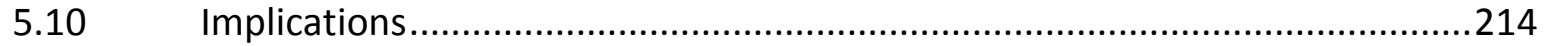

5.10.1 Yellowstone rhyolite petrogenesis .........................................................214

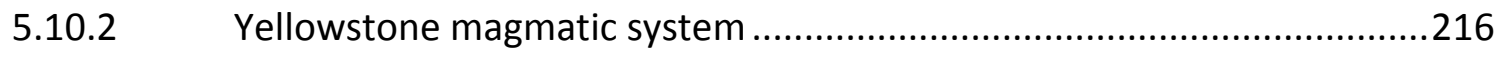

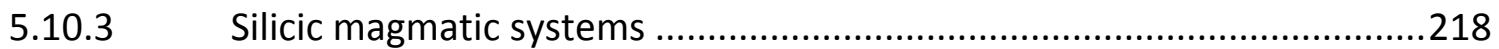

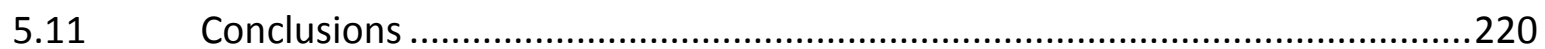

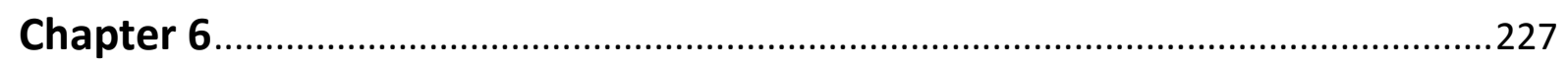

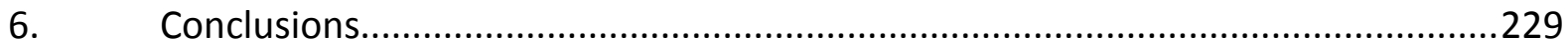

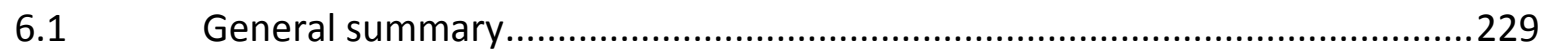

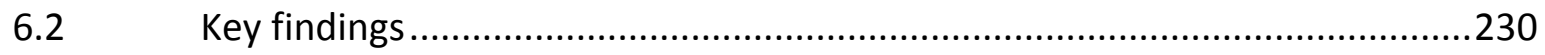

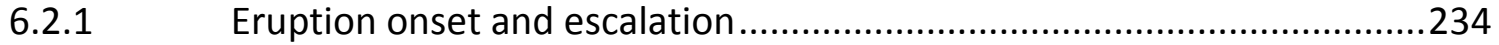

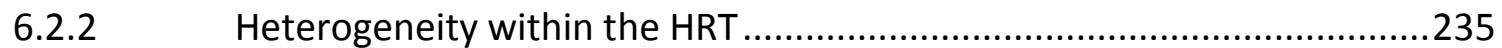

6.2.3 Thermal and chemical drivers of the silicic system ..............................237

6.2.4 Timescales of melt-dominant body formation .......................................238

6.2.5 Onset and development of caldera collapse ..........................................239

6.2.6 How can the geochemical results inform the present day geophysical image of the Yellowstone system? 
6.3 Insights for Yellowstone and silicic magmatic systems .................................241

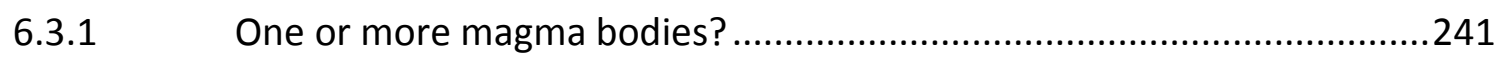

6.3.2 When is an eruption an eruption, or a magmatic system a magmatic

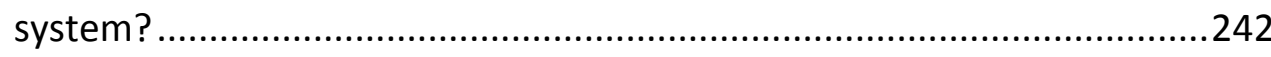

6.3.3 Comparisons with other silicic caldera-forming eruptions .....................243

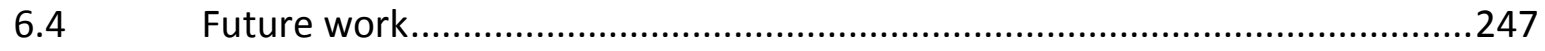

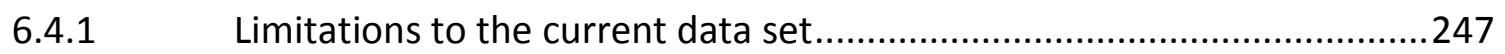

6.4.2 Constraining mixing end members...................................................249

6.4.3 Geobarometric constraints on melt-dominant body storage ..................250

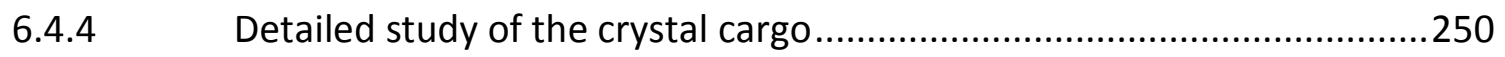

6.4.5 Constraints on timescales of syn-eruptive processes .............................252

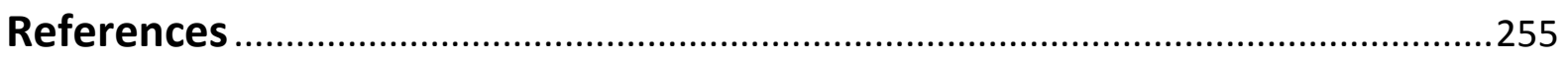

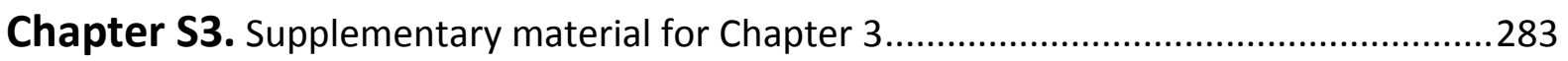

Chapter S4. Supplementary material for Chapter 4.................................................291

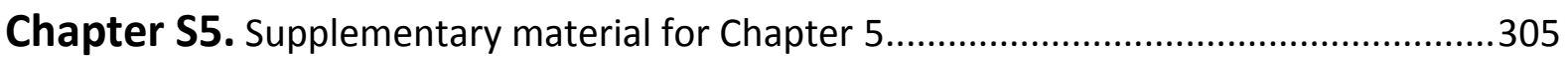

Suppplementary material and electronic appendices references....................331

\section{List of figures}

Figure 1.1 Schematic diagram of the formation of a crystal mush .....................................10

Figure 1.2 Schematic diagram showing the architecture of a silicic magmatic system ..........11

Figure 1.3 Map of the NW U.S.A showing major tectonic and volcanic features ..................21

Figure 1.4 Simplified geological map of Yellowstone National Park ......................................22

Figure 1.5 Map of earthquake epicentres in and around Yellowstone National Park ............24

Figure 1.6 Cross sectional schematic model for the Yellowstone magmatic system ..............26

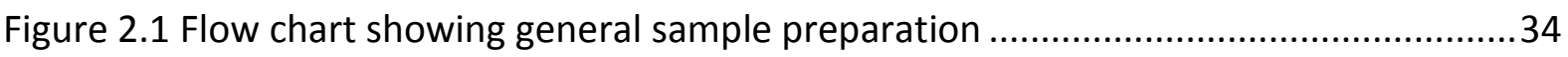

Figure 2.2 Diagram showing the element separation procedure for isotopic analysis...........44

Figure 3.1 Map of locations where the basal ignimbrite was sampled ...............................63

Figure 3.2 Major element plots of fall deposit and basal ignimbrite glassy material ............64 
Figure 3.3 Sanidine rim compositions in the fall deposit .66

Figure 3.4 Fractional crystallisation modelling of glass compositions ................................67

Figure 3.5 Ba vs $\mathrm{La}$ and $\mathrm{Ba} / \mathrm{Rb}$ vs $\mathrm{Sr} / \mathrm{Rb}$ of fall deposit and basal ignimbrite glass.................68

Figure 3.6 Glass selvedge Ba compositions vs adjacent sanidine rim Cn contents ...............69

Figure 3.7 Two-feldspar thermometry temperature estimates ...........................................71

Figure 3.8 Comb diagram showing fall deposit compositional grouping proportions ............80

Figure 3.9 Cluster abundances in the basal ignimbrite at each sample locality ....................81

Figure 3.10 Schematic flow diagram showing the compositional group linkages .................84

Figure 3.11 Schematic diagram of magma domain configuration ........................................86

Figure 4.1 Map of Yellowstone-Snake River Plain ............................................................96

Figure 4.2 Photographs of representative HRT mafic material .........................................101

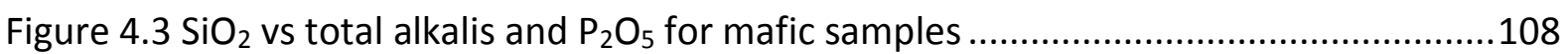

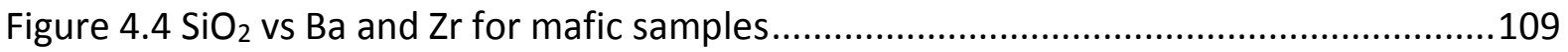

Figure 4.5 Chondrite-normalised rare-earth element plot for mafic samples .....................110

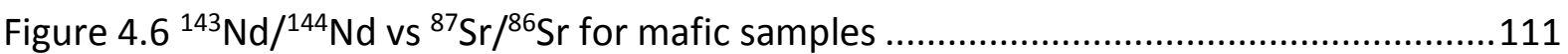

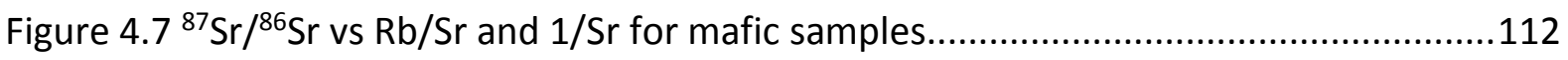

Figure 4.8 Pb-isotopic compositions for mafic samples .................................................113

Figure 4.9 Sr vs $\mathrm{Rb}, \mathrm{Ba}$ and $\mathrm{Zr} / \mathrm{Nb}$ and fractional crystallisation modelling........................119

Figure 4.10 OIB-normalised multi-element diagram for mafic samples .............................124

Figure 4.11 Cartoon showing the proposed model for HRT mafic generation ....................127

Figure 5.1 Map of the Yellowstone Plateau volcanic field ...............................................144

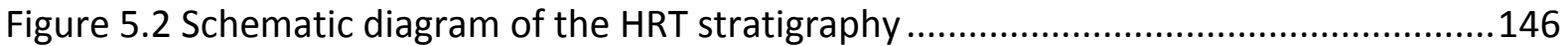

Figure $5.3 \mathrm{SiO}_{2}$ vs total alkalis for the entire HRT and individual members .......................157

Figure $5.4 \mathrm{SiO}_{2}$ vs $\mathrm{Al}_{2} \mathrm{O}_{3}$ for the entire $\mathrm{HRT}$ and individual members ..............................158

Figure $5.5 \mathrm{SiO}_{2}$ vs $\mathrm{FeO}$ for the entire HRT and individual members ..................................159

Figure $5.6 \mathrm{SiO}_{2}$ vs $\mathrm{Ba}$ for the entire HRT and individual members ....................................161

Figure $5.7 \mathrm{SiO}_{2}$ vs $\mathrm{Sr}$ for the entire HRT and individual members ...................................162

Figure $5.8 \mathrm{SiO}_{2}$ vs $\mathrm{Nb}$ for the entire HRT and individual members ..................................164

Figure $5.9 \mathrm{SiO}_{2}$ vs Sc for the entire HRT and individual members ....................................165

Figure $5.10 \mathrm{SiO}_{2}$ vs La for the entire HRT and individual members ..................................166 


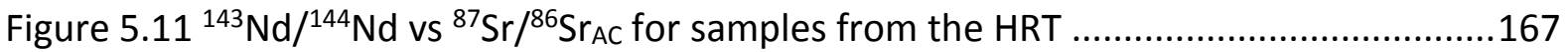

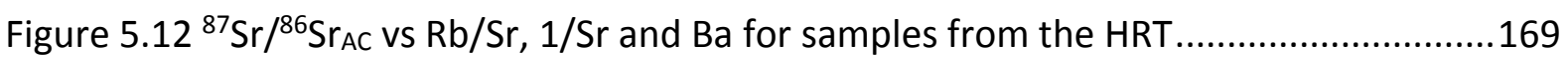

Figure $5.13 \mathrm{~Pb}$-isotopic compositions for samples from the HRT ....................................171

Figure 5.14 Pumice groundmass glass Ba vs La concentrations ........................................173

Figure 5.15 Pumice groundmass glass $\mathrm{Ba} / \mathrm{Rb}$ vs $\mathrm{Sr} / \mathrm{Rb}$ compositions .................................174

Figure 5.16 Sanidine rim (Or vs $\mathrm{Cn}$ ) compositions from members $A, B$ and $C$...................177

Figure 5.17 Pyroxene quadrilaterals for crystals from members A, B and C......................178

Figure 5.18 Two-feldspar and zircon saturation model temperature estimates .................182

Figure 5.19 Model pressure estimates for different clast types .......................................185

Figure 5.20 Schematic diagram showing the eruptive timescale, stratigraphy and tapped magmatic systems in the HRT

Figure 5.21 Semi-quantitative plots showing elemental behaviour and proposed petrogenetic mechanism for magmatic system 1 196

Figure 5.22 Diagram showing the HRT magmatic complex throughout the eruption ..........207

Figure 5.23 Flow chart showing the features of each magmatic system

Figure 6.1 Diagram showing the HRT stratigraphy and the magmatic systems..................231

Figure 6.2 Crustal-scale schematic diagram of the HRT magmatic complex........................233

Figure 6.3 Comparison of the Taupo Volcanic Zone flare up calderas and the HRT 240

Figure S3.1 Photograph of the sampled fall deposit section at Mt Everts .283

Figure S3.2 Feldspar ternary diagram for the fall deposit and basal ignimbrite 284

Figure S3.3 Broken stick, principal component and cluster analysis plots .285

Figure S3.4 Error propogation for analyses by LA-ICP-MS. .288

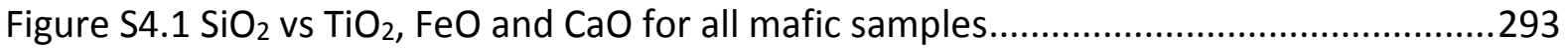

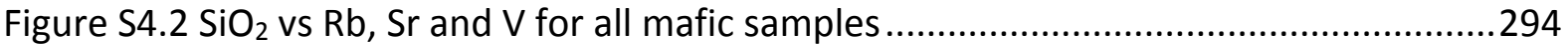

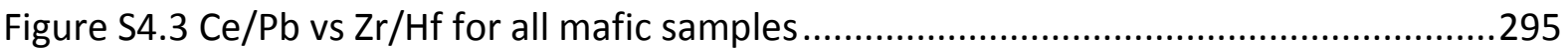

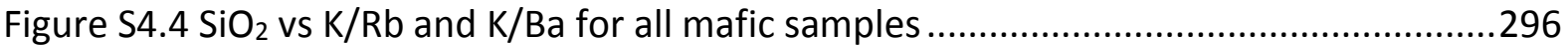

Figure S4.5 Pb-Pb pseudochrons for each mafic suite ...................................................297

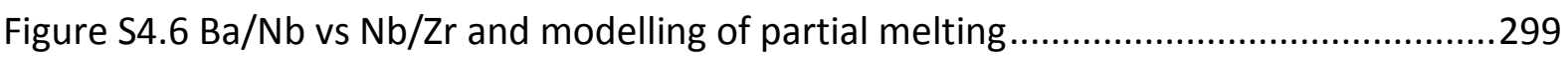

Figure S4.7 Sr isotopic pseudochron for all mafic samples .............................................300 
Figure $\mathrm{S}_{4} .8 \mathrm{CaO} / \mathrm{Al}_{2} \mathrm{O}_{3}, \mathrm{MgO}$ and $\mathrm{Ni} / \mathrm{Sc}$ plots and crystallisation modelling 301

Figure S4.9 Sr/Sc vs Ni/Cr for mafic samples and crystallisation modelling.... 302

Figure S5.1 Photographic evidence for time gaps within the HRT 306

Figure S5.2 Sample type photographs 307

Figure $\mathrm{S} 5.3 \mathrm{SiO}_{2}$ vs total $\mathrm{P}_{2} \mathrm{O}_{5}$ for the entire HRT and individual members. .308

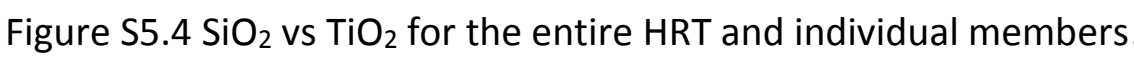
309

Figure $\mathrm{S} 5.5 \mathrm{SiO}_{2}$ vs $\mathrm{CaO}$ for the entire $\mathrm{HRT}$ and individual members 310

Figure S5.6 LOI vs K/Na for all samples analysed in this study. 311

Figure $\mathrm{S}_{5.7} \mathrm{SiO}_{2}$ vs BaxRF for the entire HRT and individual members 312

Figure $\mathrm{S}_{5.8} \mathrm{SiO}_{2}$ vs $\mathrm{Zr}$ for the entire HRT and individual members .313

Figure S5.9 Chondrite-normalised rare-earth element diagram for all HRT samples. 314

Figure $\mathrm{S} 5.10{ }^{143} \mathrm{Nd} /{ }^{144} \mathrm{Nd}$ vs $\mathrm{Rb} / \mathrm{Sr}, 1 / \mathrm{Nd}$ and $\mathrm{Ba}$ for samples from the HRT. .315

Figure S5.11 Pumice groundmass glass $\mathrm{SiO}_{2}$ vs total alkali concentrations 316

Figure S5.12 Pumice groundmass glass $\mathrm{SiO}_{2}$ vs $\mathrm{Al}_{2} \mathrm{O}_{3}$ concentrations 317

Figure S5.13 Pumice groundmass glass $\mathrm{SiO}_{2}$ vs $\mathrm{CaO}$ concentrations 318

Figure S5.14 Average vs variation single pumice groundmass glass Ba content 319

Figure S5.15 Ternary feldspar diagram for crystals from HRT members A, B and C 320

Figure S5.16 BSE images of feldspar crystal textures 321

Figure S5.17 BSE images of ferromagnesian crystal textures. .323

Figure $\mathrm{S} 5.18 \mathrm{FeO}$ vs $\mathrm{CaO}$ olivine compositions for crystals from the HRT......... 324

Figure S5.19 FeO vs MgO olivine compositions for crystals from the HRT .325

Figure $\mathrm{S} 5.20 \mathrm{Rb}$ vs $\mathrm{Nb}$ and $\mathrm{U}$ for all HRT samples .326

Figure $\mathrm{S}_{5.21} \mathrm{P}_{2} \mathrm{O}_{5}$ vs La for all HRT samples .327

Figure $\mathrm{S} 5.22 \mathrm{SiO}_{2} \mathrm{vs} \mathrm{Rb/Sr}$ for all HRT samples..... .328

Figure S5.23 Pb-Pb pseudochron for HRT silicic juvenile clasts. 329

Figure S5.24 Multi-element diagram showing glass/single clast elemental ratios .330

\section{List of tables}

Table 1.1 Features of other crystal-poor, silicic eruptions .14 
Table 2.1 X-ray fluorescence sample preparation and analysis procedure .36

Table 2.2 Accuracy and precision of repeated analyses of standard materials by XRF .37

Table 2.3 Accuracy and precision of repeated analyses of BCR-2 by ICP-MS. 40

Table 2.4 Reproducibility of duplicates of samples analysed by ICP-MS 41

Table 2.5 Accuracy and precision of standards by ICP-MS ( $\mathrm{NH}_{4} \mathrm{~F}$ digestion) 42

Table 2.6 Accuracy and precision of repeated analysis of standards by EPMA .49

Table 2.7 Accuracy and precision of repeated analysis of standards by LA-ICP-MS .51

Table 3.1 Compositional cluster means and intra-cluster variation .74

Table 4.1 Summary of the sample suites analysed. 100

Table 4.2 Selected major and trace element analyses for mafic samples .106

Table 4.3 Selected isotopic ratios for mafic samples 107

Table 4.4 Summary of possible end-member processes and applicable evidence

Table 5.1 List and characteristics of the silicic clast types in the HRT ignimbrite 149

Table 5.2 Selected major and trace element analyses for HRT silicic samples .156

Table 5.3 Selected isotopic ratios for HRT silicic samples .168

Table 5.4 Distinguishing characteristics of the four magmatic systems identified 187

Table 6.1 Repeat of Table 1.1 with the addition of the HRT 14

Table S3.1 Details of localities where the basal ignimbrite was sampled .289

Table S4.1 Details of localities where the mafic material was sampled. .292

\section{Electronic Appendix captions}

Electronic Appendix 1: Myers et al. (2016): Prolonged ascent and episodic venting of discrete magma batches at the onset of the Huckleberry Ridge supereruption, Yellowstone. I was involved in this paper and it forms the counterpart to Chapter 3.

Electronic Appendix 2: Full XRF and ICP-MS standard data associated with this thesis. 
Electronic Appendix 3.1: Major and minor element oxide (in wt\%), and trace element (in ppm) concentrations in glass, obsidian pyroclasts and glass selvedges from the fall deposit and glassy material from the basal ignimbrite along with standard data.

Electronic Appendix 3.2: Major and minor element oxide (in wt\%), and molar percentages for sanidine and plagioclase crystals in the fall deposit and basal ignimbrite, two feldspar thermometry and plagioclase hygrometer model estimates, paired glass selvedge and sanidine rim analyses and feldspar EPMA standards.

Electronic Appendix 3.3: Importance of components derived from PCA analysis.

Electronic Appendix 4.1: Full major element oxide (wt\%) and trace elemental (ppm) concentrations, and isotopic ratios for the samples analysed in this study.

Electronic Appendix 4.2: Table of published data from GEOROC database (http://georoc.mpch-mainz.gwdg.de/georoc/) which met compositional criteria.

Electronic Appendix 5.1: Major element oxide (in wt\%), trace element (in ppm) concentrations and isotopic ratios of all samples analysed in this study.

Electronic Appendix 5.2: Major and minor element oxide (in wt\%), and trace element (in ppm) concentrations in groundmass glass in HRT pumices along with thermobarometry estimates and standard data.

Electronic Appendix 5.3: Major and minor element oxide (in wt\%), and molar percentages for feldspars, pyroxene and olivine crystals, two feldspar thermometry, two pyroxene thermometry and plagioclase hygrometer model estimates, textural classifications and single clast crystal abundances.

Electronic Appendix 5.4: Locality information for sites and samples in this study. 


\section{Chapter 1}

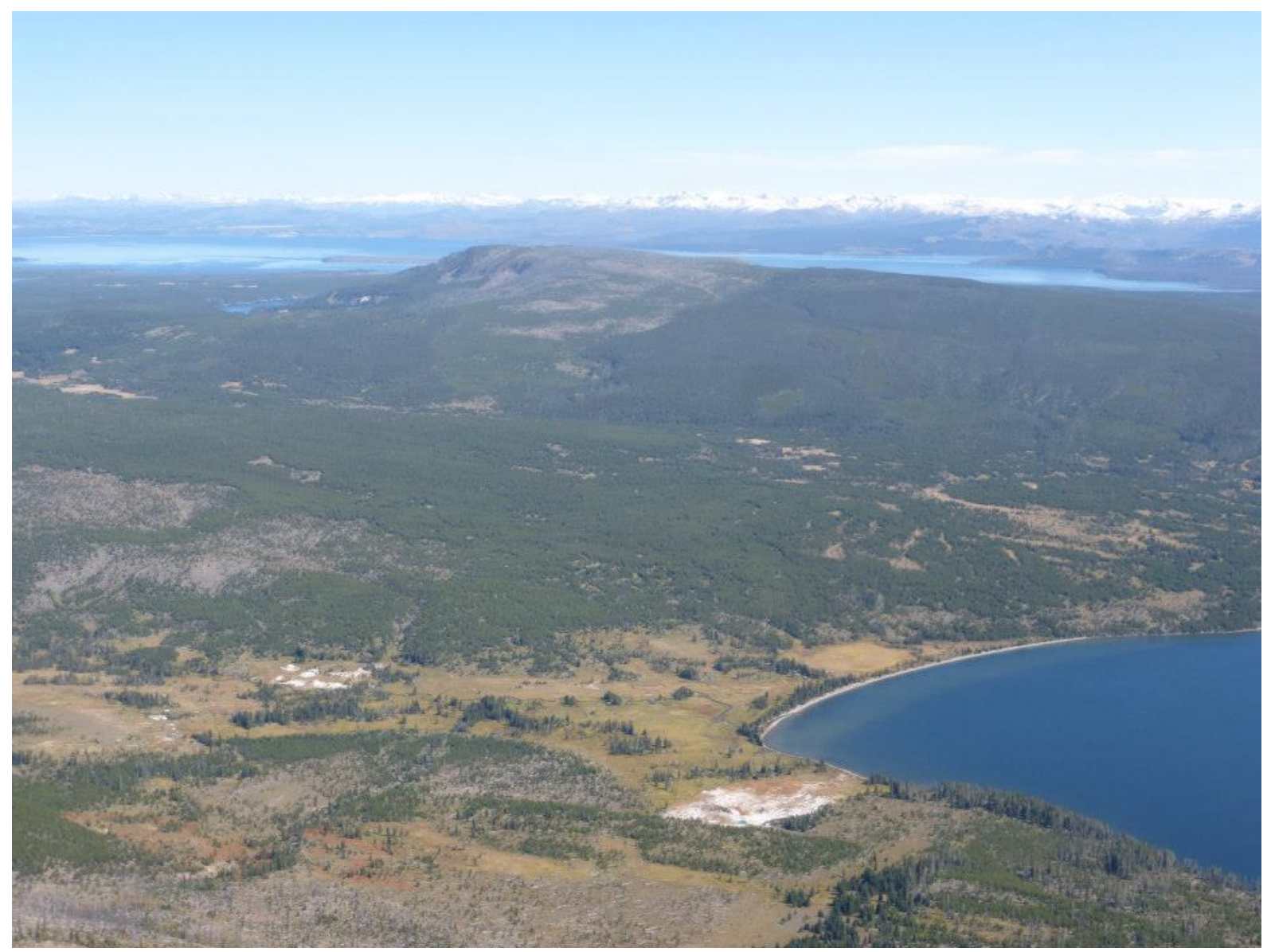

Photograph of Yellowstone National Park, U.S.A looking north-east from Mt. Sheridan over Heart Lake (foreground) and Yellowstone Lake with the Absaroka mountain range in the distance. 


\section{Introduction}

\subsection{Background to this study}

Large silicic magmatic systems are a fundamental part of crustal processes on Earth. The solidification of intruded silica-rich melt and subsequent accretion of such bodies has led to the formation of low-density material that is the predominant component of continents, the development of which has been vital throughout Earth's history for the modulation of global temperature and climate systems, and therefore plausibly evolution of land-based life (e.g. Campbell and Taylor 1983; Cook 2003; Lowe and Tice 2004; Lundstrom and Glazner 2016). Furthermore, the hydrothermal systems associated with silicic intrusions are responsible for many large ore deposits (e.g. Hedenquist and Lowenstern 1994). Although silicic systems can therefore be very beneficial, they can also be highly damaging through generation of explosive, caldera-forming eruptions, another aspect of the surficial expression of these systems. Their largest eruptions, supereruptions, involve the eruption of $>10^{15} \mathrm{~kg}$ or $>450 \mathrm{~km}^{3}$ of magma and represent a hazard that can have global impacts and consequences, similar to but more likely in a given time period than a medium-sized asteroid impact (Mason et al. 2004; Sparks et al. 2005; Self 2006). The relative infrequency of supereruptions (average 1 per 260,000 years in the Quaternary), and their absence in the historical record, means that understanding of their magmatic systems and associated eruptions needs to be developed through the geological record and/or numerical models. It is understanding of silicic magmatic systems through the geological record that this thesis focuses on. Fundamental questions regarding these systems are still debated, including:

- how are large quantities of melt formed and stored in the crust, without cooling and solidifying, or prematurely erupting?

- over what timescales are the melt-dominant bodies that erupt generated and assembled?

- how do these largest of explosive eruptions initiate and escalate?

Numerical models are based on a simple notion of a single, large, melt-dominant body, allowed to grow over tens of thousands of years with a constant magma supply rate, displacing an accommodating crust prior to reaching a critical mass leading to an explosive 
and short-lived eruption (e.g. Gregg et al. 2012, 2015; Caricchi et al. 2014). However, fieldbased investigations of the deposits of such eruptions show wide variations in the nature and behaviour of large silicic systems and their eruptions, including evidence contrary to some or all of these model assumptions (e.g. Wilson 2001; Allan et al. 2012; Cooper et al. 2012, 2016; Myers et al. 2016). A greater wealth of information, derived from the geological record, is therefore essential in order to ground-truth numerical models and to develop improved models and understanding for these systems.

At one extreme of young (Quaternary) large silicic systems lies Yellowstone. Despite having a definitive place in the psyche of not only the scientific community, but also the general public in regards to supereruptions (e.g. Brady 2012), little detailed work has been done on the explosive eruptions of the Yellowstone volcanic region. The Huckleberry Ridge Tuff, the first and largest of three Quaternary caldera-forming eruptions from the Yellowstone system, offers the chance to study an explosive event from a quintessential large silicic system, unhindered by pre-conceived ideas from a significant body of previous work.

\subsection{Thesis objectives and structure}

The nature of large-scale silicic magmatic systems can be reconstructed from detailed geochemical investigation of the eruption deposits, including the elemental and isotopic compositions of the erupted magma (crystals and melt) or the individual components. The eruption deposits represent in turn a snapshot of the magmatic system at the onset of eruption. However, the multi-stage nature of the Huckleberry Ridge Tuff (Christiansen 2001) also provides an opportunity to track any temporal variation in the nature of the magmatic system in response to the eruption of significant volumes of material. Furthermore, the varied nature of emplacement of the eruption products (i.e. pyroclastic fall and flow deposition) provides an opportunity to investigate any links between eruption style and the nature of the magmatic system.

Extensive fieldwork and mapping at the end of the $20^{\text {th }}$ century has outlined the inter-and intra-eruption stratigraphy of Yellowstone and the Huckleberry Ridge Tuff eruption, and allows this work to be placed into a temporal context (Christiansen and Blank 1972; Christiansen 2001; Christiansen et al. 2007). Previous geochemical studies, limited by one or more of sample type, sample numbers or stratigraphic scope, have provided comparators to 
other stages of Yellowstone volcanism, but not been sufficiently detailed to explore any heterogeneity in the Huckleberry Ridge Tuff (Doe et al. 1982; Hildreth et al. 1984, 1991; Christiansen 2001; Bindeman et al. 2008; Ellis et al. 2012; Rivera et al. 2014; Singer et al. 2014; Wotzlaw et al. 2015). Detailed fieldwork and sampling, incrementally developed since 2001, has been completed (Wilson et al. in prep.) and this work has provided the intra-eruption stratigraphic framework for my geochemical analyses. An extensive sample suite, covering the temporal and spatial extent of the eruption deposits, now permits a detailed and comprehensive geochemical analysis of the Huckleberry Ridge Tuff.

This thesis presents a broad geochemical overview to the Huckleberry Ridge Tuff, documenting the key features of the deposits to infer the nature of the magmatic system prior to and during the eruption. It addresses a number of key questions, including:

1. How did the eruption start and escalate?

2. Was the rhyolitic magmatic system composed of one large melt-dominant body or multiple smaller, discrete bodies?

3. What were the deep-seated thermal and chemical drivers of the rhyolitic magmatic system?

4. Are there any chemical differences between the different clast types sampled?

5. What is the degree of heterogeneity within and between different stages of the Huckleberry Ridge Tuff?

6. What is the degree and nature of any heterogeneity present?

7. What were the processes responsible for the generation of the magma erupted?

8. Over what timescales did these melts form?

9. How can the geochemical results constrain the geophysical image of the Yellowstone system?

These questions are addressed in a series of chapters, each focusing on a different aspect of the Huckleberry Ridge Tuff. The sampling strategy and analytical methods used in this thesis are outlined in Chapter 2. Chapters 3-5 are written as manuscripts and have either been submitted to peer-reviewed journals or are written in a format suitable for submission as individual articles. Each of these chapters, although able to stand alone, complement each other in building up an overall picture of the Huckleberry Ridge Tuff through the thesis. Only the format has been edited to ensure consistency. The chapters of the thesis are outlined below: 
Chapter 1 provides the background to the thesis, including the motivation for this study. This chapter also provides an introduction to large scale silicic magmatic systems, and common methods used to investigate them. An overview of the geological setting of the Yellowstone region is also provided, in order to place the Huckleberry Ridge Tuff in its spatial and temporal context. A summary of previous work and current understanding of the Huckleberry Ridge Tuff is also provided.

Chapter 2 outlines the sampling strategy used for materials analysed in this study. It also documents the methods used for sample preparation and analysis, with methods separated based upon the type of material analysed and the purpose of each technique.

Chapter 3 is a manuscript submitted to Contributions to Mineralogy and Petrology. This chapter focuses on the initial stages of the Huckleberry Ridge eruption: the initial fall deposit and the basal ignimbrite from member $A$. It builds on published work, on which I am a coauthor, focusing on the eruption initiation from study of melt inclusion volatile contents and trace element chemistry (Myers et al. 2016: in this thesis as Electronic Appendix 1). In this chapter, stratigraphically-constrained in-situ geochemical analyses of glassy material and crystals through the fall deposit and into the basal ignimbrite are used to determine the nature of the upper-levels of the magmatic system(s). Sampling of the basal ignimbrite from multiple locations around the mapped caldera permits reconstruction of the temporal and spatial development of the eruption and its relationship to the architecture of the magmatic system(s).

Chapter 4 is a manuscript accepted for publication in American Mineralogist. This chapter documents the mafic (i.e. broadly basaltic-andesitic) inputs into the rhyolitic Huckleberry Ridge magmatic system. The mafic inputs are manifested as mafic enclaves in member $A$, and as scoria clasts or scoria components in mixed pumices present in upper member B (Christiansen 2001). The chemistries of the mafic components are compared to mafic compositions of a similar silica range erupted before and after the Huckleberry Ridge Tuff in the Yellowstone area and used to construct a petrogenetic model for the melts.

Chapter 5 documents the geochemical characteristics of the silicic components (i.e. trachytic/dacitic-rhyolitic) of the three ignimbrite members (A, B and C) of the Huckleberry Ridge Tuff. Major element data from 227 silicic clasts are presented, which are representative of the range of physical clast types observed in the field. Trace element and isotopic compositions of selected samples are also presented. Major element, in-situ analysis of the 
main crystal phases (sanidine, plagioclase, pyroxene and olivine) from selected samples are also documented, as well as the major and trace element analysis of groundmass glass from pumices covering the range of single clast compositions present. This large dataset is collated to infer the nature of the magmatic system(s), the range and provenance of the magma types present and to document any syn-eruptive changes in the magmatic system(s).

Chapter 6 summarises the key findings of this thesis and addresses the main questions posed in Chapter 1. It also highlights further questions arising from this work and discusses areas for future study.

\subsection{Silicic magmatic systems}

The volcanic aspect to large silicic magmatic systems has attracted broad attention and a multi-disciplinary approach over several decades, in no small part due to the potentially catastrophic impacts of large explosive eruptions. Focus has been placed on all aspects of the evolutionary life of these systems: from inception, growth and development, to termination (see Hildreth 1981 and Bachmann and Huber 2016 for overviews). Although granitic plutons, related to silicic magmatic systems through formation either as solidified magma bodies or the residue from silicic explosive eruptions, have a permanency in the geological record, magma bodies tapped during volcanic eruptions are likely transient features, suggested by the absence of geophysically-imaged large eruptible magma bodies despite the numerous studies of global silicic systems (Lundstrom and Glazner 2016). It is the understanding of the formation and development of these bodies from (but not limited to) chemical and physical viewpoints, that is vital in evaluating and preparing for the hazard that they pose. Although this understanding may be pursued from modelling and geophysical imaging techniques, the work in this thesis focuses on the study of past deposits to gain insights into the inner workings of such systems. Studies of the deposits of past explosive silicic eruptions have split the eruptive products into two broad but simplified categories, which provide contrasting, but arguably incomplete, insights into the development of the erupted body. At one extreme are the 'monotonous intermediates' (Hildreth 1981, Christiansen 2005; Bachmann and Bergantz 2008; Bachmann and Huber 2016). These are crystal-rich deposits, commonly unzoned and which have a limited (broadly dacitic) compositional range (e.g. Fish Canyon Tuff: Bachmann et al. 2002). They are generally inferred to represent the rejuvenation of a cooling 
and solidifying crystal-rich body, through thermal and/or volatile input (e.g. Huber et al. 2011, 2012; Parmigiani et al. 2014). At the other extreme are crystal-poor rhyolitic deposits that are often chemically and thermally zoned and represent a concentration of silicic melt into a crystal-poor magma body (Hildreth 1981; Bachmann and Bergantz 2004, 2008; Christiansen 2005). It is this latter group that I will focus on in this study, beginning with the chemical and physical generation of such highly-eruptible melt-dominant bodies.

\subsubsection{Chemical generation of silicic magma}

The generation of large volumes of evolved silicic magmas (i.e. dacitic to rhyolitic: $>63$ wt\% $\mathrm{SiO}_{2}$ ) requires the presence of up to 10 times the volume of less evolved mafic materials. The conversion of mantle-derived magmas into silicic magmas can occur through sequential fractional crystallisation (e.g. Hildreth 1981; Marsh 1981; Miller and Mittlefehldt 1984; Berndt et al. 2005), or small-scale partial melting of a less evolved protolith (e.g. Sisson et al. 2005; Streck and Grunder 2008; Streck 2014), or the large-scale melting of a pre-existing silicic protolith (Bindeman and Simakin 2014; Troch et al. 2018). In all events, silicic magmas are associated with large volumes of a less-evolved crystal-rich residuum. The resulting high-silica magma is highly viscous and volatile rich, due to the dominantly anhydrous nature of the crystal residuum (Marsh 1981; Scaillet et al. 1998; Glazner 2014). Gradients in intensive parameters within the magma chamber (e.g. $\mathrm{T}, \mathrm{P}, \mathrm{H}_{2} \mathrm{O}$ content) are enhanced by the degree and nature of crystallisation/melting, leading in many examples to compositionally zoned chambers (Hildreth 1981). These compositional gradients are manifested in eruption deposits in many forms, for example, in the changing proportions of clasts with different compositional characteristics (e.g. Cooper et al. 2012), changes in the glass and/or mineral compositions or assemblages (e.g. Streck and Grunder 1997; Chamberlain et al. 2015) and degree of crystallinity of the magma (e.g. Bacon and Druitt 1988; Chesner 1998, 2012). This zoning in the deposits is commonly interpreted as providing snapshots in the fractional crystallisation

evolution of the melt from a less-evolved precursor (Bacon and Druitt 1988; Streck and Grunder 1997; Deering et al. 2011; Folkes et al. 2011) or the influx of less-evolved material (e.g. progressive melting of a crystal-rich residue: Wolff et al. 2015). Crystalline material, in the form of commonly observed granoblastic clots, or rarer macroscopic enclaves, can be coerupted with melt-dominant magma. Such clots/enclaves are often interpreted to represent fragments of the crystal residue, providing a window into the evolution of the magma, and 
providing a link to the less-evolved precursor (e.g. Deering et al. 2011; Ellis et al. 2014; Masotta et al. 2016; Troch et al. 2017). In contrast to the preceding views, other detailed elemental and isotopic analyses of eruption deposits reveal a complex picture, with meltdominant bodies comprising an accumulation of a variety of components, from highly fractionated melts to partial melts of country rocks, indicating that silicic magmatic systems are open entities (e.g. Bindeman and Valley 2001; Charlier et al. 2008, 2010; Wolff and Ramos 2014; Loewen and Bindeman 2015; Wotzlaw et al. 2015; Stelten et al. 2017). Despite this diversity of inputs into the magmatic system, similar chemistries of multiple eruptions over prolonged periods of time indicates the long-term nature of the chemical evolution of these systems, and the longevity of those characteristics, which requires the homogenisation of diverse chemical inputs (e.g. Charlier et al. 2008; Barker et al. 2015; Loewen and Bindeman 2015; Stelten et al. 2015; Troch et al. 2017). However, analysis of the crystal cargo indicates the generation of melt-dominant bodies, which represent the materials that subsequently erupt, occurs on a much shorter timescale leading to a dichotomy between the timescales of chemical and physical processes (Charlier et al. 2005; Reid 2008; Allan et al. 2013; Barker et al. 2016).

\subsubsection{Physical generation of a melt-dominant magma body}

Although both fractional crystallisation and partial melting of crustal rocks will leave a significant crystal residuum, many large silicic eruption deposits are crystal poor (Bachmann and Bergantz 2004; Wilson et al. 2006; Streck and Grunder 2008; Deering et al. 2011; Allan et al. 2017). The formation of large bodies of crystal-poor rhyolite, therefore, requires the efficient separation of crystals and melt in the sub-surface magmatic system. Early workers invoked the removal of crystals from the magma, through crystal settling or sidewall crystallisation, but the efficiency of this process is hindered by the increasing viscosity of the melt with increasing $\mathrm{SiO}_{2}$ contents as the melt evolves (Sparks et al. 1984; Martin and Nokes 1988; Jaupart and Tait 1995; Glazner 2014). Furthermore, with increased crystallisation, the bulk viscosity of the magma increases, thereby inhibiting and eventually preventing magma flow (Marsh 1981; Rosenberg and Handy 2005). Accordingly attention has turned to the removal of melt from a crystal rich body. This alternative viewpoint led to the development of the crystal mush model, where melt-dominant bodies are efficiently segregated from a crystal-rich mush residue (Fig. 1.1: Bachmann and Bergantz 2004; Hildreth 2004, building on 
early ideas by workers like Marsh 1981, 1988; Mahood 1990; Brophy 1991). Multiple processes have been proposed to initiate and/or contribute to the efficient extraction of melt from a crystal-rich body, including thermal and volatile inputs from the ascent of an underlying less-evolved intrusion, compaction, volatile exsolution, rifting, or some combination of these (e.g. Sisson and Bacon 1999; Bachmann and Bergantz 2004; Burgisser

(a)

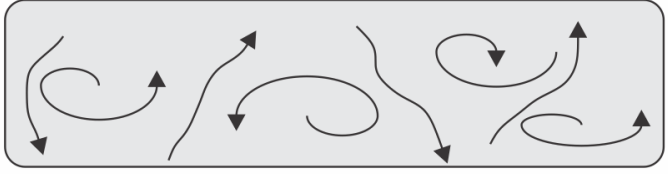

Melt-dominant body ( $<45 \%$ crystals)

convects. Body slowly cools and crystallises

(b)

Rheological

lock-up

Convection ceases in crystal mush (>45-

$50 \%$ crystals) due to crystal framework

(c)

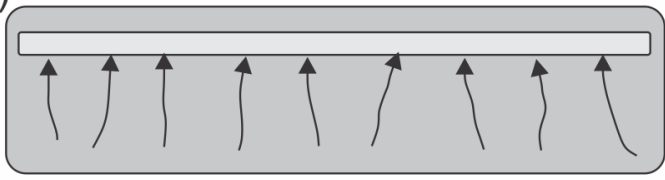

Rhyolitic melt expelled from crystal

mush, forming discrete horizon

Figure 1.1: Schematic diagram of the formation of a crystal mush and associated melt-dominant body (adapted from Bachmann and Bergantz 2004). (a) Intermediate composition magma is intruded into the crust. Crystal contents lower than $\sim 45 \%$ allow convection to occur and crystals are kept in suspension. The body gradually cools and crystallises. (b) Once crystallinity exceeds $\sim 45-$ $50 \%$, crystals form a framework and impede convection. (c) The rhyolitic interstitial melt is extracted from the crystalline framework through a combination of processes (e.g. compaction, volatile exsolution). A rhyolite melt-dominant lens forms above the crystalline residue and below a crystallising roof zone.

and Bergantz 2011; Huber et al. 2011; Allan et al. 2013, 2017; Pistone et al. 2015). Extraction of melt from the mush is aided by permeability of the mush zone, allowing thermal, volatile and magma flux from below (Figs. 1.1, 1.2). The mush model for magmatic systems is considered to be composed of several parts. There is a melt-dominant zone, where melt extracted from the surrounding crystal mush has collected, and is focused below an upper 
solidification front. Crystals within this melt-dominant body are therefore a mix of entrained and newly formed crystals (e.g. Hildreth and Wilson 2007; Allan et al. 2017). The crystal mush region is subsequently encased by a crystalline rigid zone, containing minor degrees of melt, that transitions towards the edges of the magmatic system into a solidified region devoid of melt and then into surrounding country rocks, external to the magmatic system (Fig. 1.2: Bachmann and Bergantz 2004; Hildreth 2004).

\subsubsection{Growth of large eruptible magma bodies and eruption triggering}

Although silicic systems are commonly characterised or classified in the literature by their largest explosive eruptions, smaller effusive and explosive eruptions are more frequent and

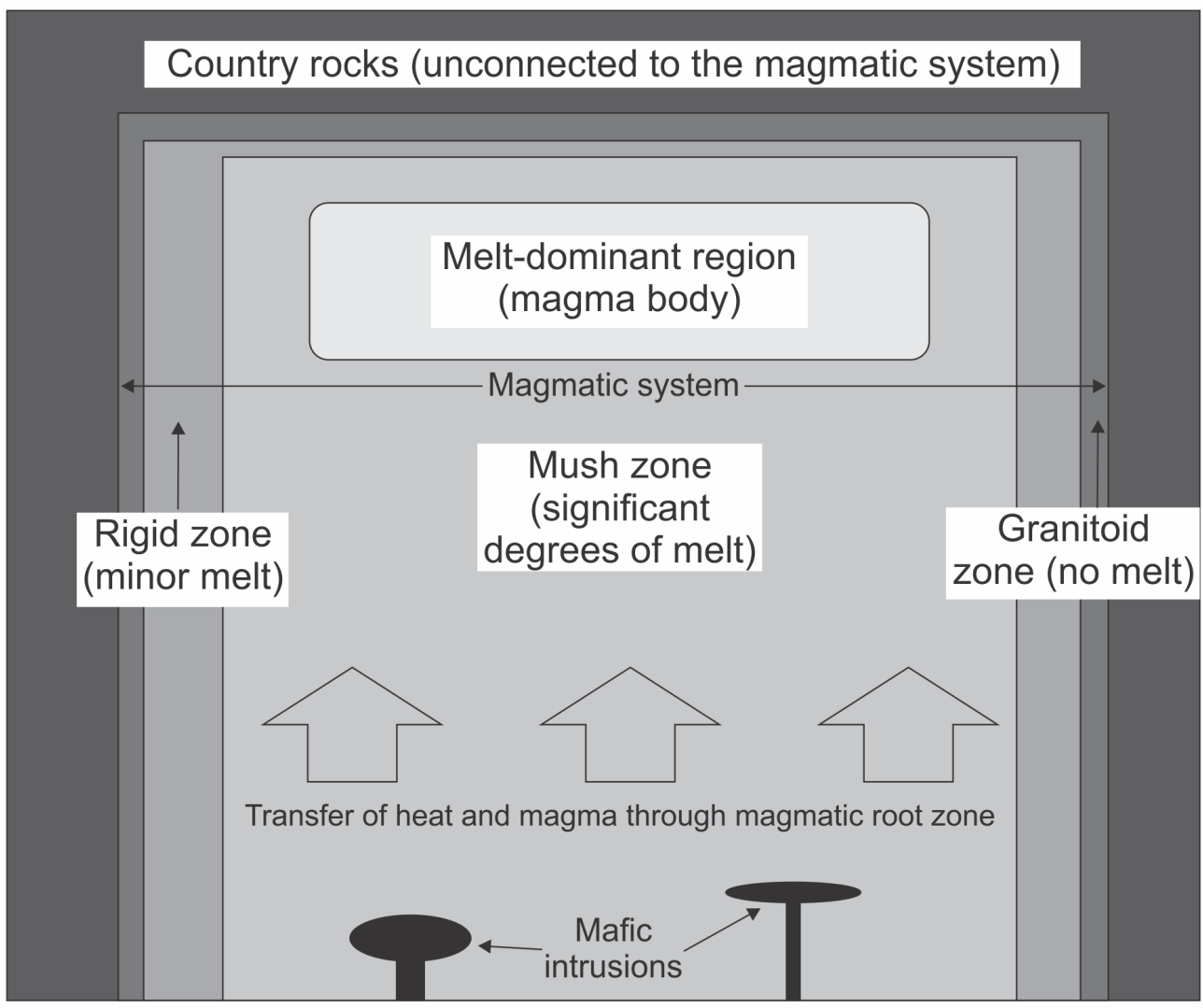

Figure 1.2: Schematic diagram showing the architecture of a silicic magmatic system and terms used in this study (adapted from Hildreth and Wilson 2007). A melt-dominant region (or magma body), that is tapped during eruption, is surrounded by a crystal rich mush zone (see Fig. 1.1). Crystal percentage increases outward through a rigid zone and into a granitoid zone. These transient regions comprise a magmatic system and are surrounded by country rocks, which are thermally and chemically discrete from the magmatic system. The significant degrees of melt still present in the mush zone allow transfer of heat and magma to the magma body, aided by mafic intrusions. 
provide snapshots in the long-term development of the relevant system (e.g. Bacon 1983; Wilson 2008; Barker et al. 2015). However, how and why the developing melt-dominant bodies responsible for the largest eruptions remain in the crust and continue to grow without prematurely erupting remains a moot point (Jellinek and DePaolo 2003).

Growing these largest single magma bodies, without premature eruption, requires the optimal combination of the myriad of processes involved in shaping the stress field surrounding silicic systems. Although growth of large bodies is aided by a thermally mature crust and a low magma input rate (Jellinek and DePaolo 2003; Gregg et al. 2012), the input rate needs to be high enough to offset heat losses to country rock and suppress crystallisation, which is precluded from the low-crystallinity of many explosive eruption deposits (Caricchi et al. 2014; Bachmann and Huber 2016). Internal forces, such as overpressure driven by magma input rate, buoyancy and crystallisation-driven volatile exsolution (Blake 1984; Caricchi et al. 2014; Degruyter and Huber 2014; Malfait et al. 2014; Tramontano et al. 2017), will evolve with the growing magma body. These forces in turn have to be compensated for by external forces, mainly the viscoelastic nature of the wall rocks and the tectonic regime (Gregg et al. 2012, 2015; de Silva and Gregg 2014), to prevent eruption and allow continued growth of the magma body. Changes in any aspect of this stress configuration, including the addition of new components such as heat and/or volatiles from an underlying intrusion, or the failure of wall rocks as a result of uplift or tectonic processes (Sparks et al. 1977; Gregg et al. 2012), can potentially tip the system irreversibly towards eruption. When and why this switch occurs is a current fundamental question of volcanology and its answer is likely complicated by a difficulty in scaling up smaller magma bodies in numerical models (Malfait et al. 2014) and different predicted predominant triggering mechanisms for large and small magma bodies. Eruption triggering of smaller bodies is controlled more by internal processes (e.g. magma input rate), but larger eruptions are controlled by external forces (e.g. uplift related faulting of country rocks: Jellinek and DePaolo 2003; Gregg et al. 2012, 2015). Furthermore, the presence of multiple melt-dominant bodies within a larger magmatic system would complicate the stress field greatly and has not commonly been included in numerical models (Gudmundsson 2012). Following initiation of the eruption, which may or may not begin with fall deposition (Cashman and Giordano 2014), underpressurisation of the system, with respect to the surrounding country rocks, following magma withdrawal is predicted to control the onset of caldera collapse and hence the further escalation of the eruption due to the 
opening up of multiple vent locations around the caldera ring fracture (e.g. Roche and Druitt 2001).

Based on the physical properties of magma bodies and their surroundings, silicic eruptions are expected to show a relationship between their size and repose period, i.e. the more time since the previous eruption the magma has to accumulate, the larger the eruption (e.g. Smith 1979; Reid 2008). However, as previously discussed, magma accumulation can occur from a variety of sources and over short timescales. The concept of a simple relationship between eruption size and repose period, therefore, does not apply to many silicic systems (e.g. Wilson 1993; Wilson et al. 2009).

\subsubsection{The diversity of natural systems from eruption deposits}

Despite being based on a simplistic foundation of the instantaneous evacuation of a single unitary melt-dominant body, numerical models come to a wide variety of conclusions regarding the formation and eruption of these bodies. This is due to the non-linear nature of many of the processes being modelled. There is an even greater degree of variation and complexity of these systems inferred from the deposits of large caldera-forming eruptions (summarised in Table 1.1) that are absent from numerical models. Although single meltdominant bodies, which form the foundation of numerical models, have been inferred for some eruptions, there is diversity in their inferred longevity in the crust and their rapidity of accumulation from an underlying crystal mush (cf. Bishop Tuff: Hildreth and Wilson 2007, Chamberlain et al. 2014a, 2015; and Oruanui: Charlier et al. 2005; Allan et al. 2013, 2017). Once eruptions are triggered, there is further disparity in the longevity of eruptions, from short-lived events (e.g. Bishop Tuff: Wilson and Hildreth 1997) to episodic, prolonged eruptions (e.g. Oruanui: Wilson 2001). Furthermore, some deposits show geochemical variations consistent with the continued eruption of a heterogeneous single body (e.g. Rattlesnake Tuff: Streck and Grunder 1997) or the sequential or simultaneous tapping of multiple melt-dominant bodies in the eruptive episode(s) (e.g. Kidnappers-Rocky Hill eruptions: Cooper et al. 2012, 2016, 2017; Mamaku-Ohakuri eruptions: Gravley et al. 2007, Bégué et al. 2014). Evidence from eruption products indicate that although some eruptions were triggered by input of mafic magma (e.g. Fish Canyon: Bachmann et al. 2002), others show evidence of magma input that is temporally disconnected from the onset of eruption 


\begin{tabular}{|c|c|c|c|c|c|}
\hline Eruption & $\begin{array}{l}\text { Eruption style and } \\
\text { chronology }\end{array}$ & $\begin{array}{l}\text { Fall deposit chemical } \\
\text { composition }\end{array}$ & $\begin{array}{l}\text { Ignimbrite chemical } \\
\text { composition }\end{array}$ & $\begin{array}{l}\text { Role/presence of } \\
\text { mafic magma on } \\
\text { the silicic system }\end{array}$ & $\begin{array}{l}\text { Nature of magmatic } \\
\text { system }\end{array}$ \\
\hline $\begin{array}{l}\text { Crater Lake, Mt. } \\
\text { Mazama (Bacon } \\
\text { 1983; Bacon and } \\
\text { Druitt 1988; Suzuki- } \\
\text { Kamata et al. 1993). }\end{array}$ & $\begin{array}{l}\text { Continuous eruption of } \\
\sim 50 \mathrm{~km}^{3} \text { with initial fall } \\
\text { activity transitioning } \\
\text { into widespread } \\
\text { ignimbrite deposition. }\end{array}$ & $\begin{array}{l}\text { Homogenous } \\
\text { rhyodacite fall } \\
\text { deposit from a single } \\
\text { vent. }\end{array}$ & $\begin{array}{l}\text { Zoned ignimbrite deposition } \\
\text { from a widened single vent } \\
\text { (pre-caldera collapse) } \\
\text { transitioning to multiple vents } \\
\text { along ring fractures (following } \\
\text { caldera collapse). }\end{array}$ & $\begin{array}{l}\text { Subordinate } \\
\text { andesite and } \\
\text { cumulate scoriae } \\
\text { in the upper parts } \\
\text { of the ignimbrite } \\
\text { and rarely in the } \\
\text { fall deposit. }\end{array}$ & $\begin{array}{l}\text { Single, melt-dominant } \\
\text { body, homogeneous } \\
\text { melt compositions but } \\
\text { variation in crystal } \\
\text { contents, underlain by } \\
\text { andesitic melts and } \\
\text { cumulates. }\end{array}$ \\
\hline $\begin{array}{l}\text { Oruanui, Taupo } \\
\text { Volcanic Zone } \\
\text { (Wilson 2001; } \\
\text { Wilson et al. 2006; } \\
\text { Allan et al. 2012, } \\
2013,2017 \text { ). }\end{array}$ & $\begin{array}{l}\text { Eruption of } \sim 530 \mathrm{~km}^{3} \\
\text { in } 10 \text { eruptive phases } \\
\text { with coeval fall and } \\
\text { ignimbrite deposition. } \\
\text { Three initial fall } \\
\text { deposits show } \\
\text { evidence for time } \\
\text { breaks and deposition } \\
\text { over up to a year. }\end{array}$ & $\begin{array}{l}\text { Heterogenous fall } \\
\text { deposit, modulated } \\
\text { by tectonic forces, } \\
\text { and involving syn- } \\
\text { eruptive } 10-15 \mathrm{~km} \\
\text { lateral transport of } \\
\text { distinctive magma, } \\
\text { 'foreign' to the main } \\
\text { magmatic system. }\end{array}$ & $\begin{array}{l}\text { Compositional variation (low to } \\
\text { high-silica rhyolite) uniform at } \\
\text { each stratigraphic level. }\end{array}$ & $\begin{array}{l}\text { Mafic enclaves } \\
\text { defining two } \\
\text { compositional } \\
\text { trends: one } \\
\text { tholeiitic, one } \\
\text { calc-alkaline. }\end{array}$ & $\begin{array}{l}\text { Single, thermally and } \\
\text { chemically homogenous } \\
\text { melt-dominant body } \\
\text { extracted from crystal } \\
\text { mush zone in }<2,000 \\
\text { years. Subordinate, co- } \\
\text { erupted low-silica } \\
\text { rhyolite body. }\end{array}$ \\
\hline $\begin{array}{l}\text { Mamaku-Ohakuri, } \\
\text { Taupo Volcanic } \\
\text { Zone (Gravley et al. } \\
\text { 2007; Bégué et al. } \\
\text { 2014). }\end{array}$ & $\begin{array}{l}\text { Paired eruptions from } \\
\text { adjacent calderas ( 30 } \\
\text { km apart) erupting a } \\
\text { cumulative }>245 \mathrm{~km}^{3} \text {. } \\
\text { Interfingering of } \\
\text { deposits from both } \\
\text { sources. }\end{array}$ & $\begin{array}{l}\text { Homogenous } \\
\text { Ohakuri fall deposit. }\end{array}$ & $\begin{array}{l}\text { Compositionally heterogenous, } \\
\text { with clustered single clast and } \\
\text { glass compositions. Ignimbrite } \\
\text { deposition initiated following } \\
\text { change in local stress field } \\
\text { following fall deposition. }\end{array}$ & No evidence. & $\begin{array}{l}\text { Five magma bodies } \\
\text { juxtaposed in the crust } \\
\text { and generated from a } \\
\text { common, heterogeneous } \\
\text { crystal mush zone. }\end{array}$ \\
\hline $\begin{array}{l}\text { Kidnappers-Rocky } \\
\text { Hill, Taupo Volcanic } \\
\text { Zone (Cooper et al. } \\
\text { 2012, 2016, 2017) }\end{array}$ & $\begin{array}{l}\text { Closely spaced } \\
\text { eruptions (time gap of } \\
\text { years-decades) from } \\
\text { the same source } \\
\text { region. Kidnappers fall }\end{array}$ & $\begin{array}{l}\text { Systematic tapping } \\
\text { of three } \\
\text { homogeneous melt- } \\
\text { dominant bodies, } \\
\text { representing two }\end{array}$ & $\begin{array}{l}\text { Ignimbrite deposition } \\
\text { coincidental with wholesale } \\
\text { caldera collapse. Evacuation of } \\
\text { three magma bodies, } \\
\text { representing the two magmatic }\end{array}$ & $\begin{array}{l}\text { Mixing of small- } \\
\text { volume rhyolitic } \\
\text { magma with } \\
\text { more primitive } \\
\text { mafic melt. }\end{array}$ & $\begin{array}{l}\text { Two laterally adjacent } \\
\text { magmatic systems } \\
\text { remain independent } \\
\text { throughout the eruption. } \\
\text { Systems generate three }\end{array}$ \\
\hline
\end{tabular}




\begin{tabular}{|c|c|c|c|c|c|}
\hline & $\begin{array}{l}\text { and subsequent } \\
\text { ignimbrite (total } \sim 1200 \\
\mathrm{~km}^{3} \text { ) deposition } \\
\text { followed by Rocky Hill } \\
\text { ignimbrite }\left(\sim 200 \mathrm{~km}^{3}\right) \text {. }\end{array}$ & $\begin{array}{l}\text { independent } \\
\text { magmatic systems. }\end{array}$ & $\begin{array}{l}\text { systems present in the fall } \\
\text { deposit. Rocky Hill ignimbrite } \\
\text { represents rejuvenation of the } \\
\text { same magmatic systems. }\end{array}$ & & $\begin{array}{l}\text { discrete heterogeneous } \\
\text { melt-dominant bodies } \\
\text { (Kidnappers fall- } \\
\text { ignimbrite) and } \\
\text { regenerate in } \sim 10-20 \\
\text { years with formation of } \\
\text { two homogenous melt- } \\
\text { dominant bodies (Rocky } \\
\text { Hill ignimbrite). }\end{array}$ \\
\hline $\begin{array}{l}\text { Averno } 2 \text { and } \\
\text { Solftara eruptions, } \\
\text { Campi Flegrei } \\
\text { (Pistolesi et al. } \\
\text { 2016) }\end{array}$ & $\begin{array}{l}\text { Simultaneous } \\
\text { eruptions from } \\
\text { multiple vents } 5.4 \mathrm{~km} \\
\text { apart. Fall deposition } \\
\text { with minor pyroclastic } \\
\text { density currents due to } \\
\text { ash column collapse. } \\
\text { Total eruptive volume } \\
\text { of } \sim 0.1 \mathrm{~km}^{3} \text {. }\end{array}$ & $\begin{array}{l}\text { Clustered } \\
\text { compositions. }\end{array}$ & $\begin{array}{l}\text { Only minor pyroclastic density } \\
\text { current deposition. }\end{array}$ & No evidence. & $\begin{array}{l}\text { Discrete melt-dominant } \\
\text { bodies from different } \\
\text { shallow portions of } \\
\text { common magmatic } \\
\text { system. }\end{array}$ \\
\hline $\begin{array}{l}\text { Bishop Tuff, Long } \\
\text { Valley (Wilson and } \\
\text { Hildreth 1997; } \\
\text { Hildreth and Wilson } \\
\text { 2007; Chamberlain } \\
\text { et al. 2014a, 2014b, } \\
\text { 2015) }\end{array}$ & $\begin{array}{l}\text { Short-lived (six days) } \\
\text { eruption of }>600 \mathrm{~km}^{3} \text {, } \\
\text { comprising nine phases } \\
\text { of coeval fall and } \\
\text { ignimbrite deposition. }\end{array}$ & $\begin{array}{l}\text { Continuum of trace } \\
\text { element glass } \\
\text { compositions with } \\
\text { broadly uniform } \\
\text { major element } \\
\text { compositions. }\end{array}$ & $\begin{array}{l}\text { Continuum of glass } \\
\text { compositions. }\end{array}$ & No evidence. & $\begin{array}{l}\text { Single, zoned magma } \\
\text { body formed over } \sim 80 \\
\text { kyr with intrusion of less- } \\
\text { evolved melt (>500 } \\
\text { years) prior to eruption. }\end{array}$ \\
\hline $\begin{array}{l}\text { Rattlesnake Tuff, } \\
\text { Oregon (Streck and } \\
\text { Grunder 1997, } \\
1999,2008 \text { ) }\end{array}$ & $\begin{array}{l}\text { Single cooling unit } \\
\text { comprising } \sim 280 \mathrm{~km}^{3} \\
\text { magma. }\end{array}$ & $\begin{array}{l}\text { Rare basal fallout, } \\
\text { homogeneous. }\end{array}$ & $\begin{array}{l}\text { Compositionally zoned } \\
\text { ignimbrite contains pumice and } \\
\text { glass shards that cluster into } \\
\text { five, physically-distinct chemical } \\
\text { groups, formed through varying } \\
\text { degrees of fractionation of a } \\
\text { common parent. }\end{array}$ & $\begin{array}{l}\text { Quenched mafic } \\
\text { inclusions found } \\
\text { at the top of the } \\
\text { ignimbrite as well } \\
\text { as dacitic pumices } \\
\text { (mix of mafic and } \\
\text { rhyolitic melts). }\end{array}$ & $\begin{array}{l}\text { Single compositionally } \\
\text { and density stratified } \\
\text { magma chamber. }\end{array}$ \\
\hline
\end{tabular}




\begin{tabular}{|c|c|c|c|c|c|}
\hline $\begin{array}{l}\text { Youngest Toba Tuff } \\
\text { (Chesner 1998, } \\
\text { 2012; Westgate et } \\
\text { al. 2013) }\end{array}$ & $\begin{array}{l}\text { Eruption of } \sim 2800 \mathrm{~km}^{3} \\
\text { magma in a few weeks } \\
\text { from ring fractures } \\
\text { during caldera collapse. }\end{array}$ & No evidence. & $\begin{array}{l}\text { Pumice and fiamme range from } \\
\text { high-silica rhyolite to dacite. } \\
\text { Composition varies } \\
\text { systematically with crystal } \\
\text { content. Co-ignimbrite ash } \\
\text { uniformly high-silica rhyolite } \\
\text { but forms four distinct } \\
\text { compositional clusters. No } \\
\text { geographical or stratigraphic } \\
\text { separation of compositional } \\
\text { variation. }\end{array}$ & No evidence. & $\begin{array}{l}\text { Compositionally zoned } \\
\text { melt-dominant body, } \\
\text { with increasing crystal } \\
\text { content towards the } \\
\text { base. }\end{array}$ \\
\hline
\end{tabular}


(Chamberlain et al. 2014b), or for episodic triggering modulated by tectonic processes (Allan et al. 2012; Bégué et al. 2014). These diversities highlight the uniqueness of individual eruptions and the importance of interrogating single case studies through analysis of eruption deposits.

\subsubsection{The role of mafic magma in silicic magmatism}

Irrespective of whether silicic magmas are generated through crystal fractionation or partial melting, the role of less-evolved magmas is central to the generation and longevity of silicic magmas in the crust (Hildreth 1981). This is indicated by the significant volumes of erupted mafic material that is spatially and/or temporally related to large silicic centres (e.g. Bacon and Metz 1984; Rowe et al. 2007; Lake and Farmer 2015), incorporation of mafic material within silicic eruptions (Table 1.1; e.g. Bachmann et al. 2002; Wilson et al. 2006, Singer et al. 2016) and the geophysical imaging of lower crustal root zones (e.g. Huang et al. 2015; Wilson and Rowland 2016).

Mafic magma can act as the parent to silicic melts, either through significant fractional crystallisation of a basaltic melt, partial melting of a solidified mafic precursor or some combination of assimilation and fractional crystallisation processes (Sisson et al. 2005; Christiansen and McCurry 2008; Streck and Grunder 2008; Loewen and Bindeman 2015; Stelten et al. 2017). Furthermore mafic magma is important in controlling the longevity of the silicic system through thermally maturing the lithosphere and maintaining magma flow rates (Price et al. 2005). Fluctuations in the mafic magma supply can control the tempo of rhyolitic eruptions, through initiating extraction of melts from a crystal mush, generating silicic partial melts, or triggering eruption of melt-dominant silicic bodies (e.g. Sparks et al. 1977; Bachmann et al. 2002; Barker et al. 2015; Till et al. 2015; Wilson and Charlier 2016). Therefore, understanding the nature of the mafic root zone is also important in discerning the nature of the silicic magmatic system and how it is erupted.

\subsection{Petrological investigation of silicic systems}

Ideally, petrological investigations of silicic systems would be based on analyses of stratigraphically-constrained, coherent erupted material which could be used in principle to reconstruct the temporal and spatial evolution of the magmatic system. For this reason, 
analyses of single pumices or coherent lava samples, which represent aliquots of the magma present on eruption, are considered preferable to bulk samples of a pyroclastic flow deposit (ignimbrite: Walker 1972). With coherent erupted material, relationships between crystals and glass, of which the latter represents the melt composition on eruption, can be investigated to reveal the degrees of compositional variation and whether this variation reflects single or multiple melt-dominant bodies (e.g. Hildreth and Wilson 2007; Bégué et al. 2014; Chamberlain et al. 2015). Furthermore, the clast composition can be used to investigate the petrogenetic processes that gave rise to the erupted magma (e.g. Wolff and Ramos 2014). In contrast, bulk samples contain a mix of juvenile material, blurring the proportions and compositional relationships between crystals and glass (Walker 1972), and may include xenolithic material that is unrelated to the magmatic system. Geochemical analysis of bulk rock can thus give misleading results and inferences for constraining the characteristics of the magmatic system and is ideally substituted by analysis of single pumice and/or fiamme clasts if possible. However, for densely welded tuffs, single clasts are either absent or difficult to extract, forcing studies to focus on bulk rock samples and components within them (e.g. Branney et al. 2008).

Stratigraphic control is equally valuable in reconstructing the nature of the magmatic system, providing a temporal framework for any variation observed. Effusive events are advantageous, with individual lava flows recording pulses of activity. In contrast, stratigraphic constraints are blurred in the largest and most explosive eruptions, due to the chaotic eruption and emplacement of pyroclastic flow deposits.

Where juvenile clasts can be collected within a stratigraphic framework, the relationships between the single clast and its glass (if not devitrified) and mineral chemistry can be determined and a picture of the magma body reconstructed (e.g. Hildreth and Wilson 2007; Allan et al. 2012). However this situation is not common. On the one hand, where pumices/fiamme are present, but stratigraphic constraints limited, geochemical variation is interpreted within traditional concepts of large-scale silicic systems (e.g. Streck and Grunder 1997). On the other hand, where eruptives are stratigraphically constrained, but pumice is not present, variations within individual components, i.e. glass and/or crystals, can be documented in deposits where the relationships between the two are not easily accessible, and then compared to pumice where they are (e.g. Cooper et al. 2012, 2016). Where pumice is absent, reconstruction of the magmatic system needs to be achieved through the analysis 
of individual components, i.e. crystals and glass (where present), without the relationships between the two being known (e.g. Cathey and Nash 2004; Ellis and Wolff 2012). In such cases, it is unclear whether chemical variations, either elemental or isotopic, in whole-rock samples could be due to the different component proportions controlled by depositional processes, real compositional variations in the original magmatic system, or the presence of non-juvenile material (e.g. Doe et al. 1982; Hildreth et al. 1991; Bachmann et al. 2002). Variation within crystals, without the associated pumice or glass chemistry, therefore lacks context and there is limited constraint on the reasons for variability (e.g. Cathey and Nash 2004; Ellis and Wolff 2012; Rivera et al. 2014; Wotzlaw et al. 2015).

The work in this thesis represents an adaptation to the challenges and issues detailed above in a petrological study of the Huckleberry Ridge Tuff (HRT), Yellowstone. Where possible only single clasts of pumices or fiamme were sampled and analysed. Where pumices and fiamme are present, however, only broad scale stratigraphic constraints (based on work undertaken by my supervisor) are available. In other parts of the HRT deposits analysed, i.e. in the fall deposits and into the basal ignimbrite, tightly constrained stratigraphic controls are available but pumices are of small size or absent. In such circumstances, glass and crystals are analysed and compared to those analysed within single clasts in order to infer crystal-glass relationships and to reconstruct the magmatic system that produced the early-erupted parts of the HRT.

With the above constraints in mind, I focus on three sampling scales in this thesis:

1. Single clasts: part of a single pumice clast or fiamme (or bulk rock if pumice or fiamme absent), large enough to be representative, is powdered to generate a homogenous material to analyse. Major and trace element, and isotopic compositions of single clast material represent the composition of the magma erupted. They can inform regarding the petrogenesis of the magma (e.g. Bacon and Druitt 1988; Streck and Grunder 1997; Folkes et al. 2011; this thesis chapters 4 and 5). However, they constitute a mix of crystals and glass, and the compositions are therefore controlled by the proportion of the different components and consequently variation in either or both of the components is blurred (e.g. Chesner 1998, 2012). Single clast analysis is useful, though, in providing an overview of the deposit, highlighting trends and samples for further 
study, and comparing between intrusive/extrusive and effusive/explosive deposits (e.g. Bacon and Druitt 1988; Sutton et al. 1995; Chesner 2012; Watts et al. 2016).

2. Single crystal: major and minor elemental compositions of crystal phases are analysed in this study. Crystals present are dominantly minerals that grew in the magma (phenocrysts), but also may include those that are incorporated into the magma, either from a related part of the magmatic system (antecrysts) or from a foreign body (xenocrysts; Charlier et al. 2005, 2008; Hildreth and Wilson 2007; Troch et al. 2017). Mineral compositions reflect the composition of the melt they grew in, and so chemical variation, or zonation, in a crystal can therefore reflect changes in the chemical or physical properties of the melt (e.g. Bachmann et al. 2002; Davidson et al. 2007; Charlier et al. 2008; Vazquez et al. 2009; Barker et al. 2015). In particular, mineral compositions, and especially paired compositions, can be used to estimate the intensive parameters of the magmatic system (e.g. T, P, $\mathrm{H}_{2} \mathrm{O}$ content: e.g. Putirka 2008 for a review). Crystal compositions can also inform about the nature and number of melt-dominant bodies tapped during the eruption (e.g. Cathey and Nash 2004; Ellis and Wolff 2012; this thesis chapters 3 and 5).

3. Glass matrix and shards: in-situ analysis of the chemical composition of the glass provides a snapshot into the melt composition on eruption. These analytical data, especially when constrained stratigraphically, indicate the nature of heterogeneity in the melt phase, i.e. whether unzoned (Allan et al. 2017), zoned in continuous or step-wise fashion (e.g. Vogel et al. 1987; Hildreth and Wilson 2007; Chamberlain et al. 2015), mingled (e.g. Sampson and Cameron 1987; Vogel et al. 1989), or composed of multiple melt-dominant bodies (Cathey and Nash 2004; Cooper et al. 2012, 2016; Westgate et al. 2013; this thesis chapters 3 and 5).

\subsection{Geological background}

\subsubsection{Yellowstone Plateau volcanic field}

The Yellowstone Plateau volcanic field (YPVF) lies at the eastern end of the Snake River Plain (SRP), a $700 \mathrm{~km}$ arcuate northeast-trending volcano-tectonic depression extending from western Idaho to Wyoming (Figs. 1.3, 1.4). The SRP consists of eastward propagating silicic volcanic centres and intercalated and younger basaltic lava flows (Armstrong et al. 1975; 
Pierce and Morgan 1992, 2009). The time-progressive sequence of volcanism (which began at 16 Ma: Coble and Mahood 2012, 2015), elevated heat flow and tectonics have been attributed to the movement of the North American plate over a fixed mantle plume, now located beneath the Yellowstone area (Pierce and Morgan 1992; 2009; Lowenstern and Hurwitz 2008). This interpretation is supported by the seismic imaging of a low-velocity body extending deep into the mantle beneath the YPVF (Yuan and Dueker 2005; Smith et al. 2009;

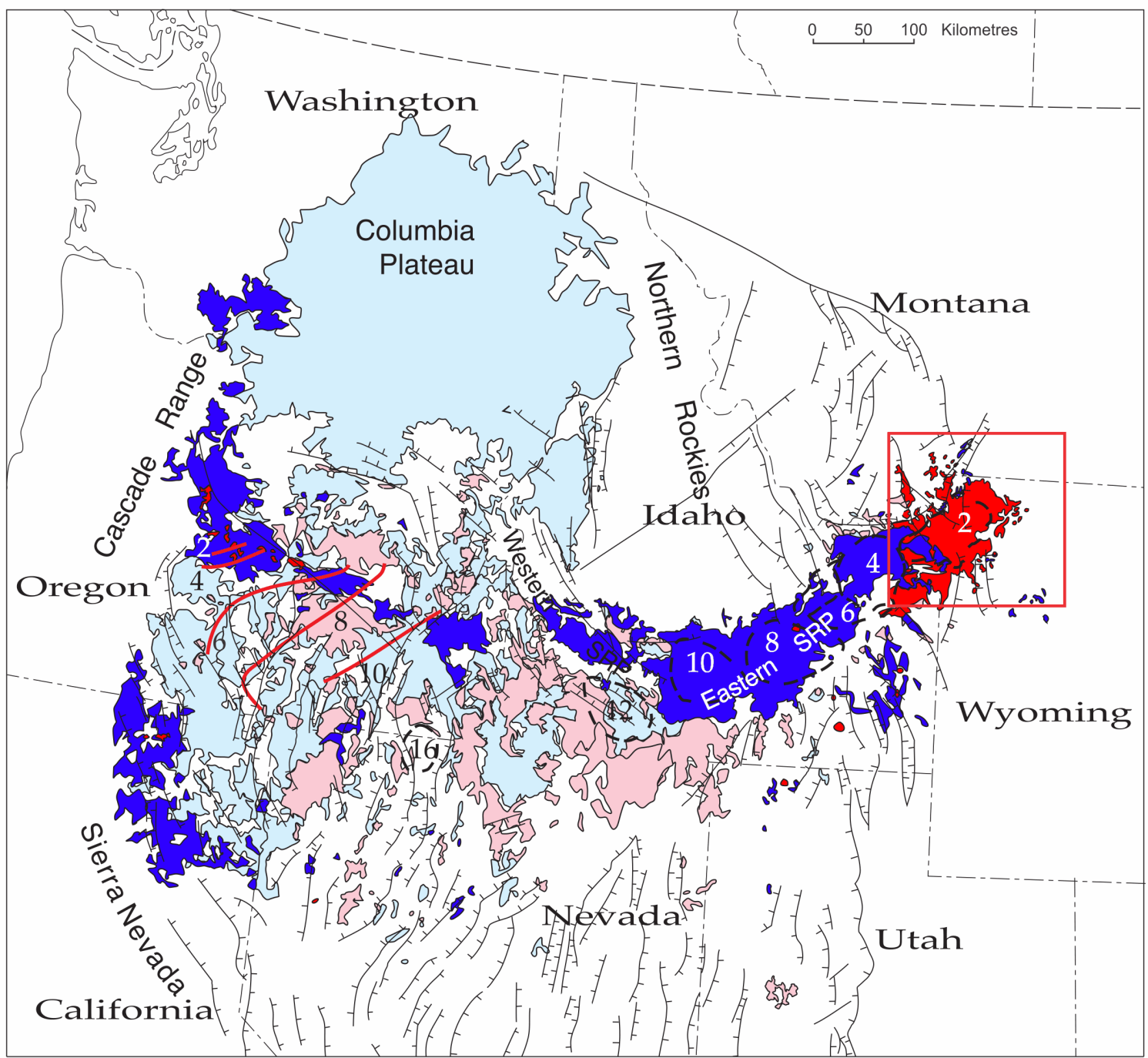

Figure 1.3: Map of the northwestern U.S.A showing the major $\leq 17 \mathrm{Ma}$ tectonic and volcanic features pertinent to this study. The extent of rhyolites (red) and basalts (blue) are shown, with the youngest deposits indicated by darker shades. Eastward propagating rhyolitic caldera complexes, and their associated ages, are shown, with Yellowstone (red box) representing the youngest of these. An antithetic northwestward volcanic trend towards the Cascade Range is indicated by age contours (red lines). Hachured lines indicate Basin and Range faults. Map adapted from Christiansen et al. (2007). 


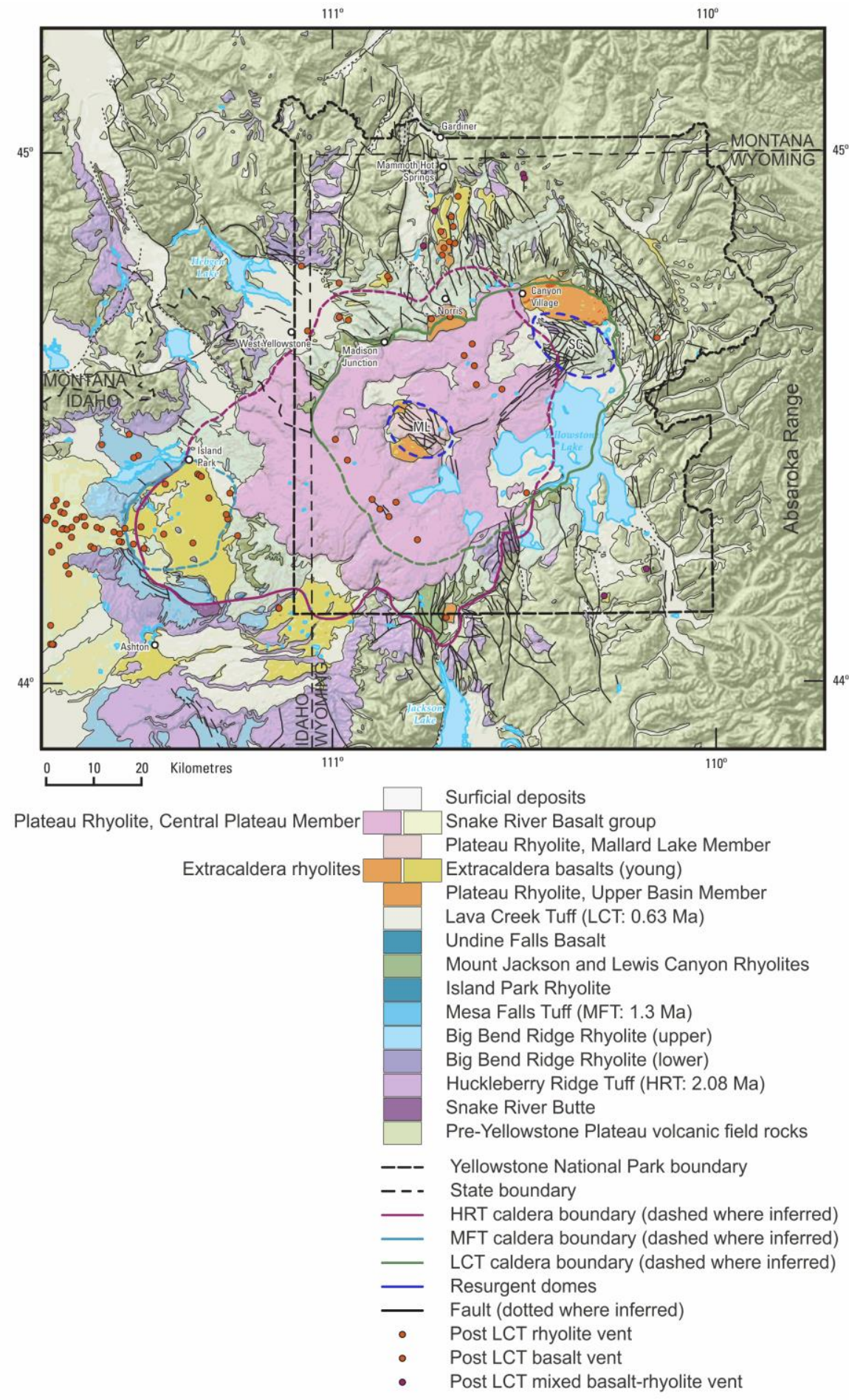

Figure 1.4: Simplified geological map of Yellowstone National Park and surrounding region, showing eruptive units associated with the Yellowstone Plateau volcanic field and major fault traces. Also shown are the outlines (dashed where inferred) of the mapped calderas for climactic explosive eruptions of the three volcanic cycles in Yellowstone, vent locations for lava flows that postdate the Yellowstone caldera (Lava Creek Tuff eruption $\sim 630 \mathrm{ka}$ ) and the two structurally resurgent domes in the field: Mallard Lake (ML) and Sour Creek (SC) domes. Map modified after Christiansen et al. (2007). 
Schmandt et al. 2012) and the primitive composition of geothermal gases at Yellowstone (Lowenstern et al. 2015). However features inconsistent with the plume model, such as the antithetically propagating Newberry volcanic track (Fig. 1.3), have generated debate (e.g. Humphreys et al. 2000). The presence of an upper mantle seismic anomaly along the length of the SRP, rather than simply focused beneath the YPVF, has also led to the hypothesis that the elevated heat flow and associated volcanism is due to upwelling around the descending Farallon slab (James et al. 2011; Zhou et al. 2018). Flat-slab subduction of the Farallon plate during the Eocene Laramide orogeny and the subsequent foundering of the slab has been used to explain converging volcanic fronts and regional volcanism during this time, including the Absaroka Volcanic Province, which lies at the eastern edge of the YPVF (Fig. 1.4; Christiansen and Yeats 1992; Humphreys 1995; Feeley 2003; Schmandt and Humphreys 2011).

The YPVF is embedded in a broad region of east-west extension, the Basin and Range Province (Parsons 1995). Across the YPVF, fault orientations and historical seismicity forms a $\mathrm{V}$ pattern, with an E-W trending zone of active seismicity north of the Yellowstone caldera and a separate band extending south to the northern caldera rim (Figs. 1.4, 1.5; Pierce and Morgan 1992; Smith et al. 2009). Extension is continuing within the YPVF at $4.3 \mathrm{~mm} / \mathrm{yr}$, as indicated by GPS data (Puskas et al. 2007), and historic extensional earthquakes (e.g. the Ms7.5 Hebgen Lake event: Smith et al. 2009 and references therein). This extension is a controlling factor on volcanism within the field, highlighted by the linear alignment of vents active during the most recent volcanic episodes (Fig. 1.4; Christiansen 2001) and the inferred tectonic control on the initial stages of the HRT eruption (Myers et al. 2016, Electronic Appendix 1). A strong control of tectonics on the alignment of vents and the modulation of eruption timings and styles has previously been proposed in other extensional volcanic regions, e.g. Taupo Volcanic Zone, New Zealand (Nairn et al. 1998; Gravley et al. 2007; Rowland et al. 2010; Allan et al. 2012; Cooper et al. 2012).

The YPVF has been active for the past $\sim 2.1 \mathrm{Myr}$ (Christiansen 2001). It has generated predominantly silicic eruptives, both lava flows and ignimbrites (with associated, enormously widespread fall deposits: Izett and Wilcox 1982), but also subordinate basaltic lava flows. The volcanic history of the field is defined around three eruptive cycles, each of which is climaxed by a large caldera-forming eruption and associated ignimbrite: the $\sim 2.1 \mathrm{Ma}, 2,500 \mathrm{~km}^{3}$ (DRE) Huckleberry Ridge Tuff, the $\sim 1.3 \mathrm{Ma}, 280 \mathrm{~km}^{3}$ Mesa Falls Tuff and the $\sim 0.63 \mathrm{Ma}, 1000 \mathrm{~km}^{3}$ Lava Creek Tuff (Fig. 1.4; Christiansen 2001; Rivera et al. 2014, 2016, 2017; Singer et al. 2014; 


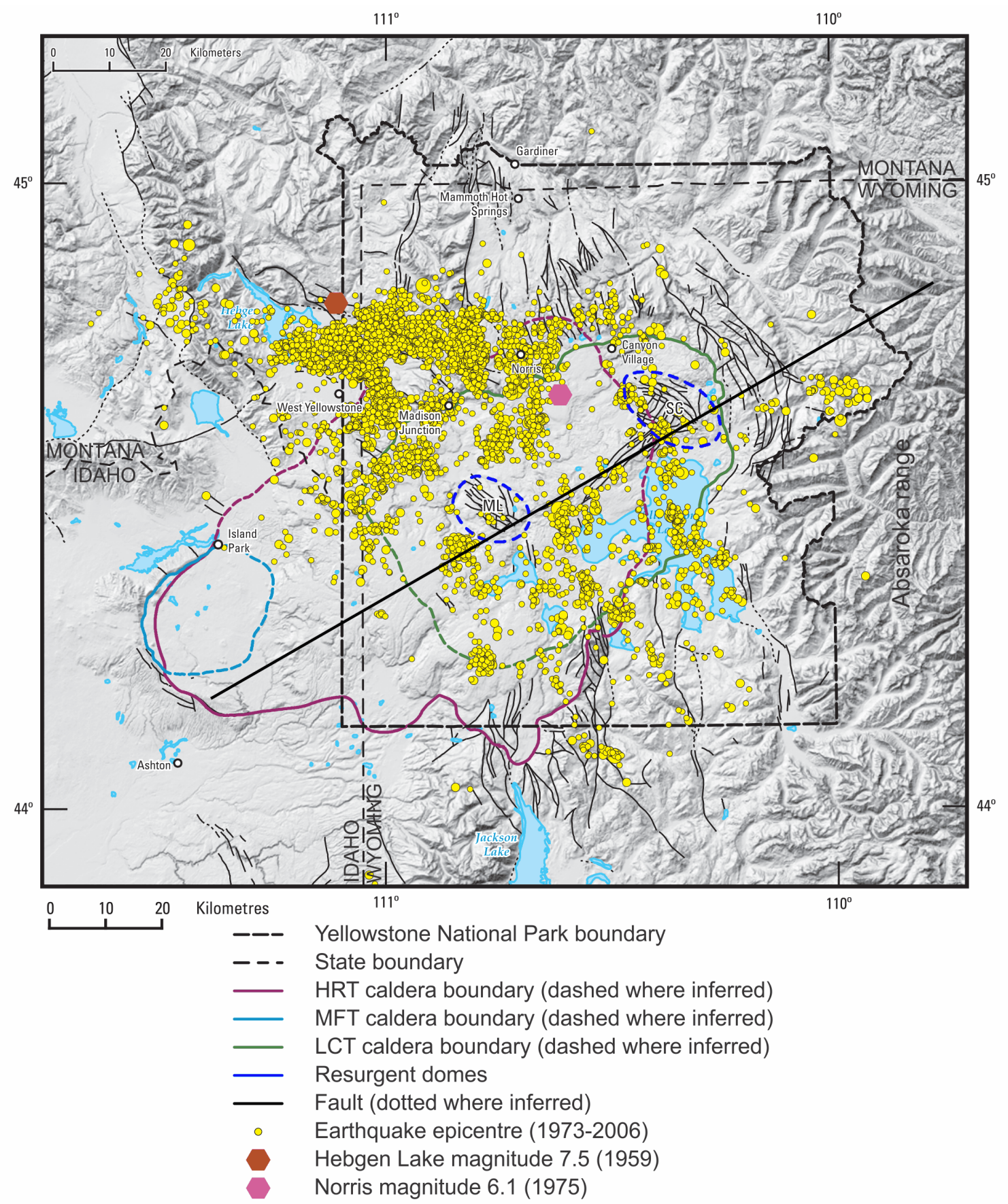

Figure 1.5: Map of well-resolved earthquake epicentres in and around Yellowstone National Park between 1973 and 2006 (sizes scaled to magnitude). Epicentres show NW-SE alignment through the calderas and an E-W zone of high seismicity between Hebgen Lake and the northern rim of the youngest caldera (Yellowstone Caldera). Coloured hexagons show the epicentres of the two largest historical earthquakes. Solid black line indicates line of cross-section in Fig. 1.6. Other features as in Fig. 1.4. Modified from Christiansen et al. (2007).

Matthews et al. 2015; Wotzlaw et al. 2015; Jicha et al. 2016; Ellis et al. 2017). Each climactic eruption is preceded and succeeded by rhyolitic and basaltic lava flows (Hildreth et al. 1984, 
1991; Christiansen 2001; Girard and Stix 2009, 2010; Watts et al. 2012; Stelten et al. 2015; Befus and Gardner 2016; Troch et al. 2017; Stelten et al. 2018).

Although the latest volcanism occurred at $\sim 70$ ka (Christiansen 2001), modern day geothermal and tectonic activity demonstrates the continued presence of a shallow magmatic system. Geophysical investigations have inferred the presence of a $90 \mathrm{~km}$-long, up to 10,000 $\mathrm{km}^{3}$, upper-crustal (5-17 km depth) inferred-rhyolitic magma chamber, containing up to $15 \%$ partial melt, which underlies the Yellowstone caldera area (Fig. 1.6: Smith et al. 2009; Farrell et al. 2014; Huang et al. 2015). Two resurgent domes in the YPVF, Sour Creek Dome and Mallard Lake Dome, are inferred to lie above two high-points in the underlying rhyolitic body (Fig. 1.4; Christiansen 2001; Smith et al. 2009). Although these geophysical data imply that a large volume of melt is present overall, the resolution of the geophysical methods is not sufficient to determine whether the melt is uniformly distributed within the reservoir or concentrated in regions, with consequently enhanced eruptive capability.

A large hydrothermal system is the current surface expression of the magmatic system, generating approximately 5-6 GW of convective heat flow, 30 times the continental average for the relevant area (Smith and Braile 1994; Lowenstern and Hurwitz 2008). Associated with the hydrothermal system is a significant gas flux, dominated by a $\sim 37 \times 10^{10} \mathrm{~mol} / \mathrm{yr} \mathrm{CO}_{2}$ output but also includes significant contributions from other gases (e.g. $\mathrm{Ar}, \mathrm{H}_{2}, \mathrm{H}_{2} \mathrm{~S}$, He: Kennedy et al. 1985; Werner and Brantley 2003; Lowenstern and Hurwitz 2008; Lowenstern et al. 2014). Although these gases are derived from a variety of sources within the mantle and crust, the flux and the mantle signature imply the presence of large volumes of young basaltic magma being intruded into the lower crust beneath the YPVF (Werner and Brantley 2003;

Lowenstern and Hurwitz 2008; Lowenstern et al. 2015). This interpretation has been supported by the seismic imaging of a large, $\sim 46,000 \mathrm{~km}^{3}$ lower-crustal magma body beneath the YPVF (Fig. 1.6: Huang et al. 2015).

Early work on the YPVF focused on the broad-scale mapping and stratigraphic overview of the field (Christiansen and Blank 1972; Christiansen 2001). These studies facilitated geochemical investigations that encompassed the temporal span of YPVF volcanism, almost entirely using selected whole-tuff or lava flow samples to investigate the elemental and isotopic evolution of the field (Doe et al. 1982; Hildreth et al. 1984; 1991; Christiansen 2001). Major-element compositions of YPVF eruptives indicate a bimodality, with tholeiitic basalts and ferroan rhyolites dominant and a general paucity of intermediate compositions or 


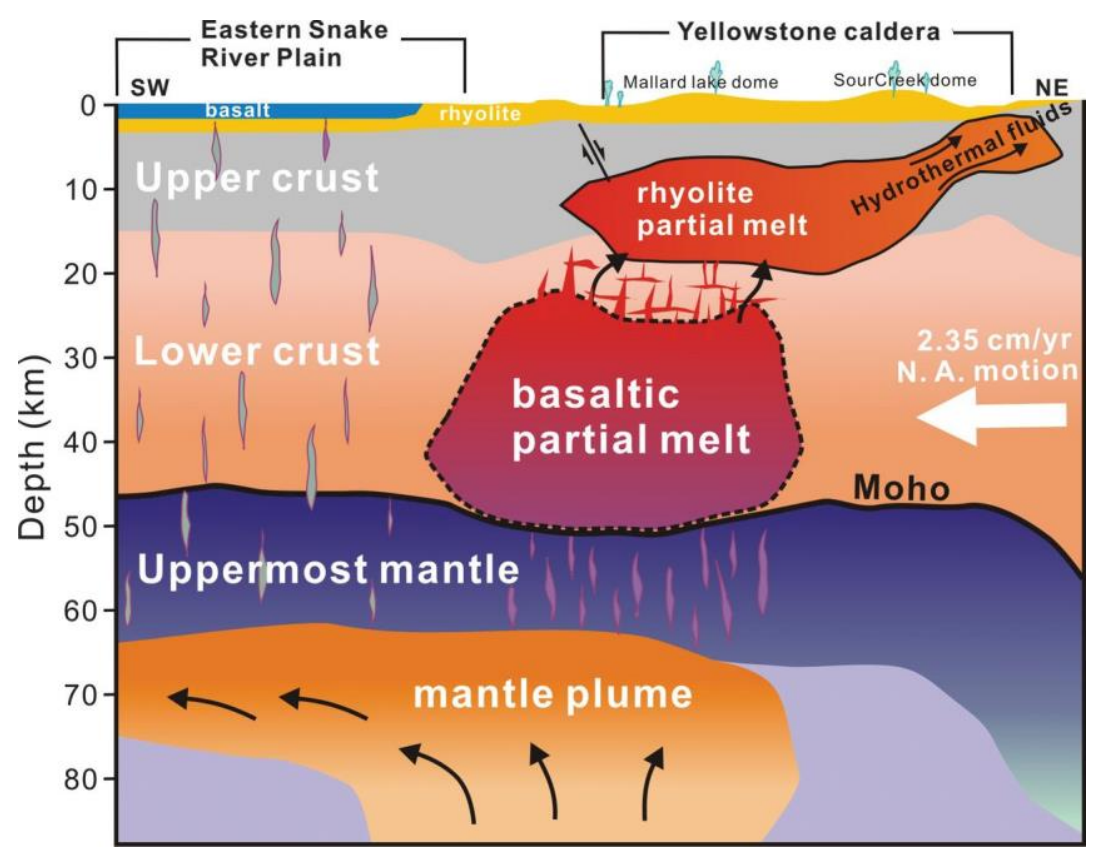

Figure 1.6: Cross-sectional schematic model for the Yellowstone magmatic system from the crust to the upper mantle along the Yellowstone-Snake River Plain axis (from Huang et al. 2015; see Fig. 1.5 for cross section). Below the Yellowstone area, there is interpreted to be upper and lower crustal partial melt bodies (inferred to be rhyolitic and basaltic respectively) and the top of a mantle plume, deflected by the $2.35 \mathrm{~cm} / \mathrm{yr}$ southwestward motion of the North American plate. Crustal partial melt bodies correspond to $\geq 5 \%$ reduction in $p$-wave velocities in the tomographic model used by Huang et al. (2015). Dashed outline to the basaltic body indicates the larger uncertainties in the position of its boundaries.

mingled magmas erupted in the volcanic field, similar to the Snake River Plain as a whole (Christiansen 2001; Christiansen and McCurry 2008; Szymanowski et al. 2015; Pritchard et al. 2016). The rhyolites have been interpreted as being derived from partial melts of solidified basaltic intrusives that were subsequently modified on their ascent to the surface by assimilation of Archean crustal rocks (Hildreth et al. 1991; Christiansen 2001; Christiansen and McCurry 2008). Snake River Plain and YPVF rhyolites are commonly labelled as 'hot' $\left(>900^{\circ} \mathrm{C}\right)$ and 'dry', due to their anhydrous phenocryst assemblages and inferred magmatic temperatures from Fe-Ti oxide and other mineral equilibria. These features are considered to be a reflection of the intracontinental setting and relationship with the underlying mantle thermal anomaly (Branney et al. 2008; Christiansen and McCurry 2008; Ellis et al. 2013; Loewen and Bindeman 2016).

Subsequent to early mapping efforts, work on the products of YPVF rhyolitic eruptions has aimed to determine the nature of rhyolite petrogenesis at Yellowstone and the source regions 
for the resultant melts. This work has predominantly focused on the more recent volcanic activity represented by the post-Lava Creek Tuff lava flows (Girard and Stix 2009, 2010; Vazquez et al. 2009; Loewen and Bindeman 2015; Stelten et al. 2015, 2017; Befus and Gardener 2016), and/or single-crystal investigations of eruptive units (Bindeman and Valley 2001; Bindeman et al. 2008; Watts et al. 2012; Rivera et al. 2014, 2016, 2017; Matthews et al. 2015; Till et al. 2015; Wotzlaw et al. 2015). The global debate on rhyolite petrogenesis is encapsulated in recent Yellowstone volcanism, with the most recent series of lavas, the Central Plateau Member, being interpreted alternatively as representing basalt-modulated pulses of crustal melting (Loewen and Bindeman 2015) or repeated melt extractions from a long-lived fractionating crystal mush system (Girard and Stix 2010; Stelten et al. 2015; Befus and Gardner 2016). The complex crystal-scale records from individual samples reported by these workers suggest the existence of a complex magmatic system encompassing a wide variety of melt compositions. These melts could plausibly be derived from a plethora of sources, including Archean basement and lithospheric mantle, Eocene igneous rocks, asthenospheric mantle melts and hydrothermally-altered crust (Hildreth et al. 1984, 1991; Rivera et al. 2014; Loewen and Bindeman 2015; Stelten et al. 2015; Wotzlaw et al. 2015; Troch et al. 2017, 2018). These components are then inferred to be assembled in the upper crust prior to eruption, at levels currently represented by the geophysically-imaged upper crustal magma body (Fig. 1.6: Farrell et al. 2014; Huang et al. 2015). The resulting eruptives are therefore a mix, in various proportions, of these components. Changes in the proportions of these components can be significant on a geologically short period of time following perturbations in the magmatic system (Doe et al. 1982; Hildreth et al. 1984). However, work on YPVF volcanism is generally founded on the simple notion that eruptions emanated from a single, large, rhyolitic magma body that accumulated at upper-crustal levels and was erupted in a single episode (Christiansen 2001). I reconsider these notions as part of this thesis (see chapters 3 and 5).

\subsubsection{The Huckleberry Ridge Tuff}

The $\sim 2,500 \mathrm{~km}^{3}, 2.08 \mathrm{Ma}$ Huckleberry Ridge Tuff (HRT) is the product of the climactic calderaforming eruption associated with the first cycle of volcanism in the YPVF (Fig. 1.4; Christiansen 2001; Rivera et al. 2014; Singer et al. 2014; Wotzlaw et al. 2015). It is preceded only by one known episode of rhyolitic volcanism, the 2.15 Ma Snake River Butte, and several mafic lavas 
grouped as the Junction Butte Basalt (Christiansen 2001; Wotzlaw et al. 2015). The HRT comprises three ignimbrite units: members $A, B$, and C, together with two sequences of fall deposits, one prior to member $\mathrm{A}$ and another prior to member $\mathrm{C}$. The overall ignimbrite was inferred to represent one compound cooling unit as no evidence for time breaks was observed (Christiansen 2001). However, more recent extensive fieldwork by my supervisor has shown that there is evidence for multiple time breaks, the longest a few decades long, within the initial fall deposits and between the three ignimbrite members (Chapter 5: Wilson 2009 , in prep). It has been proposed by Ellis et al. (2012) that, based on ${ }^{40} \mathrm{Ar} /{ }^{39} \mathrm{Ar}$ age determinations that are in conflict with both earlier and more recent studies (e.g. Singer et al. 2014), there is a $18 \pm 12$ kyr (2sd) time gap between members $B$ and $C$. However, palaeomagnetic work by Reynolds (1977) demonstrated that all parts of the ignimbrite contained a similar transitional polarity suggesting that the whole eruption was geologically rapid and hence, based on current understanding of the rapidity of palaeomagnetic excursions (e.g. Valet and Fournier 2016), any time breaks were limited to 1-2 centuries at most. The HRT is generally thought to conform to the standard model for Yellowstone calderaforming eruptions (e.g. Christiansen 1979, 2001; Hildreth et al. 1991), with the runaway evacuation of a single, zoned magma body. The resulting caldera is inferred to be a composite structure, with each member having emanated from a distinct source region that represented three high-level culminations of the unitary magma body (Christiansen 2001).

Although it is thought that the HRT was derived from a unitary magma body dominantly composed of high-silica rhyolite, whole-rock elemental and isotopic variations have been documented in the deposit. Low-silica rhyolite, sampled from the top of the mapped HRT member B, has been inferred to represent the base of a zoned magma body, inversely tapped during the course of the eruption (Hildreth et al. 1991; Christiansen 2001). Member C, in contrast, is distinctively different in its isotopic signature. Its $\mathrm{Sr}$ and $\mathrm{Nd}$ isotopic characteristics are distinctly more evolved than members $A$ and $B$, which has been inferred to represent widespread crustal assimilation following the eruption of members $A$ and $B$ and associated decompression and foundering of the magma chamber roof, despite its emplacement being inferred to have immediately succeeded members A and B (Reynolds 1977; Doe et al. 1982; Hildreth et al. 1984 1991). Although post-collapse isotopic excursions have been documented after subsequent explosive eruptions in the YPVF and also attributed to crustal assimilation, where observed in post-caldera lava flows they are also associated with depletions in $\delta^{18} \mathrm{O}$ 
values (Hildreth et al. 1984; Bindeman and Valley 2001). In contrast, HRT member C exhibits similar $\delta^{18} \mathrm{O}$ values to members $A$ and $B$, implying that any processes, however rapid, occurring during the HRT eruption are unique in the YPVF record. Trace element and isotopic compositions of zircon crystals from the HRT suggest complexity in the parental magmatic system, with clustering of compositions indicating the presence of multiple melt domains that amalgamated rapidly to form the melt-dominant body tapped to form the HRT (Rivera et al. 2014; Wotzlaw et al. 2015). A major issue, however, is that virtually all the samples used for the aforementioned studies and representing the body of knowledge about the HRT and its parental magma system have been carried out on whole-rock samples. This is known to be problematic because of the changes in proportions of dense to light juvenile fractions (e.g. Walker 1972) and the incorporation of accidental lithic components (e.g. Hildreth and Wilson 2007). The work presented in this thesis, therefore, provides a detailed overview to the HRT to determine the degree of heterogeneity in the eruption products and uses detailed sampling to reconstruct the nature of the magmatic system. 


\section{Chapter 2}

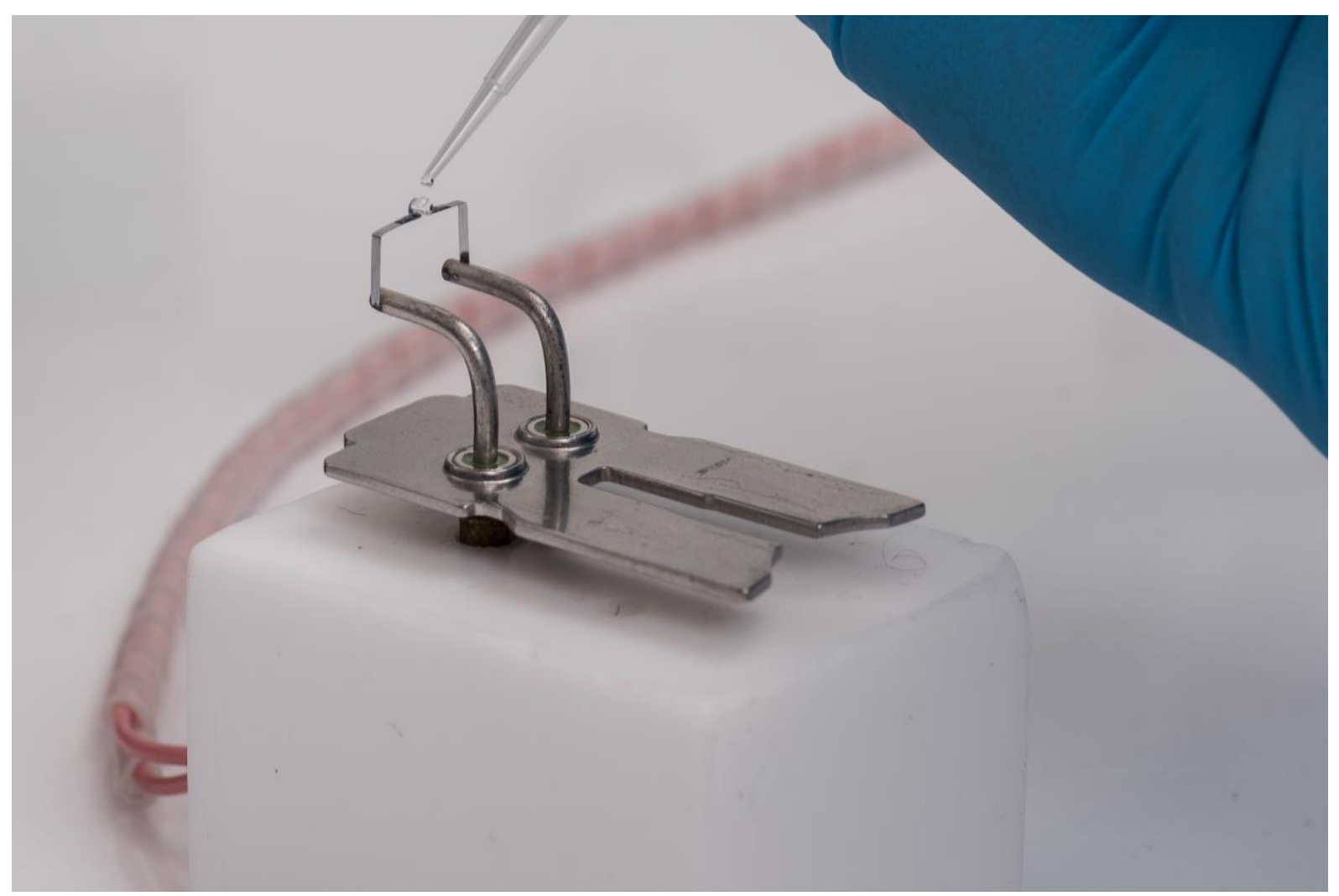

Photograph of loading a Re filament in preparation for isotopic analysis by Thermal Ionisation Mass Spectrometry. (c) Victoria University of Wellington. 


\section{Methods}

\subsection{Sampling methodology}

As discussed in Chapter 1, previous work on the HRT has almost exclusively used whole-rock samples that, although are often difficult to avoid, have limitations associated with them (see section 1.4). Therefore focus was placed on sampling single clasts present in the deposits, and particularly glassy juvenile clasts where possible. Due to the dominantly welded and devitrified nature of the HRT, occurrence of glassy material and non-welded material is severely limited. Locations where these occurred were extensively sampled. Although not representative of the spatial extent of the HRT deposits, a suite of samples representative of the range of the physical nature of the clasts were collected where possible (see section 5.3 for discussion of clast types). This was repeated for members A, B and C of the ignimbrite to enable investigation of any inter-member variation of physically similar clasts. Where clasts were sampled from welded ignimbrite, only partial removal was often possible, although enough of the clast to be representative of the overall physical characteristics was sampled. I collected samples over two field seasons in the YPVF. This sample suite is supplemented by samples collected on previous trips by my supervisor, Colin Wilson.

I sampled the initial fall deposit at Mt. Everts (UTM references $0526522 \mathrm{~m} \mathrm{E;} 4979967 \mathrm{~m}$ $\mathrm{N})$. The $2.5 \mathrm{~m}$ of initial fall deposits exposed here are characteristic of fall deposits observed elsewhere. The deposits are largely unconsolidated, with some fusing and blackening of matrix glass (due to exsolution of iron oxides) in the upper part from the heat of the overlying ignimbrite. The fall deposit comprises a crude tripartite structure, with fines-rich lower and upper portions sandwiching a coarser middle section. The deposit shows evidence for reworking at multiple horizons, with wind ripples and thickening of beds into palaeo-gullies observed. A bulk sample was collected from multiple horizons approximately every $15-20 \mathrm{~cm}$ through the entire sequence, focusing on coarser horizons for suitably-sized glass and crystals, and bracketing regions of reworking. Horizons sampled by Myers et al. (2016, Electronic Appendix 1) were re-sampled. See chapters 3 and S3 for more details. 


\subsection{General sample preparation}

Two groups of materials were sampled for this study: single clasts large enough to collect, and bulk samples of the pre-A and pre-C fall deposits where no juvenile clasts large enough to sample were present (i.e. all pumices were $<1-2 \mathrm{~cm}$ across). Single juvenile clasts (glassy pumice for preference, where available) were sampled wherever possible in order to determine the nature of the erupted material and to be able to discern any heterogeneities present. Only clasts large enough to give a representative sample of all of the constituents were used. Samples were trimmed with a Bianco Saw and washed with water to remove any adhering matrix and then systematically treated to ensure enough material was available for the variety of approaches used in this study (Fig. 2.1). Cleaned samples were coarsely crushed in a Rocklabs Boyd crusher to $\sim 2 \mathrm{~mm}$ or the size of the largest crystals, whichever was larger. The Boyd crusher is of value because it liberates crystals from the pumices intact, rather than fracturing them as often occurs with impact crushing. The crushed sample was then manually split into two parts, one for single-clast analysis and the other to be further processed for

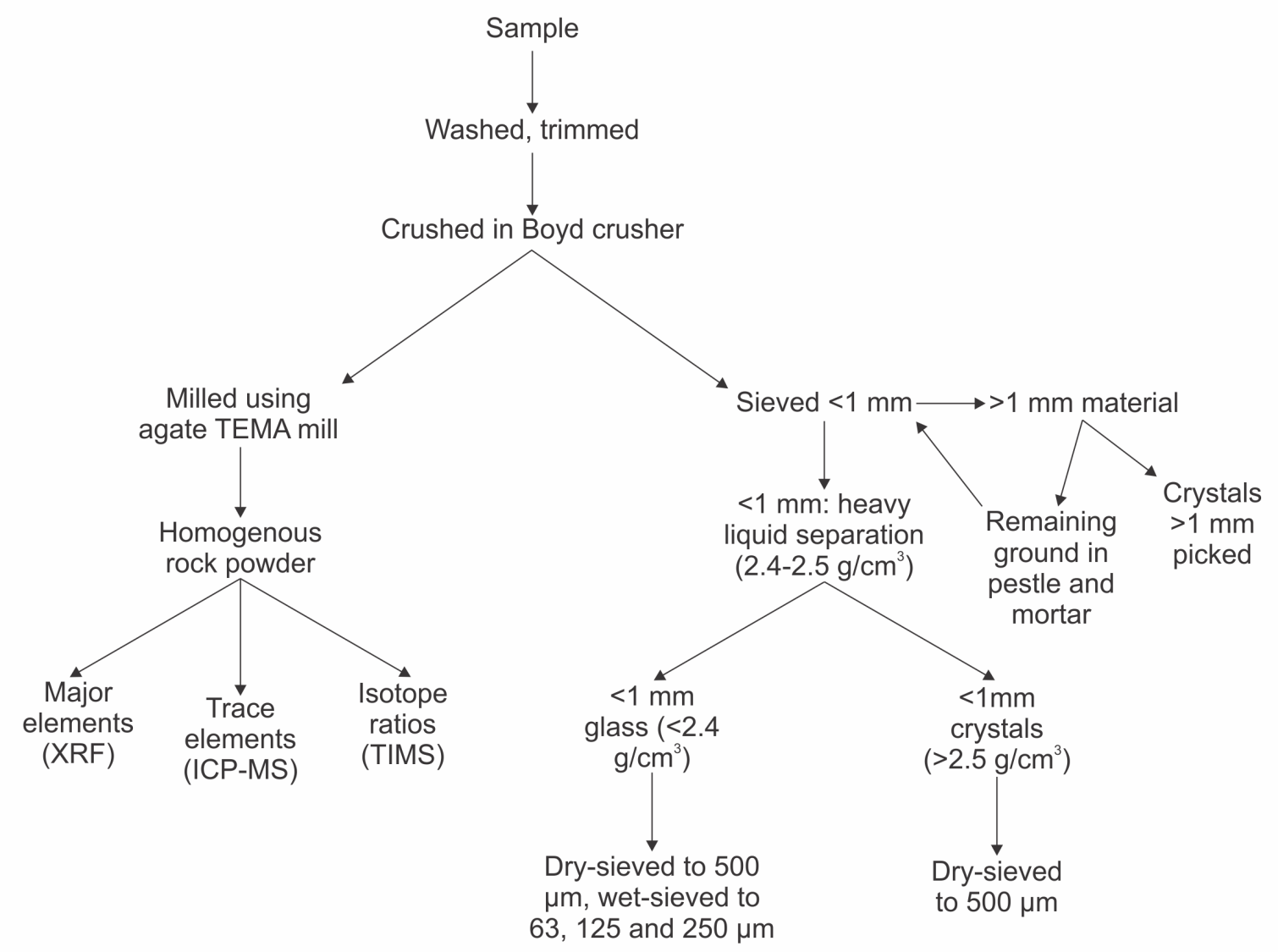

Figure 2.1: Flow chart showing general sample preparation for the variety of techniques used in this study 
component-specific analysis. The single clast portion was then ground to a fine powder using an agate Rocklabs ring mill. The remaining sample was sieved to $1 \mathrm{~mm}$. Coarser material was gently ground by hand using an ceramic mortar and pestle to liberate any remaining crystals intact and to reduce the size of any matrix to $<1 \mathrm{~mm}$ so the sample could be separated using heavy-liquid techniques. Crystals $>1 \mathrm{~mm}$ were hand picked. Crystals $\left(>2.5 \mathrm{~g} / \mathrm{cm}^{3}\right)$ and rhyolite glass $\left(<2.4 \mathrm{~g} / \mathrm{cm}^{3}\right)$ were separated from the sieved fraction using lithium-polytungstate (LST) heavy-liquid with a reduced density of $2.4-2.5 \mathrm{~g} / \mathrm{cm}^{3}$. The crystal fraction was weighed to give an approximate crystal wt\% for each sample. Crystals were sieved again to give a $0.5-1 \mathrm{~mm}$ fraction, found to be sufficiently large to encompass any textural variety observed in the crystal cargo. The glass portion was dry- and wet-sieved to 63, 125, 250 and $500 \mu \mathrm{m}$ size fractions and glass shards in the $250-500 \mu \mathrm{m}$ fraction were hand picked for in situ microanalysis. Unconsolidated (bulk) samples, almost entirely from the fall deposits, were sieved to the same mesh sizes as the crushed materials, and then hand-picked for mineral phases and glass shards.

\subsection{Single-clast compositions}

\subsubsection{XRF: single-clast major and minor elements}

Single clast major and selected trace element analyses were conducted at the Open University, United Kingdom (OU) and at the University of Auckland, New Zealand (UA). Sample preparation and analytical procedure for the two laboratories are documented in Table 2.1. Any samples yielding loss on ignition (LOI) values $>5 \mathrm{wt} \%$ were removed from the dataset as they were suspected/confirmed to be secondarily hydrated or contain carbonate. XRF data were normalised to $100 \%$. Replicate analysis of multiple standards in each laboratory return individual 2 sd precisions of better than $3 \%$ for almost all major element oxides, with most better than $1 \%$. Offsets from preferred or recommended values are generally $<5 \%$ for all elements. Analytical 2 sd precisions for Ba are mostly better than $6 \%$ with offsets $<7 \%$ from preferred or recommended values (Table 2.2). Duplicates analysed between laboratories show offsets $<5 \%$ for all element oxides $>0.1 \mathrm{wt} \%$ and $\leq 5 \%$ for Ba. Full standard data given in Electronic Appendix 2. 


\begin{tabular}{|c|c|c|}
\hline & Open University, United Kingdom & University of Auckland, New Zealand \\
\hline Instrument & $\begin{array}{l}\mathrm{ARL}^{\circ} 8420+\text { dual goniometer } \\
\text { wavelength dispersive } \mathrm{X} \text {-ray } \\
\text { fluorescene spectrometer with } \mathrm{Rh} \\
\text { tube. }\end{array}$ & $\begin{array}{l}\text { PANalytical }{ }^{\circ} \text { Axios } 1 \mathrm{~kW} \text { wavelength } \\
\text { dispersive X-ray fluorescene } \\
\text { spectrometer with Rh tube. }\end{array}$ \\
\hline $\begin{array}{l}\text { Fused disk } \\
\text { Preparation }\end{array}$ & $\begin{array}{l}1 \text { part dried powder ( } 0.7 \mathrm{~g} \text {; dried at } \\
110^{\circ} \mathrm{C} \text { ) with } 5 \text { parts lithium } \\
\text { tetraborate/metaborate ( } 20: 80 \text { ) flux. } \\
\text { Fused in Pt-Au crucibles ( } 95: 5 \text { ) at } \\
1100^{\circ} \mathrm{C} \text { for } 15 \text { minutes. Pressed to } \\
\text { form } 1.5 \mathrm{~mm} \text { thick, } 35 \mathrm{~mm} \text { diameter } \\
\text { disks. }\end{array}$ & $\begin{array}{l}1 \text { part dried powder ( } 3.5 \mathrm{~g} \text {; dried at } \\
110^{\circ} \mathrm{C} \text { ) with } 2 \text { parts lithium } \\
\text { tetraborate/metaborate ( } 35: 65 \text { ) flux. } \\
\text { Fused in Pt-Au crucibles }(95: 5) \text { at } \\
1050^{\circ} \mathrm{C} \text { for } 15 \text { minutes. Formed into } \\
1.5 \mathrm{~mm} \text { thick, } 40 \mathrm{~mm} \text { diameter disks. }\end{array}$ \\
\hline $\begin{array}{l}\text { Loss on ignition } \\
\text { (LOI) } \\
\text { determination }\end{array}$ & $\begin{array}{l}\text { Dried rock powder (dried at } 110^{\circ} \mathrm{C} \text { ) } \\
\text { heated in a pre-ignited aluminium } \\
\text { cruicible to } 1000^{\circ} \mathrm{C} \text { for } 1 \text { hour. The } \\
\text { percentage weight loss was then } \\
\text { calculated. }\end{array}$ & $\begin{array}{l}\text { Dried powder (dried at } 105^{\circ} \mathrm{C} \text { for } 24 \\
\text { hours) was heated at } 1050{ }^{\circ} \mathrm{C} \text { for } 12 \\
\text { hours. The percentage weight loss was } \\
\text { then calculated. }\end{array}$ \\
\hline
\end{tabular}

\subsubsection{Solution ICP-MS: trace elements}

Selected single clast samples, from the same powders that were used for XRF analysis, were prepared for trace element analysis by inductively coupled plasma mass spectrometry (ICPMS) at Victoria University of Wellington (VUW), New Zealand. All sample preparation took place in the ultra-clean geochemistry facility, with air filtered to Class 100 or better and only ultra-purity acids (key metals $<10$ ppt) were used in sample preparation. Acids used in the initial stages of beaker cleaning were analytical reagent (AR) grade. Acids were diluted with Milli-Q water (MQ) and molarities checked with a density meter. Due to the presence of zircon in many samples in this study, and the inefficient breakdown of this refractory mineral by standard low-pressure digestion techniques (Hu et al. 2013 and references therein), two methods were used in sample preparation for solution ICP-MS analysis. 


\begin{tabular}{|c|c|c|c|c|c|c|c|c|c|c|c|c|}
\hline & & $\mathrm{SiO}_{2}$ & $\mathrm{TiO}_{2}$ & $\mathrm{Al}_{2} \mathrm{O}_{3}$ & $\mathrm{Fe}_{2} \mathrm{O}_{3}(\mathrm{~T})$ & $\mathrm{MnO}$ & $\mathrm{MgO}$ & $\mathrm{CaO}$ & $\mathrm{Na}_{2} \mathrm{O}$ & $\mathrm{K}_{2} \mathrm{O}$ & $\mathrm{P}_{2} \mathrm{O}_{5}$ & $\mathrm{Ba}$ \\
\hline \multirow{5}{*}{$\begin{array}{c}\text { WS-E } \\
n=16\end{array}$} & Preferred & 51.07 & 2.43 & 13.77 & 13.09 & 0.17 & 5.63 & 9.00 & 2.48 & 1.00 & 0.30 & 335.00 \\
\hline & Average & 51.11 & 2.42 & 13.83 & 13.14 & 0.17 & 5.55 & 8.98 & 2.43 & 1.00 & 0.30 & 330.79 \\
\hline & Offset \% & 0.08 & -0.13 & 0.46 & 0.36 & 1.39 & -1.35 & -0.17 & -2.08 & -0.03 & -1.01 & -1.26 \\
\hline & $2 s d$ & 0.14 & 0.01 & 0.07 & 0.03 & 0.00 & 0.04 & 0.06 & 0.06 & 0.01 & 0.01 & 18.09 \\
\hline & $2 s d \%$ & 0.27 & 0.61 & 0.49 & 0.25 & 1.79 & 0.66 & 0.67 & 2.66 & 1.44 & 2.44 & 5.47 \\
\hline \multirow{5}{*}{$\begin{array}{l}\text { OU-3 } \\
\mathrm{n}=16 \\
\text { Long-term ou } \\
\text { average }\end{array}$} & Preferred & 74.09 & 0.22 & 11.11 & 3.83 & 0.09 & - & 0.20 & 3.68 & 4.55 & - & 29.00 \\
\hline & Average & 74.15 & 0.22 & 11.03 & 3.87 & 0.09 & 0.03 & 0.21 & 3.72 & 4.57 & 0.02 & 30.04 \\
\hline & Offset \% & 0.09 & 0.36 & -0.73 & 1.16 & 2.14 & & 4.47 & 1.12 & 0.43 & & 3.60 \\
\hline & $2 s d$ & 0.21 & 0.01 & 0.06 & 0.04 & 0.00 & 0.01 & 0.01 & 0.08 & 0.03 & 0.00 & 12.65 \\
\hline & $2 s d \%$ & 0.29 & 2.36 & 0.52 & 0.92 & 2.93 & 38.83 & 3.47 & 2.24 & 0.65 & 14.62 & 42.12 \\
\hline \multirow{5}{*}{$\begin{array}{c}\text { SY-2 } \\
\mathrm{n}=12 \\
\text { Gladney and } \\
\text { Roelandts (1990) }\end{array}$} & Preferred & 60.11 & 0.15 & 12.04 & 6.31 & 0.32 & 2.69 & 7.96 & 4.45 & 4.31 & 0.43 & 464.00 \\
\hline & Average & 59.81 & 0.13 & 11.97 & 6.19 & 0.32 & 2.62 & 7.90 & 4.46 & 4.22 & 0.43 & 435.00 \\
\hline & Offset \% & -0.51 & -11.33 & -0.60 & -1.98 & -1.48 & -2.65 & -0.75 & 0.30 & -2.09 & -0.33 & -6.25 \\
\hline & $2 s d$ & 0.17 & 0.00 & 0.06 & 0.02 & 0.01 & 0.05 & 0.02 & 0.01 & 0.01 & 0.00 & 13.49 \\
\hline & $2 s d \%$ & 0.28 & 2.38 & 0.53 & 0.25 & 2.97 & 2.05 & 0.21 & 0.33 & 0.34 & 1.09 & 3.10 \\
\hline \multirow{5}{*}{$\begin{array}{c}\text { JA-2 } \\
n=10 \\
\text { Jochum et al. (2016) }\end{array}$} & Preferred & 56.39 & 0.67 & 15.51 & 6.29 & 0.11 & 7.84 & 6.26 & 1.78 & 3.07 & 0.15 & 308.40 \\
\hline & Average & 56.46 & 0.67 & 15.64 & 6.11 & 0.11 & 7.21 & 6.15 & 1.80 & 3.10 & 0.15 & 314.20 \\
\hline & Offset \% & 0.12 & -0.43 & 0.83 & -2.86 & -3.85 & -8.10 & -1.77 & 1.29 & 1.04 & 0.72 & 1.88 \\
\hline & $2 s d$ & 0.28 & 0.01 & 0.06 & 0.04 & 0.00 & 0.13 & 0.03 & 0.02 & 0.01 & 0.00 & 6.68 \\
\hline & $2 s d \%$ & 0.50 & 1.06 & 0.36 & 0.59 & 4.26 & 1.84 & 0.54 & 0.97 & 0.32 & 1.31 & 2.13 \\
\hline \multirow{6}{*}{ Duplicates } & YR253 & 50.40 & 1.92 & 16.49 & 12.65 & 0.17 & 5.66 & 8.72 & 2.87 & 0.81 & 0.29 & 406 \\
\hline & YR253D & 50.52 & 1.97 & 16.37 & 12.66 & 0.17 & 5.64 & 8.67 & 2.89 & 0.82 & 0.28 & 427 \\
\hline & Offset \% & 0.23 & 2.27 & -0.71 & 0.05 & 1.99 & -0.44 & -0.60 & 0.78 & 0.56 & -1.34 & 5.20 \\
\hline & YR275 & 74.48 & 0.04 & 14.90 & 0.25 & 0.01 & 0.14 & 1.59 & 4.33 & 4.19 & 0.06 & 4181 \\
\hline & YR275D & 74.67 & 0.03 & 14.96 & 0.24 & 0.00 & 0.14 & 1.55 & 4.14 & 4.21 & 0.05 & 4118 \\
\hline & Offset \% & 0.25 & -14.88 & 0.44 & -4.59 & -45.84 & -3.93 & -2.36 & -4.55 & 0.44 & -13.31 & -1.50 \\
\hline
\end{tabular}




\subsubsection{Hydrofluoric acid digestion}

Samples with < $65 \mathrm{wt} \% \mathrm{SiO}_{2}$ and inferred to contain no or minimal zircon were prepared using standard techniques. Approximately $50 \mathrm{mg}$ of sample powder was weighed into precleaned $23 \mathrm{ml}$ Savillex screw-top Teflon beakers using a high precision balance (to $\pm 0.0001 \mathrm{~g}$ ). Subsequently, $\sim 2 \mathrm{ml}$ concentrated hydrofluoric acid (29 M HF) and $\sim 0.5 \mathrm{ml}$ concentrated nitric acid $\left(16 \mathrm{M} \mathrm{HNO}_{3}\right)$ were added to the powders. The beakers were then capped and placed on a hotplate at $120^{\circ} \mathrm{C}$ for 3-4 days to ensure complete digestion of the samples. The samples were visually inspected to check that no solid materials remained. Following digestion, the solution was evaporated to incipient dryness to prevent sample loss and formation of insoluble fluorides. The sample cake was then refluxed twice in $\sim 2 \mathrm{ml}$ concentrated $\mathrm{HNO}_{3}$ and taken to incipient dryness. Subsequently $\sim 5 \mathrm{ml} 6 \mathrm{M}$ hydrochloric acid $(\mathrm{HCl})$ was added and the beakers placed on a hotplate overnight. Following complete dissolution, the $\mathrm{HCl}$ was evaporated to dryness and the sample taken up in $\sim 2 \mathrm{ml}$ concentrated $\mathrm{HNO}_{3}$ for 2-3 days. After further evaporation, the sample was refluxed in $9 \mathrm{ml}$ $1 \mathrm{M} \mathrm{HNO}_{3}$ for 2-3 days. The final solutions were run through a centrifuge at $2000 \mathrm{rpm}$ for 5 minutes to ensure no solids remained before being transferred into pre-cleaned $10 \mathrm{ml}$ polyethylene centrifuge-tubes (c-tube) and precisely weighed $( \pm 0.0001 \mathrm{~g}$ ), ensuring all of the solution was removed from the beaker. The sample was further diluted by taking a $50 \mu \mathrm{l}$ aliquot of the final solution and transferring into another pre-cleaned polyethylene c-tube and adding $\sim 9 \mathrm{ml} 1 \% \mathrm{HNO}_{3}$. The c-tube was weighed prior to and following the addition of all solutions to enable the calculation of the final dilution factor. International rock standards (BHVO-2 and BCR-2) and a procedural blank were processed in the same way along with each sample batch.

\subsubsection{Ammonium fluoride digestion}

Following the procedure of Hu et al. (2013), approximately $50 \mathrm{mg}$ of powder was weighed in pre-cleaned $60 \mathrm{ml}$ Savillex screw top Teflon beakers. High-purity ammonium fluoride $\left(\mathrm{NH}_{4} \mathrm{~F}\right.$; Alfa-Aesar) was added to yield a sample: $\mathrm{NH}_{4} \mathrm{~F}$ ratio of 1:6. A few drops of $\mathrm{MQ}$ water was added to each sample and the beakers were shaken to ensure all the powder was wetted. The beakers were then placed in a Thermo Scientific Heratherm oven at $210^{\circ} \mathrm{C}$ for 60 hours, a temperature and duration chosen to avoid softening of the Teflon at higher temperatures, yet ensuring complete digestion of the powder. 
Once the beakers had cooled, approximately $4 \mathrm{ml}$ concentrated $\mathrm{HNO}_{3}$ (or enough to cover the base of the beakers) was added and immediately dried down on a hot plate at $160^{\circ} \mathrm{C}$. This step was repeated before the samples were refluxed in $5 \mathrm{ml}$ of $6 \mathrm{M} \mathrm{HNO}_{3}$ overnight at $120^{\circ} \mathrm{C}$. The resulting limpid solution was transferred to a c-tube, weighed and diluted with $1 \% \mathrm{HNO}_{3}$ to a 10,000-fold dilution for analysis. International standards GSP-2 and JR-1, and a procedural blank were processed alongside each batch of samples.

\subsubsection{Analysis and correction}

Trace element measurements were carried out using a Thermo-Fisher Element2 sector-field ICP-MS at VUW equipped with an ESI autosampler. Analysis procedure was similar to that of Eggins et al. (1997). Tuning of the ICP-MS was undertaken using a $10 \mathrm{ppb}$ multi-element standard, diluted to $1 \mathrm{ppb}$, and the torch position, gas flows and ion optics adjusted to optimise performance (i.e. low relative standard deviations of $<1-2 \%$; low oxide abundances: $\mathrm{UO}^{+} / \mathrm{U}^{+}<6-7 \%, \mathrm{BaO}^{+} / \mathrm{Ba}^{+}<2 \%$ and $\left.\mathrm{Ba}^{++} / \mathrm{Ba}^{+}<5 \%\right)$. Some isotopes were analysed at higher resolution to resolve the relevant peak (e.g. ${ }^{45} \mathrm{Sc},{ }^{47} \mathrm{Ti},{ }^{51} \mathrm{~V}$ ) or to reduce counts on highly abundant isotopes (e.g. ${ }^{25} \mathrm{Mg},{ }^{43} \mathrm{Ca},{ }^{55} \mathrm{Mn}$ ). Solutions were analysed for $90 \mathrm{~s}$ and were preceded by a $120 \mathrm{~s}$ washout using $1 \% \mathrm{HNO}_{3}$.

Concentrations of samples prepared using conventional HF digestion were calculated by correcting to an identically prepared rock standard of known composition (BHVO-2). Unknown samples (blocks of 3) were bracketed by repeated analyses of BHVO-2. Repeated analyses of a secondary standard, BCR-2, used to determine accuracy of the measurements and to monitor drift, were done after each block of unknowns. A procedural blank was analysed at the beginning of each run, with counts recorded being within the range of background levels for all elements. Abundances of elements were calculated using the following calculations:

$$
\begin{aligned}
& \text { Sample } C_{i}=\left(\text { Sample }_{C P S} / B H V O-2_{C P S}\right) \times\left(\text { Sample }_{\text {Dil }} / \text { BHVO-2 }{ }_{\text {Dil }}\right) \times \text { ref. } \\
& \text { Sample } C_{i}(\text { Ca corr. })=e q . \text {. (1) } \times\left(C_{C a} X R F / C_{C a} \text { ICP-MS }\right)
\end{aligned}
$$

where $C_{i}$ and $C_{C a}$ are the concentrations of the measured isotope $\mathrm{i}$ and $\mathrm{Ca}$, respectively, and $X_{\text {Dil }}$ is the dilution factor of the relevant solution. Reference values for BHVO-2 and BCR-2 were taken from Jochum et al. (2016). Repeated analyses of BCR-2 was used to estimate external precisions, which were $<6-7 \%$ for most elements except $\mathrm{Li}, \mathrm{Nb}, \mathrm{Cs}, \mathrm{Lu}, \mathrm{Ta}, \mathrm{Tl}, \mathrm{Pb}, \mathrm{Th}, \mathrm{U}, \mathrm{Ni} \mathrm{Cu}$, Zn $(<20 \%)$ and Mo (>20\%). Offsets relative to preferred values are $<6-7 \%$ for all elements, 
apart from Ta, TI, Cu (<15\%) and Mo (>15\%: Table 2.3; Electronic Appendix 2). Duplicate samples analysed within and between runs show 2 sd\% precisions of typically $<10 \%$ for all elements except $\mathrm{Zn}, \mathrm{Nb}$ and Th (<15 \%: Table 2.4).

Concentrations of samples digested by $\mathrm{NH}_{4} \mathrm{~F}$ were calculated relative to a calibration curve, constrained using multiple gravimetric dilutions ( $0.1 \mathrm{ppb}, 0.2 \mathrm{ppb}, 0.5 \mathrm{ppb}, 1 \mathrm{ppb}, 2 \mathrm{ppb}$ ) of a $1 \mathrm{ppm}$ stock standard solution comprising 57 elements. This procedure was undertaken to quantitatively calculate the concentrations of both standards run (GSP-2 and JR-1) and to

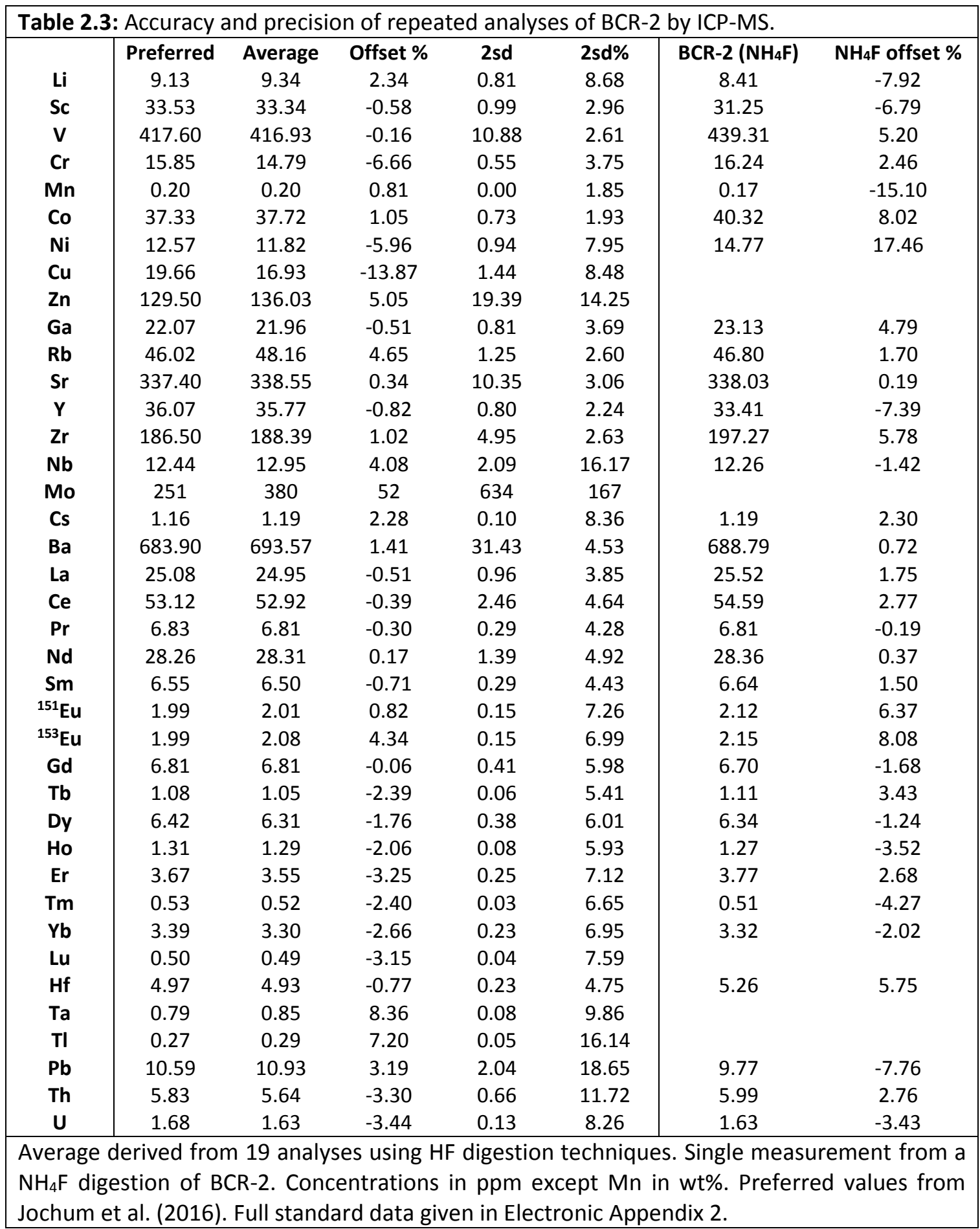




\begin{tabular}{|c|c|c|c|c|c|c|c|c|c|c|c|c|c|c|c|c|c|}
\hline & YP188 & YP188a & YP188b & $2 s d \%$ & YP244 & YP244a & 2sd\% & YP334B & YP334Ba & YP334Bb & $2 s d \%$ & YP382 & YP382a & $2 s d \%$ & YR425 & YR425a & $2 s d \%$ \\
\hline $\mathbf{L i}$ & 22.14 & 22.42 & 21.89 & 1.97 & 5.39 & 5.06 & 6.34 & 21.24 & 18.44 & 21.40 & 0.77 & 21.79 & 26.13 & 18.14 & 17.42 & 15.79 & 9.82 \\
\hline Sc & 16.91 & 16.86 & 17.34 & 2.53 & 21.06 & 21.11 & 0.22 & 26.28 & 26.35 & 25.51 & 2.95 & 37.93 & 38.74 & 2.12 & 22.69 & 22.42 & 1.19 \\
\hline v & 25.12 & 26.11 & 25.74 & 3.19 & 69.05 & 68.70 & 0.50 & 79.71 & 76.34 & 79.17 & 0.67 & 119.99 & 124.06 & 3.34 & 103.94 & 102.02 & 1.86 \\
\hline $\mathrm{Cr}$ & 3.88 & 3.80 & 3.75 & 2.84 & 5.89 & 6.08 & 3.04 & 5.38 & 3.62 & 4.51 & 17.61 & 7.31 & 7.18 & 1.83 & 2.90 & 2.90 & 0.04 \\
\hline$M n$ & 0.14 & 0.16 & 0.15 & 7.20 & 0.11 & 0.11 & 0.34 & 0.22 & 0.22 & 0.22 & 3.09 & 0.06 & 0.06 & 3.16 & 0.27 & 0.26 & 3.00 \\
\hline Co & 13.38 & 14.99 & 14.76 & 9.88 & 11.30 & 11.16 & 1.25 & 20.58 & 19.75 & 20.86 & 1.39 & 12.27 & 12.55 & 2.26 & 31.19 & 30.14 & 3.42 \\
\hline $\mathbf{N i}$ & 2.41 & 2.31 & 1.99 & 16.16 & 5.98 & 5.84 & 2.40 & 5.17 & 5.43 & 5.20 & 0.54 & 3.99 & 3.63 & 9.49 & 3.33 & 3.02 & 9.86 \\
\hline $\mathrm{Zn}$ & 174 & 199 & 210 & 15.31 & 231 & 255 & 10.06 & 194 & 190 & 217 & 11.26 & 330 & 349 & 5.45 & 181 & 196 & 7.95 \\
\hline Ga & 26.75 & 27.22 & 27.83 & 3.24 & 26.01 & 26.02 & 0.06 & 24.26 & 24.09 & 25.21 & 3.86 & 28.79 & 29.70 & 3.12 & 24.34 & 23.95 & 1.59 \\
\hline $\mathbf{R b}$ & 98.62 & 102.05 & 99.65 & 2.87 & 62.92 & 61.46 & 2.36 & 68.00 & 67.36 & 67.95 & 0.07 & 46.99 & 47.93 & 1.98 & 33.75 & 33.18 & 1.69 \\
\hline $\mathrm{Sr}$ & 138 & 138 & 139 & 0.33 & 247 & 247 & 0.05 & 265 & 267 & 272 & 2.42 & 338 & 344 & 1.84 & 347 & 334 & 3.82 \\
\hline $\mathbf{Y}$ & 313 & 293 & 294 & 6.13 & 74 & 76 & 2.41 & 73 & 70 & 72 & 0.91 & 108 & 113 & 4.28 & 92 & 88 & 3.64 \\
\hline $\mathrm{Zr}$ & 792 & 827 & 814 & 3.56 & 1386 & 1334 & 3.82 & 1353 & 1367 & 1407 & 3.92 & 1755 & 1760 & 0.25 & 753 & 744 & 1.20 \\
\hline $\mathrm{Nb}$ & 44.37 & 48.55 & 46.02 & 7.44 & 42.57 & 36.67 & 14.89 & 38.98 & 33.27 & 36.75 & 5.89 & 35.44 & 39.23 & 10.16 & 61.45 & 64.63 & 5.05 \\
\hline Cs & 1.58 & 1.68 & 1.70 & 6.15 & 0.76 & 0.75 & 1.55 & 0.98 & 0.95 & 1.04 & 6.41 & 0.67 & 0.73 & 9.71 & 0.52 & 0.49 & 5.80 \\
\hline $\mathrm{Ba}$ & 2722 & 2812 & 2816 & 3.11 & 3508 & 3514 & 0.15 & 3530 & 3488 & 3661 & 3.64 & 3432 & 3487 & 1.58 & 1262 & 1214 & 3.89 \\
\hline La & 324 & 328 & 322 & 1.59 & 76 & 76 & 0.89 & 72 & 63 & 70 & 3.04 & 111 & 113 & 1.79 & 92 & 88 & 4.66 \\
\hline $\mathrm{Ce}$ & 192 & 190 & 187 & 2.41 & 150 & 153 & 1.90 & 141 & 131 & 145 & 2.76 & 207 & 197 & 4.82 & 198 & 189 & 4.46 \\
\hline $\mathrm{Pr}$ & 69.08 & 73.31 & 70.64 & 4.92 & 18.98 & 18.89 & 0.47 & 17.74 & 16.10 & 17.76 & 0.10 & 27.85 & 27.91 & 0.20 & 23.14 & 22.64 & 2.21 \\
\hline $\mathbf{N d}$ & 261 & 289 & 279 & 8.20 & 78.96 & 77.67 & 1.64 & 72.80 & 66.41 & 74.07 & 1.73 & 119 & 120 & 0.49 & 95.84 & 90.97 & 5.21 \\
\hline Sm & 52.42 & 54.54 & 53.79 & 3.28 & 16.21 & 16.21 & 0.00 & 15.27 & 14.29 & 15.34 & 0.47 & 25.80 & 26.13 & 1.30 & 19.06 & 18.49 & 3.05 \\
\hline $\mathrm{Eu}$ & 7.42 & 7.44 & 7.89 & 5.73 & 6.37 & 6.90 & 8.02 & 6.56 & 6.35 & 7.22 & 9.49 & 8.06 & 8.77 & 8.43 & 6.00 & 5.36 & 11.34 \\
\hline Gd & 56.58 & 60.66 & 60.00 & 6.06 & 16.41 & 17.38 & 5.76 & 15.78 & 14.75 & 16.05 & 1.68 & 26.39 & 27.44 & 3.91 & 20.03 & 18.56 & 7.59 \\
\hline Tb & 8.24 & 8.80 & 8.68 & 5.58 & 2.41 & 2.43 & 0.91 & 2.29 & 2.15 & 2.31 & 0.59 & 3.82 & 4.02 & 5.12 & 2.79 & 2.62 & 6.49 \\
\hline Dy & 48.02 & 51.09 & 49.94 & 5.09 & 13.85 & 13.88 & 0.18 & 13.19 & 12.58 & 13.32 & 0.94 & 21.61 & 21.90 & 1.36 & 15.89 & 15.32 & 3.65 \\
\hline Ho & 9.47 & 9.93 & 9.82 & 4.10 & 2.71 & 2.70 & 0.40 & 2.59 & 2.46 & 2.66 & 2.92 & 3.98 & 4.18 & 5.01 & 3.24 & 2.92 & 10.14 \\
\hline $\mathrm{Er}$ & 24.90 & 26.64 & 26.14 & 5.67 & 7.28 & 7.36 & 1.03 & 7.15 & 6.66 & 7.24 & 1.27 & 10.28 & 10.66 & 3.65 & 8.72 & 8.23 & 5.78 \\
\hline $\mathrm{Tm}$ & 3.46 & 3.55 & 3.58 & 2.86 & 0.98 & 0.96 & 1.47 & 1.02 & 0.93 & 0.99 & 2.66 & 1.33 & 1.38 & 3.43 & 1.25 & 1.16 & 6.84 \\
\hline $\mathrm{Yb}$ & 20.89 & 21.48 & 20.89 & 2.67 & 5.79 & 5.76 & 0.57 & 6.63 & 6.15 & 6.28 & 5.54 & 7.86 & 7.88 & 0.24 & 7.75 & 7.56 & 2.41 \\
\hline Lu & 3.02 & 3.22 & 3.01 & 6.20 & 0.86 & 0.82 & 4.05 & 0.98 & 0.89 & 0.96 & 2.42 & 1.12 & 1.13 & 1.15 & 1.18 & 1.12 & 5.73 \\
\hline $\mathrm{Hf}$ & 16.98 & 17.59 & 17.24 & 2.90 & 25.82 & 24.91 & 3.58 & 25.79 & 23.95 & 25.19 & 2.34 & 30.18 & 30.93 & 2.44 & 14.00 & 13.42 & 4.23 \\
\hline $\mathrm{Ta}$ & 2.82 & 2.63 & 2.73 & 5.88 & 2.27 & 1.90 & 17.93 & 2.19 & 2.02 & 2.18 & 0.42 & 2.17 & 2.33 & 6.95 & 3.31 & 3.54 & 6.87 \\
\hline $\mathrm{Pb}$ & 23.74 & 26.56 & 21.53 & 17.21 & 33.69 & 34.55 & 2.53 & 46.41 & 39.96 & 50.00 & 7.44 & 30.32 & 29.19 & 3.77 & 14.34 & 13.23 & 8.05 \\
\hline Th & 14.67 & 16.34 & 13.36 & 16.50 & 10.12 & 9.64 & 4.84 & 11.55 & 10.15 & 11.36 & 1.69 & 7.56 & 6.69 & 12.22 & 4.71 & 4.50 & 4.50 \\
\hline $\mathbf{U}$ & 5.69 & 5.89 & 5.75 & 3.00 & 2.60 & 2.53 & 2.51 & 2.57 & 2.26 & 2.50 & 2.71 & 2.14 & 2.21 & 3.34 & 1.35 & 1.31 & 2.72 \\
\hline
\end{tabular}


confirm the accuracy of results and efficacy of the method (i.e. full sample digestion). The 0.5 ppb calibration solution was measured after every four samples to monitor instrumental drift. Procedural blanks were $<0.1 \mathrm{ppb}$ for all elements, with most within the range of background counts. Abundances were calculated using the following equation:

$$
\text { Sample } C_{i}=\left(\left(\text { Sample }_{\text {CPS }} \times \mathrm{c}\right) / \text { Sample }_{\text {Dil }}\right) / 1000
$$

where $c$ is the gradient of the calibration slope. Measured counts from calibration and unknown solutions were blank-corrected using the acid blank and procedural blank,

\begin{tabular}{|c|c|c|c|c|c|c|c|c|c|c|}
\hline & \multicolumn{5}{|c|}{ GSP-2 } & \multicolumn{5}{|c|}{ JR-2 } \\
\hline & Preferred & Average & $\begin{array}{c}\text { Offset } \\
\%\end{array}$ & $2 s d$ & $2 s d \%$ & Preferred & Average & $\begin{array}{c}\text { Offset } \\
\%\end{array}$ & $2 s d$ & $2 \mathrm{sd} \%$ \\
\hline Li & 36 & 35.45 & -1.52 & 0.90 & 2.53 & 61.4 & 64.38 & 4.85 & 1.35 & 2.10 \\
\hline Sc & 6.3 & 6.38 & 1.29 & 0.35 & 5.43 & 5.07 & 5.17 & 2.05 & 0.45 & 8.69 \\
\hline V & 52 & 51.12 & -1.69 & 1.94 & 3.80 & 7 & 5.44 & -22.22 & 0.08 & 1.41 \\
\hline $\mathrm{Cr}$ & 20 & 18.97 & -5.13 & 0.84 & 4.43 & 2.83 & 1.26 & -55.60 & 0.70 & 55.71 \\
\hline Co & 7.3 & 6.99 & -4.19 & 0.25 & 3.51 & 0.83 & 0.55 & -33.73 & 0.00 & 0.04 \\
\hline $\mathrm{Ni}$ & 17 & 15.33 & -9.82 & 1.11 & 7.23 & 1.67 & 0.37 & -77.83 & 0.04 & 10.64 \\
\hline $\mathrm{Cu}$ & 43 & 40.12 & -6.71 & 2.76 & 6.87 & 2.68 & 1.78 & -33.76 & 0.30 & 16.76 \\
\hline $\mathrm{Zn}$ & 120 & 94.96 & -20.87 & 7.50 & 7.90 & 30.6 & 23.70 & -22.54 & 3.27 & 13.82 \\
\hline Ga & 22 & 21.33 & -3.04 & 0.67 & 3.16 & 16.1 & 16.15 & 0.30 & 1.38 & 8.52 \\
\hline $\mathbf{R b}$ & 245 & 233 & -4.74 & 9.14 & 3.91 & 257 & 247.10 & -3.85 & 20.60 & 8.34 \\
\hline $\mathrm{Sr}$ & 240 & 218 & -9.11 & 8.44 & 3.87 & 29.1 & 26.00 & -10.67 & 1.68 & 6.45 \\
\hline $\mathbf{Y}$ & 28 & 23.38 & -16.50 & 0.81 & 3.44 & 45.1 & 37.72 & -16.37 & 2.61 & 6.91 \\
\hline $\mathrm{Zr}$ & 550 & 594 & 7.98 & 9.33 & 1.57 & 99.9 & 88.57 & -11.34 & 7.21 & 8.14 \\
\hline Nb & 27 & 26.82 & -0.65 & 1.14 & 4.24 & 15.2 & 15.61 & 2.69 & 1.06 & 6.77 \\
\hline Cs & 1.2 & 1.11 & -7.72 & 0.05 & 4.87 & 20.8 & 19.21 & -7.63 & 1.44 & 7.50 \\
\hline $\mathrm{Ba}$ & 1340 & 1318 & -1.67 & 29.59 & 2.25 & 50.3 & 44.37 & -11.79 & 2.80 & 6.30 \\
\hline La & 180 & 178 & -1.41 & 4.52 & 2.55 & 19.7 & 18.45 & -6.33 & 1.11 & 6.03 \\
\hline $\mathrm{Ce}$ & 410 & 421 & 2.73 & 3.02 & 0.72 & 47.2 & 44.91 & -4.85 & 2.19 & 4.87 \\
\hline $\mathrm{Pr}$ & 51 & 53.22 & 4.35 & 1.37 & 2.58 & 5.58 & 5.62 & 0.77 & 0.27 & 4.79 \\
\hline Nd & 200 & 194 & -3.09 & 3.41 & 1.76 & 23.3 & 21.82 & -6.36 & 1.09 & 5.01 \\
\hline Sm & 27 & 24.87 & -7.89 & 0.59 & 2.35 & 6.03 & 5.58 & -7.47 & 0.43 & 7.72 \\
\hline Eu & 2.3 & 2.50 & 8.89 & 0.17 & 6.59 & 0.3 & 0.28 & -8.28 & 0.02 & 6.21 \\
\hline Gd & 12 & 18.83 & 56.88 & 2.91 & 15.48 & 5.06 & 5.46 & 7.82 & 0.48 & 8.79 \\
\hline Tb & & 1.79 & & 0.16 & 9.21 & 1.01 & 0.99 & -1.80 & 0.07 & 6.65 \\
\hline Dy & 6.1 & 5.51 & -9.59 & 0.08 & 1.41 & 5.69 & 5.96 & 4.81 & 0.30 & 5.03 \\
\hline Ho & 1 & 0.89 & -10.87 & 0.04 & 4.46 & 1.11 & 1.23 & 10.90 & 0.05 & 3.77 \\
\hline $\mathrm{Er}$ & 2.2 & 3.05 & 38.83 & 0.18 & 6.01 & 3.61 & 4.06 & 12.40 & 0.24 & 5.97 \\
\hline $\mathrm{Tm}$ & 0.29 & 0.27 & -5.34 & 0.01 & 2.85 & 0.67 & 0.63 & -5.90 & 0.03 & 5.27 \\
\hline $\mathrm{Yb}$ & 1.6 & 1.70 & 6.11 & 0.07 & 3.94 & 4.55 & 4.37 & -3.98 & 0.24 & 5.57 \\
\hline Lu & 0.23 & 0.26 & 12.76 & 0.00 & 1.92 & 0.71 & 0.72 & 1.17 & 0.02 & 2.30 \\
\hline $\mathrm{Hf}$ & 14 & 15.24 & 8.84 & 0.10 & 0.65 & 4.51 & 4.61 & 2.27 & 0.32 & 6.88 \\
\hline Ta & & 1.02 & & 0.02 & 2.06 & 1.86 & 1.90 & 1.88 & 0.07 & 3.70 \\
\hline $\mathrm{Pb}$ & 42 & 44.70 & 6.42 & 4.60 & 10.30 & 19.3 & 16.78 & -13.05 & 0.83 & 4.97 \\
\hline Th & 105 & 101.62 & -3.22 & 0.61 & 0.60 & 26.7 & 24.79 & -7.14 & 0.68 & 2.74 \\
\hline $\mathbf{U}$ & 2.4 & 2.37 & -1.43 & 0.06 & 2.65 & 8.88 & 8.32 & -6.26 & 0.36 & 4.33 \\
\hline
\end{tabular}


respectively. Repeated analyses of rock standards GSP-2 and JR-1 yielded offsets from preferred values of $<10 \%$ for all elements except Ho, Er ( $<15 \%)$, Y $(<20 \%)$ and $\mathrm{Zn}(>20 \%)$, and 2 sd $\%$ similarly of $<10 \%$ for all elements (Table 2.5; Electronic Appendix 2). To check for consistency between the two methods ran, $\mathrm{BCR}-2$ was also digested using the $\mathrm{NH}_{4} \mathrm{~F}$ method. Measurements of this solution gave offsets from preferred values of $\leq 8 \%$ for all elements except $\mathrm{Mn}$ and $\mathrm{Ni}(<20 \%)$, comparable to, if not better than, offsets derived from analysis using the HF technique (Table 2.3).

\subsubsection{Sample preparation for isotope ratio measurements}

Samples were selected for isotopic analysis to cover the range of compositions measured by XRF and ICP-MS. Separation methodologies for $\mathrm{Sr}, \mathrm{Nd}$ and $\mathrm{Pb}$ were based on those of Pin et al. (2014), with minor modification where appropriate (Fig. 2.2). Rock powders were digested in pre-cleaned Savillex screw-topped Teflon beakers using the $\mathrm{HF}$ and $\mathrm{NH}_{4} \mathrm{~F}$ digestion techniques detailed above for 'mafic' ( $<65$ wt $\% \mathrm{SiO}_{2}$ ) and 'silicic' ( $>65 \mathrm{wt} \% \mathrm{SiO}_{2}$ ) samples, respectively. Two aliquots of the final solution, one for $\mathrm{Sr}$ and $\mathrm{Nd}$ (containing $\geq 200 \mathrm{ng} \mathrm{Nd}$ ), and one for $\mathrm{Pb}$ (containing $\geq 200 \mathrm{ng} \mathrm{Pb}$ ) were taken and transferred into pre-cleaned beakers. Solutions were dried ready for processing.

Prior to element-specific columns, 'silicic' Sr and Nd solutions were passed through precleaned cation columns filled with AG50W-X8 resin in order to pre-concentrate the Sr due to the high $\mathrm{Rb} / \mathrm{Sr}$ ratio in these samples. Separation was achieved by loading the sample in $1 \mathrm{ml}$ $2.5 \mathrm{M} \mathrm{HCl}$, then eluting to waste $1 \mathrm{ml}$ then $6 \mathrm{ml} 2.5 \mathrm{M} \mathrm{HCl}$. Sr was subsequently collected in 10 $\mathrm{ml} 2.5 \mathrm{M} \mathrm{HCl}$. A further $7 \mathrm{ml}$ of $2.5 \mathrm{M} \mathrm{HCl}$ was eluted to waste, then $10 \mathrm{ml}$ of $6 \mathrm{M} \mathrm{HCl}$ was added to collect a Nd fraction. All fractions were dried. The Sr-bearing fractions were then taken up in $9 \mathrm{M} \mathrm{HNO}_{3}$ to ensure conversion to nitrates prior to being dried again in preparation for further separation. The 'mafic' $\mathrm{Sr}$ and $\mathrm{Nd}$ aliquots did not require preconcentration on the cation column. For Sr separation, all fractions were taken up in $6 \mathrm{M} \mathrm{HNO}$ ready to pass through cleaned columns loaded with pre-cleaned Sr-Spec resin. The Sr-Spec resin was pre-conditioned with $\sim 0.5 \mathrm{ml} 9 \mathrm{M} \mathrm{HNO}_{3}$. The sample was loaded before sequential elution to waste of 100,200 and $3 \times 1000 \mu \mathrm{l} 9 \mathrm{M} \mathrm{HNO}_{3}$ removed $\mathrm{Ba}$, $\mathrm{Ca}$ and other unwanted elements. For 'mafic' samples, these elutions were collected for further separation of $\mathrm{Nd} .2$ $\mathrm{ml} 0.05 \mathrm{M} \mathrm{HNO}_{3}$ was then passed through the Sr-Spec column to back extract the $\mathrm{Sr}$. 


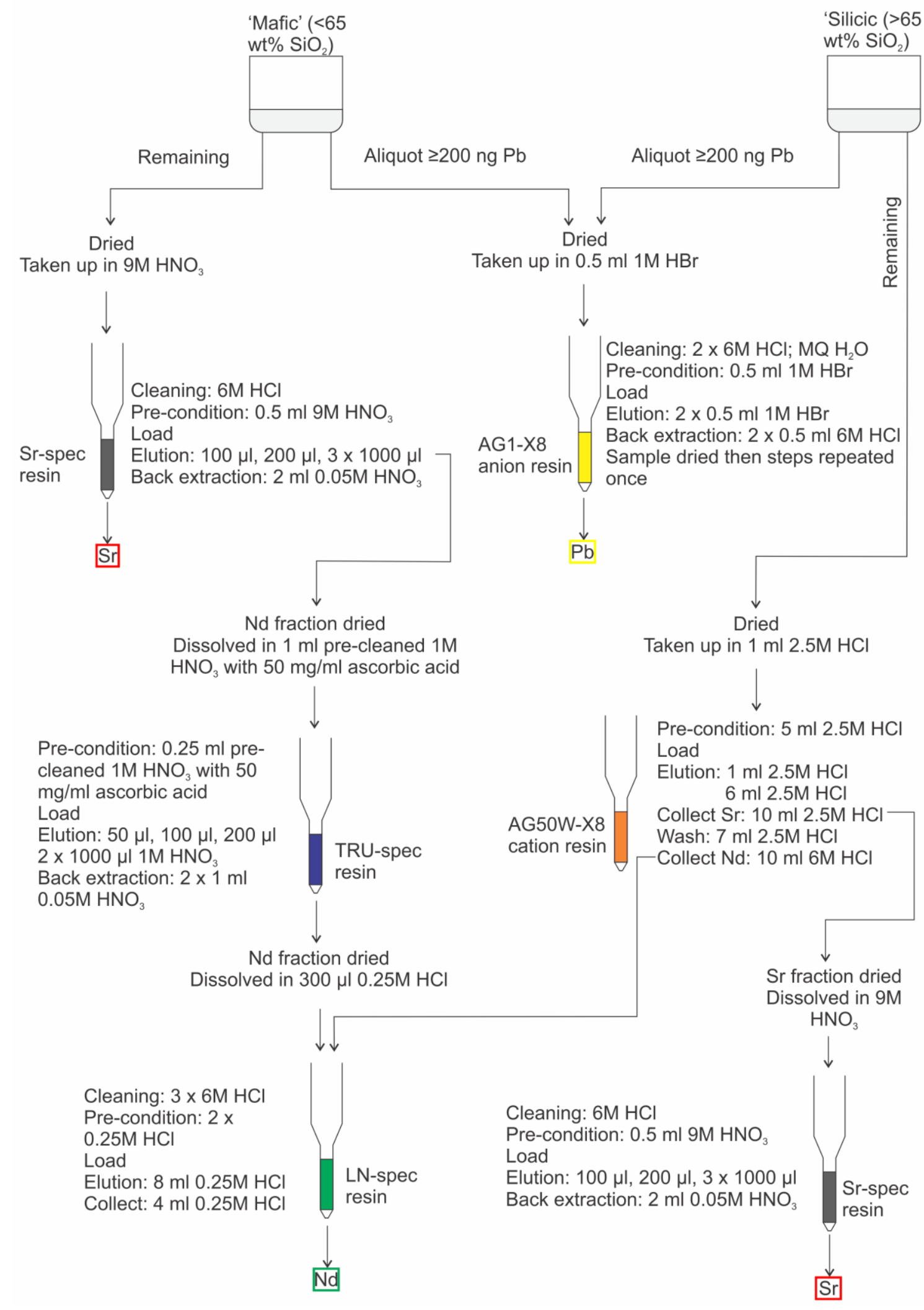

Figure 2.2: Schematic showing the procedure for separation of $\mathrm{Sr}, \mathrm{Nd}$ and $\mathrm{Pb}$ for isotopic analysis by extraction chromatography based on the method of Pin et al. (2014). 
For 'mafic' samples, the dried $\mathrm{Nd}$ fraction was taken up with $1 \mathrm{ml}$ of $1 \mathrm{M} \mathrm{HNO}_{3}$ containing $50 \mathrm{mg} \mathrm{ml}^{-1}$ ascorbic acid $\left(\mathrm{C}_{6} \mathrm{H}_{8} \mathrm{O}_{6}\right)$ in order to reduce the $\mathrm{Fe}_{(I I I)}$ to $\mathrm{Fe}_{(I I)}$ because the oxidation state of the Fe has been shown to be important in obtaining good yields for the REE (Horwitz et al. 1993; Pin and Zaldeugui 1997). To reduce the blank inherent in the ascorbic acid, the nitric-ascorbic acid solution was pre-cleaned by passing it through a TRU-Spec column. Reduction of the Fe was accompanied by a colour change - when the sample solution turned pale yellow the solution was ready for column separation. The TRU-Spec columns were preconditioned with $0.25 \mathrm{ml}$ of the $\mathrm{HNO}_{3}$-ascorbic solution before addition of the sample solution. Then $50,100,200$ and $2 \times 1000 \mu l$ of $1 \mathrm{M} \mathrm{HNO}_{3}$ was eluted to waste. Then a LREE-, Th- and Ubearing fraction was back extracted in $2 \times 1 \mathrm{ml}$ of $0.05 \mathrm{HNO}_{3}$, then dried. The pre-concentrated 'silicic' samples did not require pre-concentration on TRU-Spec columns.

For final separation of $\mathrm{Nd}$ from other REE, dried fractions were taken up in $300 \mu \mathrm{l} 0.25 \mathrm{M}$ $\mathrm{HCl}$ and passed through $\mathrm{LN}-\mathrm{Spec}$ columns that had been pre-cleaned with $6 \mathrm{M} \mathrm{HCl}$ (three times) before being pre-conditioned with $0.25 \mathrm{M} \mathrm{HCl}$ (twice). The lanthanides were separated chromatographically through further addition of $0.25 \mathrm{M} \mathrm{HCl}$. Column calibrations were undertaken to identify the position of the $\mathrm{Nd}$ fraction in the elution profile, and to minimise Ce and Pr overlap. LN-Spec column calibration was carried out by collecting $400 \mu$ increments of $0.25 \mathrm{M} \mathrm{HCl}$ until $22 \mathrm{ml}$ of $0.25 \mathrm{M} \mathrm{HCl}$ had been passed through the column. A subsequent $1 \mathrm{ml}$ addition of $6 \mathrm{M} \mathrm{HCl}$ was collected. The $400 \mu \mathrm{l}$ increments were dried and taken up in $1 \%$ $\mathrm{HNO}_{3}$ for semi-quantitative analysis on the Element 2. The peak in $\mathrm{Nd}$ counts in the column increments indicated that collection of the 8 to $12 \mathrm{ml} 0.25 \mathrm{M}$ fraction produced good separation for $\mathrm{Nd}$. These $0.25 \mathrm{M} \mathrm{HCl}$ fractions did not contain Sm (Electronic Appendix 2).

Separation of $\mathrm{Pb}$ was achieved using the traditional 'bromide separation' approach on AG1-X8 anion resin (e.g. Strelow and von Toerien 1966; Oversby 1975). The pre-cleaned resin was transferred to columns made from $1 \mathrm{ml}$ pipette tips, then finally cleaned by passing $\mathrm{MQ}$ water then $6 \mathrm{M} \mathrm{HCl}$ through the resin twice, then residual $\mathrm{HCl}$ was washed out with $\sim 2.5 \mathrm{ml}$ $\mathrm{MQ} \mathrm{H}_{2} \mathrm{O}$. The resin was then pre-conditioned with $0.5 \mathrm{ml} 1 \mathrm{M} \mathrm{HBr}$ and the sample loaded in $0.5 \mathrm{ml} 1 \mathrm{M} \mathrm{HBr}$. Two passes of $0.5 \mathrm{ml} 1 \mathrm{M} \mathrm{HBr}$ were eluted to waste, then the $\mathrm{Pb}$ back extracted in two $0.5 \mathrm{ml}$ washes of $6 \mathrm{M} \mathrm{HCl}$. Approximately $0.05 \mathrm{ml}$ conc. $\mathrm{HNO}_{3}$ was added to the collected solution to exsolve the remaining $\mathrm{Br}$ and the solution taken to dryness. The sample was then taken up once again in $0.5 \mathrm{ml} 1 \mathrm{M} \mathrm{HBr}$ and the entire process repeated. 


\subsubsection{Isotope ratio mass spectrometry}

$\mathrm{Sr}, \mathrm{Nd}$ and $\mathrm{Pb}$ isotope ratios were measured using a ThermoFisher Triton Thermal lonisation Mass spectrometer (TIMS) first at the Open University, UK (by BLA Charlier), then at Victoria University of Wellington, New Zealand (by EJ Swallow), using the same instrument.

The dried $\mathrm{Sr}$ fractions were dissolved in concentrated $\mathrm{HNO}_{3}$ with a ratio of $\sim 1 \mu \mathrm{l}$ to 1000 ng Sr. $0.7 \mu$ l of pre-cleaned $\mathrm{TaF}_{2}$ activator (Birck 1986; Charlier et al. 2006) was loaded onto outgassed, zone refined single Re filaments. Samples were added to the filament before the activator had dried to ensure the load was mixed on the filament, then glowed to a dull red. Filaments were heated sufficiently to $1450-1500{ }^{\circ} \mathrm{C}$ in order to generate $\sim 50 \mathrm{mV}$ on ${ }^{84} \mathrm{Sr}$ ( 7 to $8 \mathrm{~V}$ on ${ }^{88} \mathrm{Sr}$ ), and measurements consisted of 240 ratios measured in blocks of 10 with an integration time of $16.777 \mathrm{~s}$ for each ratio measured. A peak-centre and tune was automated at the beginning of every 10 blocks and a 1 min baseline was measured at half mass at the beginning of every block (and rotation of the amplifiers). Measurements were fractionation corrected using the exponential law to ${ }^{86} \mathrm{Sr} /{ }^{88} \mathrm{Sr}=0.1194$, and $\mathrm{Rb}$ interference was corrected by measuring ${ }^{85} \mathrm{Rb}$ and applying a correction using ${ }^{87} \mathrm{Rb} /{ }^{85} \mathrm{Rb}=0.385707$ (Rosman and Taylor 1998). Repeated analyses of NBS987 yield an average of $0.710255 \pm 0.0000013$ (2sd; $n=25$ ). Isotopic ratios from different runs were normalised to a value of 0.71025 for NBS987 (Thirlwall 1991) to ensure internal consistency. Sr procedural blanks were 110 and $200 \mathrm{pg}$ for the 'mafic' and 'silicic' samples, respectively, insignificant compared to the $1000 \mathrm{ng}$ sample load.

The dried $\mathrm{Nd}$ fractions $(200-800 \mathrm{ng}$ ) were taken up in 1-2 $\mu \mathrm{l} \mathrm{conc.} \mathrm{HCl}$ then loaded onto outgassed, zone refined double Re filaments following the addition, and drying, of $1 \mu \mathrm{l} 0.1 \mathrm{M}$ $\mathrm{H}_{3} \mathrm{PO}_{4}$ loading solution. A further $1 \mu \mathrm{l}$ of loading solution was then added following evaporation of the sample solution and dried. The filament was then turned up to a dull red glow. Nd was run using a double filament assembly with an evaporation filament (containing the sample) and a hotter ionisation filament $\left(1650-1800{ }^{\circ} \mathrm{C}\right)$ to generate $2-8 \mathrm{~V}$ on ${ }^{142} \mathrm{Nd}$ depending on the size of the sample. 270 ratios, each with an integration time of $8.389 \mathrm{~s}$, were analysed in blocks of 10 with a baseline measured at half mass before each block. $A$ peak-centre and tune was completed after each block of 10 ratios. Ratios were fractionation corrected using the exponential law to ${ }^{143} \mathrm{Nd} /{ }^{144} \mathrm{Nd}=0.7219$, and any presence of Ce and Sm corrected using values of ${ }^{140} \mathrm{Ce} /{ }^{142} \mathrm{Ce}=0.20667$ and ${ }^{144} \mathrm{Sm} /{ }^{147} \mathrm{Sm}=7.97297$ (Rosman and Taylor 1998). Repeated analyses of standards J\&M (internal standard) and La Jolla 
(international standard) yield values of $0.511818 \pm 0.000004(2 \mathrm{sd} ; \mathrm{n}=26)$ and $0.511845 \pm$ $0.000002(2 \mathrm{sd} ; \mathrm{n}=6)$, respectively, similar to the long term laboratory average (J\&M: $0.511821 \pm 0.0000022 \mathrm{sd})$ and the value of Thirlwall (1991) for La Jolla (0.511856 \pm 0.000007 2sd). Procedural blanks were 8 and 300 pg for the 'mafic' and 'silicic' samples, respectively.

The dried $\mathrm{Pb}$ fraction was taken up in $2 \mathrm{\mu l} \mathrm{H}_{3} \mathrm{PO}_{4}$-silica gel mix (Gerstenberger and Haase 1996). $\mathrm{Pb}$ was analysed using a double-spike methodology (Thirlwall 2000). Half the sample (approximately $150 \mathrm{ng}$ ), was loaded onto single outgassed, zone refined Re filaments and measured for 180 ratios at 8.389 second integrations. Subsequently, $1 \mu$ l of a ${ }^{207} \mathrm{~Pb} /{ }^{204} \mathrm{~Pb}$ spike (Thirlwall 2000) per $100 \mathrm{ng} \mathrm{Pb}$ was admixed to the remaining sample and measured as before for 120 ratios. The data were then deconvolved using a modified Newton-Raphson inversion to determine the isotope ratios without recourse to internal normalisation, and the uncertainties determined using a 5000 iteration Monte-Carlo simulation. Values for NBS981 were ${ }^{206} \mathrm{~Pb} /{ }^{204} \mathrm{~Pb}=16.945 \pm 0.001,{ }^{207} \mathrm{~Pb} /{ }^{204} \mathrm{~Pb}=15.503 \pm 0.001$ and ${ }^{208} \mathrm{~Pb} /{ }^{204} \mathrm{~Pb}=36.737 \pm$ 0.004 ( $2 \mathrm{sd} ; n=32$ ). Isotopic measurements from different runs were normalised to the NBS981 values of Todt et al. (1996). The procedural blanks for Pb were 10 pg ('mafic' samples) and 2 ng ('silicic'). Even the higher blank content for the 'silicic' samples is considered insignificant when compared to the $>200 \mathrm{ng}$ of sample analysed.

\subsection{In-situ glass and mineral analysis}

Glass and crystals were hand-picked from the preferred size fractions, mounted onto doublesided sticky tape and cast in $25 \mathrm{~mm}$ epoxy mounts and polished. Crystals were orientated parallel to the c-axis where identifiable and polished down to expose the cores. Basal ignimbrite vitrophyre samples were analysed through the mounting of rock chips in epoxy and some pumice samples from polished thin-sections.

\subsubsection{Electron Probe Micro-analysis (EPMA): major and minor elements}

Major and minor elements were determined by electron probe micro-analysis (EPMA) using a JXA 8230 Superprobe at Victoria University of Wellington. Backscattered electron images were made of all samples and qualitative and quantitative analysis of samples was achieved using an energy dispersive spectometer and five wavelength dispersive spectrometers (WDS), respectively. All analytical data in this study were determined using WDS. A $\sim 25 \mathrm{~nm}$ carbon 
film was applied to samples prior to analysis. A ZAF correction (where $Z$ is atomic number, A is absorption and $\mathrm{F}$ is fluorescence) was used to calculate all elemental concentrations (e.g. Carpenter 2008). Calibration for quantitative analysis was undertaken using international standards of similar composition and structure to materials being analysed in order to reduce the effects of different matrices on the accuracy of the measurments. Count times were similar for both calibration standards and samples. Minor elements ( $<1 \mathrm{wt} \%)$ were calibrated against synthetic oxides. Calibration standards and secondary standards were also run as unknowns to check the precision and accuracy of each run and to monitor any instrumental drift.

Glass was analysed by EPMA using a $15 \mathrm{kV}$ accelerating voltage and a defocused $20 \mu \mathrm{m}$ spot size. $\mathrm{Si}, \mathrm{Al}, \mathrm{Na}, \mathrm{K}$, Fe Ca were analysed using a $2 \mathrm{nA}$ sample current recommended by Humphreys et al. (2006) to minimise alkali migration. Electron-beam effects were further reduced by the analysis of $\mathrm{Si}$ and $\mathrm{Na}$ first. Subsequently, $\mathrm{Ti}, \mathrm{Mg}$ and $\mathrm{Mn}$ were analysed using an $8 \mathrm{nA}$ current. Count times (on peak/background) were 15/8 (Na), 30/15 (Si, Al), 40/20 (K, $\mathrm{Ca}, \mathrm{Ti}, \mathrm{Mg}$ ) and 60/20 s (Fe, Mn). A $15 \mathrm{kv}$ accelerating voltage was used for the analysis of all crystal phases with a sample current of $12 \mathrm{nA}$ and a spot size of $\sim 1 \mu \mathrm{m}$. Feldspars and pyroxenes were analysed with $30 \mathrm{~s}$ count time on peak and a $15 \mathrm{~s}$ background count for all elements. For olivines, $\mathrm{Ti}, \mathrm{Si}, \mathrm{Mg}$, Fe and $\mathrm{Al}$ were analysed with a $30 \mathrm{~s}$ count time on peak and a $15 \mathrm{~s}$ background count, whereas $\mathrm{Ca}, \mathrm{Mn}$ and $\mathrm{Ni}$ were analysed over 60 and $30 \mathrm{~s}$ to improve counting statistics. Accuracy and precision of repeated standard analysis are given in Table 2.6 .

\subsubsection{Laser ablation (LA-ICP-MS): trace elements}

Following determination of major and minor element concentrations by EPMA, glassy material was analysed for trace elements by Laser-Ablation Inductively Coupled Plasma Mass Spectrometry (LA-ICP-MS) using a RESOlution S155-SE 193nm Excimer Laser coupled to an Agilent 7500CS ICP-MS at Victoria University of Wellington.

LA-ICP-MS analysis of glass was conducted using a $35 \mu \mathrm{m}$ spot size which was placed coincident with the EPMA spot. Each analysis was preceded by two $70 \mu \mathrm{m}$ diameter cleaning pulses followed by a $20 \mathrm{~s}$ pause to allow counts to return to background levels. Analyses consisted of a $30 \mathrm{~s}$ ablation at $5 \mathrm{~Hz}$ with a laser energy $\sim 5 \mathrm{~mJ} / \mathrm{cm}^{2}$. Each ablation was followed by a $15 \mathrm{~s}$ washout to allow a return to background. As some doubt has been expressed 


\begin{tabular}{|c|c|c|c|c|c|c|c|c|c|c|c|c|c|}
\hline & Analysis & $\mathrm{SiO}_{2}$ & $\mathrm{TiO}_{2}$ & $\mathrm{Al}_{2} \mathrm{O}_{3}$ & FeOt & $\mathrm{MnO}$ & MgO & $\mathrm{CaO}$ & $\mathrm{Na}_{2} \mathrm{O}$ & $\mathrm{K}_{2} \mathrm{O}$ & $\mathrm{BaO}$ & $\mathrm{NiO}$ & $\mathrm{Cr}_{2} \mathrm{O}_{3}$ \\
\hline & Preferred & 76.96 & 0.08 & 12.17 & 1.08 & 0.02 & 0.03 & 0.45 & 3.52 & 4.93 & & & \\
\hline Rhyolitic glass (VG-568) & Average & 77.32 & 0.12 & 12.18 & 1.21 & 0.07 & 0.07 & 0.50 & 3.45 & 4.73 & & & \\
\hline$n=348$ & Offset \% & 0.47 & 54.93 & 0.05 & 11.69 & 251.67 & 138.24 & 11.05 & -2.06 & -4.02 & & & \\
\hline \multirow[t]{2}{*}{ Jarosewich et al. (1980) } & $2 s d$ & 1.53 & 0.18 & 0.46 & 0.23 & 0.12 & 0.11 & 0.11 & 0.36 & 0.47 & & & \\
\hline & $2 s d \%$ & 1.98 & 148.52 & 3.77 & 18.92 & 177.02 & 155.45 & 21.62 & 10.40 & 9.87 & & & \\
\hline & Preferred & 64.39 & & 18.19 & 0.03 & & & & 1.14 & 14.92 & 0.82 & & \\
\hline Orthoclase (Or-1A) & Average & 64.42 & & 18.30 & 0.01 & & & & 1.14 & 14.95 & 0.79 & & \\
\hline$n=460$ & Offset \% & 0.05 & & 0.58 & -71.44 & & & & 0.05 & 0.19 & -3.44 & & \\
\hline \multirow{2}{*}{ Ingamells (1980) } & $2 s d$ & 0.81 & & 0.44 & 0.02 & & & & 0.10 & 0.35 & 0.16 & & \\
\hline & $2 s d \%$ & 1.25 & & 2.39 & 269.56 & & & & 8.87 & 2.33 & 19.78 & & \\
\hline & Preferred & 51.25 & 0.05 & 30.91 & 0.46 & & 0.14 & 13.64 & 3.45 & 0.18 & 0.05 & & \\
\hline Plagioclase (NMNH 115900) & Average & 51.15 & 0.03 & 29.36 & 0.45 & & 0.14 & 13.68 & 4.03 & 0.12 & 0.01 & & \\
\hline$n=438$ & Offset \% & -0.19 & -39.36 & -5.02 & -2.23 & & 3.02 & 0.32 & 16.78 & -31.78 & -71.95 & & \\
\hline \multirow[t]{2}{*}{ Jarosewich et al. (1980) } & $2 s d$ & 0.92 & 0.03 & 0.95 & 0.17 & & 0.03 & 0.52 & 0.42 & 0.08 & 0.04 & & \\
\hline & $2 s d \%$ & 1.79 & 88.83 & 3.24 & 37.95 & & 19.68 & 3.79 & 10.52 & 65.42 & 276.96 & & \\
\hline & Preferred & 49.78 & & 25.05 & 0.17 & & & 13.58 & 5.20 & 0.94 & & & \\
\hline Scapolite P.S.U & Average & 50.01 & & 25.07 & 0.10 & & & 13.49 & 5.18 & 0.94 & & & \\
\hline$n=107$ & Offset \% & 0.45 & & 0.10 & -43.67 & & & -0.67 & -0.42 & 0.01 & & & \\
\hline \multirow[t]{2}{*}{ Ingamells (1983) } & $2 s d$ & 0.72 & & 0.23 & 0.06 & & & 0.40 & 0.31 & 0.03 & & & \\
\hline & $2 s d \%$ & 1.45 & & 0.93 & 62.68 & & & 2.94 & 6.00 & 3.42 & & & \\
\hline & Preferred & 38.95 & & & 16.62 & 0.30 & 43.58 & & & & & & \\
\hline Olivine (Springwater 2566) & Average & 38.96 & & 0.00 & 16.82 & 0.28 & 43.55 & & & & & & \\
\hline$n=114$ & Offset \% & 0.04 & & & 1.19 & -8.12 & -0.08 & & & & & & \\
\hline \multirow[t]{2}{*}{ Jarosewich et al. (1980) } & $2 s d$ & 0.26 & & 0.01 & 0.59 & 0.17 & 0.37 & & & & & & \\
\hline & $2 s d \%$ & 0.66 & & 326.33 & 3.53 & 62.96 & 0.86 & & & & & & \\
\hline
\end{tabular}




\begin{tabular}{|c|c|c|c|c|c|c|c|c|c|c|c|c|c|}
\hline & Analysis & $\mathrm{SiO}_{2}$ & $\mathrm{TiO}_{2}$ & $\mathrm{Al}_{2} \mathrm{O}_{3}$ & FeOt & $\mathrm{MnO}$ & MgO & $\mathrm{CaO}$ & $\mathrm{Na}_{2} \mathrm{O}$ & $\mathrm{K}_{2} \mathrm{O}$ & $\mathrm{BaO}$ & $\mathrm{NiO}$ & $\mathrm{Cr}_{2} \mathrm{O}_{3}$ \\
\hline \multirow{5}{*}{$\begin{array}{l}\text { Pyroxene (Px-1) } \\
\qquad \mathrm{n}=197 \\
\text { Ingamells (1980) }\end{array}$} & Preferred & 53.94 & 0.26 & 0.66 & 2.91 & 0.07 & 16.93 & 24.55 & 0.24 & & & & 0.21 \\
\hline & Average & 53.88 & 0.26 & 0.67 & 2.93 & 0.06 & 17.14 & 24.49 & 0.25 & & & & 0.22 \\
\hline & Offset \% & -0.11 & 0.43 & 1.28 & 0.75 & 13.23 & 1.25 & -0.25 & 4.85 & & & & 4.79 \\
\hline & $2 s d$ & 1.17 & 0.06 & 0.12 & 0.60 & 0.04 & 0.78 & 0.45 & 0.10 & & & & 0.12 \\
\hline & $2 \mathrm{sd} \%$ & 2.17 & 21.18 & 17.27 & 20.30 & 69.07 & 4.57 & 1.82 & 41.40 & & & & 54.78 \\
\hline \multirow{5}{*}{$\begin{array}{l}\text { Ilmenite (NMNH96189) } \\
\qquad \mathrm{n}=114 \\
\text { Jarosewich et al. (1980) }\end{array}$} & Preferred & & 45.70 & & 46.54 & 4.77 & 0.31 & & & & & & \\
\hline & Average & & 54.12 & & 46.82 & 4.15 & 0.28 & & & & & & \\
\hline & Offset \% & & 18.42 & & 0.60 & 13.08 & -8.99 & & & & & & \\
\hline & $2 s d$ & & 6.01 & & 1.48 & 2.46 & 0.06 & & & & & & \\
\hline & $2 s d \%$ & & 11.11 & & 3.16 & 59.45 & 22.91 & & & & & & \\
\hline \multirow{5}{*}{$\begin{array}{l}\text { Hypersthene (USNM746) } \\
\qquad n=83 \\
\text { Jarosewich et al. (1980) }\end{array}$} & Preferred & 54.09 & 0.16 & 1.23 & 15.22 & 0.49 & 26.79 & 1.52 & 0.05 & 0.01 & & & 0.75 \\
\hline & Average & 54.41 & 0.10 & 0.98 & 15.29 & 0.48 & 27.51 & 1.23 & 0.02 & 0.13 & & & 0.67 \\
\hline & Offset \% & 0.59 & $\begin{array}{c}- \\
37.01\end{array}$ & -20.27 & 0.49 & -1.51 & 2.70 & 19.23 & -67.95 & 1239.38 & & & $\begin{array}{c}- \\
10.91\end{array}$ \\
\hline & $2 s d$ & 3.09 & 0.04 & 0.22 & 0.70 & 0.11 & 1.23 & 0.28 & 0.04 & 0.74 & & & 0.20 \\
\hline & $2 \mathrm{sd} \%$ & 5.67 & 41.66 & 22.78 & 4.60 & 23.51 & 4.47 & 23.08 & 245.12 & 551.65 & & & 29.65 \\
\hline \multirow{5}{*}{$\begin{array}{c}\text { Augite (Kakanui) } \\
n=82 \\
\text { Jarosewich et al. (1980) }\end{array}$} & Preferred & 50.73 & 0.74 & 8.73 & 6.34 & 0.13 & 16.65 & 15.82 & 1.27 & & & & 0.15 \\
\hline & Average & 50.76 & 0.95 & 8.85 & 6.41 & 0.14 & 16.73 & 15.79 & 1.60 & & & & 0.15 \\
\hline & Offset \% & 0.06 & 28.12 & 1.41 & 1.03 & 5.39 & 0.50 & -0.16 & 25.74 & & & & -0.70 \\
\hline & $2 s d$ & 0.40 & 0.10 & 0.48 & 0.65 & 0.05 & 0.31 & 0.35 & 0.55 & & & & 0.05 \\
\hline & $2 s d \%$ & 0.80 & 10.13 & 5.45 & 10.16 & 34.09 & 1.87 & 2.21 & 34.51 & & & & 34.38 \\
\hline
\end{tabular}




\begin{tabular}{|c|c|c|c|c|c|c|c|c|c|c|c|c|c|c|c|}
\hline & \multicolumn{5}{|c|}{ BHVO-2G $n=116$} & \multicolumn{5}{|c|}{ BCR-2G $n=116$} & \multicolumn{5}{|c|}{ NIST $612 n=210$} \\
\hline & Pref. & Average & Offset \% & $2 s d$ & $2 s d \%$ & Pref. & Average & Offset \% & $2 s d$ & $2 s d \%$ & Pref. & Average & Offset \% & $2 s d$ & $2 s d \%$ \\
\hline Li & 4.4 & 4.19 & -4.82 & 1.84 & 43.94 & 9 & 8.99 & -0.14 & 2.60 & 28.90 & 40.2 & 40.49 & 0.71 & 5.34 & 13.20 \\
\hline $\mathrm{Ti}$ & 16300 & 15867 & -2.65 & 1890 & 11.91 & 14100 & 13439 & -4.69 & 1545 & 11.50 & 44 & 42.72 & -2.90 & 16.09 & 37.65 \\
\hline Mn & 1317 & 1403 & 6.59 & 221.5 & 15.79 & 1550 & 1679 & 8.32 & 272.7 & 16.24 & 38.7 & 40.90 & 5.70 & 5.16 & 12.61 \\
\hline $\mathrm{Zn}$ & 102 & 114.9 & 12.60 & 14.95 & 13.02 & 125 & 153.2 & 22.52 & 18.45 & 12.04 & 39.1 & 38.23 & -2.22 & 7.00 & 18.30 \\
\hline Ga & 22 & 20.80 & -5.45 & 2.53 & 12.17 & 23 & 22.31 & -2.98 & 2.77 & 12.43 & 36.9 & 36.58 & -0.88 & 3.41 & 9.33 \\
\hline $\mathbf{R b}$ & 9.2 & 8.88 & -3.44 & 1.18 & 13.23 & 47 & 46.14 & -1.82 & 3.97 & 8.60 & 31.4 & 30.83 & -1.81 & 2.49 & 8.07 \\
\hline $\mathrm{Sr}$ & 396 & 386.9 & -2.30 & 43.68 & 11.29 & 342 & 341.4 & -0.18 & 32.82 & 9.61 & 78.4 & 82.35 & 5.04 & 7.01 & 8.51 \\
\hline$Y$ & 26 & 24.29 & -6.57 & 3.20 & 13.17 & 35 & 34.66 & -0.97 & 4.29 & 12.38 & 38.3 & 42.64 & 11.33 & 3.94 & 9.24 \\
\hline $\mathrm{Zr}$ & 170 & 163.3 & -3.94 & 19.17 & 11.74 & 184 & 183.4 & -0.31 & 20.78 & 11.33 & 37.9 & 41.87 & 10.49 & 4.20 & 10.04 \\
\hline $\mathrm{Nb}$ & 18.3 & 16.79 & -8.23 & 2.19 & 13.06 & 12.5 & 11.71 & -6.32 & 1.39 & 11.89 & 38.9 & 40.31 & 3.63 & 3.27 & 8.12 \\
\hline Mo & 3.8 & 4.11 & 8.20 & 1.83 & 44.59 & 270 & 265.6 & -1.61 & 23.90 & 9.00 & 37.4 & 38.28 & 2.36 & 4.35 & 11.36 \\
\hline $\mathrm{Ba}$ & 131 & 123.4 & -5.79 & 15.86 & 12.85 & 683 & 668.5 & -2.12 & 77.36 & 11.57 & 39.3 & 39.83 & 1.35 & 5.19 & 13.02 \\
\hline La & 15.2 & 14.68 & -3.39 & 1.85 & 12.58 & 24.7 & 25.15 & 1.83 & 3.01 & 11.97 & 36 & 38.75 & 7.65 & 3.68 & 9.50 \\
\hline $\mathrm{Ce}$ & 37.6 & 36.36 & -3.30 & 4.44 & 12.22 & 53.3 & 53.02 & -0.53 & 6.36 & 11.99 & 38.4 & 40.69 & 5.95 & 3.34 & 8.22 \\
\hline $\mathrm{Pr}$ & 5.35 & 4.93 & -7.85 & 0.77 & 15.55 & 6.7 & 6.58 & -1.84 & 0.92 & 14.06 & 37.9 & 40.15 & 5.92 & 3.28 & 8.17 \\
\hline Nd & 24.5 & 23.76 & -3.00 & 4.06 & 17.10 & 28.9 & 28.87 & -0.11 & 4.54 & 15.74 & 35.5 & 39.06 & 10.04 & 4.26 & 10.90 \\
\hline Sm & 6.1 & 5.77 & -5.33 & 1.80 & 31.23 & 6.59 & 6.50 & -1.29 & 1.65 & 25.39 & 37.7 & 40.72 & 8.02 & 4.69 & 11.51 \\
\hline Eu & 2.07 & 2.01 & -2.70 & 0.57 & 28.18 & 1.97 & 1.97 & -0.13 & 0.55 & 28.09 & 35.6 & 38.29 & 7.56 & 3.37 & 8.79 \\
\hline Gd & 6.16 & 6.15 & -0.17 & 1.80 & 29.34 & 6.71 & 6.82 & 1.71 & 1.97 & 28.83 & 37.3 & 42.82 & 14.80 & 5.40 & 12.60 \\
\hline $\mathbf{T b}$ & 0.92 & 0.87 & -5.37 & 0.26 & 30.14 & 1.02 & 0.98 & -3.93 & 0.30 & 30.32 & 37.6 & 40.06 & 6.55 & 3.96 & 9.89 \\
\hline Dy & 5.28 & 4.94 & -6.38 & 1.15 & 23.28 & 6.44 & 6.25 & -2.97 & 1.32 & 21.19 & 35.5 & 38.70 & 9.00 & 4.42 & 11.43 \\
\hline Ho & 0.98 & 0.94 & -4.52 & 0.28 & 30.28 & 1.27 & 1.25 & -1.57 & 0.33 & 26.72 & 38.3 & 40.70 & 6.26 & 3.94 & 9.67 \\
\hline Er & 2.56 & 2.49 & -2.61 & 0.76 & 30.36 & 3.7 & 3.71 & 0.14 & 0.96 & 25.89 & 38 & 42.66 & 12.25 & 4.96 & 11.62 \\
\hline $\mathrm{Tm}$ & 0.34 & 0.31 & -10.02 & 0.17 & 55.32 & 0.51 & 0.50 & -1.81 & 0.22 & 44.50 & 36.8 & 39.32 & 6.84 & 3.88 & 9.87 \\
\hline $\mathrm{Yb}$ & 2.01 & 1.84 & -8.60 & 0.96 & 52.02 & 3.39 & 3.35 & -1.31 & 1.18 & 35.31 & 39.2 & 41.63 & 6.21 & 5.13 & 12.33 \\
\hline Lu & 0.28 & 0.26 & -6.30 & 0.17 & 63.36 & 0.50 & 0.49 & -3.49 & 0.25 & 51.87 & 37 & 39.82 & 7.62 & 4.28 & 10.75 \\
\hline $\mathrm{Hf}$ & 4.32 & 4.18 & -3.35 & 1.00 & 23.86 & 4.84 & 4.73 & -2.23 & 1.13 & 23.78 & 36.7 & 38.66 & 5.35 & 4.15 & 10.72 \\
\hline Ta & 1.15 & 1.01 & -12.16 & 0.26 & 26.08 & 0.78 & 0.71 & -8.88 & 0.23 & 32.11 & 37.6 & 39.14 & 4.09 & 3.84 & 9.80 \\
\hline $\mathrm{Pb}$ & 1.7 & 1.80 & 5.79 & 0.57 & 31.89 & 11 & 10.96 & -0.40 & 1.44 & 13.17 & 38.57 & 40.46 & 4.91 & 4.23 & 10.44 \\
\hline Th & 1.22 & 1.19 & -2.73 & 0.41 & 34.54 & 5.9 & 5.97 & 1.25 & 1.06 & 17.81 & 37.79 & 41.21 & 9.06 & 4.79 & 11.61 \\
\hline $\mathbf{U}$ & 0.40 & 0.42 & 4.85 & 0.22 & 53.00 & 1.69 & 1.73 & 2.18 & 0.47 & 27.00 & 37.38 & 38.56 & 3.15 & 4.16 & 10.79 \\
\hline
\end{tabular}


regarding the homogeneity of NIST synthetic glasses (e.g. Eggins and Shelley 2002), a synthetic basaltic glass GSD-1G was used for calibration (Guillong et al. 2005). ${ }^{29} \mathrm{Si}$ concentrations, derived from EPMA results for each sample, were used to standardise the LAICP-MS data. This is preferable to other major elements due to lower uncertainty of EPMA results for Si. BHVO-2G, BCR-2G and NIST 612 were analysed as secondary standards to cover a wide range in concentrations for each element and allow propagation of element uncertainties. Data were processed using LaserTRAM software (see Loewen and Kent 2012 for details).

The mass spectrometer was tuned for optimal performance by running a $50 \mu \mathrm{m}$ raster on NIST 612 and simultaneously adjusting the torch and lens positions and gas flows. Pulse/analog (P/A) factors were measured prior to every analytical run to ensure correct adjustment of the ICP-MS when switching between low (P) and high ( $\left.\mathrm{A}:>10^{6} \mathrm{cps}\right)$ counting modes. Five unknowns and a secondary standard (alternating NIST 612, BCR-2G and BHVO2G) were bracketed by a calibrating standard (GSD-1G). Offsets for NIST 612 from preferred values (Jochum et al. 2011) are $\leq 9 \%$ for all elements except $\mathrm{Y}, \mathrm{Zr}, \mathrm{Nd}(<12 \%)$ and $\mathrm{Er}, \mathrm{Gd}$ (<15\%). 2sd\% precisions are better than $13 \%$ except for $\mathrm{Li}, \mathrm{Zn}(<20 \%)$ and $\mathrm{Ti}(<30 \%)$. Full standard data is detailed in Table 2.7.

\subsection{Glass compositional data analysis}

\subsubsection{Component and cluster analysis}

The controls on, and the nature of, compositional clustering present in glass analyses were assessed using $R^{\circledast}$ ( $R$ Development Core Team 2016). This assessment was achieved through two approaches. In the first instance, principal component analysis (PCA) was undertaken. This analysis takes a multivariate dataset and finds arithmetically independent, orthogonal, linear combinations of potentially correlated input variables (i.e. elemental data), known as principal components (PCs). Principal components are able to be related directly back to their contributory elements, and the chemical variance in the dataset can be described in terms of the PCs (i.e. combinations of elements) that explain more of the compositional variation in the dataset than that which would be expected by chance.

A robust sparse PCA (Croux et al. 2007; Filzmoser et al. 2014) was run on centred log-ratio transformed data for selected elements (Mueller and Grunsky 2016 and references therein). 
The log-ratio transform is used to transform compositional data out of the simplex and into a Euclidean sample space appropriate for PCA and further statistical analysis (i.e. to remove the effect of correlations caused by elemental data being reported as percentages or parts per million). The dataset was scaled by the median absolute deviation, centred on the median and processed using a Qn method. The resulting PCs were then compared to a broken stick distribution (i.e. the distribution of randomly divided inertia, or variance, between multiple components) and those that plotted above the broken stick were retained as explaining more variance than random (Jackson 1993). Following the PCA, a Bayesian mixture-modelling cluster analysis (Fraley et al. 2012) was undertaken using the retained PCs. Probabilities for each data point were assigned for each cluster generated, and the highest probability was used to allocate the cluster for each analysis.

\subsubsection{Estimation of analytical uncertainties}

Due to measured glass compositional variation being larger than the range of standards used in this thesis, the relationship between standard elemental abundance and analytical variation is utilised to propagate analytical uncertainties to the extrema of the measured compositional range. Repeated ( $\sim 80)$ measurements of glass secondary standards BHVO-2G and BCR-2G by LA-ICP-MS result in estimates of standard deviation as a percentage of the abundance (i.e. 2 sd\%) for each measured element. 2 sd\% estimates fall as abundance, represented by the preferred values for the standards, increase. For 23 elements (Ga, Rb, Sr, $\mathrm{Y}, \mathrm{Zr}, \mathrm{Nb}, \mathrm{Mo}, \mathrm{Ba}, \mathrm{La}, \mathrm{Ce}, \mathrm{Pr}, \mathrm{Nd}, \mathrm{Sm}, \mathrm{Eu}, \mathrm{Gd}, \mathrm{Tb}, \mathrm{Dy}, \mathrm{Ho}, \mathrm{Er}, \mathrm{Tm}, \mathrm{Yb}, \mathrm{Lu}, \mathrm{Hf})$, a simple regression was fitted to $\log (2 \mathrm{sd} \%)$ v. $\log ($ abundance). Using the resulting equation, the analytical uncertainty of any element can be estimated at a given concentration.

The $2 s d \%$ analytical uncertainties were subsequently used to estimate uncertainties in abundance ratios of selected elements. For each ratio, values of the element abundance have been simulated using the appropriate 2 sd\% uncertainty estimates to scale 5000 standard Gaussian variates. A 2 sd uncertainty for the estimate was generated by doubling the standard deviation of the resulting 5000 ratios. 


\section{Chapter 3}

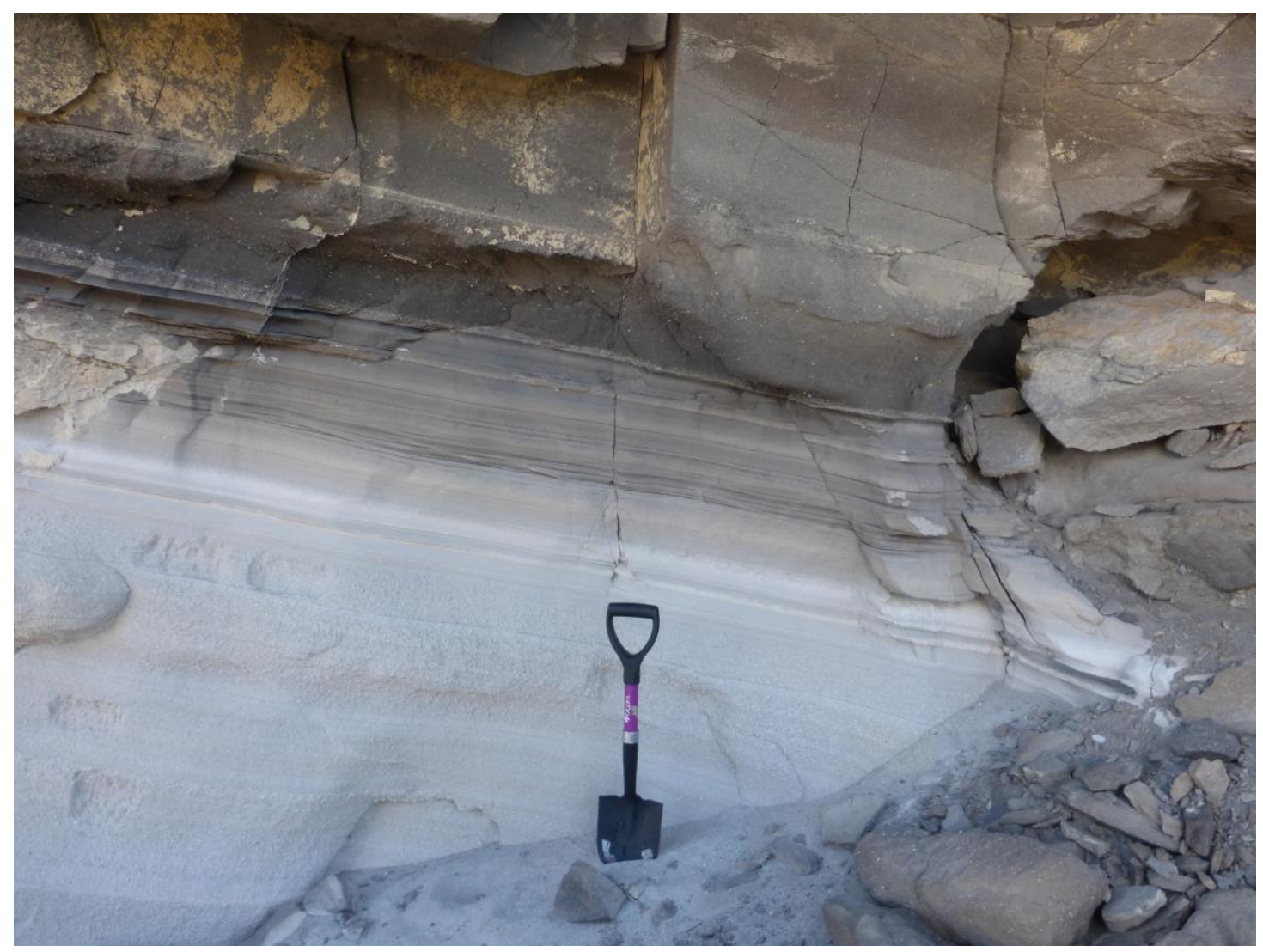

Photograph of the initial fall deposit of the HRT, overlain by ignimbrite member $A$, where sampled at Mt. Everts, Wyoming, USA. Spade is $\sim 70 \mathrm{~cm}$ tall.

This chapter has been accepted by Contributions to Mineralogy and Petrology as a journal article: Swallow EJ, Wilson CJN, Myers ML, Wallace PJ, Collins KS, Smith EGC (2018) Evacuation of multiple magma bodies and the onset of caldera collapse in a supereruption, captured in glass and mineral compositions. Contrib Mineral Petrol 173:33.

Author contributions as followed:

EJS: Sampled the initial fall deposit, collected all data and wrote the text.

CNJW: Completed background fieldwork and collected basal ignimbrite samples, edited text. MLM and PJW: Provided thorough discussions and edited text.

KSC: Devised computer code and assistance with data analysis using $\mathrm{R}^{\circledR}$.

EGCS: Provided assistance with analytical errors and cluster mean uncertainties. 


\title{
3. Evacuation of multiple magma bodies and the onset of caldera collapse in a supereruption, captured in glass and mineral compositions
}

\begin{abstract}
Complexities in the nature of large-scale silicic eruptions and their magmatic systems can be discerned through micro-analytical geochemical studies. We present high-resolution, stratigraphically-constrained compositional data on glassy matrix material and feldspar crystals from the initial fall deposits and earliest ignimbrite (base of member A) of the 2.08 $\mathrm{Ma}, \sim 2,500 \mathrm{~km}^{3}$ Huckleberry Ridge Tuff (HRT), Yellowstone. We use these data to document the nature of the magmatic system and compositional changes related to the transition from fall to widespread ignimbrite deposition, inferred to mark the onset of caldera collapse. Although major element glass compositions are relatively uniform, trace elements span a large range (e.g. Ba 10-900 ppm, $\mathrm{Sr} / \mathrm{Rb}=0.005-0.09)$, with highly evolved glasses dominating in the fall deposits. Several trace elements (e.g. Ba and light rare-earth elements) in the glass samples serve to define statistically significant compositional clustering in the fall deposits and basal ignimbrite. These clusters are inferred to reflect melt compositions controlled by fractional crystallisation processes and are interpreted to represent multiple, discrete meltdominant domains that were tapped by multiple vents. The onset of widespread ignimbrite deposition is marked by an increase in the number of erupted melt compositional clusters from four in the fall deposits to eight, representing nine melt-dominant domains. There is an absence of geographical variation of glass compositions within the basal ignimbrite, with samples from proximal to distal localities north, west and south of the HRT caldera exhibiting similar variability. Pairing of glass analyses with sanidine major and minor element compositional data suggests that the nine melt compositional domains converged at depth into two compositionally distinct upper-crustal magmatic lineages that were both active during these early stages of the eruption. Our data collectively indicate the evacuation of an exceptionally complex and heterogeneous magma system. The onset of widespread ignimbrite deposition, inferred to relate to caldera collapse, occurred after $\sim 50 \mathrm{~km}^{3}$ of magma had been discharged. Although external controls were important as an eruption
\end{abstract}


trigger, depressurisation of the system led to caldera collapse with the eruption of numerous discrete melt-dominant domains. 


\subsection{Introduction}

The explosive evacuation of large volumes of silicic magma represents the culmination of growth of crustal magma bodies and their release in catastrophic eruptions, at one extreme those termed supereruptions with $>10^{15} \mathrm{~kg}$ of magma ejected (Miller and Wark 2008). Observations of historic events and studies of eruption products have long demonstrated that three transitions are common to ubiquitous in large explosive eruptions:

1. from initial, buoyant plume activity (yielding fall deposits) into column-collapse (yielding ignimbrite: e.g. Wilson et al. 1980; Sparks et al. 1997);

2. from a single-vent to multiple-vents accompanying the onset of caldera collapse due to depressurisation of the system (e.g. Hildreth and Mahood 1986; Suzuki-Kamata et al. 1993); and

3. from compositional uniformity into coherent diversity as different levels of a zoned unitary chamber are sequentially tapped (e.g. Bacon and Druitt 1988; Schuraytz et al. 1989; Hildreth and Fierstein 2012; Bachmann et al. 2014).

These transitions, collectively exemplified by the Mazama eruption (Bacon 1983; SuzukiKamata et al. 1993), involve a transition from initial fall activity from a single vent that causes depressurisation of a unitary, compositionally stratified magma chamber, leading directly to caldera collapse and widespread ignimbrite deposition sourced from multiple vents along ring fractures. However in other large eruptions, particularly of crystal-rich magmas, one or more of these transitions appears to be absent (e.g. Fish Canyon: Bachmann et al. 2002; Cerro Galan: Cas et al. 2011; Ongatiti: Cooper and Wilson 2014). The presence, ordering and nature of these transitions and their development with respect to the elapsed time into the eruption or volume of magma erupted yield important insights into the pre-eruptive state of the subsurface magma body or bodies, and the mechanisms of eruption initiation and magma release.

Although these proposed transitions are straightforward and readily explained and modelled, there is debate centred on each aspect, together with the influences on eruption onset. Multiple factors have been proposed for eruption triggering, both internal, such as large mass influx (which may also lead to volatile exsolution), vigorous convection and buoyancy-generated overpressures (Caricchi et al. 2014; Degruyter and Huber 2014; Malfait et al. 2014), and external, such as roof destabilisation (Gregg et al. 2012) and tectonic forces 
(Allan et al. 2012; Myers et al. 2016). The balance between internal and external factors may reflect the magma body size (Gregg et al. 2015), as numerical models imply that smaller and larger bodies will exhibit contrasting behaviour and require different trigger mechanisms (Jellinek and DePaolo 2003; Gregg et al. 2012).

In turn, the timing and mechanisms of caldera collapse and associated widespread ignimbrite deposition, with or without generation of a preceding fall deposit, are also debated (e.g. Roche and Druitt 2001; Gregg et al. 2012; Cashman and Giordano 2014). Field evidence shows that in some eruptions the relationship between caldera collapse and eruptive dynamics is more complex than can be simply modelled. For example, in the Bishop Tuff, fall and flow deposition were coeval through most (if not all) of the eruption (Wilson and Hildreth 1997) and began prior to large-scale caldera collapse, the latter as inferred from changes in the lithic lithologies in the deposits (Hildreth and Mahood 1986).

Below the surface, models have predominantly focused on a single, unitary zoned magma body, with the accompanying view that the magmas ejected need be closely linked physically and/or compositionally and/or thermally (Hildreth 1981; Bacon and Druitt 1988; Singer et al. 2016). Field and geochemical data indicate that although this may be the case for some events (e.g. Mazama: Bacon 1983, Bacon and Druitt 1988; Novarupta: Hildreth and Fierstein 2012; Oruanui: Allan et al. 2017), others show the simultaneous or sequential tapping of multiple adjacent magma chambers in single or paired events (see Cashman and Giordano 2014 for overview). Published examples include the systematic involvement of separate large-scale magma bodies into a single caldera-forming event (e.g. Cooper et al. 2012, 2016), tectonically linked sequential eruption of two independent magma systems from separate vent areas (e.g. Nairn and Kohn 1973; Gravley et al. 2007; Bégué et al. 2014) and the 'accidental' involvement of magma from an independent magmatic system into a large caldera-forming eruption (e.g. Allan et al. 2012). These kinds of scenarios, because of their possible complexity, have seldom been incorporated into numerical models and therefore the role of multiple magma bodies in the dynamics of single eruptions has not been fully explored (Gudmundsson 2012).

Here we consider the three transitions listed above and show how the possible complexities in large-scale magmatic systems are reflected during the early stages of an archetypal silicic supereruption. We document products of early eruptive stages of the Huckleberry Ridge Tuff (HRT: Christiansen 2001), the second-largest Quaternary eruption on Earth. Although generally treated as conforming to the conventional view given above (e.g. 
Hildreth 1981; Hildreth et al. 1984, 1991; Christiansen 2001), our work shows a contrasting picture. A study of quartz-hosted melt inclusions and reentrants, and obsidian pyroclasts from its lowest fall layers (Myers et al. 2016, Electronic Appendix 1) proposed that the earliest stages of the HRT eruption occurred from three compositionally distinct cupolas, erupting spasmodically in an overlapping sequence. We build on this work by using samples of glassy matrix materials to document melt compositions through the entire thickness of the initial fall deposits and across the transition into the earliest ignimbrite. We show how the compositional diversity in the earliest fall deposits further develops into an extraordinary degree of complexity in the ignimbrite. This complexity reflects the pre-eruptive configuration of the HRT magma system and illustrates the style of, and controls on, the onset of caldera collapse in this event.

\subsection{Geological background}

The $\sim 2.08 \mathrm{Ma} \mathrm{HRT}$ supereruption is the earliest and largest $\left(\sim 2,500 \mathrm{~km}^{3}\right)$ of three calderaforming eruptions at the Yellowstone Plateau volcanic field (YPVF; Christiansen 2001; Singer et al. 2014). The HRT consists of initial fall deposits overlain by three ignimbrite units (members A, B and C), together with additional, but more localised, fall deposits between members B and C (Christiansen 2001). The overall $\sim 95 \times 65 \mathrm{~km}$ HRT caldera is of irregularly ovoid shape. Within it, three vent foci for the three ignimbrite members were proposed by Christiansen (2001), but it is not established when and how the overall caldera structure developed during the eruption.

The initial fall deposits, particularly at the Mount Everts section studied by Myers et al. (2016), consist of multiple bedded layers, many of which are normally graded to fine-ash tops, indicating that the eruption was episodic in its early stages. This inference is reinforced at this locality and elsewhere by evidence for minor reworking at several horizons, particularly in the earliest fall deposits, interpreted to reflect short-term hiatuses that collectively represent a period of days to weeks. Once ignimbrite deposition commenced, however, only rarely are flow unit boundaries seen (most commonly within 1-3 metres of the basal contact), and no traces of erosional hiatuses are present within ignimbrite member $A$. The onset of ignimbrite A deposition appears to have been in close succession at locations situated $>180 \mathrm{~km}$ apart and on opposite sides of the caldera. We thus infer that the base of ignimbrite A reflects the 
onset of column collapse, the start of energetic, voluminous pyroclastic flow activity, and hence the beginning of caldera collapse (e.g. Wilson et al. 1980; Rosi et al. 1996).

\subsection{Samples and analytical methods}

Samples of glassy material and co-erupted (glass-coated) feldspar crystals were collected from eighteen horizons through the entire thickness of the initial fall deposits at the same location as Myers et al. (2016), a site north of the inferred eruptive source on the western rim of Mt. Everts near Mammoth, Wyoming (Figs. 3.1, S3.1). The upper part of the fall deposits (top $1 / 3$ ) is locally fused by the overlying ignimbrite, and the glass is darkened through microlite growth; although this material is studied here, it was not analysed by Myers et al. (2016) because the quartz-hosted melt inclusions were devitrified. Within the fall deposits, pumices are almost entirely $<1 \mathrm{~cm}$ long and hence unsuitable for individual clast analysis. We therefore sampled both the fragmented pale glass shards and co-erupted sparse $(<0.1 \%$ by volume) ash-grade fragments of black obsidian. The latter still contain appreciable amounts of $\mathrm{CO}_{2}(20-50 \mathrm{ppm})$ and are hence inferred to be juvenile material rather than recycled earliererupted dome material (Myers et al. 2016; Watkins et al. 2017).

Glassy samples were also collected from the base of ignimbrite A from 17 localities across a 180 degree sector around the caldera (Fig. 3.1; Table S3.1). Sampled materials include matrix shards from non-welded ignimbrite, fragments of basal vitrophyre, and glass kernels extracted from fiamme within the basal vitrophyre. Feldspar crystals from selected basal ignimbrite samples at a range of sites were also analysed. All samples were crushed, sieved, and glass and crystals picked, mounted into 1-inch epoxy mounts and polished.

Glass and crystals were analysed at Victoria University of Wellington for major elements by Electron Microprobe (EPMA) using a JEOL JXA-8230 SuperProbe and for trace elements by Laser-Ablation Inductively Coupled Plasma Mass Spectrometry (LA-ICP-MS) using a RESOlution S155-SE 193nm Excimer Laser coupled with an Agilent 7500CS ICPMS. Glass and obsidian shards were analysed by EPMA using a $15 \mathrm{kV}$ accelerating voltage and a $20 \mu \mathrm{m}$ spot size. Si, $\mathrm{Al}, \mathrm{Na}, \mathrm{K}, \mathrm{Fe}$ and $\mathrm{Ca}$ were analysed using a $2 \mathrm{nA}$ beam current as recommended by Humphreys et al. (2006) to minimise alkali migration. Si and Na were analysed first to further reduce electron-beam effects. $\mathrm{Ti}, \mathrm{Mg}$ and $\mathrm{Mn}$ were subsequently analysed using an $8 \mathrm{nA}$ current. Count times on peak were $15(\mathrm{Na}), 30(\mathrm{Si}, \mathrm{Al}), 40(\mathrm{~K}, \mathrm{Ca}, \mathrm{Ti}, \mathrm{Mg})$ and $60 \mathrm{~s}(\mathrm{Fe}, \mathrm{Mn})$. For 


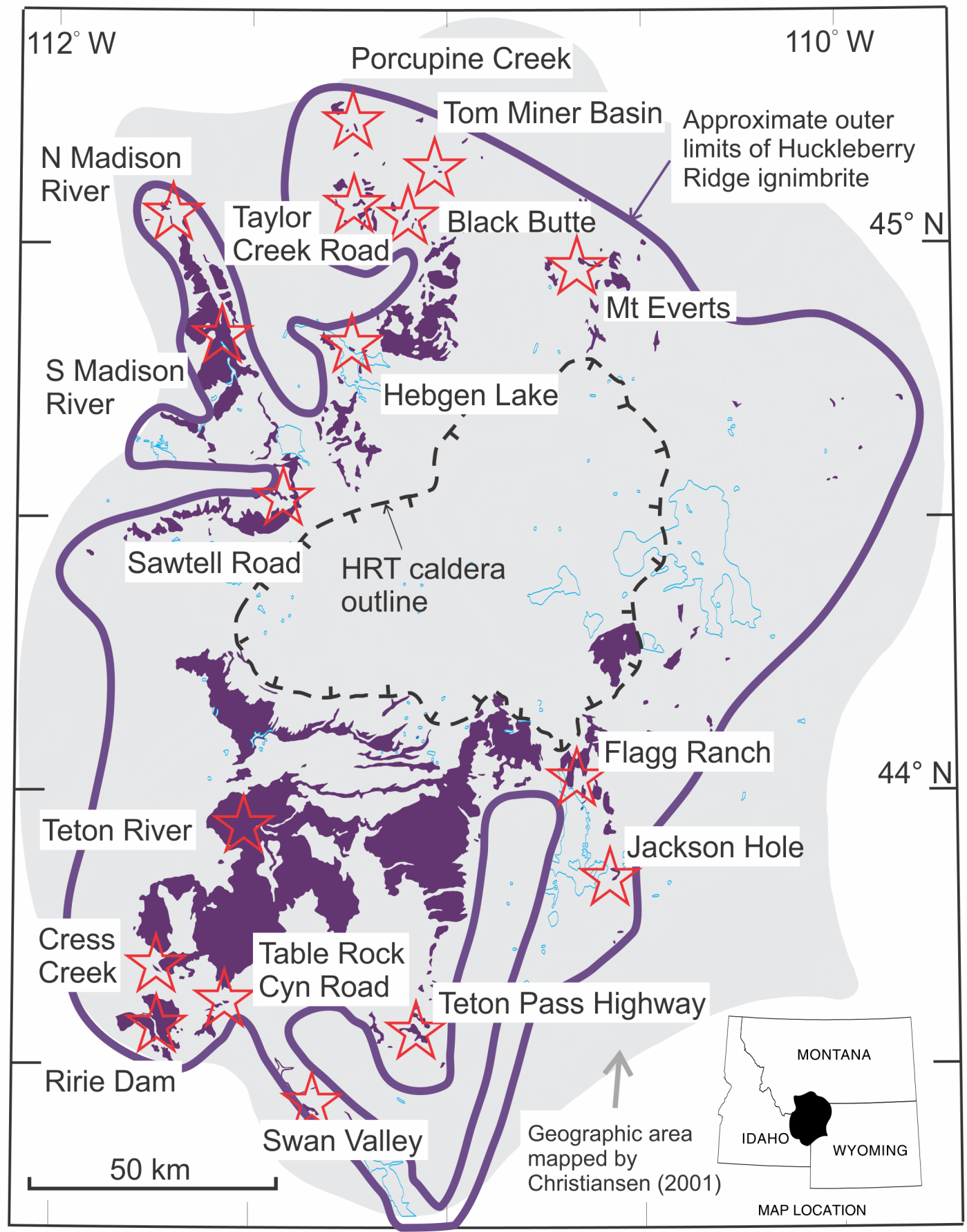

Figure 3.1: Map of outcrop areas of the HRT ignimbrite (purple regions) and the inferred original extent of the ignimbrite (purple line). Red stars indicate locations where the basal ignimbrite was sampled. Further location details are given in Table S3.1. HRT outcrop areas and caldera outline from Christiansen (2001).

EPMA analysis of feldspar, an accelerating voltage of $15 \mathrm{kV}$, a sample current of $12 \mathrm{nA}$, a spot size of $\sim 1 \mu \mathrm{m}$ and a $30 \mathrm{~s}$ count time on peak were used for all elements. LA-ICP-MS analysis of glass was conducted using a $35 \mu \mathrm{m}$ spot size. Each analysis was preceded by two $70 \mu \mathrm{m}$ 


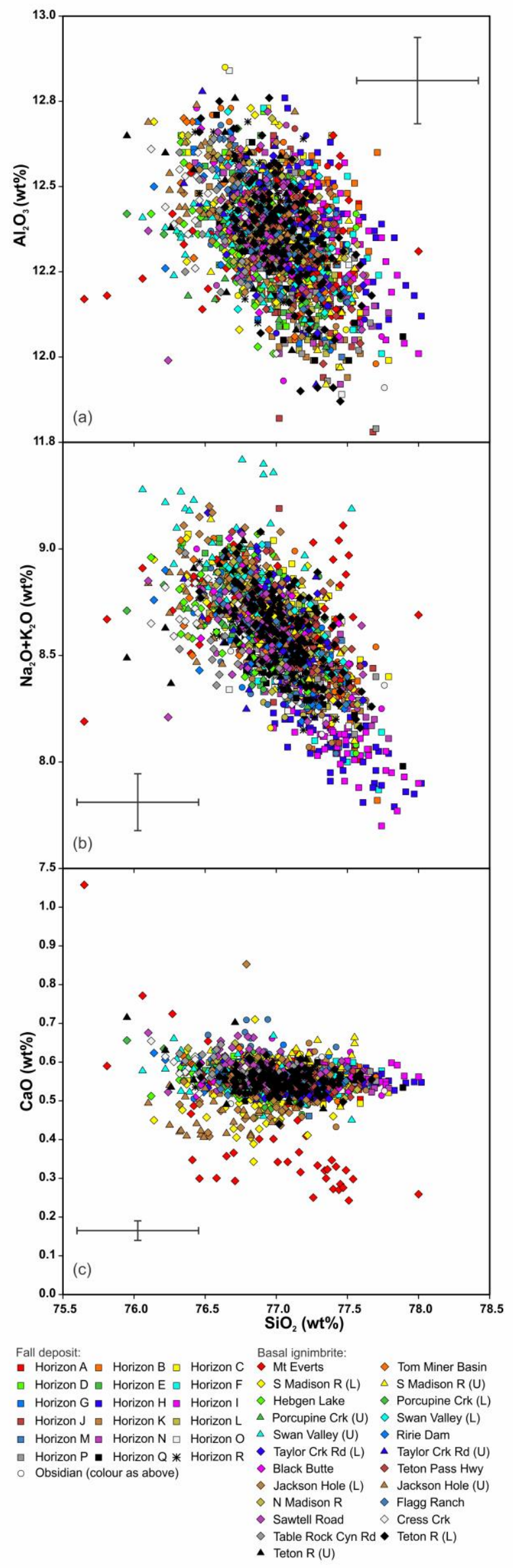

Figure 3.2: Major element plots of fall glass, obsidian pyroclasts and basal ignimbrite glass. There is minimal variation with $\mathrm{SiO}_{2}$ in (a) $\mathrm{Al}_{2} \mathrm{O}_{3}$ or (b) $\mathrm{Na}_{2} \mathrm{O}+\mathrm{K}_{2} \mathrm{O}$ but glass from the basal ignimbrite at some localities shows depletions in $\mathrm{CaO}$ (c). The negative correlation of alkalis and alumina with $\mathrm{SiO}_{2}$ is consistent with the crystallisation of feldspar. Error bars are 1sd analytical uncertainties. 
cleaning pulses. ${ }^{29} \mathrm{Si}$ was used as an internal standard, GSD-1G for calibration and BHVO-2G, BCR-2G and NIST612 used as secondary standards.

\subsection{Results}

\subsubsection{Major element compositions of glasses and feldspar}

All glass and obsidian shards from the fall deposits and basal ignimbrite are high silica rhyolite (75.5-78.0 wt\% $\mathrm{SiO}_{2}$, normalised to $100 \%$ anhydrous: Electronic Appendix 3.1 ) and show major element trends broadly consistent with the crystallisation of the major and minor mineral phases present in the deposits (quartz, sanidine, plagioclase, clinopyroxene, Fe-rich olivine, Fe-Ti oxides: Fig. 3.2). Glass compositions within the fall deposits show little major element variation $\left(\mathrm{SiO}_{2}:\right.$ 76.3-78.0 wt\%, $\mathrm{CaO}$ : 0.46-0.63 wt\%). Samples from the basal ignimbrite extend to lower $\mathrm{SiO}_{2}$ values (75.5 wt\%) with lower $\mathrm{CaO}$ (down to 0.24 wt\%; Fig. 3.2) in some samples.

Alkali feldspars from the fall deposits and basal ignimbrite are dominantly sanidine but have a significant celsian ( $\mathrm{Cn}$ : i.e. Ba) component (Fig. S3.2; Electronic Appendix 3.2). In the fall deposits they preserve oscillatory zonation where compositions from all zones range over $A n_{1-5} A b_{38-46} \mathrm{Or}_{47-58}$ and up to $\mathrm{Cn}_{3.7}$. Sanidine also occurs as inclusions in plagioclase, and these sanidine inclusions are in some cases $C n$ rich ( $u p$ to $C n_{5.6}$ ). Sanidine rims range over $A n_{1-3} A b_{40}$ ${ }_{46} \mathrm{Or}_{51-58}$ and $\mathrm{Cn}_{0-2.4}$ but exhibit a bimodality, with clusters of data with $<0.35$ and $0.4-1$ mol\% $\mathrm{Cn}$ (Fig. 3.3). Sanidine cores ( $\mathrm{Or}_{47-58}$ and $\mathrm{Cn}_{0-3.6}$ ) exhibit a greater compositional range than the rims but show a similar bimodal clustering pattern in Cn content to the sanidine rims (Fig. 3.3). Alkali feldspars from the basal ignimbrite show a greater range in composition ( $A n_{0}$ $\left.{ }_{14} \mathrm{Ab}_{39-68} \mathrm{Or}_{36-59}\right)$ with rare (2.5\% of all analyses) anorthoclase $\left(\mathrm{An}_{2-4} \mathrm{Ab}_{64-68} \mathrm{Or}_{28-32}\right)$ additionally present (Fig. S3.2). Celsian contents in these crystals range up to $10.2 \mathrm{~mol} \%$ in the cores and $4.1 \mathrm{~mol} \%$ in the rims (Electronic Appendix 3.2).

Plagioclases in both the fall deposits and ignimbrite, whether as free crystals or inclusions in sanidine, are dominantly oligoclase $\left(\mathrm{An}_{13-31} \mathrm{Ab}_{62-77} \mathrm{Or}_{5-15}\right.$ : Fig. S3.2) and homogenous, but rare more calcic zones $\left(\mathrm{An}_{43-48} \mathrm{Ab}_{49-53} \mathrm{Or}_{2}\right)$ are also found $(<2 \%$ of all analyses: Electronic Appendix 3.2$)$. The basal ignimbrite samples also include calcic anorthoclase $\left(A n_{12-18} A b_{60}\right.$ ${ }_{65} \mathrm{Or}_{17-24)}$ in $15 \%$ of analyses. 


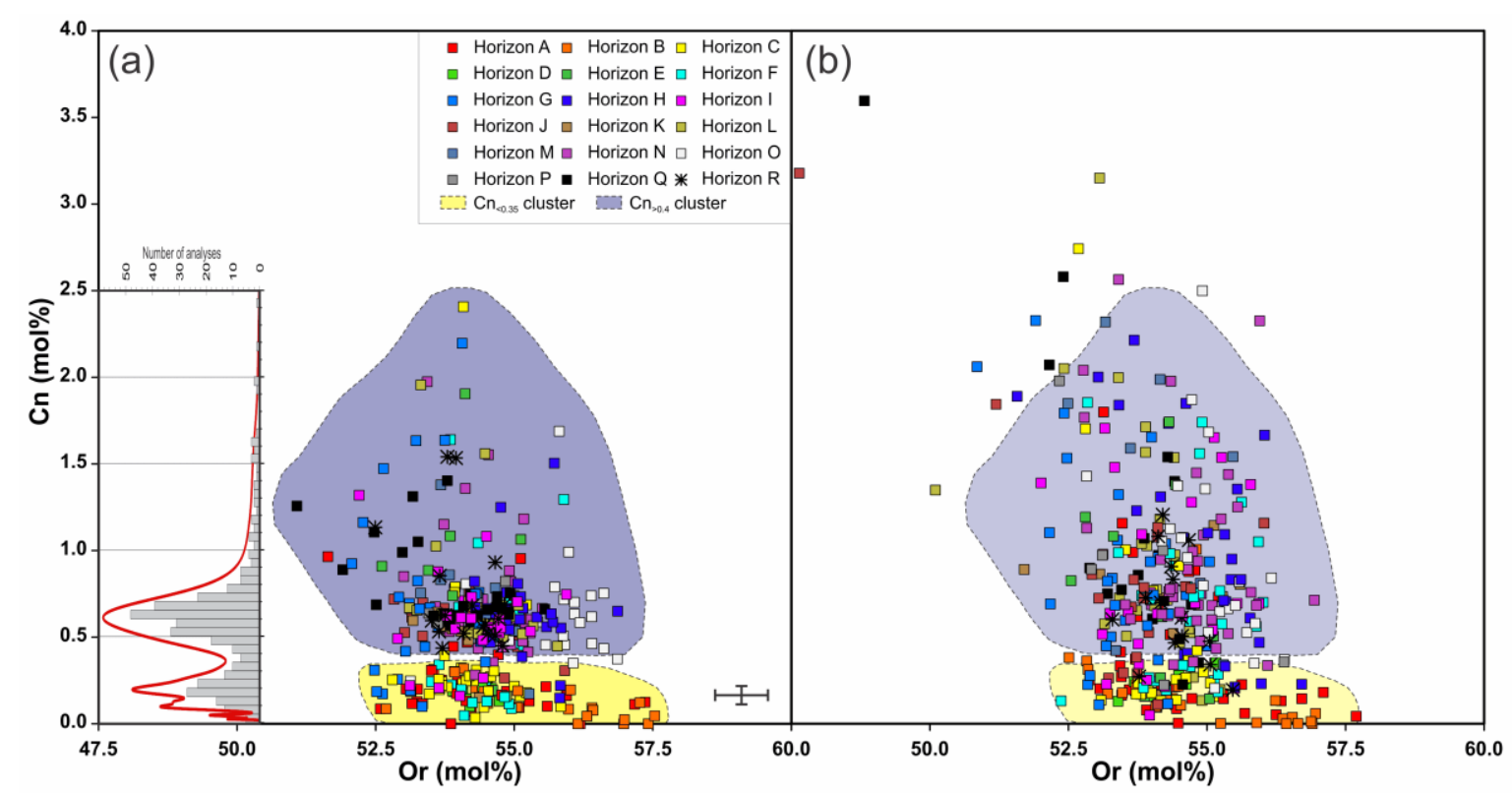

Figure 3.3: (a) Sanidine rim compositions in the fall deposit showing the presence of two clusters, one with $<0.35 \mathrm{~mol} \% \mathrm{Cn}$ (yellow highlight) and a higher Cn cluster ( $>0.4 \mathrm{~mol} \%$ : purple highlight), based on the bimodality of rim compositions seen in a histogram of rim compositions (inset; bin widths are $0.05 \mathrm{~mol} \% \mathrm{Cn}$ ). The red curve is a probability density function generated using Isoplot (Ludwig 2008), plotted with the average 2 sd of $22 \%$ for $\mathrm{BaO}$ analyses in sanidine. Cluster colours are based on glass selvedge compositions and the link to fall glass clusters (see Fig. S3.3 and text for details). (b) Sanidine core compositions. The fields of rim compositions from panel (a) are copied here to show the comparative ranges in compositions. Error bars in the bottom right corner of (a) show 2sd analytical uncertainties.

\subsubsection{Trace element compositions of glassy materials}

In glassy material from the fall deposits and basal ignimbrite, concentrations of incompatible trace elements such as $\mathrm{Rb}(164-362 \mathrm{ppm})$ and $\mathrm{U}$ (5-12 ppm) show coherent variations (Electronic Appendix 3.1). If these variations result from crystallisation differentiation, they indicate up to $\sim 60 \%$ fractional crystallisation (Fig. 3.4) from the least- to most-evolved glasses, using the partition coefficients of Lu et al. (1992) and Anderson et al. (2000). Trace element ratios indicative of the degree of melt evolution (e.g. $\mathrm{Ba} / \mathrm{Rb}, \mathrm{Sr} / \mathrm{Rb}$ ) also show lineages that trace back to the least-evolved glass compositions (Fig. 3.5). However, within the fall deposits, samples of glass shards and obsidian fragments show compositional clustering in certain elements (e.g. Ba, Sr, light rare earth elements [LREE]: Fig. 3.5a). Individual glass and obsidian fragments are homogenous in composition based on multiple 


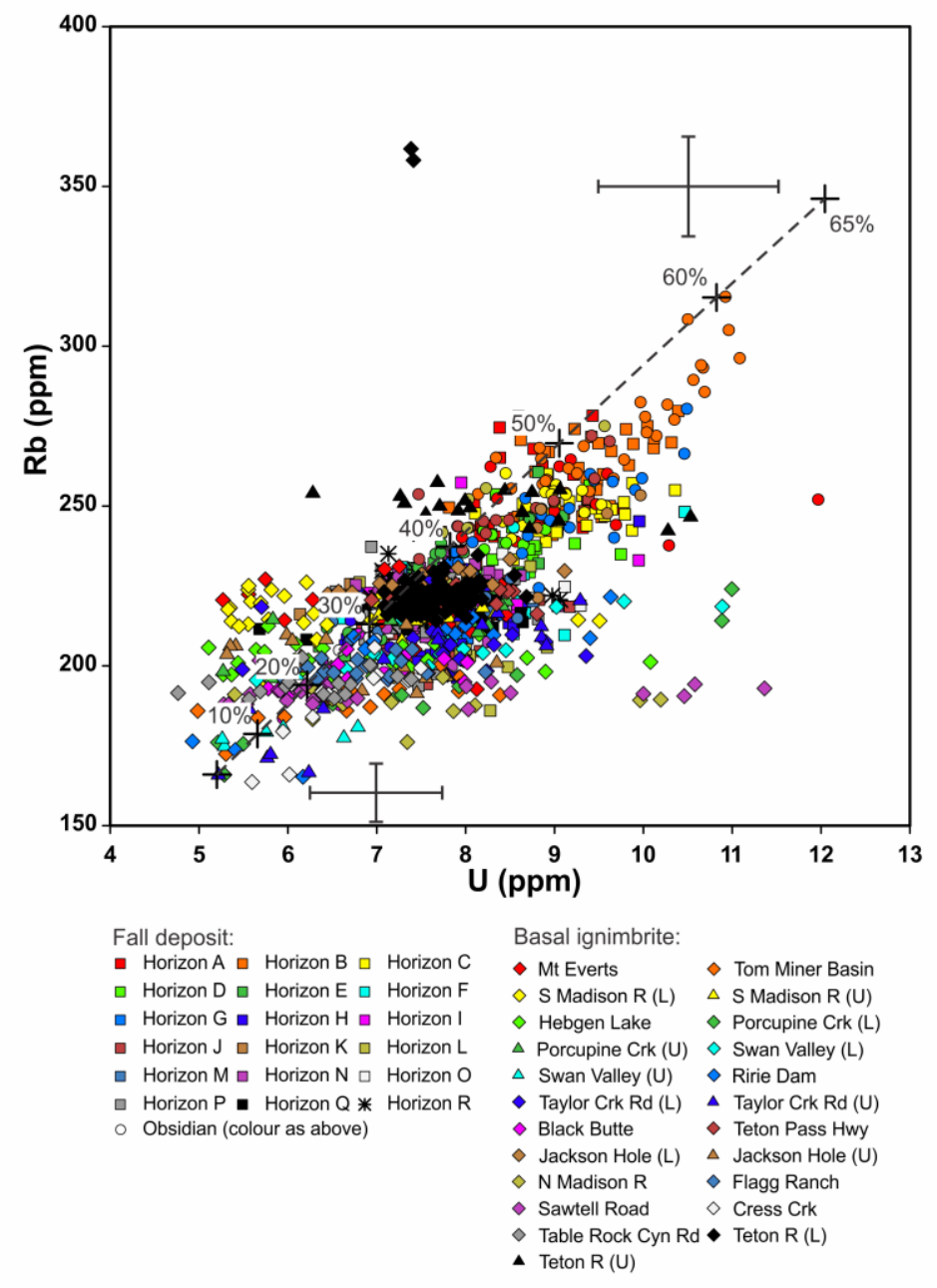

Figure 3.4: Fractional

crystallisation modelling of the range in glass shard compositions analysed in this study. Partition coefficients of $D_{U}=0.2$ and $D_{R b}=0.3$ are used (from Lu et al. 1992 and Anderson et al. 2000, respectively) to model the range in fractional crystallisation across the observed range in compositions. Error bars show projected 2 sd analytical uncertainties based on error slope regression at the relevant concentrations (see Chapter S3).

analyses on the same shard, with any intra-shard variation limited to the range of the respective compositional cluster. Several of the horizons sampled contain glass and obsidian from more than one compositional group. There is more compositional variation within the obsidian fragments (predominantly in Ba concentrations) than the glass shards, possibly due to microlite growth and/or partial hydration, but they fall within the same broad groups. The cluster with the lowest $\mathrm{Ba}(10-30 \mathrm{ppm})$ is LREE depleted relative to the other clusters (Fig. 3.5; Table 3.1) and has the lowest $\mathrm{Sr} / \mathrm{Rb}$ ratio (down to 0.004 ; equivalent to $\mathrm{Rb} / \mathrm{Sr}$ of up to 250). Variations in LREE concentrations are consistent with the effects of fractionation of trace amounts of chevkinite, identified through qualitative EPMA analysis. The other clusters are distinguishable in Ba concentration (33-65 ppm; 90-175 ppm; >360 ppm) but have overlapping LREE ranges (e.g. La: Fig. 3.5). Trace element compositions of glass selvedges on sanidine crystals from selected fall deposit horizons show a compositional range (e.g. 19-369 ppm Ba) but have similar clustering to that seen in the matrix glass (Fig. 3.6). Lower Ba glass 

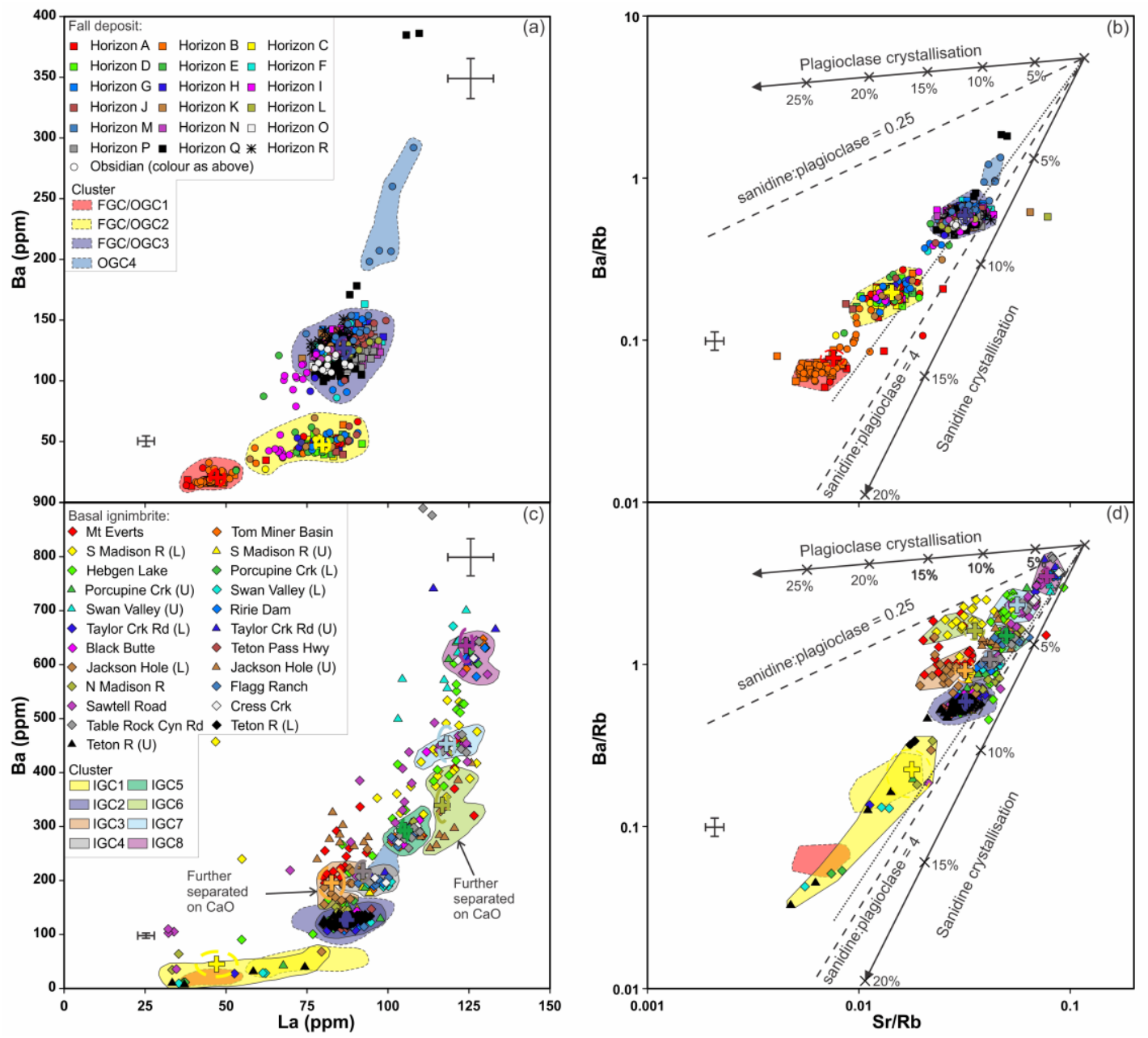

Figure 3.5: (a) Plot of Ba vs La abundances in glass shards and obsidian pyroclasts from the fall deposits showing the grouping of four clusters, identified using cluster analysis (colours as in Fig. $\mathrm{S} 3.3$ ). (b) $\mathrm{Ba} / \mathrm{Rb}$ vs $\mathrm{Sr} / \mathrm{Rb}$ ratios for the samples plotted in (a) and corresponding cluster fields. Solid lines indicate sense and magnitude (degrees in wt\%) of exclusively plagioclase and sanidine crystallisation from a starting value that represents the least-evolved composition measured in this study. Dashed lines reflect crystallisation of a mineral assemblage with 4:1 ratios of the two feldspars. Dotted line is best fit through the least evolved ends of each cluster and has a slope of 1.68, which corresponds to a sanidine:plagioclase ratio of 1.7. (c) Plot of Ba vs La concentrations in glassy material from the basal ignimbrite. Fields of clusters in panel (a) are copied here for comparison. In addition fields showing the eight compositional clusters identified by cluster analysis in the basal ignimbrite are shown. (d) $\mathrm{Ba} / \mathrm{Rb}$ vs $\mathrm{Sr} / \mathrm{Rb}$ ratios for basal ignimbrite glass compositions. Cluster fields are copied from (b) and supplemented by fields denoting the dominant region of each cluster in the basal ignimbrite. Solid and dashed crystallisation lines are as in (b). Dotted line represents a best fit line through each of the basal ignimbrite clusters and has a slope of 2.1, consistent with crystallisation of an assemblage with a sanidine:plagioclase ratio of 3. Large crosses 
indicate the mean for each cluster and dashed ellipses show $95 \%$ confidence about the mean. Error bars show projected $2 \mathrm{sd}$ analytical uncertainties based on error slope regression at the relevant concentrations (see Chapter S3).

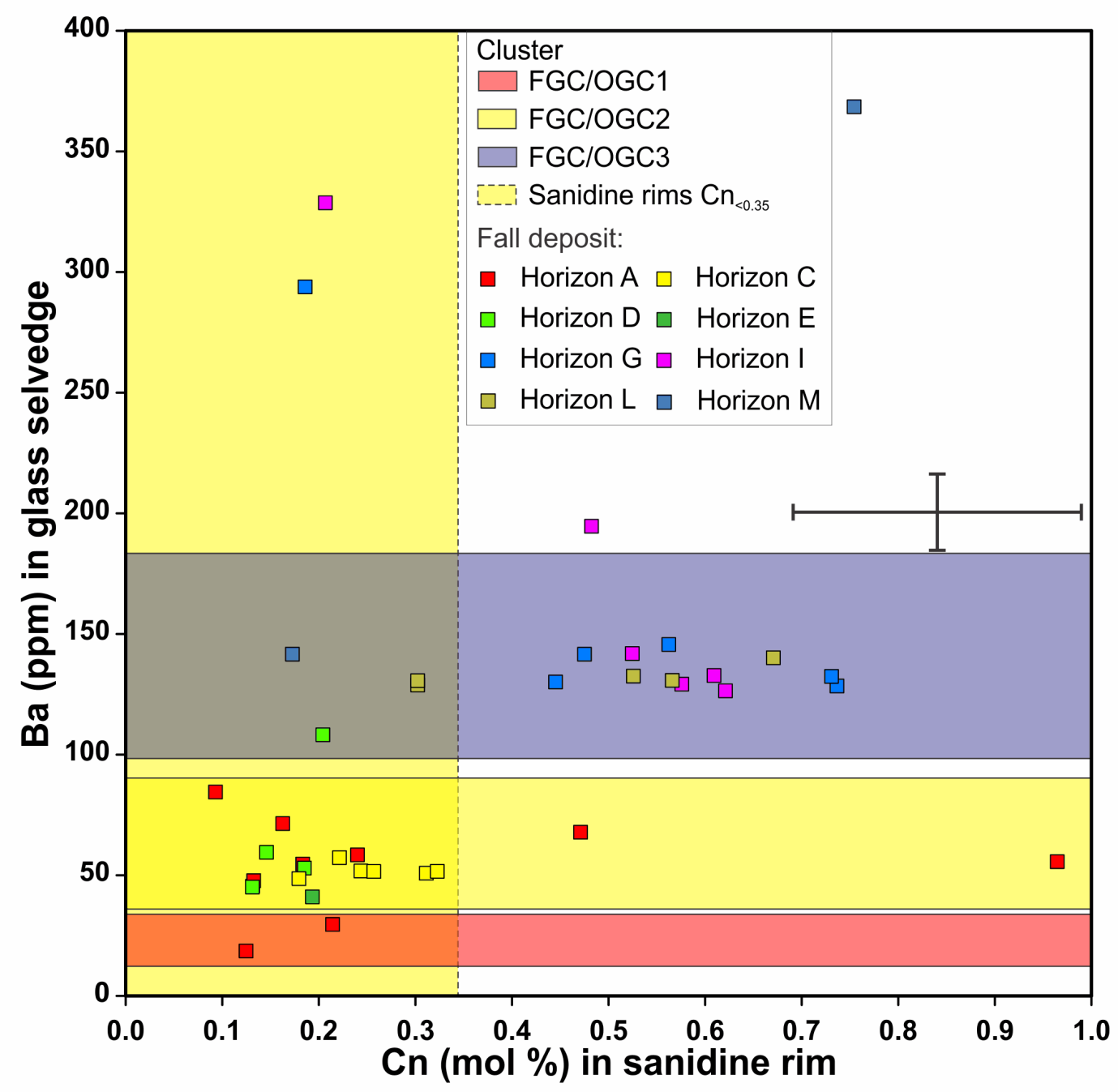

Figure 3.6: Glass-selvedge Ba compositions plotted relative to their adjacent sanidine rim celsian component $(\mathrm{Cn})$ from selected fall deposit horizons (Electronic Appendices 3.1 and 3.2). Shaded regions show the compositional ranges of the glass clusters (solid outline) and low $\mathrm{Cn}$ sanidine rim cluster (dashed outline). Colour coding as in Figs. 3.3 and 3.5. The data indicate that the low-Cn sanidine cluster (see Fig. 3.3) is associated with FGC1 and 2 (Fig. 3.5). The clustered sanidine compositions (Fig. 3.3) suggest that FGC1 and 2 emanated from a distinct upper-level magmatic lineage, separate from the magmatic lineage with higherCn sanidines associated with FGC3. Error bars represent 2sd Ba error bar derived for 200 ppm through percentage error regression (see Chapter S3 for details). 
selvedge compositions are dominantly found coating low $\mathrm{Cn}(<0.35 \mathrm{~mol} \%)$ sanidine rims (Fig. 3.6).

Glass compositions from the basal ignimbrite samples extend the range observed in the fall deposits to higher Ba (890 ppm) but continue to show clustering (Fig. $3.5 \mathrm{c}$ ), including replicating those compositional clusters represented in the fall deposit data. These clusters form a coherent overall evolutionary trend between the fall deposit compositions and the least-evolved glass in the basal ignimbrite (Fig. 3.5d). Glass shards sampled from any one ignimbrite sample contain compositions falling into multiple clusters, analogous to what is seen in individual stratigraphic horizons from the fall deposit.

\subsubsection{Thermometry calculations}

We used the Elkins and Grove (1990) two-feldspar thermometer in conjunction with major element analyses of plagioclase inclusions in sanidine (and vice versa) to calculate feldspar crystallisation temperatures. Feldspar compositions were normalised on a $\mathrm{Cn}$-free basis. Feldspars from all but two fall deposit horizons ( $E$ and $O)$ had suitable inclusions and yielded temperature estimates from $768-855^{\circ} \mathrm{C}$ with a mean and median of $819^{\circ} \mathrm{C}$ (Fig. 3.7; Electronic Appendix 3.2). The temperature estimates from the basal ignimbrite show a greater range $\left(768-918^{\circ} \mathrm{C}\right)$ and extend to higher temperatures, with a mean of $832^{\circ} \mathrm{C}$ and a median of 843 ${ }^{\circ} \mathrm{C}$.

For comparison, zircon saturation temperatures were calculated for the matrix and obsidian glasses. Calculated temperatures from the fall deposit yield ranges of $782-838{ }^{\circ} \mathrm{C}$ with a mean of $815^{\circ} \mathrm{C}$, and $733-803^{\circ} \mathrm{C}$ with a mean of $776^{\circ} \mathrm{C}$ using the calibrations of Watson and Harrison (1983) and Boehnke et al. (2013), respectively (Fig. 3.7; Electronic Appendix 3.1). Zircon saturation temperatures calculated from basal ignimbrite glasses extend to hotter temperatures with a range of $783-878{ }^{\circ} \mathrm{C}$ and a mean of $823^{\circ} \mathrm{C}$, and $733-851^{\circ} \mathrm{C}$ with a mean of $784{ }^{\circ} \mathrm{C}$, respectively, using the same calibrations. We note that here, as in other studies where alternative estimates of magma temperature are available (e.g. Barker et al. 2014), the calibration of Watson and Harrison (1983) yields temperature estimates that are closely comparable, whereas the Boehke et al. (2013) calibration yields values that are consistently lower than with other methods. We were unable to further investigate this disparity by comparing our results with Fe-Ti oxide thermometry, due to the exsolved nature of one or both minerals in oxide pairs. 


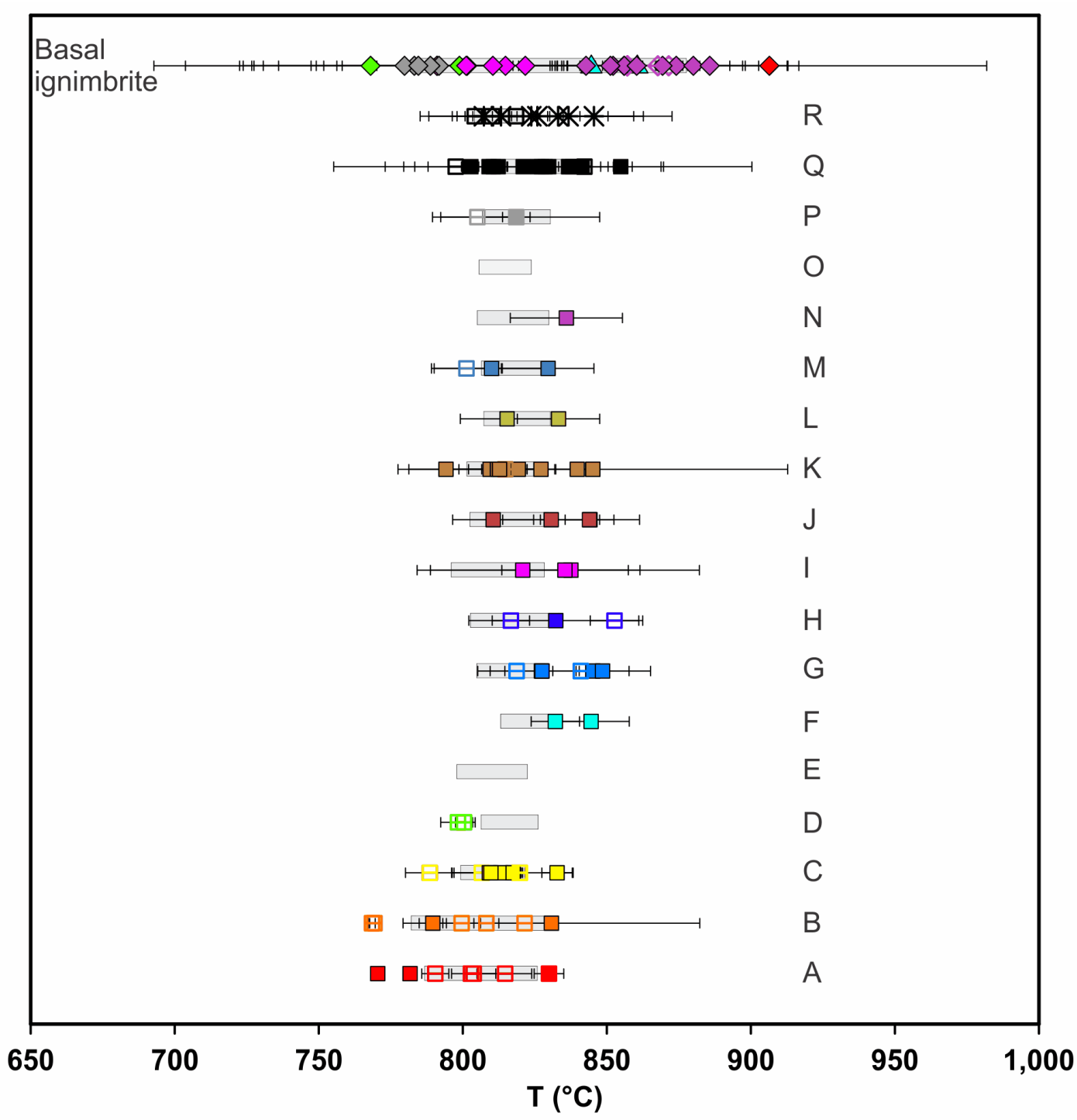

Figure 3.7: Temperature estimates using two-feldspar thermometry (Elkins and Grove 1990) through the fall deposits at the Mount Everts location (lettered levels: see Fig. 3.8 for stratigraphic log) and into the basal ignimbrite at multiple locations (Fig. 3.1). Data point colours as in Fig. 3.5. Filled symbols show sanidine inclusions in plagioclase, open symbols indicate plagioclase inclusions in sanidine. No suitable inclusions were found in horizons $E$ and $\mathrm{O}$. Shaded grey bars show the range in zircon saturation temperatures calculated from glass and obsidian compositions using the calibration of Watson and Harrison (1983).

\subsubsection{Plagioclase-melt hygrometer}

The plagioclase-melt hygrometer of Waters and Lange (2015) was used to estimate melt $\mathrm{H}_{2} \mathrm{O}$ concentrations. Given the uniformity of major element glass compositions within each fall horizon sampled (Fig. 3.2), an average glass composition for each horizon was used for the 
melt composition, coupled with a mean pressure of $200 \mathrm{MPa}$ (after Myers et al. 2016). However, pressure has little effect on the hygrometer: for example, adoption of the lowest restored pressure of $80 \mathrm{MPa}$ from Myers et al. (2016) only changes the hygrometry estimates by 0.03 wt $\% \mathrm{H}_{2} \mathrm{O}$. Using the mean two-feldspar thermometry model temperature for each horizon, corresponding calculated $\mathrm{H}_{2} \mathrm{O}$ contents in samples from the fall deposits range from 3.2-4.5 wt\% (Electronic Appendix 3.2). These values are similar to the estimates of 3.2-4.9 wt\% $\mathrm{H}_{2} \mathrm{O}$ based on melt inclusion data (Myers et al. 2016).

Given that plagioclase-melt hygrometer results for the fall samples are consistent with $\mathrm{H}_{2} \mathrm{O}$ estimates from melt inclusions, we apply this hygrometer method to basal ignimbrite samples for which $\mathrm{H}_{2} \mathrm{O}$ concentrations are otherwise unknown. Again using mean model temperatures from each locality, the hygrometer yields $\mathrm{H}_{2} \mathrm{O}$ contents of $2.4-4.5$ wt\%, with one outlier at $1.4 \mathrm{wt} \%$ reflecting a single feldspar pair from the basal ignimbrite at Mt. Everts that yielded an estimate of $918^{\circ} \mathrm{C}$.

\subsection{Discussion}

\subsubsection{Clustering of melt compositions: controls and significance}

To quantify the degree of compositional clustering and determine the dominant processes responsible, principal component analysis (PCA) and Bayesian mixture-modelling cluster analysis (MMCA) were conducted using $R^{\otimes}$ (R Development Core Team 2016). PCA works by analysing correlations between elements in a dataset to select the minimum number of variables that constitute the overall compositional variation present. These calculations were conducted independently for the fall deposit glass, fall deposit obsidian and basal ignimbrite glass, using 16 selected elements that show the greatest degree of clustering (Ca measured as $\mathrm{CaO}, \mathrm{Ti}, \mathrm{Rb}, \mathrm{Sr}, \mathrm{Y}, \mathrm{Zr}, \mathrm{Nb}, \mathrm{Ba}, \mathrm{La}, \mathrm{Ce}, \mathrm{Pr}, \mathrm{Nd}, \mathrm{Ta}, \mathrm{Th}, \mathrm{U})$. Significant principal components (PCs), i.e. the components that extract more variance, or inertia, than a randomly generated broken stick model (Jackson 1993), represent 47\% (PCs 1-3), 68\% (PCs 1+2) and 69\% (PCs 1+2) of the variance in the fall deposit glass, obsidian and basal ignimbrite glass compositions, respectively (Fig. S3.3; full importance of components is detailed in Electronic Appendix 3.3). PCA results indicate that the primary control on compositional variation is the compatibility of elements in the crystallising mineral assemblage. This conclusion is supported by the variations in $\mathrm{Ba}, \mathrm{Sr}$, LREE, Ti and $\mathrm{Zr}$ (notably compatible in the crystallising HRT minerals: 
sanidine, plagioclase, chevkinite, Fe-Ti oxides and zircon, respectively), driving the bulk of the variance in the dataset and plotting antithetically to incompatible elements (e.g. Rb, Nb, U: Fig. S3.3). An alternative possibility is that the variations are due to mixing (for which, however, there is no evidence on macro- or microscopic scales) of a common initial melt composition with variable amounts of a high- or low-Ba assimilant (e.g. mafic magma, country rock). However, mixing between two end-members is more likely to generate a continuum of glass compositions, rather than the clustered pattern observed (Fig. 3.5). Furthermore, magma mixing commonly generates multi-modal crystal major element compositions (e.g. Streck and Grunder 1999), not what is observed here, particularly in the fall deposit (Fig. S3.2). Also, why mafic magma would be expected to infiltrate such upper levels of the HRT magmatic system or why rhyolitic melts with similar, cool temperatures would assimilate variable amounts of country rock is puzzling. We, therefore, propose that the observed compositional variation is predominantly related to variations in the degree of fractional crystallisation.

The MMCA, using only significant principal components, distinguishes five clusters in the PCA of the fall glass compositions (labelled FGC1 to FGC5, ordered by their Ba concentrations; Fig. S3.3a). However, three of these (clusters three to five) have overlapping $95 \%$ confidence ellipses in all significant principal components and are hereafter treated as one cluster (FGC3). Six clusters are distinguished by MMCA in obsidian clasts from the fall deposit (Fig. S3.3b). Based on overlapping 2sd confidence ellipses we combine obsidian clusters 1 and 5 into one (hereafter OGC1), and 3 and 6 into another (hereafter OGC3). These combined clusters in turn show similarity in compositions (overlapping means at the 1sd level: Table 3.1) to FGC1 and FGC3, respectively. Another independent cluster (OGC4) is discerned by MMCA but is a minor component ( $0.5 \%$ of fall deposit glassy material) relative to the others. The compositions of clusters FGC-OGC 1-3 identified in this study correspond within error to those associated with the eruptive clusters 1-3, respectively, proposed by Myers et al. (2016) based on the compositions of reentrants (unsealed melt inclusions) in quartz phenocrysts. Therefore, like Myers et al. (2016), we interpret each cluster to represent a melt-dominant domain that is physically separate, as there is no evidence of mingling between different cluster compositions. In the fall deposit, FGC-OGC 3 is dominant, comprising $76 \%$ of analysed glassy material (glass shards and obsidian). 


\begin{tabular}{|c|c|c|c|c|c|c|c|c|c|c|c|c|c|c|}
\hline \multirow[b]{2}{*}{$\mathrm{SiO}_{2}$} & \multicolumn{2}{|c|}{ FGC1 } & \multicolumn{2}{|c|}{ FGC2 } & \multicolumn{2}{|c|}{ FGC3 } & \multicolumn{2}{|c|}{ OGC1 } & \multicolumn{2}{|c|}{ OGC2 } & \multicolumn{2}{|c|}{ OGC3 } & \multicolumn{2}{|c|}{ OGC4 } \\
\hline & 77.28 & 0.2 & 77.10 & 0.3 & 77.12 & 0.3 & 77.12 & 0.3 & 77.08 & 0.2 & 77.09 & 0.2 & 76.80 & 0.2 \\
\hline $\mathrm{TiO}_{2}$ & 0.08 & 0.0 & 0.05 & 0.0 & 0.09 & 0.0 & 0.08 & 0.0 & 0.08 & 0.0 & 0.09 & 0.0 & 0.12 & 0.0 \\
\hline $\mathrm{Al}_{2} \mathrm{O}_{3}$ & 12.43 & 0.1 & 12.33 & 0.2 & 12.32 & 0.2 & 12.38 & 0.2 & 12.36 & 0.1 & 12.36 & 0.1 & 12.41 & 0.1 \\
\hline FeOt & 1.23 & 0.0 & 1.33 & 0.1 & 1.39 & 0.1 & 1.25 & 0.1 & 1.35 & 0.1 & 1.40 & 0.1 & 1.51 & 0.0 \\
\hline $\mathrm{CaO}$ & 0.56 & 0.0 & 0.54 & 0.0 & 0.56 & 0.0 & 0.54 & 0.0 & 0.56 & 0.0 & 0.56 & 0.0 & 0.66 & 0.0 \\
\hline $\mathrm{Na}_{2} \mathrm{O}$ & 3.43 & 0.2 & 3.47 & 0.2 & 3.34 & 0.2 & 3.53 & 0.2 & 3.43 & 0.1 & 3.37 & 0.1 & 3.30 & 0.2 \\
\hline $\mathrm{K}_{2} \mathrm{O}$ & 4.96 & 0.1 & 5.15 & 0.2 & 5.13 & 0.1 & 5.05 & 0.1 & 5.09 & 0.1 & 5.08 & 0.1 & 5.15 & 0.1 \\
\hline $\mathrm{Ti}$ & 456 & 40 & 501 & 30 & 598 & 39 & 449 & 42 & 498 & 31 & 583 & 48 & 708 & 39 \\
\hline $\mathbf{R b}$ & 265 & 9 & 245 & 7 & 219 & 7 & 271 & 18 & 246 & 14 & 222 & 15 & 214 & 4 \\
\hline $\mathrm{Sr}$ & 1.77 & 0.4 & 3.43 & 0.5 & 6.91 & 0.9 & 2.22 & 0.7 & 3.47 & 0.5 & 6.58 & 0.8 & 9.22 & 0.6 \\
\hline$Y$ & 103 & 6 & 97 & 5 & 87 & 5 & 99 & 6 & 96 & 7 & 86 & 7 & 82 & 4 \\
\hline $\mathrm{Zr}$ & 176 & 11 & 220 & 9 & 218 & 11 & 180 & 16 & 216 & 15 & 215 & 16 & 241 & 12 \\
\hline $\mathrm{Nb}$ & 72 & 3 & 69 & 2 & 61 & 2 & 73 & 5 & 68 & 5 & 61 & 4 & 61 & 2 \\
\hline $\mathrm{Ba}$ & 18 & 2 & 47 & 5 & 128 & 18 & 23 & 8 & 48 & 6 & 121 & 18 & 233 & 37 \\
\hline La & 46 & 3 & 81 & 4 & 87 & 4 & 49 & 7 & 79 & 6 & 84 & 7 & 100 & 5 \\
\hline $\mathrm{Ce}$ & 95 & 4 & 158 & 6 & 166 & 7 & 102 & 15 & 154 & 12 & 160 & 14 & 191 & 10 \\
\hline $\mathrm{Yb}$ & 9.93 & 1.0 & 9.44 & 1.0 & 8.43 & 0.9 & 9.91 & 0.9 & 9.17 & 0.9 & 8.32 & 0.9 & 8.17 & 0.5 \\
\hline $\mathrm{Pb}$ & 47.60 & 1.8 & 45.29 & 2.6 & 40.60 & 2.2 & 47.25 & 4.1 & 43.89 & 3.8 & 40.94 & 4.3 & 49.78 & 4.9 \\
\hline Th & 33.03 & 2.1 & 34.82 & 2.0 & 31.67 & 2.0 & 33.39 & 3.4 & 34.24 & 3.4 & 31.54 & 3.1 & 31.12 & 1.9 \\
\hline U & 9.29 & 0.6 & 8.93 & 0.6 & 7.64 & 0.5 & 9.61 & 0.9 & 8.76 & 0.9 & 7.49 & 0.7 & 6.99 & 0.4 \\
\hline
\end{tabular}

\begin{tabular}{|c|c|c|c|c|c|c|c|c|c|c|c|c|c|c|c|c|}
\hline & \multicolumn{2}{|c|}{ IGC1 } & \multicolumn{2}{|c|}{ IGC2 } & \multicolumn{2}{|c|}{ IGC3 } & \multicolumn{2}{|c|}{ IGC4 } & \multicolumn{2}{|c|}{ IGC5 } & \multicolumn{2}{|c|}{ IGC6 } & \multicolumn{2}{|c|}{ IGC7 } & \multicolumn{2}{|c|}{ IGC8 } \\
\hline $\mathrm{SiO}_{2}$ & 77.09 & 0.3 & 77.03 & 0.2 & 77.08 & 0.3 & 76.86 & 0.3 & 76.79 & 0.3 & 76.66 & 0.3 & 76.68 & 0.3 & 76.48 & 0.2 \\
\hline $\mathrm{TiO}_{2}$ & 0.04 & 0.0 & 0.06 & 0.0 & 0.06 & 0.0 & 0.05 & 0.1 & 0.05 & 0.1 & 0.07 & 0.1 & 0.08 & 0.1 & 0.10 & 0.1 \\
\hline $\mathrm{Al}_{2} \mathrm{O}_{3}$ & 12.41 & 0.2 & 12.36 & 0.2 & 12.29 & 0.2 & 12.39 & 0.2 & 12.41 & 0.1 & 12.43 & 0.1 & 12.35 & 0.1 & 12.40 & 0.1 \\
\hline FeOt & 1.23 & 0.1 & 1.33 & 0.1 & 1.31 & 0.2 & 1.42 & 0.1 & 1.52 & 0.1 & 1.65 & 0.1 & 1.58 & 0.2 & 1.74 & 0.1 \\
\hline $\mathrm{CaO}$ & 0.55 & 0.1 & 0.55 & 0.0 & 0.46 & 0.1 & 0.55 & 0.0 & 0.57 & 0.0 & 0.44 & 0.0 & 0.58 & 0.1 & 0.61 & 0.0 \\
\hline $\mathrm{Na}_{2} \mathrm{O}$ & 3.43 & 0.2 & 3.43 & 0.2 & 3.32 & 0.2 & 3.37 & 0.2 & 3.43 & 0.2 & 3.30 & 0.2 & 3.41 & 0.2 & 3.44 & 0.1 \\
\hline $\mathrm{K}_{2} \mathrm{O}$ & 5.24 & 0.2 & 5.22 & 0.2 & 5.46 & 0.2 & 5.34 & 0.2 & 5.23 & 0.1 & 5.43 & 0.1 & 5.30 & 0.2 & 5.22 & 0.1 \\
\hline $\mathrm{Ti}$ & 451 & 49 & 608 & 23 & 591 & 45 & 652 & 35 & 736 & 26 & 864 & 51 & 856 & 59 & 952 & 46 \\
\hline $\mathbf{R b}$ & 215 & 21 & 219 & 15 & 219 & 29 & 205 & 12 & 197 & 7 & 213 & 10 & 198 & 12 & 185 & 14 \\
\hline $\mathrm{Sr}$ & 3.64 & 1.9 & 6.90 & 0.6 & 6.75 & 1.4 & 8.42 & 1.7 & 9.70 & 1.1 & 7.37 & 1.8 & 10.84 & 2.4 & 14.06 & 1.2 \\
\hline $\mathbf{Y}$ & 103 & 6 & 88 & 3 & 84 & 5 & 82 & 4 & 80 & 3 & 72 & 3 & 74 & 3 & 72 & 2 \\
\hline $\mathrm{Zr}$ & 182 & 21 & 219 & 7 & 211 & 9 & 226 & 13 & 255 & 7 & 286 & 19 & 292 & 19 & 327 & 23 \\
\hline $\mathrm{Nb}$ & 75 & 4 & 63 & 2 & 63 & 3 & 61 & 2 & 60 & 1 & 57 & 2 & 57 & 2 & 55 & 1 \\
\hline $\mathrm{Ba}$ & 45 & 34 & 127 & 11 & 196 & 72 & 220 & 43 & 293 & 25 & 339 & 53 & 453 & 56 & 635 & 75 \\
\hline La & 47 & 16 & 87 & 3 & 82 & 10 & 92 & 5 & 105 & 3 & 117 & 5 & 118 & 6 & 124 & 5 \\
\hline $\mathrm{Ce}$ & 102 & 28 & 167 & 5 & 162 & 16 & 179 & 8 & 201 & 7 & 223 & 8 & 225 & 10 & 234 & 7 \\
\hline $\mathrm{Yb}$ & 10.53 & 1.0 & 8.46 & 0.6 & 8.19 & 0.9 & 8.06 & 0.8 & 7.70 & 0.7 & 7.00 & 0.7 & 7.28 & 0.7 & 7.07 & 0.6 \\
\hline $\mathrm{Pb}$ & 48.90 & 2.9 & 41.53 & 2.8 & 46.13 & 6.5 & 42.58 & 5.3 & 38.05 & 2.1 & 38.44 & 1.6 & 39.76 & 8.7 & 37.87 & 10.1 \\
\hline Th & 35.48 & 2.5 & 31.48 & 1.4 & 31.21 & 1.7 & 30.52 & 1.6 & 30.68 & 1.2 & 29.66 & 1.0 & 29.97 & 1.4 & 29.10 & 1.4 \\
\hline$U$ & 9.92 & 0.9 & 7.82 & 0.5 & 7.85 & 0.7 & 7.37 & 0.5 & 6.65 & 0.4 & 5.98 & 0.3 & 5.98 & 0.4 & 5.51 & 0.3 \\
\hline
\end{tabular}


MMCA of the basal ignimbrite samples yields eight distinguishable compositional clusters (correspondingly labelled IGC1-8), but some of these have partially overlapping 2sd confidence ellipses (Fig. S3.3c). IGC1 (4\% of basal ignimbrite analyses) is notable for comprising compositions that span the ranges of FGC-OGC 1 and 2, and therefore represents two of the melt-dominant domains tapped during fall deposition. IGC2 overlaps within $1 \mathrm{sd}$ of FGC-OGC 3 (Table 3.1) and is also the dominant basal ignimbrite cluster (46\% of analyses: Fig. 3.5). The compositional similarities and proportions of the relevant shards in the basal ignimbrite samples indicate that the magma bodies that vented to feed the fall deposits were still being evacuated at the onset of widespread ignimbrite deposition, rather than these shards representing surficial pick-ups. Furthermore, some sparsely present, less-evolved glass compositions in the fall deposits (e.g. OGC 4: $0.5 \%$ of analyses), are replicated in the basal ignimbrite as clusters IGC4 and 5 (collectively $21 \%$ of analyses). This observation suggests that OGC4 represents early erupted material of those clusters that were evacuated in greater proportions during ignimbrite generation. Although previously unrecognized (cf. Myers et al. 2016), they are identified here probably due to a larger number of glass shards being analysed relative to those of unsealed melt inclusions. All clusters are statistically significant, indicated by the discrete means and $95 \%$ confidence ellipses (Fig. 3.5) determined through standard error slope regression (see Chapter S3 and Fig. S3.4).

The clustered nature of glass compositions in the fall deposits and basal ignimbrite suggests that the HRT magmatic system was not a unitary, continuously zoned or homogenous magma body, but rather consisted of multiple discrete domains. The absence of significant intra-shard heterogeneity also suggests that there was limited mixing between these domains at depth or within shallow conduits, and that the domains remained distinct upon evacuation (cf. Mahood et al. 1985; Streck and Grunder 1997; Aguirre-Díaz 2001). However, the trace element compositional variations within each cluster, oblique to the overall trend (Fig. 3.5), imply that each domain itself underwent some degree of melt compositional evolution following its isolation. We infer a fractional crystallisation control on the compositional variations observed within and between individual clusters, as indicated by the association of element eigenvectors in the PCA (Fig. S3.3) and variously sloped inter- and intra-cluster trends (Fig. 3.5). 


\subsubsection{Modelling of compositional trends}

Crystallisation modelling was performed to explore the significance of the observed inter- and intra-cluster trends. Because plagioclase and sanidine are co-crystallising, we consider the concentrations of feldspar-compatible $\mathrm{Ba}$ and $\mathrm{Sr}$. The relationship between $\mathrm{Ba}$ and $\mathrm{Sr}$ will be controlled by their differing partition coefficients (e.g. Ba more compatible in sanidine) and by the proportion of plagioclase to sanidine crystallisation. Assuming constant bulk partition coefficients, expected due to the uniform major element compositions (Fig. S3.2), linear slopes should result from the logarithmic relationship between $\mathrm{Ba}$ and $\mathrm{Sr}$ if fractional crystallisation is the dominant control. We use $\mathrm{Ba} / \mathrm{Rb}$ and $\mathrm{Sr} / \mathrm{Rb}$ ratios, rather than $\mathrm{Ba}$ and $\mathrm{Sr}$ concentrations, to minimise analytical scatter. In addition, as $\mathrm{Rb}$ is very incompatible in the HRT mineral assemblage, it will have contrasting behaviour to $\mathrm{Ba}$ and $\mathrm{Sr}$ with fractional crystallisation leading to greater variation in the ratios relative to elemental concentrations. Algebraic manipulation of the Rayleigh fractionation differential equation gives:

$$
\delta \log (\mathrm{Ba})=\left(D_{\mathrm{Ba}}-1\right) \delta \log f,
$$

where $f$ is the mass fraction of melt remaining and $D_{B a}$ is the partition coefficient of $\mathrm{Ba}$. This subsequently yields the equation expressing the changes in the respective ratios related to their partition coefficients:

$$
\frac{\delta \log (\mathrm{Ba} / \mathrm{Rb})}{\delta \log (\mathrm{Sr} / \mathrm{Rb})}=\frac{\left(D_{\mathrm{Ba}}-D_{\mathrm{Rb}}\right)}{\left(D_{\mathrm{Sr}}-D_{R b}\right)} .
$$

Partition coefficients of 28.4, 11.3 and 0.08 for $\mathrm{Ba}$, Sr and $\mathrm{Rb}$, respectively, in sanidine were used and a coefficient of 0.08 for Rb in plagioclase (from Anderson et al. 2000 and references therein). In plagioclase, partition coefficients of 1.33 and 10.60 for Ba and Sr, respectively, were used, calculated using the parameterisations of Blundy and Wood (1991) at $A n_{20}$ and $820{ }^{\circ} \mathrm{C}$ (the average plagioclase composition and two-feldspar temperature estimates, respectively, for the combined fall deposit and basal ignimbrite data sets).

Bulk partition coefficients were calculated for different ratios of plagioclase to sanidine crystallisation (ignoring the minor effect of other phases on the relevant coefficients) to model feldspar crystallisation and compare against inter- and intra-cluster trends. Starting compositions of 900,163 and $19 \mathrm{ppm}$ for $\mathrm{Ba}, \mathrm{Rb}$ and $\mathrm{Sr}$, respectively, were used, determined from the least-evolved concentrations of each element in this data set. Joining the leastevolved (i.e. highest $\mathrm{Sr} / \mathrm{Rb}$ and $\mathrm{Ba} / \mathrm{Rb}$ ) points of FGC-OGC 1-3 results in a slope with a gradient of $1.68\left(r^{2}=0.99\right)$, which could be generated by a sanidine:plagioclase ratio of 1.7 (Fig. 3.5b). 
Similarly, a trend connecting the least-evolved ends of IGC $1,2,4,5,7$, and 8 has a slope of 2.01 $\left(r^{2}=0.99\right)$, which can be replicated through crystallisation of an assemblage with a sanidine:plagioclase ratio of 3 (Fig. $3.5 \mathrm{~d}$ ). Intra-cluster trends, although with weaker constraints, have shallower slopes of $0.72,0.4$ and 0.59 for FGC-OGC 1,2 and $3\left(r^{2}=0.52\right.$, $0.24,0.32)$, respectively, that could reflect a lower sanidine:plagioclase ratio of $<0.2$.

The linear compositional trends observed in log-log plots (Fig. 3.5) indicate a fractional crystallisation control on the subtle chemical differences observed between the clusters. This modelling further suggests that although the overall trend (across all clusters) in the glass compositions can be explained by a sanidine-dominant crystallising assemblage, the intracluster trends suggest a plagioclase-dominant assemblage (Fig. 3.5). The simplest explanation for this contrast arises from the experimental results of Almeev et al. (2012). The early separation of the melt-dominant bodies (demonstrated by the bimodal compositions of sanidine cores and rims: Fig. 3.3) means that their compositions diverge along chemical trends driven by higher temperature, sanidine-dominant crystal fractionation. Once separated, each body then evolved with lowering temperatures, with increased proportions of plagioclase in the crystallising assemblage. However, the relative proportions of sanidine and plagioclase are also dependent on $\mathrm{H}_{2} \mathrm{O}$ contents, and so the changes in crystallisation assemblages may also in part reflect coupled temperature and $\mathrm{H}_{2} \mathrm{O}$ activity variations, with decreased activity favouring plagioclase crystallisation (e.g. Wilke et al. 2017). The clusters characterised by lower $\mathrm{CaO}(\mathrm{IGC} 3+6)$ in particular may reflect prolonged plagioclase-dominant crystallisation (Fig. 3.5d). This distinctive combination of characteristics implies the presence of a complex magmatic system consisting of multiple, individually diverse melt-dominant bodies within a larger-scale compositionally heterogeneous system.

\subsubsection{Pre-eruptive state of the Huckleberry Ridge magmatic system}

Thermometry and hygrometry calculations applied to the initial deposits of the HRT indicate that significant variations in temperature and $\mathrm{H}_{2} \mathrm{O}$ concentration were present in the upper parts of a complex HRT magmatic system prior to early evacuation. Here we present combined two-feldspar and Watson and Harrison (1983) zircon saturation temperatures to reconstruct the temperature conditions in these upper parts.

Model temperatures range from $768^{\circ} \mathrm{C}$ in the earliest erupted material to $>900{ }^{\circ} \mathrm{C}$ in the basal ignimbrite (which, however, still represents an 'early' stage in the overall eruption). 
Increasing calculated model temperatures are correlated with increased sanidine $\mathrm{Cn}$ component and inversely correlated with Or content, implying that the temperature calculations genuinely represent a pre-eruptive variability across the melt-dominant bodies. Although a $\mathrm{Cn}$ component in the sanidine was not included in the original experiments of Elkins and Grove (1990), we note that almost the full range $\left(768-871{ }^{\circ} \mathrm{C}\right)$ of two-feldspar model temperatures are represented in pairs with $<1$ mol\% Cn (Fig. 3.7). Furthermore, an upper limit of model temperatures in the fall deposit samples of $854^{\circ} \mathrm{C}$ is also consistent with the upper limit of stability for sanidine at $2 \mathrm{kbar}$ and $4 \mathrm{wt} \% \mathrm{H}_{2} \mathrm{O}$ in experimental studies (Almeev et al. 2012). The similarity between two-feldspar temperature estimates and zircon saturation temperatures (Fig. 3.7; Watson and Harrison 1983) also supports the temperature estimates from sanidines with a broad range of $\mathrm{Cn}$ compositions. Melt $\mathrm{H}_{2} \mathrm{O}$ contents inferred using the Waters and Lange (2015) hygrometer similarly decrease with height in the fall deposits. Although the plagioclase hygrometer is strongly temperature dependent, within our estimated temperature range it yields values consistent with the Myers et al. (2016) data for melt inclusions, which also indicated an overall decrease in magmatic $\mathrm{H}_{2} \mathrm{O}$ contents upsection through the fall deposits.

The distinctive Cn compositions of the alkali feldspars from clusters FGC1+2 and FGC3 allow us to investigate whether the different melt-dominant compositional domains had different temperatures. Temperatures calculated from plagioclase inclusions in sanidines that had rims with $\mathrm{Cn}_{<0.35}$ (i.e. $\mathrm{FGC1}+2$ ) range from $768-820{ }^{\circ} \mathrm{C}$ with a mean of $789{ }^{\circ} \mathrm{C}$. In comparison temperatures calculated from sanidines with $\mathrm{Cn}_{>0.4}$ (i.e. FGC3) range from 798$853{ }^{\circ} \mathrm{C}$ with a mean of $819{ }^{\circ} \mathrm{C}$. The presence of lower, but overlapping, temperatures associated with $\mathrm{FGC1}+2$ is also consistent with zircon saturation temperatures. Temperatures calculated from FGC-OGC 1 are the lowest, with a range of $782-826^{\circ} \mathrm{C}$ and a mean and median of $798{ }^{\circ} \mathrm{C}$. Glass and obsidian from FGC-OGC 2 yield temperatures from $796-830{ }^{\circ} \mathrm{C}$ with a mean and median of $816{ }^{\circ} \mathrm{C}$, which overlap those calculated from FGC-OGC 3 glass and obsidian $\left(797-838^{\circ} \mathrm{C}\right.$ with a mean and median of $\left.817^{\circ} \mathrm{C}\right)$.

The cooler, but overlapping nature of temperatures obtained from lower $\mathrm{Cn}$ sanidines and glass from FGC-OGC 1 suggests that there were modest (up to $\sim 20-30{ }^{\circ} \mathrm{C}$ ) temperature differences between the different melt-dominant bodies. However, this lower temperature, more-evolved glass compositional group (FGC-OGC 1) is associated with higher restored pressures (142-189 $\mathrm{MPa}$, based on $\mathrm{H}_{2} \mathrm{O}$ and $\mathrm{CO}_{2}$ solubility in melt inclusions from quartz 
population 1 of Myers et al. 2016, compared to the total range of 85-204 MPa). This observation indicates that there is not a simple temperature-depth-melt evolution relationship in the HRT magmatic system as would be expected with a single, coherent magma body (cf. Bishop Tuff: Wallace et al. 1999; Hildreth and Wilson 2007).

\subsubsection{The HRT magma body: configuration and early evacuation}

Systematic sampling of glassy material through the fall deposits and basal ignimbrite at multiple localities around three sides of the HRT caldera allows for temporal and spatial reconstruction of evacuation during the opening eruptive stages. Our data show that three magmatic domains were systematically and sequentially evacuated through the fall deposits (Fig. 3.8), consistent with and extending the findings of Myers et al. (2016). Although there was a hiatus in evacuation of compositional groups FGC-OGC1 and FGC-OGC2 in the upper parts of the fall deposits, these groups then reappear in the basal ignimbrite collectively as IGC1. The similar trends in abundance of low-Cn sanidines and glassy material from clusters FGC-OGC1+2 further support their link, as inferred from glass selvedge analyses (Fig. 3.6).

When considered by locality, basal ignimbrite A samples show that multiple compositional clusters are present in samples in all directions around and distances from the caldera rim (Fig. 3.9), with no clear patterns. On this basis, we infer that material from a greater number of melt-dominant bodies were simultaneously incorporated into the earliest widespread ignimbrite-forming flows when compared with the fall deposits. This, plus the preservation of fall sequences with broadly similar overall stratigraphy beneath the full extent of the ignimbrite, implies two things. First, that the onset of continuous ignimbrite deposition was effectively synchronous at all localities studied here. Second, that the fall-to-flow transition must have been accompanied both by an escalation in eruption rates and a sharp increase in the number of magma bodies evacuated.

Determining the configuration and state of the magmatic system(s) is important in understanding the nature and magnitude of internal stresses (e.g. buoyancy) present during the onset of eruption. It is therefore important to consider whether the individual HRT meltdominant bodies, each with their own internal compositional variability, existed as discrete isolated domains or were instead sills forming part of a larger interconnected magma reservoir (cf. Tarasewicz et al. 2012; Cashman and Giordano 2014). In the latter case, temporal trends are observed that have been related to tapping of different levels within a 


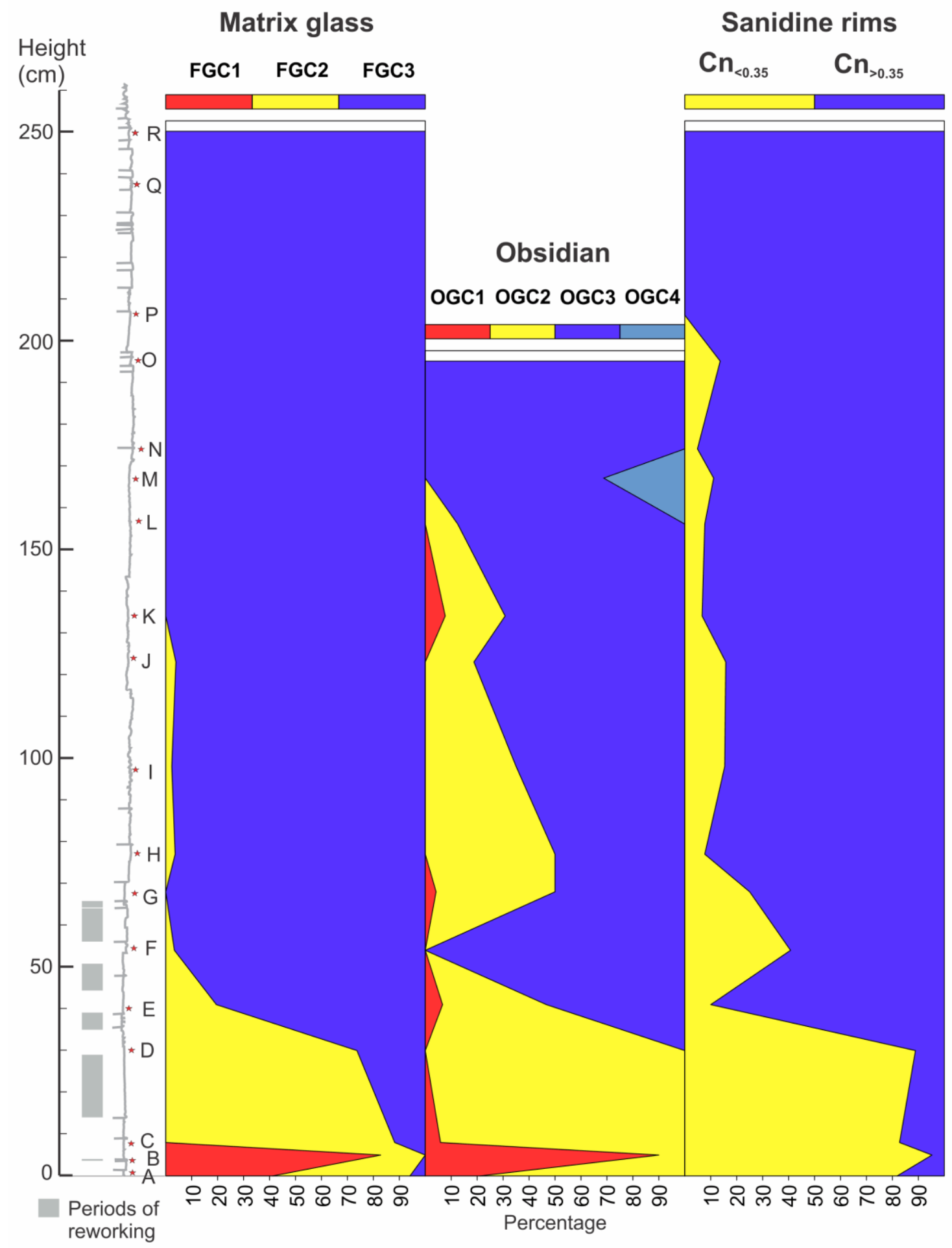

Figure 3.8: Comb diagram showing the changes in proportions of the compositional groupings of matrix glass, obsidian pyroclasts and sanidine rims through the fall deposit sequence at Mt. Everts. Colours of the groupings in the 'glass' and 'obsidian' column match those of the fields in Fig. 3.5 and the sanidine rim compositions of Fig. 3.3. A schematic stratigraphic log of the Mt. Everts section is shown, along with the horizons sampled. See Fig. S3.1 for a photograph of the sampled section. 


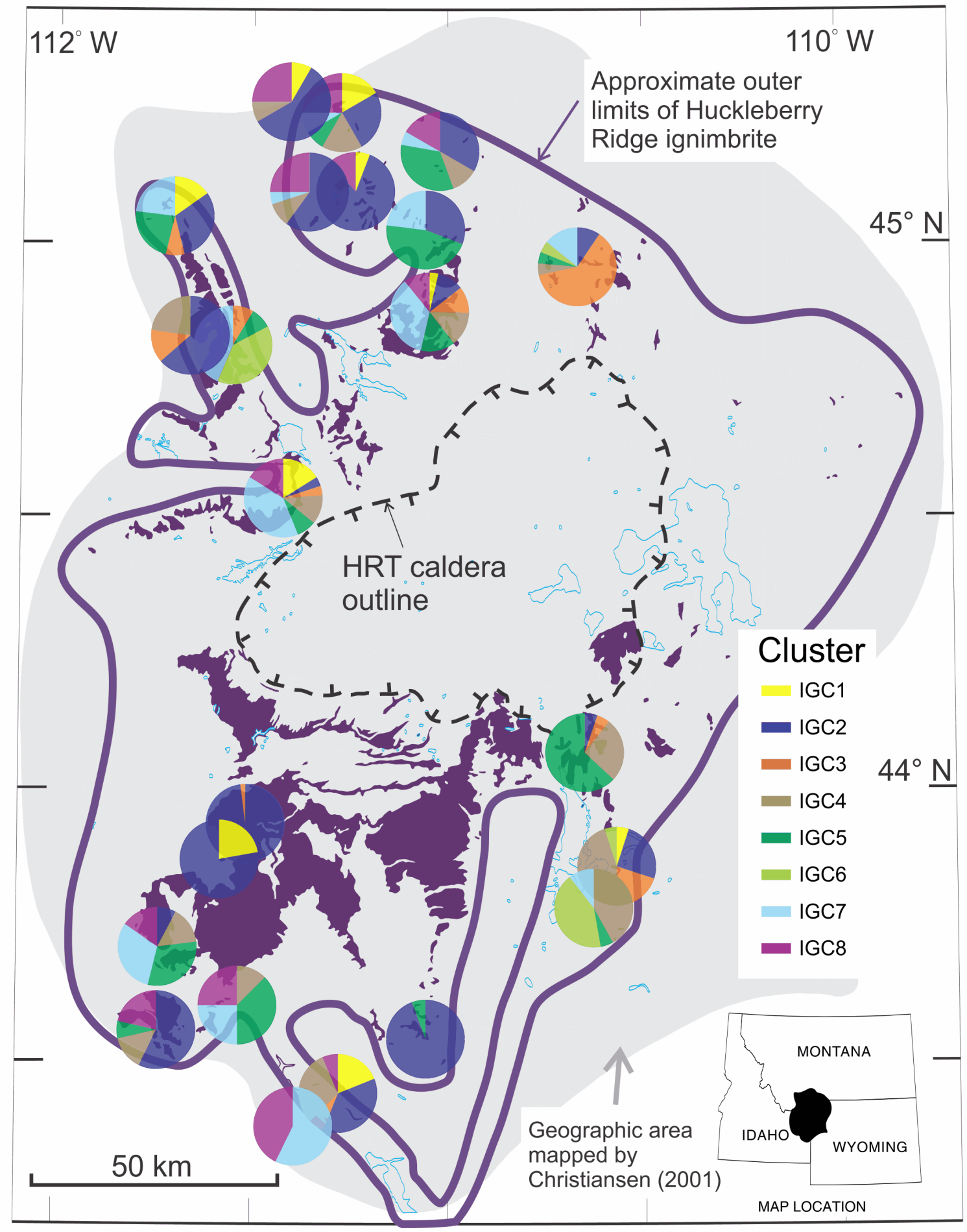

Figure 3.9: Pie charts showing the relative abundances of different clusters in basal ignimbrite glass compositions at each sample locality (see Fig. 3.1 for location names. Colours as in Fig. S3.2c). Where samples were collected from multiple levels at the same location, pie charts overlap. No strong sectorial or proximal-to-distal (i.e. temporal) pattern to glass compositions in the basal ignimbrite is evident. 
sill-dominated magmatic system. In contrast, the absence of any temporal trend in glass compositions in the basal HRT ignimbrite A (i.e. a systematic change from proximal to distal localities: Fig. 3.9) suggests that the bodies were predominantly laterally, rather than vertically separated, and were tapped collectively at the onset of ignimbrite deposition. Additional constraints come from restored entrapment pressures (storage depths) from melt inclusions (Myers et al. 2016) in quartz populations 5+6 (upper fall) that are compositionally equivalent (high $\mathrm{Ba}$, low $\mathrm{CaO}$ of population 5 ) to matrix glass only observed by us in the basal ignimbrite (IGC6: Table 3.1). These restored entrapment pressures indicate depths as shallow (85-160 MPa: 3-6 km depth), if not shallower, than those of the three magma domains tapped during the earliest fall deposit stages (106-204 MPa: 4-8 km depth). We interpret these data to indicate that at least some of the magma bodies tapped at the onset of ignimbrite-forming activity were laterally separated from, and in some cases at shallower depths than, those that fed the fall deposit (rather than beneath them). Furthermore, twofeldspar and zircon saturation temperature estimates in basal ignimbrite samples overlap with those of the fall deposits, precluding a significant increase in temperature being associated with the melt-dominant bodies tapped at the onset of ignimbrite deposition (Fig. 3.7).

The clustered nature of the glass shard, obsidian clast and sanidine rim compositions in the fall deposits and basal ignimbrite in turn raise questions about whether the multiple meltdominant bodies reflect extracts from a common root zone, or were derived from two (or more) adjacent root zones. The clustering observed in sanidine rim compositions is mirrored in the core compositions (Fig. 3.3) implying that the melt bodies became physically separated and chemically distinct prior to the onset of sanidine crystallisation. This onset is estimated to be at $\geq 850{ }^{\circ} \mathrm{C}$, based on our two-feldspar thermometry (Fig. 3.7) and published experimental work (Almeev et al. 2012). The low-Cn sanidine group is linked to FGC1 and FGC2 through glass selvedge analyses (Fig. 3.6) and comparable changes in sanidine rim, glass and obsidian cluster proportions through the fall deposits (Fig. 3.8). These observations imply that the separation between FGC1+2 and FGC3 occurred prior to the last $\sim 50{ }^{\circ} \mathrm{C}$ of cooling and crystallisation, based on the temperature range determined from low-Cn sanidines. This inference is in turn consistent with the quartz-hosted melt-inclusion compositional patterns (Myers et al. 2016), as the onset of quartz crystallisation is inferred to occur at a lower temperature than that of sanidine (Almeev et al. 2012). Of the quartz grains that contained a 
re-entrant and a melt inclusion studied by Myers et al. (2016), only one has a re-entrant from their eruptive cupolas 1 or 2 (equivalent to our FGC1/2) and a melt inclusion from another cluster, indicating also that there was chemical and physical separation of these bodies prior to the co-crystallisation of quartz and sanidine.

Myers et al. (2016) found that some quartz-hosted melt-inclusion compositions from the fall deposits (their quartz populations $5+6$ ) did not correspond to compositions of the meltdominant domains active during generation of the fall deposits studied by them. However, the low $\mathrm{CaO}$, higher Ba melt-inclusion composition of quartz population 5 is replicated in glass from the basal ignimbrite (IGC6; Table 3.1). Single quartz grains that hosted melt-inclusions from multiple populations always contained glass compositions that linked to quartz populations 5 or 6 and $3+4$ types, the latter of which is comparable to our FGC-OGC3. These observations indicate that there was some exchange of crystals between the domains which hosted quartz populations $5+6$ (i.e. IGC6) and FGC-OGC3 after the onset of quartz crystallisation (Fig. 3.10).

The separation of low-Ba melt-bodies (represented by FGC1+2) prior to sanidine crystallisation and the interchange of quartz crystals between melt-bodies tapped only by the ignimbrite and FGC3 suggests there are two distinct larger-scale magmatic lineages (i.e. two compositionally independent entities) present in the HRT magmatic system and tapped in these early stages of the HRT (Fig. 3.10). The first is characterised by the low-Cn sanidines that are present in FGC1 and FGC2 and the second is associated with the higher-Cn sanidines linked to FGC3. From these two lineages were developed multiple cupolas, each of which developed its own distinctive traits in melt composition and which were systematically tapped in the opening stages (Fig. 3.10). The term 'cupolas' was used to describe these bodies by Myers et al. (2016) as their focus on only the earliest erupted material precluded an insight into the relation of these bodies to the larger magmatic system(s). With our extended dataset, we can show that these domains, representing two melt-dominant lineages, persist through into the onset of basal ignimbrite deposition. We, however, retain the use of 'cupola' as their relationship to the overall HRT magmatic system(s) requires geochemical investigation of the volumetrically dominant later-erupted material (Swallow et al. manuscript in preparation, Chapter 5). Complexity in the HRT magma system has previously been discerned in the overall chemical and isotopic characteristics of the ignimbrite units (Doe et al. 1982; Hildreth et al. 1984, 1991; Bindeman et al. 2008; Wotzlaw et al. 2015). However, these documented 


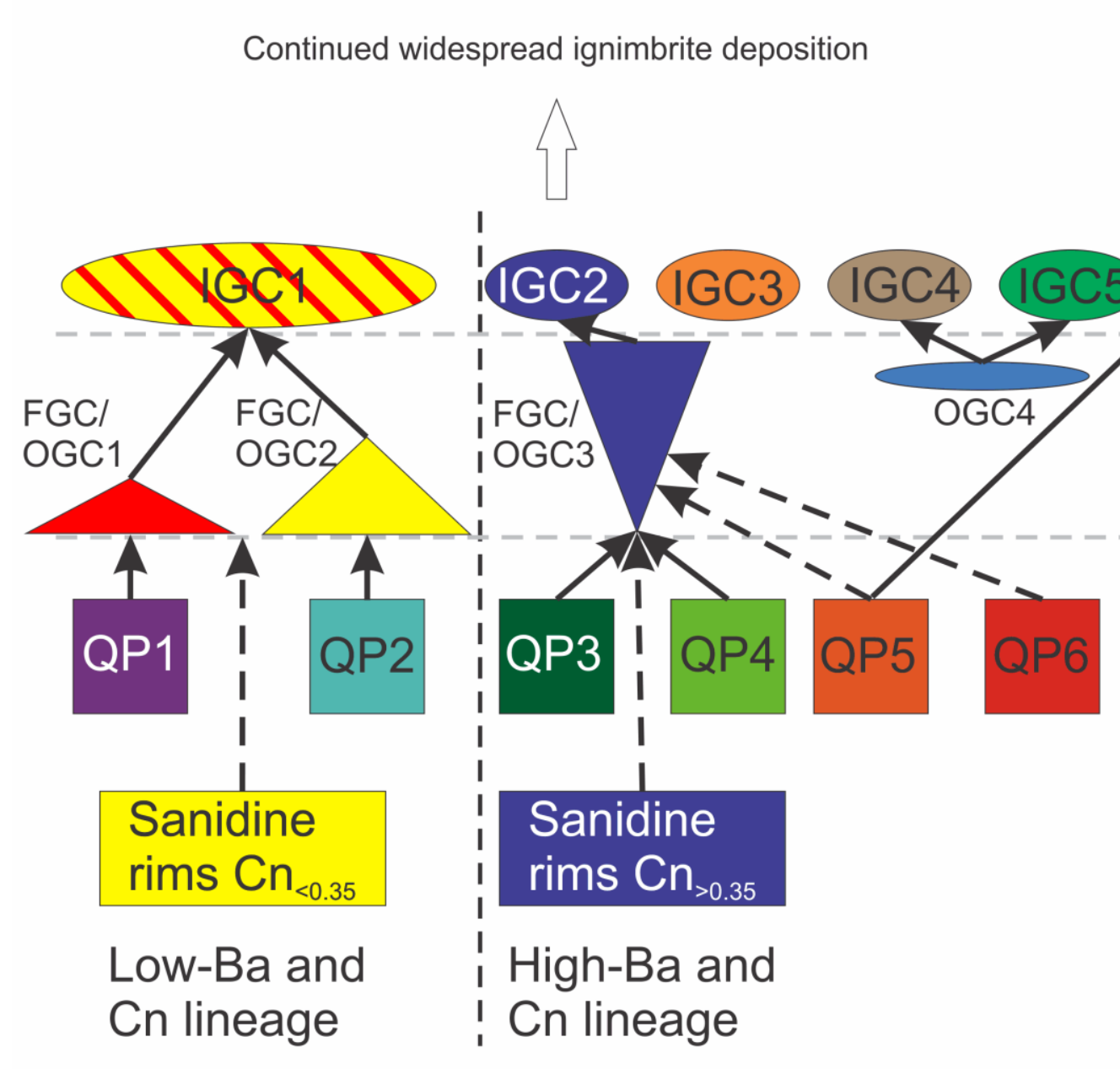

(d) Onset of widespread ignimbrite deposition: eight compositional basal ignimbrite A glass clusters (IGC)

including those present in the fall deposit and crystal populations as well as others previously unseen

IGC6 IGC7

(c) Onset of eruptive activity: three domains simultaneously tapped. Fall deposit glass (FGC) and obsidian clusters (OGC) equivalent to eruption cupolas 1-3 from Myers et al. (2016)

\section{(b) Continued crystallisation:}

development of distinct melt-dominant domains. Six quartz populations (QPs) from melt-inclusion compositions of Myers et al. (2016)

(a) Early crystallisation: two magmatic lineages distinguished on Cn component in sanidine

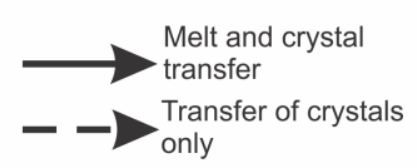

Figure 3.10: Schematic flow diagram showing the relationships and links between the clusters inferred from (a) sanidine rim compositions (this study), (b) quartz populations based on melt-inclusion analyses (Myers et al. 2016), (c) fall deposit glass shard and obsidian clast compositional characteristics (Myers et al. 2016 and this study) and (d) basal ignimbrite glass compositions. 
complexities apply over much larger time and length scales, involving volumes of magma that are 1-3 orders of magnitude larger than those detailed in our study. The subtle variations we see at the start of the HRT eruption have not previously been discerned.

The complex magma system configuration and episodic style of eruption onset shown by the HRT is not unique within the Yellowstone-Snake River Plain volcanic province (Ellis and Wolff 2012) and also has analogues worldwide, particularly in New Zealand (e.g. Gravley et al. 2007; Allan et al. 2012, 2017; Cooper et al. 2012, 2016; Bégué et al. 2014; Cashman and Giordano 2014; Pistolesi et al. 2016). Many of these examples involved magma systems distributed beneath geographic areas that are smaller than that encompassed by the mapped HRT caldera (Christiansen 2001). Available data do not, however, permit us to outline the specific areas involved in the initial development of HRT caldera collapse. However, the complexities represented by the individual cupolas in the HRT have not been observed before and would escape notice unless trace element data and thermobarometric estimations are considered together using material derived from high-resolution, stratigraphicallyconstrained sampling.

\subsection{Implications for eruption behaviour}

The presence and complex evacuation of multiple melt-dominant bodies is not readily incorporated in the variety of numerical models used to investigate the onset of large silicic eruptions (e.g. Jellinek and DePaolo 2003; Gregg et al. 2012, 2015; Caricchi et al. 2014; Degruyter and Huber 2014; Malfait et al. 2014). Jellinek and DePaolo (2003) highlight a contrasting model behaviour between smaller magma bodies that are expected to generate sufficient overpressure to cause dike propagation and hence erupt, versus large bodies that heat the wall rocks sufficiently to suppress dike propagation. Furthermore, small systems are predicted to be triggered in a different manner to larger systems, with a greater emphasis on internal processes in smaller systems (Gregg et al. 2015). The HRT magma body appears to fit both model end members, with multiple compositionally and physically discrete meltdominant domains capping the larger-scale overall magmatic system beneath what became the overall HRT caldera (Fig. 3.11). This configuration would result in a significantly different stress field when compared to a single large magma body and has important thermomechanical implications. For example if one or more smaller-scale melt-dominant bodies 

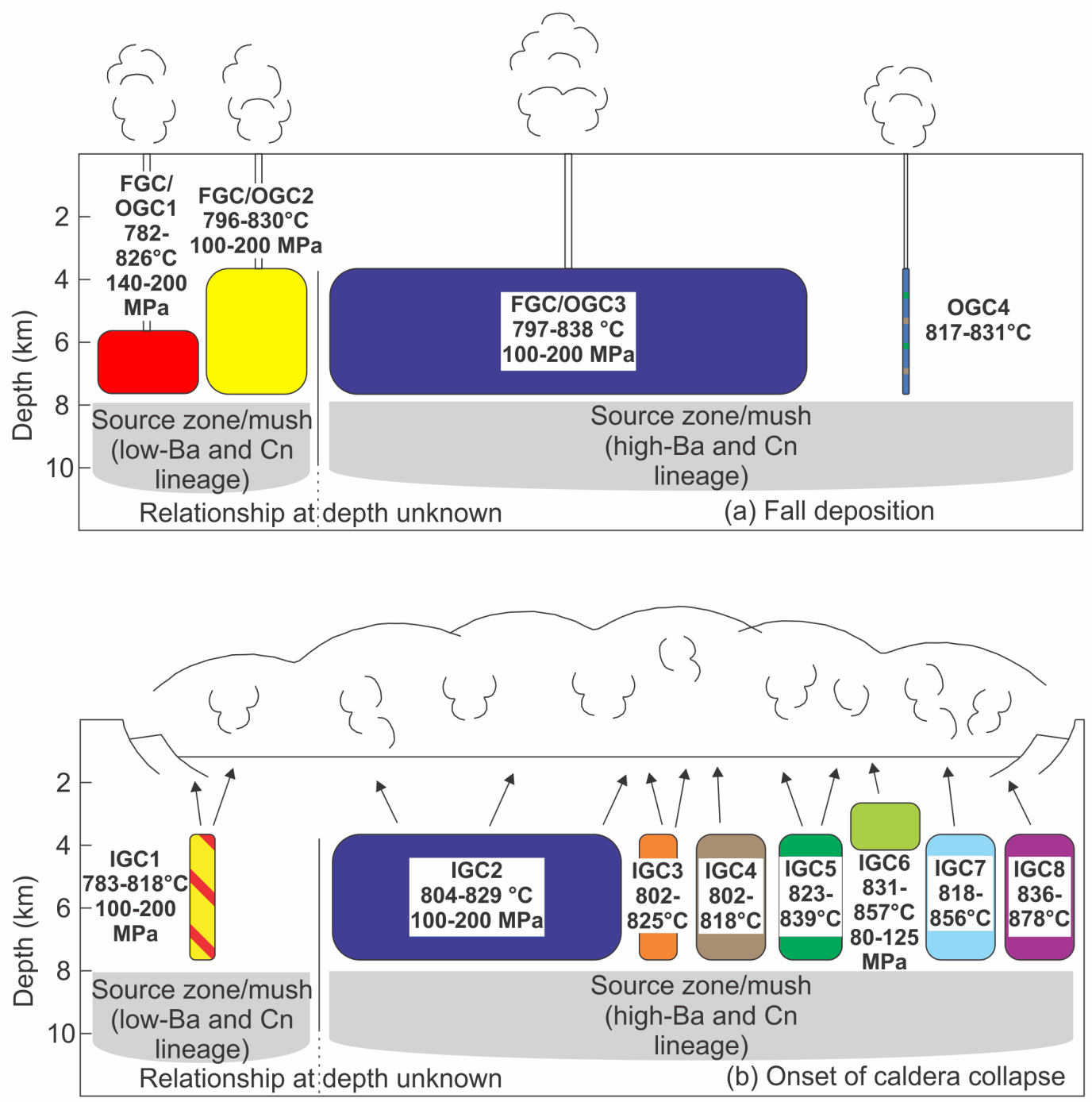

Figure 3.11 Schematic diagram showing the configuration of the tapped magma domains (a) at the onset of fall deposition, and (b) at the onset of caldera collapse and deposition of ignimbrite member A. The HRT magmatic system tapped in these stages of the eruption is inferred to consist of multiple discrete, laterally-adjacent melt-dominant bodies representing two magmatic lineages. Three bodies (FGC-OGC 1-3: Fig. 3.10) were erupted at the onset of fall deposition (Fig. 3.8). Eight compositional clusters, representing nine melt-dominant bodies (IGC1 represents two bodies, FGCOGC1+2), including the three tapped during fall deposition, were simultaneously evacuated following caldera collapse at the onset of ignimbrite deposition. The sizes of the rectangles representing the melt-dominant bodies is in proportion to the numerical abundance of analyses assigned to that cluster within each data set. Temperatures are from zircon saturation thermometry (Watson and Harrison 1983) and cupola pressures, where given, are derived from melt inclusion volatile contents from the relevant cluster (Myers et al. 2016). The melt-dominant bodies with unknown storage depths are assumed to be laterally adjacent at depths equivalent to $\sim 100-200$ MPa. 
were tapped then this could serve to change the stress state in the upper crust and thereby destabilise adjacent bodies and influence the rate of any decline in overpressure in the system, potentially prolonging the time before caldera collapse (Gudmundsson 2012; Bégué et al. 2014).

Our reconstruction for the HRT system yields further implications. Magmatic systems composed of multiple smaller melt-dominant domains rather than a single continuous magma body require different conditions to survive at shallow depths in the crust. Smaller bodies will cool more rapidly and therefore require either greater thermal inputs into the overall magmatic system, or are subject to shorter lifespans as bodies of eruptible magma. Thus the potential existence of small (i.e. short-lived) melt-dominant bodies has important implications for monitoring. Although the Yellowstone magmatic system is currently thought to contain melt in average proportions too low to permit eruption (Huang et al. 2015 and references therein), current resolution levels of geophysical imaging techniques are too coarse to define small ( $<\sim 10 \mathrm{~km}$ wide) bodies with higher proportions of melt that could potentially be erupted (Lowenstern et al. 2006).

The simultaneous tapping of multiple melt-dominant cupolas at the start of the HRT eruption (Figs. $3.8,3.10$ ), the eruptive hiatuses observed in the fall deposits, and the highly variable and unusually slow pre-eruption magma ascent rates inferred from melt inclusion data have been used to infer that an external rather than an internal mechanism triggered the eruption onset (Myers et al. 2016). An alternative view for the compositional diversity is from the work by Cashman and Giordano (2014) who argue that multiple distinct melt domains can be tapped by one conduit from a variety of depths. As previously discussed, however, the absence of mixing in glass and obsidian shards between the various compositional clusters and the overlapping restored entrapment pressures (Myers et al. 2016) suggest that multiple vents were active, tapping three broadly laterally adjacent (not vertically arrayed) magma cupolas during the fall activity.

The transition from fall deposits into basal ignimbrite in the HRT is marked by an increase in the range of melt compositions and number of inferred compositional groupings from four to eight, representing melt-dominant domains evacuated during the onset of widespread ignimbrite deposition (Fig. 3.10). The inferred increase in eruption rate and involvement of such diverse melt domains imply that this transition is associated with the onset of roof instability and the beginning of caldera collapse. The transition followed the evacuation of 
roughly $50 \mathrm{~km}^{3}$ of magma (minor, when compared to the total $\sim 2,500 \mathrm{~km}^{3}$ erupted: Christiansen 2001). This estimate is based on available isopach data from the fall deposits below the ignimbrite (CJNW, unpublished data) and assuming that the magma volume is one third that of the bulk fall deposits. Evacuation of a portion of the magma chamber leading to underpressure has long been proposed as a means of inducing caldera collapse (e.g. Roche and Druitt 2001). Important to note is the reappearance in the basal ignimbrite of glass compositions similar to FGCs $1+2$, which are absent from the middle to upper parts of the fall deposits. This observation indicate that the vent areas and feeder cupolas for FGCs 1+2, which were active briefly at the eruption onset (Fig. 3.8), were reactivated during the onset of ignimbrite activity, further consistent with onset of caldera collapse.

The continuingly clustered nature of glass compositions in the basal ignimbrite indicates also that caldera collapse was probably not due to the over-pressurisation of a single larger, deeper melt-dominant body. Such a scenario would be expected to yield a more coherent, unitary glass compositional array (cf. Chamberlain et al. 2015). Christiansen (2001) proposed that the overall HRT caldera is a composite structure resulting from collapses associated with each of the three ignimbrite packages. However, we infer that the caldera collapse associated just with the onset of ignimbrite $A$ is in itself a composite structure, incorporating multiple vent locations.

\subsection{Comparisons and contrasts}

The combination of features we and Myers et al. (2016) describe from the Huckleberry Ridge Tuff make it without a direct comparator. Notable variations and clustering in erupted melt compositions are known from other ignimbrite-forming events, but such occurrences have typically been interpreted to represent sampling of compositional zones or gradients within a unitary chamber (e.g. Mahood et al. 1985; Fridrich and Mahood 1987; Schuraytz et al. 1989; Aguirre-Díaz 2001; Kaneko et al. 2007), rather than tapping of discrete magmatic bodies. At an extreme, the $7.05 \mathrm{Ma}, 280 \mathrm{~km}^{3}$ Rattlesnake Tuff has a visually spectacular diversity of juvenile components, which were clustered into five groups by Streck and Grunder (1997). In this and other examples, though, the diversity is evident in pumice and shard colours and reflected in wide ranges in major element abundances. In contrast, the major element 
variations in the HRT glasses studied here are barely larger than analytical uncertainties, and there are no colour variations that can be linked to composition.

In turn, the presence of multiple discrete melt dominant bodies has previously been proposed for several eruptions. One is the paired Mamaku-Ohakuri eruptions that exhibit compositional clustering in matrix glass and melt inclusion compositions, inferred to represent a magmatic system composed of multiple smaller melt-dominant bodies (Bégué et al. 2014). However these events, unlike the HRT, started with a homogenous fall deposit and only following this were other bodies tapped. Another, the $1.0 \mathrm{Ma}, \sim 1200 \mathrm{~km}^{3}$ Kidnappers eruption deposits show, through subtle variations in glass and mineral compositions, that three magma bodies were tapped in overlapping sequence (Cooper et al. 2012, 2016). This sequence matches the opening HRT stages, but the Kidnappers withdrawal dynamics were systematic and the magma bodies concerned were collectively one or more orders of magnitude larger than the cupolas proposed to feed the early HRT. Four glass groups have been proposed on the basis of trace element data to be present in the Youngest Toba Tuff (Westgate et al. 2013). However, all four groups are represented in some single pumices, suggesting that these groups represent large bodies that were in close spatial proximity and spanning the entire multi-thousand cubic kilometre eruption.

Tapping of melts from each of the two magmatic lineages in the early HRT was intermittent. For example, the low-Cn-sanidine, lower Ba-in-glass, magmatic lineage is present early in the fall deposits $(\mathrm{FGC1}+2)$, disappears, then reappears in the basal ignimbrite (Fig. 3.8). A compound 4.3 ka eruption deposit from Campi Flegrei shows the closest match to our inferences from the HRT, with clustering expressed dominantly in trace elements, and with a clear link to multiple vent sites active sequentially and simultaneously (Pistolesi et al. 2016). However, this example is on a volumetrically smaller scale and did not subsequently lead into ignimbrite formation, or subsequent caldera collapse.

The combination of immense overall volume, multiple small-scale definable meltdominant magma domains and subtlety of the geochemical variations makes the HRT unique. The level of stratigraphic control that we have reveals more detail within the first $2-3 \%$ of the eruption volume than is known from any other eruption of this size. Although the transition from fall to widespread ignimbrite deposition is simple, the magma system tapped even at these early stages of the eruption was remarkably complex. The significant trace elemental variations reported here thus represent a challenge for stratigraphically linked correlations of 
near-source HRT fall deposits and ignimbrite with any equivalent distal tephra deposits (cf. Perkins and Nash 2002).

\subsection{Conclusions}

Detailed geochemical investigations of matrix glass and feldspar in the initial fall deposits and earliest ignimbrite (basal vitric parts of member A) of the HRT show wide variations that form statistically-robust clusters. When coupled with depth estimates from $\mathrm{H}_{2} \mathrm{O}$ and $\mathrm{CO}_{2}$ in quartzhosted melt-inclusions these data show that a complex magmatic system was present, reaching to shallow levels (4-8 km depth: Myers et al. 2016) in the crust prior to eruption. Nine compositionally distinct melt-dominant domains are determined from the material studied here, which in turn can be interpreted to represent two distinct magmatic lineages that were evacuated during the opening stages of the HRT eruption. Overlaps in inferred storage depths (Myers et al. 2016), and the presence of the two distinct lineages imply that these melt-dominant domains were spatially separated, predominantly laterally rather than simply being vertically stacked (cf. Cashman and Giordano 2014). The fall deposit sequentially and systematically tapped three of these cupolas at the beginning of the eruption, under conditions inferred to reflect control by an external, tectonic trigger (Myers et al. 2016). The onset of widespread deposition of ignimbrite member $A$ is associated with evacuation of nine melt-dominant domains, including the three bodies that were tapped earlier during fall deposition (Fig. 3.10). The onset of ignimbrite deposition was broadly synchronous (within the limits of field evidence) from proximal to distal areas in the sectors north, west and south of the final, overall caldera structure (cf. Bishop and Oruanui ignimbrites: Wilson and Hildreth 1997; Wilson 2001). This rapid onset of flow activity, coupled with the diversity of melt groupings represented in all areas sampled in the basal ignimbrite across a 180 degree sector (Fig. 3.9), is interpreted to mean that caldera collapse began at this early stage (after $\sim 50 \mathrm{~km}^{3}$ of a 2,500 $\mathrm{km}^{3}$ eruption), plausibly due to depressurisation of the magmatic system. Our work shows that, although the physical appearance of the deposits can appear relatively straightforward, high-resolution micro-analytical data can reveal remarkable complexities in large silicic magma systems. Whether the remarkable diversity shown by the Huckleberry Ridge Tuff is unique or turns out to be common awaits the documentation in equivalent detail of other examples. 


\section{Chapter 4}

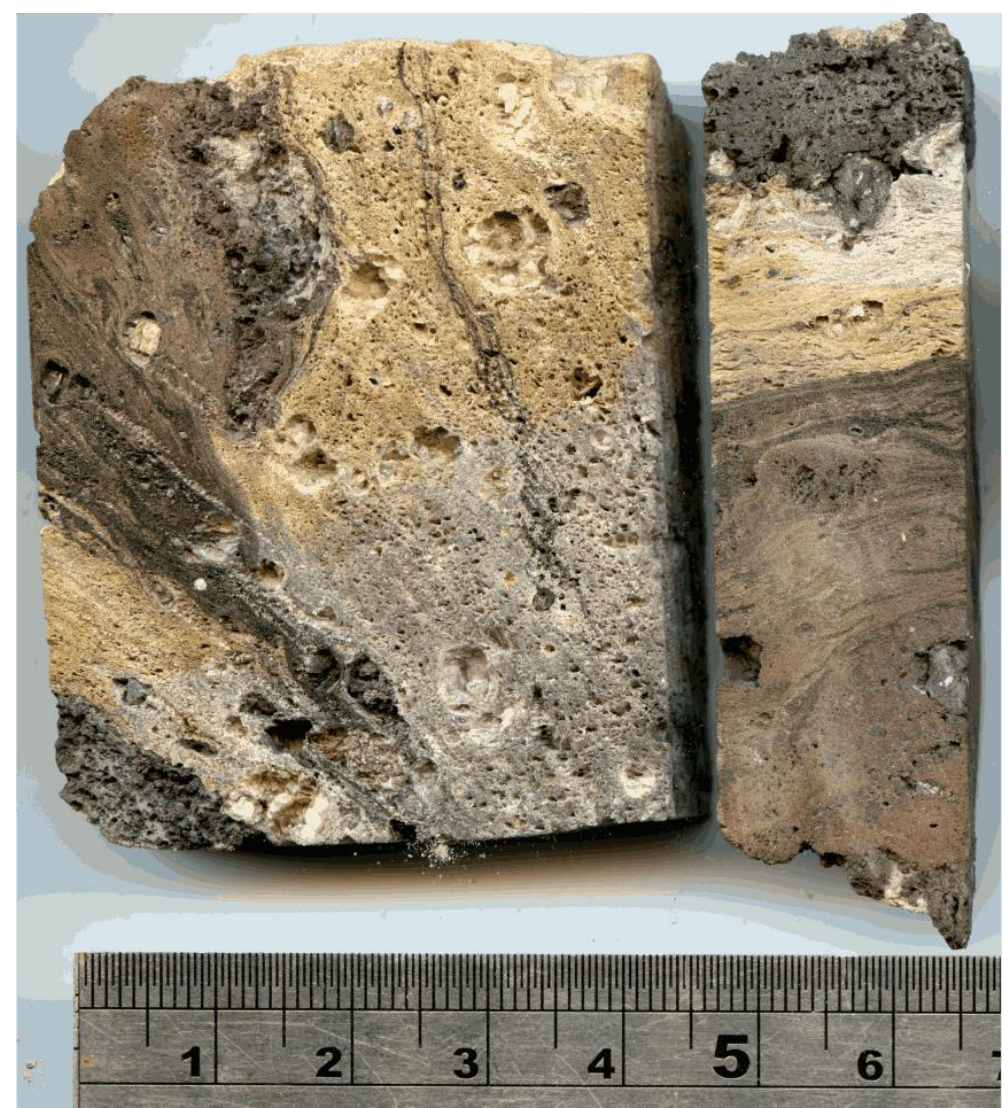

Photograph of two sections of YP266 showing mingled member B pumice with HRT mafic scoria (black) within a rhyolitic (white-yellow) pumice. Scale in centimetres.

This chapter has been accepted by American Mineralogist as a journal article: Swallow EJ, Wilson CJN, Charlier BLA, Gamble JA (2018) Mafic inputs into the rhyolitic magmatic system of the 2.08 Ma Huckleberry Ridge eruption, Yellowstone. Am Mineral 103:757-775.

Author contributions as followed:

EJS: Contributed towards sample collection, collected majority of data and wrote the text. CNJW: Completed background fieldwork and collected majority of samples, edited text. BLAC: Analysed Suite 2 elemental and $\mathrm{Sr}$ and $\mathrm{Pb}$ isotopic data, and edited text. JAG: Provided thorough discussions and edited text. 


\title{
4. Mafic inputs into the rhyolitic magmatic system of the $\mathbf{2 . 0 8}$ Ma Huckleberry Ridge eruption, Yellowstone
}

\begin{abstract}
The silicic (broadly dacitic to rhyolitic) magmatic systems that feed supereruptions show great diversity, but have in common a role for mafic (broadly basaltic to andesitic) magmas as drivers of the systems. Here we document the mafic component in the rhyolitic magmatic system of the $2.08 \mathrm{Ma}$ Huckleberry Ridge Tuff (HRT, Yellowstone), and compare it to mafic materials erupted prior to and following the HRT eruption in the area within and immediately around its associated caldera. The HRT eruption generated initial fall deposits, then three ignimbrite members A, B and C, with further fall deposits locally separating B and C. A 'scoria' component was previously known from the upper $B$ ignimbrite, but we additionally recognise juvenile mafic material as a sparse component in early $A$, locally abundant in upper $A$ and sparsely in lower B. It has not been found in the C ignimbrite. In upper B the mafic material is vesicular, black to oxidised red-brown scoria, but at other sites is overwhelmingly nonvesicular, and sparsely porphyritic to aphyric. Despite their contrasting appearances and occurrences, the mafic components form a coherent compositional suite from 49.3-63.3 wt \% $\mathrm{SiO}_{2}$, with high alkalis $\left(\mathrm{Na}_{2} \mathrm{O}+\mathrm{K}_{2} \mathrm{O}=4.5-7.3 \mathrm{wt} \%\right)$, high $\mathrm{P}_{2} \mathrm{O}_{5}(0.52-1.80 \mathrm{wt} \%)$, and notably high concentrations of both high field strength and large-ion lithophile elements (e.g. Zr = 7901830 ppm; $\mathrm{Ba}=2650-3800$ ppm). Coupled with the trace-element data, Sr-Nd-Pb isotopic systematics show influences from Archean age lower crust and lithospheric mantle modified by metasomatism during the late Cretaceous to Eocene, as previously proposed for extensive Eocene magmatism/volcanism around the Yellowstone area. The HRT mafic compositions contrast markedly with the Snake River Plain olivine tholeiites erupted before and after the HRT eruption, but are broadly similar in several respects to the generally small-volume Craters of the Moon-type mafic to intermediate lavas erupted recently just west of the HRT caldera, as well as farther west in their type area. The combination of trace element and isotopic data on the HRT mafics are only consistent with an origin for their parental magma as melts from mantle enriched by high temperature and pressure melts, most likely from the underlying Farallon slab. Subsequent interaction of the HRT mafic magmas occurred with the Archean
\end{abstract}


lower crust and lithospheric mantle, but not the highly radiogenic upper crust in this area. The close temporal and spatial relationships of the HRT mafic compositions and the preceding Snake River Plain olivine tholeiite eruptives suggest a high degree of spatial heterogeneity in the mantle beneath the Yellowstone area during the early (and subsequent) development of its modern magmatic system. 


\subsection{Introduction}

Mafic magmas (in this context basaltic to andesitic in composition) are widely considered to exert a fundamental control on the generation and development of large-scale silicic (dacitic to rhyolitic) magmatic systems in the crust (e.g. Hildreth 1981; Bachmann and Bergantz 2008). Over the long-term, mafic magmas provide heat and mass that drive the development of the silicic system (e.g. Bindeman et al. 2008; Christiansen and McCurry 2008). Over short timescales, inferences on the effects of mafic magma are generally focused around the associated influxes of heat and/or volatiles into the silicic system that may mobilise it and trigger eruptions (e.g. Sparks et al. 1977; Bachmann et al. 2002; Huber et al. 2011). As silicic magmatic systems act as density traps, evidence of the direct influence of mafic magmas on silicic systems is often limited to one or more of co-erupted mafic enclaves or mingled magmas, and up-temperature geochemical signals in the growth records of crystals in the eruption products (e.g. Sparks et al. 1977; Bacon and Metz 1984; Bachmann et al. 2002; Wilson et al. 2006; Pritchard et al. 2013; Barker et al. 2016; Singer et al. 2016; Stelten et al. 2017). The most primitive compositions are, however, often not represented in the coerupted mafic components when compared with mafic magmas erupted away from the focus of silicic volcanism suggesting that some hybridisation has taken place (e.g. Bacon and Metz 1984). Stalling of mafic magmas beneath a silicic system due to density trapping may serve to enhance the interaction of mafic magmas with host rocks and/or silicic magmas and the generation of distinct compositions not seen in adjacent areas (e.g. Wilson et al. 2006). Analysis of mafic inclusions, therefore, can give valuable insights into the thermal and chemical driving mechanisms beneath silicic systems. To illuminate these mechanisms, we here present data on the mafic compositions of inclusions and surficial lavas associated with the Yellowstone Plateau volcanic field, specifically those associated with the earliest calderaforming cycle that generated the Huckleberry Ridge Tuff.

\subsection{Geological Setting}

\subsubsection{Yellowstone and the Snake River Plain}

The Yellowstone Plateau volcanic field (YPVF) is the youngest (active since $\sim 2.1 \mathrm{Ma}$ ) volcanomagmatic system at the northeastern end of the Yellowstone-Snake River Plain (YSRP) volcanic area (Christiansen 2001). The YSRP area is a $700 \mathrm{~km}$ long, NE-ward progressing 


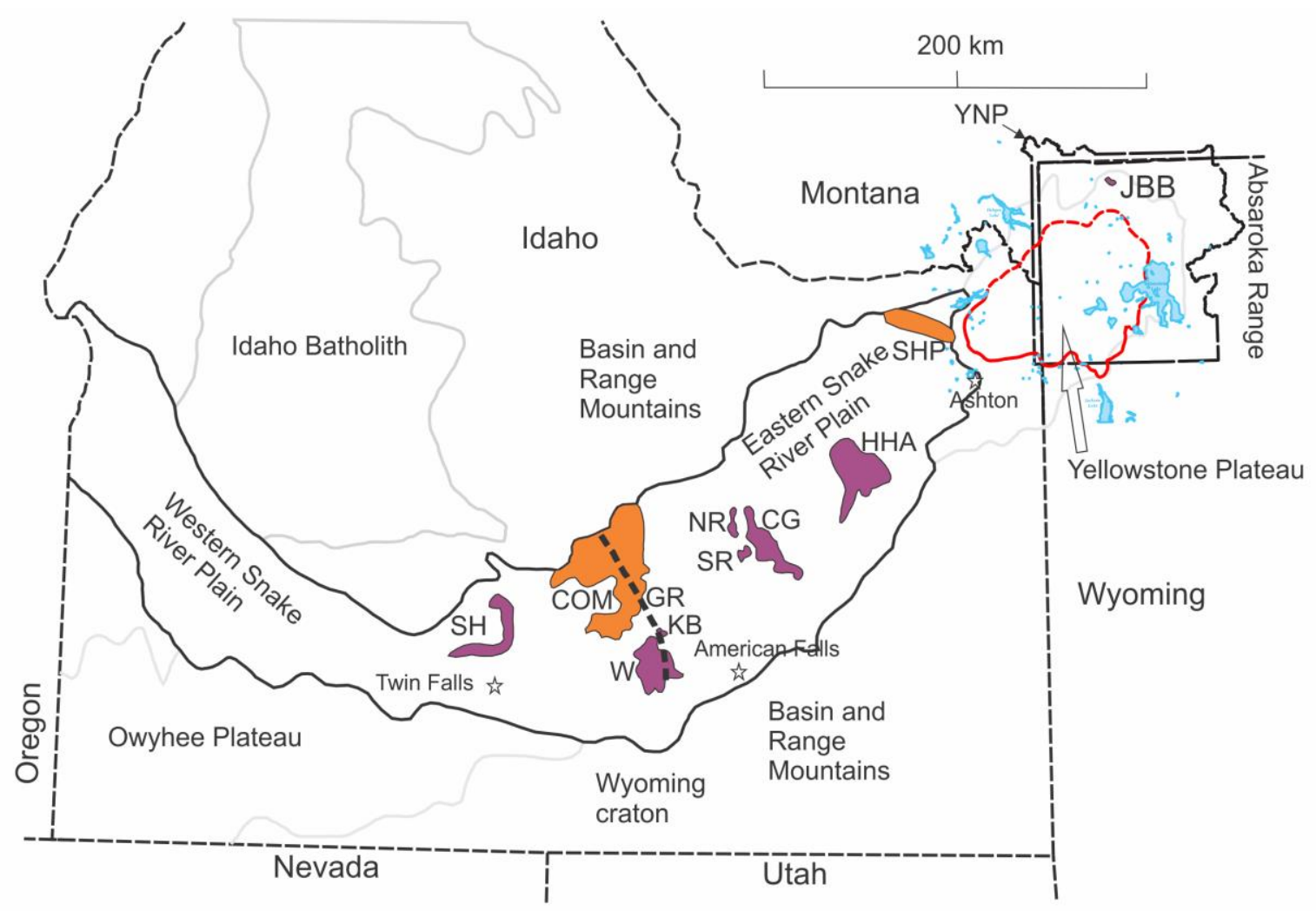

Figure 4.1: Map of the Yellowstone-Snake River Plain area (adapted from Kuntz et al. 1982 and Christiansen et al. 2007). Within the Yellowstone Plateau volcanic field, the red line marks the mapped rim of the caldera for the Huckleberry Ridge Tuff (HRT) eruption, and the location of the pre-HRT Junction Butte Basalt (JBB) is also shown (from Christiansen 2001). Quaternary basaltic lava fields along the Snake River Plain (SRP) are also outlined, including those of olivine tholeiitic affinity (purple; SH-Shoshone, W-Wapi, KB-King's Bowl, NR-North Robbers, SR-South Robbers, CG-Cerro Grande, HHA-Hells Half Acre) and those containing Craters of the Moon-type magmas (orange; COM-Craters of the Moon, SHP-Spencer-High Point). The $85 \mathrm{~km}$ Great Rift (GR) and the boundary of Yellowstone National Park (YNP) are also shown for reference.

volcanic province extending from eastern Oregon and northern Nevada to northwestern Wyoming (Fig. 4.1; Pierce and Morgan 2009). The province contains a series of caldera complexes associated with voluminous silicic volcanism, followed by voluminous basaltic activity. The caldera systems were initiated at $\sim 16 \mathrm{Ma}$ in northernmost Nevada, broadly coincident with the eruption of the Columbia River Basalts to the north (e.g. Coble and Mahood 2012, 2015) and have migrated spasmodically eastward. Although the focus of silicic volcanism has migrated to the northeast (at a rate and in a direction corresponding to movement of the North American Plate over a fixed point), voluminous basaltic volcanism has persisted along the YSRP into Holocene time (Armstrong et al. 1975; Kuntz et al. 1992). 
The northeastward propagating volcanism of the YSRP has been often been attributed to the movement of the North American plate over a stationary mantle plume, forming a 'hotspot track' (Pierce and Morgan 1992, 2009). This hypothesis is supported by the imaging of a weak thermal anomaly, inferred to represent material containing small degrees of partial melt, down to and across the 660 km discontinuity (Yuan and Dueker 2005; Smith et al. 2009; Schmandt et al. 2012). However, a high-velocity zone located in the mantle beneath the Snake River Plain and Yellowstone at $\sim 400-500 \mathrm{~km}$ depth has been interpreted as a remnant of the subducted Farallon plate, that foundered beneath the western US at 50 Ma (Schmandt and Humphreys 2011; James et al. 2011). The presence of this high-velocity zone has led to an alternative model for YSRP volcanism invoking poloidal asthenospheric upwelling around the foundering slab. It has been proposed that the northern and eastern edges of the slab serve to delineate the margins of the YSRP, creating a low-velocity zone observed in the upper mantle along the length of the YSRP (James et al. 2011; Zhou et al. 2018). This low-velocity zone is inferred to contain partial melt and to be hydrated, explaining the continuing basaltic volcanism along the SRP even after the termination of local silicic volcanism (Armstrong et al. 1975; Schmandt and Humphreys 2010; James et al. 2011). However, despite the presence of the low-velocity zone along the length of the YSRP, elevated heat and mantle-derived-gas fluxes in the Yellowstone area (e.g. Hurwitz and Lowenstern 2014) require there to be a deepseated thermal anomaly distinct from that extending westwards into the Snake River Plain.

Volcanism along the YSRP locus has typically been considered as bimodal. Olivine tholeiites dominate the mafic compositions and are inferred to provide heat to partially melt solidified, underplated tholeiitic intrusive forerunners which, in turn, become parental magmas to the voluminous ferroan rhyolites (Christiansen and McCurry 2008; McCurry and Rodgers 2009). Basaltic activity typically precedes and follows silicic volcanism at individual volcanic centers along the YSRP, with intervening periods of no basaltic volcanism while the silicic magmatic systems act as an effective density trap (Christiansen 2001). Petrological and isotopic studies collectively infer that the olivine tholeiites result from the hybridisation of young, asthenosphere-derived melts with partial melts of the lithospheric mantle, which last equilibrated in an ancient, dry lithospheric mantle keel at depths of $70-100 \mathrm{~km}$ and at temperatures consistent with an only slightly elevated geothermal gradient (Doe et al. 1982; Hildreth et al. 1991; Hanan et al. 2008; Leeman et al. 2009). The basalts are also considered to show signatures of minimal crustal contamination on their rise to the surface (Doe et al. 
1982; Menzies et al. 1984; Hildreth et al. 1991; Leeman et al. 2009). The tholeiites are dominantly olivine and plagioclase phyric with a notable lack of clinopyroxene, indicating minimal significant mid-crustal crystallisation, where clinopyroxene would be the primary liquidus phase (Thompson 1975; Leeman et al. 2009). Olivine tholeiites erupted in the Yellowstone area are similar to those elsewhere in the Snake River Plain but extend to more evolved compositions (Christiansen and McCurry 2008). In addition to the olivine tholeiites, some mafic to minor silicic lavas of contrasting affinity are also found in the eastern Snake River Plain. The mafic lavas, predominantly found at the Craters of the Moon lava field, form a distinctly alkalic trend characterised by high $\mathrm{TiO}_{2}, \mathrm{P}_{2} \mathrm{O}_{5}, \mathrm{Ba}, \mathrm{Zr}$ and rare-earth elements (REE), and lower $\mathrm{MgO}$ and $\mathrm{CaO}$ relative to olivine tholeiites and are referred to as the Craters of the Moon (COM) trend (Leeman et al. 1976; Christiansen and McCurry 2008; McCurry et al. 2008; Putirka et al. 2009).

Whether the silicic magma erupted in the YSRP province is generated through fractional crystallisation (e.g. McCurry et al. 2008) or through partial melting of basaltic and/or felsic crust (e.g. Hildreth et al. 1991; Bindeman and Simakin 2014), a large amount of basaltic magma is required to provide heat, volatiles and fractionated material. The $>3,700 \mathrm{~km}^{3}$ of silicic magma erupted in the YPVF alone over the last $\sim 2$ Ma requires a voluminous supply of basaltic melt from the mantle to drive the silicic volcanism (Christiansen 2001; McCurry and Rodgers 2009; Stelten et al. 2017). This basaltic flux has also been inferred from the modern large thermal and $\mathrm{He}$ and $\mathrm{CO}_{2}$ fluxes within the volcanic field (Hurwitz and Lowenstern 2014) and is linked to the imaging of a large $\left(46,000 \mathrm{~km}^{3}\right)$ lower-crustal, melt-bearing body inferred to be basaltic in composition (Huang et al. 2015).

Although there is voluminous basaltic volcanism preceding and subsequent to the focus of silicic volcanism at Yellowstone, and its presence has been invoked as a key driver in the generation and triggering of rhyolitic bodies (e.g. Loewen and Bindeman 2015), there is a paucity of basaltic material erupted penecontemporaneously with the voluminous silicic eruptions (Christiansen 2001). Rarely in the volcanic field, and mostly in extra-caldera rhyolites, is evidence for magma mingling observed (Wilcox 1944; Pritchard et al. 2013). Therefore, previous inferences on the mantle inputs into Yellowstone have been solely derived from basalts erupted peripherally to the field or long after caldera formation (Doe et al. 1982; Hildreth et al. 1991; Hanan et al. 2008). To provide a contrasting perspective, we here document the mafic components (including the 'scoria' previously described by 
Christiansen 2001) that were discharged during the large caldera-forming rhyolitic eruption of the Huckleberry Ridge Tuff. We compare their compositions to mafic (basaltic to andesitic) compositions erupted before and afterwards in the geographic area within and around the Huckleberry Ridge Tuff caldera to investigate the nature of the mafic lineages in this area and consider their likely origins.

\subsubsection{The Huckleberry Ridge Tuff}

The $\sim 2.08 \mathrm{Ma}, \sim 2,500 \mathrm{~km}^{3}$ Huckleberry Ridge Tuff (HRT) is the product of the climactic eruption of the first of three volcanic cycles in the YPVF (Christiansen 2001; Rivera et al. 2014; Singer et al. 2014; Wotzlaw et al. 2015). The HRT consists of initial fall deposits, which are overlain by three ignimbrite packages (members A, B and C), with additional fall deposits beneath member C (Christiansen 2001).

The HRT eruption was shortly preceded by two episodes of volcanism, generating the rhyolitic Snake River Butte lava, and the lavas collectively mapped by Christiansen (2001) as the Junction Butte Basalt. Other precursory eruptions may well have occurred in areas now down-dropped and buried in the HRT and younger calderas, but any direct evidence for these is now lost. The Junction Butte Basalt is composed of multiple independent flows which crop out at the northern end of the Yellowstone Plateau and northeast of the mapped HRT caldera (Fig. 4.1; Christiansen 2001). Although the Junction Butte Basalt flows are amongst the least primitive mafic compositions erupted at Yellowstone (and Junction Butte itself is intermediate in composition), they are here grouped in with the SRP olivine tholeiites, albeit with these flows containing plagioclase phenocrysts and groundmass olivine (Hildreth et al. 1991; Christiansen 2001).

\subsection{Sampled materials}

We present data here on eruptive materials from the Yellowstone area and for descriptive convenience group these into three suites (Table 4.1). These suites encompass juvenile mafic material erupted in the Huckleberry Ridge event, together with comparator lavas which are temporally close to the eruption and/or were erupted spatially adjacent to or within the HRT caldera. Sample and locality information are given in Table S4.1. 


\begin{tabular}{|l|l|l|}
\hline \multicolumn{3}{|l|}{ Table 4.1: Summary of the sample suites analysed for this study. } \\
\hline Sample group & Host unit & Characteristics \\
\hline maite 1: dense & $\begin{array}{l}\text { HRT member A and } \\
\text { rarely in member B }\end{array}$ & $\begin{array}{l}\text { Small (<10 cm), dense, rounded, grey-green (rarely } \\
\text { oxidised red) clasts often with a crenulated margin } \\
\text { indicating a juvenile nature (Fig. 4.2a). Commonly } \\
\text { aphyric (devitrified) with rare sparsely porphyritic } \\
\text { samples containing euhedral feldspars. }\end{array}$ \\
\hline Suite 1: scoria & $\begin{array}{l}\text { Top of HRT member } \\
\text { B }\end{array}$ & $\begin{array}{l}\text { Black, or purple-red (where oxidised), aphyric, } \\
\text { moderately vesicular material which occurs as discrete } \\
\text { clasts or streaks within rhyolitic pumice. Where mingled } \\
\text { in pumice, the scoria often includes up to 1 cm feldspar } \\
\text { xenocrysts derived from the host pumice (Fig. 4.2b). }\end{array}$ \\
\hline $\begin{array}{l}\text { Suite 2: Snake } \\
\text { River Plain } \\
\text { olivine } \\
\text { tholeiites }\end{array}$ & $\begin{array}{l}\text { Pre and post HRT } \\
\text { olivine tholeiites } \\
\text { lava flows } \\
\text { (Christiansen 2001) }\end{array}$ & $\begin{array}{l}\text { Aphyric to sparsely porphyritic lava flows with olivine } \\
\text { and plagioclase dominant mineral assemblages. }\end{array}$ \\
\hline $\begin{array}{l}\text { Suite 3: COM } \\
\text { eruptives }\end{array}$ & $\begin{array}{l}\text { Spencer-High Point } \\
\text { (SHP) volcanic field } \\
\text { (Iwahashi 2010) }\end{array}$ & $\begin{array}{l}\text { Black-red scoriaceous bombs and lava flows (only } \\
\text { pyroclastic material sampled). Ranges in crystallinity } \\
\text { from 0-15\%. Porphyritic crystal-rich materials contain } \\
\text { euhedral feldspars up to 2 cm in length. }\end{array}$ \\
\hline
\end{tabular}

\subsubsection{Suite 1: HRT mafic materials}

Although the HRT is composed dominantly of high-silica rhyolite, scoriaceous material has been reported as commonly present in the upper part of member B (Hildreth et al. 1991; Christiansen 2001). Reported analyses of this scoriaceous material (samples 81YH-79: Hildreth et al. 1984; 74IP-149B: Hildreth et al. 1991; Christiansen 2001), however, return rhyodacite compositions (70.5 and $70.8 \mathrm{wt} \% \mathrm{SiO}_{2}$ respectively). Extensive fieldwork on the HRT by Wilson shows, however, that there is a comparable juvenile mafic component in both ignimbrite members $A$ and $B$ (Table 4.1). This component matches physically the scoria described by Christiansen (2001) where it is found in upper ignimbrite B. However, our analyses yield greatly contrasting compositional characteristics when compared to the previously reported data. In member A, especially at exposures southwest of the caldera, poorly to non-vesicular clasts of dark-grey to greenish-grey, rarely red-oxidised material (Fig. 
4.2a) occur within the dense-welded rheomorphic tuff attributed by Christiansen (2001) to member B, but identified by us as member A. Briefly, this identification is made on the basis that the relevant tuff can be traced continuously downwards to the HRT basal contact, and upwards to where a horizon representing a short hiatus (reworked ash materials, minor welding reversal) separates the lower ignimbrite (i.e. A) from an upper ignimbrite unit that has scoria present in its upper parts (i.e. B). Non-vesicular mafic material is also rarely found in lower ignimbrite B in the same area southwest of the caldera. Moderately to highly vesicular black to purple- to red-oxidised scoria is also widespread as a component in mingled pumices (Fig. 4.2b) and as discrete lapilli-grade clasts in upper member B, as previously reported. We sampled individual clasts of the poorly vesicular material from ignimbrite A mostly from localities southwest of the caldera, and extracted the vesicular scoria from

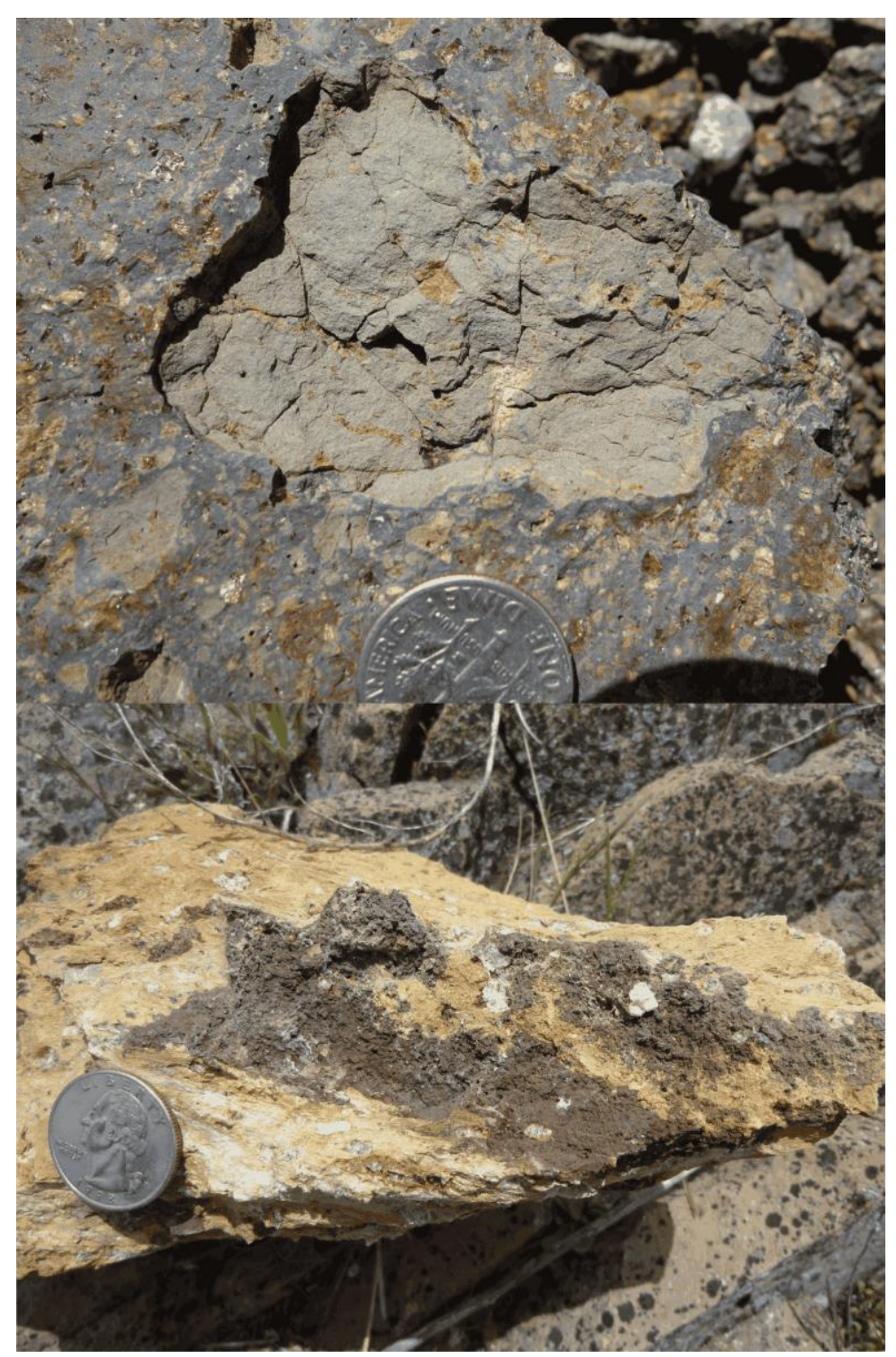

Figure 4.2: Photographs of representative HRT dense mafic (top) and scoria (bottom) clasts found dominantly in HRT members A and $B$, respectively. The crenulated margin of the HRT dense mafic clast indicates its juvenile nature. 
mingled pumices in upper ignimbrite B from a site southwest of the caldera where glassy, non-welded material occurs (Table S4.1). Elsewhere, the discrete scoria clasts in upper ignimbrite B are either too small to sample effectively, or are vapor-phase altered and recrystallised along with their host tuff. Also, rare macroscopically mingled scoria clasts were found in member A and sampled, and are labelled as such here.

\subsubsection{Suite 2: SRP olivine tholeiites}

We sampled a selection of the lavas generally attributed to the SRP olivine tholeiite suite (Table S4.1), including several examples reported on by Hildreth et al. (1991). These lavas represent flows (i) pre-dating the HRT and exposed around the caldera margin (including one example underlying the HRT southwest of the caldera), and (ii) post-dating the HRT, forming part of the extensive flows flooring the Island Park segment of the combined HRT and Mesa Falls Tuff-related calderas, and elsewhere in the Yellowstone caldera.

\subsubsection{Suite 3: COM eruptives}

We sampled pyroclasts from several scoria cones linked to young eruptions of the COM suite in the Spencer-High Point Field (Fig. 4.1; Table S4.1). These cones were sampled from an area on, or immediately west of, the western rim of the mapped HRT caldera and were selected on the basis of information in Iwahashi (2010).

\subsubsection{Published data}

We compare our data from all three suites to published data from spatially and chemically comparable deposits. The Suite 2 literature field comprises data from olivine tholeiites along the Yellowstone-Snake River Plain volcanic area (but does not include data from the Columbia River Basalt group). This field also includes examples of olivine tholeiites from the Craters of the Moon lava field (NEOT flows of Putirka et al. 2009), from the Spencer-High Point Field (Type 1 flows of Iwahashi 2010) and compositions from two databases: the North American Volcanic Rock Data Base (NAVDAT: http://www.navdat.org/) and the Geochemistry of Rocks of the Oceans and Continents (GEOROC: http://georoc.mpch-mainz.gwdg.de/georoc/). Published data for Suite 3 comparisons were derived from studies of the Craters of the Moon area (Leeman 1974; Leeman et al. 1976: COME flows of Putirka et al. 2009) and from the 
Spencer-High Point Field (Type 2 flows of Iwahashi 2010). All mafic data (i.e. $<65$ wt\% $\mathrm{SiO}_{2}$, the range of compositions analysed in this study) were selected based on location, as we did not want to restrict comparisons to basalts only (cf. Hildreth et al. 1991). No screening for perceived contamination or primitive compositions was undertaken so as to allow us to compare compositional ranges and degrees of evolution in all suites related to the broad range of petrogenetic processes occurring in volcanic rocks in this region.

\subsection{Analytical methods}

Samples from the three suites were collected and any adhering matrix or visible xenocrysts removed by hand picking to isolate the mafic component. In two clasts (YP185 and YP188, both from early member A) mingling was too complex to allow complete separation. These clasts therefore represent a mixture of mafic and rhyolitic components (denoted by ' $M$ ' in geochemical plots). Samples were subsequently crushed and milled in an agate TEMA mill to yield a homogenous powder. Powders were analysed for major element concentrations by Xray fluorescence (XRF) at the Open University (OU), UK and at the University of Auckland, New Zealand following the methods of Ramsey et al. (1995). Replicate analyses of standards give approximate 2 standard deviation ( $2 \mathrm{sd}$ ) external precisions of $<3 \%$ for all elements, with most $<1 \%$ (Chapter 2). Accuracies are within 5\% for all elements compared to preferred values for replicate standard analyses. Duplicates run between institutions show $<5 \%$ offset for all elements with $>0.1$ wt\% abundance. Trace element concentrations were measured by solution inductively-coupled plasma mass-spectrometry (ICP-MS) at the OU and Victoria University of Wellington, New Zealand (VUW) using an Agilent 7500 and a Thermo Scientific Element2 sector-field ICP-MS, respectively. Abundances of trace elements were calculated by external normalisation relative to a bracketing standard (BHVO-2). A secondary standard (BCR-2) was used to estimate external precisions, which were $<6-7 \%$ for most elements except $\mathrm{Li}, \mathrm{Nb}, \mathrm{Cs}, \mathrm{Lu}, \mathrm{Ta}, \mathrm{Tl}, \mathrm{Pb}, \mathrm{Th}, \mathrm{U}, \mathrm{Ni} \mathrm{Cu}, \mathrm{Zn}(<20 \%)$ and $\mathrm{Mo}(>20 \%)$. Accuracies are $<6-7 \%$ for all elements, apart from Ta, TI, Cu (<15\%) and Mo (>15\%: Chapter 2; Electronic Appendix 4.1).

Isotope analyses were conducted using a Finnigan Triton Thermal Ionisation MassSpectrometer (TIMS) in the laboratories at the OU and VUW, but on the same instrument. Chromatographic element separation was based on the procedure of Pin et al. (2014; see chapters 2 and $\mathrm{S} 4$ for more information). Sr was analysed on single Re filaments, using a $\mathrm{TaF}_{2}$ 
activator (Charlier et al. 2006), for 240 ratios with an integration time for each ratio of 16.777 s. Measurements were internally normalised to ${ }^{86} \mathrm{Sr} /{ }^{88} \mathrm{Sr}=0.1194$ and $\mathrm{Rb}$ interference was corrected by measuring ${ }^{85} \mathrm{Rb}$ and applying a correction using ${ }^{87} \mathrm{Rb} /{ }^{85} \mathrm{Rb}=0.385707$ (Rosman and Taylor 1998). Repeated analyses of NBS987 yield an average of $0.710254 \pm 0.000015$ (2sd, $\mathrm{n}=16$ ). Isotopic ratios from different runs were normalised to a value of 0.71025 for NBS987, the long-term mean reported by Thirlwall (1991). Procedural blank was 110 pg, insignificant when compared to the $\sim 1000$ ng loaded onto each filament and thus necessitated no blank correction.

$\mathrm{Nd}$ was analysed on double Re filaments with a $\mathrm{H}_{3} \mathrm{PO}_{4}$ loading solution over 270 ratios with an integration time of $8.389 \mathrm{~s}$ for each measurement. Ratios were internally normalised using a value of ${ }^{146} \mathrm{Nd} /{ }^{144} \mathrm{Nd}=0.7219$ and any presence of $\mathrm{Ce}$ and $\mathrm{Sm}$ corrected using values of ${ }^{140} \mathrm{Ce} /{ }^{142} \mathrm{Ce}=7.97297$ and ${ }^{144} \mathrm{Sm} /{ }^{147} \mathrm{Sm}=0.20667$ (Rosman and Taylor 1998). Repeated analyses of standards J\&M (internal) and La Jolla yield values of $0.511818 \pm 0.000004$ (2sd, $n=11)$ and $0.511845 \pm 0.000002(2 s d, n=3)$, respectively, the former consistent with the longterm laboratory average $(0.511821 \pm 0.0000022 \mathrm{sd})$ and the latter similar to $0.511856 \pm$ 0.000007 (2sd) measured by Thirlwall (1991). Procedural blank was $8 \mathrm{pg}$ and thus warranted no blank correction.

$\mathrm{Pb}$ was analysed using a double-spike method (see Todt et al. 1996). Half the sample (approximately $150 \mathrm{ng}$ ), was run naturally on single Re filaments for 180 ratios using a silica gel activator (Gerstenberger and Haase 1996). Subsequently, the remaining sample and a ${ }^{207} \mathrm{~Pb} /{ }^{204} \mathrm{~Pb}$ double spike (Thirlwall 2000 ) were thoroughly mixed and analysed on single Re filaments for 120 ratios in the same way as the natural run. Integration times for both runs were $8.389 \mathrm{~s}$. The data were then deconvolved to determine the isotopic ratios. Values for NBS981 were ${ }^{206} \mathrm{~Pb} /{ }^{204} \mathrm{~Pb}=16.945 \pm 0.001,{ }^{207} \mathrm{~Pb} /{ }^{204} \mathrm{~Pb}=15.503 \pm 0.001$ and ${ }^{208} \mathrm{~Pb} /{ }^{204} \mathrm{~Pb}=$ $36.737 \pm 0.004(2 \mathrm{sd}, \mathrm{n}=32$ ). Isotopic measurements from different runs were normalised to the values of Todt et al. (1996). The procedural blank for Pb was $10 \mathrm{pg}$ and warranted no correction. 


\subsection{Results}

Full major element, trace element and isotopic data for the samples analysed in this study are given in Electronic Appendix 4.1, and a representative selection of analyses is given in Tables 4.2 and 4.3 .

\subsubsection{Major elements}

HRT dense mafic and scoria clasts (hereafter HRT mafics, constituting Suite 1) form a coherent trend from $49-63 \mathrm{wt} \% \mathrm{SiO}_{2}$, regardless of their stratigraphic position or degree of vesiculation. They are characterised by high alkalis $\left(\mathrm{Na}_{2} \mathrm{O}+\mathrm{K}_{2} \mathrm{O}=4.5-7.3\right.$ wt\%: Fig. 4.3a), $\mathrm{P}_{2} \mathrm{O}_{5}(0.52-1.8$ wt\%: Fig. 4.3b), $\mathrm{TiO}_{2}$ (1.5-3.5 wt\%) and FeO (9.6-16.1 wt\%: Fig. S4.1). Suite 1 samples also have low $\mathrm{MgO}$ (0.6-3.0 wt\%) and $\mathrm{CaO}$ (1.6-7.2 wt\%: Fig. S4.1) values.

Samples from flows with olivine tholeiitic affinity (Suite 2) erupted throughout the volcanic history of Yellowstone form a coherent compositional group with $\mathrm{SiO}_{2}$ ranging from 46-54 wt\%. They are distinct from Suite 1 samples with higher MgO (4.2-11 wt\%) and $\mathrm{CaO}$ (7.7-11 wt\%: Fig. S4.1), which are negatively correlated with $\mathrm{SiO}_{2}$, and contain low total alkalis $\left(\mathrm{Na}_{2} \mathrm{O}+\mathrm{K}_{2} \mathrm{O} ; 2.4-4.7\right.$ wt\%: Fig. 4.3a) and $\mathrm{P}_{2} \mathrm{O}_{5}$ (0.19-0.62 wt\%: Fig 4.3b). Mg\# values (defined as $\mathrm{Mg \#}=100\left[\mathrm{X}_{\mathrm{MgO}} /\left(\mathrm{X}_{\mathrm{MgO}}+\mathrm{X}_{\mathrm{FeO}}\right)\right]$ on a molar basis, where $\mathrm{FeO}=0.9\left[\mathrm{Fe}_{2} \mathrm{O}_{3}(\mathrm{~T})\right]$ on a wt\% basis $)$ of up to 64 show that the primitive end of the range in YSRP tholeiites is represented in our Yellowstone Suite 2 samples (cf. Leeman et al. 2009).

There are broad major element similarities between our COM-type samples (Suite 3) and HRT mafics (Suite 1). Suite 3 samples cover a similar $\mathrm{SiO}_{2}$ range to Suite 1 samples (47-57 wt\%), with similarly high $\mathrm{FeO}\left(10-14\right.$ wt\%), $\mathrm{TiO}_{2}$ (up to 3.0 wt\%: Fig. S4.1) and $\mathrm{P}_{2} \mathrm{O}_{5}$ (0.60-2.2 wt \%: Fig. 4.3b), and depletions in $\mathrm{MgO}$ (1.6-3.7 wt\%) and $\mathrm{CaO}$ (4.7-8.3 wt\%) when compared to the olivine tholeiites. Their compositions are mildly alkalic (total alkalis 5.0-7.6 wt\%: Fig. 4.3a) and are similar to the published COM-trend for rocks with this silica percentage (Fig. 4.3; Leeman et al. 1976; Christiansen and McCurry 2008; Putirka et al. 2009). Note, however, that in general, the Suite $1 \mathrm{HRT}$ mafic compositions form arrays in Harker plots that are parallel to, but slightly offset from, our Suite 3 samples and the overall COM fields (see Fig. 4.3), particularly with respect to lower total alkalis, $\mathrm{P}_{2} \mathrm{O}_{5}$ and $\mathrm{TiO}_{2}$ in the Suite 1 samples. 


\begin{tabular}{|c|c|c|c|c|c|c|c|c|c|c|c|c|c|c|c|c|c|c|c|c|c|c|c|c|}
\hline \multirow{8}{*}{ 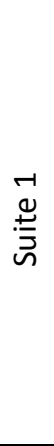 } & Sample & Host unit & $\mathrm{SiO}_{2}$ & $\mathrm{TiO}_{2}$ & FeO & MgO & $\mathrm{CaO}$ & $\mathrm{Na}_{2} \mathrm{O}$ & $\mathrm{K}_{2} \mathrm{O}$ & $\mathrm{P}_{2} \mathrm{O}_{5}$ & Mg\# & Sc & v & $\mathrm{Cr}$ & $\mathbf{N i}$ & $\mathbf{R b}$ & Sr & $\mathrm{Zr}$ & $\mathrm{Nb}$ & $\mathrm{Ba}$ & La & $\mathrm{Yb}$ & Hf & U \\
\hline & YP122 & HRT A Dense mafic & 50.79 & 3.00 & 14.22 & 2.42 & 7.24 & 3.32 & 1.80 & 1.52 & 23 & 36 & 132 & 5.1 & 5.8 & 46 & 340 & 1575 & 29 & 2863 & 95 & 10.1 & 26 & 1.7 \\
\hline & YP244 & HRT A Dense mafic & 59.50 & 2.09 & 10.46 & 0.60 & 4.12 & 3.62 & 2.97 & 1.09 & 9 & 21 & 69 & 5.9 & 6.0 & 63 & 247 & 1386 & 43 & 3508 & 76 & 5.8 & 26 & 2.6 \\
\hline & YP246 & HRT A Dense mafic & 58.10 & 2.51 & 9.58 & 0.83 & 4.94 & 3.84 & 2.92 & 1.39 & 13 & 25 & 107 & 5.3 & 5.2 & 61 & 269 & 1099 & 58 & 2641 & 85 & 6.2 & 22 & 2.4 \\
\hline & YP449 & HRT A Dense mafic & 52.28 & 3.47 & 13.10 & 0.74 & 5.66 & 3.26 & 2.23 & 1.69 & 9 & 43 & 121 & 21.2 & 4.7 & 46 & 342 & 1828 & 40 & 3430 & 142 & 9.9 & 33 & 2.1 \\
\hline & YP071 BLACK & HRT B Scoria & 55.08 & 2.20 & 12.46 & 2.52 & 6.03 & 3.39 & 2.40 & 1.12 & 27 & 29 & 88 & 5.2 & 5.4 & 54 & 277 & 1545 & 37 & 3802 & 59 & 6.6 & 28 & 2.2 \\
\hline & YP266 SCORIA & HRT B Scoria & 57.98 & 1.94 & 11.10 & 2.19 & 5.21 & 2.90 & 2.95 & 0.97 & 26 & 24 & 76 & 2.8 & 5.0 & 67 & 247 & 1266 & 39 & 3358 & 67 & 6.3 & 23 & 2.5 \\
\hline & YP334B & HRT B Scoria & 56.79 & 2.03 & 11.50 & 2.36 & 5.40 & 3.41 & 2.90 & 1.00 & 27 & 26 & 80 & 5.4 & 5.2 & 68 & 265 & 1353 & 39 & 3530 & 72 & 6.6 & 26 & 2.6 \\
\hline \multirow{5}{*}{$\begin{array}{l}\stackrel{N}{ఖ} \\
\stackrel{ \pm}{\Xi} \\
\sim\end{array}$} & YR291 & Warm River Basalt & 47.18 & 1.20 & 10.71 & 10.77 & 10.70 & 2.19 & 0.21 & 0.19 & 64 & 22 & 241 & 538 & 190 & 3.1 & 152 & 77 & 17 & 120 & 6.3 & 1.3 & 1.9 & 0.1 \\
\hline & YR292 & Basalt of the Narrows & 49.39 & 1.91 & 10.35 & 6.68 & 8.48 & 3.30 & 1.15 & 0.36 & 53 & 20 & 223 & 48 & 44 & 22 & 546 & 172 & 33 & 423 & 26 & 1.5 & 3.9 & 0.6 \\
\hline & YR294 & Junction Butte Basalt & 54.28 & 1.94 & 10.24 & 4.24 & 7.68 & 3.06 & 1.62 & 0.41 & 42 & 20 & 213 & 20 & 26 & 36 & 366 & 236 & 19 & 641 & 30 & 2.1 & 5.4 & 0.9 \\
\hline & YR297 & Junction Butte Basalt & 49.09 & 1.92 & 11.45 & 6.90 & 9.97 & 2.65 & 0.40 & 0.23 & 52 & 17 & 258 & 65 & 83 & 5.2 & 320 & 146 & 12 & 168 & 9.0 & 1.2 & 3.6 & 0.2 \\
\hline & YR302 & Gerrit Basalt & 46.39 & 1.96 & 12.63 & 7.67 & 10.02 & 2.74 & 0.27 & 0.30 & 52 & 21 & 278 & 101 & 104 & 2.1 & 250 & 137 & 10 & 174 & 8.9 & 1.3 & 3.2 & 0.2 \\
\hline \multirow{4}{*}{$\begin{array}{l}m \\
\stackrel{m}{ \pm} \\
\stackrel{+}{二} \\
\sim\end{array}$} & YR305 & High Point scoria cone & 56.53 & 1.31 & 10.72 & 1.55 & 4.74 & 4.28 & 3.35 & 0.60 & 20 & 19 & 2.8 & 37 & 1.0 & 58 & 185 & 1973 & 87 & 2185 & 63 & 8.1 & 36 & 3.5 \\
\hline & YR418 & Un-named scoria cone & 50.19 & 2.47 & 13.71 & 3.09 & 6.58 & 3.69 & 2.30 & 1.61 & 29 & 24 & 68 & 11 & 2.2 & 65 & 234 & 1089 & 83 & 1716 & 107 & 9.2 & 20 & 2.2 \\
\hline & YR420 & Un-named scoria cone & 50.53 & 2.45 & 13.62 & 3.07 & 6.49 & 3.58 & 2.33 & 1.58 & 29 & 25 & 73 & 3.2 & 2.4 & 70 & 245 & 1182 & 87 & 1814 & 114 & 9.2 & 22 & 2.3 \\
\hline & YR425 & Blacks Knoll & 47.26 & 3.01 & 14.13 & 3.72 & 8.01 & 3.79 & 1.57 & 2.20 & 32 & 23 & 104 & 2.9 & 3.3 & 34 & 347 & 753 & 61 & 1262 & 92 & 7.7 & 14 & 1.3 \\
\hline
\end{tabular}


Table 4.3: Isotopic ratios from selected samples from each of the suites in this study.

\begin{tabular}{|c|c|c|c|c|c|c|c|c|c|c|c|c|}
\hline \multirow{8}{*}{$\begin{array}{l}\overrightarrow{0} \\
\stackrel{\oplus}{\vec{J}}\end{array}$} & Sample & Host unit & ${ }^{87} \mathrm{Sr} /{ }^{86} \mathrm{Sr}$ & 2se & ${ }^{143} \mathrm{Nd} /{ }^{144} \mathrm{Nd}$ & 2 se & ${ }^{206} \mathrm{~Pb} /{ }^{204} \mathrm{~Pb}$ & 2 se & ${ }^{207} \mathrm{~Pb} /{ }^{204} \mathrm{~Pb}$ & 2 se & ${ }^{208} \mathrm{~Pb} /{ }^{204} \mathrm{~Pb}$ & 2 se \\
\hline & YP122 & HRT A Dense mafic & 0.70721 & 3.69E-06 & 0.51231 & 2.79E-06 & 16.952 & 2.75E-03 & 15.445 & $3.65 \mathrm{E}-03$ & 37.919 & $1.18 \mathrm{E}-02$ \\
\hline & YP244 & HRT A Dense mafic & 0.70754 & 3.43E-06 & 0.51229 & 6.18E-06 & 16.892 & 1.12E-03 & 15.463 & 1.37E-03 & 37.943 & $4.28 \mathrm{E}-03$ \\
\hline & YP246 & HRT A Dense mafic & 0.70728 & 3.57E-06 & 0.51232 & 4.73E-06 & 16.878 & $9.26 \mathrm{E}-04$ & 15.458 & 9.98E-04 & 37.925 & $2.92 \mathrm{E}-03$ \\
\hline & YP449 & HRT A Dense mafic & 0.70731 & 3.94E-06 & 0.51229 & $3.84 \mathrm{E}-06$ & 16.882 & $9.26 \mathrm{E}-04$ & 15.461 & 1.05E-03 & 37.937 & $3.18 \mathrm{E}-03$ \\
\hline & YP071BLACK & HRT B Scoria & 0.70751 & 3.46E-06 & 0.51235 & 5.15E-06 & 16.968 & $1.98 \mathrm{E}-03$ & 15.481 & 2.55E-03 & 38.028 & 8.17E-03 \\
\hline & YP266SCORIA & HRT B Scoria & 0.70771 & 3.63E-06 & 0.51231 & 2.42E-06 & 16.947 & 7.74E-04 & 15.476 & $8.22 \mathrm{E}-04$ & 38.016 & $2.36 \mathrm{E}-03$ \\
\hline & YP334B & HRT B Scoria & 0.70769 & $3.76 \mathrm{E}-06$ & 0.51232 & 4.10E-06 & 16.978 & 1.07E-03 & 15.482 & $1.24 \mathrm{E}-03$ & 38.023 & 3.79E-03 \\
\hline \multirow{5}{*}{ 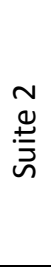 } & YR291 & Warm River Basalt & 0.70604 & 3.13E-06 & 0.51244 & $3.82 \mathrm{E}-06$ & 17.309 & 2.41E-03 & 15.511 & 2.35E-03 & 38.233 & $6.31 \mathrm{E}-03$ \\
\hline & YR292 & Basalt of the Narrows & 0.70373 & 5.03E-06 & 0.51251 & $4.81 \mathrm{E}-06$ & 16.665 & 3.35E-03 & 15.297 & 4.55E-03 & 36.466 & $1.44 \mathrm{E}-02$ \\
\hline & YR294 & Junction Butte Basalt & 0.70756 & 3.87E-06 & 0.51207 & $3.71 E-06$ & 15.859 & $1.68 \mathrm{E}-03$ & 15.272 & 2.26E-03 & 36.782 & 7.05E-03 \\
\hline & YR297 & Junction Butte Basalt & 0.70561 & 3.89E-06 & 0.51251 & 4.03E-06 & 16.943 & 1.27E-03 & 15.415 & $1.32 \mathrm{E}-03$ & 37.505 & $3.68 \mathrm{E}-03$ \\
\hline & YR302 & Gerrit Basalt & 0.70808 & 3.81E-06 & 0.51244 & $4.25 \mathrm{E}-06$ & 17.031 & 2.04E-03 & 15.478 & $2.62 \mathrm{E}-03$ & 37.811 & $8.32 \mathrm{E}-03$ \\
\hline \multirow{4}{*}{$\begin{array}{l}m \\
\stackrel{m}{ \pm} \\
\stackrel{ \pm}{二}\end{array}$} & YR305 & High Point scoria cone & 0.70577 & 3.66E-06 & 0.51239 & $5.56 \mathrm{E}-06$ & 17.218 & 1.06E-03 & 15.479 & $1.28 \mathrm{E}-03$ & 38.142 & 3.97E-03 \\
\hline & YR418 & Un-named scoria cone & 0.70581 & 3.70E-06 & 0.51239 & $3.25 \mathrm{E}-06$ & 17.208 & 1.36E-03 & 15.476 & $1.34 \mathrm{E}-03$ & 38.131 & $3.71 \mathrm{E}-03$ \\
\hline & YR420 & Un-named scoria cone & 0.70588 & 3.56E-06 & 0.51240 & 2.65E-06 & 17.158 & 1.10E-03 & 15.479 & $1.05 \mathrm{E}-03$ & 38.150 & $2.82 \mathrm{E}-03$ \\
\hline & YR425 & Blacks Knoll & 0.70789 & 4.43E-06 & 0.51225 & $3.32 \mathrm{E}-06$ & 17.361 & 5.73E-03 & 15.507 & 5.28E-03 & 38.069 & $1.34 \mathrm{E}-02$ \\
\hline
\end{tabular}




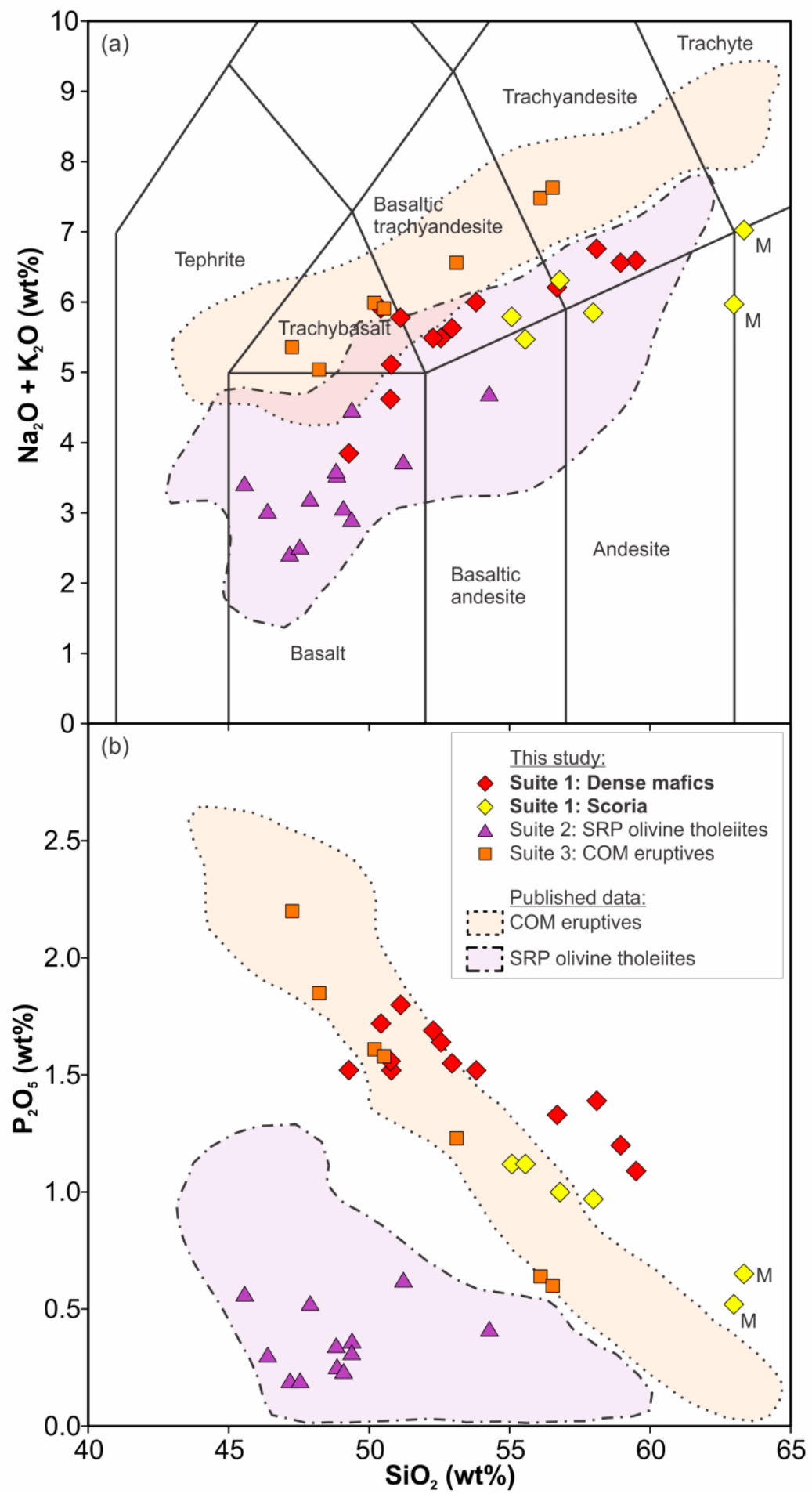

Figure 4.3: $\mathrm{SiO}_{2}$ versus

(a) total alkalis and b)

$\mathrm{P}_{2} \mathrm{O}_{5}$ for the three

suites of mafic samples

analysed in this study

and relevant

compositional fields

from published data

(see text for details).

Although there is

overlap between the

alkali compositions of

the mafic suites, $\mathrm{P}_{2} \mathrm{O}_{5}$

compositions are

distinctly higher in the

Suite 1 HRT samples. M

denotes mingled clasts

(YP185 and YP188

discussed in the text).

Classification fields in

panel (a) are from Le

Bas and Streckeisen

(1991). 2sd

uncertainties are

smaller than the

symbol sizes.

\subsubsection{Trace elements}

The clear separation between the Suite 1 HRT mafic samples and Suite 3 COM-type samples when compared to the Suite 2 olivine tholeiites is also apparent in trace element abundances. The Suite 1 HRT mafics and Suite 3 COM-type materials have notably high concentrations of incompatible elements including large-ion lithophile elements (LILE), e.g. 
Rb (25-99 ppm: Fig. S4.2a) and Ba (1120-3800 ppm: Fig. 4.4a), high field strength elements (HFSE), e.g. Zr (660-1970 ppm: Fig. 4.4b) and Nb (29-87 ppm), and actinides e.g. U (1.2-3.5 ppm with outliers at 4.7 and $5.7 \mathrm{ppm})$. In contrast, olivine tholeiite samples have notably higher V (210-280 ppm: Fig. S4.2c), Ni (26-190 ppm) and Cr (20-540 ppm). Sr concentrations are similar among both the mafic suites 1 and 3 (140-550 ppm: Fig. S4.2b) and within the range defined by our Suite 2 olivine tholeiite samples. Suite 1 HRT mafic and Suite 3 COMtype samples are elevated in all rare-earth elements (REE) relative to the Suite 2 olivine tholeiites and have sub-parallel trends (Fig. 4.5) with (La/Yb) $)_{N}$ ratios (5.0-10 with outlier YP242

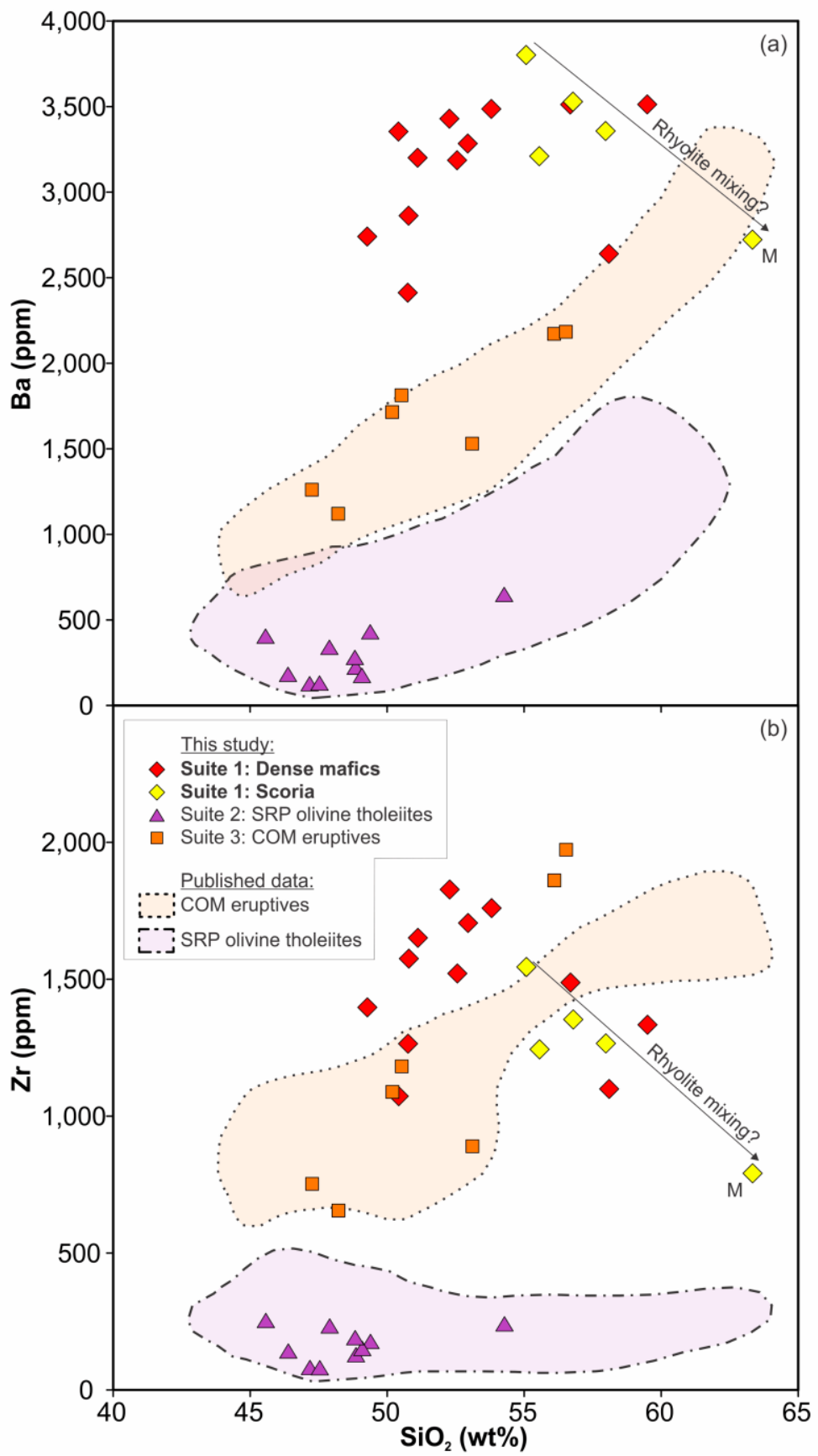

Figure 4.4: Compositional diagrams for the samples analysed in this study and relevant compositional fields from published data for $\mathrm{SiO}_{2}$ versus (a) $B a$ and (b) $Z r$, showing the enrichment in both LILE and HFSE in samples from suites 1 and 3. HRT dense mafics and scoria (Suite 1) are further enriched in Ba relative to COMtype flows, including our Suite 3 samples. See text for sources of published data fields. A possible mixing trend with rhyolite is defined by the scoria samples, trending towards the mingled clast (M). 2sd uncertainties are smaller than the symbol size. 


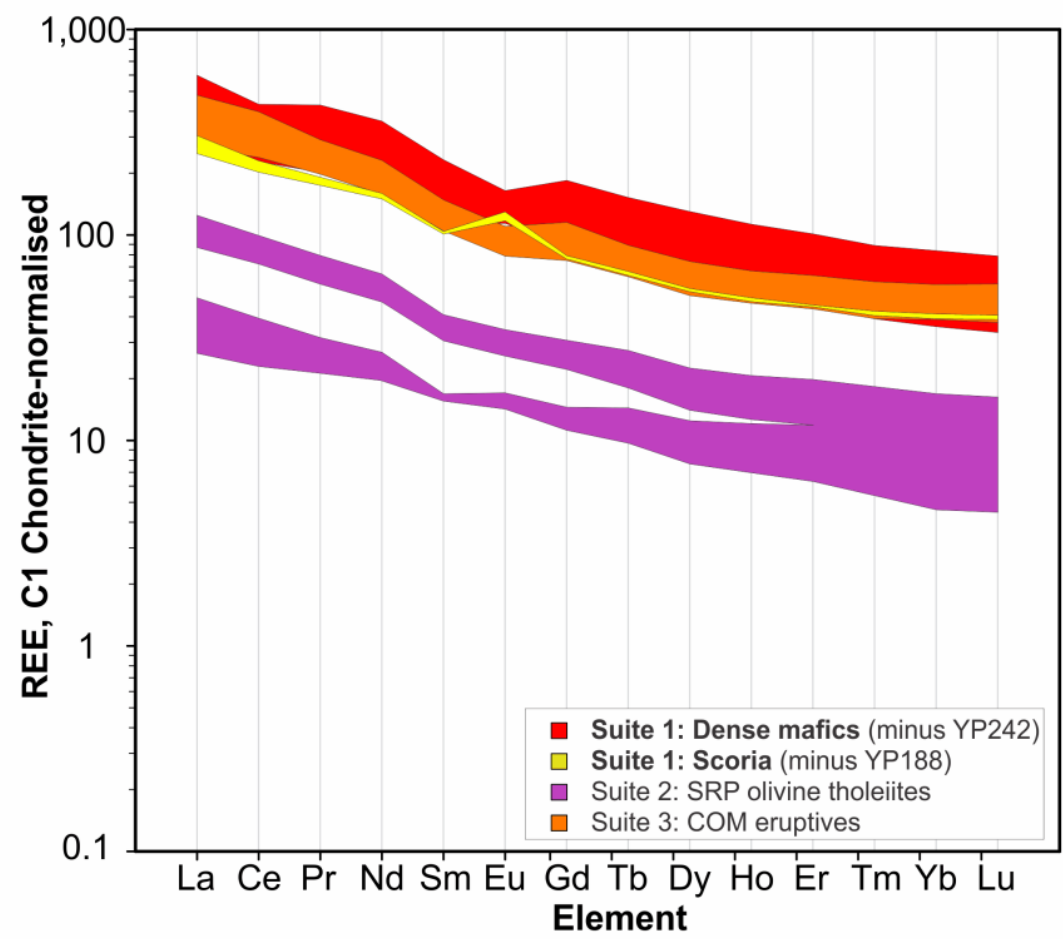

Figure 4.5: Chondritenormalised (McDonough and Sun 1995) REE plot showing enriched but sub-parallel trends in the samples from suites 1 and 3 relative to Suite 2 . There is no significant Eu anomaly in any of the samples analysed in this study.

at 18) overlapping with those of the olivine tholeiites (2.6-11). $\mathrm{Zr} / \mathrm{Hf}$ ratios are elevated in the Suite 1 (47-61) and Suite 2 samples (52-55) relative to the Suite 3 samples (40-49) but other incompatible element ratios are similar between the different suites (e.g. Ce/Pb: Fig. S4.3).

The only major divergence between the trace element compositions of the Suite 1 HRT mafic samples and Suite 3 COM-samples is in Ba where there are two apparent trends when plotted versus $\mathrm{SiO}_{2}$ (Fig. 4.4a). The moderate $\mathrm{Ba}$ trend in our Suite 3 samples aligns with the typical COM-trend reported elsewhere (Leeman et al. 1976; Christiansen and McCurry 2008) whereas the Suite 1 HRT mafic samples define a parallel trend with roughly double the Ba concentrations at a given value of $\mathrm{SiO}_{2}$ (Fig. 4.4a).

\subsubsection{Isotopic ratios}

${ }^{87} \mathrm{Sr} /{ }^{86} \mathrm{Sr}$ values for all samples range from $0.70373-0.70808$, with the highest and lowest values measured from Suite 2 olivine tholeiite samples, similar to the range of 0.70377 0.70886 reported by Hildreth et al. (1991) from Yellowstone basalts. Suite 3 samples are tightly clustered (0.70574-0.70585) with one outlier (YR425: $0.70788 \pm 0.00004$ 2se: Fig. 4.6). Suite 1 HRT dense mafics and scoria have broadly similar ${ }^{87} \mathrm{Sr} /{ }^{86} \mathrm{Sr}$ values (0.70709-0.70771), which are more radiogenic than our Suite 3 COM-type samples (Figs. 4.6, 4.7). However, both suites are notably less radiogenic than the COM samples reported on by Putirka et al. (2009: 


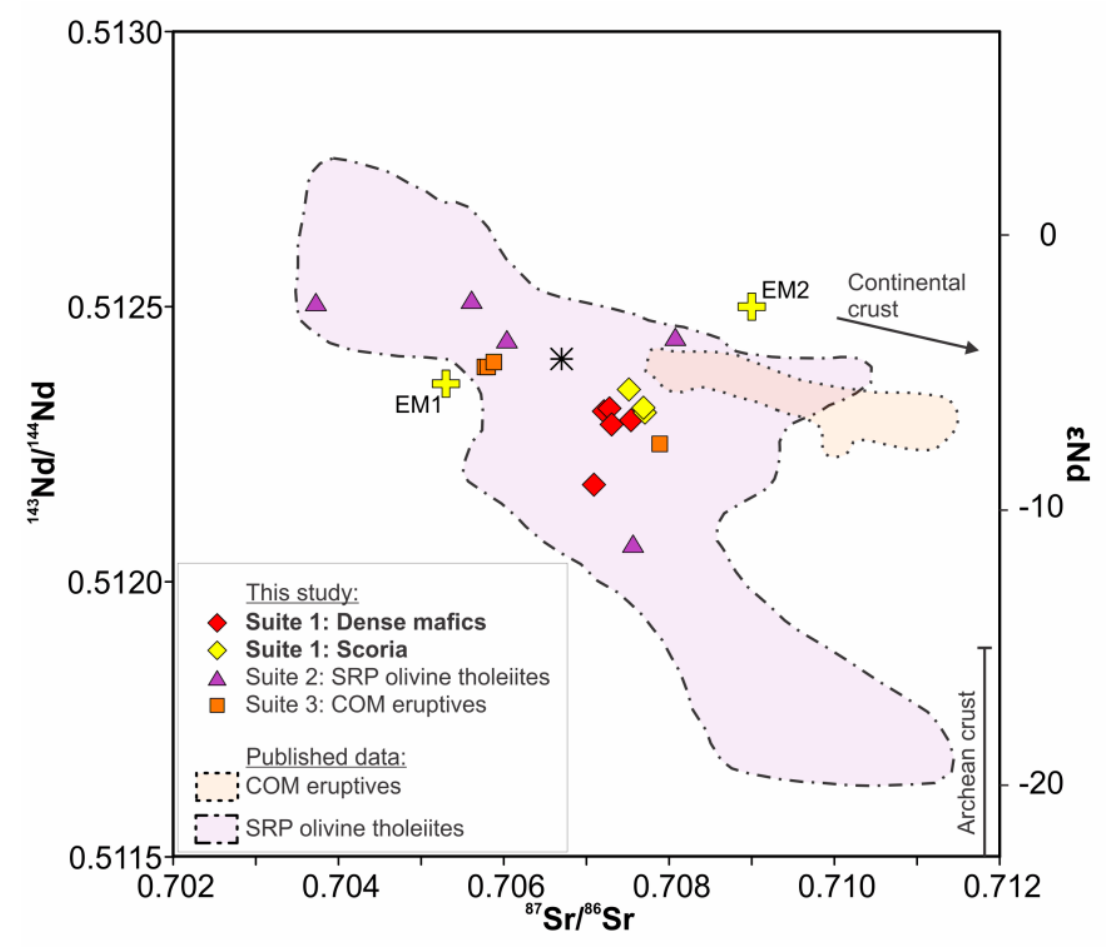

Figure 4.6: ${ }^{143} \mathrm{Nd} /{ }^{144} \mathrm{Nd}$ versus ${ }^{87} \mathrm{Sr} /{ }^{86} \mathrm{Sr}$ for samples analysed in this study and isotopic fields for relevant comparators from the YSRP area (see text for published data sources). All of the samples analysed in this study fall within the field covered by Snake River Plain basalts. The radiogenic nature of the $\mathrm{Sr}$ isotopic systematics, and unradiogenic $\mathrm{Nd}$ isotopic compositions, is taken to indicate interaction of the mafic suites with Archean subcontinental lithospheric mantle (Hanan et al. 2008). Arrow indicates trend of evolved lava flows from Craters of the Moon (Putirka et al. 2009) towards average continental crust $\left({ }^{87} \mathrm{Sr} /{ }^{86} \mathrm{Sr}=0.72 ;{ }^{143} \mathrm{Nd} /{ }^{144} \mathrm{Nd}=0.5118\right.$ : Hofmann 1997). Black asterisk represents the focus of collated Yellowstone-Snake River Plain basalts $\left({ }^{87} \mathrm{Sr} /{ }^{86} \mathrm{Sr}=0.7067\right.$, ${ }^{143} \mathrm{Nd} /{ }^{144} \mathrm{Nd}=0.510245$ : McCurry and Rodgers 2009). Archean crust typically has $\varepsilon_{\mathrm{Nd}}<-15$ (McCurry and Rodgers 2009 and references therein). Approximate values for enriched mantle 1 (EM2) and 2 (EM2) from Zindler and Hart (1986). See text for explanation of $\varepsilon_{\mathrm{Nd}}$. 2se errors are smaller than the symbol size.

$\left.{ }^{87} \mathrm{Sr} /{ }^{86} \mathrm{Sr}=0.70784-0.71130\right)$ and Leeman $\left(1974:{ }^{87} \mathrm{Sr} /{ }^{86} \mathrm{Sr}=0.70810-0.71240\right) .{ }^{87} \mathrm{Sr} /{ }^{86} \mathrm{Sr}$ variations in the Suite $1 \mathrm{HRT}$ mafic samples correlate positively with respect to whole-rock $\mathrm{Rb} / \mathrm{Sr}$ ratios $\left(\mathrm{R}^{2}=0.65\right)$ whereas the olivine tholeiites show isotopic variability at similar $\mathrm{Rb} / \mathrm{Sr}$ ratios (Fig. 4.7a). There is no clear correlation between ${ }^{87} \mathrm{Sr} /{ }^{86} \mathrm{Sr}$ and $1 / \mathrm{Sr}$ in any of our samples (Fig. 4.7b).

In similar fashion to $\mathrm{Sr}$, the full range in ${ }^{143} \mathrm{Nd} /{ }^{144} \mathrm{Nd}$ values $(0.51207-0.51251)$ for our data is spanned by Suite 2 olivine tholeiite samples (Fig. 4.6). HRT dense mafic clasts from 


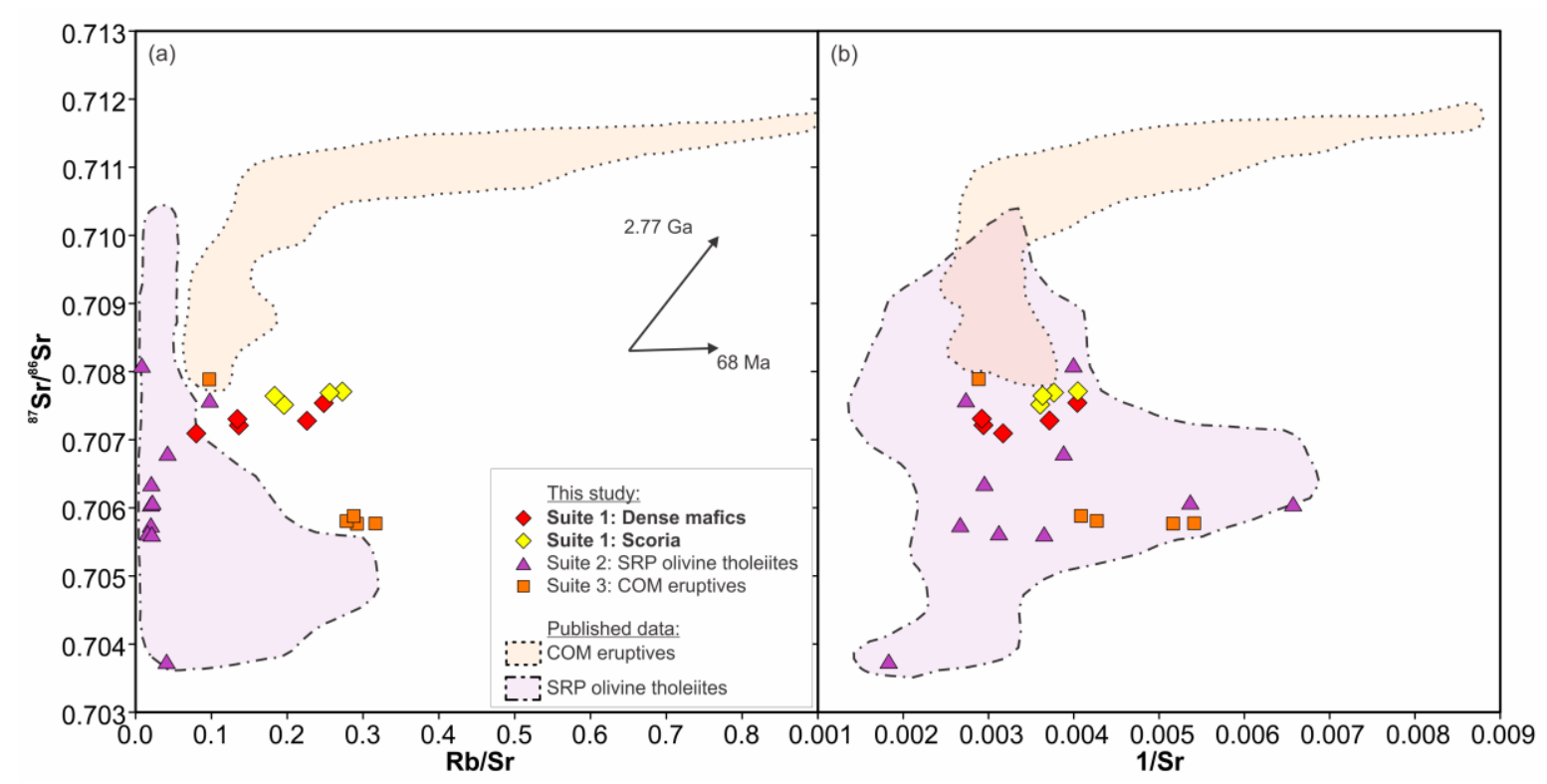

Figure 4.7: Plots showing the relationship between elemental and isotopic $\mathrm{Sr}$ compositions. ${ }^{87} \mathrm{Sr} /{ }^{86} \mathrm{Sr}$ values versus (a) $\mathrm{Rb} / \mathrm{Sr}$ and (b) $1 / \mathrm{Sr}$ show a positive relationship between ${ }^{87} \mathrm{Sr} /{ }^{86} \mathrm{Sr}$ and $\mathrm{Rb} / \mathrm{Sr}$ for the Suite 1 HRT mafics $\left(R^{2}=0.65\right)$ but no clear relationship with $1 / \mathrm{Sr}$. Suite 2 olivine tholeiite samples analysed for this study show a large range in isotopic compositions with a minimal range in $\mathrm{Rb} / \mathrm{Sr}$. See text for published data sources. Vectors show modelled gradients for hypothetical $\mathrm{Rb} / \mathrm{Sr}$ enrichment events at $2.77 \mathrm{Ga}$ and $68 \mathrm{Ma}$ from a common initial ${ }^{87} \mathrm{Sr} /{ }^{86} \mathrm{Sr}$ and multiple initial $\mathrm{Rb} / \mathrm{Sr}$ ratios. 2se error bars $\left({ }^{87} \mathrm{Sr} /{ }^{86} \mathrm{Sr}\right)$ are smaller than the symbols.

ignimbrite A (0.51218-0.51232), HRT vesicular scoria from ignimbrite $B(0.51231-0.51235)$ and Suite 3 samples $(0.51225-0.51240)$ all cover similar, largely overlapping ranges. All samples give negative $\varepsilon_{N d}$ values (-2 to -10$)$, where

$$
\varepsilon_{N d}=\left[\frac{\left({ }^{143} N d /{ }^{144} N d\right)_{m e a s}}{\left({ }^{143} N d /{ }^{144} N d\right)_{C H U R}}-1\right] \times 10^{4}
$$

from DePaolo and Wasserburg (1976). A value of CHUR (chondritic uniform reservoir) of 0.51263 was used, from Bouvier et al. (2008). Three of four Suite 3 samples have Nd isotopic values very similar to the median of Yellowstone-Snake River Plain basalts (0.512405: McCurry and Rodgers 2009), whereas three of four Suite 2 samples have ratios more radiogenic than the median and the Suite 1 samples are less radiogenic. However, all except three samples (one from each suite), have $\varepsilon_{N d}$ values $>-7$, below which value basalts are interpreted by McCurry and Rodgers (2009) to be contaminated. There is also no clear correlation in any of the suites between ${ }^{143} \mathrm{Nd} /{ }^{144} \mathrm{Nd}$ and ${ }^{87} \mathrm{Sr} /{ }^{86} \mathrm{Sr}$ (Fig. 4.6). 
$\mathrm{Pb}$ isotopic compositions also follow $\mathrm{Sr}$ and $\mathrm{Nd}$ in showing the greatest range in the Suite 2 olivine tholeiite samples $\left({ }^{206} \mathrm{~Pb} /{ }^{204} \mathrm{~Pb}=15.86-17.64 ;{ }^{207} \mathrm{~Pb} /{ }^{204} \mathrm{~Pb}=15.27-15.53 ;{ }^{208} \mathrm{~Pb} /{ }^{204} \mathrm{~Pb}\right.$ = 36.47-38.23: Fig. 4.8). In contrast in Suite 1, HRT dense mafics $\left({ }^{206} \mathrm{~Pb} /{ }^{204} \mathrm{~Pb}=16.88-16.95\right.$; $\left.{ }^{207} \mathrm{~Pb} /{ }^{204} \mathrm{~Pb}=15.45-15.46 ;{ }^{208} \mathrm{~Pb} /{ }^{204} \mathrm{~Pb}=37.92-37.94\right)$ and HRT vesicular scoria $\left({ }^{206} \mathrm{~Pb} /{ }^{204} \mathrm{~Pb}=\right.$ $\left.16.95-16.98 ;{ }^{207} \mathrm{~Pb} /{ }^{204} \mathrm{~Pb}=15.48 ;{ }^{208} \mathrm{~Pb} /{ }^{204} \mathrm{~Pb}=38.02-38.03\right)$ show much more restricted ranges with the scoria being more radiogenic. Our Suite 3 COM-type samples $\left({ }^{206} \mathrm{~Pb} /{ }^{204} \mathrm{~Pb}=\right.$ $\left.17.16-17.36 ;{ }^{207} \mathrm{~Pb} /{ }^{204} \mathrm{~Pb}=15.48-15.51 ;{ }^{208} \mathrm{~Pb} /{ }^{204} \mathrm{~Pb}=38.07-38.15\right)$ also show a modest range.

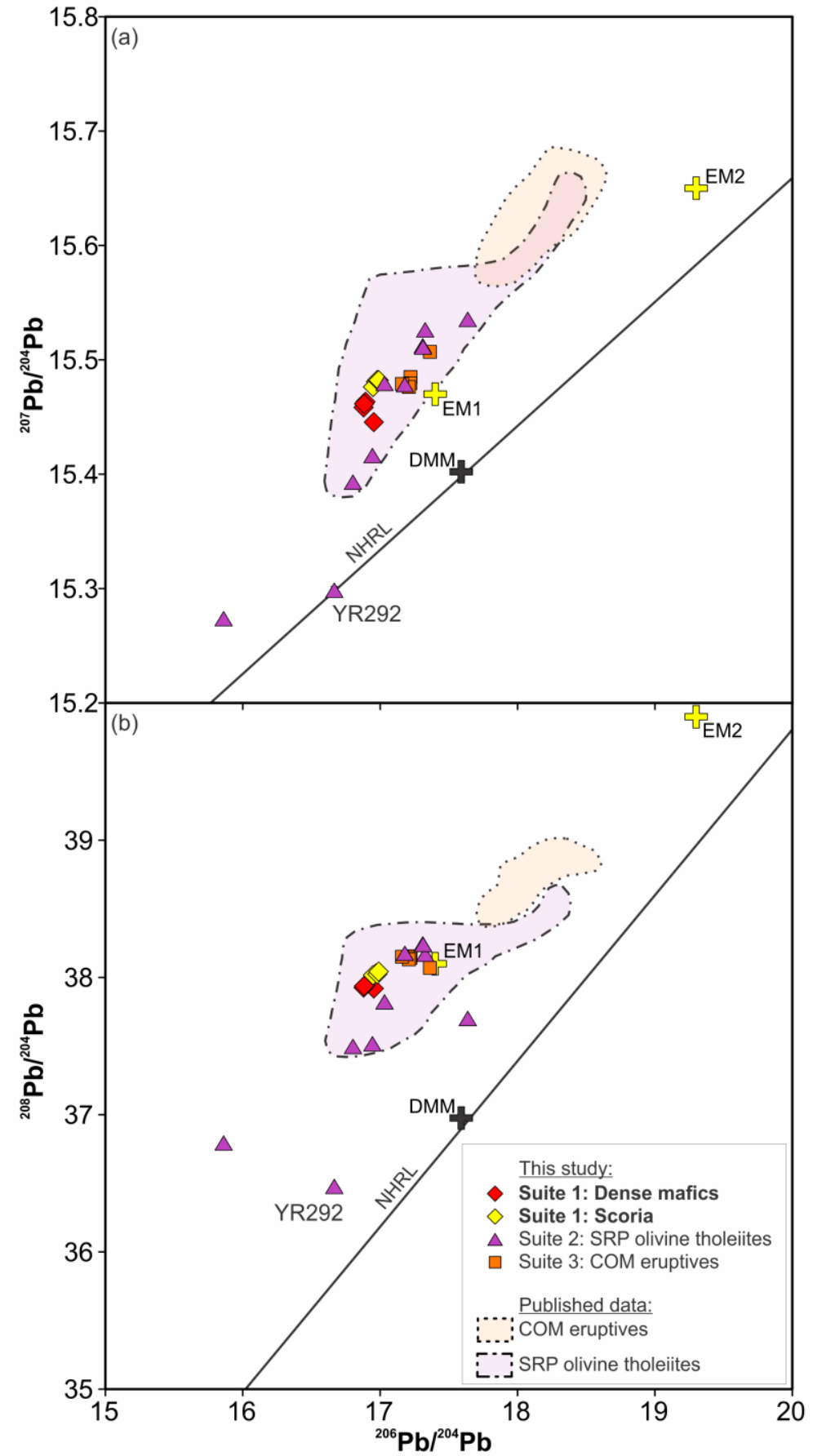

Figure 4.8: $\mathrm{Pb}$-isotopic compositions for the samples analysed for this study and fields for published data (see text for published data sources). All samples, except for the Basalt of the Narrows (YR292) in panel (a), plot above the Northern Hemisphere reference line (NHRL: Hart 1984). Suite 1 HRT mafics show elevated ${ }^{207} \mathrm{~Pb} /{ }^{204} \mathrm{~Pb}$ and ${ }^{208} \mathrm{~Pb} /{ }^{204} \mathrm{~Pb}$ ratios for a given value of ${ }^{206} \mathrm{~Pb} /{ }^{204} \mathrm{~Pb}$ relative to the Suite 2 olivine tholeiites. Enriched mantle 1 (EM1) and 2 (EM2) and depleted mantle (DMM) values from Zindler and Hart (1986). Individual 2se errors are smaller than the symbol size unless indicated otherwise. 
Suite 1 samples collectively form a sub-parallel trend to the Suite 2 olivine tholeiite samples, offset to higher ${ }^{207} \mathrm{~Pb} /{ }^{204} \mathrm{~Pb}$ for a given value of ${ }^{206} \mathrm{~Pb} /{ }^{204} \mathrm{~Pb}$ (Fig. 4.8). All except one sample (the ${ }^{207} \mathrm{~Pb} /{ }^{204} \mathrm{~Pb}$ composition of Basalt of the Narrows [YR292], which also has notably unradiogenic Sr isotopic characteristics) plot above the Northern Hemisphere Reference Line (Hart 1984).

\subsection{Discussion}

\subsubsection{The context of the HRT mafic magmas}

In considering the nature and range of compositions of the Suite 1 HRT mafic compositions and the comparator materials from suites 2 and 3 there are two aspects that need to be borne in mind. First, as seen elsewhere (e.g. Bacon and Metz 1984; Hildreth et al. 1991; Wilson et al. 2006; Pritchard et al. 2013), these mafic compositions related to silicic systems show features in their trace element and isotopic characteristics that suggest they do not generally represent pristine melts or magmas coming directly from a uniform mantle source. Even the least evolved compositions sampled in each of the case studies cited above show evidence for some variability in the mantle source, and/or fractionation or assimilation, but when and where these processes occurred is open to debate, as is the role of mantle versus crustal processes (cf. Rasoazanamparany et al. 2015). Second, the mafic compositions sampled in single silicic eruptions are rarely uniform in composition (see examples cited above), and the processes whereby the compositional variations within each suite are generated also need to be considered.

In addition, there needs to be taken into consideration the regional setting of the HRT mafics we document. Although lavas of olivine tholeiite affinity were erupted before and after the HRT in the Yellowstone area, major and trace element characteristics of the Suite 1 HRT mafics show closer links with COM-type compositions represented here by Suite 3 samples from the late Pleistocene Spencer-High Point volcanic field. The latter eruptives have in turn been linked with distinctly alkalic lava flows from the Craters of the Moon lava field (Kuntz et al. 1992; Iwahashi 2010). The Craters of the Moon lava field consists of $\sim 30 \mathrm{~km}^{3}$ of late Quaternary ( 15-2.1 ka) lava flows, erupted from monogenetic and polygenetic vents along a volcanic rift zone, the $85 \mathrm{~km}$ long Great Rift in the eastern Snake River Plain (Fig. 4.1: Kuntz et al. 1986). During the total lifespan of the Craters of the Moon lava field, several other 
olivine tholeiite lava fields were erupted in the eastern Snake River Plain, two of which (Kings Bowl and Wapi lava fields) were also sourced from the Great Rift (Fig. 4.1) and were contemporaneous with the final eruptive phase of the Craters of the Moon lava field (Kuntz et al. 1986, 1992).

The contemporaneity of young COM and olivine tholeiitic lavas along the Great Rift is analogous to what we report here from the HRT, which occurred between episodes of olivine tholeiite extrusion. This complexity within the YPVF has not been recognised before, with the prevailing view being that olivine tholeiites dominate the YPVF mafic suite and are intimately linked to the rhyolites (e.g. Hildreth et al. 1991; Christiansen and McCurry 2008). It is thus apparent that the sharp contrasts in composition between the COM and olivine tholeiite magma types reflect sources and processes that can act contemporaneously to feed vents contained within quite limited geographic areas.

In the subsequent discussion, we first consider the various controls on the compositions of the least-evolved magmas erupted within the three suites reported on here, and in particular address whether the Suite 1 HRT mafics could be generated from the same source region/primary magma as gave rise to the volumetrically dominant olivine tholeiites at Yellowstone and elsewhere in the SRP. Evidence for and against each of the processes put forward is summarised in Table 4.4. We then focus on the variability within each of the suites in order to address whether these variations follow a common pattern, or whether there are unique features to the compositional variations shown within each suite. Finally, we compare and contrast our data and inferences with the published array of compositional information on SRP volcanism, with particular reference to the main Craters of the Moon area.

\subsubsection{Generation of the parental magma for the Suite 1 HRT mafic compositions}

The least evolved of the Suite $1 \mathrm{HRT}$ mafics (Table 4.2) has a bulk $\mathrm{SiO}_{2}$ composition close to those of the olivine tholeiites in the Yellowstone area (Suite 2 data, and Hildreth et al. 1991), but radically contrasting values for many major and trace elements (Table 4.2, Figs. 4.3, 4.4). We here consider the diverse and sometimes contradictory models (summarised in Table 4.4) proposed for generation of the parental COM-type magmas (including our Suite 3 samples) and compare them against the data we present here for the Suite 1 HRT mafics. 


\subsubsection{Fractional crystallisation}

The most commonly invoked mechanism for generation of magmas in the COM-trend in general has been through extreme fractional crystallisation of an olivine tholeiite parent (Christiansen and McCurry 2008; McCurry et al. 2008). In support of this view, experimental studies by Whitaker et al. (2008) derived liquids with major element compositions similar to primitive COM lava flows through $\sim 80 \%$ crystallisation ( $~ 40 \%$ plagioclase, $\sim 22 \%$ olivine and $\sim 18 \%$ pyroxene) of an olivine tholeiite starting material at $1,100{ }^{\circ} \mathrm{C}, 4.3 \mathrm{kbar}$ and $0.4 \mathrm{wt} \%$ $\mathrm{H}_{2} \mathrm{O}$. However, there was also early recognition that fractional crystallisation alone cannot completely replicate the observed compositional variations, particularly with regard to trace elements (Leeman et al. 1976). Our Suite 1 HRT mafics data allow us to consider a fractional crystallisation mechanism through simple modelling of trace elements to try and replicate the distinctive signatures of the least evolved members of the suite. Fractional crystallisation modelling used the Rayleigh fractionation equation:

$$
\frac{C_{L}}{C_{O}}=F^{(\bar{D}-1)},
$$

where $C_{L}$ and $C_{O}$ are the elemental concentrations in the derived and original liquids respectively, $F$ is the fraction of melt remaining and $\bar{D}$ is the bulk distribution coefficient:

$$
\overline{D_{a}}=\sum W_{B} D_{a B},
$$

where $W_{B}$ is the weight \% of the mineral $B$ in the rock and $D_{a B}$ is the distribution coefficient of element $a$ in mineral $B$.

Warm River basalt (sample YR291) was used as the starting composition due to its similarity in composition to the starting material of Whitaker et al. (2008) and it having characteristics of a relatively 'primitive' lava (e.g. Mg\# of 64.1 [Leeman et al. 2009] with high $\mathrm{Ni}$ and $\mathrm{Cr}$ : Table 4.2). Using $\bar{D}=0$ (i.e. perfect incompatibility) for $\mathrm{Ba}, \mathrm{Zr}, \mathrm{Rb}, \mathrm{U}, \mathrm{Hf}$, Th, and $\mathrm{Y}$, $\geq 84 \%$ crystallisation generates liquids similar in trace element composition to the aphyric samples at the least-evolved end of our HRT Suite 1 samples. This degree of crystallisation is similar to that proposed by Whitaker et al. (2008) from experimental studies. To test this possible fractionation pathway, we model Sr values on the basis that the experimental and petrographic crystal assemblages are dominated by plagioclase in which $\mathrm{Sr}$ is compatible. To generate a composition similar to the HRT suite with $\sim 84 \%$ crystallisation, $\bar{D}=0.7$ is required. Using the partitioning relationship of Sr in plagioclase from Blundy and Wood (1991), at a temperature of $1,100{ }^{\circ} \mathrm{C}$ (Whitaker et al. 2008; Putirka et al. 2009) and $X_{A n}=0.63$ (Whitaker 
Table 4.4: Summary of the possible end-member processes for generation of the parental melt to the Suite 1 HRT mafics, together with respective evidence for or against the relevant process. See text for further discussion.

\begin{tabular}{|c|c|c|}
\hline Process & Evidence for & Evidence against \\
\hline $\begin{array}{l}\text { Extreme } \\
\text { fractional } \\
\text { crystallisation of } \\
\text { an olivine } \\
\text { tholeiitic parent } \\
\text { magma }\end{array}$ & $\begin{array}{l}\text { Using } \bar{D}=0 \text { for selected trace } \\
\text { elements (e.g. Ba, } \mathrm{Zr}, \mathrm{U}),>80 \% \\
\text { crystallisation required to generate } \\
\text { Suite } 1 \text { compositions. Similar amount } \\
\text { to experimentally-determined degree } \\
\text { required to generate liquids with } \\
\text { similar major element characteristics } \\
\text { to a COM from a tholeiitic parent } \\
\text { (Whitaker et al. 2008). }\end{array}$ & $\begin{array}{l}\text { Similar Sr concentrations between } \\
\text { the olivine tholeiite and HRT/COM } \\
\text { suites and absence of an Eu anomaly } \\
\text { in suites } 1 \text { and } 3 \text { which would be } \\
\text { expected from plagioclase dominated } \\
\text { fractionation. }\end{array}$ \\
\hline $\begin{array}{l}\text { Crustal } \\
\text { assimilation }\end{array}$ & $\begin{array}{l}\text { Elevated }{ }^{87} \mathrm{Sr} /{ }^{86} \mathrm{Sr} \text { isotopic ratios in } \\
\text { suites } 1 \text { and } 3 \text {, and particularly in } \\
\text { published data from the Craters of } \\
\text { the Moon lava field (Leeman 1976; } \\
\text { Putirka et al. 2009). }\end{array}$ & $\begin{array}{l}\text { Absence of a viable assimilant in } \\
\text { databases with high } \mathrm{Ba} \text {, } \mathrm{Zr} \text { and } \mathrm{FeO} \text {, } \\
\text { moderate } \mathrm{K}_{2} \mathrm{O} \text { and } \mathrm{Sr} \text {, and with a flat } \\
\text { REE pattern. } \\
\text { Comparable }{ }^{87} \mathrm{Sr} /{ }^{86} \mathrm{Sr} \text { between the } \\
\text { different mafic suites and lack of a } \\
\text { strong relationship between }{ }^{87} \mathrm{Sr} /{ }^{86} \mathrm{Sr} \\
\text { and } 1 / \mathrm{Sr} \text {, which would be expected } \\
\text { with assimilation. }\end{array}$ \\
\hline Depth of melting & $\begin{array}{l}\text { Elevated HREE concentrations in the } \\
\text { suites } 1 \text { and } 3 \text { apparently rules out } \\
\text { residual garnet in the source. }\end{array}$ & $\begin{array}{l}\text { Similar }(\mathrm{Gd} / \mathrm{Yb})_{\mathrm{N}} \text { between the } \\
\text { different suites indicating similar } \\
\text { depths of equilibration for suite } 1 \\
\text { and } 3 \text { melts to the olivine tholeiites } \\
\text { that equilibrated with spinel } \\
\text { lherzolite lithospheric mantle } \\
\text { (Leeman et al. 2009). }\end{array}$ \\
\hline $\begin{array}{l}\text { Degree of } \\
\text { melting }\end{array}$ & $\begin{array}{l}\text { Incompatible element enrichment } \\
\text { favours small degree of partial } \\
\text { melting. }\end{array}$ & $\begin{array}{l}\text { Negative correlation between } \mathrm{Nb} / \mathrm{Zr} \\
\text { and } \mathrm{Ba} / \mathrm{Nb} \text { in Suite } 1 \text { samples. } \\
\text { Different degrees of partial melting } \\
\text { would generate a positive trend due } \\
\text { to relative degrees of incompatibility } \\
(\mathrm{Ba}>\mathrm{Nb}>\mathrm{Zr} \text { ). }\end{array}$ \\
\hline $\begin{array}{l}\text { Aqueous fluid } \\
\text { enrichment }\end{array}$ & $\begin{array}{l}\text { Enrichment of LILE and mechanism } \\
\text { invoked for Eocene regional } \\
\text { volcanism due to dehydration of } \\
\text { underlying Farallon slab (Feeley } \\
\text { 2003). }\end{array}$ & $\begin{array}{l}\text { Enrichment in aqueous fluid } \\
\text { immobile HFSE (e.g. Zr, Ti) in suites } 1 \\
\text { and } 3 \text {, resulting in similar LILE/HFSE } \\
\text { ratios in the mafic suites, and lack of } \\
\text { significant } \mathrm{K}_{2} \mathrm{O} \text { enrichment in suites } 1 \\
\text { and } 3 \text {. }\end{array}$ \\
\hline $\begin{array}{l}\text { Hydrous melt } \\
\text { enrichment }\end{array}$ & $\begin{array}{l}\text { Enrichment in LILE and HFSE in suites } \\
1 \text { and 3, and parallel REE patterns } \\
\text { between the mafic suites, with } \\
\text { enrichment in all REE aided by } \\
\text { hydrous melts (Tsay et al. 2014). }\end{array}$ & $\begin{array}{l}\text { Localised nature of enrichment and } \\
\text { significantly different characteristics } \\
\text { to contemporaneously derived } \\
\text { aqueous fluids. }\end{array}$ \\
\hline
\end{tabular}

et al. 2008), $D_{S r}=2.4$, (similar to $D_{S r}=2.31$ at $1194{ }^{\circ} \mathrm{C}, 5 \mathrm{kbar}$ and $\mathrm{An}=0.59$ proposed by Sun et al. 2017). Based on the experimental crystallisation of $50 \%$ plagioclase, and ignoring the minimal effects of olivine and clinopyroxene on the Sr partition coefficient, this approach 
would yield a value of $\bar{D}_{S r}=1.4$ and generate Sr-depleted melts (105 ppm with 84\% crystallisation) that have lower Sr concentrations than any Suite 1 samples analysed in this study (Electronic Appendix 4.1; Fig. 4.9). Using only the most calcic plagioclase composition $\left(X_{A n}=0.85\right)$ from Putirka et al. (2009), with the other parameters unchanged, would a plagioclase $D_{s r}=1.4$ and therefore a required $\bar{D}_{S r}=0.7$ be generated. Although it is possible to replicate the observed patterns with variable Sr partition coefficients, we additionally note that there are no strong negative Eu anomalies in any Suite 1 samples (Fig. 4.5), which would be expected with significant plagioclase fractionation. A similar degree of fractionation (>80\%) would be required to generate the Eu signature of the HRT Suite 1 samples with $D=0$, a very unlikely situation in a plagioclase-dominated assemblage. Using $D_{E u}=2.39$ at $1194{ }^{\circ} \mathrm{C}, 5 \mathrm{kbar}$ and $A n=0.59$ (Sun et al. 2017), a resulting $\bar{D}_{E u}=1.2$ would generate melts depleted in Eu (0.6 ppm with $84 \%$ crystallisation), the opposite to what is seen (Fig. 4.5). Therefore we consider extreme fractionation of an olivine tholeiite parent to be not viable as the sole or even necessarily a major mechanism for the generation of the parental Suite 1 HRT compositions.

\subsubsection{Crustal assimilation}

Another possibility to generate the least-evolved HRT Suite 1 melts is assimilation of crustal rocks by olivine tholeiites as they ascend. Any variations within the HRT suite, e.g. Ba (Fig. 4.4a), would then be explained through varying degrees of assimilation. In this context, Geist et al. (2002) proposed assimilation of a P-rich ferrogabbro, whereas Putirka et al. (2009) proposed a two-stage assimilation-fractional crystallisation (AFC) model. The latter invoked early assimilation of 'mafic pods' in the lower crust followed by mid-crustal assimilation of wall-rocks similar in composition to the rhyolite inclusions reported from the COM suite (but not found in the centres sampled for this work). We use a similar approach to Putirka et al. (2009) here to evaluate possible assimilants to explain the least evolved Suite 1 HRT mafic compositions.

To generate the HRT primitive end-member through dominantly assimilation processes requires that the assimilant has elemental concentrations at least as high as that end-member. NAVDAT and GEOROC databases were thus used to search for plausible end members (see Electronic Appendix 4.2 for search parameters). Although no results fitted the search criteria in NAVDAT, 18 samples were returned from GEOROC, predominantly lamproites. Although 


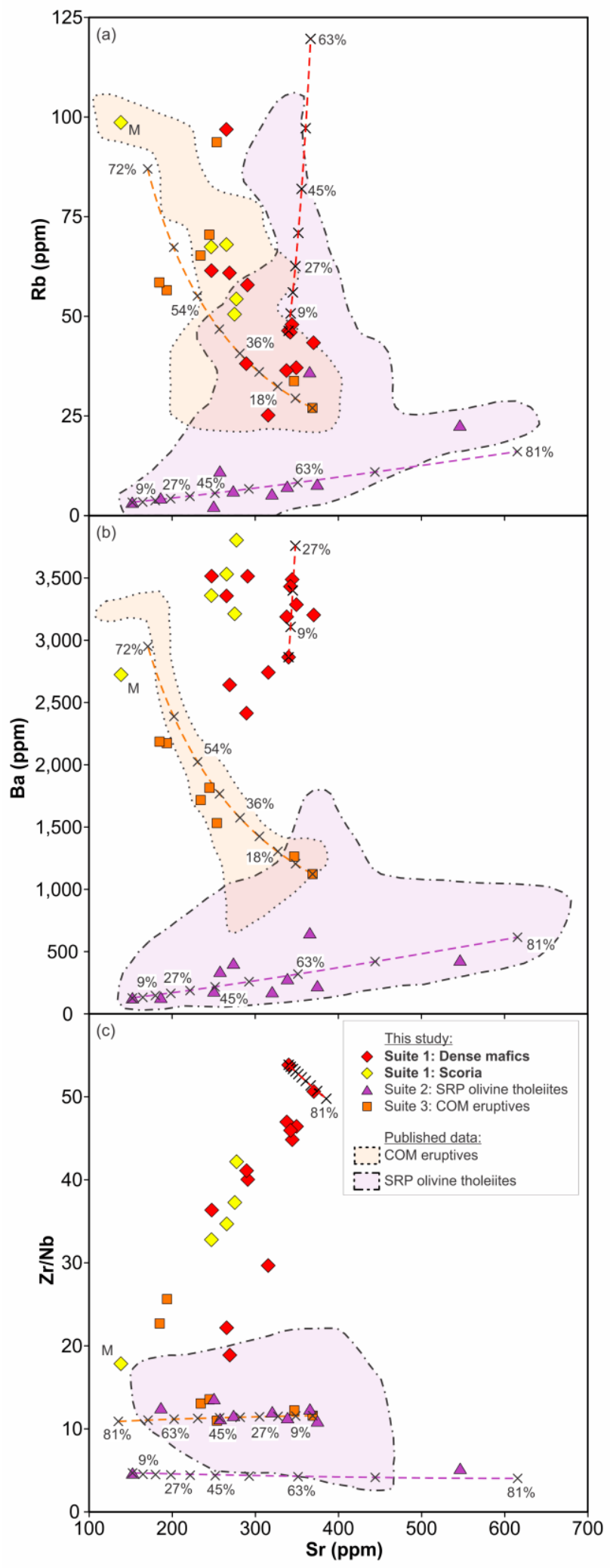

Figure 4.9: $\mathrm{Sr}$ vs (a) $\mathrm{Rb}$, (b) $\mathrm{Ba}$ and (c) $\mathrm{Zr} / \mathrm{Nb}$ for samples analysed in this work. Suite 1 HRT mafics are differentiated from Suite 3 COM samples by their elevated Ba and no correlation with $\mathrm{Sr}$, (panel b) and strongly decreasing $\mathrm{Zr} / \mathrm{Nb}$ (panel $\mathrm{c}$ ), the latter which requires crystallisation of zircon or a $\mathrm{Nb}$ rich phase, both of which are unlikely to have been present. Note the positive correlation between Sr and other LILE in Suite 2 olivine tholeiite samples, indicating the incompatibility of $\mathrm{S} r$ in these samples despite the presence of plagioclase. Red, purple and orange dashed lines show modelled fractional crystallisation trends for Suite 1 (YP122 as starting composition, crystallising assemblage of $45 \%$ plagioclase, $30 \%$ olivine, $25 \%$ clinopyroxene), Suite 2 (YR291 as starting composition, crystallising assemblage of $60 \%$ clinopyroxene, $35 \%$ olivine, 5\% plagioclase) and Suite 3 (YR422 as starting composition, crystallising assemblage of $80 \%$ plagioclase, $15 \%$ olivine, $5 \%$ clinopyroxene), respectively. Modelling was done using the modeller from Ersoy and Helvaci (2010). Black crosses represent $9 \%$ increments of crystallisation. Suite 1 samples have $\mathrm{Zr} / \mathrm{Nb}$ ratios not consistent with a fractionation control. Suite 2 and 3 samples are consistent with an clinopyroxene- and plagioclase-dominated fractionation signature, respectively, suggested by antithetic behaviour of $\mathrm{Sr}$ with increasing $\mathrm{Ba}$ (panel b) and uniformity in $\mathrm{Zr} / \mathrm{Nb}$ (panel c). See text for sources of published data. $\mathrm{M}$ denotes mingled scoria clast YP188. 
these samples have the low-moderate $\mathrm{SiO}_{2}$ (37-59 wt\%) required to be a plausible assimilant, they are generally much higher in Sr, with all except one with Sr concentrations least twice as high (>1110 ppm), and with $\mathrm{K}_{2} \mathrm{O}$ values mostly greater than three times the concentration of any Suite 1 sample at a given $\mathrm{SiO}_{2}$ concentration. Furthermore, the REE trend of the GEOROC sample group is very unlike the sub-parallel trends of the olivine tholeiites and HRT suites, being highly LREE enriched and having $(\mathrm{La} / \mathrm{Yb})_{N}$ ratios $(\geq 52)$ at least three times those of any samples reported here. Any AFC trend with a lamproitic or similar assimilant would then require a second AFC stage with a strongly heavy-REE enriched assimilant of which a composition has yet to be found. Additionally, although lamprophyres occur on the Colorado Plateau and in Wyoming, they have low Zr and high Sr concentrations (Mirnejad and Bell 2006; Lake and Farmer 2015), contrasting strongly with the Suite 1 mafics.

Considering other possible assimilants, rhyolite and granulite xenoliths found in lavas along the SRP have low $\mathrm{TiO}_{2}$, lower REE abundances and, in most cases, steeper REE slopes than their host lavas (Leeman et al. 1985), antithetic to the elevated $\mathrm{TiO}_{2}$, parallel REE trends but enriched concentrations of the least-evolved Suite 1 melts compared to Suite 2 parental compositions. Another characteristic precluding a strong control of assimilation on magma genesis is the high FeO of the Suite 1 parental compositions. The GEOROC comparator samples, with the exception of one, and COM rhyolite inclusions have lower FeO contents than olivine tholeiites ( $<7.4$ and $<3.5 \mathrm{wt} \%$ respectively) and thus cannot cause the FeO increase required to generate the Suite 1 parent from an olivine tholeiite. Furthermore, the lower $\mathrm{K} / \mathrm{Ba}$, and similar $\mathrm{K} / \mathrm{Rb}$ with increasing $\mathrm{SiO}_{2}$ in the Suite 1 samples relative to Suite 2 samples (Fig. S4.4), which ratios would be expected to increase and decrease, respectively, with crustal assimilation, argue against significant contamination (as concluded by Leeman et al. 1976). High K/Ba values occur in HRT rhyolitic samples (Hildreth et al. 1991), assimilation of which would lead to increased $\mathrm{K} / \mathrm{Ba}$ in the basalts, as is observed particularly in Suite 2 samples. Nevertheless, these HRT analyses have $<650 \mathrm{ppm} \mathrm{Zr}$, values that would be insufficient to generate the Suite 1 mafic parent through assimilation alone. There is an apparent trend defined by scoria samples (Fig. 4.4) with a visibly mingled sample (YP188) at the silicic end. However, this trend is antithetic to that of the overall Suite 1 mafics, indicating that mixing with rhyolite is not a plausible general mechanism for generation of the overall Suite 1 geochemical characteristics. Furthermore, the HRT rhyolites have $\mathrm{Zr} / \mathrm{Nb}$ ratios of 4-13 (Hildreth et al. 1991). Mixing with rhyolite would require a mafic end-member $\mathrm{Zr} / \mathrm{Nb}$ ratio 
of $>50$, which in turn would require the presence of an implausible and unseen $\mathrm{Nb}$-rich phase (Fig. 4.9).

All samples analysed in this study have higher $\mathrm{Sr}$ and lower $\mathrm{Nd}$ isotopic signatures than normal mantle-derived magmas, but which are consistent with values in basalts from the Yellowstone-Snake River Plain area that have equilibrated with lithospheric mantle (Fig. 4.6; Hanan et al. 2008; McCurry and Rodgers 2009). The elevated ${ }^{87} \mathrm{Sr} /{ }^{86} \mathrm{Sr}$ ratios of the published COM-type compositions relative to olivine tholeiites have been used to suggest that crustal contamination is important in the generation of the COM-type parent (Leeman and Manton 1971; Menzies et al. 1984; Putirka et al. 2009). In contrast, the Suite $1 \mathrm{HRT}$ mafic ${ }^{87} \mathrm{Sr} /{ }^{86} \mathrm{Sr}$ values are bracketed by our olivine tholeiite data, and all suite 1 and 3 samples fall within the broad field of SRP basalts (Fig. 4.6). It is possible that Suite 2 olivine tholeiites may have assimilated small amounts of very radiogenic Archean upper crust, whereas suites 1 and 3 magmas assimilated larger amounts of moderately radiogenic lower crust. From the perceived off- and on-axis spatial relationships of the COM-type and olivine tholeiites respectively, it has been argued that the ascent of the former is hindered by passage through primary granitic crust compared to the relatively fast ascent of the olivine tholeiites through crust replaced by basaltic sills (Christiansen and McCurry 2008; Putirka et al. 2009). A similar explanation for the differences between the least evolved samples from suites 1 and 2 presented here is difficult to uphold. This difficulty arises from the close spatial and temporal proximity of the earliest olivine tholeiite eruptions, the Junction Butte Basalt, traditionally viewed as contaminated, $\left({ }^{87} \mathrm{Sr} /{ }^{86} \mathrm{Sr}=0.70562 \pm 0.00004\right.$ and $0.70756 \pm 0.000042$ se, in our examples), to the HRT mafics $\left({ }^{87} \mathrm{Sr} /{ }^{86} \mathrm{Sr}=0.70709-0.70771\right)$. All these compositions were erupted at the beginning of known Yellowstone volcanism when the least replacement of the pre-existing crust would be expected to have occurred.

\subsubsection{Depth/degree of partial melting}

Another possible mechanism for generating mafic melts with differing chemical characteristics in the same geographic area is through source partial melting variations. Leeman et al. (2009) proposed that the Snake River Plain olivine tholeiites reflected melting of and equilibration with a spinel Iherzolite source containing minimal or no garnet at 70-100 $\mathrm{km}$ depth $(\leq 2.8 \mathrm{GPa})$. They cited the flat chondrite-normalised REE trends of primitive Snake River Plain olivine tholeiites, and low chondrite-normalised $G d / Y b$ ratios $\left([G d / Y b]_{N}=1.1-1.7\right)$ 
which would increase strongly if there was residual garnet in the source. The parallel REE slopes of the suites 1 and 3 samples when compared to those of Suite 2 (Fig. 4.5) suggest, however, that there was no significant difference in the depth of melting, consistent with the overlapping $(\mathrm{Gd} / \mathrm{Yb})_{\mathrm{N}}$ values of samples from Suite $2(1.4-2.5)$ versus suites 1 and $3(1.5-2.8)$.

Isotopic ratios of the different mafic suites can also provide clues on their source zones. The slope of the Suite 2 olivine tholeiite ${ }^{207} \mathrm{~Pb} /{ }^{204} \mathrm{~Pb}$ and ${ }^{206} \mathrm{~Pb} /{ }^{204} \mathrm{~Pb}$ ratios (Fig. 4.8), if interpreted as a pseudochron, gives an age of $2.77 \pm 0.52 \mathrm{Ga}$ (Fig. S4.5a). This apparent age is broadly comparable to the 'secondary-isochron' age of 2.5 Ga reported by Doe et al. (1982), and a $2.8 \mathrm{Ga}$ age from crustal xenoliths, the latter inferred to represent establishment of the Wyoming craton (Leeman et al. 1985). Similar pseudochrons can be regressed through data from our Suite 1 mafic samples (3.0 $\pm 0.22 \mathrm{Ga}$; excluding YP122: Fig. S4.5b) and Suite 3 samples $(2.56 \pm 1.1 \mathrm{Ga}$ : Fig. S4.5c). The similar pseudochron ages between all three mafic suites indicate, based on our earlier conclusion that assimilation has been minimal, that the melts of all three mafic suites equilibrated with similar Archean-age regions. This inference, coupled with the unradiogenic and overlapping ${ }^{143} \mathrm{Nd} /{ }^{144} \mathrm{Nd}$ isotope ratios between the different mafic suites (Fig. 4.6) and, with the exception of one sample from our data set, plotting above the Northern Hemisphere Reference Line (Fig. 4.8), collectively require sources for all three suites within regions with ancient $\mathrm{U}$ and $\mathrm{Nd}$ enrichment. As the Suite 2 olivine tholeiite values are taken to indicate that they last equilibrated with Archean subcontinental lithospheric mantle (Doe et al. 1982; Hanan et al. 2008; Leeman et al. 2009), then the similarity in REE patterns and $\mathrm{Pb}$ and $\mathrm{Nd}$ isotopic systematics requires that our suites 1 and 3 compositions also last equilibrated with a similar source with a similar Archean history.

We now consider the possibility of varying degrees of partial melting of this common source to generate the contrasts between the different suites, using $\mathrm{Ba}, \mathrm{Nb}$ and $\mathrm{Zr}$ as discriminants. Although all three elements are incompatible with respect to mantle mineral assemblages, their degrees of incompatibility vary, with $\mathrm{Ba}>\mathrm{Nb}>\operatorname{Zr}\left(\mathrm{D}_{\mathrm{Ba}}=0.01, \mathrm{D}_{\mathrm{Nb}}=0.04\right.$, $D_{z r}=0.08$ : Hofmann 1988). Therefore, smaller degrees of partial melting than that associated with the olivine tholeiites should lead to elevated $\mathrm{Ba} / \mathrm{Nb}, \mathrm{Ba} / \mathrm{Zr}$ and $\mathrm{Nb} / \mathrm{Zr}$ ratios in the resulting melts. Although the Suite 1 mafics show elevated $\mathrm{Ba} / \mathrm{Nb}$ ratios, their $\mathrm{Nb} / \mathrm{Zr}$ ratios are lower and negatively correlated with $\mathrm{Ba} / \mathrm{Nb}$ (this is also seen in Suite 3 samples). These relationships are the opposite to what would be expected if the Suite 1 mafics were derived from smaller-degree partial melts from a source common to the olivine tholeiites (Fig. S4.6). 
Our data are thus consistent with variations within the olivine tholeiites being due to varying degrees of partial melting (Leeman et al. 2009) but extrapolation of this hypothesis to generation of the parental melts for suites 1 and 3 is incompatible with our data.

\subsubsection{Enrichment of the mantle source}

We next consider the possibility that magmas of suites 1 and 3 were generated from mantle sources contrasting in some respect to the Suite 2 samples. Although the ferroan and isotopically more crustal nature of the least evolved COM lavas have led to this possibility being dismissed by earlier workers (e.g. Leeman and Manton 1971; Leeman et al. 1976; Reid 1995; Putirka et al. 2009), Suite 1 compositions show contrasts with these 'type' COM flows (see subsequent section) that make a mantle contrast worth investigating. Differing mafic compositions erupted within a single volcanic field or province have elsewhere been attributed to source heterogeneity, with origins in regions of variably enriched or metasomatised mantle (e.g. Feeley 2003; McGee et al. 2013; Rasoazanamparany et al. 2015). Aqueous fluid has often been invoked as a mechanism for locally enriching mantle sources, particularly in subduction zones through dehydration of the subducting slab (e.g. McCulloch and Gamble 1991). Such aqueous-rich fluids are typically enriched in LILE, and depleted in HFSE and REE that remain in the slab (McCulloch and Gamble 1991; Green and Adam 2003, and references therein).

Eocene subduction and source enrichments associated with the Farallon slab have previously been invoked in the timing and characteristics of the 55-45 Ma Absaroka Volcanic Province, overlapping with the eastern border of Yellowstone (Fig. 4.1; Christiansen and Yeats 1992; Feeley 2003; Schmandt and Humphreys 2011). The calc-alkaline, andesitic Absaroka eruptives have eastward-increasing $\mathrm{K}_{2} \mathrm{O}$ contents and elevated LILE/HFSE ratios (Fig. 4.10: Chadwick 1970; Feeley 2003). These features have been linked to partial melting of a lithospheric mantle source that had been metasomatically enriched at $<100$ Ma by aqueous fluids derived from the Farallon slab (Feeley 2003). As the slab foundered, asthenospheric upwelling is proposed to have led to partial melting of the enriched region and generation of Absaroka magmas. A comparable scenario has also been invoked for other volcanic fields in the western U.S. (e.g. Mirnejad and Bell 2006; Lake and Farmer 2015; Brueseke et al. 2017). A modern low-velocity layer atop the mantle transition zone beneath the YSRP has also been 


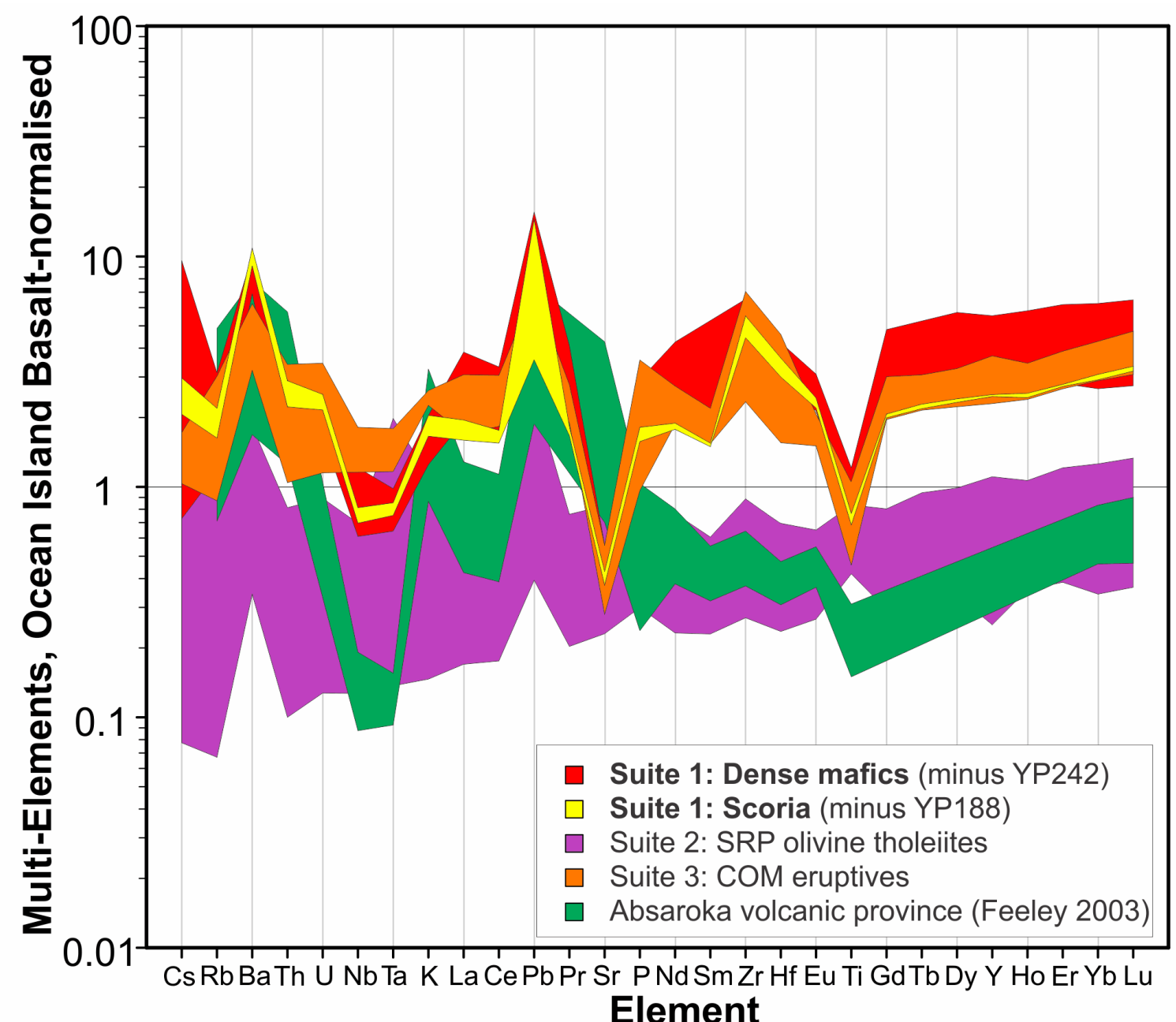

Figure 4.10: Ocean Island Basalt-normalised (Sun and McDonough 1989) multi-element diagram showing the enriched nature in LILE and HFSE of the Suite 1 HRT mafics and Suite 3 COM-type materials relative to Suite 2 olivine tholeiites. Absaroka Volcanic Province data from Feeley (2003) show a high LILE/HFSE ratio typical of hydrous fluid-enriched subduction zone volcanism.

attributed to a zone of partial melt caused by ascending volatiles from a still-dehydrating Farallon slab (Hier-Majumder and Tauzin 2017).

Although such a model may be applicable to the Quaternary Yellowstone eruptives, a distinctive signature of samples from suites 1 and 3 is their enrichment not only in typically fluid-mobile LILE (Ba, Rb) but also immobile HFSE ( $\mathrm{Zr}, \mathrm{Ti}, \mathrm{Nb})$ and REE relative to Suite 2 samples and the Absaroka volcanics (Fig. 4.10). In suites 1 and 3, the Ba enrichment coupled with the lack of a significant $\mathrm{K}_{2} \mathrm{O}$ enrichment (or depletion) precludes a significant role for phlogopite while the lack of Sr enrichment precludes a significant role for carbonate in any source enrichments, as mantle carbonates are commonly Sr enriched (Hoernle et al. 2002). These features indicate that aqueous fluids alone cannot have generated any proposed 
enrichment of the source zones for suites 1 and 3 . However, at high pressures and temperatures $\left(>600^{\circ} \mathrm{C}\right.$ and $>0.5 \mathrm{GPa}$ ), HFSE, such as $\mathrm{Zr}$ and $\mathrm{Ti}$, can be soluble in high total solute aqueous fluids or hydrous melts relative to dilute aqueous fluids (Manning et al. 2008; Hayden and Manning 2011; Wilke et al. 2012; Louvel et al. 2013, 2014). Under such circumstances HFSE may have been transported upwards from the Farallon slab to enrich the overlying mantle in HFSE. Although normally this metasomatised region would descend with the subducted plate to the deep mantle, thus causing the HFSE-depleted signature of subduction-zone volcanism (McCulloch and Gamble 1991; Louvel et al. 2013, 2014), the slowly sinking nature of the Farallon slab beneath the YSRP would mean that this HFSEenriched zone remained in the upper mantle and became available as a source region for subsequent melting.

The geochemical signatures of suites 1 and 3 place further constraints on the nature of any fluids from the Farallon slab. The similar REE patterns between the different suites (Fig. 4.5) suggest that enrichment was uniform for all REE. Experimental data show that minimal REE fractionation occurs in melts when compared to aqueous fluids, suggesting that a hydrous melt was more likely the agent for HFSE enrichment (Tsay et al. 2014). Although fluids generated within the garnet stability field would have an elevated LREE/HREE ratio (Green and Adam 2003; Green et al. 2000), equilibration with spinel Iherzolite lithospheric mantle melts would likely mask any deeper signature. We thus cannot preclude ascent of HFSEenriched melts contributing to mantle enrichment from depths appropriate to the garnet stability field, but the source of the parental melts to suites 1 and 3 has to have been at levels above the garnet stability field.

The HFSE-enriched nature of suites 1 and 3 relative to the olivine tholeiites thus suggests that melting of a melt-enriched mantle source is a plausible mechanism for the generation of their parental melts. Following the $2.8 \mathrm{Ga}$ magmatic/metamorphic enrichment event (inferred here and in other works from Pb isotopic signatures: Doe et al. 1982; Leeman et al. 1985), a second, Cretaceous-Eocene enrichment event has been proposed for the Absaroka Volcanic Province by Feeley (2003) and for volcanism farther east by Mirnejad and Bell (2006). We consider the possible role of this second enrichment event in our Suite 1 samples through the $\mathrm{Sr}$ isotopic systematics, where there is a positive correlation between ${ }^{87} \mathrm{Sr} /{ }^{86} \mathrm{Sr}$ and $\mathrm{Rb} / \mathrm{Sr}$ and no apparent relationship to 1/Sr (Fig. 4.7). We argue (as contrasted previously for the olivine tholeiites) that this trend is not due to crustal contamination but instead controlled by 
$\mathrm{Rb}$, which is enriched in the Suite 1 samples (Fig. 4.9). One interpretation for this trend, therefore, is as a pseudochron, potentially reflecting the age of the secondary Rb-enrichment event. Using age-corrected (to $2.08 \mathrm{Ma}$ ) ${ }^{87} \mathrm{Sr} /{ }^{86} \mathrm{Sr}$ and ${ }^{87} \mathrm{Rb} /{ }^{86} \mathrm{Sr}$ ratios, a pseudochron of $68 \pm 45$ Ma (MSWD=193) is generated using Isoplot (Fig. S4.7). Although imprecise, this age estimate is the same within error as that proposed for the metasomatic event associated with volcanism in the Absaroka field and elsewhere in Wyoming (Feeley 2003; Mirnejad and Bell 2006; Schmandt and Humphreys 2011). Note also that this pseudochron correlation, if valid, would indicate an original ${ }^{87} \mathrm{Sr} /{ }^{86} \mathrm{Sr}$ for the source region of the Suite $1 \mathrm{HRT}$ mafics of 0.7069 \pm 0.0004 , identical within error to the inferred initial ${ }^{87} \mathrm{Sr} /{ }^{86} \mathrm{Sr}$ ratios of Yellowstone-Snake River Plain olivine tholeiites $(0.7067 \pm 0.001$ : McCurry and Rodgers 2009). If, in contrast, measured ${ }^{87} \mathrm{Sr} /{ }^{86} \mathrm{Sr}$ values are age-corrected to an Archean age (i.e. $\geq 2.5 \mathrm{Ga}$ ), then initial ${ }^{87} \mathrm{Sr} /{ }^{86} \mathrm{Sr}$ values would have been $<0.7$ and the slope of the pseudochron much steeper (Fig. 4.7a). This initial value is implausibly low and indicates that $\mathrm{Rb} / \mathrm{Sr}$ enrichment, if related to metasomatism, did not occur in the Archean but must be a more recent event. We consider that the younger event is recorded in $\mathrm{Sr}$ but not $\mathrm{Pb}$ isotopic systematics due to the elevated $\mathrm{Rb} / \mathrm{Sr}$ in Suite 1 relative to Suite 2 samples. In contrast the $\mathrm{U} / \mathrm{Pb}$ values are similar between the two suites, thus, allowing for a selective Sr isotopic overprint.

We therefore suggest that as the Farallon slab foundered in the Cretaceous-Eocene, a variety of fluids (aqueous fluids and hydrous melts) with varying compositions were released from the slab to migrate upwards into the lithospheric mantle resulting in a heterogeneous source region for subsequent melting and volcanism (Fig. 4.11). Aqueous fluids, enriched in LILE, likely migrated further (cf. Rubatto and Hermann 2003) and the LILE-enriched regions preferentially melted as a consequence of asthenospheric upwelling to generate the Absaroka volcanics with their high LILE/HFSE signature (Fig. 4.10). We infer that during subsequent impingement of the modern Yellowstone thermal anomaly (plume) the lithospheric mantle beneath the YPVF underwent partial melting. This 'modern' melting event generated parental melts for the enriched Suite 1 mafics plus Suite 3 COM-type magmas from HFSE-enriched regions, and olivine tholeiitic melts from adjacent regions that were unaltered or from which the LILE were stripped during Absaroka magmatism. 


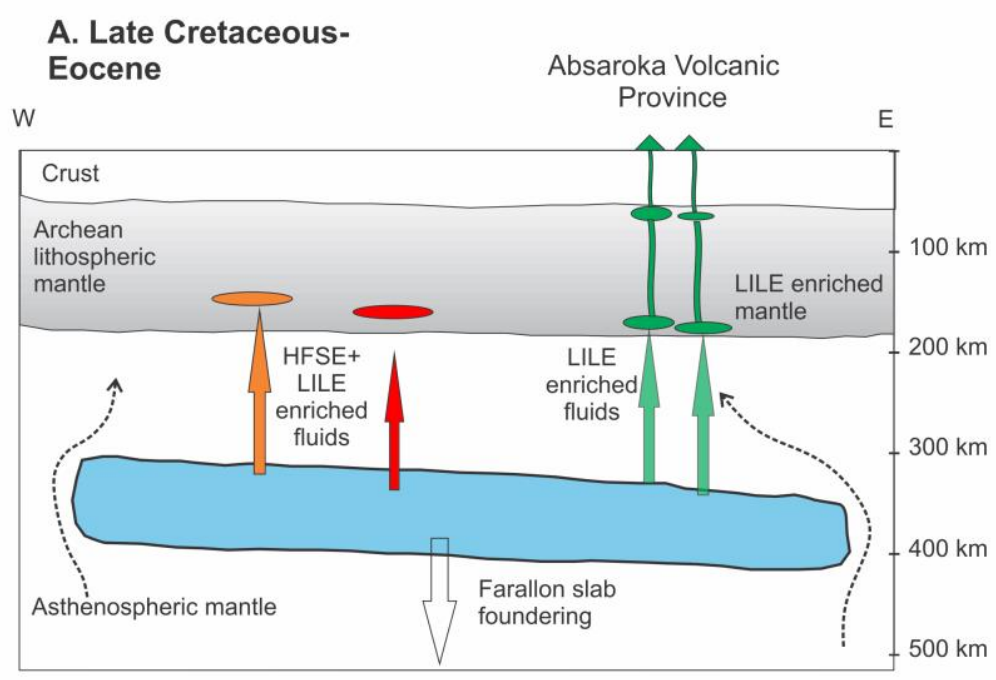

\section{B. $\sim 2 \mathrm{Ma}$ to recent}

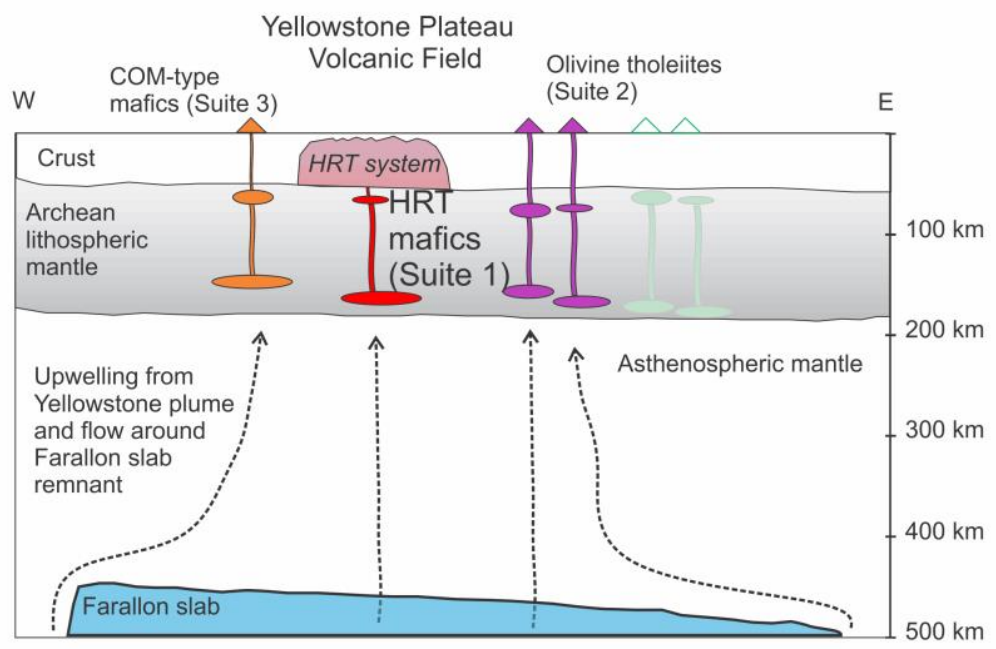

Figure 4.11: Summary cartoon showing our proposed late Cretaceous-Eocene enrichment of the lithospheric mantle beneath Yellowstone by fluids derived from the subducted and foundering Farallon slab. Aqueous fluids with high LILE/HFSE ratios ascended and enriched the source region of the Eocene Absaroka Volcanic Province. Contemporaneously, solute-rich, LILE plus HFSEenriched hydrous melts ascended into the base of the lithospheric mantle. Aqueous fluid enriched regions preferentially melted during asthenospheric upwelling to generate the Absaroka Volcanic Province. The renewal of volcanism in the YPVF in the Quaternary, with the arrival of a thermal anomaly (the Yellowstone plume), melted the heterogeneous lithospheric mantle. Unaltered regions yielded the parental melts to the olivine tholeiites (Suite 2, e.g. the Junction Butte Basalt) and enriched zones yielded the parental melts to the Suite $1 \mathrm{HRT}$ mafics. The latter ascended to be intercepted by the growing HRT silicic magma system, syn-eruptively in the case of the samples analysed here. Younger COM-type lavas erupted immediately west of the HRT caldera (Suite 3) also show evidence for derivation from a HFSE-enriched source. 


\subsubsection{Intra-suite trends}

Following generation of the parental melts, subsequent processes controlled the distinct intra-suite compositional arrays, predominantly fractional crystallisation and assimilation, that we discuss in turn below. Both processes, particularly at low pressures, have been invoked for the COM-trend along the Snake River Plain (Leeman et al. 1976; Christiansen and McCurry 2008; McCurry et al. 2008). Although plagioclase and olivine are commonly present in olivine tholeiite and COM eruptives (Putirka et al. 2009), major and trace element trends may fingerprint any other 'cryptic' fractionation effects, reflecting crystallisation of phases not observed in the erupted material. Sub-parallel major element trends (e.g. increasing $\mathrm{Na}_{2} \mathrm{O}$ $+\mathrm{K}_{2} \mathrm{O}$ with $\mathrm{SiO}_{2}$, and decreasing $\mathrm{MgO}, \mathrm{FeO}$ and $\mathrm{CaO}$ ) in all three suites suggest a control by similar olivine plus plagioclase fractionation assemblages (Tilley and Thompson 1970), with the additional presence of apatite to explain a decrease in $\mathrm{P}_{2} \mathrm{O}_{5}$ in suites 1 and 3 , as inferred for COM flows (Fig. 4.3b; Leeman et al. 1976; Reid 1995). Trace element patterns, however, indicate a contrast in the relative role of fractionation of the different phases in generating the intra-suite trends. The sharp decrease in $\mathrm{Ni} / \mathrm{Sc}$ ratios with decreasing $\mathrm{MgO}$ and $\mathrm{CaO} / \mathrm{Al}_{2} \mathrm{O}_{3}$ in Suite 2 olivine tholeiite samples, compared to a relatively flat trend defined by suites 1 and 3, suggest a much greater role for olivine in Suite 2 samples (Fig. S4.8). Conversely, the positive relationship between $\mathrm{Sr}$ and other LILE (e.g. $\mathrm{Rb}$ and $\mathrm{Ba}$ ) in Suite 2 samples, coupled with an increase of $\mathrm{Rb}$ with $\mathrm{SiO}_{2}$, indicates a bulk incompatibility of $\mathrm{Sr}$ and a reduced role for plagioclase (Fig. 4.9). This inference is supported by an increase in $\mathrm{Sr} / \mathrm{Sc}$ with increasing $\mathrm{Ni} / \mathrm{Cr}$ in Suite 2 samples (Fig. S4.9). In contrast, samples from suites 1 and 3 show an inverse relationship between $\mathrm{Sr}$ and $\mathrm{Rb}$ (Fig. 4.9) and, as $\mathrm{Rb}$ increases with $\mathrm{SiO}_{2}$ in all suites, these relationships collectively indicate a greater influence of plagioclase. Deviations from these trends (e.g. YR294, a Junction Butte Basalt sample with 36 ppm Rb: Fig. 4.9) are likely to reflect variable degrees of contamination by country rocks.

Quantitative fractional crystallisation modelling was undertaken using the modelling program of Ersoy and Helvaci (2010) with their built-in partition coefficients for "basic" magmas. Starting compositions were the samples from each suite with the highest Mg\# (YR291 and YR422 for suites 2 and 3 respectively) or a combination of high Mg\# and low $\mathrm{SiO}_{2}$ (YP122: Suite 1). Results from this modelling support the previous inferences, with the Suite 2 trend most consistent with a crystallising assemblage of $60 \%$ clinopyroxene, $35 \%$ olivine and 5\% plagioclase (Figs. 4.9, S4.9). In contrast, as shown by an antithetic evolutionary trend (Fig. 
S4.9), the Suite 3 sample variations can be replicated by a fractional crystallisation of an assemblage containing $80 \%$ plagioclase, $15 \%$ olivine and $5 \%$ clinopyroxene. This assemblage is plagioclase richer and pyroxene poorer than those observed in the experiments of Whitaker et al. (2008), conducted on a similar range of compositions. However, the model mineral assemblage and fractionation trend are at odds with the lack of a negative Eu anomaly in the Suite 3 samples (Fig. 4.5) as would be expected with significant plagioclase fractionation. The compositional variation of this suite is thus somewhat enigmatic and would benefit from further study. Both curves detailed above show uniform $\mathrm{Zr} / \mathrm{Nb}$ ratios with changing Sr (Fig. 4.9), consistent with the similar incompatible nature of both elements in the fractionating assemblage.

In Suite 1 samples, although the uniform Sr/Sc ratio with decreasing $\mathrm{Ni} / \mathrm{Cr}$ (Fig. S4.9) is consistent with a moderately plagioclase-dominant assemblage (45\% plagioclase, $30 \%$ olivine and $25 \%$ clinopyroxene), this assemblage does not fully replicate $\mathrm{Sr}$, Ba and $\mathrm{Rb}$ trends observed in the Suite 1 data. In addition, the modelled trend is antithetic to the strong correlation between $\mathrm{Zr} / \mathrm{Nb}$ and $\mathrm{Sr}$ observed in the sample data (Fig. 4.9). This correlation requires either the fractionation of zircon or a Nb-rich phases. It is possible that the decrease in $\mathrm{Zr} / \mathrm{Nb}$ ratios, with decreasing $\mathrm{Sr}$, is related to zircon fractionation accompanying the bulk fractionation trend, as zircon is inferred to be stable at $\sim 60 \mathrm{wt} \% \mathrm{SiO}_{2}$ in similarly $\mathrm{Zr}$-rich compositions (McCurry et al. 2008). There is no petrographic evidence, however, for zircon or a Nb-rich phase being present, either in Suite 1 materials or the COM lava flows (Leeman et al. 1976). Furthermore, zircon saturation temperatures (Watson and Harrison 1983 calibration), yield temperatures of $860-960{ }^{\circ} \mathrm{C}$ for the HRT mafics, similar to temperatures of $770-960{ }^{\circ} \mathrm{C}$ for Suite 3 samples that show constant $\mathrm{Zr} / \mathrm{Nb}$ values. These are too low to be plausible pre-eruptive temperatures for these melts, particularly given that only one COM flow has yielded average plagioclase thermometry estimates of $<1,000^{\circ} \mathrm{C}$ (Putirka et al. 2009). We also note that Zr concentrations broadly increase in Suite 1 dense mafics across the compositional range (Fig. 4.4b), the opposite of what would be expected with zircon fractionation. Although $\mathrm{Zr} / \mathrm{Nb}$ correlates closely with $\mathrm{Sr}$ contents in Suite 1 samples, $\mathrm{Sr}$ is scattered throughout the suite and does not show clear trends with other proxies of evolution (e.g. Rb: Fig. 4.9).

The large degrees of scatter in data from all three suites and the poor fit of some modelled trends (e.g. Fig. S4.9), indicate that not all intra-suite trends can be explained exclusively by 
fractional crystallisation and some crustal assimilation/mixing is also required. Although there is a rhyolite-mixing trend observed within the Suite 1 scoria samples (Fig. 4.4), as discussed earlier (section 4.6.2.2), this process does not explain the overall increases in Ba and $\mathrm{Zr}$ with $\mathrm{SiO}_{2}$ observed in data from this suite. A diminished role for assimilation is further supported by the decoupled behavior of $\mathrm{P}_{2} \mathrm{O}_{5}$ and $\mathrm{Zr}$ within the Suite 1 mafics (cf. Figs. 4.3b, 4.4b), which behavior is typically attributed to fractionation rather than mixing (e.g. Lee and Bachmann 2014). Furthermore, the lack of a relationship between ${ }^{87} \mathrm{Sr} /{ }^{86} \mathrm{Sr}$ and $1 / \mathrm{Sr}$ (Fig. 4.7) in the samples from suites 1 and 3 , is inconsistent with a strong assimilation control on the compositional array.

Whilst the Suite 2 samples show a large range in ${ }^{87} \mathrm{Sr} /{ }^{86} \mathrm{Sr}$ and wide ranges in incompatible elements (e.g. Rb: Fig. 4.9), commonly attributed to crustal assimilation (e.g. Hildreth et al. 1991; Christiansen and McCurry 2008), there are complexities to this simple model. For example, samples with Sr differing by a factor of 2 have very similar Sr isotopic compositions and the highest-Sr lava (YR 292, Basalt of the Narrows; $546 \mathrm{ppm}$ ) has the lowest ${ }^{87} \mathrm{Sr} /{ }^{86} \mathrm{Sr}$ $(0.70373 \pm 0.000052 \mathrm{se})$. There is also no strong correlation between ${ }^{87} \mathrm{Sr} /{ }^{86} \mathrm{Sr}$ and $1 / \mathrm{Sr}$, which would be expected with significant crustal assimilation of a homogenous contaminant (Fig. 4.7).

Therefore, although assimilation is likely to occur in all suites, any simple explanation involving incorporation of a common assimilant is insufficient to explain the compositional arrays within each suite. The diversity within the Suite 1 samples, which is incompatible with simple fractional crystallisation and assimilation models discussed above, is surprising. It is possible that variations in the suite are related to subtle differences in the degree/composition of the initial enrichment, but why any such intra-suite source variation should remain distinct during ascent through the crust and eruption is puzzling.

\subsubsection{Comparisons and contrasts with the Craters of the Moon lava field}

Our data allow us to compare our Suite 1 HRT mafics and Suite 3 local COM-type samples with their counterparts from the Craters of the Moon lava field (Leeman 1976; Putirka et al. 2009). In the first instance there are some contrasts. Suite 1 HRT mafics show relatively elevated $\mathrm{TiO}_{2}$, Ba and $\mathrm{Zr}$, and no correlation between $\mathrm{Ba}$ and $\mathrm{Sr}$ whereas Suite 3 samples and published COM data show a negative correlation (Fig. 4.9b). Furthermore, Suite 1 samples show a strong decrease in $\mathrm{Zr} / \mathrm{Nb}$ with decreasing $\mathrm{Sr}$, whereas Suite 3 samples show uniformity of $\mathrm{Zr} / \mathrm{Nb}$ (Fig. 
4.9c). Different model crystallising assemblages (see Fig. 4.9 caption) yield broadly constant $\mathrm{Zr} / \mathrm{Nb}$ with changing $\mathrm{Sr}$, indicating that the $\mathrm{Zr} / \mathrm{Nb}$ versus Sr relationships in Suite 1 samples is unlikely to be controlled by fractional crystallisation. The above two features suggest that rocks of Suite 3 and the 'type' COM areas have signatures that are more fractionationcontrolled, whereas the Suite 1 HRT mafics have a further, enriched signature, which we relate to mantle source variations (previous section).

As previously mentioned, the COM samples reported by Putirka et al. (2009) are more radiogenic (i.e. higher ${ }^{87} \mathrm{Sr} /{ }^{86} \mathrm{Sr}$ ) than our samples from suites 1 and 3 which, in simple terms, reflects variations in the amount of crustal assimilation. This explanation is supported by the negative correlation between ${ }^{143} \mathrm{Nd} /{ }^{144} \mathrm{Nd}$ and ${ }^{87} \mathrm{Sr} /{ }^{86} \mathrm{Sr}$ in COM samples, forming a trend towards the average crustal isotopic composition (Fig. 4.6: Leeman 1976; Putirka et al. 2009). Furthermore, the initial increase in ${ }^{87} \mathrm{Sr} /{ }^{86} \mathrm{Sr}$ with $\mathrm{Rb} / \mathrm{Sr}$ ratios in COM-type flows from the Craters of the Moon (Fig. 4.7a), starting from values similar to the least radiogenic Suite 1 HRT mafics, indicates enhanced incorporation of a more radiogenic assimilant than that inferred in the HRT mafics. The trend observed is that expected in material of Archean age (Fig. 4.7a), consistent with the assimilation of ancient crust in the type Craters of the Moon area.

\subsection{Implications}

Our results have a number of implications for the onset of large-scale volcanism in the Yellowstone area. The early eruption of two contrasting mafic suites ( 1 and 2 ) reflects a complex mafic root zone beneath the early Yellowstone magmatic system. Our data represent the first documentation of COM-type material associated with rhyolites within the YPVF, as all mafic rocks reported so far have been of olivine tholeiitic affinity, whether erupted close to or outside the focus of silicic volcanism (Christiansen 2001; Christiansen and McCurry 2008; Pritchard et al. 2013). The presence of the Suite 1 HRT mafic materials indicate that genesis of such 'COM-like' magmas is more widespread than previously thought, and that such magmas can be present at the onset of, rather than always post-dating, any focus of silicic volcanism. It also shows that a COM-like mafic lineage can also be intimately associated with large silicic eruptions, in contrast to its currently viewed association with small-scale basaltic and fractionated intermediate to silicic eruptives in the Snake River Plain (Kuntz et al. 1986; McCurry et al. 2008; Putirka et al. 2009). 
The Suite 1 HRT compositions have implications for modelling of the silicic magmatism at Yellowstone. Although the HRT mafics are distinct in their elemental compositions, their isotopic compositions fall within the range of the olivine tholeiites. Any isotopic leverage on the HRT silicic system from the HRT mafic compositions is thus comparable to those from olivine tholeiites. However, the HRT mafic compositions are critical when conducting elemental modelling of the Yellowstone silicic system. The least evolved published HRT analysis has 70.8 wt\% $\mathrm{SiO}_{2}$ and 2670 ppm Ba (Hildreth et al. 1991). Our discovery of basaltic compositions ( $\sim 50 \mathrm{wt} \% \mathrm{SiO}_{2}$ ) with $\sim 2,500 \mathrm{ppm} \mathrm{Ba}$, as opposed to $\sim 500 \mathrm{ppm}$ in the tholeiites at a similar silica content, has significant impacts when discussing petrogenesis of the leastevolved rhyolites at Yellowstone and the nature of the components involved (e.g. Christiansen and McCurry 2008).

Our study has shown a general spatial variation in the distribution of mafic components in the HRT, with dense clasts erupted with ignimbrite member A concentrated to the SW and scoria associated with upper member B concentrated to the north. Although only mafic eruptives belonging to the olivine tholeiite suite have so far been documented in the YPVF, we consider it possible that evidence for COM-type mafic contributions may be found in younger silicic deposits. However, such contributions may have been diluted out by continuing ascent of more voluminous olivine tholeiite melts. The close proximity of young eruptions of olivine tholeiite and COM-type magmas in and just west of the Island Park segment of the HRT caldera (e.g. Christiansen 2001; Iwahashi 2010) demonstrates that these contrasting magma types do not reflect mutually exclusive magma-generating systems.

Although our Suite 2 Yellowstone olivine tholeiites represent a limited data set, it is clear that there is significant complexity within it, as well as within the broader SRP olivine tholeiite literature data. Large variations within major and trace elemental compositions (e.g. $\mathrm{SiO}_{2}$ and $\mathrm{Sr}$ ), and isotopic compositions (e.g. $\mathrm{Pb}$ and $\mathrm{Sr}$ isotopes) have previously been ascribed to varying degrees of contamination from crustal rocks or rhyolite melts (Hildreth et al. 1991; Christiansen and McCurry 2008). However, the lack of observed trends between elemental and isotopic compositions (e.g. Fig. 4.7) suggests there are further complexities than these. Furthermore, there is considerable variation within stratigraphically-grouped basalts. The multiple flow pre-HRT Junction Butte Basalt (Christiansen 2001) is considered evolved and contaminated (Hildreth et al. 1991). Although possibly the case for some flows (e.g. YR294: $\left.\mathrm{SiO}_{2}=54.3 \mathrm{wt} \%, \mathrm{Rb}=36 \mathrm{ppm},{ }^{87} \mathrm{Sr} /{ }^{86} \mathrm{Sr}=0.70756\right)$, others show a more primitive signature 
(e.g. YR297: $\mathrm{SiO}_{2}=49.1 \mathrm{wt} \%, \mathrm{Rb}=5 \mathrm{ppm},{ }^{87} \mathrm{Sr} /{ }^{86} \mathrm{Sr}=0.70561$ ). This diversity suggests that contamination processes are localised and variable, and likely involve a variety of assimilants. Consequently, we feel that the Yellowstone olivine tholeiites deserve renewed scrutiny using current compositional and geochronological capabilities to fully identify variations within the suite and the compositional role they play in the silicic magmatic system after the HRT eruption.

Although the complex compositional characteristics of the Suite 1 HRT mafics (and other COM compositions) mean there are issues with any proposed petrogenetic process (Table 4.4), we would argue that our proposed model of HFSE-enriched melt metasomatism in the mantle source for generation of the least-evolved melts is the most compatible with our data. Although the generation of high P-T, HFSE-rich fluids is likely to be a common process in subduction zones (Louvel et al. 2013, 2014), causing enrichment of the overlying mantle wedge, primary enrichment is likely to be in a zone immediately overlying the subducted slab. The lower solubility HFSE elements would be likely to be precipitated first, leaving dominantly more-soluble elements (e.g. LILE) to ascend farther into the sub-continental lithospheric mantle into higher temperature regions and the focus of melting, while the HFSE-enriched zones founder with the subducted slab (Louvel et al. 2013, 2014). The unusual slab geometry beneath the YPVF, of a stationary or slowly descending slab in the asthenosphere, means that in this case the HFSE-enriched mantle, generated during Eocene and onwards foundering of the slab, has remained in the zone of potential melt generation. Therefore, with the arrival of a focused, albeit weak, thermal anomaly (the Yellowstone plume, sensu lato), the HFSEenriched mantle material was located in the melting window when the lithospheric mantle was raised above its solidus at the onset of YPVF volcanism and birth of the HRT silicic system. The higher alkali contents of these metasomatised regions would also promote melting through reducing the solidus temperature (Hirschmann 2000).

It seems clear that the formation of the HRT mafics and COM-type compositions is a localised feature requiring the alignment of a variety of processes. There are additional complexities related to the local setting and conditions, particularly within the $\mathrm{Sr}$ isotopic signatures, between the Suite 1 HRT mafics, the Suite 3 COM-type flows analysed here, and the more radiogenic nature of the flows from the Craters of the Moon type area (Leeman 1974; Leeman et al. 1976; Putirka et al. 2009). However, with a full major, trace and isotopic dataset we are able to offer a more consistent mechanism for generation of the parental 
magmas for the HRT mafic suite that may also be applicable to the broader COM suite. We suggest that re-evaluation of the overall characteristics of the Craters of the Moon series of rocks may also be required. 


\section{Chapter 5}

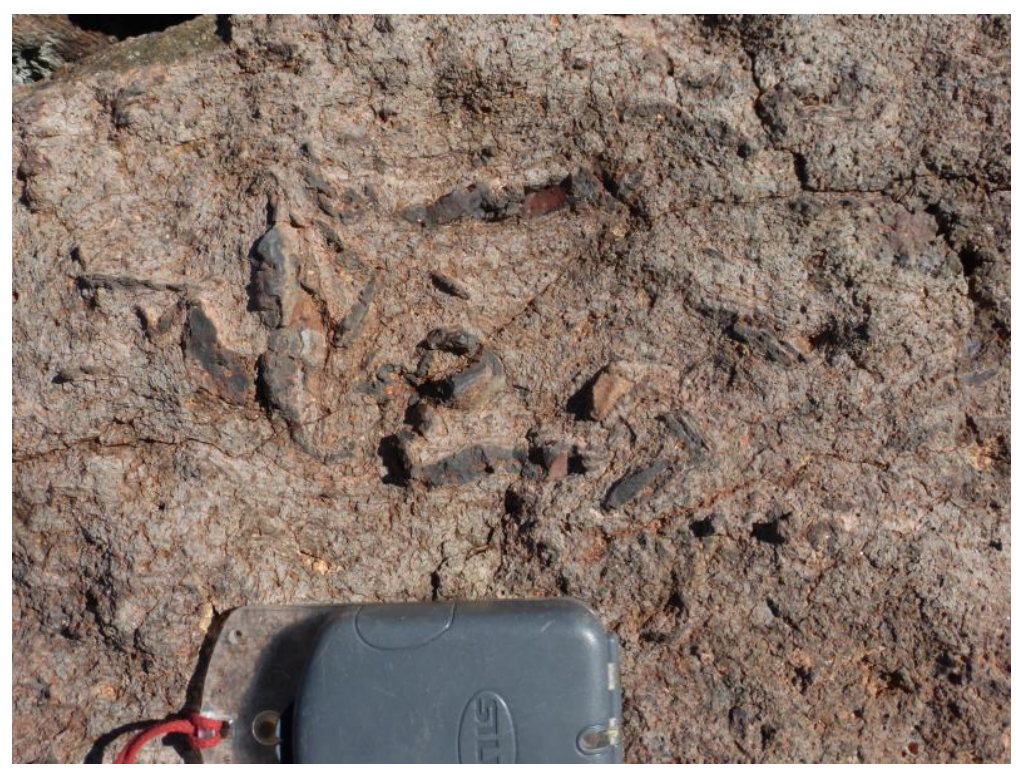

Photograph of a J5-type clast that has been deformed within the fabric of rheomorphic member $\mathrm{C}$ ignimbrite. Compass clinometer is approximately $8 \mathrm{~cm}$.

This chapter has been written to be submitted to Contributions to Mineralogy and Petrology as a journal article: Swallow EJ, Wilson CJN, Charlier BLA, Gamble JA (2018) The Huckleberry Ridge Tuff, Yellowstone: evacuation of multiple magmatic systems in a complex episodic eruption. Contrib Mineral Petrol (in prep).

Author contributions as followed:

EJS: Contributed towards sample collection, collected majority of data and wrote the text. CNJW: Completed background fieldwork and collected majority of samples, edited text.

BLAC: Analysed elemental and $\mathrm{Sr}$ and $\mathrm{Pb}$ isotopic data for selected samples. JAG: Provided thorough discussions and edited text. 


\section{The Huckleberry Ridge Tuff, Yellowstone: evacuation of multiple magmatic systems in a complex episodic eruption}

\section{Abstract}

The deposits of large caldera-forming silicic eruptions yield valuable insights into crustal magmatic systems. The $2.08 \mathrm{Ma}, \sim 2,500 \mathrm{~km}^{3}$ Huckleberry Ridge Tuff (HRT), Yellowstone, represents an archetypical Quaternary supereruption, which generated fall deposits and three voluminous ignimbrite members $(A, B, C)$. Field data imply that the initial fall deposits took weeks to be erupted, that there was a break of the order of months between members $A$ and $C$ and decades between members $B$ and $C$. Here we present a comprehensive major and trace element, and radiogenic isotopic compositional dataset, of single clasts, and their groundmass glass and crystals, from the three HRT ignimbrite members. We use these data plus that from studies of the mafic inputs into the HRT (Swallow et al. 2018a: Chapter 4) and the compositional record in the initial fall deposits and earliest ignimbrite (Myers et al. 2016; Swallow et al. 2018b: Chapter 3) to reconstruct the crustal magmatic complex that contributed to the HRT. Our dataset reveals an extraordinary degree of complexity and range of compositional variations within and between the ignimbrite members. Clast compositions (geochemical and isotopic) define four independent, crustal silicic magmatic systems that were tapped simultaneously and sequentially during the eruption. Two of these (magmatic systems 1 and 2) were vented at the eruption onset to feed the initial fall deposits as well as throughout member A, accompanied by trace amounts of mafic magma. Volumetrically dominant system 1 is represented by a moderate to high-Ba rhyolite suite (450-1680 ppm Ba) but also includes a distinct low-silica rhyolite compositional group (69-71 wt\% $\mathrm{SiO}_{2} ;>2,500$ ppm Ba), whereas volumetrically subordinate system 2 is characterised by a low-Ba, highsilica rhyolite suite ( $\leq 250 \mathrm{ppm} \mathrm{Ba).} \mathrm{Groundmass} \mathrm{glass} \mathrm{compositions} \mathrm{from} \mathrm{these} \mathrm{two} \mathrm{systems}$ additionally exhibit clustering, indicative of the presence of multiple, laterally-adjacent meltdominant bodies rather than unitary magma chambers. Samples from member B are restricted to magmatic system 1 compositions, but show evidence for mixing and reorganisation within that particular magmatic system accompanying a renewed influx of mafic magma. Member $\mathrm{C}$ compositions reflect profound and rapid changes in the overall 
magmatic complex. These include the rejuvenation of magmatic system 2 (last seen in member A) and the appearance of two new, distinct magmatic lineages, a high-silica rhyolite trend (75-78 wt\% $\mathrm{SiO}_{2}$ : magmatic system 3) and a dacitic-rhyolite suite (65-71 wt\% $\mathrm{SiO}_{2}$ : magmatic system 4). Magmatic system 3 shows clustered glass compositions, suggesting that the presence of multiple melt-dominant bodies was a common feature of the HRT magmatic complex.

Elemental and isotopic compositions of clasts from each suite show that a diversity of petrogenetic mechanisms were operating. Magmatic systems 1 and 2 show compositions that are consistent with a fractional crystallisation-dominated evolutionary pathway, punctuated by partial melting of cumulates that can be compositionally linked to earlier crustal inputs of mafic magmas. The same mafic magma compositions were subsequently tapped in the HRT eruption itself. Assimilation of country rocks in these suites was limited to incorporation of minor amounts of a more radiogenic evolved contaminant. In contrast, magmatic systems 3 and 4 in ignimbrite $\mathrm{C}$ show remarkably similar, highly radiogenic isotopic compositions, despite their strong elemental compositional contrasts. The isotopic compositions in ignimbrite $\mathrm{C}$ are consistent with significant assimilation of Archean country rock by partial melts of cumulates associated with contrasting mafic lineages. System 3 is related to HRT mafic compositions vented earlier in eruption of members $A$ and $B$, and system 4 is related to olivine tholeiite compositions erupted in the Yellowstone area before (Junction Butte Basalt) and after (numerous examples) the HRT itself.

The extraordinary diversity shown by juvenile ejecta in the HRT highlights the spatial and temporal complexities that can be associated with a large volume silicic magmatic complex. The HRT could, therefore, be considered in itself to represent an ignimbrite flare-up with the engulfment of multiple magmatic systems within a single-eruption (but multi-stage) caldera collapse. This collapse encompasses a total area comparable to that enclosing multiple calderas in comparably voluminous silicic magmatic provinces, such as those formed in the Taupo Volcanic Zone, New Zealand, during its flareup of activity from 350-240 ka. 


\subsection{Introduction}

Quaternary silicic (dacite to rhyolite in this context) magmatic systems have generated large, caldera-forming, explosive eruptions that would lead to global impacts and consequences if repeated today (Mason et al. 2004; Self 2006). The largest of these eruptions, supereruptions, involve the eruption of $>10^{15} \mathrm{~kg}\left(\sim 450 \mathrm{~km}^{3}\right)$ of magma (Sparks et al. 2005; Miller and Wark 2008). Due to a lack of supereruptions in the historical record (Mason et al. 2004), however, understanding of their crustal magmatic systems has been incrementally developed in primarily two ways. The first is through studies of eruption deposits to reconstruct their geochemical nature and infer the characteristics of the parental magmatic system, and the second is through numerical modelling of the generation, accumulation and eruptive triggering of these vast volumes of magma.

Studies of past eruptions include the analysis of the broad spectrum of the physical and/or chemical nature of erupted material, including one or more of whole rock samples (i.e. bulk ignimbrite: e.g. Hildreth et al. 1984, 1991), single clasts (i.e. individual pumice/fiamme: e.g. Bacon and Druitt 1988, Streck and Grunder 1997; Wilson and Hildreth 2007; Folkes et al. 2011), crystal cargoes (e.g. Bindeman et al. 2008; Ellis and Wolff 2012; Rivera et al. 2014; Wolff and Ramos 2014) and glass compositions (e.g. Nash et al. 2006; Roberge et al. 2013; Westgate et al. 2013). These and other works have highlighted significant diversity in silicic volcanism. A majority of silicic eruption deposits are split into two categories. First there are crystal-rich dacites, which are typically homogeneous on the bulk-rock scale (e.g. Fish Canyon Tuff, Colorado: Bachmann et al. 2002), and are widely known as 'monotonous intermediates' (Hildreth 1981; Christiansen 2005; Bachmann and Bergantz 2008; Bachmann and Huber 2016). Their magma bodies are thought to form through rejuvenation/mobilisation of a crystal-rich body (e.g. Huber et al. 2011, 2012; Parmigiani et al. 2014). Second, there is crystal-poor rhyolites that are widely, but not exclusively (e.g. Streck 2014), thought to represent rhyolitic melts extracted from a crystal-rich source region (mush: Brophy 1991; Bachmann and Bergantz 2004; Hildreth 2004) with subsequent minor crystallisation.

Crystal-poor rhyolites generally show some degree of intra-eruption compositional variation (Hildreth 1981; Christiansen 2005; Bachmann and Bergantz 2008; Bachmann and Huber 2016). Work reviewed in Hildreth (1981) related whole rock, single clast, mineral and/or glass compositional heterogeneities and zonation in eruption deposits to the inverse 
vertical zonation of the magmatic system, and overwhelmingly invoking a single magma body as the source. Subsequent work has used this framework to explain compositional variations in a similar way, whether those variations are gradational (e.g. Bishop Tuff, California: Hildreth and Wilson 2007; Chamberlain et al. 2015; Carpenter Ridge Tuff, Colorado: Bachmann et al. 2014) or stepwise (e.g. Crater Lake, Oregon: Bacon and Druitt 1988; Rattlesnake Tuff, Oregon: Streck and Grunder 1997; Grizzly Peak Tuff, Colorado: Fridrich and Mahood 1987). This compositional variability has, in turn, been related to variations in $\mathrm{T}, \mathrm{fO}_{2}$ and $\mathrm{H}_{2} \mathrm{O}$ in the magmatic system that are manifested in one or more of fractional crystallisation-controlled evolution of the magma (e.g. Streck and Grunder 1997; Hildreth and Wilson 2007; Chamberlain et al. 2015), variations in the crystal content of the magma (e.g. Bacon and Druitt 1988), or through partial melting of crystalline residuum (Deering et al. 2011; Wolff et al. 2015; Wolff 2017). Despite this, un-zoned crystal-poor deposits are also observed (e.g. Oruanui, Taupo Volcanic Zone: Wilson et al. 2006; Allan et al. 2017).

Whether chemically variable or not, eruption deposits are typically inferred to represent the evacuation of a single melt-dominant body. However, many examples show compositional diversity more consistent with the simultaneous or sequential evacuation of multiple melt-dominant bodies (e.g. Kidnappers/Rocky Hill, Mamaku-Ohakuri and Oruanui eruptions, Taupo Volcanic Zone: Allan et al. 2012; Cooper et al. 2012, 2016; Bégué et al. 2014; Snake River Plain: Ellis and Wolff 2012). These bodies, in turn, may be interpreted to represent melt extractions from a unitary, heterogenous mush zone (Bégué et al. 2014) or from multiple magmatic systems (Allan et al. 2012; Cooper et al. 2012, 2016). In contrast to these complexities, numerical models focus on the formation and evacuation of a single magma body (e.g. Jellinek and DePaolo 2003; Gregg et al. 2012, 2015; Caricchi et al. 2014; de Silva et al. 2014) and do not, therefore, take into account effects of the associated stress field (and hence eruption behaviour) of multiple melt-dominant bodies (Gudmundsson 2012; Cashman and Giordano 2014).

The formation of parental magma bodies to supereruptions is typically inferred to take of the order of $10^{5}-10^{6}$ years (e.g. Jellinek and DePaolo 2003). This arises from a presumption of a relationship between eruption size and repose period, i.e. the time between eruptions (Smith 1979; Reid 2008) although other studies demonstrate no such relationship (e.g. Wilson 1993; Wilson et al. 2009). Although some examples show evidence for prolonged accumulation of the melt-dominant body (e.g. Crater Lake: Bacon 1983; Bishop Tuff: 
Chamberlain et al. 2014a), others have demonstrated very rapid accumulation (e.g. Oruanui and Taupo: Wilson and Charlier 2009; Allan et al. 2013, 2017; Pamukcu et al. 2015; Barker et al. 2016). In addition, there is also evidence for the rapid (decadal) recovery and regeneration of magmatic systems following large caldera-forming eruptions (e.g. Barker et al. 2015; Cooper et al. 2016, 2017; Hildreth et al. 2017). These studies highlight a dichotomy of timescales associated with silicic systems. Although melt-dominant bodies can accumulate rapidly, the generation of their chemical signatures, whether through fractional crystallisation, assimilation and/or magma mixing (Christiansen and McCurry 2008; Bindeman and Simakin 2014), is a longer term process, as indicated by the long-term broad chemical similarities of erupted materials (e.g. Mazama: Bacon 1983; Taupo: Barker et al. 2015; Bruneau-Jarbidge: Cathey and Nash 2004; Yellowstone: Girard and Stix 2010, Loewen and Bindeman 2015, Stelten et al. 2015, Troch et al. 2017). Although there may be broad chemical uniformity over long periods at such systems, this masks the chemical diversity seen on smaller scales (e.g. isotopic compositions and/or crystal compositions). These diversities indicate that the meltdominant bodies are the result of the amalgamation of various components (i.e. melt and/or crystals) from a diverse range of sources including silicic fractionates from mafic precursors, partial melts of solidified intrusions and enriched partial melts from silicic country rocks (e.g. Bindeman et al. 2008; Charlier et al. 2008; Christiansen and McCurry 2008; Wolff and Ramos 2014; Stelten et al. 2017). A constant factor amongst these diversities, however, is the role of mafic magma, which provides thermal and chemical input into silicic systems, modulating the eruptive behaviour of the silicic system (e.g. Hildreth 1981; Loewen and Bindeman 2015; Barker et al. 2015, 2016; Till et al. 2015; Stelten et al. 2017).

To provide a case-study overview of the processes and products of large-scale silicic magmatism we here provide a full geochemical investigation (major and trace element, and isotopic compositions) of single pumices and fiamme, and their associated groundmass glasses and crystal cargoes, from the three ignimbrite members of the Huckleberry Ridge Tuff. These results are combined with two other studies (chapters 3 and 4, Swallow et al. 2018a, $2018 b)$ to provide a comprehensive geochemical outline of the HRT eruption products. This overall investigation reveals extraordinary, previously unrecognised, diversity and complexity within the magmatic complex that fed the first and largest of the three caldera-forming eruptions from Yellowstone. 


\subsection{Geological background}

\subsubsection{Yellowstone Plateau Volcanic Field}

Quaternary volcanism in the Yellowstone area is generally grouped under the term Yellowstone Plateau volcanic field (YPVF). The YPVF lies at the eastern end of the Snake River Plain, a $700 \mathrm{~km}$ long, ENE-trending volcanic depression comprising a series of eastwardyounging silicic caldera centres and intercalated basaltic lava flows (Armstrong et al. 1975; Pierce and Morgan 1992, 2009). The $\sim 16$ Ma to present, time-progressive volcanism, elevated heat flow, gas geochemistry and tectonic setting are consistent with the movement of the North American plate over a stationary mantle plume, with complexities arising from asthenospheric flow around the foundered Farallon slab (Pierce and Morgan 1992, 2009; Lowenstern and Hurwitz 2008; James et al. 2011; Zhou et al. 2018). Volcanism along the Snake River Plain is dominantly bimodal, with basaltic lava flows (dominantly olivine tholeiites) and high-silica rhyolitic lava flows and tuffs forming nearly all the eruption products (Christiansen 2001; Christiansen and McCurry 2008).

Volcanism in the YPVF began at $\sim 2.1 \mathrm{Ma}$. Its history is grouped into three volcanic cycles, with effusive basaltic and silicic eruptions bracketing three climactic, caldera-forming silicic eruptions (Christiansen 2001). Geophysical imaging of the Yellowstone area indicates the presence of a large (90 km long), shallow (5-17 km) crustal (inferred silicic) magma body containing 5-15 \% melt (Smith et al. 2009; Farrell et al. 2014; Huang et al. 2015). This shallow body overlies a much larger $\left(\sim 46,000 \mathrm{~km}^{3}\right)$ magma body, containing $\sim 2 \%$ melt, which is inferred to be basaltic in composition and to represent the thermal driver of the silicic magma body (Huang et al. 2015). These geophysical data, coupled with historic cyclical deformation, resurgent doming, and significant gas and thermal fluxes, indicates the continued activity of the YPVF and the importance of understanding the magmatic system (Christiansen et al. 2007; Lowenstern and Hurwitz 2008; Smith et al. 2009).

Geochemical investigations of YPVF silicic eruptives have primarily focused on (a) whole rock samples from explosive eruptions, either for bulk chemical characteristics (Doe et al. 1982; Hildreth et al. 1984, 1991; Christiansen 2001) or focused single-crystal studies (Bindeman and Valley 2001; Bindeman et al. 2008; Ellis et al. 2012; Rivera et al. 2014, 2016; Singer et al. 2014; Wotzlaw et al. 2015), or (b) samples of rhyolitic lava flows, principally from younger effusive episodes (Girard and Stix 2009, 2010; Watts et al. 2012; Loewen and 
Bindeman 2015; Stelten et al. 2015, 2017, 2018; Till et al. 2015; Befus and Gardener 2016; Troch et al. 2017). Broad-scale investigations indicate that the high-silica rhyolites of the YPVF are not simply highly fractionated melts from a mafic precursor, due to the absence of intermediate compositions and the offset between the $\mathrm{Sr}$ and $\mathrm{Pb}$ isotopic fields of YPVF rhyolites and tholeiitic basalts (Doe et al. 1982; Hildreth et al. 1991; Christiansen and McCurry 2008). It is therefore inferred that the rhyolites derive from partial melting of a hybridised middle crust, comprising Archaean basement and Cenozoic basaltic intrusions (Doe et al. 1982; Hildreth et al. 1991), followed by fractionation of feldspars and ferromagnesian minerals (Christiansen and McCurry 2008). Heterogeneity observed in the crystal cargoes from single eruptive units attest to a diverse range of initial melt compositions that accumulate and hybridise themselves to smooth out isotopic variations (Bindeman et al. 2008; Wotzlaw et al. 2015; Stelten et al. 2017). Larger-scale variations in isotopic systematics are attributed to upper crustal processes, including the melting of the foundering magma chamber roof or assimilation of hydrothermally altered country rock (Doe et al. 1982; Hildreth et al. 1984, 1991; Bindeman and Valley 2001; Bindeman et al. 2008).

A consistency in major and trace elemental compositions of rhyolitic lavas spanning whole eruptive periods indicates the magmatic conditions present during effusive episodes remain uniform. This uniformity is generally attributed to the presence of a crystal mush zone, with YPVF volcanism characterised by quiescence punctuated by rapid generation of meltdominant bodies (Girard and Stix, 2009; Loewen et al. 2015; Stelten et al. 2015, 2018). The generation of these melt-dominant bodies is debated, however, with opposing views of generation through partial melting of a rhyolitic crystalline protolith, or expulsion of melt from a crystal-rich mush zone being aired for the same series of lavas (cf. Loewen and Bindeman 2015; Stelten et al. 2015). What is generally accepted, however, is the prominent role mafic magmas play in Yellowstone rhyolitic volcanism, whether through providing mass and thermal inputs into a long-lived crystal mush zone (Stelten et al. 2015), generating meltdominant bodies through partial melting of upper crustal rocks (Loewen and Bindeman 2015; Troch et al. 2018), providing fractionated melts to the rhyolitic system (Stelten et al. 2017), or triggering the eruption (Till et al. 2015). 


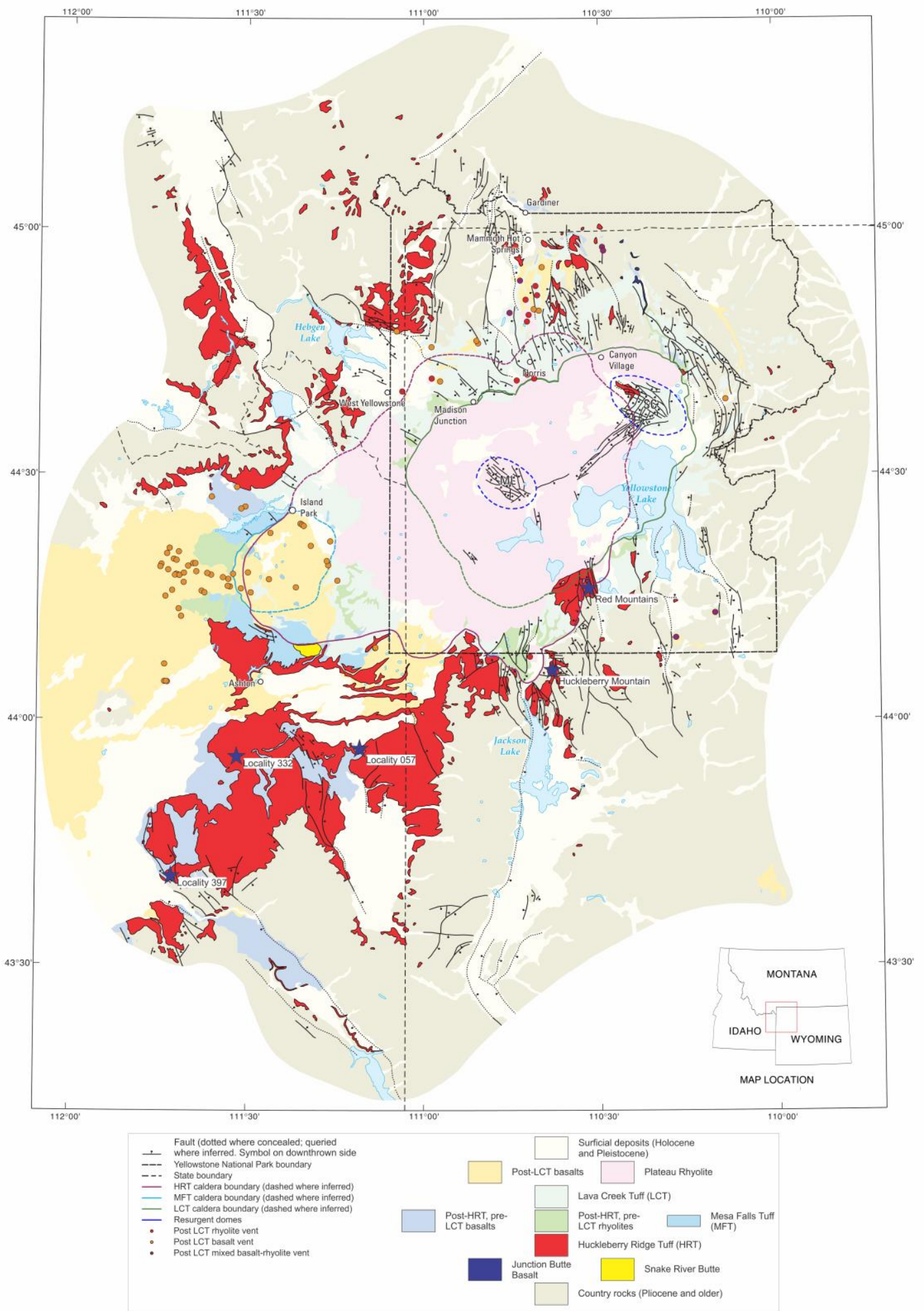

Figure 5.1: Simplified geological map of the YPVF, (adapted from Christiansen 2001; Christiansen et al. 2007). Outcrop of the HRT is shown (red) and key sampling localities in this study are marked. Also shown is the outcrop of the pre-HRT Snake River Butte (rhyolite: yellow) and Junction Butte Basalt (dark blue). Locations of the two resurgent domes (ML-Mallard Lake, SC-Sour Creek), postLava Creek Tuff lava flow vents, regional faults and mapped caldera boundaries are also located. 


\subsubsection{Huckleberry Ridge Tuff}

The $2.08 \mathrm{Ma}, \sim 2,500 \mathrm{~km}^{3}$ Huckleberry Ridge Tuff (HRT: Fig. 5.1) is the deposit of the first and largest of the three caldera-forming eruptions in the YPVF (Christiansen 2001). It comprises three ignimbrite members (A, B and C) and two fall deposits, initial pre-A fall deposits and others between members B and C. Although Ellis et al. (2012) proposed an $18 \pm 12 \mathrm{kyr}$ (2sd) gap between members B and C this inference is at odds with earlier studies (Reynolds 1977; Christiansen, 2001) and not matched by subsequent age determinations (Rivera et al. 2014; Singer et al. 2014; Wotzlaw et al. 2015). The published consensus therefore is that the HRT was erupted geologically rapidly from discrete parts of a single, zoned magma body and was emplaced in thermal terms as a composite sheet (Christiansen 1979).

However, extensive fieldwork by CJNW, which will be fully presented elsewhere (Wilson et al. in prep), has indicated that the eruption was prolonged and episodic, with time breaks observed within and between eruptive deposits (Figs. 5.2, S5.1). As has been noted elsewhere (Myers et al. 2016; Swallow et al. 2018b, Chapter 3), the initial fall deposits exhibit evidence for reworking and fine ash tops to individual horizons, indicative of episodic activity and hiatuses in the eruption. In addition, welding contrasts between ignimbrite members $\mathrm{A}$ and B, particularly where deposits are thinnest, and the rheomorphic folding of member A seen in contrast to a planar member B (Fig. S5.1), suggest a time gap of weeks to months occurred between these events. Widespread welding breaks between members $B$ and $C$, balanced against the fumarolic alteration of pre-C fall deposits (Fig. S5.1) and member C ignimbrite by gases from the underlying $A+B$ package, constrain the time gap between $B$ and $C$ to be years to decades in length. Therefore, the eruption was neither instantaneous (Christiansen 2001), nor protracted over thousands of years (Ellis et al. 2012). This revised chronostratigraphic framework provides context to this detailed geochemical overview.

Although reported whole rock major and trace elemental compositional variations are minor, significant isotopic heterogeneity has been revealed by several studies (Doe et al. 1982; Hildreth et al. 1984, 1991; Christiansen 2001). Analysis of whole rock samples has indicated that although members $A$ and $B$ are similar in their isotopic characteristics, member $C$ is distinctly more radiogenic with respect to $\mathrm{Sr}, \mathrm{Pb}$ and $\mathrm{Nd}$ isotopes, interpreted to reflect the rapid crustal assimilation of a foundering chamber roof following eruption of members $A$ and B (Doe et al. 1982; Hildreth et al. 1984, 1991). However, any crustal contaminant is precluded 


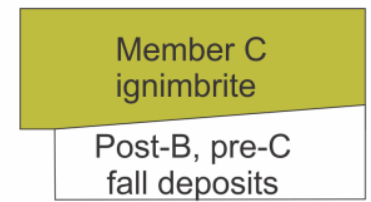

fall deposits
Diachronous, complex, multiple facies

Slightly prolonged:

some erosion, fine ash
Years to decades: distinct welding break, pre-C fall deposits

fumarolically altered, minor erosion

Weeks-Months: distinct welding break only where deposits thin, member A rheomorphically folded, member B planar, minor erosion

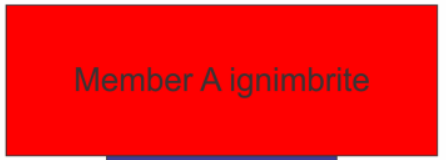

Initial fall

deposits
Short-lived, essentially continuous

Short-lived, essentially continuous

Episodic and prolonged (one wet/dry season?) some reworking, fine ash tops to horizons

Figure 5.2: Schematic diagram of the stratigraphy of the HRT and estimates for intra-eruption timescales based on extensive fieldwork by CJN Wilson (Wilson 2009 and manuscript in preparation). Initial fall deposits were episodic, with short time breaks indicated by reworking and fine ash tops to individual horizons (see Myers et al. 2016; Swallow et al. 2018b, Chapter 3). A cessation in activity of months between members $B$ and $C$ is inferred from welding breaks, and rheomorphic deformation of member A but not B (see Fig. S5.1). A longer, years to decades time break between members $B$ and $C$ is estimated from cooling breaks indicated by welding intensities, but the presence of vapour-phase alteration of pre- $C$ fall deposits or the base of member $C$ ignimbrite where it rests directly on the top of ignimbrite member B (Fig. S5.1).

from being hydrothermally altered from the constancy of whole-rock O isotopic compositions in the HRT, in sharp contrast to subsequent variations (Hildreth et al. 1984, 1991).

Isotopic heterogeneity is also observed within crystal populations from single HRT samples, with zircons showing clustering in $\mathrm{Hf}$, but minor variation in $\mathrm{O}$ isotopes, interpreted as reflecting a heterogeneous magmatic system comprising distinct magma reservoirs with crustal and mantle signatures (Bindeman and Valley 2001; Bindeman et al. 2008; Wotzlaw et al. 2015). However, these heterogeneities are difficult to relate to specific magmatic domains due to the lack of context arising from use of whole rock samples. Consequently, current inferences on the architecture of the HRT magmatic system, which is thought to be heterogeneous and to have undergone rapid formation and evolution, are vague and lack detailed investigation of juvenile products from the eruption. 
Recent studies on the initial fall deposits and basal member $A$ ignimbrite have indicated that the upper levels of the HRT magmatic system were remarkably complex, comprising multiple, laterally-adjacent, discrete melt-dominant bodies that represented two distinct magmatic lineages (Myers et al. 2016, Electronic Appendix 1). The initial fall stages of the eruption saw the simultaneous and sequential tapping of three melt-dominant bodies before escalating into the evacuation of nine bodies (including the three previously tapped) at the onset of ignimbrite deposition and associated caldera collapse (Swallow et al. 2018b, Chapter 3). However, the nature of these discrete bodies and independent magmatic lineages is unclear. They could represent:

a) complexity only within the upper levels of a magmatic system that merges downwards into homogeneity during later stages of the eruption,

b) two magmatic lineages that remain discrete throughout eruption (e.g. Kidnappers: Cooper et al. 2012, 2016) or

c) an increase in complexity from the fall deposition through the eruption (e.g. Mamaku/Ohakuri: Bégué et al. 2014).

In this chapter data is presented of elemental and isotopic compositions of single clasts from stratigraphically controlled parts of members A, B and C in order to test these three possibilities and provide context for the overall crustal magmatic complex that gave rise to the HRT deposits. For the most part, the HRT is densely welded and devitrified, as well as heavily jointed on the metre-scale and hackly fractured in hand specimen. Juvenile materials, that is, inferred to have been molten at the time of eruption, were predominantly collected from a limited number of sites where unusual circumstances led to glassy clasts being preserved (Fig. 5.1). The data thus allow delimitation of the full compositional range and degree of compositional clustering in the juvenile materials, but (unlike in the fall deposits: Myers et al. 2016; Swallow et al. 2018b, Chapter 3) we are not able to interrogate any systematic compositional zonation that might have been present within the ignimbrite sheets (cf. Cooper et al. 2016). 


\subsection{Sampled components of the HRT}

\subsubsection{Juvenile components}

\subsubsection{Members A and B}

The juvenile components in members $A$ and $B$ are dominantly felsic clasts that range from poorly to extremely vesicular (but are mostly pumice: Table 5.1), together with minor amounts of mafic material that is dense and non-vesicular in member $A$, but vesicular scoria in member B (see Swallow et al. 2018a, Chapter 4). Focus was mostly placed on finding glassy clasts in non-welded ignimbrite, but glassy groundmass and whole fiamme (where they could be extracted) from vitrophyric zones and fiamme from the densely welded, devitrified parts of the ignimbrite were also collected. The most common pumice (type J1: Table 5.1; Fig. S5.2a) is white where freshest, tan brown where thermally oxidised, and exhibits a continuous spectrum in vesicle textures from a rounded, cellular-like foam through to elongated vesicles yielding a fibrous texture, with common schlieren and 'adobe-type' textures, the latter closely similar to those in some Bishop Tuff pumices (Hildreth and Wilson 2007). Variations from type J1 pumice (and their devitrified fiamme equivalents) include dense, poorly vesicular juvenile material that, where glassy, is dark grey to black through the exsolution of iron oxide microlites (type J2: Fig. S5.2b). Another variant is represented by black to dark brown, poorly vesicular clasts that are distinctive through containing 10-20\% of euhedral feldspar crystals up to 8-10 mm in length (type J3: Fig. S5.2c). In upper member B (and very rarely in A), mingled clasts are observed (type J4 clasts: Fig. S5.2a), with centimetre-scale lumps of lenses of scoriaceous material, and occasionally J3-type material, distributed within type J1 pumice.

The felsic clasts are moderate to rich in crystals (11-22 wt\%, with rare examples up to 35 wt\%), as determined through crystal-glass separation using heavy liquids (Electronic Appendix 5.3). The crystal phases are generally coarse grained, with single crystals up to 7-8 $\mathrm{mm}$ and crystal clots sometimes up to $2 \mathrm{~cm}$ across. The crystal assemblage is dominated by quartz, sanidine and plagioclase feldspar either as single crystals or commonly forming the crystal clots. Ferromagnesian minerals are a minor component, comprising pyroxene, olivine and FeTi oxides. 


\begin{tabular}{|c|c|c|c|}
\hline Clast type & $\begin{array}{l}\text { Members where } \\
\text { clasts present }\end{array}$ & Physical characteristics & $\begin{array}{l}\text { Geoch- } \\
\text { emical } \\
\text { Suite(s) }\end{array}$ \\
\hline $\mathrm{J} 1$ & $\begin{array}{l}\text { Members } A \text { and } B \\
\text { (although also } \\
\text { found in member } \\
\text { C as surficial pick- } \\
\text { ups) }\end{array}$ & $\begin{array}{l}\text { - Pumices white, brown where oxidised (Fig. S5.2a) } \\
\text { - Vesicular (rounded to elongate vesicles) } \\
\text { - Fibrous, common schlieren and 'adobe-type' textures } \\
\text { - Coarse crystals (up to } 8 \mathrm{~mm} \text { ), crystal-rich (11-20 wt\%), } \\
\text { common glomerocrysts } \\
\text { - Flattened, devitrified fiamme equivalents also sampled }\end{array}$ & $\begin{array}{l}\text { A1, A3, } \\
B 1\end{array}$ \\
\hline $\mathrm{J} 2$ & Members $A$ and $B$ & $\begin{array}{l}\text { - Dark grey-black through microlite growth (Fig. S5.2b) } \\
\text { - Dense, poorly vesicular } \\
\text { - Coarse crystals (up to } 8 \mathrm{~mm} \text { ), crystal rich (27-35 wt\%) }\end{array}$ & A1 \\
\hline J3 & Member A & $\begin{array}{l}\text { - Black to dark brown (Fig. S5.2c) } \\
\text { - Poorly vesicular } \\
\text { - } 10-20 \% \text { euhedral feldspars up to } 10 \mathrm{~mm}\end{array}$ & $A 2, B 1$ \\
\hline J4 & $\begin{array}{l}\text { Members B } \\
\text { (upper) and C } \\
\text { (pickups) }\end{array}$ & $\begin{array}{l}\text { - Mingled, scoria-bearing rhyolitic clasts (Fig. S5.2a) } \\
\text { - Cm-scale lenses of scoria within pumices similar to J1-type }\end{array}$ & B1 \\
\hline J5 & Member C & $\begin{array}{l}\text { - Black, devitrified material (Fig. S5.2d) } \\
\text { - Non-vesicular } \\
\text { - Angular-rounded clasts } \\
\text { - Equant (welded) to elongate (rheomorphic ignimbrite) } \\
\text { - Small crystals (<2 mm) and crystal poor ( }<15 \%) \text {; feldspar } \\
\text { and rare quartz }\end{array}$ & $\mathrm{C} 1, \mathrm{C} 2$ \\
\hline J6 & $\begin{array}{l}\text { Member C (Red } \\
\text { Mountains) }\end{array}$ & $\begin{array}{l}\text { - Visually identical to J5-type } \\
\text { - Minor intrusions cross-cutting member C ignimbrite }\end{array}$ & $\mathrm{C} 1$ \\
\hline J7 & $\begin{array}{l}\text { Member C (Teton } \\
\text { River: loc. 332) }\end{array}$ & $\begin{array}{l}\text { - Rounded pumices with equant vesicles (Fig. S5.2e) } \\
\text { - Small crystals ( }(<2 \mathrm{~mm}) \text {, crystal poor-moderate (11-15 } \\
\text { wt\%) }\end{array}$ & C3 \\
\hline J8 & $\begin{array}{l}\text { Member C (Bitch } \\
\text { Creek: loc. 057) }\end{array}$ & $\begin{array}{l}\text { - Light brown-grey or pale buff pumices (Fig. S5.2f) } \\
\text { - Elongate to platy in shape } \\
\text { - Extremely vesicular, fibrous } \\
\text { - Small crystals }(<2 \mathrm{~mm} \text { ) and crystal poor (7-11 wt\%) } \\
\end{array}$ & $\mathrm{C} 2$ \\
\hline J9 & $\begin{array}{l}\text { Member C (Red } \\
\text { Mountains and } \\
\text { Huckleberry } \\
\text { Mountain) }\end{array}$ & $\begin{array}{l}\text { - Pale-yellow to grey devitrified fiamme } \\
\text { - Vuggy appearance } \\
\text { - Occasionally micro- to macro-spherulitic } \\
\text { - Similar crystal size and abundance to J8-type pumices }\end{array}$ & $\mathrm{C} 2$ \\
\hline $\begin{array}{l}\text { F1: } \\
\text { granitoids } \\
\text { (sensu lato) }\end{array}$ & $\begin{array}{l}\text { Members A } \\
\text { (sparse) and C (up } \\
\text { to the \% level) }\end{array}$ & $\begin{array}{l}\text { - Commonly non-deformed, but occasionally deformed } \\
\text { - Micro-crystalline (<1 mm cyrstals) in member C } \\
\text { - Leucocratic } \\
\text { - Vuggy appearance }\end{array}$ & $\begin{array}{l}\mathrm{A} 1, \mathrm{~A} 3 \\
\mathrm{C} 1 \text { and } \\
\mathrm{C} 2\end{array}$ \\
\hline $\begin{array}{l}\text { F2: felsite/ } \\
\text { rhyolite lava }\end{array}$ & $\begin{array}{l}\text { Coarsest in } \\
\text { member A, but } \\
\text { present } \\
\text { throughout }\end{array}$ & $\begin{array}{l}\text { - Non-deformed } \\
\text { - Fine grained }(<1 \mathrm{~mm})\end{array}$ & A1 \\
\hline $\begin{array}{l}\text { F3: recycled } \\
\text { welded tuff }\end{array}$ & $\begin{array}{l}\text { Members A, B } \\
\text { and C }\end{array}$ & - Partially deformed & $\begin{array}{l}\mathrm{A} 1, \mathrm{~A} 3 \\
\text { and B1 }\end{array}$ \\
\hline $\begin{array}{l}\text { F4: } \\
\text { granophyres }\end{array}$ & $\begin{array}{l}\text { Member A } \\
\text { (uppermost), } \\
\text { locally as swarms } \\
\text { (up to } 10 \% \text { of } \\
\text { ignimbrite) }\end{array}$ & $\begin{array}{l}\text { - Vuggy appearance } \\
\text { - Non-flattened clasts } \\
\text { - Intergrowths of quartz and feldspar }\end{array}$ & A1 \\
\hline
\end{tabular}




\subsubsection{Member C}

Juvenile materials in member $\mathrm{C}$ are visibly distinctive (Table 5.1), aiding sampling. All but one of the juvenile clast variants are characterised by finer crystal sizes $(<2 \mathrm{~mm})$ and crystalpoorer natures ( $<15 \mathrm{wt} \%$ crystals) than the great majority of juvenile clasts in members $\mathrm{A}$ and B. Quartz, commonly bi-pyramidal, and feldspar dominate, with trace amounts of ferromagnesian minerals (pyroxene, olivine and Fe-Ti oxides). The exceptional variant is pumices found within member $\mathrm{C}$ that are in all features identical to type $\mathrm{J} 1$ pumice (and often admixed with scoria: J4-type) found in member B. These are found only in areas where the non-welded top to member B was exposed at the time of member $C$ emplacement and are chemically similar to member B pumices (see below for further discussion). For these reasons we infer that these clasts represent pick-ups of exposed clasts from the eroded top of member $B$ and are considered in with that unit.

Of the other juvenile materials in member $\mathrm{C}$, there is a great range in physical appearance. Non-vesicular, devitrified, black juvenile material occurs as angular to rounded clasts which range in shape from equant in normally welded tuff to highly elongate, stretched clasts in rheomorphic ignimbrite (type J5: Table 5.1; Fig. S5.2d). These contain sparse feldspar and rare quartz. Visually identical material also is found as minor intrusions invading member $\mathrm{C}$ ignimbrite in the Red Mountains (type J6). These intrusions are closely related in time to the HRT eruption as the margins of the intrusions show crenulated and embayed contacts with the ignimbrite and have only poorly developed chilled margins. Glassy pumices were collected from sites along the Teton River, which are rounded, contain equant vesicles and are crystal poor-moderate (type J7: 11-15 wt\% crystals: Fig. S5.2e). Glassy pumices from the non-welded base of member $\mathrm{C}$ at locality 057 (Bitch Creek) are light brown-grey, elongate to platy in shape and extremely vesicular, fibrous and crystal poor (type J8: 7-11 wt\% crystals: Fig. S5.2f). Devitrified fiamme from welded, often rheomorphic, ignimbrite in the Red Mountains and on Huckleberry Mountain are pale yellow-grey, exhibit a vuggy appearance, are sometimes micro- to macro-spherulitic and contain similar crystal proportions to pumices found elsewhere in non-welded member C (clast type J9).

\subsubsection{Foreign materials}

The ignimbrite members in general are very poor in non-juvenile (lithic) materials ( $<1 \%$ by area on clean exposures of welded tuff). These lithics are identified as such by their non- 
flattened nature and clearly contrasting lithology (e.g. sediments, metamorphic lithologies, weathered [Tertiary] mafic lavas). However, some other non-juvenile materials (Table 5.1) were observed and examples collected because of the possibility that they represented precursor materials to the HRT magmatic complex. These include the following.

(a) Granitoid (sensu lato) clasts (type F1), sparsely present in A and more abundant (locally to the percent level) in C in the Red Mountains. The clasts were mostly rigid on incorporation but are sometimes deformed into the local welding fabric suggesting that they were plastic and/or partially molten on eruption. Examples in member $\mathrm{C}$ include microcrystalline $(<1 \mathrm{~mm})$, crystal rich, rounded clasts, possibly representative of crystal mush fragments. Most examples found in member $\mathrm{C}$ are fine-grained, leucocratic with vuggy textures.

(b) Rhyolite lava or felsite (type F2), sparsely found through the ignimbrite, but only in sizes suitable for analysis in member A. None of this material is deformed into the welding fabric of the host tuff.

(c) Clasts of recycled welded tuff (type F3) that have partially deformed into the welding fabric of the subsequent host ignimbrite, found in all three ignimbrite members.

(d) Vuggy porphyritic granophyre (type F4), only found in the uppermost (top few metres) of the dense-welded and devitrified parts of ignimbrite member $A$ in a limited area along the valley of the Teton River. These clasts are not flattened in the plane of the eutaxitic fabric, contain intergrowths of quartz and feldspars and occur locally as swarms forming up to $\sim 10$ volume $\%$ of the ignimbrite.

\subsection{Methods}

Glassy pumices were sampled, wherever possible, to allow chemical determination of the erupted material and its various glass and crystal components. Where this was not possible, individual devitrified fiamme were also sampled to compare with glassy material. In a few cases (mostly the basal vitrophyre in member A), groundmass glass was sampled from fiamme where the whole clast could not be extracted. Sampling of whole rock (i.e. bulk tuff) was avoided, if possible, to minimise blurring and averaging out of heterogeneities. Some crystalpoor examples of the recycled welded tuff fragments (F3 clasts) were analysed to investigate the bulk composition of earlier erupted material in relation to any single pumice/fiamme 
compositional heterogeneity. We use single clast to refer to individual pumice/fiamme analysed in this study.

\subsubsection{Single clast analysis}

Samples were washed, trimmed of any adhering matrix and dried before being crushed in a Rocklabs Boyd crusher to $\sim 2 \mathrm{~mm}$ diameter. This material was then split. At least $100 \mathrm{~g}$ of crushed material, providing a representative sample, was milled using an agate TEMA ring mill to a homogenous fine powder that was then used for major and trace element, and isotopic ratio determinations. Single clast major (and limited trace) element abundances were determined through X-Ray Fluorescence (XRF) on fused discs at the Open University, U.K. (OU) and the University of Auckland, New Zealand based on the methods of Ramsey et al. (1995). Individual $2 \mathrm{sd} \%$ precisions, determined through repeated analysis of multiple standards in each laboratory, are $<3 \%$ for almost all major element oxides, with most $<1 \%$, and offsets from preferred or recommended values are generally $<5 \%$ for all elements (Chapter 2 ). Of the trace elements determined by XRF, only Ba returned meaningful values and corresponding precisions and offsets are mostly $<6 \%$ and $<7 \%$ respectively. Samples duplicated between laboratories show offsets of $<5 \%$ for all major and minor element oxides $>0.1 \mathrm{wt} \%$ in abundance with Ba offsets $\leq 5 \%$ between laboratories (Chapter 2; Electronic Appendix 5.1).

Trace element analysis of rock powders was conducted using inductively-coupled plasma mass-spectrometry (ICP-MS) at Victoria University of Wellington, New Zealand (VUW). Due to the zircon-bearing nature of samples analysed in this study, and the refractory nature of zircon, powders were digested using ammonium fluoride based on the method of Hu et al. (2013). Solutions were then analysed on a ThermoFisher Element2 sector-field ICP-MS at VUW. Concentrations were determined using a calibration curve generated from multiple dilutions of a $1 \mathrm{ppm}$ stock solution comprised of standard solutions of all elements of interest. Procedural blanks were $<0.1 \mathrm{ppb}$ for all elements, with most within background levels. Repeated analyses of rock standards GSP-2 and JR-1 yielded offsets from preferred values of $<10 \%$ for all elements except Ho, $\operatorname{Er}(<15 \%), \mathrm{Y}(<20 \%)$ and $\mathrm{Zn}(>20 \%)$, and 2sd\% similarly of $<10 \%$ for all elements (Chapter 2; Electronic Appendix 5.1).

Aliquots of the solutions prepared for trace element analysis were taken and processed for separation of $\mathrm{Sr}, \mathrm{Nd}$ and $\mathrm{Pb}$ for isotopic ratio determination based on the method of Pin et al. (2014: full methodology given in section 2.3.3). An aliquot of $\geq 200 \mathrm{ng} P \mathrm{~b}$ 
was dissolved in $1 \mathrm{M} \mathrm{HBr}$ and twice passed through anion resin. A separate aliquot containing $\geq 200 \mathrm{ng}$ Nd was pre-concentrated using a cation column, to reduce the abundance of $\mathrm{Rb}$ in the samples. The Sr fraction was further concentrated by passing through Sr-spec resin. Chromatographic separation of $\mathrm{Nd}$ was undertaken by passing the $\mathrm{Nd}$-enriched cation column fraction through LN-spec resin.

Isotopic ratio measurements were conducted on the same ThermoFisher Triton Thermal lonisation Mass spectrometer (TIMS) instrument, initially at the OU and later at VUW. Dried $\mathrm{Sr}$ fractions were loaded onto a single Re filament assembly with concentrated $\mathrm{HNO}_{3}$ and a $\mathrm{TaF}_{2}$ emitter solution (Birck 1986; Charlier et al. 2006). Measurements were internally normalised to ${ }^{86} \mathrm{Sr} /{ }^{88} \mathrm{Sr}=0.1194$ and ${ }^{85} \mathrm{Rb}$ was measured to correct for any $\mathrm{Rb}$ interference using ${ }^{87} \mathrm{Rb} /{ }^{85} \mathrm{Rb}=0.385707$ (Rosman and Taylor 1998). Repeated analyses of NBS987 averaged $0.710255 \pm 0.0000013(2 \mathrm{sd}, \mathrm{n}=25)$. Isotopic ratios from different runs were normalised to a value of 0.71025 for NBS987 (following Thirlwall 1991). Procedural blank was $200 \mathrm{pg}$, insignificant compared to the $\sim 1000 \mathrm{ng}$ loaded onto each filament. Measured Sr isotopic compositions were age-corrected (AC) using 2.08 Ma (Rivera et al. 2014; Singer et al. 2014; Wotzlaw et al. 2015), to account for the large Rb/Sr in some samples. Nd fractions were loaded onto a Re filament using $\mathrm{HCl}$ and $\mathrm{H}_{3} \mathrm{PO}_{4}$ loading solution. $\mathrm{Nd}$ fractions were analysed using a double filament assembly and ratios were internally normalised using ${ }^{143} \mathrm{Nd} /{ }^{144} \mathrm{Nd}$ and corrected for any Ce and Sm using ${ }^{140} \mathrm{Ce} /{ }^{142} \mathrm{Ce}=7.97279$ and ${ }^{144} \mathrm{Sm} /{ }^{147} \mathrm{Sm}=0.20667$ (Rosman and Taylor 1998). Repeated analyses of J\&M and La Jolla standards yield values of 0.511818 $\pm 0.000004(2 \mathrm{sd}, \mathrm{n}=26)$ and $0.511845 \pm 0.000002(2 \mathrm{sd}, \mathrm{n}=6)$ both similar to the long term laboratory average (J\&M: $0.511821 \pm 0.0000022 \mathrm{sd}$ ) and the value of Thirlwall (1991) for La Jolla $(0.511856 \pm 0.0000072 \mathrm{sd})$. Procedural blank was $300 \mathrm{pg}$. Pb fractions were analysed using the double-spike method (see Todt et al. 1996). Half the sample was loaded naturally onto a Re filament using a $\mathrm{H}_{3} \mathrm{PO}_{4}$-silica gel mix loading solution (Gerstenberger and Haase 1996). Subsequently, the remaining half was mixed with the loading solution and a ${ }^{207} \mathrm{~Pb} /{ }^{204} \mathrm{~Pb}$ spike and loaded onto a separate filament (Thirlwall 2000). Natural and spiked samples were analysed successively before deconvolution of the data to determine the isotopic ratios. Values for standard NBS981 were ${ }^{206} \mathrm{~Pb} /{ }^{204} \mathrm{~Pb}=16.945 \pm 0.001,{ }^{207} \mathrm{~Pb} /{ }^{204} \mathrm{~Pb}=15.503 \pm 0.001$ and ${ }^{208} \mathrm{~Pb} /{ }^{204} \mathrm{~Pb}=36.737 \pm 0.004(2 \mathrm{sd}, \mathrm{n}=32)$. Isotopic measurements from different runs were normalised to the values of Todt et al. (1996). The procedural blank was $2 \mathrm{ng}$, considered 
insignificant when compared to the $>200 \mathrm{ng}$ analysed. No blank correction was applied due to the small blank levels when compared to the amount loaded.

\subsubsection{In-situ analysis}

The remaining crushed material was sieved to $1 \mathrm{~mm}$ and any $>1 \mathrm{~mm}$ crystals picked out. Material from glassy, non-mingled pumices was then immersed in lithium polytungstate heavy liquid (adjusted to a density of $\sim 2.4 \mathrm{~g} / \mathrm{cm}^{3}$ ) to separate out glass and crystals. Starting and crystal weights were recorded in order to derive a wt\% crystal fraction. Samples were subsequently dry-sieved at $0.5 \mathrm{~mm}$ and wet-sieved at 250, 125 and $63 \mu \mathrm{m}$ mesh sizes. Crystals were picked from the $0.5-1 \mathrm{~mm}$ size fraction and mounted in $25 \mathrm{~mm}$ epoxy mounts with the crystals oriented parallel to their c-axes where possible. Glass was picked from the $250-500$ $\mu \mathrm{m}$ sieve fraction and similarly mounted. The mounts were polished and coated with a $\sim 25$ $\mathrm{nm}$ carbon film. In situ major element analysis was conducted by electron probe microanalysis (EPMA) using five wavelength dispersive spectrometers (WDS) on a JXA 8230 Superprobe at VUW. All samples were initially imaged using backscattered electron imaging. Crystals were analysed using a $15 \mathrm{kV}$ accelerating voltage, a $12 \mathrm{nA}$ beam current and a $\sim 1 \mu \mathrm{m}$ spot size. All elements in feldspars and pyroxenes were analysed with $30 \mathrm{~s}$ count time on peak and a $15 \mathrm{~s}$ background count. Ti, Si, Mg, Fe and Al in olivines were similarly analysed with $30 / 15 \mathrm{~s}$ count times, whereas $\mathrm{Ca}, \mathrm{Mn}$ and $\mathrm{Ni}$ were analysed over $60 \mathrm{~s}$ (peak) and $30 \mathrm{~s}$ (background) to improve precision and accuracy. Glass was analysed using a $15 \mathrm{kV}$ accelerating voltage and a defocused $20 \mu \mathrm{m}$ spot size. To reduce the effect of alkali migration a $2 \mathrm{nA}$ beam current was used to analyse $\mathrm{Si}, \mathrm{Al}, \mathrm{Na}, \mathrm{K}, \mathrm{Fe}$ and $\mathrm{Ca}$, with $\mathrm{Si}$ and $\mathrm{Na}$ analysed first, as recommended by Humphreys et al. (2006). Subsequently, Ti, Mg and Mn were analysed using an 8 nA current. Peak and background count times were 15/8 (Na), 30/15 (Si, Al), 40/20 (K, Ca, Ti, Mg) and $60 / 20$ s (Fe, Mn). Unknown samples were bracketed by internationally accredited samples to monitor accuracy and precision of the analytical sequence and to measure any drift present. Standard data are given in Chapter 2 and electronic appendices 5.2 and 5.3.

In-situ trace element analysis of glass, encompassing the same area as analysed by EPMA, was conducted at VUW using laser ablation inductively-coupled plasma mass spectrometry (LA-ICP-MS) on a RESOlution S155-SE $193 \mathrm{~nm}$ Excimer Laser coupled with an Agilent 7500CS ICP-MS. A $35 \mu \mathrm{m}$ spot size was analysed, preceded by two $70 \mu \mathrm{m}$ diameter cleaning pulses. Synthetic glass GSD-1G was used for calibration with ${ }^{29}$ Si concentrations, derived from EPMA 
analyses, used as an internal standard. NIST 612, BCR-2G and BHVO-2G were analysed repeatedly as secondary standards. Unknown samples were bracketed by calibrating and secondary standards. Data was processed using LaserTRAM software (Loewen and Kent 2012) to derive concentrations. Standard data is given in Electronic Appendix 5.2.

\subsection{Single clast geochemistry}

\subsubsection{Major elements}

Silicic (>65 wt\% $\mathrm{SiO}_{2}$ ) juvenile materials are dacite to high-silica rhyolite (66-79 wt\% $\mathrm{SiO}_{2}$, recalculated volatile free: Table 5.2; Electronic Appendix 5.1). Multiple distinct trends are observed in major element compositions and within single ignimbrite members. Type J1 pumice and fiamme (see Table 5.1) from member $\mathrm{A}$ form a coherent trend ( $72-78 \mathrm{wt} \% \mathrm{SiO}_{2}$ ) that is elevated in alkalis $\left(\mathrm{Na}_{2} \mathrm{O}+\mathrm{K}_{2} \mathrm{O}=8.3-9.3 \mathrm{wt} \%\right)$ and $\mathrm{Al}_{2} \mathrm{O}_{3}(11.7-13.8 \mathrm{wt} \%)$ but depleted in $\mathrm{FeO}\left(1.2-3.4\right.$ wt\%), $\mathrm{P}_{2} \mathrm{O}_{5}\left(0.01-0.04\right.$ wt\%) and $\mathrm{TiO}_{2}(0.09-0.39$ wt\%) relative to other $\mathrm{HRT}$ juvenile material (suite A1: Figs. 5.3-5.5, S5.3, S5.4). There is a compositional gap in HRT member $A$ between suites $A 1$ and $A 3$ (the latter is defined on trace element characteristics; see below), and a field defined by type J3 clasts (69-71 wt\% $\mathrm{SiO}_{2}$ : suite $\mathrm{A} 2$ ). This last suite is further enriched in $\mathrm{Al}_{2} \mathrm{O}_{3}$ (13.8-14.5 wt\%), $\mathrm{FeO}$ (4.0-4.5 wt\%) and $\mathrm{TiO}_{2}$ (0.45-0.54 wt\%) but depleted in total alkalis $\left(\mathrm{Na}_{2} \mathrm{O}+\mathrm{K}_{2} \mathrm{O}=8.5-9.1 \mathrm{wt} \%\right)$ relative to the least-evolved end of the $\mathrm{A} 1$ suite (Figs. 5.3-5.5, S5.3). Member B exhibits a single compositional trend (suite B1). Suite B1 comprises clasts of types J1 (including 'B in C' samples), J3 and the rhyolitic component in type J4. It covers almost the entire range, and rarely extends, the variation observed in member $A$ (suites $\mathrm{A} 1$ and $\mathrm{A} 2$ inclusive) but with no compositional gaps evident (e.g. $\mathrm{SiO}_{2}=71-79, \mathrm{Na}_{2} \mathrm{O}$ $+\mathrm{K}_{2} \mathrm{O}=7.1-9.1, \mathrm{Al}_{2} \mathrm{O}_{3}=11.4-13.8, \mathrm{FeO}=0.8-4.1$ wt\%: Figs. 5.3-5.5). Compositional suites $\mathrm{A} 1$, A2 and B1 trend back towards HRT mafic samples (Swallow et al. 2018a, Chapter 4).

Ignimbrite member $\mathrm{C}$ exhibits three contrasting suites:

- Suite $\mathrm{C} 1$ : a dacite trend (66-75 wt\% $\left.\mathrm{SiO}_{2}\right)$ is represented by types $\mathrm{J} 5$ and $\mathrm{J} 6$ clasts. Suite $\mathrm{C} 1$ is notably enriched in $\mathrm{CaO}$ (1-4 wt\%), $\mathrm{FeO}$ (4.1-9.6 wt\%) and $\mathrm{P}_{2} \mathrm{O}_{5}(0.03-0.39)$, and depleted in $\mathrm{Al}_{2} \mathrm{O}_{3}$ (11.4-12.1 wt\%) relative to compositions from members $\mathrm{A}$ and $\mathrm{B}$ (Figs. 5.4, 5.5, S5.3, S5.5).

- Suite C2: clast types J8 and J9, with rare J5-type clasts, comprise a high-silica rhyolite suite $\left(75-78\right.$ wt\% $\left.\mathrm{SiO}_{2}\right)$, but it is moderate in its $\mathrm{FeO}\left(1.2-3.0\right.$ wt\%) and $\mathrm{TiO}_{2}$ contents 


\begin{tabular}{|c|c|c|c|c|c|c|c|c|c|c|c|c|c|c|c|c|c|c|c|}
\hline Sample & $\begin{array}{l}\text { Host } \\
\text { Unit }\end{array}$ & $\begin{array}{l}\text { Clast } \\
\text { type }\end{array}$ & $\begin{array}{l}\text { Geochemical } \\
\text { suite }\end{array}$ & $\mathrm{SiO}_{2}$ & $\mathrm{TiO}_{2}$ & $\mathrm{Al}_{2} \mathrm{O}_{3}$ & $\mathrm{FeO}$ & $\mathrm{CaO}$ & $\mathrm{Na}_{2} \mathrm{O}$ & $\mathrm{K}_{2} \mathrm{O}$ & $\mathrm{P}_{2} \mathrm{O}_{5}$ & $\mathbf{R b}$ & $\mathrm{Sr}$ & $\mathrm{Zr}$ & Nb & $\mathrm{Ba}$ & La & $\mathbf{U}$ & Sc \\
\hline YP255 & $(\mathrm{A})$ & $\mathrm{J} 1$ & $\mathrm{~A} 3$ & 77.00 & 0.11 & 11.85 & 1.42 & 0.61 & 2.89 & 5.83 & 0.02 & 161 & 12 & 155 & 53 & 251 & 81 & 5.5 & 1.5 \\
\hline YP457 & (A) & $\mathrm{J} 1$ & A1 & 74.10 & 0.21 & 12.73 & 2.21 & 1.19 & 2.98 & 6.16 & 0.03 & 110 & 38 & 283 & 40 & 1453 & 82 & 3.6 & 2.3 \\
\hline YP459 & (A) & $\mathrm{J} 1$ & $\mathrm{~A} 1$ & 77.30 & 0.12 & 11.69 & 1.43 & 0.70 & 2.86 & 5.64 & 0.02 & 124 & 21 & 158 & 45 & 566 & 70 & 4.7 & 1.4 \\
\hline YP251 & (A) & $\mathrm{J} 2$ & A1 & 75.01 & 0.17 & 12.72 & 1.93 & 0.80 & 3.58 & 5.45 & 0.03 & 119 & 34 & 222 & 46 & 1204 & 90 & 4.0 & 2.1 \\
\hline YP191 & (A) & $\mathrm{J3}$ & $A 2$ & 69.87 & 0.47 & 14.05 & 4.38 & 1.65 & 3.68 & 4.94 & 0.11 & 83 & 76 & 604 & 40 & 2762 & 75 & 2.8 & 5.8 \\
\hline YP078 & (B) & $\mathrm{J} 1$ & B1 & 76.27 & 0.14 & 12.21 & 1.67 & 0.74 & 3.39 & 5.27 & 0.02 & 126 & 35 & 186 & 44 & 899 & 87 & 4.3 & 1.8 \\
\hline YP023 & (B) & J1 & B1 & 76.20 & 0.13 & 12.49 & 1.53 & 0.70 & 3.18 & 5.49 & 0.02 & 144 & 36 & 182 & 45 & 1233 & 81 & 4.4 & 1.8 \\
\hline YP208 & (B) & $\mathrm{J} 1$ & B1 & 72.23 & 0.29 & 13.42 & 3.04 & 1.38 & 4.03 & 5.06 & 0.04 & 98 & 54 & 428 & 45 & 2159 & 79 & 3.3 & 3.7 \\
\hline YP061 & (B) & J4 & B1 & 71.43 & 0.33 & 13.75 & 3.49 & 1.49 & 3.68 & 5.14 & 0.05 & 106 & 67 & 488 & 46 & 2792 & 79 & 3.4 & 4.5 \\
\hline YP299 & (C) & $\mathrm{J} 5$ & $\mathrm{C} 1$ & 69.39 & 0.81 & 11.55 & 7.85 & 3.22 & 3.53 & 2.09 & 0.23 & 46 & 228 & 475 & 21 & 964 & 54 & 3.5 & 25.2 \\
\hline YP648 & (C) & $\mathrm{J} 5$ & C1 & 66.46 & 1.09 & 11.54 & 9.62 & 3.91 & 2.91 & 2.18 & 0.38 & 57 & 245 & 310 & 17 & 674 & 32 & 2.5 & 38.8 \\
\hline YP282 & (C) & $\mathrm{J} 8$ & $\mathrm{C} 2$ & 75.78 & 0.25 & 12.77 & 2.52 & 0.81 & 2.72 & 4.76 & 0.03 & 101 & 108 & 379 & 28 & 2157 & 59 & 4.0 & 3.2 \\
\hline YP105 & (C) & $\mathrm{J} 8$ & $\mathrm{C} 2$ & 76.84 & 0.12 & 12.35 & 1.46 & 0.43 & 2.85 & 5.72 & 0.01 & 138 & 19 & 210 & 32 & 411 & 70 & 6.0 & 2.6 \\
\hline YP133 & (C) & $\mathrm{J} 7$ & $\mathrm{C} 3$ & 76.69 & 0.10 & 12.04 & 1.40 & 1.45 & 3.03 & 4.85 & 0.02 & 175 & 25 & 158 & 60 & 83 & 42 & 6.4 & 1.2 \\
\hline YR275 & (C) & F1 & $\mathrm{N} / \mathrm{A}$ & 74.48 & 0.04 & 14.90 & 0.23 & 1.59 & 4.33 & 4.19 & 0.06 & 83 & 304 & 7.8 & 0.6 & 4066 & 9.8 & 0.4 & 0.3 \\
\hline
\end{tabular}




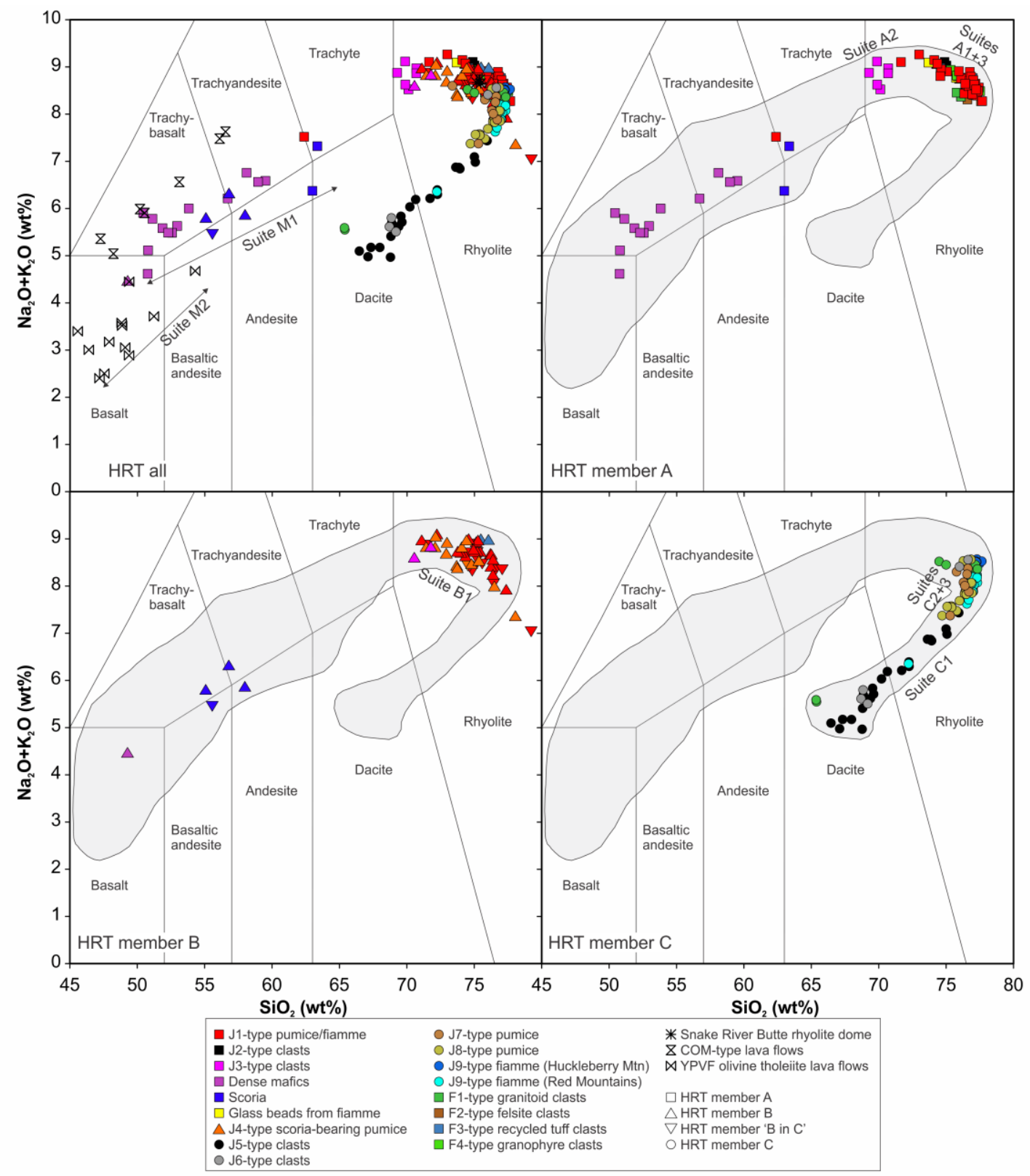

Figure 5.3: A total alkalis-silica plot for samples analysed in this study for the entire HRT (and relevant regional eruptives) and individual members. Symbol shapes relate to the ignimbrite member the clast was sampled from. Symbol colours denote the clast type (see Table 5.1 for details). Silicic suites (A1, B1 etc.) are those defined from compositional groupings (see text for details). Mafic suites 1 and 2 are defined in Swallow et al. (2018a, Chapter 4) and labelled as M1 and $\mathrm{M} 2$ here for clarity. A bifurcating relationship is observed with trends defined by members $\mathrm{A}$ and $B$ combined, versus member $C$. A compositional gap between suites $A 1$ and $A 2$ is infilled in member B (suite B1). All member C suites are depleted in total alkalis relative to members A and B. Classification fields from Le Bas and Streckeisen (1991). Compositional fields (grey shaded regions) from the entire HRT are copied across to plots for individual members for comparison. Analytical $2 s d$ precisions are smaller than the symbol size. 


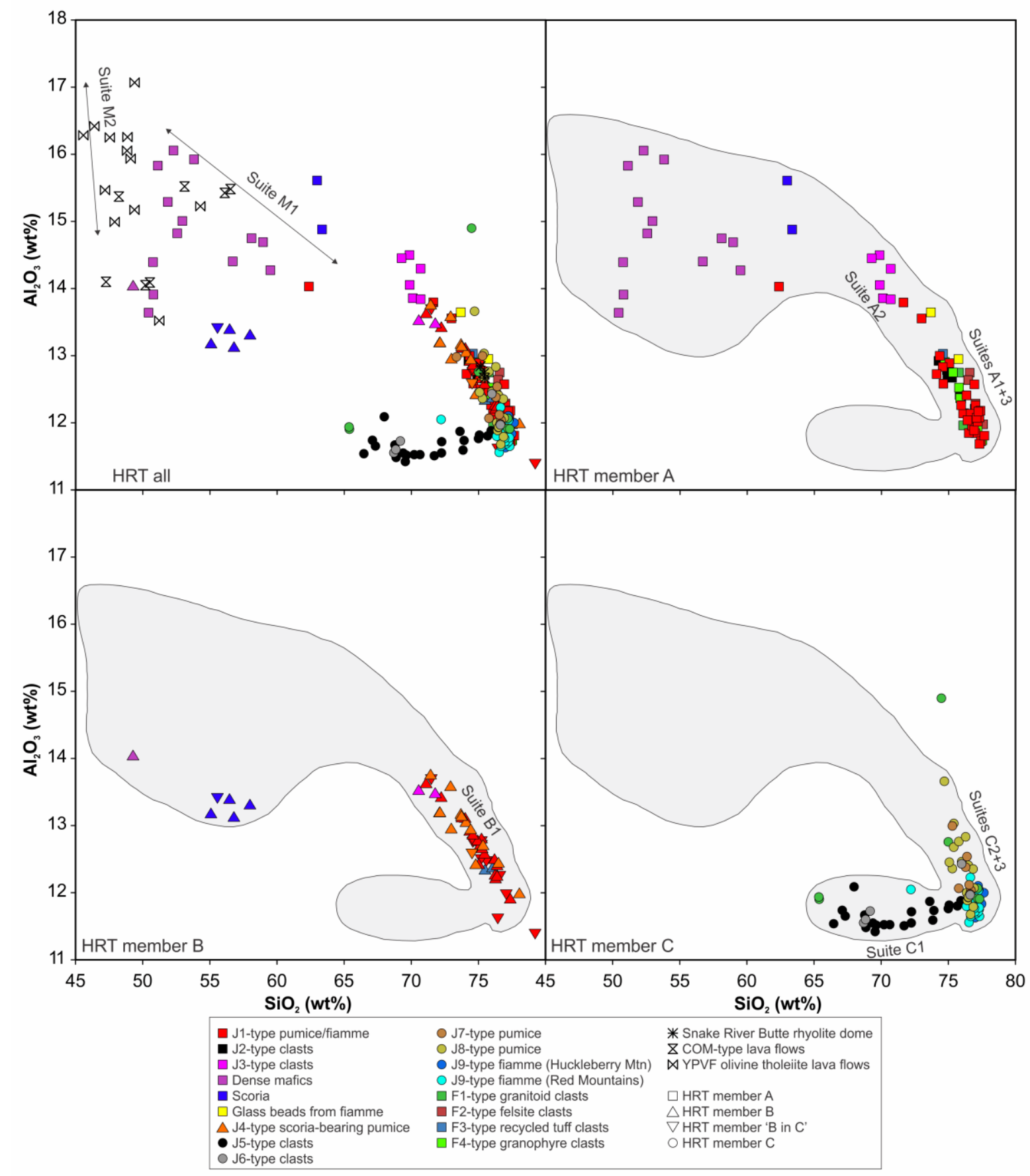

Figure 5.4: $\mathrm{SiO}_{2}$ vs. $\mathrm{Al}_{2} \mathrm{O}_{3}$ for the entire $\mathrm{HRT}$ (and relevant regional eruptives) and individual members. See Fig. 5.3 for symbol and suite details. Two distinct trends are observed, one defined by suite $\mathrm{C} 1$ and the other by suites $\mathrm{A} 1-3, \mathrm{~B} 1$ and $\mathrm{C} 2-3$. Both silicic trends project towards mafic compositions inconsistent with either of suites M1 or M2 (from Swallow et al. 2018a, Chapter 4). Compositional fields (grey shaded regions) from the entire HRT are copied across to plots for individual members for comparison. Analytical 2sd precisions are smaller than the symbol size. 


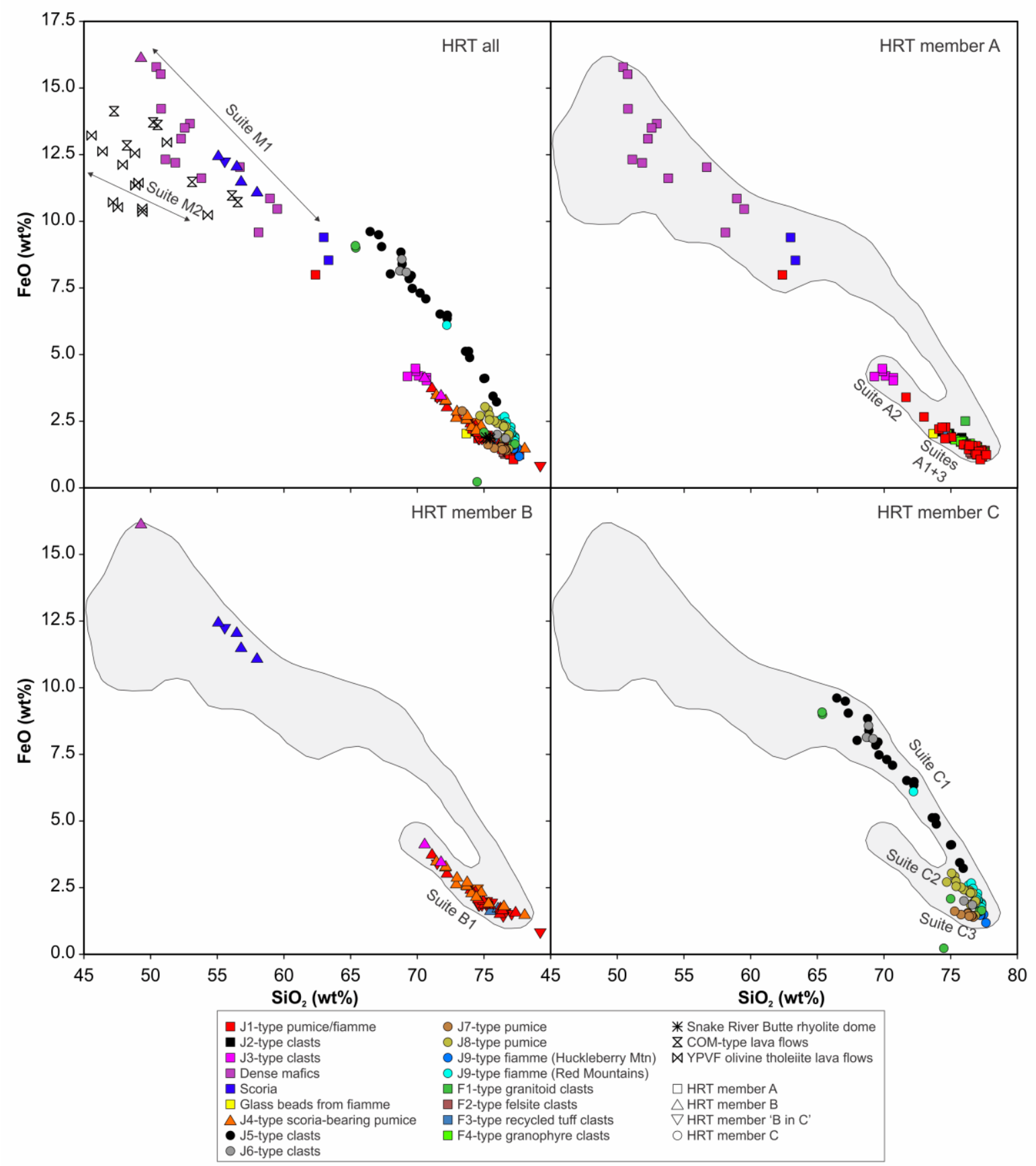

Figure 5.5: $\mathrm{SiO}_{2}$ vs. FeO for samples analysed in this study for the entire HRT (and relevant regional eruptives) and individual members. A compositional gap between suites $A 1$ and $A 2$ is infilled in member B (suite B1). Three sub-parallel compositional suites are apparent in member $C$, with the most Fe-rich suite (C1) trending back to more Fe-rich compositions than either of suites M1 or M2 (from Swallow et al. 2018a, Chapter 4). See Fig. 5.3 for symbol and suite details. Compositional fields (grey shaded regions) from the entire HRT are copied across to plots for individual members for comparison. Analytical 2sd precisions are smaller than the symbol size. 
(0.12-0.29 wt\%: Figs. 5.4, S5.4).

- Suite C3: a further suite (C3: 75-77 wt\% $\mathrm{SiO}_{2}$ ), more consistent with compositions from member A, comprises clast type $\mathbf{J 7}$ from a site (loc. 332) along the Teton River valley. It is further depleted in $\mathrm{FeO}(1.4-1.6 \mathrm{wt} \%)$ and $\mathrm{TiO}_{2}(0.10-0.11 \mathrm{wt} \%)$ relative to suites $\mathrm{C} 1$ and C2 (Figs. 5.5, S5.4).

All member $C$ suites are depleted in total alkalis relative to the suites in members $A$ and $B$ ( $\mathrm{C} 1$ and $\left.\mathrm{C} 3: \mathrm{Na}_{2} \mathrm{O}+\mathrm{K}_{2} \mathrm{O}=7.4-8.6 \mathrm{wt} \%\right)$ with suite $\mathrm{C} 1$ particularly so $\left(\mathrm{Na}_{2} \mathrm{O}+\mathrm{K}_{2} \mathrm{O}=5.0-7.1 \mathrm{wt} \%\right.$ : Fig. 5.3).

Foreign clasts plot within the main suites detailed above. F1-4 samples from members A and $B$ are consistent with the $A 1$ and B1 suites respectively. The Snake River Butte rhyolite lava, which preceded the HRT, also plots within the A1 suite. F1 samples in member $\mathrm{C}$ are split between the $\mathrm{C} 1$ suite (YR254 and YR256: $65 \mathrm{wt} \% \mathrm{SiO}_{2}$ ) and suite C2. One exception is YR275, which is distinct in $\mathrm{FeO}\left(0.25\right.$ wt\%), $\mathrm{Al}_{2} \mathrm{O}_{3}$ (14.9 wt\%) and $\mathrm{TiO}_{2}$ (0.04 wt\%) contents (Figs. 5.4, 5.5, S5.4).

There are no discernible differences in major element compositions between devitrified and glassy pumice and fiamme, and in particular there are no signs of significant alkali mobility. Although pumices typically have higher loss on ignition (LOI) measurements, $\mathrm{K} / \mathrm{Na}$ ratios, which would be expected to increase with hydration (Hildreth and Wilson 2007), broadly overlap (Fig. S5.6).

\subsubsection{Trace elements}

The trace element characteristics of the samples from the HRT further demonstrate an extraordinary diversity, broader than those covered in any other large silicic eruption (Table 5.2; Electronic Appendix 5.1). The compositional suites identified from major element analyses are also represented in trace elements, with additional suites also identifiable. $\mathrm{Ba}$ compositions of all samples conducted by XRF (BaxRF) highlight these trends (Fig. S5.7). In member $A$, suite $A 2$ is Ba-rich $(B a \times R F=3130-4170 \mathrm{ppm})$ and distinct from the $A 1$ suite. $A$ distinct low-Ba cluster (suite A3: BaXRF $=49-300$ ppm) is separated from the $A 1$ suite (BaXRF $=$ 400-2400 ppm). The trace element characteristics of member B samples, like major elements, show a single suite $(B 1: B a \times R F=540-3030$ ppm), but compositions comparable to suite $A 3$ are 


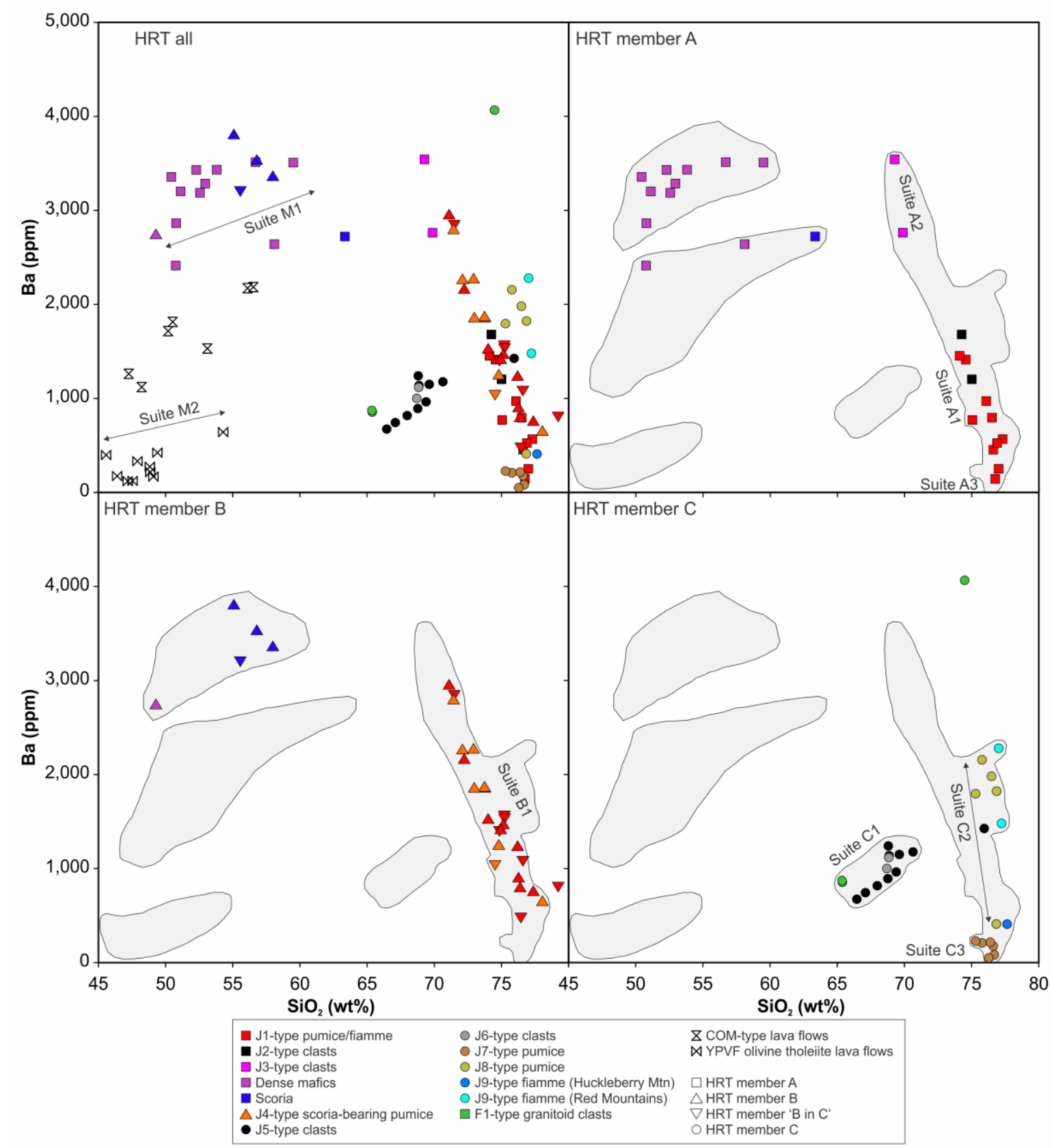

Figure 5.6: $\mathrm{SiO}_{2}$ vs. Ba for samples from the entire HRT (and relevant regional eruptives) and individual members. Suites observed in major element characteristics are also seen in trace elements with the addition of suite $A 3$, distinguished by its low Ba contents. Suites A1, A3, B1, C2 and C3 trend towards HRT mafic compositions (suite M1) whereas suite C1 trends towards the field of regional olivine tholeiite lavas. See Fig. 5.3 for symbol and suite details. Compositional fields (grey shaded regions) from the entire HRT are copied across to plots for individual members for comparison. Analytical 2sd precisions are smaller than the symbol size.

absent. In contrast, the three suites in member $\mathrm{C}$ from major element compositions are also delineated in BaXrF abundances ( $C 1=750-1430$ ppm; $C 2=450-2840$ ppm; $C 3=100-280$ ppm). 
Notably, the last of these is comparable in composition to the A3 suite. Suite classification of foreign material is unchanged from major elemental compositions, except one F1 and one F3 sample (YP380 and YP187, respectively) are more consistent with the A3 suite. YR275, with 4200 ppm BaxRF, remains distinct (Fig. S5.7).

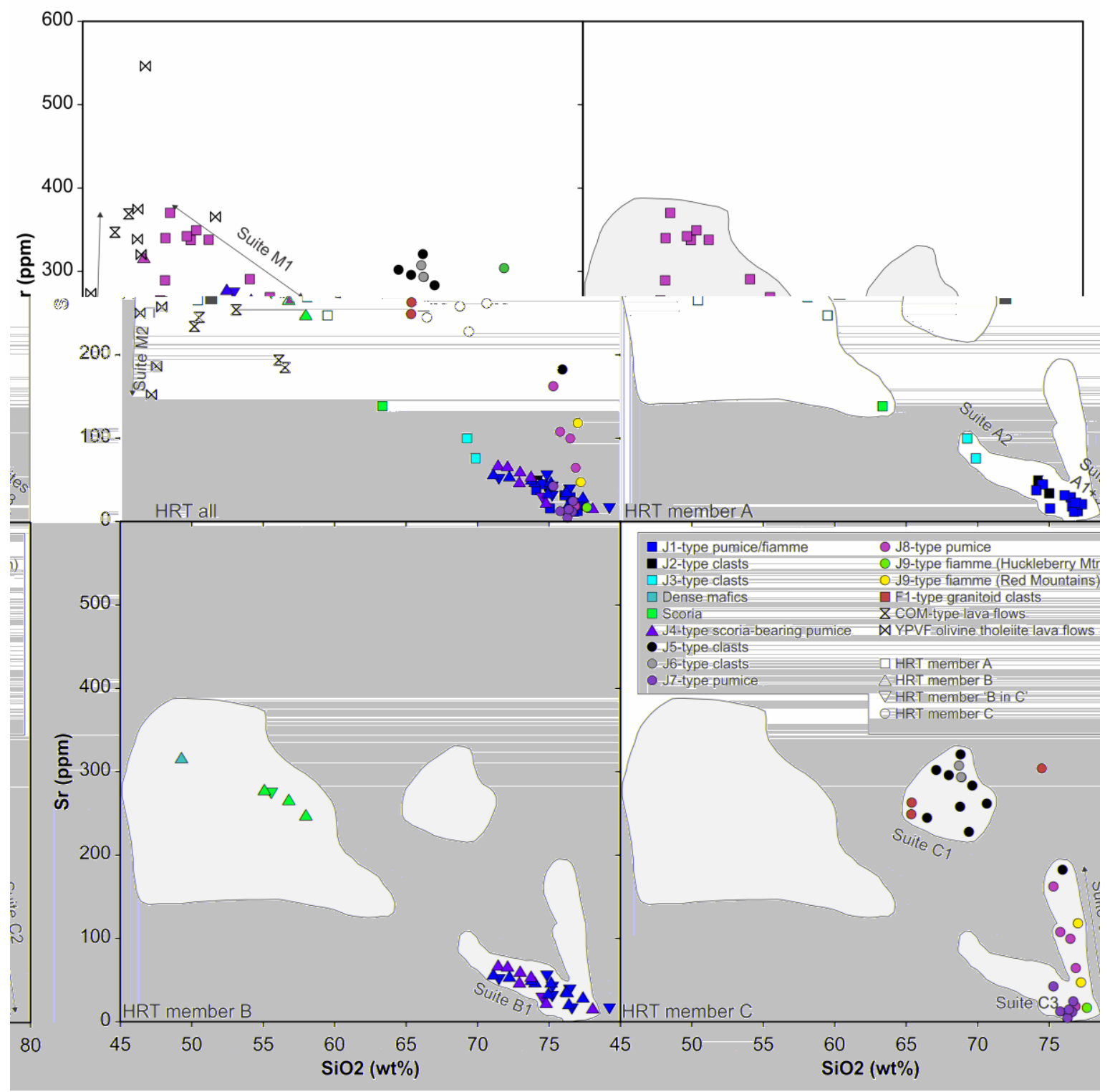

Figure 5.7: $\mathrm{SiO}_{2}$ vs. $\mathrm{Sr}$ for samples from the entire HRT (and relevant regional eruptives) and individual members. Despite its low-Ba nature, suite C1 is clustered and elevated in $\mathrm{Sr}$ relative to either mafic suite. Suite $\mathrm{C} 2$ trends towards elevated $\mathrm{Sr}$ concentrations relative to suites $\mathrm{A} 1-\mathrm{A} 3$ and B1. See Fig. 5.3 for symbol and suite details. Compositional fields (grey shaded regions) from the entire HRT are copied across to plots for individual members for comparison. Analytical 2sd precisions are smaller than the symbol size. 
Full trace element analyses for selected samples, based on their BaxrF concentrations, were conducted by ICP-MS. Suite A1 clasts show wide compositional variation in many trace elements (450-1680 ppm Ba, 12-49 ppm Sr, 155-283 ppm Zr, 40-52 ppm Nb: Figs. 5.6-5.8, S5.8). Compositional gaps distinguish this suite from suites A2 (2760-3540 ppm Ba, 76-100 ppm Sr, 605 ppm Zr, 40 ppm Nb) and A3 (144-251 ppm Ba, 12 ppm Sr, 155-158 ppm Zr, 53$61 \mathrm{ppm} \mathrm{Nb}$ ). Coherency in compositions within the B1 suite is mirrored in other elements with compositions straddling the A1-A2 divide, but not extending to A3 compositions (485-2950 ppm Ba, 15-67 ppm Sr, 149-488 ppm Zr: Figs. 5.6, 5.7, S5.8).

Member $\mathrm{C}$ suites are distinct in other trace elements. Suite $\mathrm{C} 1$ is characterised by higher Sc (25-46 ppm) and Sr (228-321 ppm), and lower Ba (674-1240 ppm) and Zr (194-590 ppm) concentrations than the maximum concentrations of members $A$ and $B$ suites (Figs. 5.6, $5.7,5.9, \mathrm{~S} 5.8)$, with the latter two positively correlated with $\mathrm{SiO}_{2}$. Suite $\mathrm{C} 2$ exhibits large ranges in trace elements over small ranges in $\mathrm{SiO}_{2}$. This suite is characterised by $\mathrm{Ba}$ (409-2280 ppm), $\mathrm{Sr}(17-182 \mathrm{ppm})$ and $\mathrm{Zr}(197-481 \mathrm{ppm})$ values that are negatively correlated with $\mathrm{SiO}_{2}$ (Figs. 5.6, 5.7, S5.8). Both suites C1 and C2 are distinctly lower in Nb (17-33 ppm: Fig. 8) relative to clasts from members $A$ and $B$. Suite $C 3$ is further comparable to suite $A 3$ in some elements (e.g. 50-230 ppm Ba, 5-43 ppm Sr, 60 ppm Nb) but distinct in others (e.g. lower La $=42$ ppm: Figs. 5.6-5.8, 5.10). F1 sample YR275 is notably distinct from any juvenile trend, and particularly notable for its low Zr and Nb concentrations (4066 ppm Ba, 8 ppm Zr; 0.6 ppm $\mathrm{Nb}$ : Figs. 5.6, 5.8, S5.8).

Juvenile clasts from members $A$ and $B$, inclusive of suites $A 1-3$ and $B 1$, have similar rareearth element (REE) patterns, with moderate light-REE enrichments ( $\mathrm{La} / \mathrm{Yb}=12-21$ : Fig. S5.9). Distinctions between suites are observed in Eu anomalies $\left(E u^{*}=E u_{N} /\left[S_{N} \times G d_{N}\right]^{0.5}\right.$ normalised ( $\mathrm{N}$ ) using chondrite values from McDonough and Sun 1995) in member A (suite A1 $=0.25-0.56$, suite $A 2=0.94$, suite $A 3=0.12-0.18)$, but have a narrower but continuous range in member $B$ (suite $B 1=0.26-0.90$ ). Suite $C 1$ has flatter REE patterns than members $A$ and $B$ $(\mathrm{La} / \mathrm{Yb}=11-15)$ but has small, both positive and negative, Eu anomalies (Eu* $=0.80-1.18)$. Suite $\mathrm{C} 2$ has similarly flat trends $(\mathrm{La} / \mathrm{Yb}=11-20)$ but variable and larger Eu anomalies $\left(\mathrm{Eu}^{*}=\right.$ 0.24-1.25). In contrast, suite $\mathrm{C} 3$ has flatter REE trends ( $\mathrm{La} / \mathrm{Yb}=6-10)$ relative to other member $\mathrm{C}$ suites and its member $\mathrm{A}$ (suite $\mathrm{A} 3$ ) comparator, but a stronger negative Eu anomaly (Eu* = 0.11-0.16), comparable to that in suite $\mathrm{A} 3$. 


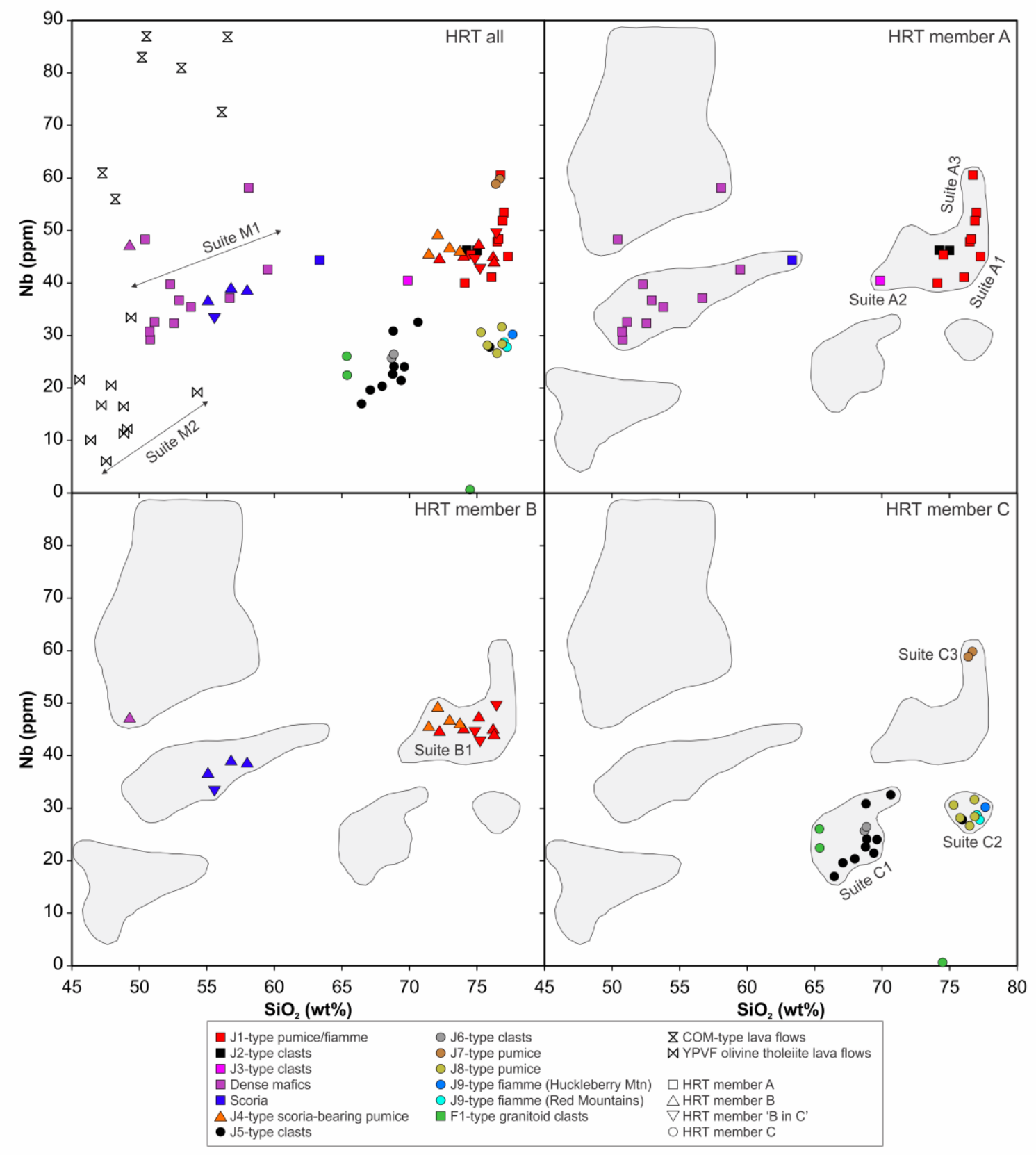

Figure 5.8: $\mathrm{SiO}_{2}$ vs. $\mathrm{Nb}$ for samples from the entire HRT (and relevant regional eruptives) and individual members. Suite $\mathrm{A} 2$ shows similar $\mathrm{Nb}$ contents to the most evolved mafic suite 1 compositions, despite the major element compositional gap. Comparable suites $A 1$ and $A 3$ are enriched in $\mathrm{Nb}$ relative to other suites. In contrast, suites $\mathrm{C} 1$ and $\mathrm{C} 2$ are both depleted in $\mathrm{Nb}$ relative to member A and B compositions. See Fig. 5.3 for symbol and suite details. Compositional fields (grey shaded regions) from the entire HRT are copied across to plots for individual members for comparison. Analytical 2sd precisions are smaller than the symbol size. 


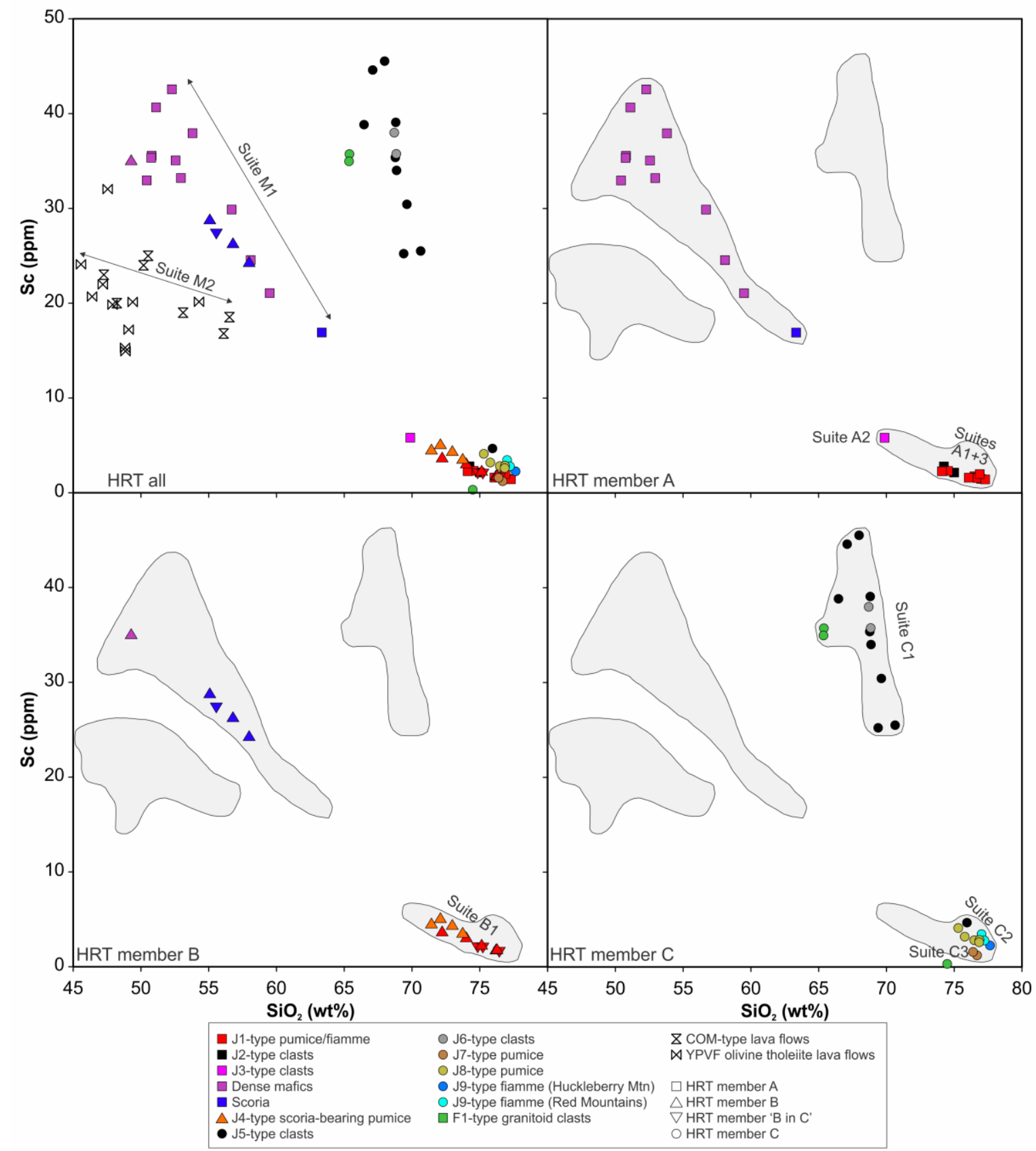

Figure 5.9: $\mathrm{SiO}_{2}$ vs. Sc for samples from the entire HRT (and relevant regional eruptives) and individual members. Suite $\mathrm{C} 1$ is notably enriched in Sc, with concentrations extending to greater values than any mafic or silicic concentrations analysed in this study. Suite C2 exhibits a steeper trend than members A and B samples. See Fig. 5.3 for symbol and suite details. Compositional fields (grey shaded regions) from the entire HRT are copied across to plots for individual members for comparison. Analytical 2 sd precisions are smaller than the symbol size. 


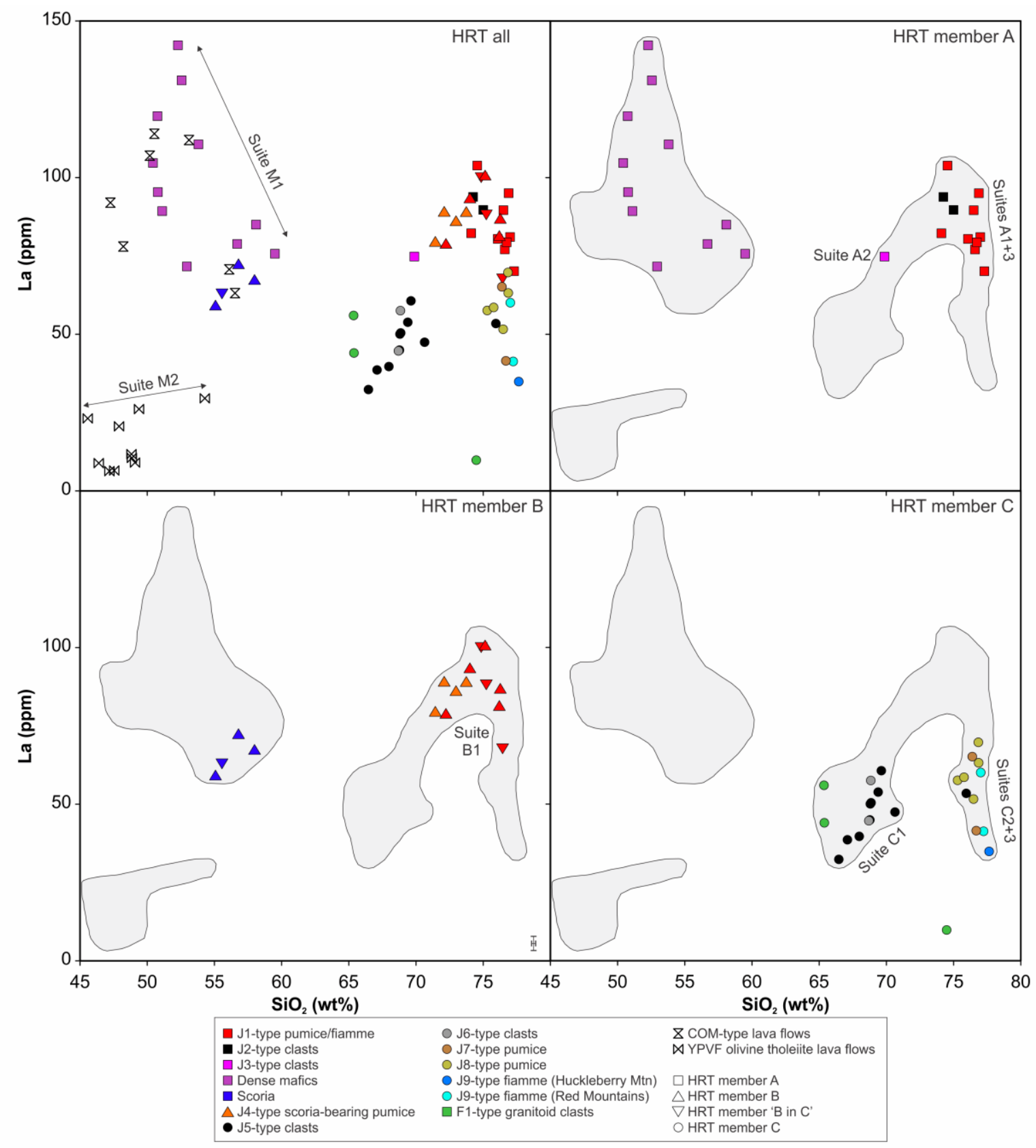

Figure 5.10: $\mathrm{SiO}_{2}$ vs. La for samples from the entire HRT (and relevant regional eruptives) and individual members (excluding YP188 and YP242). Suite A2 shows similar La contents to the most evolved suite 1 mafic compositions, despite the major element compositional gap. The leastevolved clasts from suite 1 shows an increase in La contents relative to suite $A 2$, antithetic to the decrease in $\mathrm{La}_{\text {with }} \mathrm{SiO}_{2}$ in suite $\mathrm{M} 1$ mafics. Suite $\mathrm{C} 3$ shows depleted La contents to comparable $\mathrm{A} 3$ suite clasts. See Fig. 5.3 for symbol and suite details. Compositional fields (grey shaded regions) from the entire HRT are copied across to plots for individual members for comparison. Cross in bottom right hand corner of the member B plot represents analytical 2 sd precisions. 


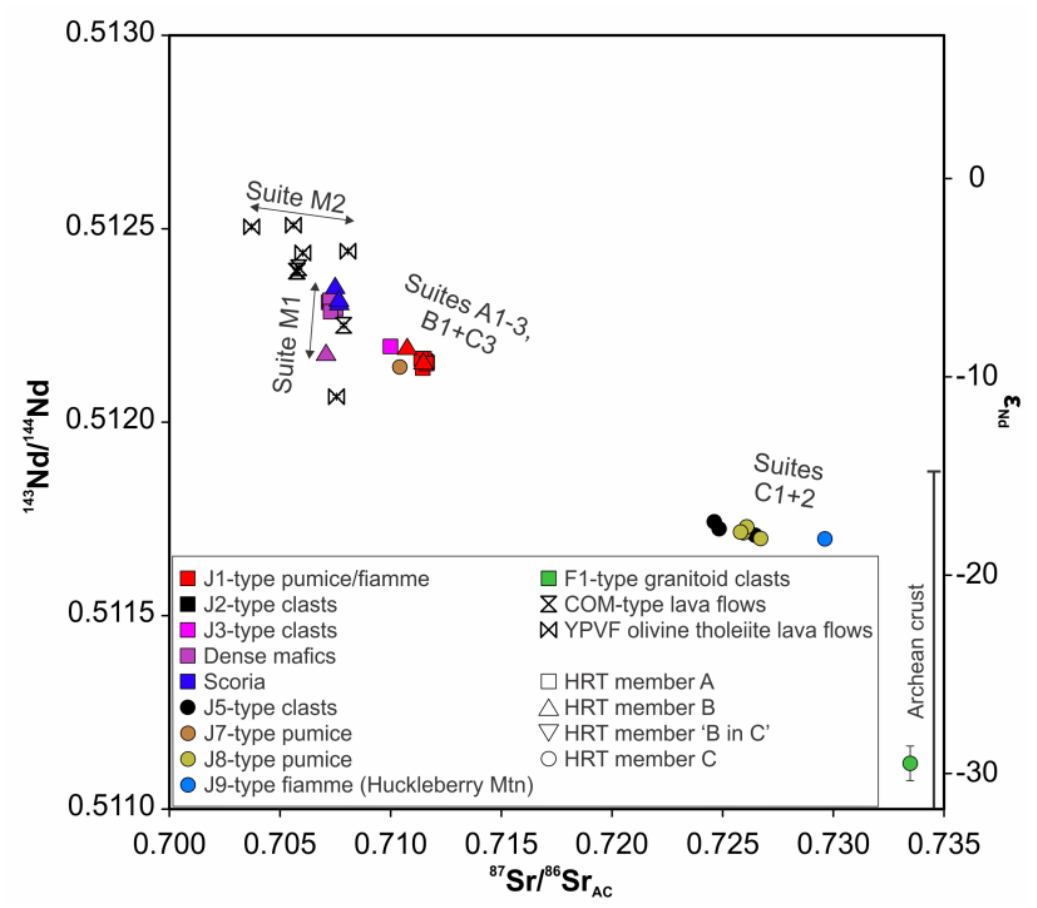

Figure 5.11: ${ }^{87} \mathrm{Sr} /{ }^{86} \mathrm{Sr}_{\mathrm{AC}}$ VS ${ }^{143} \mathrm{Nd} /{ }^{144} \mathrm{Nd}$ for samples from the HRT and relevant regional eruptives. All suites from members $A$ and $B$, plus suite $C 3$ show tightly clustered values and are offset to elevated ${ }^{87} \mathrm{Sr} /{ }^{86} \mathrm{Sr}_{\mathrm{AC}}$ values than mafic samples but with broadly overlapping $\mathrm{Nd}$ isotopic compositions. Suites $\mathrm{C} 1$ and $\mathrm{C} 2$ overlap in isotopic compositions but are distinct from members $\mathrm{A}$ and $\mathrm{B}$ and show more radiogenic (crust-like) values (field of Archean crust from McCurry and Rogers 2009). Granitoid sample YR275 is noticeably unradiogenic in Nd isotopic compositions. See Fig. 5.3 for symbol and suite details. $\varepsilon_{\mathrm{Nd}}$ calculated from DePaolo and Wasserburg (1976: see text for details). Individual 2se analytical uncertainties are smaller than symbol size unless shown.

\subsubsection{Isotopic ratios}

Single-clast, age-corrected (to $2.08 \mathrm{Ma}$ ) values of ${ }^{87} \mathrm{Sr} /{ }^{86} \mathrm{Sr}\left({ }^{87} \mathrm{Sr} /{ }^{86} \mathrm{Sr}_{\mathrm{AC}}\right.$ hereafter) in clasts from members A and B are clustered (0.70958-0.71256: Table 5.3; Electronic Appendix 5.1) with suite A2 clasts falling at the less radiogenic end of the spectrum (0.70958-0.71009: Fig. 5.11). ${ }^{87} \mathrm{Sr} /{ }^{86} \mathrm{Sr}_{\mathrm{AC}}$ ratios show a positive correlation with $\mathrm{Rb} / \mathrm{Sr}$, with the trend levelling off at higher $\mathrm{Rb} / \mathrm{Sr}$ values (Fig. 5.12). A similar pattern is observed between $\mathrm{Sr}$ isotopic values and values of trace elements indicative of melt evolution. For example, samples from members $A$ and $B$ show an increase in ${ }^{87} \mathrm{Sr} /{ }^{86} \mathrm{Sr}_{\mathrm{AC}}$ with decreasing Ba content (Fig. 5.12). Suite C3 pumices are less radiogenic than members $A$ and $B$ for a given elemental value (e.g. $1 / \mathrm{Sr}$ ) and exhibit a flat trend with indicators of magma evolution (e.g. Rb/Sr). In sharp contrast, all other juvenile components from member $\mathrm{C}$ are significantly more radiogenic than any other samples from the HRT (cf. Doe et al. 1982). ${ }^{87} \mathrm{Sr} /{ }^{86} \mathrm{Sr}_{\mathrm{AC}}$ values range from $0.72465-0.73026$, obtained on 


\begin{tabular}{|c|c|c|c|c|c|c|c|c|c|c|c|c|c|}
\hline Sample & $\begin{array}{l}\text { Host } \\
\text { Unit }\end{array}$ & $\begin{array}{l}\text { Clast } \\
\text { type }\end{array}$ & $\begin{array}{l}\text { Geochemical } \\
\text { suite }\end{array}$ & ${ }^{87} \mathrm{Sr} /{ }^{86} \mathrm{Sr}_{\mathrm{AC}}$ & $2 \mathrm{se}$ & ${ }^{143} \mathrm{Nd} /{ }^{144} \mathrm{Nd}$ & 2 se & ${ }^{206} \mathrm{~Pb} /{ }^{204} \mathrm{~Pb}$ & 2 se & ${ }^{207} \mathrm{~Pb} /{ }^{204} \mathrm{~Pb}$ & 2 se & ${ }^{208} \mathrm{~Pb} /{ }^{204} \mathrm{~Pb}$ & 2 se \\
\hline YP255 & (A) & $\mathrm{J} 1$ & $\mathrm{~A} 3$ & 0.71256 & $6.0 \mathrm{E}-06$ & 0.51214 & $2.3 \mathrm{E}-06$ & 17.02 & $9.6 \mathrm{E}-04$ & 15.50 & 1.1E-03 & 38.06 & $3.4 \mathrm{E}-03$ \\
\hline YP459 & (A) & $\mathrm{J} 1$ & $\mathrm{~A} 1$ & 0.71213 & $3.6 \mathrm{E}-06$ & 0.51215 & $6.6 \mathrm{E}-06$ & 17.01 & 8.0E-04 & 15.49 & 8.8E-04 & 38.06 & $2.6 \mathrm{E}-03$ \\
\hline YP457 & (A) & $\mathrm{J} 1$ & $\mathrm{~A} 1$ & 0.71163 & $3.6 \mathrm{E}-06$ & 0.51216 & $4.5 \mathrm{E}-06$ & 17.01 & $8.5 \mathrm{E}-04$ & 15.49 & 9.9E-04 & 38.05 & $3.0 \mathrm{E}-03$ \\
\hline YP251 & (A) & $\mathrm{J} 2$ & $\mathrm{~A} 1$ & 0.71188 & $3.5 \mathrm{E}-06$ & 0.51216 & $2.9 \mathrm{E}-06$ & 16.99 & $8.2 \mathrm{E}-04$ & 15.49 & 9.2E-04 & 38.05 & $2.7 \mathrm{E}-03$ \\
\hline YP191 & (A) & $\mathrm{J3}$ & $\mathrm{A} 2$ & 0.71009 & $3.9 \mathrm{E}-06$ & 0.51220 & $2.5 \mathrm{E}-06$ & 16.95 & $1.0 \mathrm{E}-03$ & 15.48 & $1.3 \mathrm{E}-03$ & 38.02 & $3.9 \mathrm{E}-03$ \\
\hline YP078 & (B) & $\mathrm{J} 1$ & $\mathrm{~B} 1$ & 0.71179 & $3.8 \mathrm{E}-06$ & 0.51215 & $2.7 \mathrm{E}-06$ & 16.99 & $2.2 \mathrm{E}-03$ & 15.49 & 3.0E-03 & 38.03 & $9.6 \mathrm{E}-03$ \\
\hline YP023 & (B) & $\mathrm{J} 1$ & $\mathrm{~B} 1$ & & & & & & & & & & \\
\hline YP208 & (B) & $\mathrm{J} 1$ & $\mathrm{~B} 1$ & 0.71091 & 4.1E-06 & 0.51219 & $3.6 \mathrm{E}-06$ & 16.98 & $1.1 \mathrm{E}-03$ & 15.49 & $1.3 \mathrm{E}-03$ & 38.03 & $3.9 \mathrm{E}-03$ \\
\hline YP061 & (B) & $\mathrm{J} 4$ & $\mathrm{~B} 1$ & 0.71076 & $2.6 \mathrm{E}-06$ & & & 16.90 & $5.4 \mathrm{E}-03$ & 15.46 & 5.2E-03 & 37.95 & $1.4 \mathrm{E}-02$ \\
\hline YP299 & (C) & $\mathrm{J} 5$ & $\mathrm{C} 1$ & 0.72486 & $3.5 \mathrm{E}-06$ & 0.51172 & 2.7E-06 & 18.16 & $1.3 \mathrm{E}-03$ & 15.76 & $1.5 \mathrm{E}-03$ & 37.88 & 4.7E-03 \\
\hline YP648 & (C) & $\mathrm{J} 5$ & $\mathrm{C} 1$ & 0.72464 & $3.4 \mathrm{E}-06$ & 0.51174 & 8.0E-06 & 18.16 & $8.8 \mathrm{E}-04$ & 15.75 & 9.2E-04 & 37.92 & $2.6 \mathrm{E}-03$ \\
\hline YP282 & (C) & $\mathrm{J8}$ & $\mathrm{C} 2$ & 0.72590 & $3.9 \mathrm{E}-06$ & 0.51172 & $2.6 \mathrm{E}-06$ & 17.91 & $1.1 \mathrm{E}-03$ & 15.70 & 1.4E-03 & 37.90 & $4.2 \mathrm{E}-03$ \\
\hline YP105 & (C) & $\mathrm{J} 8$ & $\mathrm{C} 2$ & 0.72735 & $4.1 \mathrm{E}-06$ & 0.51170 & $2.8 \mathrm{E}-06$ & 17.89 & $1.5 \mathrm{E}-03$ & 15.69 & $1.8 \mathrm{E}-03$ & 37.89 & $5.7 \mathrm{E}-03$ \\
\hline YP133 & (C) & $\mathrm{J7}$ & $\mathrm{C} 3$ & 0.71102 & $3.7 \mathrm{E}-06$ & 0.51214 & $2.6 \mathrm{E}-06$ & 16.99 & $1.4 \mathrm{E}-03$ & 15.48 & $1.8 \mathrm{E}-03$ & 38.03 & $5.8 \mathrm{E}-03$ \\
\hline YR275 & (C) & F1 & $\mathrm{N} / \mathrm{A}$ & 0.73350 & 3.7E-06 & 0.51112 & $4.5 \mathrm{E}-05$ & 16.28 & $1.1 \mathrm{E}-03$ & 15.38 & $1.3 \mathrm{E}-03$ & 35.97 & $3.5 \mathrm{E}-03$ \\
\hline
\end{tabular}




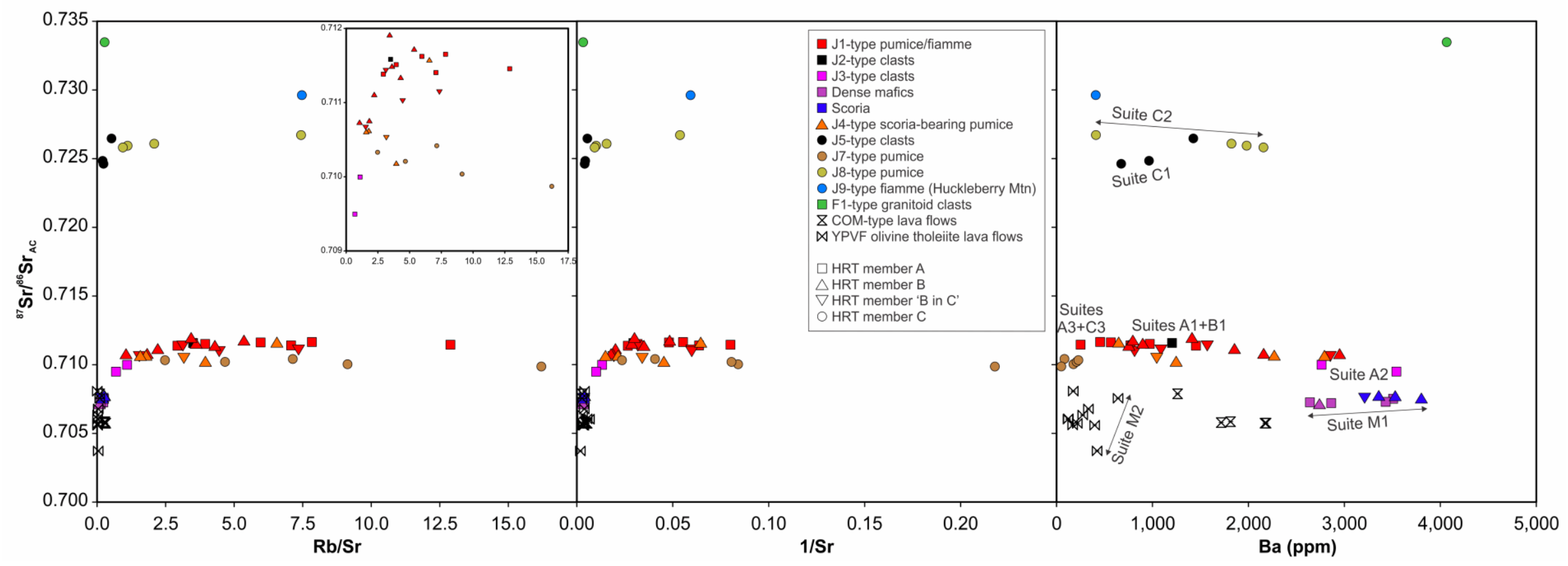

Figure 5.12: ${ }^{87} \mathrm{Sr} /{ }^{86} \mathrm{Sr}_{\mathrm{AC}}$ vs indices of evolution for samples from the HRT and relevant regional eruptives. Members $\mathrm{A}$ and B compositions are offset to elevated ${ }^{87} \mathrm{Sr} /{ }^{86} \mathrm{Sr}_{\mathrm{AC}}$ values with respect to mafic samples. Isotopic compositions increase with evolution (e.g. increasing Rb/Sr, decreasing Ba) in less evolved samples before flattening off. Suite C3 samples are less radiogenic than their suite A3 comparators, but show positive trends with increased degrees of evolution. Suites C1 and C2 are remarkably more radiogenic. Inset: enlarged field of data from all suites from members A and B, plus suite C3. See Fig. 5.3 for symbol and suite details. Individual 2 se analytical uncertainties are smaller than symbol size unless shown. 
clasts ranging between dacite and high-silica rhyolite compositions (Figs. 5.11, 5.12). These samples show a positive correlation between isotopic ratios and $\mathrm{Rb} / \mathrm{Sr}$ and $1 / \mathrm{Sr}$, but samples with significantly different Ba compositions have similar isotopic ratios. One lithic intrusive clast, YR275, shows an even more radiogenic isotopic signature, with ${ }^{87} \mathrm{Sr} /{ }^{86} \mathrm{Sr}_{\mathrm{AC}}=0.73350 \pm$ 0.000004 (2se: Fig. 5.11).

Similar relationships are observed in the $\mathrm{Nd}$ isotopic compositions measured on the same dissolutions of the same samples. $\varepsilon_{\mathrm{Nd}}$ is calculated from measured ${ }^{143} \mathrm{Nd} /{ }^{144} \mathrm{Nd}$ ratios by:

$$
\varepsilon_{N d}=\left[\frac{\left({ }^{143} N d /{ }^{144} N d\right)_{\text {meas }}}{\left({ }^{143} N d /{ }^{144} N d\right)_{C H U R}}-1\right] \times 10^{4},
$$

from DePaolo and Wasserburg (1976) with a value of CHUR (chondritic uniform reservoir) of 0.51263 (Bouvier et al. 2008). Samples from members $A$ and $B$ have ${ }^{143} \mathrm{Nd} /{ }^{144} \mathrm{Nd}$ ratios from 0.51214-0.51220 ( $\varepsilon_{\mathrm{Nd}}=-8.5$ to -9.6$)$, that are negatively correlated with ${ }^{87} \mathrm{Sr}^{866} \mathrm{Sr}_{\mathrm{AC}}$ (Fig. 5.11). Suite C3 sample YP133 has ${ }^{143} \mathrm{Nd} /{ }^{144} \mathrm{Nd}=0.51214 \pm 0.000001\left(2 \mathrm{se} ; \varepsilon_{\mathrm{Nd}}=-9.5\right)$, identical to comparable suite A3 sample YP255. Other juvenile samples from member $C$ are more radiogenic: ${ }^{143} \mathrm{Nd} /{ }^{144} \mathrm{Nd}$ ranges from $0.51174-0.51170\left(\varepsilon_{\mathrm{Nd}}=-17.3\right.$ to -18.2$)$ and is negatively correlated with ${ }^{87} \mathrm{Sr} /{ }^{86} \mathrm{Sr}_{\mathrm{AC}}$ (Fig. 5.11). YR275 is more radiogenic still, with ${ }^{143} \mathrm{Nd} /{ }^{144} \mathrm{Nd}=$ $0.51112 \pm 0.00002\left(2 \mathrm{se} ; \varepsilon_{\mathrm{Nd}}=-29.5\right)$. There is no variation in $\mathrm{Nd}$ isotopic compositions with any elemental measures of magmatic evolution (e.g. Ba: Fig. S5.10).

$\mathrm{Pb}$ isotopic compositions of members A and B samples are tightly clustered (Fig. 5.13), with positive correlations observed between ${ }^{206} \mathrm{~Pb} /{ }^{204} \mathrm{~Pb}(16.90-17.02),{ }^{207} \mathrm{~Pb} /{ }^{204} \mathrm{~Pb}(15.46-$ $15.50),{ }^{208} \mathrm{~Pb} /{ }^{204} \mathrm{~Pb}(37.95-38.06)$. Values from suite $\mathrm{C} 3$ pumices are tightly clustered and comparable to juvenile clasts in members $\mathrm{A}$ and $\mathrm{B}\left({ }^{206} \mathrm{~Pb} /{ }^{204} \mathrm{~Pb}=16.99-17.00\right),{ }^{207} \mathrm{~Pb} /{ }^{204} \mathrm{~Pb}=$ $15.35-15.49$ and $\left.{ }^{208} \mathrm{~Pb} /{ }^{204} \mathrm{~Pb}=38.03-38.06\right)$. In contrast, other samples from member $\mathrm{C}$ show distinctly different $\mathrm{Pb}$ isotopic signatures, with more radiogenic ${ }^{206} \mathrm{~Pb} /{ }^{204} \mathrm{~Pb}(17.89-18.16)$ and ${ }^{207} \mathrm{~Pb} /{ }^{204} \mathrm{~Pb}(15.69-15.78)$, which are positively correlated and fall along a linear extension of the $A$ and $B$ trend. However, they have less radiogenic ${ }^{208} \mathrm{~Pb} /{ }^{204} \mathrm{~Pb}(37.87-37.92)$, which is negatively correlated with ${ }^{206} \mathrm{~Pb} /{ }^{204} \mathrm{~Pb}$ and ${ }^{207} \mathrm{~Pb} /{ }^{204} \mathrm{~Pb}$ (Fig. 5.13). YR275 exhibits much less radiogenic $\mathrm{Pb}$ isotopic compositions than juvenile material found in the HRT (cf. Sr, $\mathrm{Nd}$ isotopes, above; ${ }^{206} \mathrm{~Pb} /{ }^{204} \mathrm{~Pb}=16.28 \pm 0.001,{ }^{207} \mathrm{~Pb} /{ }^{204} \mathrm{~Pb}=15.38 \pm 0.001,{ }^{208} \mathrm{~Pb} /{ }^{204} \mathrm{~Pb}=35.97$ $\pm 0.0032 \mathrm{se})$. 


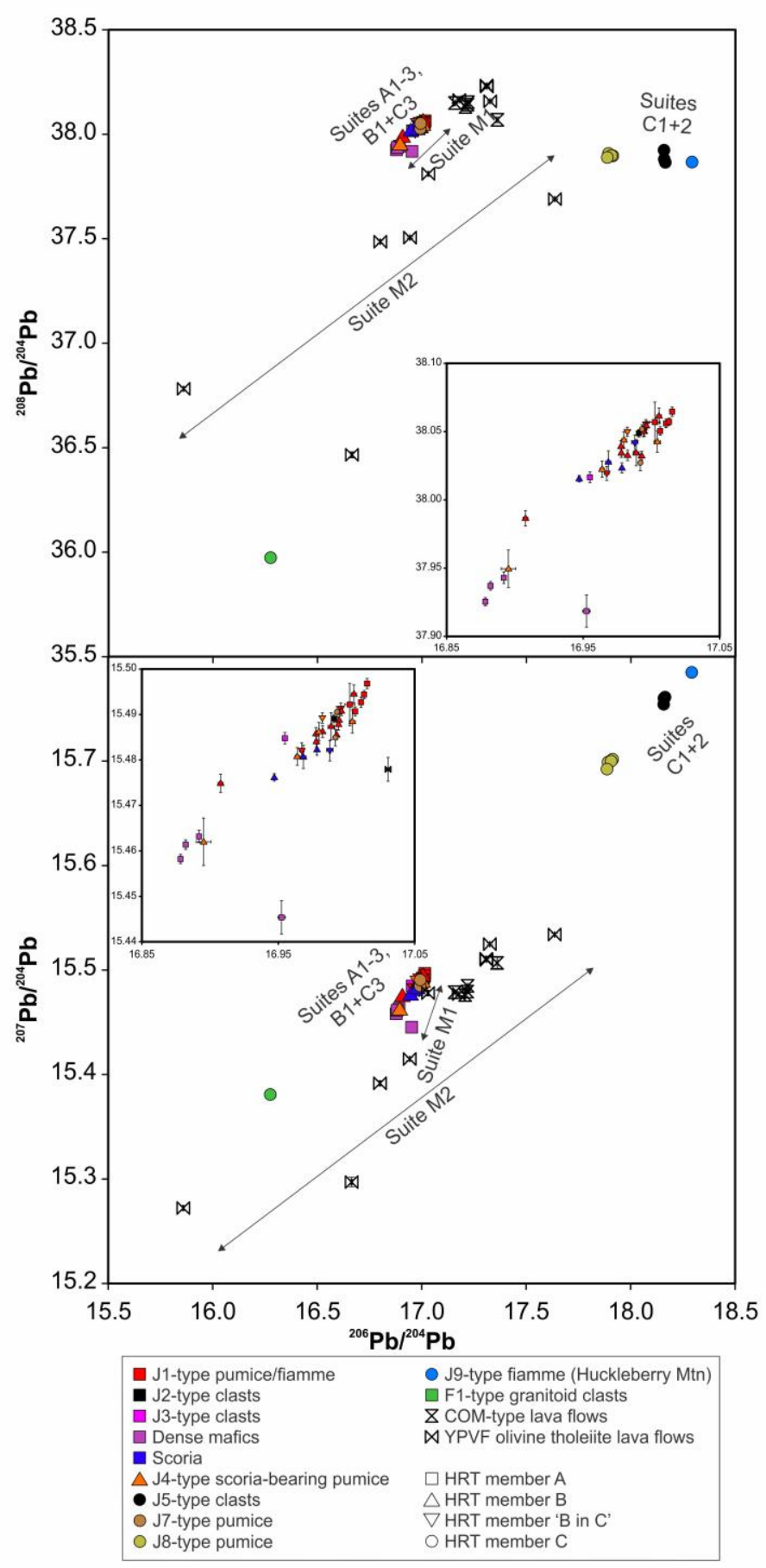

Figure 5.13: $\mathrm{Pb}$ isotopic compositions for samples from the HRT and relevant regional eruptives. Suites A1 to A3, B1 and C3 are tightly clustered and overlap with suite M1 (HRT mafics). All HRT samples show a positive correlation between ${ }^{206} \mathrm{~Pb} /{ }^{204} \mathrm{~Pb}$ and ${ }^{207} \mathrm{~Pb} /{ }^{204} \mathrm{~Pb}$ with suites $\mathrm{C} 1$ and $\mathrm{C} 2$ more radiogenic. In contrast, suites $\mathrm{C} 1$ and $\mathrm{C} 2$ are negatively correlated with respect to ${ }^{206} \mathrm{~Pb} /{ }^{204} \mathrm{~Pb}$ and ${ }^{208} \mathrm{~Pb} /{ }^{204} \mathrm{~Pb}$ compositions and extend to less radiogenic values than members $\mathrm{A}$ and $\mathrm{B}$, and suite $\mathrm{C} 3$, compositions. Insets show enlarged fields of data from all suites from members A and B plus suite C3. See Fig. 5.3 for symbol and suite details. Individual 2 se analytical uncertainties are smaller than symbol size unless shown. 


\subsection{Groundmass glass chemistry}

Groundmass glass from pumices from members A and B is dominantly high-silica rhyolite (75$78 \mathrm{wt} \% \mathrm{SiO}_{2}$ : Electronic Appendix 5.2) with extensions to low-silica rhyolitic compositions observed in glass from type $\mathrm{J} 3$ (dominantly $72-74 \mathrm{wt} \% \mathrm{SiO}_{2}$ ) and $\mathrm{J} 4$ samples (71-77 wt\% $\mathrm{SiO}_{2}$ ). Glass from members $\mathrm{A}$ and $\mathrm{B}$ is alkali-rich $\left(\mathrm{Na}_{2} \mathrm{O}+\mathrm{K}_{2} \mathrm{O}=7.6-9.4\right.$ wt\%), with glass from type $\mathrm{J} 2$ samples clustered to higher alkali (8.5-9.3 wt\%) and lower $\mathrm{CaO}$ (0.24-0.49 wt\%) concentrations for a given value of $\mathrm{SiO}_{2}$ (Figs. S5.11, S5.12). Low-Ca and elevated alkali contents in $\mathrm{J} 2$ sample groundmass glass, which is blackened through Fe-Ti oxide exsolution, indicates some alkali mobility may have occurred. These compositions are not further considered. J3 and J4 samples extend to higher $\mathrm{CaO}$ values (up to 2.2 and $1.5 \mathrm{wt} \%$, respectively). The negative correlations between $\mathrm{Al}_{2} \mathrm{O}_{3}$, alkalis and $\mathrm{CaO}$, versus $\mathrm{SiO}_{2}$ are consistent with a dominant role for feldspar crystallisation on the juvenile material compositions (Figs. S5.11-13).

Groundmass glasses from members A and B form a continuum in incompatible trace elements (e.g. 3.7-10.6 ppm U, 104-262 ppm Rb: Electronic Appendix 5.2). However, glass from suite $\mathrm{A} 1$ samples spans a wide compositional range but is clustered in composition in some compatible elements (108-730 ppm Ba, 81-138 ppm La, Ba/Rb $=0.49-4.23, \mathrm{Sr} / \mathrm{Rb}=$ 0.01-0.1 excluding one outlier: Figs. 5.14, 5.15). Glass from suite A2 clasts form a distinct cluster with elevated Ba (1306-3358 ppm Ba, 88-108 ppm La, Ba/Rb $=9.24-24.4, \mathrm{Sr} / \mathrm{Rb}=0.22-$ 0.47 ) and suite $A 3$ likewise with lower Ba concentrations (31-62 ppm Ba, 49-81 ppm La, Ba/Rb $=1.3-0.24, \mathrm{Sr} / \mathrm{Rb}=0.01-0.04$ excluding two outliers). The clustered nature of the glass compositions is similar to what is observed in the initial fall deposit and basal ignimbrite (Myers et al. 2016; Swallow et al. 2018b, Chapter 3), with strong apparent similarity between the fall deposit/basal ignimbrite glass cluster averages and those clusters observed in the groundmass glass (Figs. 5.14, 5.15). Groundmass glass fragments extracted from single pumice clasts in member $A$ are compositionally homogeneous within themselves, with limited compositional variation observed within a single pumice, particularly when compared to the overall range observed (Fig. S5.14). Glass compositions from type J1 samples in member B focus at the less-evolved end (e.g. 119-1675 ppm Ba, 62-135 ppm La) of the compositional spectrum shown by suite A1 sample glass data. Rhyolitic glass from scoria-bearing (J4-type) samples covers the entire glass compositional range of J1 samples in member B ( $\geq 180 \mathrm{ppm}$ 


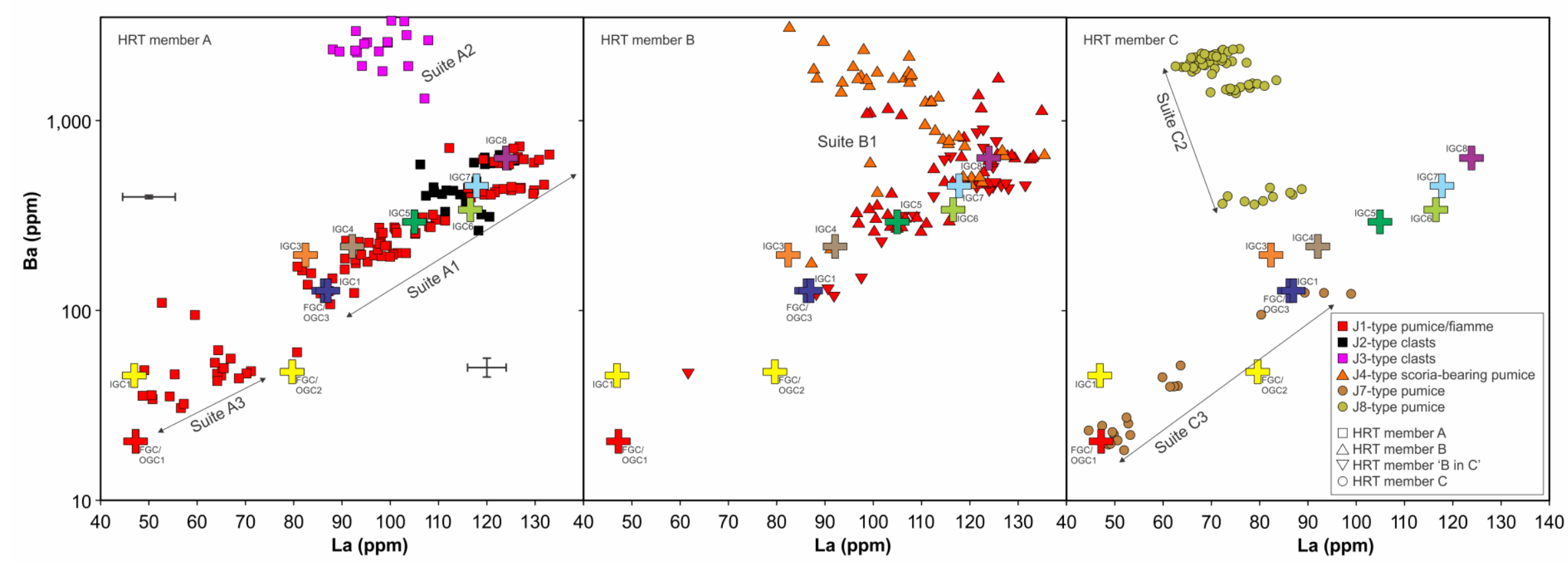

Figure 5.14: La vs Ba concentrations of groundmass glass from pumice from members A, B and C of the HRT. The range and clustered nature of glass compositions in suites $\mathrm{A} 1$ and $\mathrm{A} 3$ is analogous to the fall deposit and basal member $\mathrm{A}$ ignimbrite. Large crosses show the means of each cluster in the fall deposit (FGC/OGC) and basal ignimbrite (IGC; from Swallow et al. 2018b, Chapter 3). Suite A3 samples have low Ba and La compositions in the groundmass glass that are distinct from suite $A 1$ compositions. Suite $A 2$ glass compositions are distinct and offset to higher Ba and lower La values than suite A1 samples. The compositional gap between $\mathrm{A} 1$ and $\mathrm{A} 2$ groundmass glass is infilled in member B, predominantly by glass from J4-type scoria bearing pumices. Glass that is compositionally characteristic of suite A3 is absent from member B. Analogous low-Ba suite C3 glass is present in member C, however. Suite C2 glass is similarly clustered, but forms a trend (increasing La with decreasing $\mathrm{Ba}$ ) distinct from the suites $\mathrm{A} 1$ and $\mathrm{B} 1$ compositions that are absent in member $\mathrm{C}$. Black crosses in member A plot represent 2sd analytical uncertainties at the plotted concentrations $(50,400$ and 120,50$)$ derived through error slope regression (as in Swallow et al. 2018b, Chapter 3; see Chapter S3 for details). See Fig. 5.3 for symbol and suite details. 


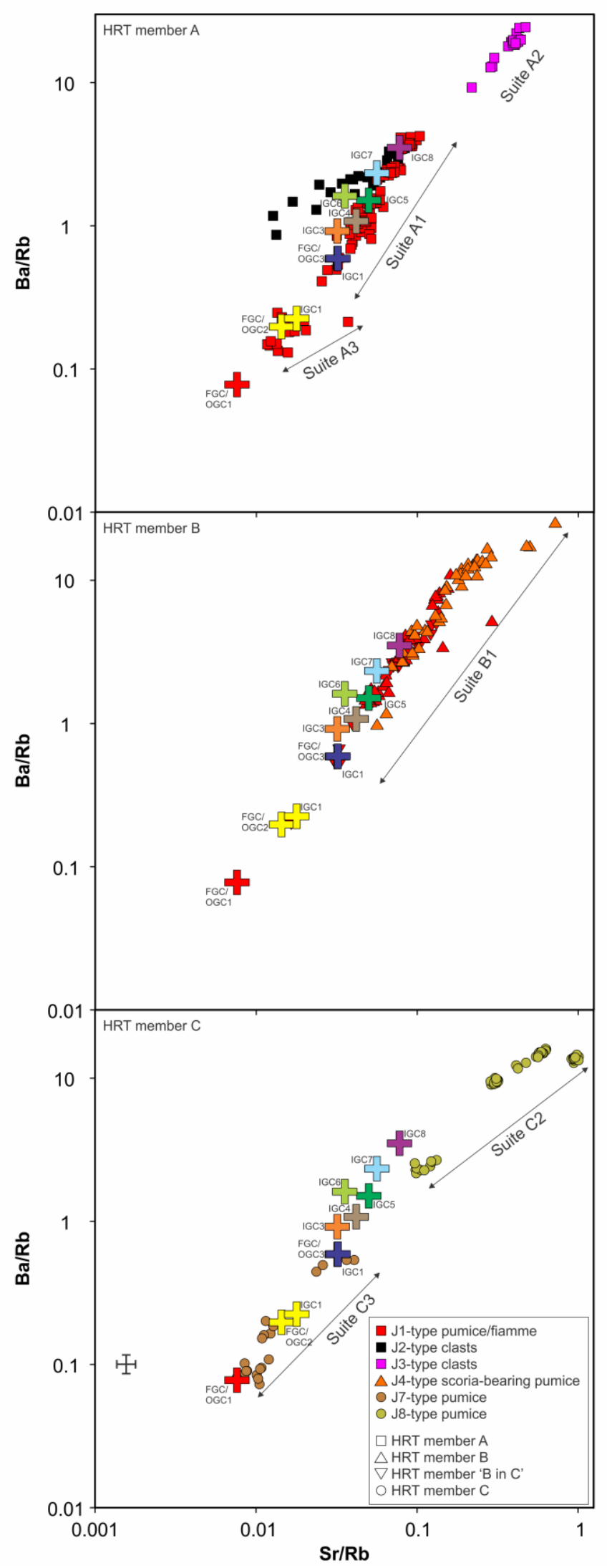

Figure 5.15: $\mathrm{Sr} / \mathrm{Rb}$ vs $\mathrm{Ba} / \mathrm{Rb}$ of groundmass glass from pumice from members A, B and C of the HRT. Large crosses show the means of each compositional cluster in the fall deposit (FGC/OGC) and basal ignimbrite (IGC: from Swallow et al. 2018b, Chapter 3). The range exhibited by suite $A 1$ and $A 3$ glass is analogous to that seen in the fall deposit and basal member $A$ ignimbrite. Suite $\mathrm{A} 2$ glass compositions are distinct and offset to less evolved compositions than suite $A 1$ samples but form a parallel trend. The compositional gap between $\mathrm{A} 1$ and $\mathrm{A} 2$ groundmass glass is infilled in member B, predominantly by glass from J4-type scoria bearing pumices. Glass that is compositionally characteristic of suite $A 3$ is absent from member $B$.

Analogous low-Ba/Rb suite $\mathrm{C} 3$ glass is present in member $\mathrm{C}$, however. Suite C2 glass is similarly clustered, but forms a distinct trend (offset to elevated $\mathrm{Sr} / \mathrm{Rb}$ for a given value of $\mathrm{Ba} / \mathrm{Rb}$ ) from the suites $A 1$ and $B 1$ compositions that are absent in member $\mathrm{C}$. Black crosses in member A plot represent 2sd analytical uncertainties at the plotted concentration derived through error slope regression (as in Swallow et al. 2018b, Chapter 3; see Chapter S3 for details). See Fig. 5.3 for symbol and suite details. 
Ba) but also define an antithetic trend, extending from the highest Ba J1 pumice glass to higher Ba and lower La compositions similar to the J3 glass in member A (extends to 3098 ppm Ba, 83 ppm La: Fig. 5.14).

Groundmass glasses from member C juvenile clasts are all high-silica rhyolite (76-78 wt\% $\mathrm{SiO}_{2}$ ). Glass from type J8 (i.e. suite $\mathrm{C} 2$ ) clasts extends to higher $\mathrm{CaO}$ concentrations (0.34-1.27 wt\%) when compared to glass from type $\mathrm{J} 7$ samples (i.e. suite C3: 0.48-0.65 wt\%), whereas the opposite holds for total alkali concentrations $\left(\mathrm{Na}_{2} \mathrm{O}+\mathrm{K}_{2} \mathrm{O}=7.2-8.8\right.$ versus $7.8-9.1$ wt\%, respectively: Figs. S5.11, S5.12). Glasses in $\mathrm{J} 8$ pumices are also lower in $\mathrm{Al}_{2} \mathrm{O}_{3}(11.6-12.5 \mathrm{wt} \%)$ for a given value of $\mathrm{SiO}_{2}$ than $\mathrm{J} 7$ sample glasses (12.2-12.7 wt\%: Fig. S5.13). The member $\mathrm{C}$ groundmass glasses also show strong location-specific trace element abundances. Glass from J7 pumices (locality 332) is highly evolved, with low Ba (18-124 ppm), low La (45-64 ppm) and low $\mathrm{Ba} / \mathrm{Rb}$ and $\mathrm{Sr} / \mathrm{Rb}$ ratios (0.07-0.54 and 0.01-0.04, respectively: Figs. 5.14, 5.15), compositionally similar to glass from suite A3 samples. Pumice from J8 samples (locality 057) is compositionally unique, however, with elevated, but clustered, Ba compositions (363-2393 ppm) for a given, but uniform, La value (63-89 ppm) when compared to glass present in pumices from members $A$ and $B$. Type $J 8$ groundmass glass is poorer in $U$ (5.1-8.5 ppm) for a given value of $\mathrm{Rb}(139-178 \mathrm{ppm})$ and plots below the $\mathrm{Ba} / \mathrm{Rb}-\mathrm{Sr} / \mathrm{Rb}$ curve $(\mathrm{Ba} / \mathrm{Rb}=2.2-16.0$ and $\mathrm{Sr} / \mathrm{Rb}=0.1-1.0$ ) relative to the $\mathrm{A}$ and $\mathrm{B}$ trend (Fig. 5.15). It is also characteristically depleted in $\mathrm{Nb}(28-36 \mathrm{ppm})$ and Th (17-30 ppm) relative to glass from clasts in members $\mathrm{A}$ and B (Electronic Appendix 5.2). There is no groundmass glass found in any clasts from member $\mathrm{C}$ that plots along the trend defined by suite A1 or B1 samples.

\subsection{Crystal chemistry}

\subsubsection{Feldspar}

Potassium-rich feldspar crystals in members $A$ and $B$ are dominantly sanidine but with minor anorthoclase, and commonly contain a high $\mathrm{Cn}$ (i.e. Ba) component $\left(\mathrm{An}_{1-10} \mathrm{Ab}_{36-65} \mathrm{Or}_{29-59} \mathrm{Cn}_{0-11}\right.$ : Figs. 5.16, S5.15; Electronic Appendix 5.3). Rim compositions fall within a more restricted range, with lower $\mathrm{An}$ and $\mathrm{Cn}$ values $\left(\mathrm{An}_{1-7} \mathrm{Ab}_{40-65} \mathrm{Or}_{29-58} \mathrm{Cn}_{0-6}\right)$ with overgrowths (e.g. antirapakivi feldspars) being more $\mathrm{Cn}$ rich (1.7-7.5 mol\%: Fig. 5.16). Sanidine crystals from suite $\mathrm{A} 3$ clasts lie at the potassic end of the range $\left(\mathrm{An}_{1-2} \mathrm{~A} \mathrm{~b}_{39-44} \mathrm{Or}_{53-59} \mathrm{Cn}_{0-1}\right)$. Potassium-rich feldspars in member $C$ form a similar trend to members $A$ and $B$, but isolated crystals extend to higher 
Or values ( $\left.\mathrm{An}_{0-10} \mathrm{Ab}_{21-59} \mathrm{Or}_{29-78} \mathrm{Cn}_{0-7}\right)$. Sanidine crystals from $\mathrm{J7}$ (i.e. suite $\mathrm{C} 3$ ) clasts are typically more potassic and have lower $\mathrm{Cn}$ contents $\left(\mathrm{An}_{1-4} \mathrm{Ab}_{39-46} \mathrm{Or}_{49-59} \mathrm{Cn}_{0-2}\right)$ than those from suite $\mathrm{C} 2$ samples ( $\mathrm{An}_{1-9} \mathrm{~A} \mathrm{~b}_{40-59} \mathrm{Or}_{29-56} \mathrm{Cn}_{0-7}$ : Fig. 5.16).

Plagioclase feldspars from members $A$ and $B$ are mostly andesine-oligoclase in composition, but form a continuum to anorthoclase compositions ( $\mathrm{An}_{11-46} \mathrm{Ab}_{50-76} \mathrm{Or}_{3-28} \mathrm{Cn}_{0-4}$ : Fig. S5.15). The more potassic compositions are dominated by interior domains and 'plutonictextured' crystals (see below). Grains from suite A3 samples plot at the albite-richer end of the trend $\left(\mathrm{An}_{15-20} \mathrm{Ab} \mathrm{b}_{71-76} \mathrm{Or}_{8-11} \mathrm{Cn}_{0}\right)$. Plagioclase compositions in member $\mathrm{C}$ are more clustered, with a) a trend extending to higher An contents $\left(\mathrm{An}_{33-52} \mathrm{Ab}_{46-61} \mathrm{Or}_{2-5} \mathrm{Cn}_{0}\right)$ dominantly defined by grains in $\mathrm{C} 1$ suite clasts, b) an oligoclase-centred cluster $\left(\mathrm{An}_{14-30} \mathrm{Ab}_{62-77} \mathrm{Or}_{4-15} \mathrm{Cn}_{0-2}\right)$ with grains from suite $\mathrm{C} 3$ samples $\left(\mathrm{An}_{14-22} \mathrm{Ab}_{68-75} \mathrm{Or}_{8-12} \mathrm{Cn}_{0-1}\right)$ at the albite-richer end of the cluster, and $c)$ an anorthoclase cluster $\left(\mathrm{An}_{10-15} \mathrm{Ab} \mathrm{b}_{60-66} \mathrm{Or}_{17-27} \mathrm{Cn}_{1-4}\right)$ dominated by grains from suite $\mathrm{C} 2$ samples.

Texturally, sanidines from suite A3 clasts are dominantly homogenous ( $80 \%$ of crystals: Electronic Appendix 5.3) whereas sanidines from suite A1 and member B samples are more commonly zoned in backscattered electron imagery $(57 \%$ and $70 \%$ of crystals respectively: Fig. S5.16) but with no coherent sense of zoning. Suite A2 samples exhibit an equal split of homogeneous and zoned sanidines but also contain crystals with high-Ba overgrowths, represented as either anti-rapakivi textures or sanidine rims ( $7 \%$ of feldspar crystals). Antirapakivi textures are also sparsely present in member B samples ( $2 \%$ of feldspar crystals; Fig. S5.16). Sanidines from member C show approximately equal proportions of zoned and homogenous crystals irrespective of locality or compositional suite. In contrast to the sanidine record, plagioclase is dominantly homogeneous in all compositional suites from the whole HRT (>80 \% of crystals in each suite).

Feldspar crystals cemented or coated in a carbonate matrix are present in sparse abundance ( $3 \%$ of all feldspar crystals) in suite A1 samples. 'Plutonic-textured' feldspars, characterised by feldspar intergrowths and dissolution textures (Parsons 1978; Fig. S5.16), are present in all suites (although $<10 \%$ of feldspar crystals) but most common in scoria bearing (J4-type) pumices in member B (17\%). 


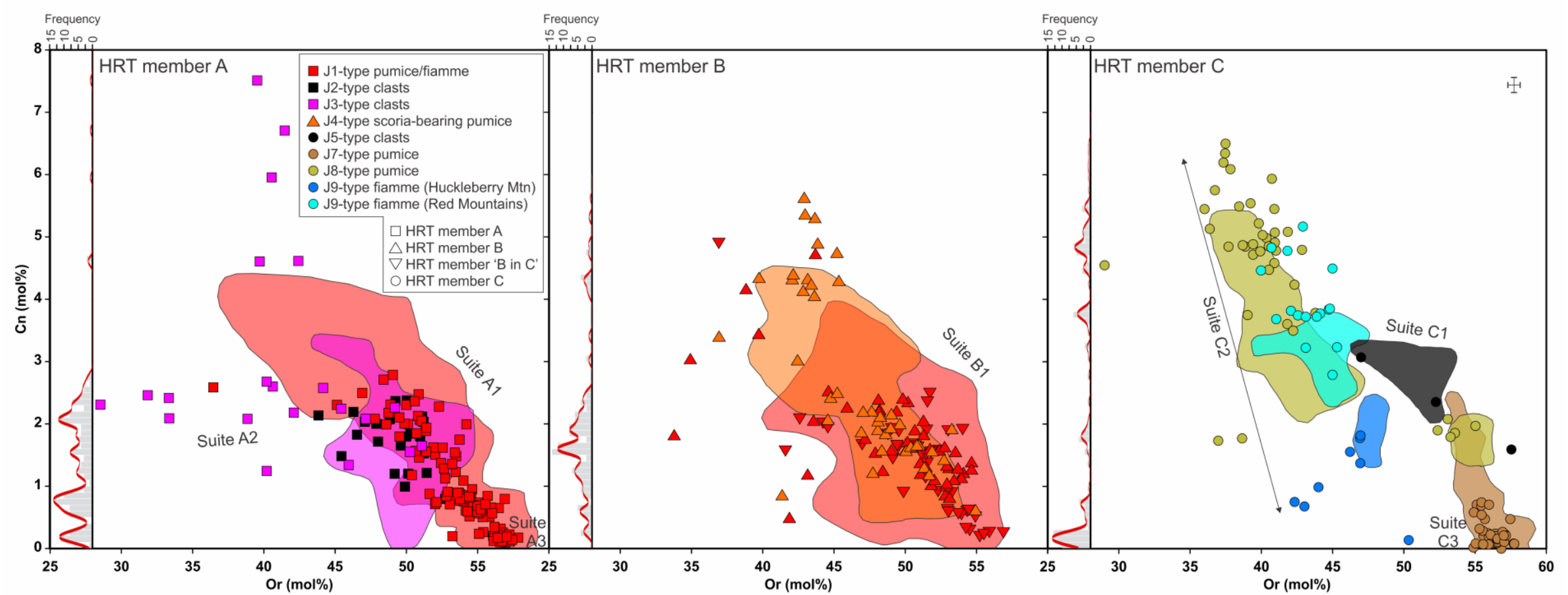

Figure 5.16: Mol\% Or vs Cn contents of sanidine rim compositions (including overgrowths) in samples from HRT members A, B and C. Compositional fields of interior zones (cores and intermediate zones) are shown for comparison. There is a bimodality in rim compositions in member $\mathrm{A}$ with a low-Cn cluster ( $<0.35 \mathrm{~mol} \% \mathrm{Cn}$ ), analogous to the fall deposit (Swallow et al. 2018b, Chapter 3) representing crystals from suite A3 pumices. Rims from suite A2 samples extend to less evolved compositions (lower Or, higher $\mathrm{Cn}$ ) than interior zones. The low-Cn cluster is absent in B but compositions, particularly in scoriabearing J4-type pumices, extend to less evolved values. Member $\mathrm{C}$ shows a reappearance in the low-Cn group (suite $\mathrm{C} 3$ samples) and the presence of $\mathrm{Cn}$ rich compositions from suite $\mathrm{C} 2$ samples, also with rim compositions extending to higher $\mathrm{Cn}$ and lower Or than interior domains. Histogram bin widths are $0.1 \mathrm{~mol} \% \mathrm{Cn}$ and red lines are pdf curves derived from Isoplot using an error of $0.3 \mathrm{~mol} \% \mathrm{Cn}$ (Ludwig 2008). See Fig. 5.3 for symbol and suite details. Cross in the top right indicates 2 sd analytical precisions. 

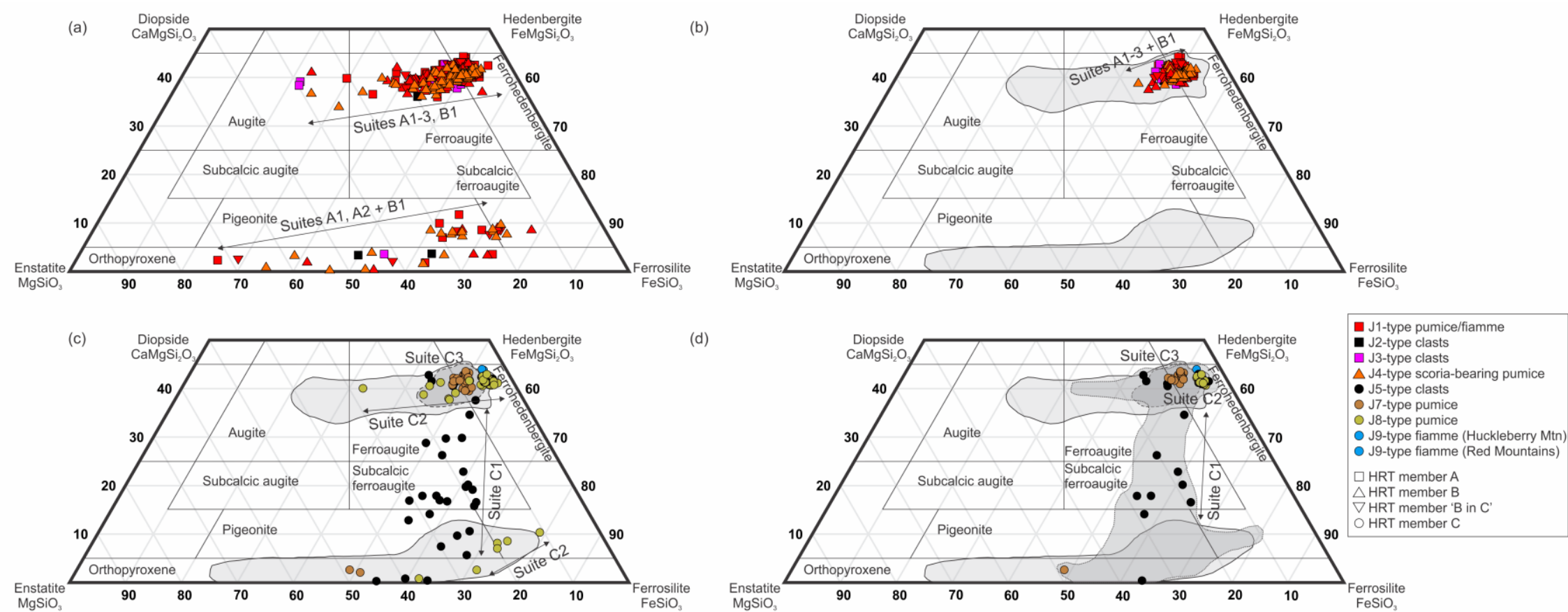

Figure 5.17: Pyroxene quadrilaterals for crystals from members A, B and C of the HRT. (a) All pyroxene analyses from members A and B. A bimodality of compositions is present, with sub-parallel trends present in calcic ('augite') and calcium poor ('pigeonite') compositions. Pigeonite compositions are only found in interior domains (cores and intermediate zones), and are absent from suite A3 samples. (b) Pyroxene rim compositions from member A and B samples. Only augite compositions occur as rim compositions and are tightly clustered at the Fe-rich end of the compositional spectrum shown in panel (a). (c) All pyroxene analyses from member C. Although pigeonite compositions are also present in member C, compositions from sample YP648 (J5-type clast in suite $\mathrm{C}$ ) form a continuum between pigeonite and augite. (d) Pyroxene rim compositions from member $\mathrm{C}$. Rim compositions are dominantly augite and are clustered into different suites. Suite C3 samples fall within the members A and B field whereas C2 crystals cluster on the edge of this field. Compositional fields (grey shaded regions) copied across from the previous panel for comparison. See Fig. 5.3 for symbol and suite details. Compositional fields from Poldervaart and Hess (1951). 


\subsubsection{Pyroxene}

Pyroxene compositions in members $A$ and $B$ show a bimodality in their interior compositions (Fig. 5.17). Low-Ca pyroxenes (hereafter pigeonite for simplicity despite extending to lower Ca than the pigeonite field: Poldervaart and Hess 1951) are present as cores, inclusions or intermediate zones ( $\left.\mathrm{En}_{13-72} \mathrm{Fs}_{25-78} \mathrm{Wo}_{0-12}\right)$ in $\sim 9 \%$ of pyroxene crystals. Alternatively, interior domains of clinopyroxene composition (i.e. augite) occur, spanning a range in the diopsidehedenbergite solid solution field $\left(\mathrm{En}_{4-40} \mathrm{Fs}_{22-55} \mathrm{Wo}_{34-43}\right)$. In contrast, rims in members $\mathrm{A}$ and $\mathrm{B}$ are Fe-rich augite and are tightly clustered (En6-17 $\left.\mathrm{Fs}_{44-53} \mathrm{Wo}_{38-44}\right)$ with no discernible difference between clast compositional types.

Member $\mathrm{C}$ pyroxenes present variable compositions, depending on the clast type and/or locality. Pyroxenes from suite C1 clasts show a continuum from Ca-poor to Ca-rich compositions ( $\mathrm{En}_{3-45} \mathrm{Fs}_{43-68} \mathrm{Wo}_{0-43}$ ) but with only crystals from YP648 plotting in the subcalcic augite field (Fig. 5.17). In contrast, pyroxenes from suite C2 and C3 samples show a more clustered nature. Although there is a subset of suite $\mathrm{C} 2$ grains with pigeonitic compositions $\left(\mathrm{En}_{11-37} \mathrm{Fs}_{62-79} \mathrm{Wo}_{1-11}\right)$, these are found in interior domains (similarly to pyroxenes in samples from members $A$ and $B$ ) and in crystals apparently in disequilibrium (e.g. containing sieve textures). Augite compositions from suite $\mathrm{C} 2$ form a similar compositional trend to members $A$ and $B$ but extend to more Fe-rich compositions ( $\mathrm{En}_{3-28} \mathrm{Fs}_{32-56} \mathrm{Wo}_{38-43}$ ) with rims tightly clustered at the Fe-rich end $\left(\mathrm{En}_{4-41} \mathrm{Fs}_{53-55} \mathrm{WO}_{41-43}\right)$. Suite $\mathrm{C3}$ grains are homogenous, tightly clustered and plot within the $A$ and $B$ augite field ( $\left.\mathrm{En}_{7-11} \mathrm{Fs}_{48-52} \mathrm{Wo}_{39-44}\right)$ with the exception of one pigeonite grain (out of 15 analysed). Pyroxene crystals in the HRT are dominantly (normally) zoned (>60 \% of crystals in all suites: Fig. S5.17; Electronic Appendix 5.3).

\subsubsection{Olivine}

All olivines are fayalitic ( $\left.\mathrm{Fa}_{86-100}\right)$ but compositional diversity is present within the different juvenile clast types. Olivines in members A and B are similar in composition and encompass the entire range in the HRT (Fa86-100: Electronic Appendix 5.3), but some clustering is present. There is a bimodality in $\mathrm{CaO}$ compositions, with one cluster with elevated $\mathrm{CaO}$ contents $(\geq 0.32$ wt\%), dominated by crystals from J4-type pumices, in contrast to modal concentrations of 0.18-0.3 wt\% CaO from J1-type pumices (Fig. S5.18). A similar bimodality, although evident in different clast types, is present in $\mathrm{MgO}$ concentrations. A lower $\mathrm{MgO}$ cluster (1.4-1.8 wt\%) is 
defined by crystals from suite A1 samples, whereas olivines from other clast types define a cluster with a peak at 1.9-3.0 wt\% MgO (Fig. S5.19). Olivines in member C also show suitespecific variations. There is a narrower range in fayalite compositions (Fa94-100) than in members $\mathrm{A}$ and $\mathrm{B}$ but a greater range in $\mathrm{CaO}$ contents (0-0.41 wt\%: Fig. S5.18). There are distinct differences, however, between olivines from suites C1 and C2 compared to suite C3. Olivines from the latter are more similar to member A and B compositions, and overlap with the compositions from suite A3 olivines (1.43-2.34 wt\% MgO: Fig. S5.19). Olivines from the other $\mathrm{C}$ suites are predominantly elevated in $\mathrm{CaO}(0.24-0.41 \mathrm{wt} \%)$ with a minor group with $\leq 0.04$ wt\% $\mathrm{CaO}$. They also extend to lower $\mathrm{MgO}$ values $(0.44-1.48$ wt\% with a subset at $<0.03$ wt\%). Olivine crystals are unzoned and homogenous in all samples studied. However, they commonly show oxidation alteration features on rims and along fractures (Fig. S5.17) involving the conversion of original compositions to iron oxides and hydroxides. Such alteration is seen in other units from the YPVF (Troch et al. 2017).

\subsubsection{Accessory phases}

As previously documented (Macdonald and Belin 2002), chevkinite is present within the HRT (Fig. S5.17; Electronic Appendix 5.3). Individual phenocrysts $(0.5-1 \mathrm{~mm}$ ) are found predominantly within suite $A 3$ samples ( $9 \%$ of picked ferromagnesian minerals) but also occur in J1 samples from suite B1 (<1\% of picked ferromagnesian minerals) and suite C3 (3\% picked ferromagnesian minerals). Accessory apatite and zircon are also present. Fe-Ti oxide pairs are also present, but commonly one or both of the phases show evidence for exsolution.

\subsection{Estimates of intensive variables}

\subsubsection{Temperature}

Zirconium concentrations in groundmass glass were used to estimate pre-eruptive melt temperatures of juvenile materials using zircon saturation calibrations (Electronic Appendix 5.2). This was only done in samples where zircon was inferred to be stable through petrography or Zr concentrations (i.e. all except C3 suite samples). Due to the consistency of the Watson and Harrison (1983) calibration with other temperature estimates for the HRT (Myers et al. 2016; Swallow et al. 2018b, Chapter 3) we focus on this method here. Samples of $\mathrm{J} 1$ and $\mathrm{J} 2$-type clasts from members $\mathrm{A}$ and $\mathrm{B}$ yield a wide temperature range $\left(792-891^{\circ} \mathrm{C}\right)$, 
with suite $A 3$ pumices clustering at the cooler end of the range $\left(792-835{ }^{\circ} \mathrm{C}\right.$ : Fig. 5.18 ; Electronic Appendix 5.2). Suite A2 pumices give hotter temperatures (892-962 ${ }^{\circ} \mathrm{C}$ ) whereas glasses from scoria-bearing $\mathrm{J} 4$ pumices in member B yield a wide temperature range (820$948^{\circ} \mathrm{C}$ ). J7-type (i.e. suite C3) pumices yield comparably lower temperature estimates than their suite $A 3$ equivalents, with limited variations $\left(800-840{ }^{\circ} \mathrm{C}\right)$. In contrast, the wide glass compositional variation from J8-type samples result in wide temperature estimates (819$904{ }^{\circ} \mathrm{C}$ ) and a bimodal distribution (Fig. 5.18). If single-clast compositions are used for devitrified member $\mathrm{C}$ clasts (type J9) from the Red Mountains $\left(808{ }^{\circ} \mathrm{C}\right)$ and Huckleberry Mountain $\left(871-897^{\circ} \mathrm{C}\right)$, their temperature values are comparable to those of J8-type samples. The two-feldspar thermometry calibration of Elkins and Grove (1990) was also used on plagioclase inclusions in sanidine and vice versa (Electronic Appendix 5.3). All feldspar compositions were normalised to Cn-free (following Swallow et al. 2018b, Chapter 3). Samples from $\mathrm{J} 1$ and $\mathrm{J} 2$ clast types from members $\mathrm{A}$ and $\mathrm{B}$ show a large range in temperature estimates $\left(771-953^{\circ} \mathrm{C}\right)$ with medians of $842{ }^{\circ} \mathrm{C}$ and $857^{\circ} \mathrm{C}$ respectively, slightly hotter than the respective zircon saturation median temperature for each group (831 and $844{ }^{\circ} \mathrm{C}$ : Fig. 5.18). As with the zircon saturation temperature estimates, suite $A 3$ clasts are offset to cooler temperatures $\left(745-821^{\circ} \mathrm{C}\right)$ with a median of $787^{\circ} \mathrm{C}, \sim 20^{\circ} \mathrm{C}$ cooler than the zircon saturation median $\left(811^{\circ} \mathrm{C}\right)$. Feldspars from suite $\mathrm{A} 2$ pumices in member $\mathrm{A}$ yield hotter estimates (836$920^{\circ} \mathrm{C}$ ) that overlap with the cooler end of the zircon saturation range for the same sample. Wide temperature ranges occur in samples from member B: J1-type pumices yield a comparable range to member $\mathrm{A}\left(772-937^{\circ} \mathrm{C}\right)$, whereas scoria-bearing J4-type pumices extend to higher temperatures $\left(755-986^{\circ} \mathrm{C}\right)$. However, both ranges are comparable to those derived from zircon saturation estimates. Member C J7-type clasts exhibit a wider range than their member A (low-Ba) comparators $\left(767-860^{\circ} \mathrm{C}\right.$ ) but have an almost identical median temperature $\left(790{ }^{\circ} \mathrm{C}\right)$. J8-type samples show the largest temperature range of all compositional groups $\left(721-924^{\circ} \mathrm{C}\right)$ which encompasses the range in compositionally similar clasts from Huckleberry Mountain $\left(776-899^{\circ} \mathrm{C}\right)$. Sparse suitable feldspars from J5 clasts in member $C$ yield a wide range of temperature estimates, extending to cooler temperatures (647-808 $\left.{ }^{\circ} \mathrm{C}\right)$.

Utilising the presence of pigeonite compositions as cores or inclusions in augite crystals, two-pyroxene thermometry was also undertaken (Electronic Appendix 5.3). Out of 58 potential pairings, only four passed the Fe-Mg exchange equilibrium test of $K_{D}=1.09 \pm 0.14$ 


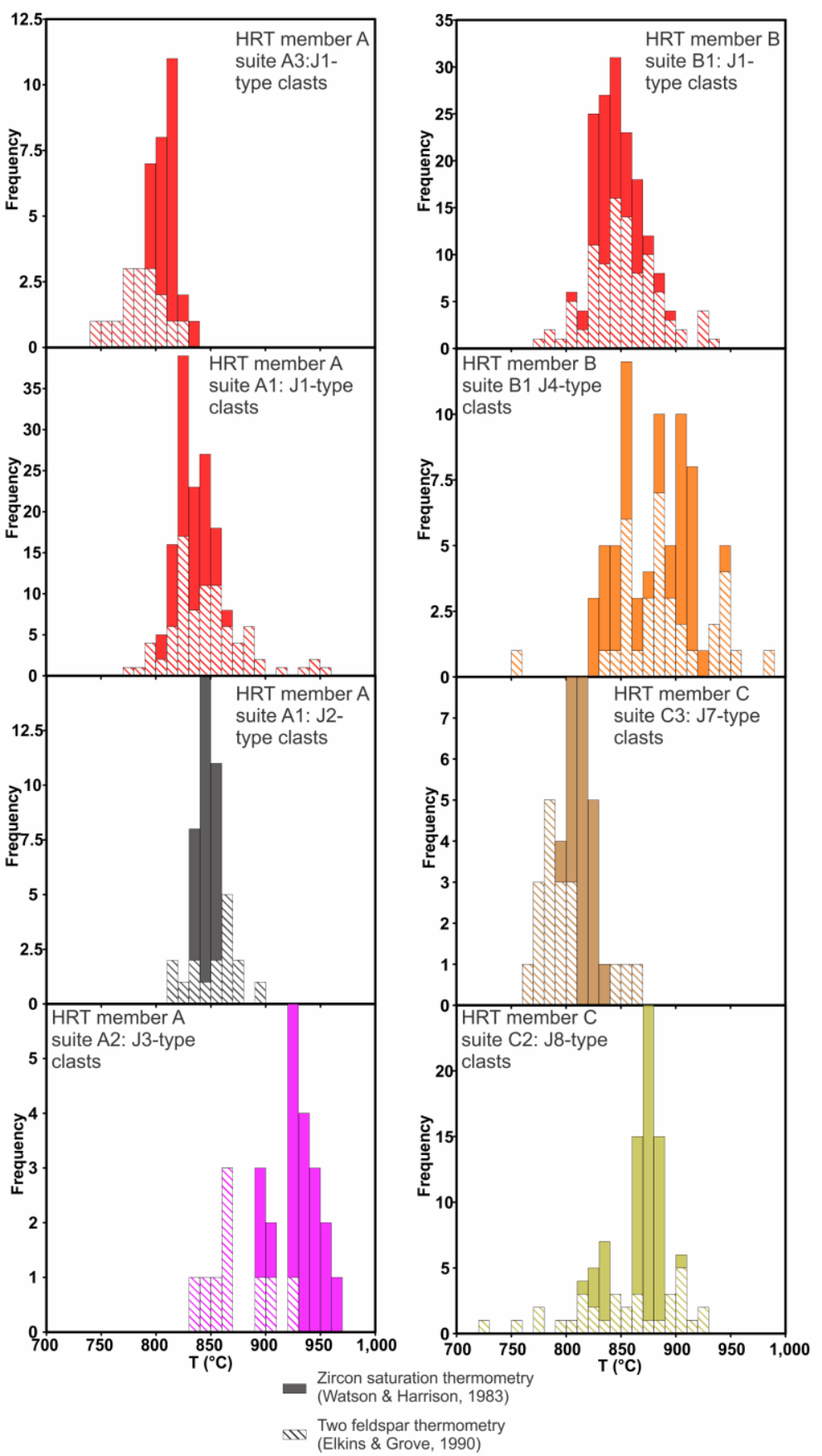

Figure 5.18: Model temperature estimates from different clast types from members $A, B$ and $C$ of the HRT. Temperatures estimates are derived using two feldspar (Elkins and Grove 1990) and zircon saturation (Watson and Harrison 1983) thermometry. Suite A3 samples yield cooler temperatures than suite $\mathrm{A} 1$ and $\mathrm{B} 1$ samples, and are similar to comparable low-Ba suite C3 pumices. Zircon saturation temperatures from suite $\mathrm{A} 2$ clasts are offset to elevated temperatures. J4-type mixed pumices yield a wide temperature range, encompassing suites $\mathrm{A} 1, \mathrm{~A} 2$ and $\mathrm{B} 1$ (J1-type) temperature estimates. Suite C2 samples yield a multi-modal temperature distribution consistent with a large compositional range. Frequencies from the two datasets are stacked. See Fig. 5.3 for colour and suite details. 
proposed by Putirka (2008). Using the calibration of Brey and Köhler (1990), temperature estimates are $817-1096^{\circ} \mathrm{C}$ from J1- $\left(872{ }^{\circ} \mathrm{C}\right), \mathrm{J4}-\left(1005^{\circ} \mathrm{C}\right)$, J8- $\left(1096^{\circ} \mathrm{C}\right)$ and J5-type $\left(817^{\circ} \mathrm{C}\right)$ crystals. Temperature estimations using the calibration for low Mg\# clinopyroxenes of Putirka (2008) yield seemingly implausible and inaccurate results (temperatures up to $1813^{\circ} \mathrm{C}$ ).

\subsubsection{Oxidation state and $\mathrm{H}_{2} \mathrm{O}$ content}

The presence of fayalite, magnetite and quartz in all compositional suites constrains the oxygen fugacity for the HRT magmas to be close to the QFM buffer. This inference is consistent with other studies of rhyolites along the Yellowstone-Snake River Plain volcanic track (Christiansen and McCurry 2008; Almeev et al. 2012; Befus and Gardner 2016).

The plagioclase-melt hygrometer of Waters and Lange (2015) was used to estimate preeruptive melt $\mathrm{H}_{2} \mathrm{O}$ contents (Electronic Appendix 5.3). Due to the temperature dependence of the calibration, and the wide range of two-feldspar thermometry estimates, we use zircon saturation thermometry estimates as inputs into the model. Other inputs are measured plagioclase rim compositions, mean major element compositions of groundmass glass (or single clast compositions in the case of devitrified member $\mathrm{C}$ samples), appropriate due to the homogeneity of major element glass compositions within each sample, and a pressure of 200 MPa (a mean pressure from Myers et al. 2016, Electronic Appendix 1). We use mean temperature estimates to calculate mean $\mathrm{H}_{2} \mathrm{O}$ contents. Samples from suite A1 yield 2.7-3.6 wt\% $\mathrm{H}_{2} \mathrm{O}$, a similar range to that from J1-type clasts in member B (suite B1: 2.1-3.6 wt\%). In comparison, maximum $\mathrm{H}_{2} \mathrm{O}$ contents in suite $\mathrm{A} 3$ pumices are higher $\left(3.8-4.0\right.$ wt\% $\mathrm{H}_{2} \mathrm{O}$ ) whereas contents in samples from suite A2 and J4-type clasts (suite B1) are lower (1.2-1.3 and 1.7-3.0 wt\% $\mathrm{H}_{2} \mathrm{O}$, respectively). In member $\mathrm{C}$, suite $\mathrm{C} 3$ pumices are similarly $\mathrm{H}_{2} \mathrm{O}$-enriched (3.7-4.0 wt\%) to their member A counterparts (suite A3), whereas in contrast suite C2 samples yield $\mathrm{H}_{2} \mathrm{O}$ contents of 2.0-3.5 wt\%, with one sample from the Red Mountains yielding 4.1 wt\%. The hygrometer yields unlikely maximum $\mathrm{H}_{2} \mathrm{O}$ estimations of $8.5 \mathrm{wt} \% \mathrm{H}_{2} \mathrm{O}$ for suite $\mathrm{C} 1$ samples, but this reflects implausibly low two-feldspar model temperatures (down to $647^{\circ} \mathrm{C}$ ) in these samples. 


\subsubsection{Pressure}

Pre-eruptive storage pressures were estimated from groundmass glass major element compositions using the DERP geobarometer of Wilke et al. (2017; Electronic Appendix 5.2). Glasses analysed in this study meet the requirements of the barometer, namely equilibration with quartz and at least one feldspar. J1- and J2-type clasts from member A (i.e. suite A1) yield a similar distribution and range of pressures from $\sim 100-450 \mathrm{MPa}$ (Fig. 5.19). The lower figure is consistent with the lowest pressures determined from quartz-hosted melt inclusion volatile contents from the initial fall deposits (80 MPa: Myers et al. 2016). J3-type (i.e. suite A2) clasts from member A yield an offset to greater pressure estimates (predominantly >800 MPa: Fig. 5.19), although these figures are outside the range of model calibration (Wilke et al. 2017). Although some samples return impossibly negative pressures, J1-type clasts in member B (i.e. suite B1) yield a broader distribution of pressures than their counterparts in member A, but have similar mean and median values (318 and $325 \mathrm{MPa}$, respectively, in member A; 312 and $319 \mathrm{MPa}$ in member B). Scoria-bearing clasts in member B exhibit a bimodal distribution, with one mode similar to J1-type clasts (mode peak 325 MPa), and another at higher pressures (mode peak 800 MPa: Fig. 5.19). Glasses from member C pumices show overlapping distributions, with J8-type sample glass extending to lower pressures (mean of $201 \mathrm{MPa}$, median $225 \mathrm{MPa}$ ) compared to $J 7$ samples (mean $256 \mathrm{MPa}$, median $273 \mathrm{MPa}$ ), while the latter estimates are closely similar to their member A suite A3 comparators (mean $266 \mathrm{MPa}$, median $273 \mathrm{MPa})$.

However, the pressure estimates can only be as precise as the data inputted. We tested the model using an average major element glass composition from all analyses in this study and absolute 2sd EPMA uncertainties (notably $\mathrm{SiO}_{2} \pm 1.16 \mathrm{wt} \%$ and $\mathrm{K}_{2} \mathrm{O} \pm 0.48 w t \%$ ). Using these uncertainties about the glass mean yield approximate differences in model pressures of $\pm 50 \mathrm{MPa}$ from $\mathrm{SiO}_{2}$ and $\pm 100 \mathrm{MPa}$ from $\mathrm{K}_{2} \mathrm{O}$ analytical uncertainties. These variations in model pressures are much greater than the range for different $\mathrm{H}_{2} \mathrm{O}$ contents. Variations in input $\mathrm{H}_{2} \mathrm{O}$ contents of \pm 2 wt\%, around a starting point of the mean glass composition and 4 wt\% $\mathrm{H}_{2} \mathrm{O}$, yield pressure differences of approximately $\pm 20 \mathrm{MPa}$. As a result, pressure differences of less than $\sim 200 \mathrm{MPa}$ are effectively unresolvable with analytical uncertainties attained in this study. This is important to note as pressures estimated using EPMA data on (hydrated) natural glasses can be a recurring focal point of debate regarding the nature of large magmatic systems (cf. Gualda and Ghiorso 2013; Chamberlain et al. 2015). 

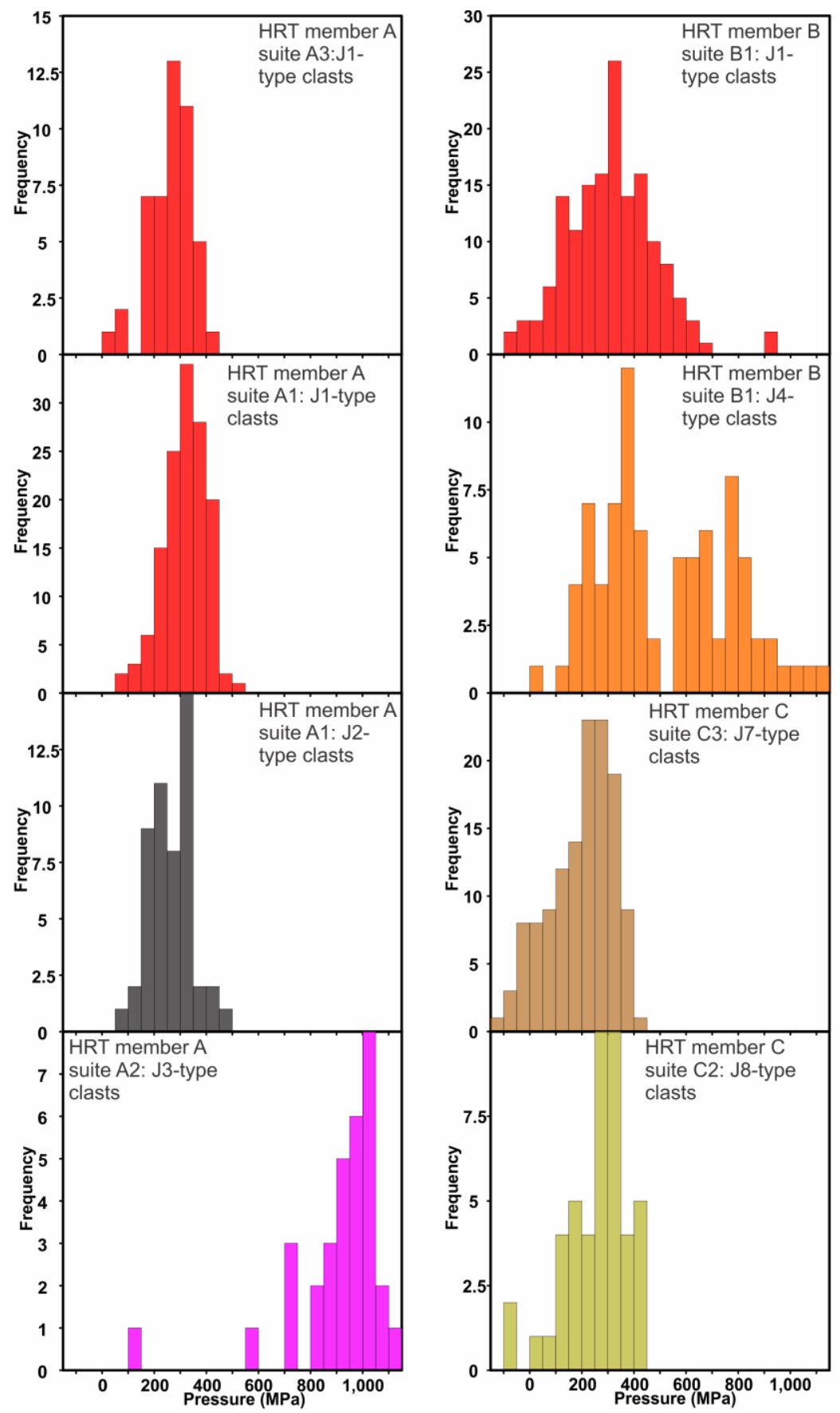

Figure 5.19: Model pressure estimates from different clast types from members $A, B$ and $C$ of the HRT. Suites (A1, B1, etc.) are defined from compositional groupings (see text for details). Pressure estimates are derived from groundmass glass major element compositions using the calibration of Wilke et al. (2017). Similar modal pressures are observed in suites A1, A3 and B1 (J1-type pumices). Suite A2 samples yield elevated pressures, although this is out of the range of the calibration (Wilke et al. 2017). J4-type mixed pumices yield bimodal pressure estimates, with one peak consistent with suites $A 1, A 2$ and $B 1$, and another broader peak of elevated pressure. Suites $C 2$ and $C 3$ have overlapping pressure ranges, consistent with peaks observed in suites A1, A3 and B1. See Fig. 5.3 for colour and suite details. 


\subsection{Discussion}

\subsubsection{Multiple magmatic systems in the HRT}

Major, trace element, and isotopic compositions of single clasts, coupled with their associated glass (where available) and mineral compositional characteristics, are taken to indicate the presence of four magmatic systems that were active prior to and evacuated at different times during the HRT eruption. The pronounced differences between the geochemistries of each system indicate that these are discrete systems (e.g. Cooper et al. 2012, 2016) and not subtly different components of a heterogeneous single system (e.g. Bégué et al. 2014). The key features of each system are summarised in Table 5.4 and discussed in more detail below. For clarity also, we refer to the whole assemblage of systems that were vented during the HRT eruption as a magmatic complex.

\subsubsection{Magmatic system 1}

Magmatic system 1 is volumetrically-dominant within the HRT, feeding the majority of the initial fall deposits and basal ignimbrite (FGC/OGC3 and IGC2-8; Swallow et al. 2018b, Chapter 3), and HRT members A and B (Fig. 5.20). It comprises compositional suites $A 1, A 2$ and $B 1$, the latter linking the earlier distinct compositional fields of the A1 and A2 suites. This system shows a wide elemental compositional range (e.g. 454-2792 ppm Ba) but moderate isotopic range (e.g. ${ }^{87} \mathrm{Sr} /{ }^{86} \mathrm{Sr}_{\mathrm{AC}}=0.71009-0.71256$ : Figs. 5.6, 5.11). The single clast compositions are enriched in alkalis, $\mathrm{Al}_{2} \mathrm{O}_{3}, \mathrm{Zr}$ and $\mathrm{Ba}$, and depleted in $\mathrm{FeO}, \mathrm{CaO}, \mathrm{Sr}$ and $\mathrm{Sc}$ relative to other systems (Figs. 5.3-5.9, S5.5, S5.8). Clustered glass compositions are indicative of multiple melt-dominant bodies (Figs. 5.14, 5.15), some of which were tapped from the start of the eruption (Myers et al. 2016) and others of which first vented at the onset of ignimbrite emplacement (Swallow et al. 2018b, Chapter 3). In its mineralogical characteristics, sanidines from this system contain dominantly $>0.4 \mathrm{~mol} \% \mathrm{Cn}$ and although pigeonite cores are present, clinopyroxene rims are Fe-rich and tightly clustered (Figs. 5.16, 5.17).

\subsubsection{Magmatic system 2}

Magmatic system 2 is minor in volume when compared to system 1 and comprises the lowBa material in the initial fall deposits (FGC/OGC1+2, IGC1; Swallow et al. 2018b, Chapter 3) and member $A$ (suite $A 3$ ), is absent from member $B$ but reappears in member $C$ (suite C3; 


\begin{tabular}{|c|c|c|c|c|c|c|}
\hline $\begin{array}{l}\text { Magmatic } \\
\text { system }\end{array}$ & $\begin{array}{l}\text { Members, suites } \\
\text { and clast types }\end{array}$ & $\begin{array}{l}\text { Major element } \\
\text { characteristics }\end{array}$ & $\begin{array}{l}\text { Trace element } \\
\text { characteristics }\end{array}$ & Isotopic characteristics & Glass characteristics & $\begin{array}{l}\text { Crystal } \\
\text { characteristics }\end{array}$ \\
\hline $\begin{array}{l}\text { Magmatic } \\
\text { system } 1\end{array}$ & $\begin{array}{l}\text { Members A and } \\
\text { B. Suites A1 (J1- } \\
\text { and J2-type } \\
\text { clasts) and A2 (J3- } \\
\text { type) in member } \\
\text { A, that are linked } \\
\text { in member B by } \\
\text { suite B1 (J1-, J3- } \\
\text { and J4-type } \\
\text { clasts) }\end{array}$ & $\begin{array}{l}\text { - High in alkalis, } \\
\mathrm{Al}_{2} \mathrm{O}_{3} \\
\text { - Depleted in } \\
\mathrm{FeO}, \mathrm{CaO}\end{array}$ & $\begin{array}{l}\text { - Large range in } \\
\text { Ba and } \mathrm{Zr} \\
\text { - Low Sr and Sc } \\
\text { abundances } \\
\text { - None to } \\
\text { negative Eu } \\
\text { anomaly }\end{array}$ & $\begin{array}{l}\text { - Moderately radiogenic } \\
\text { isotope systematics } \\
\text { - Increasing }{ }^{87} \mathrm{Sr} /{ }^{86} \mathrm{Sr}_{\mathrm{AC}} \text { with } \\
\text { increasing } 1 / \mathrm{Sr} \text { and decrease in } \\
\mathrm{Ba} \\
\text { - Constrained } \mathrm{Pb} \text { isotopic ratios } \\
\text { identical to HRT mafics. }\end{array}$ & $\begin{array}{l}\text { - Clustered } \\
\text { compositions } \\
\text { - Similar to FGC/OGC3 } \\
\text { and IGC2-8 in the fall } \\
\text { deposit and basal } \\
\text { ignimbrite } \\
\text { - Suite A2 unique to } \\
\text { member A, gap with } \\
\text { A1 infilled by J4-type } \\
\text { pumices in member B }\end{array}$ & $\begin{array}{l}\text { - }>0.4 \text { mol\% Cn in } \\
\text { sanidines } \\
\text { - Orthopyroxene } \\
\text { cores/inclusions, } \\
\text { clinopyroxene rims } \\
\text { - Olivines in J4- } \\
\text { type clasts have } \\
\text { higher CaO }\end{array}$ \\
\hline $\begin{array}{l}\text { Magmatic } \\
\text { system } 2\end{array}$ & $\begin{array}{l}\text { Members A and } \\
\text { C. Suites A3 (J1- } \\
\text { type pumices) } \\
\text { and C3 (J7-type } \\
\text { clasts) }\end{array}$ & $\begin{array}{l}\text { - Similar to } \\
\text { magmatic } \\
\text { system } 1\end{array}$ & $\begin{array}{l}\text { - Elevated } \mathrm{Nb}, \mathrm{Rb} \\
\text { - Low } \mathrm{Ba}, \mathrm{Sr}, \mathrm{LREE} \\
\text { - Moderate to } \\
\text { high negative Eu } \\
\text { anomaly }\end{array}$ & $\begin{array}{l}\text { - Similar to system } 1 \text { for } \mathrm{Pb} \text { and } \\
\mathrm{Nd} \text { isotopes and } \mathrm{Sr} \text { in member } \mathrm{A} \\
\text { - Regeneration in member } \mathrm{C} \\
\text { contains less radiogenic } \\
{ }^{87} \mathrm{Sr} /{ }^{86} \mathrm{Sr}_{\mathrm{AC}}\end{array}$ & $\begin{array}{l}\text { - Low } \mathrm{Ba} \text { and } \mathrm{Sr} \\
\text { (similar to } \\
\text { FGC/OGC1+2 and } \\
\text { IGC1) }\end{array}$ & $\begin{array}{l}\text { - Low (<0.35 mol\%) } \\
\text { Cn sanidines } \\
\text { - Lower MgO } \\
\text { olivines relative to } \\
\text { system } 1\end{array}$ \\
\hline $\begin{array}{l}\text { Magmatic } \\
\text { system } 3\end{array}$ & $\begin{array}{l}\text { Member C. Suite } \\
\text { C2 comprised of } \\
\text { J8-type pumices } \\
\text { together with J9- } \\
\text { and rare J5-type } \\
\text { clasts }\end{array}$ & $\begin{array}{l}\text { - Offset to } \\
\text { higher } \mathrm{SiO}_{2} \text { from } \\
\text { the system } 1 \\
\text { trends } \\
\text { - Low in alkalis } \\
\text { - Moderate in } \\
\text { FeO and } \mathrm{TiO}_{2}\end{array}$ & $\begin{array}{l}\text { - Trend back to } \\
\text { higher } \mathrm{Ba}, \mathrm{Sr}, \mathrm{Zr} \\
\text { - Low } \mathrm{Nb}, \mathrm{LREE} \text {, } \\
\text { - No Eu anomaly } \\
\text { to moderately } \\
\text { negative Eu } \\
\text { anomaly }\end{array}$ & $\begin{array}{l}\text { - Highly radiogenic isotopic } \\
\text { systematics } \\
\text { - Negative }{ }^{208} \mathrm{~Pb} /{ }^{204} \mathrm{~Pb} \\
\text { correlation with }{ }^{206} \mathrm{~Pb} /{ }^{204} \mathrm{~Pb} \\
\text { - Positive correlation between } \\
{ }^{87} \mathrm{Sr} /{ }^{86} \mathrm{Sr}_{\mathrm{AC}} \text { and } 1 / \mathrm{Sr}\end{array}$ & $\begin{array}{l}\text { - Clustered } \\
\text { compositions } \\
\text { - Offset to higher Ba, } \\
\text { Sr and lower } \mathrm{La}, \mathrm{Zr} \\
\text { compared to system } 1 \\
\text { - Negatively correlated } \\
\text { Ba and La }\end{array}$ & $\begin{array}{l}\text { - Fe-rich olivines } \\
\text { and clinopyroxenes } \\
\text { - High Cn sanidine }\end{array}$ \\
\hline $\begin{array}{l}\text { Magmatic } \\
\text { system } 4\end{array}$ & $\begin{array}{l}\text { Member C. Suite } \\
\text { C1 comprised of } \\
\text { J5- and J6-type } \\
\text { juvenile clasts }\end{array}$ & $\begin{array}{l}\text { - Elevated in } \\
\mathrm{FeO}, \mathrm{CaO}, \mathrm{P}_{2} \mathrm{O}_{5} \\
\text { and } \mathrm{TiO}_{2} \\
\text { - Low in } \mathrm{Al}_{2} \mathrm{O}_{3} \\
\text { and alkalis }\end{array}$ & $\begin{array}{l}\text { - Elevated in Sr } \\
\text { and Sc } \\
\text { - Low in } \mathrm{Ba}, \mathrm{Zr} \text {, } \\
\text { Nb and LREE } \\
\text { - No Eu anomaly }\end{array}$ & $\begin{array}{l}\text { - Highly radiogenic isotopic } \\
\text { systematics } \\
\text { - Negative }{ }^{208} \mathrm{~Pb} /{ }^{204} \mathrm{~Pb} \\
\text { correlation with }{ }^{206} \mathrm{~Pb} /{ }^{204} \mathrm{~Pb} \\
\text { - Positive correlation between } \\
{ }^{87} \mathrm{Sr} /{ }^{86} \mathrm{Sr}_{\mathrm{AC}} \text { and } 1 / \mathrm{Sr}\end{array}$ & $\begin{array}{l}\text { - N/A- only ever found } \\
\text { as devitrified clasts }\end{array}$ & $\begin{array}{l}\text { - Continuum in } \\
\text { compositions } \\
\text { between ortho- } \\
\text { and clinopyroxene } \\
\text { - Calcic plagioclase }\end{array}$ \\
\hline
\end{tabular}




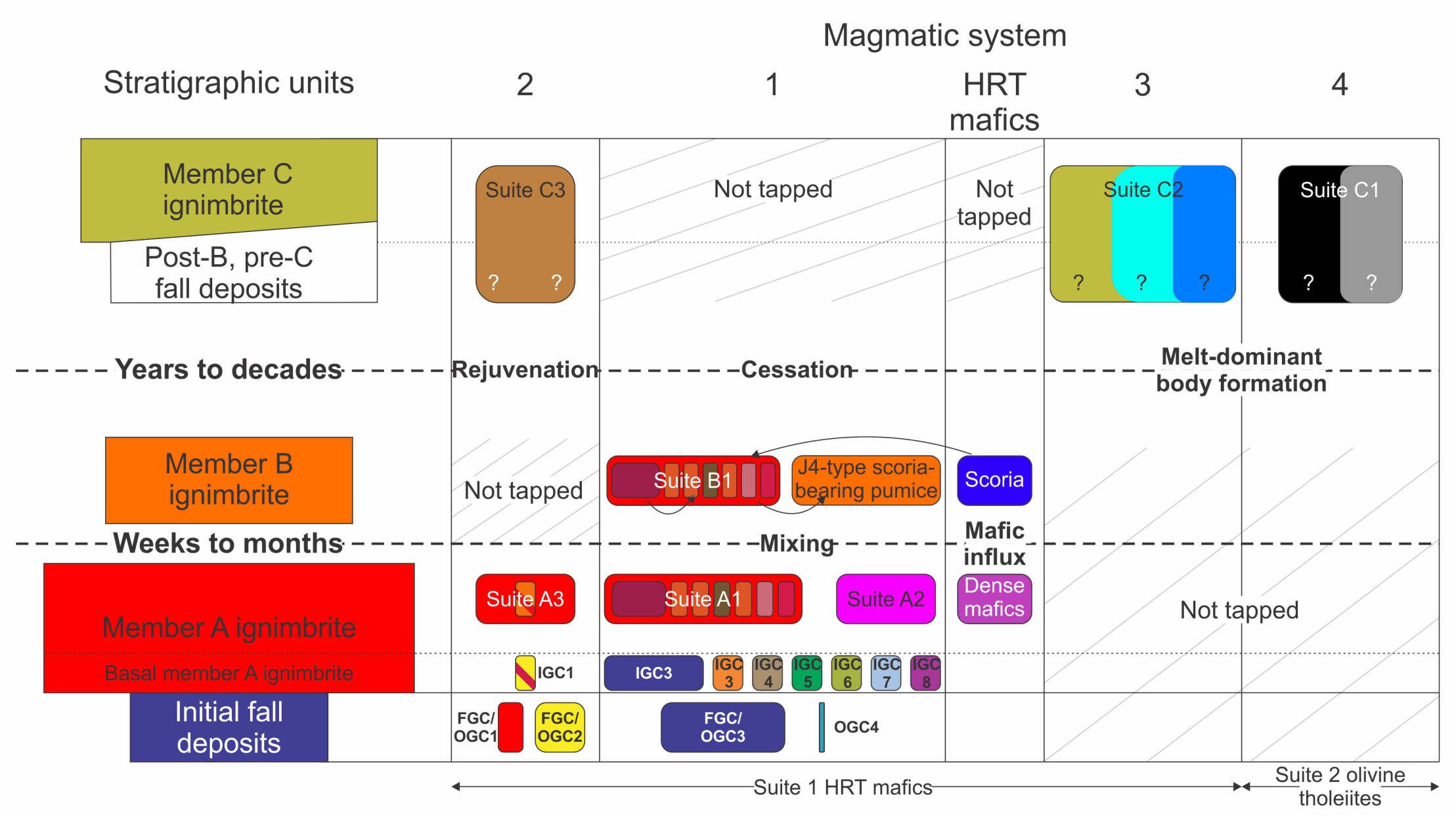

Figure 5.20: Schematic diagram showing the broad eruptive timescale and stratigraphy of the HRT (CJN Wilson, manuscript in preparation) along with the four inferred silicic magmatic systems (with their associated magmatic suites and mafic root zones) tapped during the eruption. Magmatic systems 1 and 2 were active in the initial fall deposits and ignimbrite member A with only system 1 evacuated in member $B$. Member $C$, following a time break, evacuated a rejuvenated magmatic system 2 and newly formed melt-dominant bodies of magmatic systems 3 and 4 . Colours as in the figures in chapter 3 , this chapter. 
Fig. 5.20). Although suite $A 3$ has comparable isotopic compositions to the suites from magmatic system 1, suite C3 samples are less radiogenic for a given elemental value (e.g. Ba: Fig. 5.12). Although compositions of materials from magma system 2 could be argued to fall on a continuum of those for suite A1 (e.g. Figs. 5.3-5.7), the contrasting evacuation history relative to the magmatic system 1 , its distinctive sanidine $(<0.35 \mathrm{~mol} \% \mathrm{Cn}$ : Fig. 5.16$)$ and olivine compositions (Fig. S5.19), and the lack of evidence for mixing/mingling with any other compositional trend distinguish it as a separate magmatic system albeit related to magmatic system 1 . The finer-scale vesicular texture in member $C$ pumices and notably smaller crystal sizes, notwithstanding the isotopic compositions, preclude suite C3 materials from simply being recycled magma or pick-up clasts from member A deposits. It is thus inferred that this system was vented at the very start of the eruption and throughout the fall deposit and member A ignimbrite activity, ceased venting through member B activity, reactivated to produce new melt-dominant magma during the $\mathrm{B}: \mathrm{C}$ time break (Fig. 5.2), then vented during eruption of member $\mathrm{C}$.

\subsubsection{Magmatic system 3}

Magmatic system 3 is represented by suite $C 2$ and is the dominant lineage in member $C$ and probably the second largest system within the HRT (Fig. 5.20). Suite C2 covers a comparable compositional range to the suites in magmatic system 1 (e.g. Ba 409-2279 ppm: Fig. 5.6) but is offset to higher silica concentrations. This system exhibits a unique compositional trend with large variations in trace elements occurring over narrow $\mathrm{SiO}_{2}$ ranges (75-78 wt\%; e.g. Figs. 5.6, 5.7, 5.9). It is depleted in $\mathrm{Nb}(27-32 \mathrm{ppm})$ relative to member $\mathrm{A}$ and $\mathrm{B}$ samples but has moderate $\mathrm{FeO}(1.2-6.1 \mathrm{wt} \%)$ and $\mathrm{TiO}_{2}$ (0.12-0.56 wt\%) concentrations (Figs. 5.5, 5.8, S5.4). Similarly to the suite C1 samples of magmatic system 4 (and despite their elemental differences), this magmatic system has highly radiogenic isotopic signatures (e.g. ${ }^{87} \mathrm{Sr} /{ }^{86} \mathrm{Sr}_{\mathrm{AC}}=$ 0.72590-0.73026: Figs. 5.11-5.13; cf. Doe et al. 1982). Glass compositions of samples from this system are clustered, indicating the likely presence of multiple melt-dominant bodies (Figs. 5.14, 5.15; cf. Myers et al. 2016; Swallow et al. 2018b, Chapter 3), although glass compositional trends are offset from those in members A and B. Characteristic crystal compositions include Fe-rich olivines and Cn-rich sanidines (Figs. 5.16, S5.18, S5.19). 


\subsubsection{Magmatic system 4}

Magmatic system 4 is represented by suite $\mathrm{C} 1$ and is the minor of the two newly erupted systems represented in member $\mathrm{C}$. Despite their low $\mathrm{SiO}_{2}$ values, suite $\mathrm{C} 1$ samples return remarkably radiogenic isotopic compositions (e.g. ${ }^{87} \mathrm{Sr}^{86}{ }^{8} \mathrm{Sr}_{\mathrm{AC}}=0.72464-0.72486$ : Fig. 5.11). Suite $\mathrm{C} 1$ is distinctly elevated in $\mathrm{CaO}, \mathrm{FeO}, \mathrm{Sc}$ and $\mathrm{Sr}$, and lower in $\mathrm{Al}_{2} \mathrm{O}_{3}, \mathrm{Ba}$ and $\mathrm{Nb}$ relative to other magmatic systems (Figs. 5.4-5.9, S5.5). In Ba contents, its trend with respect to silica points back towards and is aligned with the trend shown by the YPVF olivine tholeiite lavas sampled by Swallow et al. (2018a, Chapter 4; Fig. 5.20), in sharp contrast to other HRT rhyolitic suites and their close relationships to HRT mafic compositions. Like other member C material, suite C1 samples have small crystal sizes $(<2 \mathrm{~mm})$ and contain pyroxenes that form a continuum between pigeonite and augite fields (Fig. 5.17).

\subsubsection{Petrogenesis of melts}

\subsubsection{Magmatic systems 1 and 2}

As single-clast major element compositions are indistinguishable between suites $A 1$ and $A 3$, and these suites are are isotopically similar (e.g. Figs. 5.3-5.5, 5.13), we link magmatic systems 1 and 2 here, and propose a common petrogenetic history. Prior to this study, it was thought that due to the dominance of mafic compositions by olivine tholeiites, YPVF rhyolites (including the HRT) were generated by the partial melting of solidified tholeiitic intrusions (Doe et al. 1982; Hildreth et al. 1991; Christiansen and McCurry 2008). However, mafic material in the HRT (as documented by Swallow et al. 2018a, Chapter 4) is more similar to the enriched Craters of the Moon mafic suite described from elsewhere in the Snake River Plain area (Leeman et al. 1976; Christiansen and McCurry 2008; Putirka et al. 2009). Elemental and isotopic characteristics of magmatic systems 1 and 2 strongly indicate a petrogenetic link to the Craters of the Moon-like HRT mafic material. The high alkalis, Ba and Zr coupled with the low $\mathrm{CaO}$ contents of this system are coherent with the HRT mafic compositional trend (Figs. $5.3,5.6, \mathrm{~S} 5.5, \mathrm{~S} 5.8)$. In particular, the $\mathrm{Pb}$ isotopic compositions of samples representing magmatic systems 1 and 2 are coincident with those of HRT scoria samples (Fig. 5.13), suggesting that the root zone from which was generated the HRT mafics also gave rise to the these silicic systems. Based on this feature, we explore the petrogenesis of magmatic system 1 , focusing on the least-evolved compositions (i.e. least-evolved suite A1 compositions and 
the $A 2$ suite) initially before discussing intra-suite variations and the relationships between magmatic systems 1 and 2 .

Clasts from magmatic systems 1 and 2 have more radiogenic ${ }^{87} \mathrm{Sr} /{ }^{86} \mathrm{Sr}_{\mathrm{AC}}$ ratios than any of the mafic components found within the HRT (Fig. 5.12). However, the increase is minor (in comparison to the differences with member C) and ${ }^{143} \mathrm{Nd} /{ }^{144} \mathrm{Nd}$ compositions are similar in the rhyolitic and mafics samples (Fig. 5.11). These still-moderate Sr isotopic values argue against a significant role for country rock in the formation of magmatic systems 1 and 2, as surrounding upper-crustal lithologies are dominantly Archean and have highly radiogenic Sr isotopic characteristics (e.g. Doe et al. 1982; Wooden and Mueller 1988; Hildreth et al. 1991; Frost et al. 2006). In detail, however, Sr isotopic compositions form an asymptotic increasing trend when plotted against indices of melt evolution (e.g. increasing Rb/Sr, decreasing Ba: Fig. 5.12). This increase, and the offset of the silicic components in members $A$ and $B$ to higher ${ }^{87} \mathrm{Sr} /{ }^{86} \mathrm{Sr}_{\mathrm{AC}}$ values at similar elemental concentrations relative to the mafic suites (e.g. Ba: Fig. 5.12), implies some incorporation of a radiogenic component during melt evolution. This component cannot be any of the member $\mathrm{C}$ melts (magmatic systems 3 and 4 ) with their crustally-influenced (i.e. upper-crustal) isotopic signatures, due to the lack of mixing trends in elemental (e.g. $\mathrm{Nb}$ ) and isotopic (e.g. Pb) compositions (Figs. 5.8, 5.13). However, the moderate changes in isotopic values observed within magmatic systems 1 and 2 (relative to systems 3 and 4) and slight positive correlation with 1/Sr (particularly relative to magmatic system 3), suggest that the final evolution of systems 1 and 2 magma was dominantly controlled by fractional crystallisation. This conclusion is similar to that for the compositionally similar Cedar Butte domes by McCurry et al. (2008) who also noticed minor changes towards more radiogenic (crustal) Sr-isotopic signatures correlated with melt evolution. It is also supported by the relative uniformity of $\mathrm{Nd}$ isotopic compositions (which are less susceptible to crustal contamination) with degrees of fractionation (Fig. S5.10; Wolff et al. 2015).

As assimilation is thus inferred to be of secondary importance in generating magmatic systems 1 and 2, we focus on closed-system processes linked to the HRT mafics for the formation of the least evolved compositions within these systems, specifically fractional crystallisation from a HRT mafic-like parent or partial melting of a protolith of related composition. Analogues to these HRT silicic compositions are the rhyolites of Cedar Butte dome in the eastern Snake River Plain, which have been interpreted to reflect extensive 
( $~ 80 \%, 4.3 \mathrm{kbar}$ ) fractional crystallisation of a basaltic trachyandesite parent, comparable in composition to the HRT mafics (McCurry et al. 2008; Whitaker et al. 2008; Swallow et al. 2018a, Chapter 4).

As magmatic system 2 is isotopically related to, but distinct from the volumetricallydominant magmatic system 1 , we focus primarily on the petrogenesis of magmatic system 1 and specifically suites A1 and A2 (as suite B1 is a combination of these). Key geochemical features that need to be considered in any petrogenetic model are as follows.

1) A large compositional gap in $\mathrm{SiO}_{2}(\sim 10 \mathrm{wt} \%$, excluding the macroscopically mingled member A scoria) between the most evolved HRT mafics and the suite A2 samples, then a smaller gap ( $\sim 1 \mathrm{wt} \% \mathrm{SiO}_{2}$ ) between suites $\mathrm{A} 2$ and $\mathrm{A} 1$ (Figs. 5.3-5.5).

2) Stepwise decreases in some major $\left(\mathrm{TiO}_{2}, \mathrm{FeO}, \mathrm{P}_{2} \mathrm{O}_{5}\right.$, and $\left.\mathrm{CaO}\right)$ and trace elements (e.g. $\mathrm{Ba}, \mathrm{Zr}$, Sr, Sc) between the main field of HRT mafics and suites A1 and A2 (Figs. 5.5-5.9, S5.3$\mathrm{S} 5.5, \mathrm{~S} 5.8)$. Of these, $\mathrm{Ba}$ and $\mathrm{Zr}$ show broad increases in the HRT mafics whereas $\mathrm{TiO}_{2}, \mathrm{FeO}$, $\mathrm{P}_{2} \mathrm{O}_{5}, \mathrm{CaO}, \mathrm{Sr}$ and $\mathrm{Sc}$ show broad decreases.

3) Comparable but somewhat scattered $\mathrm{Al}_{2} \mathrm{O}_{3}$ concentrations between the most-evolved samples of the HRT mafics suite and suite $\mathrm{A} 2$, as well as comparable $\mathrm{Nb}$ and $\mathrm{Rb}$ concentrations, which were increasing with $\mathrm{SiO}_{2}$ in the HRT mafics (Figs. 5.4, 5.8). $\mathrm{Al}_{2} \mathrm{O}_{3}$ then decreases with increasing $\mathrm{SiO}_{2}$ from suites $\mathrm{A} 2$ to $\mathrm{A} 1$, whereas $\mathrm{Nb}$ and $\mathrm{Rb}$ tend to increase (Fig. S5.20).

4) A decrease in LREE concentrations (e.g. La) with increasing $\mathrm{SiO}_{2}$ through the HRT mafics suite, similar values maintained across the compositional gap to suite $A 2$, then an offset to higher LREE abundances in the least-evolved suite A1 compositions that then subsequently decrease with increasing $\mathrm{SiO}_{2}$ (Fig. 5.10). This pattern is in contrast to the Cedar Butte trend (McCurry et al. 2008) where there is a continuous increase in LREE compositions within intermediate compositions to a peak at $\sim 70 \mathrm{wt} \% \mathrm{SiO}_{2}$ prior to what was there inferred to be the onset of chevkinite crystallisation.

5) The absence of a large negative Eu anomaly $\left(\mathrm{Eu}^{*}=0.94\right)$ in the suite $\mathrm{A} 2$ material, as also noted in the HRT mafics (Swallow et al. 2018a, Chapter 4), but in contrast to all samples from suite $\mathrm{A} 1$ that show negative Eu anomalies (0.25-0.56) and a relative depletion in MREE relative to the HRT mafics (Fig. S5.9).

We first focus on the generation of the least-evolved compositions of the volumetrically dominant A1 suite, before discussing the compositionally-related A2 suite. Large compositional gaps in major elemental compositions are a characteristic feature of 
Yellowstone-Snake River Plain volcanism (Hildreth et al. 1991; Christiansen 2001; Christiansen and McCurry 2008; Szymanowski et al. 2015). The paucity of intermediate compositions is generally inferred to reflect silicic magma genesis through partial melting of mafic intrusive rocks rather than extreme fractionation of a mafic parent (Hildreth et al. 1991; Christiansen and McCurry 2008), with compositional/density characteristics suppressing eruption of the mafic compositions. However, the relationship of intermediate composition melt inclusions to fractional crystallisation (Szymanowski et al. 2015) and evidence for extreme fractionation of a mafic parent at Cedar Butte (McCurry et al. 2008; Whitaker et al. 2008) means that a similar fractionation model for the HRT is worth exploring. Although the compositional gap between suites $\mathrm{A} 1$ and $\mathrm{A} 2$ is clear in terms of major element compositions, it is not replicated in incompatible trace elements. Elements inferred to be highly incompatible (e.g. $\mathrm{Rb}, \mathrm{Nb}, \mathrm{U}$ ) show comparable concentrations either side of the compositional gap, with increasing concentrations (versus $\mathrm{SiO}_{2}$ ) on either side but a plateau across the gap. Therefore, when plotted together, these incompatible elements show a broad continuum between HRT mafics, suite A2 and suite A1 material (Fig. S5.20). These relationships are inconsistent with a simple fractional crystallisation model and would require coincidental changes in behaviour of these diverse elements at intermediate compositions. Although the decrease in $\mathrm{Zr}$ and $\mathrm{Ba}$ values between the HRT mafics and the silicic samples implies the onset of zircon and sanidine crystallisation (Figs. 5.6, S5.8), respectively, and the change in LREE behaviour between the HRT mafics and least-evolved suite A1 samples (Fig. 5.10) requires a reduction/cessation in apatite crystallisation, the crystallisation of these phases is unlikely to have influenced $\mathrm{Rb}$ or $\mathrm{Nb}$ concentrations. We therefore conclude that extreme fractional crystallisation of a HRT mafic parent is implausible as the sole mechanism for generation of the silicic suites.

As an alternative, we consider the oft-invoked mechanism of generating Yellowstone rhyolites through partial melting of a solidified tholeiitic mafic intrusive at mid-crustal levels (Hildreth et al. 1991; Christiansen 2001; Christiansen and McCurry 2008). However, as magmatic systems 1 and 2 are related to the COM-type HRT mafics, not tholeiitic compositions (Swallow et al. 2018a, Chapter 4), we focus on partial melting of a protolith of related composition. Simple, end-member, one-stage partial melting scenarios include the following:

1) Partial melting of a source similar in composition to the most-evolved of the HRT mafics suite. This scenario is unlikely due to comparable concentrations of strongly incompatible 
elements (e.g. $\mathrm{Nb}, \mathrm{Rb}$ ) between the most-evolved HRT mafic and the suite A2 material (Fig. S5.20). Any partial melting event would, in contrast, generate melts enriched in incompatible elements. Generation of melts with similar incompatible element concentrations to the protolith would require either large degrees of partial melting and/or an increase in compatibility of the elements in residual phases. The former process would require almost $100 \%$ melting of the protolith, which in turn is precluded by large increases $\left(\mathrm{SiO}_{2}\right)$ and decreases (e.g. Ba, Zr) in other elements between the two compositional suites. Although the bulk compatibility of $\mathrm{Rb}$ would be elevated with residual alkali feldspar (suggested by the decrease in $\mathrm{Ba}$ ), $\mathrm{Nb}$ concentration changes would require the presence of a $\mathrm{Nb}$-rich phase, for which evidence is lacking (Swallow et al. 2018a, Chapter 4).

2) Partial melting of a cumulate derived from the HRT mafics suite. Although fractional crystallisation does not explain all the features of the HRT mafic compositional range (Swallow et al. 2018a, Chapter 4), some crystallisation and therefore cumulate formation is likely. This cumulate would contain apatite (decrease in $\mathrm{P}_{2} \mathrm{O}_{5}, \mathrm{LREE}$ ), plagioclase (broad decrease in $\mathrm{Sr}$ ) and pyroxene (decrease in Sc with increasing $\mathrm{SiO}_{2}$ ). Partial melting of such a cumulate would therefore generate melts enriched in these elements relative to the melts from which the cumulate formed. However, the HRT silicic compositions are further depleted in $\mathrm{P}_{2} \mathrm{O}_{5}, \mathrm{Sr}$ and Sc than any compositions within the mafics suite.

We thus conclude that a multi-stage fractionation-partial melting mechanism is required to generate the silicic melts, involving compositions not observed at the surface (Fig. 5.21). This scenario is broadly similar to the plutonic root cannibalisation model of Reubi and Blundy (2008) for generating andesites. Under the assumption that the protolith is intrusive, and at least in part of cumulative composition, the constraints on this scenario are as follows.

1) Generation of an initial melt composition that is more evolved than the most-evolved HRT mafic samples, but coherent with the HRT mafics trend. This initial melt would have Nb, $\mathrm{Rb}$ and other incompatible element concentrations higher than those of the HRT mafics, suite A2 samples and the least-evolved suite A1 material. To compensate, the protolith for these suites must be depleted in these elements, indicating partial loss of melt prior to solidification/rejuvenation. The solidified form of this melt, having been partially or fully depleted in melt, would be incompatible element depleted. Melting of this material would therefore generate melts with moderately enriched concentrations of incompatible elements, which would be similar to the suite $A 2$ and least-evolved suite $A 1$ samples. 
2) The protolith must be sanidine- and zircon-bearing to explain the decreases in $\mathrm{Ba}$ and $\mathrm{Zr}$ contents across the $\mathrm{SiO}_{2}$ compositional gap. Sanidine and zircon are inferred to begin crystallising at a similar evolutionary stage at Cedar Butte (McCurry et al. 2008), albeit slightly earlier $\left(\sim 62 \mathrm{wt} \% \mathrm{SiO}_{2}\right)$ than in this study $\left(\sim 65 \mathrm{wt} \% \mathrm{SiO}_{2}\right)$. Subsequently, these minerals would remain in the residuum during partial melting. This proposed scenario is not precluded by the continued increase in $\mathrm{K}_{2} \mathrm{O}$ across the compositional gap, however, due to the elevated compatibility of $\mathrm{Ba}$ in sanidine relative to $\mathrm{K}(\operatorname{Ren} 2004)$.

3) Continued decreases of $\mathrm{P}_{2} \mathrm{O}_{5}, \mathrm{Sc}$ and $\mathrm{Sr}$ throughout the entire sequence imply continuing roles for apatite, pyroxene and plagioclase fractionation. The role for pyroxene in the cumulate residuum is further supported by the depression of MREE in the silicic samples, the compatibility of which is seen in other silicic systems (Fig. S5.9; Olin and Wolff 2010). However, although $\mathrm{P}_{2} \mathrm{O}_{5}$ continues to decrease throughout the sequence, LREE concentrations become decoupled from $\mathrm{P}_{2} \mathrm{O}_{5}$ abundances and plateau across the compositional gap before increasing between suites A2 and A1 (Fig. S5.21). This decoupling could be related to the very low $\mathrm{P}_{2} \mathrm{O}_{5}$ contents in suites $\mathrm{A} 1$ and $\mathrm{A} 2$ (Fig. S5.3).

Within these constraints, we therefore propose a two-stage evolutionary pathway for the least-evolved suite A1 compositions (Fig. 5.21). Mafic magmatism associated with the Yellowstone plume injected a plexus of sills and dykes in the lower-mid crust of HRT mafic compositions. Melt loss depleted the intrusions in $\mathrm{Nb}, \mathrm{Rb}$ and $\mathrm{U}$. The resulting magma solidified to a broadly trachyandesitic ( 65 wt\% $\left.\mathrm{SiO}_{2}\right)$, sanidine-, plagioclase-, pyroxene-, apatite- and zircon-bearing intrusion. Partial melting of this intrusion would subsequently generate a Ba- and Zr-poorer low-silica rhyolite partial melt. The variable evolutionary trends across the compositional spectrum within the HRT, in contrast to the simpler, more consistent trends found at Cedar Butte (McCurry et al. 2008), require a multi-stage petrogenetic model for the high-silica rhyolites of the A1 suite in the HRT.

The role of the suite $A 2$ compositions, especially in relation to the least-evolved suite A1 compositions, is constrained by 1 ) the compositional gap and offset in single clast and glass LREE compositions between the two suites (Figs. 5.3, 5.14, 5.15), and 2) the similar, but marginally less radiogenic isotopic signatures and the absence of an Eu anomaly in suite A2 magmas (Figs. 5.12, S5.9). The three main sources for suite A2 we discuss below are firstly, mixing between the HRT mafics and suite A1 high-silica rhyolite, secondly, as a less-evolved parent to the A1 suite, or thirdly, as a partial melt of a cumulate, or mush, related to the 

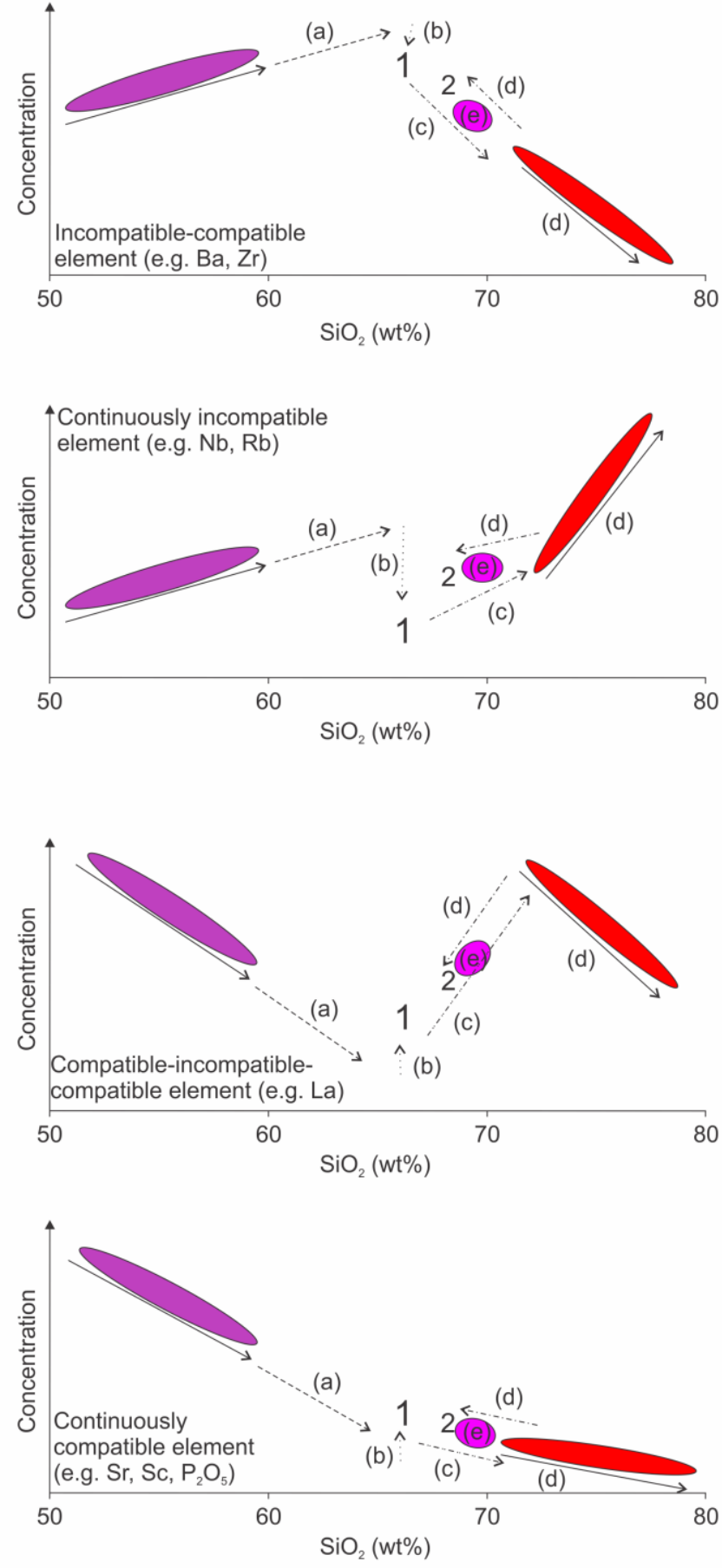

\begin{tabular}{|ll|}
\hline & Intra-suite trend \\
\hdashline & Continued compositional evolution \\
& Inferred melt loss \\
\hdashline & Cumulate formation \\
& Partial melting and fractional crystallisation \\
& Suite M1 \\
& Suite A2 \\
& Suite A1 \\
1 & Protolith for suite A1 \\
2 & Protolith for suite A2
\end{tabular}

Figure 5.21: Semi-quantitative plots showing trends of different element behaviours (i.e. compatible, incompatible) in magmatic system 1 (suites $A 1, A 2$ and $\mathrm{B} 1$ ) and the proposed petrogenetic mechanism for suites $\mathrm{A} 1$ and $\mathrm{A} 2$. Irrespective of element behaviour, five consistent stages are proposed. (a) Continued evolution of a HRT mafic-type melt to an intermediate composition ( $\sim 65$ wt\% $\mathrm{SiO}_{2}$ ). (b) Partial melt loss, indicated by comparable $\mathrm{Nb}, \mathrm{Rb}$ contents between most evolved HRT mafics and suite A2. Residue (either solidified or partially molten) forms protolith 1 . This protolith is sanidine and zirconbearing. (c) Partial melting of protolith 1 generates melts depleted in $\mathrm{Ba}, \mathrm{Zr}$ and enriched in $\mathrm{Nb}, \mathrm{Rb}$ and La. (d) Simultaneous intra-suite crystal fractionation evolution of suite $A 1$ and cumulate formation. This cumulate is similarly sanidine and zircon-bearing and forms protolith 2. (e) Partial melting of protolith 2 forms suite $A 2$ that is enriched in $\mathrm{Ba}$ and $\mathrm{Zr}$ and depleted in $\mathrm{Nb}$ and $\mathrm{Rb}$ relative to suite A1. See Fig. 5.3 and text for suite details. 
evolution of the A1 suite.

The formation of low-silica rhyolitic material in the root zones of silicic systems, particularly where there is evidence for intruding mafic magmas, has been related to mixing of mafic material and the least-evolved magmas of the main silicic body (e.g. Rattlesnake Tuff: Streck and Grunder 1999). Although the HRT similarly displays rhyodacite forming an intermedial composition between mafic enclaves and high-silica rhyolite, we argue against a similar model here. Unlike the Rattlesnake Tuff dacitic clasts, suite A2 samples in the HRT show no physical evidence of mingling. Furthermore, A2 suite compositions are offset from a tie-line between the least-evolved high-silica rhyolite and the HRT mafics (e.g. in La and $\mathrm{P}_{2} \mathrm{O}_{5}$ : Figs. 5.10, S5.3).

Alternatively, the role of low-silica rhyolite in high-silica systems has been interpreted as representing the precursor, or 'feedstock,' for the main high-silica rhyolite body (e.g. Oruanui: Allan et al. 2017). This interpretation is supported for the HRT by the coherency of the suite A1 and A2 compositions, particularly with regard to compatible elements (e.g. Ba, Zr: Figs. 5.6, S5.8), although this coherency does not, as previously noted, extend to LREE concentrations. In addition, crystal textures are variable within the suite A2 material. Sanidine crystals occasionally contain Ba-rich overgrowths and the compositions of rims are typically lessevolved than the cores (Figs. 5.16, S5.16), inconsistent with growth as phenocrysts in an evolving melt-dominant magma body. Furthermore, the zircon saturation temperature estimates are offset to higher temperatures than two-feldspar model temperatures in suite A2 samples (Fig. 5.18). This is in contrast to alignment between the models in other juvenile component types, which are inferred to be controlled by fractional crystallisation. As such, any interpretation of the suite A2 magma type as a direct precursor to the suite A1 rhyolites is unlikely.

Melting of cumulate compositions has often been invoked for generating compositional variation within silicic magmatic systems (Deering et al. 2011; Bachmann et al. 2014; Wolff et al. 2015; Wolff 2017). Although this process is thought to primarily occur in 'cold-wet' silicic systems (Wolff et al. 2015) and not in Yellowstone-Snake River Plain rhyolites, which are considered 'hot-dry' systems (Branney et al. 2008; Loewen and Bindeman 2016), we consider this possibility. We note that the HRT suite A2 compositions extend up to, but not across, the trachyte-rhyolite boundary (Fig. 5.3). Wolff (2017) focuses on the role of trachytes forming an endpoint to the evolution of magma compositions in alkaline suites but we believe that the 
reverse is applicable to the HRT. Evolution of the A1 suite is driven by a feldspar-rich crystallisation assemblage (predominantly sanidine). This evolution is indicated by the continued increase in $\mathrm{SiO}_{2}$ throughout the sequence and the earlier onset of sanidine crystallisation relative to quartz at all $\mathrm{H}_{2} \mathrm{O}$ contents in experimental studies on material of similar compositions (Almeev et al. 2012). Therefore, any resulting mush will be dominated by sanidine, and less-evolved than both the initial magma composition and the residual melt, extracted to form the melt-dominant body (or bodies) atop the mush zone. The presence of remaining interstitial melt, however, would ensure continued silica oversaturation in the sanidine-dominant, syenitic mush and subsequent melting of this crystal-rich residuum would therefore yield trachytic magmas (Wolff 2017). Melting of this fusible crystal-rich residuum would require an influx of heat and/or volatiles, which elsewhere is commonly attributed to the influx of mafic magma (Deering et al. 2011; Bachmann et al. 2014; Wolff et al. 2015; Wolff 2017), demonstrably present in both members A and B (Christiansen 2001; Swallow et al. 2018a, Chapter 4). Furthermore, the less-evolved, more Ba-rich rim compositions on sanidines from suite $A 2$ samples, and elevated zircon saturation model temperatures relative to two-feldspar model temperatures indicate a heating event that is plausibly related to genesis of the suite A2 magma type. Significant incorporation of melt from the intruding mafic magma, if similar to compositions erupted as mafic enclaves, is unlikely due to the relatively low LREE contents in the suite A2 samples.

Therefore it is proposed that magma, with a composition intermediate between the suite A2 and least-evolved suite A1 materials, i.e. in the compositional gap, was formed through partial melting of an intermediate protolith (protolith 1) and began to evolve through the crystallisation of a feldspar-dominant assemblage (with accessory ferromagnesian minerals, apatite and zircon: Fig. 5.21). The resultant melts, parental to suite $A 1$, became enriched in LREE, $\mathrm{Nb}$, and $\mathrm{Rb}$, and depleted in $\mathrm{Ba}, \mathrm{Zr}$ and $\mathrm{Sr}$. The onset of chevkinite crystallisation began to lower LREE concentrations in the subsequent melts (e.g. McCurry et al. 2008). Variable degrees of crystallisation led to a heterogeneous mush from which were extracted multiple melt-dominant bodies that experienced further evolution. An increase in temperature due to an influx of mafic magma into the lower mush zone then led to partial melting of the feldspar rich cumulate (protolith 2) and formation of the LREE depleted suite A2 magma. This petrogenetic model differs from that proposed for Cedar Butte (McCurry et al. 2008) due to 
the contrasting LREE-enriched low-silica rhyolite suite A1 samples relative to LREE-depleted suite A2 material in the HRT.

Glass compositions in the initial fall deposits and basal member A ignimbrite (Swallow et al. 2018b, Chapter 3) cover the same compositional range as glasses in suite A1 and A3 samples. This range can be modelled by $\sim 60 \%$ crystallisation from the least- to most-evolved compositions. The additional data presented here permit further evaluation of the mechanisms for the suite A1 compositional trend. Isotopic data, showing increasing ${ }^{87} \mathrm{Sr} /{ }^{86} \mathrm{Sr}_{\mathrm{AC}}$ with degrees of evolution (e.g. increasing $\mathrm{Rb} / \mathrm{Sr}$, decreasing Ba: Fig. 5.12), indicate some degree of assimilation. However, although single clast elemental and isotopic data show a simple and coherent trend, glass data are clustered and show two evolutionary trends, one inter-cluster and another, inclined intra-cluster trend (Figs. 5.14, 5.15). For this to be controlled by assimilation, two assimilants affecting all the separated melt-dominant bodies would need to be present. Furthermore, considering the likely radiogenic nature of shallow crustal assimilants in the Yellowstone region (Doe et al. 1982), large scale assimilation is precluded. Although some younger, less radiogenic silicic rocks occur in the region (e.g. Meen and Eggler 1989), these are too un-radiogenic to be plausible contaminants because the amounts required to cause the isotopic variations are not matched by any accompanying major element variations (Figs. S5.11- S5.13).

Another possibility to explain the compositional variation in suite $A 1$ is through mixing between a highly-evolved magma (i.e. suite A3) and a less-evolved end member. Of analysed compositions, the latter can only be represented by suite A2 or mafic magmas. Single clast and glass LREE (e.g. La) compositional trends preclude both scenarios, however, with the suite A1 compositions trending away from both possible end members (Figs. 5.10, 5.14). Consequently, the predominant variations within the suites $A 1$ and $A 3$ samples are inferred to be predominantly driven by fractional crystallisation. This inference is supported by the curved trend between $\mathrm{Rb} / \mathrm{Sr}$ and $\mathrm{SiO}_{2}$ in J1-type samples, in contrast to the linear trend shown by member B J4-type mingled pumices (Fig. S5.22). Elemental and isotopic diversity within the suites $\mathrm{A} 1$ and $\mathrm{A} 3$ can be attributed to a mildly heterogeneous mush source, with variations in concurrent dominant sanidine-controlled fractional crystallisation and minor assimilation, generating the inter-cluster trends. Extraction and ascent of magmas from this source initiated a more plagioclase-dominant crystallisation assemblage, possibly through changing pressure, generating shallower-sourced intra-suite trends as inferred in Swallow et al. (2018b, 
Chapter 3). It could be considered that magmatic system 2 represents further crystallisation of the same parental melts. However, its distinctive nature (e.g. sanidine core and rim compositions; absence from member $B$ ) and independent rejuvenation for member $\mathrm{C}$ (see discussion below) indicate that it is separated from the magmatic system 1 and the focus of mafic inputs, due to the absence of any evidence for mixing of suite A3 and mafic compositions. This separation of the magmatic system 2 would explain the offset to cooler temperatures and the compositional gap between suite $\mathrm{A} 3$ and the evolved end of the A1 suite (Figs. 5.6, 5.18).

\subsubsection{Magmatic systems 3 and 4}

In contrast to earlier products of the HRT eruption, most juvenile materials from member $\mathrm{C}$ show significantly more radiogenic signatures. The values are diverse, but are comparable to the two (whole rock) values from member C reported by Doe et al. (1982), used by Hildreth et al. $(1984,1991)$ and interpreted as representing up to $45 \%$ of an Archean crustal contaminant. Whilst a radiogenic (crustal) component is implicated in the generation of the magmatic systems 3 and 4 , what is striking in the data set presented here is the isotopic uniformity but chemical dichotomy between these systems (Fig. 5.12). Variations in $\mathrm{Sr}$ isotopic ratios, coupled with relatively uniform $\mathrm{Nd}$ and $\mathrm{Pb}$ ratios, have been related to lower Sr concentrations in YPVF rhyolitic melts and therefore greater susceptibility to isotopic modification by assimilation (Hildreth et al. 1991; Wolff et al. 2015). The compositional suites representing the two member $\mathrm{C}$ systems have significantly different $\mathrm{Sr}$ concentrations (suite suite $\mathrm{C} 1=228-321 \mathrm{ppm} ; \mathrm{C} 2=17-182 \mathrm{ppm}$ ) and thus require independent consideration. Both systems, however, have similar more radiogenic $\mathrm{Sr}$ and $\mathrm{Pb}$ and less radiogenic $\mathrm{Nd}$ compositions (Figs. 5.11, 5.13), collectively indicative of crustal contamination. Contamination is also indicated by the positive trends between ${ }^{87} \mathrm{Sr} /{ }^{86} \mathrm{Sr}_{\mathrm{AC}}$ and $\mathrm{Rb} / \mathrm{Sr}$ and $1 / \mathrm{Sr}$ (Fig. 5.12). Although ${ }^{206} \mathrm{~Pb} /{ }^{204} \mathrm{~Pb}$ and ${ }^{207} \mathrm{~Pb} /{ }^{204} \mathrm{~Pb}$ ratios are more radiogenic than the member $\mathrm{A}$ and $\mathrm{B}$ magmatic systems, ${ }^{208} \mathrm{~Pb} /{ }^{204} \mathrm{~Pb}$ ratios are less radiogenic and negatively correlated with other $\mathrm{Pb}$ isotope ratios (Fig. 5.13). This contrast points to a crustal component with low initial Th/ $U$ that was involved in the generation of both member $\mathrm{C}$ systems. This component, however, is likely to be Archean in age, due to the ${ }^{206} \mathrm{~Pb} /{ }^{204} \mathrm{~Pb}$ versus ${ }^{207} \mathrm{~Pb} /{ }^{204} \mathrm{~Pb}$ slope defined by HRT silicic samples yielding a pseudochron age of 3.05 Ga (Fig. S5.23), similar to the 2.63.0 Ga pseudochrons from each of the three mafic suites analysed in Swallow et al. (2018a, 
Chapter 4). Consequently, the assimilant requires $\mathrm{Pb}$ isotopic ratios of ${ }^{206} \mathrm{~Pb} /{ }^{204} \mathrm{~Pb} \geq 17.9$, ${ }^{207} \mathrm{~Pb} /{ }^{204} \mathrm{~Pb} \geq 15.7$ and ${ }^{208} \mathrm{~Pb} /{ }^{204} \mathrm{~Pb} \leq 37.9$. Although two samples (quartzofeldspathic gneisses 95PRP1, 96PRP1) from Frost et al. (2006) have suitable Pb isotopic signatures, their $\mathrm{Sr}$ and $\mathrm{Nd}$ isotopic ratios are too high and low, respectively, to be plausible end-member assimilants. Despite this, published geochemical data of regional crustal material, all related to the Archean Wyoming craton, exhibits a wide range of elemental and isotopic compositions (e.g. Wooden and Mueller 1988; Hildreth et al. 1991; Frost et al. 2006). This indicates that although no suitable end member composition is available in the literature, the presence of a plausible assimilant of Archean-age, with crust-like isotopic characteristics, low initial Th/U compositions and with variable elemental chemistry is not unlikely.

Magmatic system 3 spans a large compositional range (e.g. 409-2279 ppm Ba: Fig. 5.6) and forms a unique compositional trend (suite C2) within the HRT. Isotopic data imply that a significant contributor to the high $\mathrm{SiO}_{2}$ suite is Archean crust with initial Th/U depletion. The correlation between increasing ${ }^{87} \mathrm{Sr} /{ }^{86} \mathrm{Sr}_{\mathrm{AC}}$ values and degrees of evolution in the suite (e.g. increasing $\mathrm{Rb} / \mathrm{Sr}$, decreasing Ba: Fig. 5.12) indicates that assimilation was also important in generating the intra-suite variation. However, the curved trend shown by $\mathrm{Rb} / \mathrm{Sr}$ ratios (Fig. S5.22) suggests fractional crystallisation was the dominant process for controlling intra-suite trend variation (as seen in magmatic systems 1 and 2). Overall decreasing Sr, Ba, Zr and Sc abundances within the whole suite attests to feldspar, zircon and pyroxene fractionation within the magmatic system (Figs. 5.6, 5.7, 5.9, S5.8). This inference is supported by the increasing sizes of the Eu anomalies with evolution in the J8-type pumices (Fig. S5.9). Clustered glass and single clast compositions from J8-type pumices that almost cover the entire range in suite $\mathrm{C} 2$ (411-2157 ppm Ba) indicate the system included multiple meltdominant bodies (Figs. 5.14, 5.15). The kinked nature of the trend in the glass $\mathrm{Sr} / \mathrm{Rb}$ versus $\mathrm{Ba} / \mathrm{Rb}$ ratios (Fig. 5.15) would require two assimilants that are not indicated by single clast elemental or isotopic compositions, further supporting the inferred fractional crystallisation control. Therefore, it is likely that this kinked trend is controlled by variations in the crystallising assemblage, with initial plagioclase-dominant followed by sanidine-dominant fractionation, as reflected qualitatively through percentages of picked crystals (Electronic Appendix 5.3). Similarly, the intra-cluster trends also indicate continued evolution following formation of the individual bodies. 
The parental melt for magmatic system 3 is notably elevated in $\mathrm{Ba}, \mathrm{Zr}$ and $\mathrm{Sr}$, and depleted in $\mathrm{Nb}$ and $\mathrm{Rb}$ relative to that for magmatic systems 1 and 2 that were tapped for members $\mathrm{A}$ and B. As the isotopic systematics indicate a strong crustal component, we consider partial melting/assimilation of country rocks as a main petrogenetic mechanism. Although the influence of compositions represented by a high-Ba granitoid (YR275) lithic found in member $\mathrm{C}$ ignimbrite seems possible in some regards, its low $\mathrm{Zr}$ and unradiogenic $\mathrm{Pb}$ isotopic values preclude it from having a significant role in petrogenesis of the parental magma. However, the presence of a high- $\mathrm{Ba}$, low- $\mathrm{Nb}$ granitoid is useful in inferring the parental magma formation. The low $\mathrm{Nb}$ and $\mathrm{Rb}$ of the suite requires the influence of at least one residuum component, comprising a feldspar and zircon rich assemblage. The high $\mathrm{Ba}$ and $\mathrm{Zr}$ contents of suite 2 magmas imply that any mafic magmatic component is related to the HRT mafic compositions rather than olivine tholeiites. The interaction could be direct (i.e. mixing of HRT mafic melts and partial melts of a silicic cumulate) or indirect (i.e. mixing of partial melts from cumulates of both HRT mafics and a highly silicic assimilant). Pb isotopic compositions of suite 2 samples also align with the HRT mafics and members A and B field. However, potential melts associated with the HRT mafics, either direct mafic magmas or partial melts of derivative cumulates, would be low silica (realistically $\leq 70 \mathrm{wt} \% \mathrm{SiO}_{2}$ ), much less evolved than the $\sim 75$ $w t \% \mathrm{SiO}_{2}$ of the least-evolved compositions in this system. Simple binary mixing to generate the least-evolved high $\mathrm{SiO}_{2}$ trend magma would therefore require a highly silicic end member. The highest $\mathrm{SiO}_{2}$ sample analysed from this system is $78 \mathrm{wt} \% \mathrm{SiO}_{2}$ (YP366). If that is used as a silicic end-member then at least $\sim 50 \%$ of crustal contribution is required. In addition to being highly silicic, this assimilant would also need to be enriched in $\operatorname{Sr}(\sim 250-350 \mathrm{ppm})$ and depleted in $\mathrm{Na}_{2} \mathrm{O}+\mathrm{K}_{2} \mathrm{O}$ ( 6-7 wt\%), $\mathrm{Ba}(\sim 1500-2500$ ppm), $\mathrm{Zr}(\sim 250-500 \mathrm{ppm})$ and $\mathrm{Nb}(\sim 15-$ $25 \mathrm{ppm}$ ) relative to the more primitive end member. Given that documented shallow crustal rocks in the region extend to measured ${ }^{87} \mathrm{Sr} /{ }^{86} \mathrm{Sr}=0.89$ (Frost et al. 2006), a $\sim 0.2$ increase in ${ }^{87} \mathrm{Sr} /{ }^{86} \mathrm{Sr}_{\mathrm{AC}}$ isotopic values between the HRT mafics and magmatic system 3 is permitted by this model. Although it is challenging to constrain mixing models with limited constraints on the end members, this is a logical scenario for the generation of the least-evolved compositions of magmatic system 3 . The presence of intergrown feldspars and disequilibrium textures (e.g. sieve textures) in feldspars in this suite also provide evidence for partial melting of a feldspathic cumulate (Fig. S5.16). 
In sharp contrast, magmatic system 4, in many trace elements (e.g. Ba, Zr, La: Figs. 5.6, 5.10, S5.8) aligns with the field of YPVF olivine tholeiites (Swallow et al. 2018a, Chapter 4). However, it diverges from all mafic end members in other elements, including $\mathrm{Al}_{2} \mathrm{O}_{3}$, alkalis (both poorer than mafic end members), $\mathrm{FeO}, \mathrm{CaO}, \mathrm{Sc}$ and $\mathrm{Sr}$ (all elevated) suggesting a broad relation to olivine tholeiites, but not simple mixing between a tholeiitic melt and a high-silica component (Figs. 5.3-5.5, 5.7, 5.9, S5.5). The high FeO, $\mathrm{CaO}$ and $\mathrm{Sc}$ and low $\mathrm{Al}_{2} \mathrm{O}_{3}$ contents are indicative of a dominant role for clinopyroxene in genesis of the system. Cryptic clinopyroxene fractionation at $>25 \mathrm{~km}$ depths has been inferred for olivine tholeiites erupted in the YPVF (Thompson 1975; Hildreth et al. 1991). Consequently, there would be large quantities of pyroxene-rich cumulates in the mid-lower crust beneath Yellowstone related to the olivine tholeiite mafic root zone and represented in xenoliths of this assemblage found in lavas erupted just west of the HRT caldera (Leeman et al. 1985; Hildreth et al. 1991). The moderate $\mathrm{Sr}$, low $\mathrm{Al}_{2} \mathrm{O}_{3}$ and lack of large positive $\mathrm{Eu}$ anomalies in the suite $\mathrm{C} 1$ compositions mitigate against large degrees of plagioclase melting, consistent with an apparent preferential melting of pyroxene over plagioclase in these cumulate assemblages (Leeman et al. 1985) and the pyroxene-dominant cumulates predicted at higher pressures (Thompson 1975; Hildreth et al. 1991). The enriched isotopic signatures and elevated $\mathrm{Fe}, \mathrm{Ti}$ and $\mathrm{P}$ in some tholeiitic Yellowstone basalts (e.g. Gerrit and Snake River tholeiites) has also been attributed to interaction with apatite- and pyroxene-rich cumulates (Hildreth et al. 1991). We, therefore, propose that melting of such cumulates by further influx of tholeiitic magmas, coupled with mixing with surrounding radiogenic Archean crustal material, generated the suite C1 compositions defining magmatic system 4.

\subsubsection{Pre-eruptive intensive variables of the HRT magmatic systems}

Although geochemically distinct, proxies allow us to investigate the nature of intensive variables (i.e. temperature, $\mathrm{H}_{2} \mathrm{O}$ contents) within the magmatic systems prior to eruption. As inferred in Swallow et al. (2018b, Chapter 3), low-Ba suite A3 pumices yield cooler temperatures $\left(\sim 20-30^{\circ} \mathrm{C}\right)$ than their higher Ba equivalents (Fig. 5.18). Chemically-similar suite $\mathrm{C} 3$ clasts yield similar temperature estimates, with $a<5{ }^{\circ} \mathrm{C}$ increase in temperature compared to suite $A 3$ samples. Both suites show a peak of two-feldspar temperature estimates offset to cooler $\left(\sim 20^{\circ} \mathrm{C}\right)$ than zircon saturation temperatures, greater than the $\leq 15^{\circ} \mathrm{C}$ error associated 
with individual two feldspar temperature estimates. This could represent influx of slightly hotter, less evolved melt shortly before eruption.

Hotter temperature estimates from J1- and J2-type samples from members $A$ and $B$, and zircon saturation temperatures of up to $891{ }^{\circ} \mathrm{C}$ that are broadly similar to two-feldspar estimates (although the latter extend up to $953^{\circ} \mathrm{C}$ : Fig. 5.18), are analogous to what is seen in the non-welded basal member A ignimbrite (Swallow et al. 2018b, Chapter 3). Temperature estimates from suite $A 2$ samples, not seen in the basal ignimbrite, exhibit zircon temperatures (up to $963^{\circ} \mathrm{C}$ ) hotter than either the two-feldspar estimates from the same sample or those in suite A1 samples. Temperature estimates from scoria-bearing $\mathrm{J} 4$ pumices in member B show variable temperature estimates, but contain a mode intermediate between the two aforementioned groups $\left(\sim 900^{\circ} \mathrm{C}\right)$. Suite $\mathrm{C} 2$ clasts also show variable temperatures, particularly two-feldspar estimates. The bimodal zircon saturation thermometry distribution is due to the wide variations in single clast and glass compositions found in samples (Fig. 5.14). The wide temperature range indicated by the two thermometers in multiple magmatic systems, is similar to, but offset to higher temperatures than the $\sim 100{ }^{\circ} \mathrm{C}$ range suggested by Rivera et al. (2014) from Ti in zircon thermometry, using an assumed constant value for $\alpha_{\text {TiO2. }}$. The combined estimates do suggest, however, that there was significant thermal variation $\left(>100^{\circ} \mathrm{C}\right.$ ) within the HRT magmatic complex (i.e. across all four magmatic systems) prior to eruption.

As only a small fraction (4/58) of two-pyroxene pairs satisfied equilibrium conditions (Electronic Appendix 5.3), temperature estimates derived from pyroxene calibrations should therefore be treated with caution, as also noted by Bolte et al. (2015). Temperatures from these estimates, however, are typically offset to higher values than model temperatures yielded from other thermometers used in this study, consistent with the notion in YSRP-type silicic eruptives that pyroxene is an early crystallising phase (Almeev et al. 2012). Although pyroxene compositions have probably limited use in understanding the HRT magmatic temperature regime, the presence of pigeonite only as cores or inclusions provides further insights. In contrast to the HRT, the 'hot and dry' (Branney et al. 2008) Snake River Plain ignimbrites commonly have co-existing population(s) of phenocrystic pigeonite and augite within any one eruption (Cathey and Nash 2004; Ellis and Wolff 2012). Experimental work on these materials (Almeev et al. 2012; Bolte et al. 2015) provides constraints, as follows. 
- At water contents of $<0.5 \mathrm{wt} \%$, pigeonite is a near-liquidus phase $\left(\sim 1000^{\circ} \mathrm{C}\right)$ but augite replaces pigeonite as the earliest-forming pyroxene at higher water contents (Almeev et al. 2012).

- Augite was not observed in experiments at $\mathrm{H}_{2} \mathrm{O}>1.3 \mathrm{wt} \%$ (Almeev et al. 2012).

- Ca-rich augite compositions (i.e. $>40$ mol\% Wo), as seen predominantly in rim compositions in the HRT, are only observed in experiments with moderate-high melt $\mathrm{H}_{2} \mathrm{O}$ contents ( $>1 \mathrm{wt} \%$ at $925^{\circ} \mathrm{C}$ to $>3 \mathrm{wt} \%$ at $825^{\circ} \mathrm{C}$ : Almeev et al. 2012).

- Augite is generally stable at lower temperatures than pigeonite and the range in conditions where both can co-exist is narrow (Bolte et al. 2015).

These constraints suggest that the HRT magmatic complex and its melt-dominant bodies were initially $\mathrm{H}_{2} \mathrm{O}$-poor, and that pigeonite, possibly with co-existing augite, was stable. Increasing $\mathrm{H}_{2} \mathrm{O}$ contents and decreasing temperatures during evolution of the various magmas favoured augite stability and a continuing increase in $\mathrm{H}_{2} \mathrm{O}$ contents led to an increase in the augite Wo content, as displayed in augite rim compositions (Fig. 5.17).

Overall, the thermometry estimates, coupled with $\mathrm{H}_{2} \mathrm{O}$ contents and mineral textures, suggest that the HRT magma complex contrasts with those systems feeding earlier silicic products of the Yellowstone-Snake River Plain volcanic province. Although the HRT silicic magmas cover a large overall temperature range (zircon saturation temperatures of 790 $960{ }^{\circ} \mathrm{C}$ ), they were cooler and $\mathrm{H}_{2} \mathrm{O}$-richer (up to 5 wt\%: Myers et al. 2016, this study) than earlier silicic magmas along the Snake River Plain (>900 ${ }^{\circ} \mathrm{C}, \mathrm{H}_{2} \mathrm{O}$-poor: Branney et al. 2008). The HRT rhyolitic magmas are in turn hotter than recent YPVF lava-dominated volcanism, which yields temperature estimates as low as $\sim 750{ }^{\circ} \mathrm{C}$ (Loewen and Bindeman 2015; Befus and Gardener 2016). Feldspar and pyroxene compositions provide insight into a hotter and $\mathrm{H}_{2} \mathrm{O}$-poorer beginnings to the HRT system before its evolution to a cooler and $\mathrm{H}_{2} \mathrm{O}$-richer final state. These transitional characteristics, therefore, mean that the HRT straddles the division between 'hot-dry' and 'cold-wet' types of silicic magmas set by Loewen and Bindeman (2016) at $\sim 825^{\circ} \mathrm{C}$. One could propose on this basis that the HRT be classified as 'tepid-moist', suggesting that such arbitrary divisions are overly simplistic. 


\subsubsection{Configuration of the HRT magmatic complex}

The single-clast, major and trace element and isotopic compositions of juvenile components, coupled with their glass and mineral chemistries, indicate the presence of a multi-component magmatic complex that fed the HRT eruption sequence. It is worth investigating, however, the spatial relationship within and between these different systems and their melt-dominant bodies. The clearly distinct magma compositions present in HRT member $\mathrm{C}$, plus its temporal separation from the earlier stages of the eruption, leads us to separate discussion of members A plus $B$ from $C$.

In contrast to the variable temperature estimates, pressure estimates are more consistent across and within compositional suites. There is a peak that ranges from $\sim 100-450 \mathrm{MPa}$ (with a mode at $\sim 250-350 \mathrm{MPa}$ ) within all suites (except suite A2: Fig. 5.19 ). This peak range corresponds to $\sim 4$ to $19 \mathrm{~km}$ depths. The former is consistent with the lowest pressures estimated from quartz-hosted melt inclusions from the fall deposit ( $~ 80 \mathrm{MPa}$ : Myers et al. 2016) and the latter with the base of the geophysically-imaged modern silicic magma reservoir ( 17 km: Smith et al. 2009; Farrell et al. 2014; Huang et al. 2015). These pressures, however, contrast with those proposed for the youngest YPVF volcanism (as low as $50 \mathrm{MPa}$ ) from volatile contents of reheated and rehomogenised melt inclusions from lavas (Befus and Gardener 2016). Pressure estimates from groundmass glass compositions in scoria-bearing pumices (type $\mathrm{J} 4$ ) in member B and suite A2 have peaks of $>600 \mathrm{MPa}$. Although this is outside the range of calibration of the model and therefore should be treated with caution (Wilke et al. 2017), the less-evolved, inferred hotter nature of these samples is consistent with a greater depth of origin.

Taken together, the geobarometry estimates for all except suite A2 yield similar pressure estimates, despite the contrasting chemical natures of the various suites. These similarities imply that the various, demonstrably separate magmatic systems, and the smaller meltdominant bodies associated with them, were largely laterally, rather than vertically separated (Fig. 5.22). Although pressure differences of up to $\sim 200 \mathrm{MPa}$ are strictly unresolvable using this barometer due to the uncertainties in the compositional analyses used as inputs, we would maintain that the multiple magma bodies/systems were laterally adjacent and were extracted from broadly similar pressure ranges. Importantly, this conclusion is supported by the absence of a simple composition-depth relationship from melt inclusions (Myers et al. 2016), as would be expected in a zoned system (Wallace et al. 1999; Cashman and Giordano 

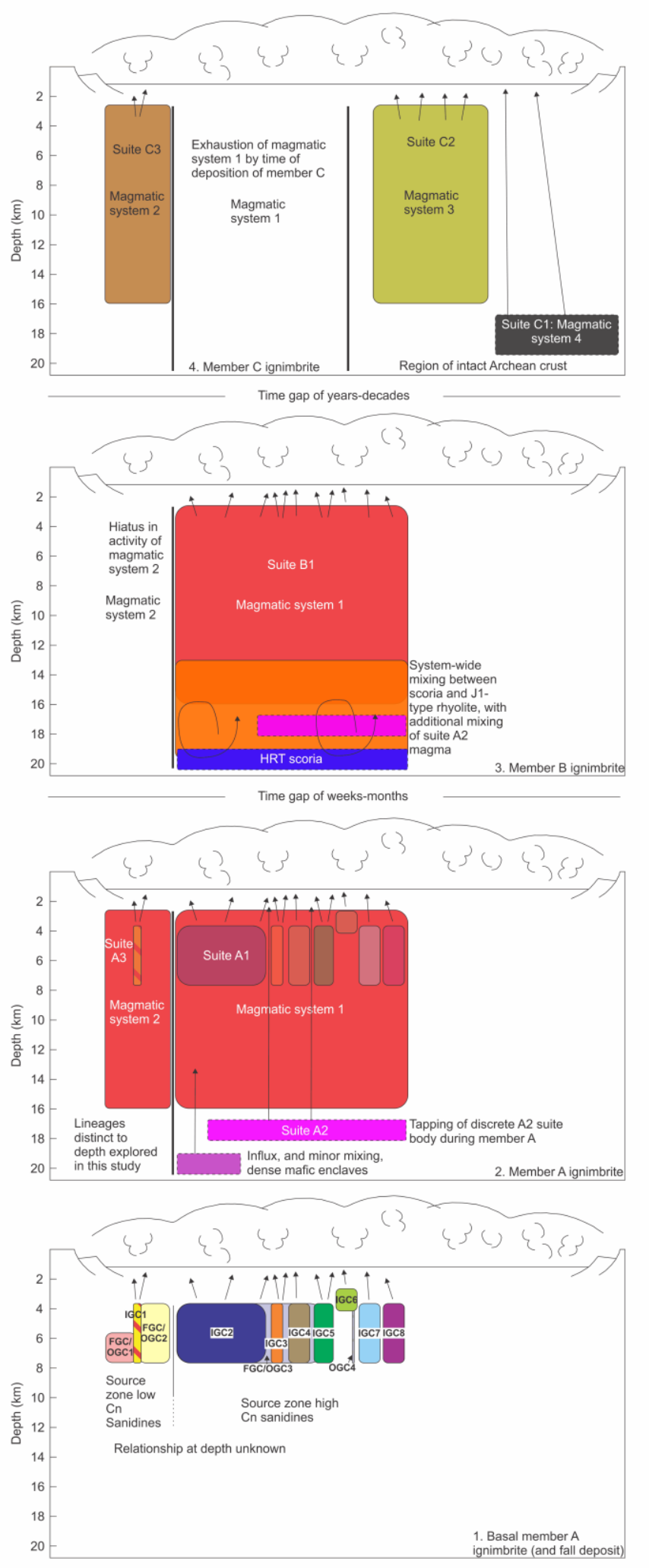

Figure 5.22: Semi-quantitative diagram showing the behaviour of the HRT magmatic complex throughout the eruption. 1. Multiple laterallyadjacent melt-dominant bodies tapped at the onset of eruption (initial fall deposits) and into widespread ignimbrite deposition represent two magmatic lineages. 2. Member A ignimbrite compositions reflect the continued tapping of these multiple melt-dominant bodies that represent magmatic systems 1 and 2 . A deeper, separate suite $A 2$ body was also tapped during member A deposition. Influx of mafic material in the form of dense mafics. 3. During a time break of weeks-months, extensive mixing occurred between a renewed influx of mafic material (erupted as scoria) and magmatic system 1 material. Member $B$ then evacuated magmatic system 1 but there is a cessation in evacuation of system 2. 4. Within a time break of years-decades, magmatic system 2 was rejuvenated, forming a new meltdominant body. Simultaneously, meltdominant bodies from two previously unrepresented magmatic systems (3 and 4) formed. Member C evacuated melt-dominant bodies from all three systems, but no material representing

system 1 is present. Colours and suite names as in Swallow et al. (2018b, Chapter 3) and Fig. 5.3. See text for classification of magmatic systems. 
2014; Chamberlain et al. 2015) and the simultaneous eruption of multiple, compositionally diverse melt-dominant bodies (Myers et al. 2016; Swallow et al. 2018b, Chapter 3). The only composition type not observed in the member $A$ basal ignimbrite is suite $A 2$, which yields inferences of significantly hotter temperatures and deeper pressures, consistent with our interpretation. Furthermore, the $\sim 95 \times 65 \mathrm{~km}$ mapped HRT caldera (Christiansen 2001) suggests a laterally-extensive magmatic entity and the wide isotopic variations observed (e.g. between systems 1 and 3 ) is implausible in a vertically stacked configuration (cf. Cashman et al. 2017).

$\mathrm{J} 1$ and J2-type samples from member A define a well-defined, coherent high-silica rhyolite trend (suites $\mathrm{A} 1$ and $\mathrm{A} 3$ ). Groundmass glass compositions indicate that, despite relative uniformity in major elements, there is significant trace element diversity (cf. Figs. 5.14, 5.15, S5.11- S5.13). The range in trace element compositions and the clustered nature of the data mirror that seen in the fall deposits and basal member A ignimbrite (Myers et al. 2016; Swallow et al. 2018b, Chapter 3). The glass compositional range in these early products indicates that the entire range in melt compositions seen in suites $\mathrm{A} 1$ and $\mathrm{A} 3$ was tapped at the onset of widespread ignimbrite deposition. The clustered nature of the compositional data, inferred to represent the presence of multiple discrete melt-dominant domains, continues throughout members $A$ and $B$. The relative homogeneity of the glass within single pumices, however, implies that these melt-dominant domains remained separate during continued eruption of ignimbrite member A (Fig. S5.14). This continuing separation in turn implies that the contrasting domains identified from glass compositions in the basal ignimbrite did not sit atop a unitary, zoned, melt-dominant body that was progressively tapped, but actually reflected almost the entire extent of the subsurface magmatic systems 1 and 2. For example, magmatic system 2, dominant at the onset of fall deposition and reappearing in the basal ignimbrite, is also represented by pumices from member A (e.g. YP255, YP416), shown by the similarity in their glass compositions to FGC/OGC1+2 and their clustered sanidine rim compositions with a low-Cn sanidine rim peak, characteristic of the fall deposit (Figs. 5.14, 5.15; Swallow et al. 2018b, Chapter 3). The only compositional group not represented at the start of ignimbrite member $A$ is that represented by suite $A 2$ clasts. Although the suite $A 2$ samples plot on a continuation of the $A 1$ suite with respect to single clast compositions and glass elemental ratios, their glass concentration data lie off this trend (Figs. 5.6, 5.14, 5.15). On the sampling scale undertaken for this study, this compositional 
separation is taken to indicate the present of a discrete, hotter and deeper melt-dominant body generating suite $\mathrm{A} 2$ in magmatic system 1.

Although suite $A 1$ is mirrored in member $B$ (as suite B1), there are important differences between data from the two ignimbrite members (Fig. 5.20). There is an absence of products from magmatic system 2, indicated by the absence of low-Ba pumice and glass, and an associated lack of a significant mode in low-Cn sandine rims (Figs. 5.14, 5.16). Our sampling thus suggests that there was a hiatus in tapping of the magmatic system 2 at the onset of member B deposition. Furthermore, there is an infilling of the compositional gap between suites $\mathrm{A} 1$ and $\mathrm{A} 2$ by the silicic component of scoria-bearing J4-type pumices in member $\mathrm{B}$ (e.g. Fig. 5.6). This infilling is also observed in groundmass glass compositions, with J4-type pumice glass linking the least-evolved glass compositions of suite A1 (and J1-type pumices in suite B1) to the field of suite A2 clasts (Fig. 5.14). The antithetic nature of this trend relative to suite A1 indicates that the filling in of the compositional gap is due to mixing between the less-evolved suite $\mathrm{A} 1$ glass and a Ba-enriched melt. The bimodality in $\mathrm{J4}$ sample olivine compositions also suggests the occurrence of mixing between a melt that yielded the J1-type clasts and a lessevolved component (Fig. S5.18). Although mafic clasts are found in member A, their isolated dense nature is in contrast to the vesicular scoria mingled in J4-type pumices in member B (Swallow et al. 2018a, Chapter 4), indicating a renewed influx and increased pervasiveness of mixing in member $B$ relative to member $A$. Because the rhyolitic components of individual scoria-bearing pumices cover in composition the entire range of suite $A 1$, mixing of the scoria component was a widespread phenomenon within magmatic system 1 , and was not limited to less-evolved compositions. The absence of evidence for mixing of HRT mafic material with any part of magmatic system 2 supports the notions of the distinct nature of this system and its lateral separation from magmatic system 1.

The compositional record from member $\mathrm{C}$ exhibits a marked contrast to members $\mathrm{A}$ and B. Following the time break of decades between members B and C (Fig. 5.2), there is the venting of magmatic systems 3 and 4, the renewed evacuation of magmatic system 2 and the absence of eruption of any material representative of magmatic system 1 (Fig. 5.20). Although magmatic system 3 exhibits a large compositional range (e.g. Fig. 5.6), compositions are clustered, particularly of groundmass glass (Figs. 5.14, 5.15), as seen in magmatic systems 1 and 2 . This suggests that magmatic system 3 similarly contained multiple melt-dominant bodies that were, based on unimodal pressure estimates (Fig. 5.19), predominantly laterally 
separated. Despite their similar isotopic compositions (Figs. 5.11-5.13), there is no physical, petrographic or geochemical evidence of significant mixing between magmatic systems 3 and 4 , suggesting a separation of the two systems. However, isotopic constraints that indicate a common assimilant for the two systems imply a shared spatial focus that is distinct from systems 1 and 2 . The lower-silica nature of devitrified samples from system 4, if pressure estimates from groundmass glass from low-silica suite A2 are used for comparison (Fig. 5.19), suggests that melt-dominant material associated with this system was stored at greater depths than that for system 3 (Fig. 5.22). The rejuvenation of magmatic system 2, but not system 1, further supports the distinction between these two systems. Suites A3 and C3 are linked by single clast elemental and isotopic compositions, and mineral compositions (e.g. Figs. 5.6, 5.13, 5.16). Broadly comparable pressure estimates between the two compositional suites ( $A 3$ and $C 3$ ) from system 2 (Fig. 5.19) suggests that the melt-dominant bodies were stored at comparable depths.

In summary, the HRT magmatic complex was an extraordinary entity, covering four compositionally and isotopically distinct magmatic systems (Fig. 5.20). The two magmatic systems ( 1 and 2 ) contained multiple, discrete, melt-dominant bodies that were vented for the fall deposits and continued to be tapped during member A deposition. Suite A2 clasts are associated with magmatic system 1 . The compositional gap between suites $A 1$ and $A 2$ was closed in the time break prior to the onset of deposition of member $B$, as mafic magma reinvaded the roots of magmatic system 1 and its melt-dominant bodies. During the longer time break between members B and C, significant changes in the HRT magmatic system occurred. Magmatic system 2 was rejuvenated, forming new, less radiogenic melt-dominant bodies, but with similar elemental and mineral compositions. Two new systems ( 3 and 4 ) were tapped, with at least the former also composed of multiple melt-dominant bodies that were stored at similar depths to those in magmatic systems 1 and 2.

\subsubsection{Syn-eruptive changes}

Several key changes to the HRT magmatic system occurred between eruption of the different members, despite the whole eruption being treated as a single, geologically instantaneous event by most authors (Reynolds 1977; Christiansen 2001; Wotzlaw et al. 2015; cf. Ellis et al. 2012). In chronological order, the break between members $A$ and $B$, inferred to be weeks to months in duration, coincides with the apparent cessation of evacuation of the low-Ba 
magmatic system 2, plausibly due to exhaustion of the melt-dominant body, and mixing of magmatic compositions (mafic and silicic) within system 1 (Fig. 5.20). This is most evident in the mingled scoria-bearing J4-type pumices with their rhyolitic components that exhibit mixing trends with a less-evolved composition. This composition is inferred to be similar to the suite A2 magma type rather than representing direct mixing with HRT scoria, due to the trend of mixed pumices to low LREE contents (Fig. 5.10). However, the presence of scoria in these clasts show that direct mechanical mingling of a wide range of magmas occurred later in the member $B$ eruption. In addition, there is greater variation in rhyolitic glass compositions within single pumices of a given composition, whether mingled or homogeneous, in member $B$ than in A (Fig. S5.14). This combination of intra-silicic and silicic-mafic mixing and mingling indicates large-scale mixing in magmatic system 1 on a multitude of scales. These interactions likely reflect two processes. First, a fresh influx of HRT mafic magma, evidenced by the generally vesicular nature of the scoria in member B relative to the dense mafic clasts in member A (Swallow et al. 2018a, Chapter 4). The vesicular scoria would have contributed heat and volatiles to the magmatic system, leading to changes in viscosity and density, aiding mixing and mingling (Sparks et al. 1977; Huber et al. 2012) that ultimately may also have acted as an eruption trigger (Till et al. 2015), although not being vented until later in eruption of member B (Christiansen 2001). Second, decompression associated with eruption of member $A$ and associated caldera formation would alter the stress field of the magmatic system and potentially trigger mixing between previously separated melt-dominant bodies (Pritchard et al. 2013). The overlapping nature of core and rim compositions in the main phenocryst phases within and between scoria-bearing J4 clasts and J1-type samples suggests, however, that the mafic-felsic mixing occurred on timescales short enough to preclude the widespread growth of rims with distinct compositions (cf. Bishop Tuff: Wark et al. 2007; Chamberlain et al. 2014b).

The largest changes occurred during the hiatus between members $B$ and C (Fig. 5.20). This hiatus is inferred to be years to decades in length. These changes are expressed by two main features: the evacuation of hitherto unrepresented magmatic systems ( 3 and 4 ), and the rejuvenation of magmatic system 2 . The first two systems, with unique elemental and crustal isotopic characteristics of single clasts and crystals, are remarkably distinct from each other and magmatic system 1. Previous work has identified highly radiogenic isotopic signatures in member C material (Doe et al. 1982; Hildreth et al. 1991) that we would link (from $\mathrm{SiO}_{2}$ contents) to our magmatic system 3 . These isotopic values have been attributed to syn- 
eruptive melting by residual member $A$ and $B$ melts of the foundering magma chamber roof during caldera collapse associated with eruption of members A and B (Hildreth et al. 1991; Christiansen 2001). In contrast, our data show that this magma type is unrelated to rhyolitic melts from members $A$ and $B$ and represents an independent magmatic system. The small crystal sizes in member $C$ pumices ( $\geq 85 \%$ of crystals $<1 \mathrm{~mm}$ ) suggests that the physical generation of the melt-dominant bodies occurred during the time gap between members $B$ and $\mathrm{C}$, but from a root zone that had a longer history. A similarly prolonged gestation is inferred for the magmatic system 4 as well. This inference is suggested by the pre-HRT eruption of the Junction Butte Basalt, which is of olivine tholeiite affinity (Christiansen 2001; Swallow et al. 2018a, Chapter 4), indicating that ascent and eruption of olivine tholeiitic-type magmas was occurring prior to the HRT and therefore contemporaneous with the ascent of earlier batches of the HRT mafics.

Despite the inferred presence of magmatic systems 3 and 4 during the eruption of HRT members $A$ and $B$, there is no evidence of evacuation of material from these systems during this time. It is possible that the melt-dominant bodies of these systems existed during earlier eruption stages, but were not tapped (e.g. Bégué et al. 2014). However, notably smaller crystal sizes in clasts from these systems (dominantly $<1 \mathrm{~mm}$ ) relative to the magmatic system 1 (up to 4-8 mm: Table 5.1), suggests that all the member $C$ eruptible melt-dominant bodies were generated in the $\mathrm{B}: \mathrm{C}$ time gap. The presence of bi-pyramidal quartz in the magmatic system 3 pumices can be interpreted to reflect a pulse of accelerated crystallisation shortly prior to eruption, as prolonged growth tends to result in crystals that are larger and more rounded, and form an equilibrium shape of bi-pyramids separated by smoothly curved regions (Laporte and Provost 1994; Hosaka et al. 1995; Manley 1996). Euhedral bi-pyramidal quartz has been experimentally produced through moderate undercooling of hydrous silicate melts (Swanson and Fenn 1986), suggesting that rapid extraction of magma from the root zone to shallow levels led to the onset of quartz crystallisation. Published quartz growth rates support this notion, with $1 \mathrm{~mm}$ quartz crystals forming in $\sim 3 \mathrm{ka}$ (using quartz rim growth rates of $10^{-}$ ${ }^{13} \mathrm{~m} / \mathrm{s}$ from Gualda et al. 2012) to $\sim 60$ days (using quartz growth rates of $2^{-10} \mathrm{~m} / \mathrm{s}$ appropriate to moderate undercooling from Swanson and Fenn 1986) that encompass the years to decades estimate for the time break based on field evidence.

Another key change between members $B$ and $C$ is the rejuvenation of the low-Ba magmatic system 2 (Fig. 5.20). Rejuvenation of magmatic systems on a years to decades 
timescale has been demonstrated in other large, caldera-forming eruptions (Barker et al. 2016; Cooper et al. 2017), and we suggest a similar scenario here. There are some subtle differences between the two extractions from magmatic system 2, however. Although glass LREE contents from pumices are similar between members $A$ and $C$, suite $C 3$ pumices have lower LREE contents. This is exhibited in the ratio of LREE contents in the glass relative to single clast compositions, with suite A3 pumices having LREE depletions in the glass (i.e. glass/clast <1) whereas C3 suite pumices have enriched LREE contents in the glass (i.e. glass/clast $>1$ : Fig. S5.24). As LREE contents in the glass are similar, the difference must reside in the crystal fraction, plausibly in the abundance of chevkinite. As temperature, pressure and $\mathrm{H}_{2} \mathrm{O}$ content estimates are comparable between suites $\mathrm{A} 3$ and $\mathrm{C} 3$, variations in chevkinite abundance may, therefore, be related to time constraints. Glass clusters from the fall deposits, FGC/OGC1+2, related to magmatic system 2 show bimodal La concentrations (Swallow et al. 2018b, Chapter 3), suggesting that degree of LREE depletion is not uniform within this system and is more pronounced in the most evolved melts. This observation implies that chevkinite crystallisation is primarily a late-stage feature, and that the rapid extraction of melt from the magmatic system 2 prior to member $\mathrm{C}$ precluded significant chevkinite fractionation. This is supported by qualitative crystal abundances, with three times the proportion of chevkinite $(0.5-1 \mathrm{~mm})$ observed in suite A3 samples relative to $C 3$ (9\% of picked ferromagnesian minerals in A3 compared to 3\% in C3: Electronic Appendix 5.3). Furthermore, the less radiogenic nature of suite C3 pumices compared to their member A counterparts, can also be used in support of a short-lived evolutionary history. As evolution of magmatic systems 1 and 2 through fractional crystallisation is associated with concurrent assimilation, rapid extraction would hinder significant crustal contamination and therefore limit increases in Sr-isotopic values.

Elsewhere, mechanisms for the rapid rejuvenation of a magmatic system commonly invoke a thermal and/or chemical pulse from the influx of hotter, plausibly mafic, magma inferred from up-temperature signals observed in the crystal cargo (e.g. Cooper et al. 2016, 2017). Rapid generation of melt-dominant bodies has also been related to tectonic processes (e.g. Allan et al. 2013). Based on current data it is unclear which mechanism was the sole or dominant driving force for the rejuvenation of magmatic system 2 and formation of meltdominant bodies within magmatic systems 3 and 4 . Although sanidine compositions extend to hotter, more Cn-rich compositions in suite C3 compared to suite A3 (Fig. 5.16), this is predominantly in core compositions and therefore crystals record an overall down 
temperature history. Furthermore, up-temperature signals are not observed in other crystal phases (e.g. Fig. 5.17), model temperature estimates are comparable between suites $A 3$ and C3 (Fig. 5.18), and system 2 is inferred to lie away from the focus of mafic influx. In contrast, sanidines from magmatic system 3 show less-evolved, more $\mathrm{Cn}$-rich rims relative to cores, indicative of a temperature increase (Fig. 5.16), although wide temperature estimates are derived from glass compositions in J8-type pumices from suite $\mathrm{C} 2$, consistent with the degree of compositional evolution (Fig. 5.18). This conflicting evidence is at odds with the consistent crystal sizes and abundances observed within all member $C$ juvenile material (Table 5.1), which indicates that a shared rejuvenation event occurred in the time break between members $B$ and $C$. This could plausibly be related to decompression of the magmatic complex related to the eruption, and associated caldera collapse, of members $A$ and $B$, as has been inferred previously for syn-eruptive changes within the HRT (Hildreth et al. 1991). But, if wide scale decompression was the dominant mechanism, it is puzzling why magmatic system 1 did not also rejuvenate, as this is where decompression was likely to have been focused. Furthermore, the low crystal abundances ( $\leq 15$ wt\%) within all member $C$ systems require a thermal influx, particularly with regard to the dacitic system 4. Further investigation of the crystal cargo is therefore required to better constrain the mechanism(s) behind development of the member $\mathrm{C}$ melt-dominant bodies.

\subsection{Implications}

\subsubsection{Yellowstone rhyolite petrogenesis}

Debate in recent times has focused on the dominant mechanism of rhyolite petrogenesis in the YPVF, with end member views encompassing crustal partial melting (Bindeman et al. 2008; Loewen and Bindeman 2015) and fractional crystallisation from a long-lived crystal mush zone (Girard and Stix 2009, 2010; Stelten et al. 2015, 2017). The data presented here on the HRT magmatic complex indicate that within the YPVF systems conforming to both views were present. The magmatic picture for subsequent volcanism is also plausibly more diverse and complex than previously recognised. The stark diversity of compositions within the HRT, particularly isotopically, is not only unique to the YPVF (Hildreth et al. 1984, 1991; Christiansen 2001) but is also unique in regard to the Snake River Plain as a whole. Large-scale isotopic studies of YSRP volcanic products indicate that although there is an increased crustal 
signature linked to the volcanic focus crossing the western edge of the North American craton, glass isotopic signatures related to hotspot volcanism are moderate $(\varepsilon N d \geq-11$ : Nash et al. $2006)$ in contrast to the HRT magmatic systems 3 and $4(\varepsilon N d=-17.3$ to -18.2 : Fig. 5.11$)$. Other explosive rhyolitic products from the Snake River Plain with similar crustal isotopic signatures (e.g. elevated ${ }^{87} \mathrm{Sr} /{ }^{86} \mathrm{Sr}_{\mathrm{AC}}$ ) to these HRT systems, e.g. the Arbon Valley Tuff (Nash et al. 2006; Drew et al. 2013, 2016), have been linked to the commencement of activity at a new centre (Colón et al. 2018). This situation is interpreted as representing either crustally-dominated magmatism prior to the full impingement of the mantle plume, or that the 'crustal' magmatic system was isolated from subsequent more mantle-like isotopic systems (Drew et al. 2013). The chemical and isotopic diversity of the magmas in the HRT show that the latter situation was the case. As the isotopic signatures of the sources to Yellowstone magmas are thought to be a result of hybridisation of Archean crust, mantle-derived melts and mafic intrusives (Doe et al. 1982; Hildreth et al. 1991; Swallow et al. 2018a, Chapter 4), more radiogenic isotopic signatures therefore logically indicate a greater crustal component. With continued mafic influx, this crustal component will be diluted and result in a trend towards less extreme radiogenic isotopic compositions as seen in the YPVF (Hildreth et al. 1984, 1991) and farther west in the Snake River Plain (Drew et al. 2013, 2016). However, the bimodality in isotopic compositions within the HRT indicates that in this case at least, dilution of the 'crustal' signature was a dominantly spatial rather than a temporal feature. It is also of note that Eocene volcanism of the Absaroka Volcanic Province overlaps with the YPVF area (Chadwick 1970; Christiansen and Yeats 1992; Feeley 2003). This Eocene magmatism would have significantly hybridised and 'pre-conditioned' the lithosphere beneath the YPVF for the onset of Quaternary hotspot-related volcanism. Therefore, one possibility is that the more radiogenic 'crustal' isotopic signatures may reflect magmatic systems in crust that happened to have not been affected by Eocene magmatism in the region (see also Swallow et al. 2018a, Chapter 4).

Published crystal-specific work has also suggested a complex nature to rhyolite petrogenesis not only in the HRT but in the YPVF as a whole (e.g. Bindeman et al. 2008; Watts et al. 2012; Wotzlaw et al. 2015). These studies suggest that melt-dominant bodies that feed volcanism in the YPVF are heterogeneous and either represent discrete melt-dominant bodies, or the late-stage and rapid accumulation of multiple melt-dominant bodies. We can demonstrate here, with a single clast-focused approach, that not only were multiple melt- 
dominant bodies present to feed the HRT eruption, but also multiple magmatic systems. We note that Wotzlaw et al. (2015) report a bimodality of zircon $\mathrm{Hf}$ isotopic compositions in member A whole rock samples, with 'more crustal' and 'more mantle-like' populations. The 'more crustal' population is absent in member B but reappears in member $\mathrm{C}$, in contrast to the 'mantle-like population' that shows the reverse. Without context regarding the chemical composition of the host material in Wotzlaw et al. (2015), it is difficult to relate their two proposed HRT magmatic systems to the work presented here. The appearance of a distinct zircon $\mathrm{Hf}$ isotopic population in members $\mathrm{A}$ and $\mathrm{C}$ but not $\mathrm{B}$ is parallel to our findings. However, the magmatic system that shows this behaviour is the low-Ba system 2, which is not strongly crustal in its isotopic nature. This dichotomy highlights the utility of extensive single clast studies to provide the context of chemical characterisation of host clasts to subsequently be able to relate crystal diversity to the nature of the magmatic system(s).

\subsubsection{Yellowstone magmatic system}

YPVF silicic volcanism has often been categorised as 'hot-dry' (Loewen and Bindeman 2016). Although this label is archetypically linked to the pumice-poor, intensely welded ignimbrites of the Snake River Plain (Branney et al. 2008; Ellis et al. 2013), explosive eruption deposits in the YPVF are somewhat different and contain more abundant pumice (Christiansen 2001). Furthermore, temperature and $\mathrm{H}_{2} \mathrm{O}$ contents estimates derived from multiple proxies for the HRT magmas straddle the division between 'hot-dry' and 'cold-wet' rhyolites (e.g. Loewen and Bindeman 2016), logically making the HRT 'tepid-moist' on the same (arbitrary and flawed) basis. There is also evidence for significant variation during the evolution of the HRT magmas in the form of two-feldspar thermometry estimates of $>900^{\circ} \mathrm{C}$ and the presence of pigeonite compositions as cores or inclusions, the latter experimentally determined to form at lower $\mathrm{H}_{2} \mathrm{O}$ contents (Almeev et al. 2012). In addition, thermometry estimates of subsequent volcanism at Yellowstone extend to temperatures as low as $\sim 720^{\circ} \mathrm{C}$, depending on the proxy and calibration used (e.g. Watts et al. 2012; Loewen and Bindeman 2015; Stelten et al. 2015; Befus and Gardener 2016). Consequently, there appears to be an overall cooling of the overall Yellowstone magmatic system, which has been interpreted in isolation for the youngest eruptive episode (Watts et al. 2012; Stelten et al. 2015). This apparent cooling, coupled with estimated elevated $\mathrm{H}_{2} \mathrm{O}$ contents in the HRT (Myers et al. 2016; Swallow et al. 2018b, Chapter 3), especially when compared to eruptions further west (e.g. Almeev et al. 2012; Bolte et al. 
2015), and the episodic and irregular eruption of hydrous mineral-bearing magma (i.e. biotite and amphibole: e.g. Christiansen 2001; Troch et al. 2017; Stelten et al. 2018) indicates the complex and variable nature of Yellowstone magmatic properties. The data are at odds with simplified categorisations commonly used.

As mentioned previously, heterogeneity is present in YPVF eruptive products on multiple scales, from crystal populations within a single eruption (e.g. Bindeman et al. 2008, Watts et al. 2012; Wotzlaw et al. 2015) to variable compositions across an eruptive episode (e.g. Girard and Stix 2009, 2010; Loewen and Bindeman 2015; Stelten et al. 2015; Troch et al. 2017) both related to heterogeneity within a single magmatic system. The perception of a single magmatic system has fitted in conveniently with the single low-velocity body (i.e. 'magma body') imaged beneath the YPVF (Smith et al. 2009; Farrell et al. 2014; Huang et al. 2015). Although broad-scale geophysical imaging, with a resolution of $\sim 10 \mathrm{~km}$ obscuring finer details (e.g. Lowenstern et al. 2006), can identify the broad dimensions of large-scale crustal anomalies, higher resolution analysis of past eruption deposits sheds light on the nature of possible heterogeneities within the 'magma body.' Post-dating the HRT, eruptives of analytically indistinguishable ages but contrasting magma sources are known, including the 1.29 Ma domes post-dating the Mesa Falls Tuff (Troch et al. 2017; Stelten et al. 2018), and the two magma types in the 0.63 Ma Lava Creek Tuff (Christiansen 2001). Even so, the presence of four independent magmatic systems contemporaneously active within the YPVF and having these venting in one (albeit punctuated) eruption is remarkable. Furthermore, these magmatic systems included multiple melt-dominant bodies that did not simply merge downwards into a unitary magma chamber but retained their distinctive natures deep into the magmatic system (e.g. magmatic system 1 that fed a majority of the eruption volume: Myers et al. 2016; Swallow et al. 2018b, Chapter 3). The presence of focused zones of eruptible melt-rich magma within a larger magmatic system is important in consideration of future eruptions and hazard modelling (Christiansen et al. 2007). This is because although the current percentage of melt in the YPVF upper crustal magmatic system is thought to be too low to be eruptible (Smith et al. 2009; Farrell et al. 2014; Huang et al. 2015), this melt could be concentrated in regions too small to be detected by the resolution of the present imaging techniques.

The evacuation of multiple melt-dominant bodies in pre-Quaternary YSRP eruptions appears to be common (Perkins et al. 1995; Cathey and Nash 2004; Bonnichsen et al. 2008; 
Ellis and Wolff 2012). Although investigations are hindered by a lack of single-clast data (Branney et al. 2008), the presence of multiple modes in crystal and glass compositions is parallel to what is reported here in the HRT. But why multiple melt-dominant bodies should form and remain molten in the crust prior to eruption is puzzling. Small melt-dominant bodies should solidify quicker than large bodies and therefore be transient features or kept meltdominant due to continuing input of heat and/or volatiles. Although volcanism in the Snake River Plain is high temperature ( $>900^{\circ} \mathrm{C}$ : Branney et al. 2008), and HRT temperature estimates extend to similar values, final storage temperature estimates for the HRT are moderate $\left(\sim 780-900{ }^{\circ} \mathrm{C}\right)$. However, the large thermal and gas emissions in the modern YPVF reflect a large magma flux from the mantle and lower crust (e.g. Lowenstern et al. 2006, 2014; Huang et al. 2015). It is possibly this abundant and significant thermal flux, related to the Yellowstone plume, along the YSRP that has thermally pre-conditioned the crust to allow small meltdominant bodies to survive in the upper crust. Another consideration is the extensional regime present along the YRSP due to Basin and Range related extension (e.g. Pierce and Morgan 1992, 2009; Smith et al. 2009) as multiple contemporaneous melt-dominant bodies are found in other extensional regimes (e.g. Taupo Volcanic Zone: Shane et al. 2007, 2008; Cooper et al. 2012; Bégué et al. 2014). Extensional regimes would likely enhance the geothermal gradient in such settings and aid ascent of magma and rapid formation of meltdominant bodies (e.g. Allan et al. 2013, 2017). Although the HRT shows evidence for rapid formation of melt-dominant bodies in member $C$, this is not shared by magmatic system 1 evacuated during members A and B. Despite this contrast, it is probable that a combination of regional elevated heat flow and extensional tectonics enhanced the likelihood for a complex, heterogeneous magmatic complex as exhibited in the HRT.

\subsubsection{Silicic magmatic systems}

Although this study has focused on a single caldera-forming eruption there are important findings applicable to general study of silicic magmatic systems. First, the HRT is another, albeit extreme, example of a silicic eruption tapping multiple melt-dominant bodies (cf. Sampson and Cameron 1987; Shane et al. 2007, 2008; Cooper et al. 2012, 2016; Westgate et al. 2013; Bégué et al. 2014). In contrast, numerical models associated with large silicic magmatic systems do not reflect this complexity and are based on single unitary bodies (e.g. Jellinek and DePaolo 2003; Gregg et al. 2012, 2015; Caricchi et al. 2014). The complex 
configurations of silicic magmatic systems indicated by field-based studies would have important thermomechanical effects on the magmatic system (Gudmundsson 2012), and it is arguably important to narrow the gap between field-based evidence and numerical model assumptions.

Second, there is evidence of the rapid (within eruption) formation of melt-dominant bodies in the HRT, with changes from members $A$ to $B$ within months and $B$ to $C$ within decades. Such rapid behaviour has been inferred elsewhere (e.g. Oruanui: Charlier et al. 2008, Allan et al. 2013, 2017; Rocky Hill/Kidnappers: Cooper et al. 2016, 2017; Santorini: Druitt et al. 2012) and is an important consideration when investigating the mechanisms of accumulation of large volumes of magma in the upper crust. However, this rapidity is in contrast to the assumption that large magma bodies take $10^{5}-10^{6}$ years to grow and this controls the repose period of eruptions (e.g. Smith 1979; Jellinek and DePaolo; Reid 2008). This study further indicates that large-scale silicic magmatic systems can rejuvenenate/form eruptible melt-dominant bodies on human-applicable timescales (i.e. within in the yearsdecades time break between members B and C for magmatic systems 2-4).

Third, not only is the presence of multiple independent melt-dominant bodies in the HRT significant, but so also is the presence of multiple independent magmatic systems. The simultaneous or systematic construction and evacuation of magma bodies related to spatially and/or chemically distinct magmatic lineages has been documented elsewhere (e.g. Long Valley: Sampson and Cameron 1987; Taupo Volcanic Zone: Brown et al. 1998; Shane et al. 2007, 2008; Allan et al. 2012, 2017; Bégué et al. 2014; Campi Flegrei: Pistolesi et al. 2016), but not on such a large scale. On a broader spatial and temporal scale, periods of intense silicic volcanism comprising multiple caldera-forming eruptions over geologically short periods of time have been labelled ignimbrite flare-ups (e.g. Bonnichsen et al. 2008; Best et al. 2013; Lipman and Bachmann 2015; Gravley et al. 2016). In the Taupo Volcanic Zone, eight calderaforming eruptions, evacuating $\sim 3,000 \mathrm{~km}^{3}$ of material, occurred within an area of $90 \times 40 \mathrm{~km}$ over a 100 kyr period (Houghton et al. 1995; Gravley et al. 2016). In comparison, the HRT erupted $\sim 2,500 \mathrm{~km}^{3}$ dense-rock equivalent of material and formed a caldera of $\sim 95 \times 65 \mathrm{~km}$ (Christiansen 2001). The HRT caldera thus covers an area large or larger, than other volcanic regions that contained multiple magmatic systems that, in the example quoted were evacuated mostly as singular eruptions separated by periods of erosion and soil formation. 


\subsection{Conclusions}

The $2.08 \mathrm{Ma}, \sim 2,500 \mathrm{~km}^{3} \mathrm{HRT}$ comprises three ignimbrite members ( $\mathrm{A}, \mathrm{B}$ and $\mathrm{C}$ ) and two fall deposits, an initial one and another pre-C (Christiansen 2001; Rivera et al. 2014; Singer et al. 2014; Wotzlaw et al. 2015). Fieldwork by CJN Wilson (Wilson 2009 and manuscript in preparation) indicates that the eruption was episodic and prolonged, with spasmodic initial fall activity, a weeks-months time break between members $A$ and $B$, and a years-decades interlude between members B and C (Fig. 5.2). The eruption products include silicic juvenile material exhibiting a wide diversity of physical characteristics, with variations in size and abundance of crystals, nature/degree of vesicularity, growth of microlites and mixing with mafic scoria. Crystal-rich (11-22 wt\%), vesicular pumices, and their devitrified equivalents, dominate in the sample suite from members $A$ and $B$, where a coarse (up to $10 \mathrm{~mm}$ ) crystal assemblage is ubiquitous (Table 5.1). Scoria-bearing variants on this dominant clast type are present in member B. Also present in these members are two types of dense clasts with darkened groundmass glass, with one type (J3) containing characteristic euhedral feldspars. Member $\mathrm{C}$ juvenile clast types are distinct for their uniformly small crystal sizes ( $<2 \mathrm{~mm}$ ) and crystal-poorer natures ( $<15 \mathrm{wt} \%$ ). In contrast, member $\mathrm{C}$ clast types range from dense, devitrified black material to highly vesicular pumices and their pale devitrified equivalents.

The variability of juvenile clast types in the HRT is mirrored in a remarkable degree of geochemical diversity within and between the ignimbrite members. This diversity reveals that the magmatic complex that gave rise to the HRT was extraordinary. Taken together, single clast major and trace element, and isotopic compositions, coupled with matrix glass and mineral compositions from samples constrained within a chronostratigraphically controlled framework show that:

1. Four magmatic systems were active during the eruption of the HRT (Fig. 5.20).

These magmatic systems have distinct chemical and radiogenic isotopic signatures (Table 5.4). The eruption started with the initial fall deposits (Myers et al. 2016; Swallow et al. 2018b, Chapter 3) and earliest member A ignimbrite in the evacuation of two of these systems, the volumetrically-dominant magmatic system 1 and the subordinate low-Ba system 2 . The former includes the low-silica A2 suite, elevated in Ba and $\mathrm{Zr}$ and separated by a compositional gap from the dominant $A 1$ suite. The latter shows large intra-suite variation 
(e.g. 450-1680 ppm Ba) but is, in turn, separated from magmatic system 2 (140$250 \mathrm{ppm} \mathrm{Ba).} \mathrm{Magmatic} \mathrm{system} 2$ is further characterised by low-Cn $(<0.35$ mol\%) sanidine rim compositions. Member B represents the evacuation of only magmatic system 1 , with a cessation in evacuation of system 2 . System-wide mixing occurred prior to the eruption of member $B$, indicated by the closing of the compositional gap in member $A$ (suites $A 1$ and $A 2$ condensed into suite $B 1$ ), the presence of mixed, scoria-bearing pumices and greater mineral and glass compositional variations within single clasts relative to member $A$. The mafic end member for this mixing belonged to the distinctive HRT mafic type (Swallow et al. 2018a, Chapter 4) consistent with its long-term role in the history of magmatic system 1 . The coherency of crystal compositions between members $A$ and $B$ indicate that this mixing was rapid, with no development of contrasting overgrowths on crystals (cf. Chamberlain et al. 2014b). Member C contains material from two new and distinct magmatic systems but with similar crustally influenced isotopic compositions: the larger magmatic system 3 and the smallest lineage in the HRT, system 4. System 3 generated magmas that are high-silica in nature but exhibit large trace element compositional variation (e.g. 410-2280 ppm Ba). Magmatic system 4 extends between rhyolitic and dacitic compositions (66-75 wt\% $\left.\mathrm{SiO}_{2}\right)$, with trends pointing towards broadly olivine tholeiitic sources. Member $\mathrm{C}$ also involved the reappearance of material from magmatic system 2, but material from magmatic system 1 is absent. Although previous studies have highlighted heterogeneity in the crystal cargo of the HRT (e.g. Wotzlaw et al. 2015), the insights that can be gleaned from that work are limited by the lack of context resulting from bulk samples. The details presented here in the HRT highlight the advantages of analysing the compositions of single clasts and their components to build up a fuller picture of the parental magmatic system.

2. Elemental and isotopic compositions of the different magma systems suggest that a variety of petrogenetic mechanisms were operating prior to the HRT eruption. $\mathrm{Pb}$ isotopic constraints, coupled with the high-Ba and $\mathrm{Zr}$ nature of magmatic system 1 , indicate that this and system 2 are petrogenetically related to the co-erupted HRT mafics (Swallow et al. 2018a, Chapter 4). 
Moderate offsets to more-crustal isotopic compositions in magmatic systems 1 and 2 relative to HRT mafic compositions suggests a control on rhyolite compositions dominantly by fractional crystallisation with only minor assimilation. Compositional variations and gaps within systems 1 and 2 can be explained through a multi-stage partial melting scenario (Fig. 5.21), with the erupted high-silica rhyolites (e.g. suite A1) extracted from a sanidine-rich mush which was in turn re-melted (e.g. Wolff 2017) to generate suite A2 compositions. In contrast, magmatic systems 3 and 4 in member $C$ contain significantly more radiogenic isotopic compositions, consistent with greater degrees of assimilation of Archean crustal rocks (Fig. 5.23). Whilst the high-Ba nature of magmatic system 3 indicates a continuing role for HRT mafic compositions, in contrast the low-Ba, high-Sc nature of system 4 is linked to a pyroxene-bearing olivine tholeiitic root zone. Despite the contrasting elemental compositions between these two member $C$ suites, their isotopic compositions are comparable and can be similarly explained through crustal contamination of partial melts of mafic cumulates, derived from contrasting mafic lineages (system 3-HRT mafics, system 4-olivine tholeiites). These newly erupted member $\mathrm{C}$ systems, coupled with the rejuvenation of the fractional crystallisation-controlled magmatic system 2, illustrates the huge diversity in petrogenetic mechanisms represented in the HRT. This variation suggests that rhyolite petrogenesis in the YPVF is complex and diverse, and is much more nuanced than proposed in other end-member models (cf. Loewen and Bindeman 2015; Stelten et al. 2015).

3. Groundmass glass compositions from all three of the magmatic systems that erupted glassy material (magmatic system 4 is only represented by devitrified material) show clustering, indicative of the presence of multiple, distinct meltdominant bodies. As this clustering is consistent in the fall deposits (Myers et al. 2016; Swallow et al. 2018b, Chapter 3) and the ignimbrite, this configuration in the relevant magmatic system was not confined to the upper (earliererupted) levels but persisted throughout evacuation of the system. Broadly comparable estimates of storage pressures/depth from volatile contents in melt inclusions (Myers et al. 2016) and glass major element compositions 


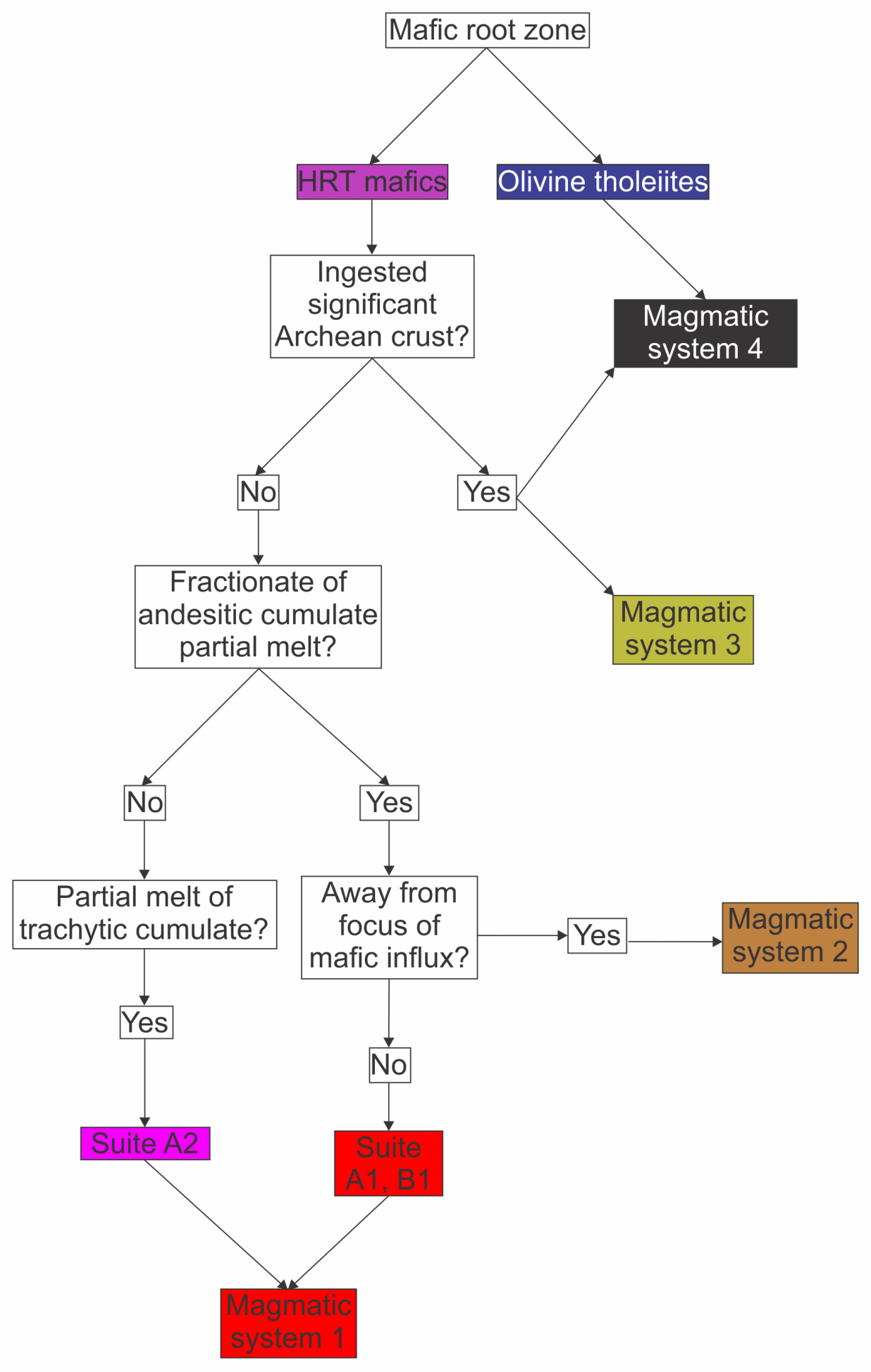

Figure 5.23: Flow chart showing the distinguishing features of each of the four magmatic systems identified in this study. The characteristics of the silicic systems are controlled by their parental mafic root zone, degrees of interaction with Archean crust and spatial relationship to the focus of mafic influx. See text for further details. Colours based on sample types that distinguish the systems/suites. 
imply that these bodies were predominantly laterally rather than vertically separated (Fig. 5.22). This arrangement appears to be a common feature in large silicic caldera-forming eruptions (e.g. Cooper et al. 2012, 2016; Ellis and Wolff 2012; Bégué et al. 2014). However, this complex, multiple-body nature of magmatic systems is not incorporated into numerical models of magma bodies, leading to a gap between field-based interpretations and model frameworks.

4. Syn-eruptive magmatic processes within the HRT were rapid (Fig. 5.20). Within the weeks-months time break between members $A$ and $B$, mixing related to renewed influx of HRT mafic material occurred, closing the compositional gap present in member $A$ between suites $A 1$ and $A 2$. Furthermore, the absence of material derived from magmatic systems 3 and 4 in members $A$ and $B$ suggest that melt-dominant bodies of these systems were not present at this time. This observation constrains rapid formation of these melt-dominant bodies to in the years-decades time break between members B and C, further linked by uniform small $(<2 \mathrm{~mm})$ crystal size across all member $\mathrm{C}$ juvenile material. This period is also contemporaneous with rejuvenation of magmatic system 2 . Estimates of timescales of crystal growth, based on published quartz growth rates, encompass field-derived estimates for the B:C time break. Whilst further mineral-specific studies are required to constrain timescales of melt-dominant body formation in the HRT, these observations are consistent with findings from other large-scale silicic systems (e.g. Charlier et al. 2008; Allan et al. 2013; Cooper et al. 2016, 2017).

5. Temperature estimates from erupted material in the HRT show a broad range indicating temporal and spatial heterogeneity in the HRT magmatic complex. These estimates yield moderate temperatures $\left(\sim 780-900^{\circ} \mathrm{C}\right)$, that lie between the high temperatures associated with most Snake River Plain silicic volcanism $\left(>900^{\circ} \mathrm{C}\right.$ : e.g. Branney et al. 2008) and lower temperatures inferred from the youngest episodes of volcanism in the YPVF $\left(<800{ }^{\circ} \mathrm{C}\right.$ : e.g. Loewen and Bindeman 2015; Stelten et al. 2015; Befus and Gardener 2016). Whether this represents a cooling overall magmatic system (e.g. Watts et al. 2012) or distinct differences between the various volcanic centres is not clearly 
established. However, incorporation of the YPVF into the 'hot-dry' rhyolite category associated with the Snake River Plain appears overly simplistic (e.g. Loewen and Bindeman 2016), and Yellowstone silicic products in general and the HRT eruption products in particular defy simple pigeonholing.

6. The mapped HRT caldera and total eruptive volume (Christiansen 2001) is comparable in size to regions in other silicic volcanic provinces that experienced clusters of caldera-forming eruptions ('flare-ups') from multiple volcanic centres over periods of $\sim 10^{5}$ years (e.g. Taupo Volcanic Zone: Houghton et al. 1995; Gravley et al. 2016). The HRT could be considered in a way as a 'flare-up' but on a highly compressed timescale, with the effectively simultaneous (rather than separated) eruption of multiple independent magmatic systems. Subsequent volcanism in the YPVF shows evidence for complex mineral assemblages and stratigraphy (e.g. Christiansen 2001; Troch et al. 2017; Stelten et al. 2018; Wilson et al. 2018). Available data suggest that other eruptive units in the YPVF deserve closer scrutiny to determine if the HRT is the norm or exception for large eruptions at Yellowstone. 


\section{Chapter 6}

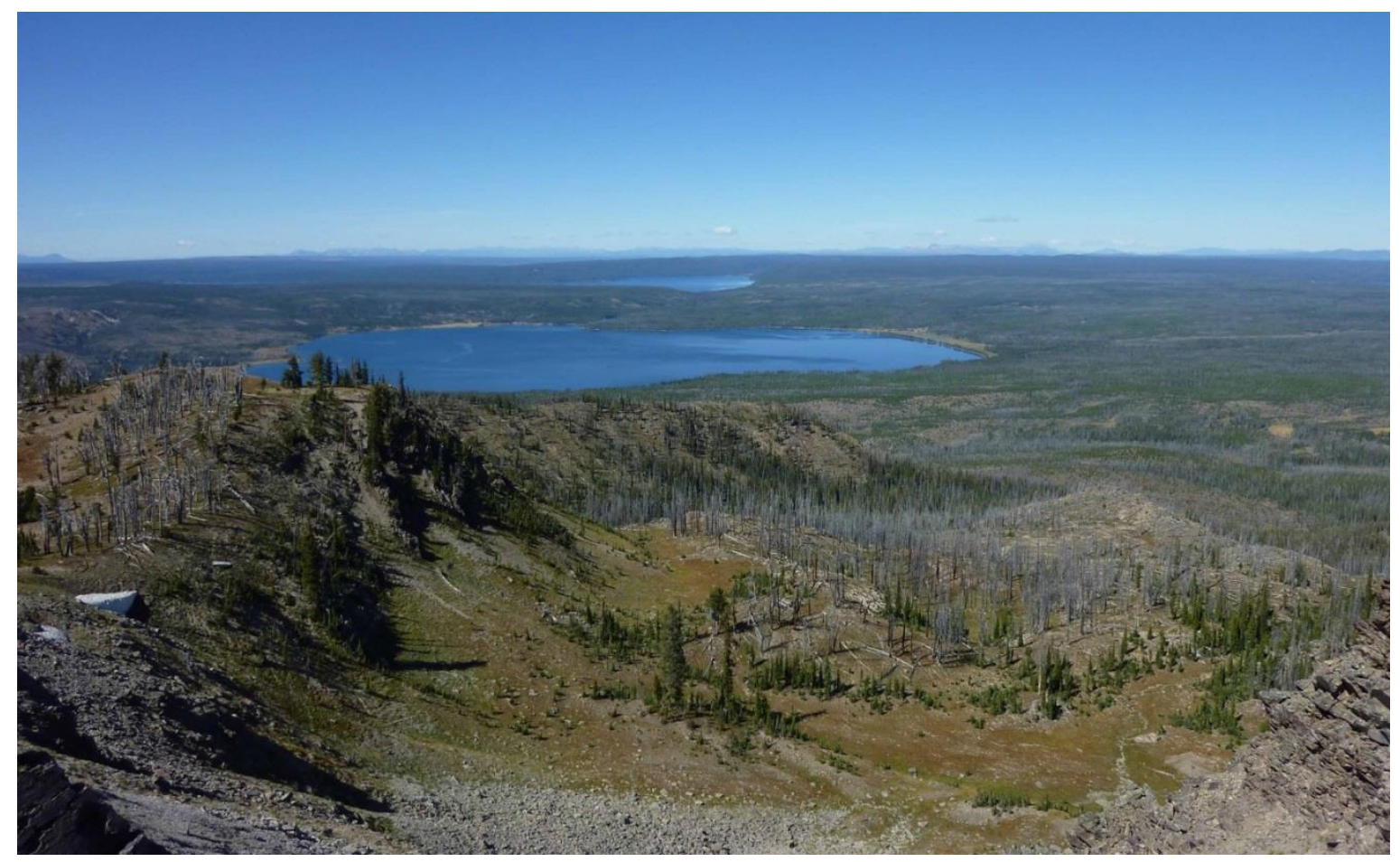

Photograph overlooking Lewis Lake (foreground), Shoshone Lake (background) and across the Central Plateau member rhyolites from the NW Red Mountains, Yellowstone National Park, Wyoming, U.S.A. Photograph courtesy of CJN Wilson. 


\section{Conclusions}

\subsection{General summary}

Silicic (dacitic to rhyolitic) magmatic systems have the potential to generate large, calderaforming, explosive eruptions (including supereruptions: $>10^{15} \mathrm{~kg}, \sim 450 \mathrm{~km}^{3}$ of erupted magma: Sparks et al. 2005; Miller and Wark 2008) that have had, and would have, global impacts and consequences (Mason et al. 2004; Self 2006). Due to the infrequency of such eruptions and the absence of supereruptions in the historical record (Mason et al. 2004), gaining knowledge of such systems is challenging. Understanding has been incrementally developed using two main techniques. Firstly, through numerical modelling of the physical processes within these systems. This focuses on the development and growth of meltdominant bodies (e.g. Bachmann and Bergantz 2004; Huber et al. 2012; Bachmann and Huber 2016) and/or the triggering of such bodies (e.g. Jellinek and DePaolo 2003; Gregg et al. 2012, 2015; Caricchi et al. 2014; Malfait et al. 2014). Secondly, through investigation of deposits from past eruptions to reconstruct the magmatic systems of individual volcanoes (e.g. Schuraytz et al. 1989; Streck and Grunder 1997; Hildreth and Wilson 2007; Allan et al. 2017).

Early understandings of these magmatic systems were focused around rapid eruption of single magma bodies, that formed over long timescales $\left(10^{5}-10^{6}\right.$ years), and any compositional variations within eruption deposits were related to zonation within the magma body (e.g. Smith 1979; Hildreth 1981). This 'traditional' view subsequently led numerical models to focus on the prolonged formation but instantaneous eruption of single magma bodies (e.g. Jellinek and DePaolo 2003; Gregg et al. 2012, 2015). However, many case studies of individual eruption deposits in contrast show compositional variations more consistent with the simultaneous or sequential evacuation of multiple magma bodies (e.g. Sampson and Cameron 1987; Wilson et al. 2006; Shane et al. 2007, 2008; Cooper et al. 2012, 2016, 2017; Allan et al. 2013; Bégué et al. 2014). These contrasting viewpoints have led to discrepancies between the foundations of numerical models and the reconstructed nature of magmatic systems from individual case studies.

Furthermore, compositional variations are typically thought to represent vertical zonation within a single body that in turn is generated from heterogeneous fractionates from a single crystal-rich magmatic root zone (i.e. mush: e.g. Schuraytz et al. 1989; Streck and Grunder 1997; 
Bachmann and Bergantz 2004; Hildreth 2004; Hildreth and Wilson 2007). In contrast, this compositional variation may represent multiple compositionally distinct bodies that are laterally-adjacent and/or reflect a wide range of petrogenetic processes (e.g. Brown et al. 1998; Deering et al. 2011; Ellis and Wolff 2012; Bachmann et al. 2014; Loewen and Bindeman 2015; Wolff et al. 2015). Moreover, multiple elemental and/or isotopic techniques, often used in isolation on bulk samples and or single crystals, may identify small-scale heterogeneity within eruption deposits but commonly are not accompanied by detailed stratigraphic control (e.g. Hildreth et al. 1984, 1991; Bindeman et al. 2008; Charlier et al. 2008; Wotzlaw et al. 2015) These examples highlight the importance of using case studies to reveal heterogeneity within individual eruption deposits and therefore individual magmatic systems, to develop understanding within the field as a whole.

This thesis has used multiple geochemical techniques, based on a stratigraphic framework developed by CJN Wilson (Wilson 2009; Wilson et al. in prep), on a single, archetypal large caldera-forming eruption, the $2.08 \mathrm{Ma}, \sim 2,500 \mathrm{~km}^{3}$ Huckleberry Ridge Tuff, Yellowstone (HRT: Christiansen 2001; Rivera et al. 2014; Singer et al. 2014; Wotzlaw et al. 2015), to reveal an extraordinary degree of complexity within the parental magmatic complex.

\subsection{Key findings}

The data in this thesis demonstrate that systematic analysis of single clasts (their major and trace element, and isotopic compositions) and their components (matrix glass major and trace element compositions, and crystal compositions), within a stratigraphically-constrained framework, can reveal unprecedented diversity within the deposits of a large, silicic, calderaforming eruption. The HRT provides an unparalleled example of complexity in the nature of its deposits and their evacuated melt-dominant bodies. Extensive fieldwork by CJN Wilson (Wilson 2009 and pers comm; Wilson et al. in prep), has identified evidence for intra-eruptive time breaks (Figs. 5.2, 6.1). The initial fall deposits represent episodic and prolonged activity, indicated by evidence for reworking and fine ash tops to individual horizons when the plume entirely dissipated (Myers et al. 2016, Electronic Appendix 1; Swallow et al. 2018b, Chapter 3). Ignimbrite members A and B were separated by a time gap of weeks to months, constrained by welding breaks and the presence of rheomorphic deformation of member $A$ but not B where they are in contact (Chapter 5). A longer time break of years to decades 


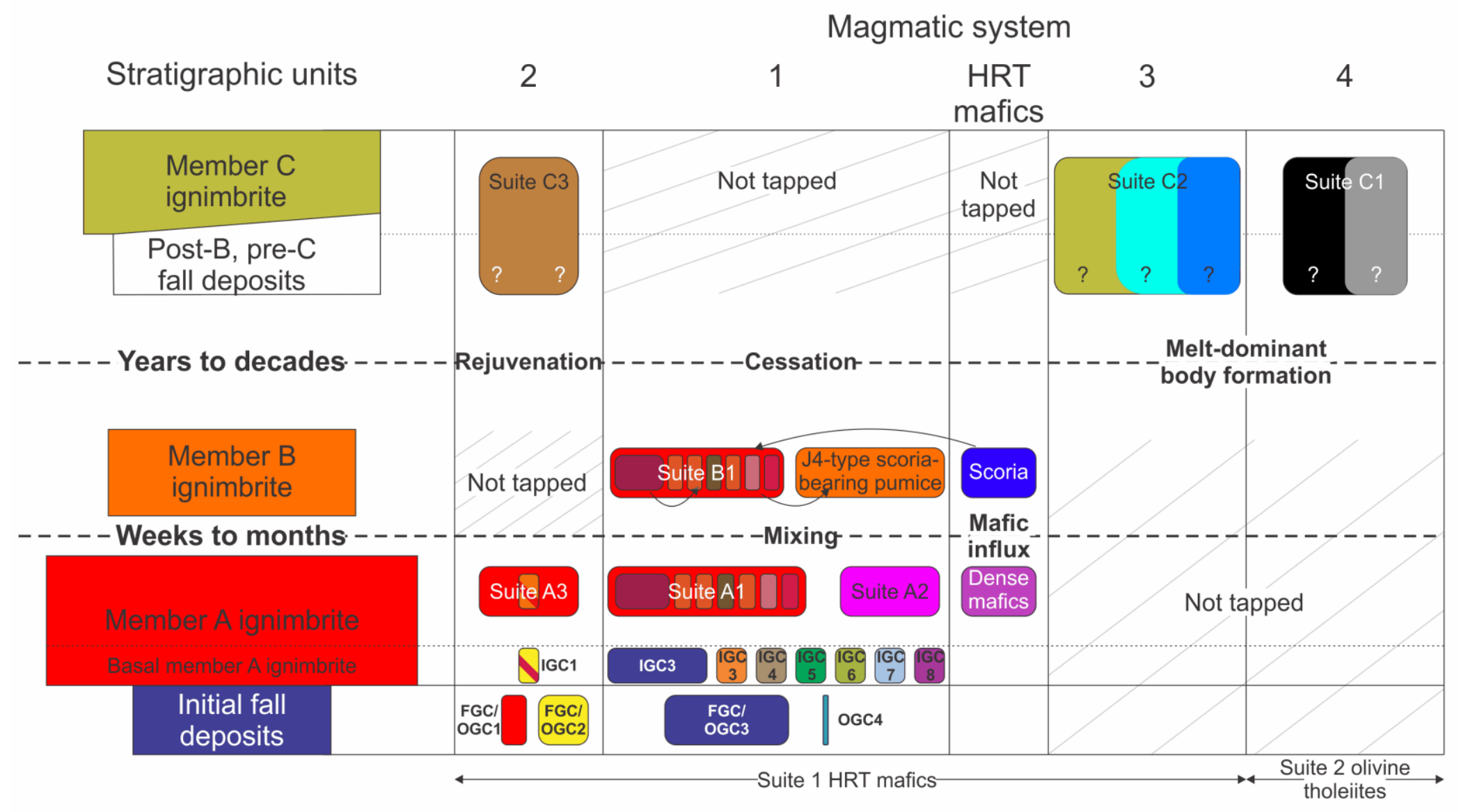

Figure 6.1: Schematic diagram showing the broad eruptive timescale and stratigraphy of the HRT (CJN Wilson, manuscript in preparation) along with the four inferred silicic magmatic systems (with their associated magmatic suites and mafic root zones) tapped during the eruption. The magmatic systems, and their melt-dominant bodies, were episodically tapped, with two systems active in the initial fall deposits and ignimbrite member A with only one (magmatic system 1) evacuated in member B. Member C, following a time break, evacuated a rejuvenated magmatic system 2 and newly formed meltdominant bodies of magmatic systems 3 and 4. Colours as in the figures in chapters 3 and 5. This figure is a duplicate of Fig. 5.20. 
occurred following ignimbrite member $\mathrm{B}$ and prior to the eruption of pre-C fall deposits and ignimbrite member $\mathrm{C}$. This duration is estimated from the presence of an extensive welding break between the two members, with a limiting duration constrained by the vapour-phase alteration of pre-C fall deposits and basal member $\mathrm{C}$ ignimbrite from the still outgassing deposits of members A plus B. This chronostratigraphic framework has provided the stratigraphic controls for this study.

Analyses of material from the initial fall deposits (Myers et al. 2016; Swallow et al. 2018b, Chapter 3) and ignimbrite members A, B and C (Chapter 5), serve to fingerprint four compositionally distinct silicic magmatic systems:

- Magmatic system 1 generated melt-dominant bodies that were evacuated for the initial fall deposits and ignimbrite members $A$ and $B$ (suites A1, A2 and B1: Chapters 3, 5; Fig. 6.1), and was volumetrically-dominant. Products of this system are characterised by moderate-high Ba single clast and glass compositions and moderately radiogenic isotopic systematics. The erupted melts were derived from partial melting of cumulates related to Suite 1 HRT mafics (see below; Fig. 6.2) but the intra-suite compositional natures and variations were controlled by fractional crystallisation. System 1 comprised multiple melt-dominant bodies.

- Magmatic system 2 is represented in the initial fall deposits and member $A$, is absent from member B but rejuvenated in member C (suites A3 and C3: Chapters 3, 5; Fig. 6.1). It is related isotopically to system 1 but distinguished by low-Ba single clast, glass and sanidine (i.e. celsian component) compositions. This system reflects further crystallisation of system 1 compositions but lies away from the thermal focus associated with mafic influx (Fig. 6.2).

- Magmatic system 3 is present solely in member C (suite C2: Chapter 5; Fig. 6.1). It has high-silica characteristics, but large compositional ranges in single clast and glass compositions that are both clustered, indicating multiple melt-dominant bodies. Highly radiogenic (i.e. crust-like) isotopic compositions indicate significant incorporation of Archean crust in formation of parental melts, followed by fractional crystallisation (Fig. 6.2). It is compositionally related to Suite $1 \mathrm{HRT}$ mafics (see below).

- Magmatic system 4 is present solely in member C (suite C1: Chapter 5; Fig. 6.1). Its dacitic, low-Ba single clast compositions make it distinct from other systems. System 4 has similar 


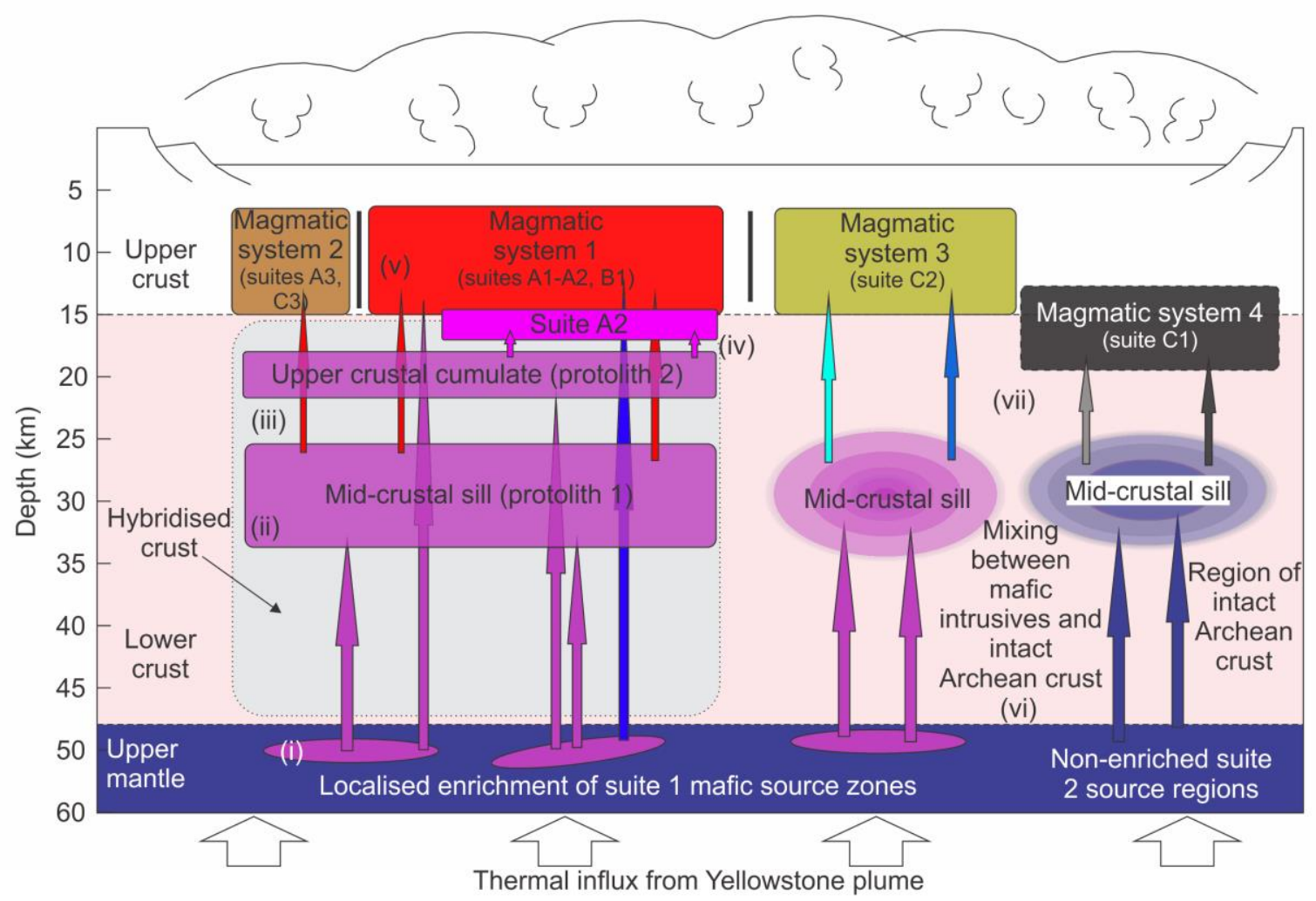

Figure 6.2: Crustal-scale schematic diagram summarising the nature of the HRT magmatic complex from the upper mantle to the surface. Bracketed numbers indicate key processes, as follows. (i) HRT mafic melts are generated from regions of the mantle enriched by high-T,P fluids derived from the subducted Farallon slab. Early HRT mafic melts ascend through contemporaneously or previously (in late Cretaceous or Eocene times) hybridised crust. (ii) Melts stall and crystallise in the middle crust to form protolith 1. (iii) Partial melts of protolith 1 ascend and become parental melts that differentiate to form the melt-dominant bodies of magmatic systems 1 and 2. (iv) Crystalline residuum associated with these fractionates form protolith 2 , which is remelted to form suite $A 2$. (v) Suite 1 HRT mafic melts ascend through the crust and intersect and mix with magmatic system 1. Magmatic system 2 is located away from the focus of mafic influx. (vi) Spatially separated from magmatic systems 1 and 2, as well as within a region of un-modified Archean crust, melts from enriched (Suite 1) and non-enriched (Suite 2) source zones ascend from the uppermost mantle, stall in the middle crust, hybridise with surrounding Archean crust, crystallise and solidify. (vii) Partial melts of these hybridised cumulates ascend and feed magmatic systems 3 (suite C1) and 4 (suite C4). Crustal/mantle boundary depths from Huang et al. (2015).

radiogenic isotopic compositions to system 3, despite its lower-silica nature, indicating significant assimilation of Archean crust in petrogenesis (Fig. 6.2). Its single clast compositions relate it to Suite 2 olivine tholeiites (see below). 
In addition to the four silicic magmatic systems, complexity was found in the nature of the mafic root zones active during the HRT (Swallow et al. 2018a, Chapter 4). Co-erupted mafic enclaves, generally rare in silicic eruptions at Yellowstone (Christiansen 2001), occur in members A and B. The compositions of these (Suite 1: Swallow et al. 2018a, Chapter 4) were distinct from olivine tholeiites (Suite 2) erupted prior to and following the HRT. Suite 1 compositions are compositionally similar to lava flows erupted further west at Craters of the Moon (Leeman et al. 1976; Putirka et al. 2009). The distinct Suite 1 magmas were the dominant mafic composition in the root zones of magmatic systems 1, 2 and 3, whereas Suite 2 compositions, not separately co-erupted with the HRT, provided the mafic input into the root zone of magmatic system 4 (Fig. 6.2).

Below, I synthesise the main conclusions from each chapter (based on the questions listed in Chapter 1), detail insights for the study of large silicic systems and identify areas for future work.

\subsubsection{Eruption onset and escalation}

Pertinent questions that were posed in Chapter 1 are:

1. How did the eruption start and escalate?

2. Was the rhyolitic magmatic system composed of one large melt-dominant body or multiple smaller, discrete bodies?

The onset of the HRT eruption, with the deposition of widespread fall deposits, involved the simultaneous tapping of multiple discrete melt-dominant bodies within magmatic systems 1 and 2 and is inferred to have been controlled by external, tectonic forces (Myers et al. 2016). The number of melt-dominant bodies increased sharply in the transition from the initial fall deposits into the basal ignimbrite (Swallow et al. 2018b, Chapter 3). These meltdominant bodies were laterally-adjacent but vertically-extensive as they continued to be evacuated throughout the eruption of member A (both systems) and member B (system 1; Chapter 5). Crystal contents from pumices spanning the spectrum of compositional variation show comparable crystal abundances (Chapter 5), suggesting that all the melt-dominant bodies had broadly similar physical properties (i.e. density, viscosity) during the eruption (cf. Tramontano et al. 2017). Although temperature differences existed between the meltdominant bodies of magmatic systems 1 and 2, bodies from both lineages were tapped at the eruption onset. The simultaneous tapping of only three bodies, when several more 
(represented by member C) were present at similar depths and with similar physio-chemical characteristics, further supports an external eruption-triggering mechanism, such as a tectonic control (Myers et al. 2016), with analogues elsewhere (Bursik et al. 2003; Allan et al. 2012; Bégué et al. 2014).

\subsubsection{Heterogeneity within the HRT}

Constraining the nature and degree of heterogeneity in the HRT addresses the following questions posed in Chapter 1:

2. Was the rhyolitic magmatic system composed of one large melt-dominant body or multiple smaller, discrete bodies?

4. Are there any chemical differences between the different clast types sampled?

5. What is the degree of heterogeneity within and between different stages of the Huckleberry Ridge Tuff?

6. What is the degree and nature of any heterogeneity present?

7. What were the processes responsible for the generation of the magma erupted?

Heterogeneity is present in all parts and at a multitude of scales within the HRT. Broad scale heterogeneity within juvenile components in the HRT is defined by the four silicic magmatic systems (Chapter 5). Within these systems, though, is further heterogeneity. Three of the systems (1, 2 and 3 ) included multiple laterally-adjacent melt-dominant bodies based on clustered glass compositions (chapters 3 and 5), indicating the presence of compositional heterogeneities within each magmatic system. Furthermore, magmatic system 1 included two compositionally-distinct eruptive suites $(A 1, A 2)$ that were separated in member $A$ but combined in member B (suite B1). This change reflects mixing and reorganisation within magmatic system 1 in the weeks to months time break between members $A$ and $B$ and is related to a renewed influx of Suite 1 mafic material (Chapters 4,5$)$. This mixing resulted in greater heterogeneity of glass compositions in member B pumice relative to comparable samples in member A, whether scoria-bearing or not. Heterogeneity related to mafic root zones is also evident in the distinction between magmatic systems 1 and 2 . Although they are isotopically similar, system 2 is distinct from system 1 due to its spatial separation from the focus of mafic influx and hence different thermal (i.e. cooler) nature from magmatic system 1 (Chapter 5). Within-system thermal heterogeneity is also observed. The presence of less evolved cores/inclusions in crystal phases (e.g. pigeonite in members $\mathrm{A}$ and $\mathrm{B}$, higher $\mathrm{Ba}$ 
sanidine in suite C3) attest to parental magmas being hotter and drier than those erupted. This is also captured by hotter two-feldspar temperature estimates and the presence of less evolved, hotter domains within magmatic systems (e.g. suite A2).

In contrast to members $\mathrm{A}$ and $\mathrm{B}$, member $\mathrm{C}$ exhibits a markedly different compositional record represented by the rejuvenation of magmatic system 2 and the appearance of systems 3 and 4 (Chapter 5). The co-eruption of three magmatic systems in member $\mathrm{C}$ is more diverse than members $\mathrm{A}$ and $\mathrm{B}$. The member $\mathrm{C}$ geochemical classifications show tight correlation with the physical differences between the various juvenile clast types observed in the unit. Distinct pumice types (J7- and J8-types) found at different localities have contrasting geochemical characteristics, forming suites C3 and C2, respectively. Furthermore, physically similar J5- and J6-type samples are dominantly found in suite C1. This physical-geochemical link is stronger in member $\mathrm{C}$ than members $\mathrm{A}$ and B. Although J3-type clasts are solely found in suite A2, J1type samples are physically indistinguishable between suites $A 1$ and $A 3$ (i.e. magmatic systems 1 and 2). Therefore, physical characteristics of HRT juvenile materials are not a definitive guide to their geochemical nature (cf. Streck and Grunder 1997).

Heterogeneity within the HRT is related to and driven by multiple components. The presence of two distinct mafic sources in the HRT magmatic complex generates inter-system heterogeneity (cf. magmatic systems 1 versus 4; Fig. 6.2; Swallow et al. 2018a, Chapter 4). In turn, these mafic systems are inferred to be distinct as a result of localised source enrichment in the lithospheric mantle, which may show heterogeneity on scales of sub-metre to kilometre and this reflected in the range of compositions observed at the surface (Chapter 4). Broad scale heterogeneity was also imparted by interactions with country rock as magma ascends. Crustal lithologies in the Yellowstone region are highly variable in their compositions, ages and isotopic characteristics (e.g. Chadwick 1970; Leeman et al. 1985; Wooden and Mueller 1988; Meen and Eggler 1989; Hildreth et al. 1991; Feeley 2003; Frost et al. 2006). Although mafic and silicic eruptives in the HRT show similar Pb isotopic compositions consistent with a common control from lithospheric components of Archean age (Swallow et al. 2018a, Chapter 4), Sr and Nd isotopes highlight stark contrasts in the degrees of interaction with shallow-level, radiogenic country rocks (cf. magmatic systems 1, 3 and 4). The interaction (or lack thereof) with highly radiogenic crustal assimilants may further have been influenced by previous Eocene magmatism in the region (Chadwick 1970; Hildreth et al. 1991; Feeley 2003). Finally, heterogeneity between the melt-dominant bodies within magmatic systems 1 and 2 reflects 
variations in the degree and nature of fractional crystallisation within the system. Coherent trends observed for some elements in glass compositions (e.g. $\mathrm{U}, \mathrm{Rb}$ ) contrasts with those for other elements (e.g. Ba, La) indicating the selective control on heterogeneity by the crystallising assemblage (Swallow et al. 2018b, Chapter 3). This heterogeneity, in turn, may be subsequently related to the underlying mafic systems and thus the thermal input. This is manifested in terms of the parental mafic magma (cf. magmatic systems 3 and 4), spatial relationship between the bodies and the focus of mafic magma (cf. magmatic systems 1 and 2) and the overall heat budget allowing multiple small melt-dominant bodies to survive within the crust.

\subsubsection{Thermal and chemical drivers of the silicic system}

The ultimate thermal and chemical driver of the silicic systems in the HRT complex (Chapter 1, Question 3: "What were the deep-seated thermal and chemical drivers of the rhyolitic magmatic system?), as in the YPVF as a whole, is mafic magmas (Hildreth et al. 1991; Christiansen 2001; Huang et al. 2015). Co-erupted mafic enclaves in members A and B (Suite 1: Swallow et al. 2018a, Chapter 4) provide an insight into the nature of the mafic root zones. These Suite 1 compositions are compositionally distinct but are closely related to Craters of the Moon eruptives (Leeman et al. 1976; Christiansen and McCurry 2008; Putirka et al. 2009). The HRT Suite 1 compositions owe their distinctive features to an origin in lithospheric mantle enriched by high-T, P fluids emanating from the subducted Farallon slab (Swallow et al. 2018a, Chapter 4). In contrast to the prevailing view (Christiansen 2001; Christiansen and McCurry 2008), we assert that the majority of erupted silicic material in the HRT (systems 1-3) are related to these Suite 1 mafics, rather than olivine tholeiitic compositions (Suite 2: Swallow et al. 2018a, Chapter 4; Fig. 6.2) erupted prior to and following the HRT eruption. However, Suite 2 compositions also have a role in driving silicic magmatism, with magmatic system 4 petrogenetically linked to this suite. Both mafic root zones were simultaneously active prior to and during the HRT eruption, reflected in the pre-HRT olivine tholeiitic Junction Butte Basalt (Christiansen 2001), presence of suite 1 compositions in members A and B, and coeruption in member $\mathrm{C}$ of magmatic systems 3 and 4 that show affinities to both mafic suites. This contemporaneity is supported by recent work (published after Chapter 4 was accepted) reporting Craters of the Moon-type lava flows along the Snake River Plain as old as $\sim 3.7 \mathrm{Ma}$ (Potter et al. 2018). 
The presence of mafic material in members $A$ and $B$, and the elevated temperatures derived from J4-type scoria-bearing pumices (Fig. 5.18), support a major thermal role for mafic magma in the HRT. The distinct stratigraphic occurrence and vesicular nature of scoria in member $B$, relative to dense mafics in member $A$, suggest a renewed mafic influx associated with member B. Influx of mafic magma has been invoked as an eruption trigger in the YPVF (e.g. Till et al. 2015). Although direct triggering links are not established in this work, the mixing between melt-dominant bodies (suites $A 1$ and $A 2$ to yield suite $B 1$ ) in the time break between members $A$ and $B$ may reflect the renewed influx of mafic magma into the silicic part of magmatic system 1. Furthermore, an influx of mafic magma plausibly led to remelting of sanidine-bearing cumulates and the generation of suite $A 2$ compositions. Although there is no physical evidence of mafic magma influx in member $C$, the presence of less evolved sanidine rim compositions relative to cores in samples from magmatic system 3 is consistent with a late-stage thermal input during formation of the melt-dominant bodies.

\subsubsection{Timescales of melt-dominant body formation}

The HRT stratigraphic framework (Fig. 6.1) allows for inferences regarding the timescales of melt-dominant body formation (Chapter 1, Question 8: "Over what timescales did these melts form?"). Although there may have been a prolonged chemical development of the overall HRT silicic complex, syn-eruptive changes imply that timescales related to growth of meltdominant bodies were more rapid. These changes can be linked to the time breaks within the eruption. Widespread mixing and reorganisation of magmatic system 1 occurred in the weeks to months hiatus between members $A$ and $B$, associated with influx of HRT mafic magma (Fig. 6.1). Furthermore, rejuvenation of magmatic system 2 to erupt again in member $C$ is constrained to occur in the years to decades time break between members B and C (Fig. 6.1). Similarly small crystal sizes in products of all the systems (2, 3 and 4 ) vented to produce member $\mathrm{C}$ indicate rapid melt-dominant body generation during the eruptive hiatus. This broader rejuvenation process is plausibly related to changes in the local stress field due to caldera collapse associated with members $A$ and $B$, and/or the further influx of mafic magma into the base of the magmatic systems. These features collectively indicate that processes relating to melt-dominant bodies can occur on much shorter timescales than those influencing the chemical development of silicic systems, as has been increasingly inferred 
elsewhere (e.g. Charlier et al. 2005; Druitt et al. 2012; Allan et al. 2013; Barker et al. 2016; Cooper et al. 2017).

\subsubsection{Onset and development of caldera collapse}

The initiation of caldera collapse is pertinent to the escalation of the HRT eruption (Chapter 1, Question 1: "How did the eruption start and escalate?"). The onset of widespread HRT ignimbrite deposition was associated with the simultaneous tapping of a much greater range of melt-dominant bodies over a much larger geographic area than the fall deposits (Swallow et al. 2018b, Chapter 3). This change is inferred to be related to caldera collapse following depressurisation of magmatic systems 1 and/or 2. Apart from the magma body for suite $A 2$, all melt-dominant bodies within the two magmatic systems ( 1 and 2 ) active at this point were being evacuated in the basal ignimbrite. However, the presence of two other magmatic systems ( 3 and 4 ) only evacuated in member $C$ indicates that this collapse region was only a portion of the overall mapped caldera. Therefore, as proposed by Christiansen (2001), caldera-collapse was likely a multi-phase and piecemeal processes that developed throughout the eruption. As the overall $\sim 95 \times 65 \mathrm{~km}$ caldera (Christiansen 2001) is equivalent in size to multiple-caldera clusters in other silicic volcanic regions (e.g. Taupo Volcanic Zone: Gravley et al. 2016; Fig. 6.3), the HRT caldera could be thought of in a similar way to the Taupo Volcanic Zone caldera complex (i.e. multiple-caldera clusters), with finer details obscured by subsequent volcanism and erosion (see below for further discussion).

\subsubsection{How can the geochemical results inform the present day geophysical image of the Yellowstone system?}

Findings and interpretations from the study of past eruptions at Yellowstone are applicable to the current understanding of the present day Yellowstone system (Chapter 1, Question 9: "How can the geochemical results constrain the geophysical image of the Yellowstone system?"). Geophysical imaging of the Yellowstone magmatic system has outlined a single low-velocity body located in the upper crust (5-17 km depth) containing up to $15 \%$ partial melt (Farrell et al. 2014; Huang et al. 2015). Despite yielding estimates of up to $600 \mathrm{~km}^{3}$ of melt, this melt is inferred to be currently in too low a concentration to erupt. However, with a resolution of only $\sim 10 \mathrm{~km}$ available from seismic imaging (Lowenstern et al. 2006), and the 


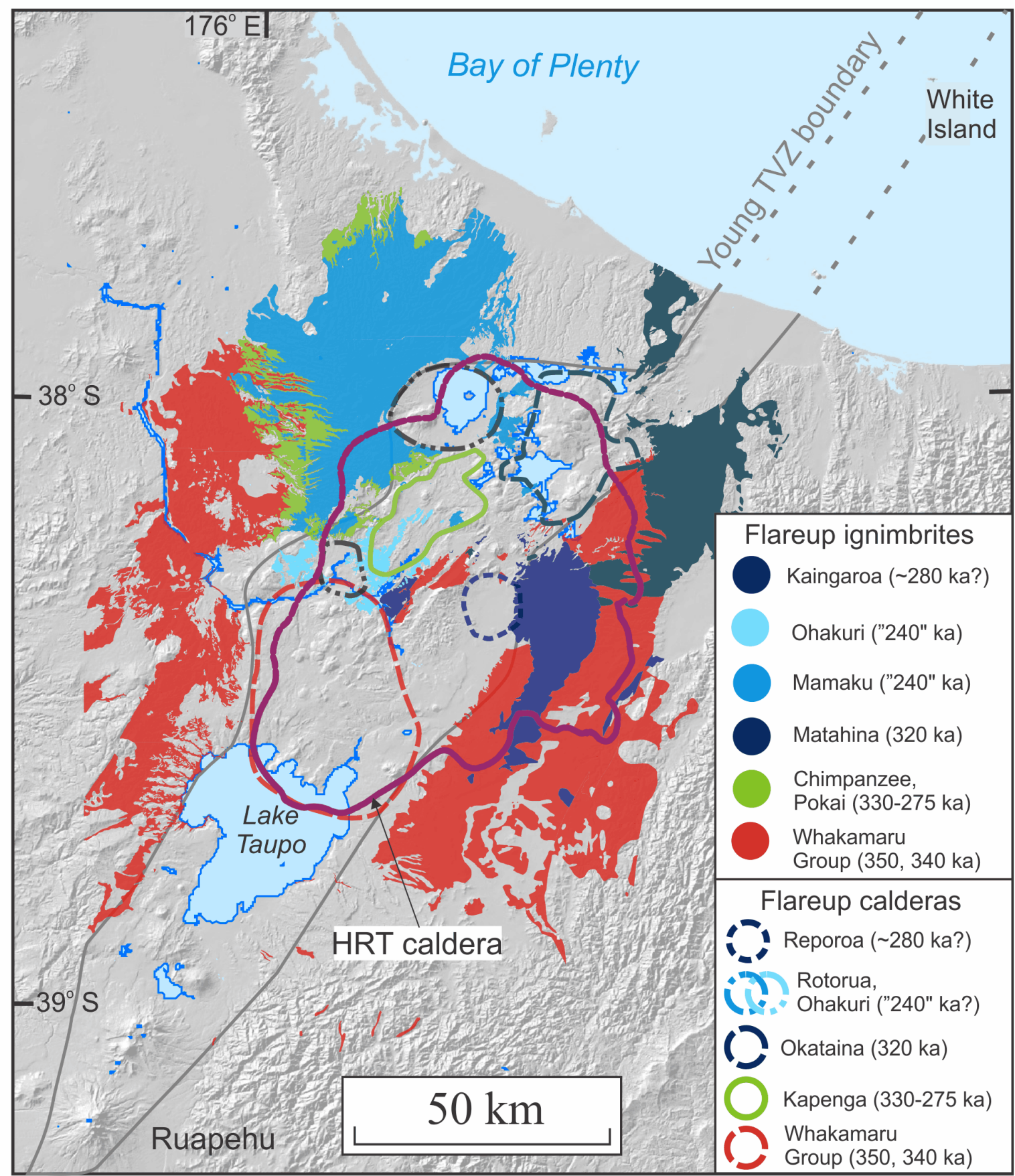

Figure 6.3: Map of the Taupo Volcanic Zone, New Zealand showing the deposits and calderas from eight ignimbrite-forming eruptions that occurred over $\sim 100 \mathrm{kyr}$ with a cumulative volume of $\sim 3,000 \mathrm{~km}^{3}$ (map from CJN Wilson; see Gravley et al. 2016). This group of eruptions was classified by Gravley et al. (2016) as an ignimbrite flare-up. Within the encompassing area, evidence is present for an additional caldera in the southeast corner of the Whakamaru caldera (Rosenberg 2017). The rotated outline of the mapped HRT caldera (purple line: from Christiansen et al. 2007) is overlain to scale, indicating the areal similarity between the cumulative HRT caldera and the six individual calderas generated in the TVZ flareup event. 
difficulty in estimating melt fraction and porosity distribution from tomography (Farrell et al. 2014), it remains unclear whether regions within this low-velocity body are melt-rich and could, therefore, erupt on short timescales. Geochemical data indicate that magma distribution in the HRT complex was heterogeneous with multiple small melt-dominant bodies present. It is possible that with continued activity at Yellowstone, the magmatic system configuration may have 'matured' to favour a large, single body. However, geochemical studies on eruption products prior to and following the HRT in and around Yellowstone indicate that the presence of multiple melt-dominant bodies is common for volcanism in the region (e.g. Ellis and Wolff 2012; Wotzlaw et al. 2015; Troch et al. 2017; Stelten et al. 2018). Therefore, this configuration must be kept in mind regarding the current geophysical image of the Yellowstone magmatic system and its hazard potential. Further, higher resolution imaging of the system would be highly beneficial, therefore, to constrain the distribution of melt in the present magmatic system.

\subsection{Insights for Yellowstone and silicic magmatic systems}

\subsubsection{One or more magma bodies?}

As alluded to previously, the HRT was the result of the evacuation of multiple melt-dominant bodies, in contrast to other silicic caldera-forming eruptions that are inferred to be dominated by a single melt-dominant body (e.g. Bacon and Druitt 1988; Streck and Grunder 1997; Hildreth and Wilson 2007; Chamberlain et al. 2015; Allan et al. 2017). The identification of multiple, laterally-adjacent magma bodies is becoming increasingly common in silicic systems (e.g. Shane et al. 2007, 2008; Cooper et al. 2012, 2016; Ellis and Wolff 2012; Bégué et al. 2014; Pistolesi et al. 2016). However, the traditional view that compositional variation is due to vertical zonation within a single magma body (see Smith 1979; Hildreth 1981; Bachmann and Huber 2016, for overviews) is still strongly held and solely reflected in numerical models (e.g. Jellinek and DePaolo 2003; Gregg et al. 2012, 2015; Malfait et al. 2014). Compositional clustering reported from large silicic caldera-related deposits (e.g. Schuraytz et al. 1989; Streck and Grunder 1997; Westgate et al. 2013) may benefit, though, from re-investigation with alternative magmatic system configurations considered. Within the Yellowstone system, further attention could be focussed on younger eruptions, particularly the Lava Creek Tuff (LCT). Compositional data for the LCT is sparse (Christiansen 2001) but zircon isotopic 
compositions exhibit a bimodality similar to that seen in the HRT (Wotzlaw et al. 2015). Furthermore, the multi-member nature of the LCT and contrasting mineral assemblages between the different units (Christiansen 2001; Wilson et al. 2018) indicate complexities that have not been addressed. Geologically contemporaneous activity from independent magma systems has also been recognised in smaller-scale events, such as the domes postdating the 1.3 Ma Mesa Falls Tuff with contemporaneous eruption of rhyolite lavas with distinct mineral assemblages (Stelten et al. 2018).

\subsubsection{When is an eruption an eruption, or a magmatic system a magmatic system?}

Should three ignimbrite caldera-forming eruptions occur today, each separated by periods of weeks to decades, and exhibit compositional differences between each eruption, they would likely be considered distinct eruptions. The HRT, considered one eruption (Reynolds 1977; Hildreth et al. 1991; Christiansen 2001), exhibits these characteristics and thus raises the issue surrounding the distinction between one, multi-phase event and multiple eruptions. Searching for and identification of evidence of short time breaks is, therefore, crucial in distinguishing individual eruptions within an eruptive sequence, thus providing a framework for geochemical studies and providing a more realistic representation of the eruption cycle. Although this is increasingly challenging further back in the geological record, eruptions separated by similar time gaps have been identified as distinct eruptions (e.g. Kidnappers/Rocky Hill eruptions, Taupo Volcanic Zone: Cooper et al. 2016).

Not only are multiple melt-dominant bodies inferred to be represented in the HRT, but also multiple magmatic systems. The divisions concerned are based on compositional distinctiveness, with differences in elemental and isotopic characteristics. However, the divisions adopted may have issues as there is arguably greater compositional contrasts between suites $A 1$ and $A 2$, which are considered part of the same system (magmatic system 1), than the suites $A 1$ and $A 3$ (systems 1 and 2, respectively). The reappearance in member $C$ of the low-Ba compositions (suite C3), but not those from magmatic system 1, however, reinforces the view that this is a separate and distinct system, first vented in the initial fall deposits (Swallow et al. 2018b, Chapter 3). In contrast, Bégué et al. (2014: Mamaku-Ohakuri, New Zealand) and Cooper et al. (2016: Kidnappers-Rocky Hill) relate closelyspaced/synchronous eruptions as emanating from the same magmatic system in the sense used here. This inference is based on the similar compositional characteristics of the juvenile 
materials, despite both examples showing evidence for multiple compositionally-distinct melt-dominant bodies and coming from different calderas (e.g. Gravley et al. 2007). Although the compositional variation within the HRT is much greater than these examples, thermally and geochronologically (CJN Wilson et al. unpublished data) the HRT magmatic systems are comparable in their history and related to the onset of thermal input beneath Yellowstone, which is in turn related to the impingement of the Yellowstone plume. Distinguishing the degree of similarity in the thermal histories versus the compositional and spatial distinctness is important in understanding dynamics in the broader magmatic complex (i.e. multiple magmatic systems), as events within one region of a magmatic system are inferred to exert a strong control on the stress field in surrounding regions (Gudmundsson 2012; Bégué et al. 2014).

The complexity surrounding the definition of magmatic systems is evident in the TVZ examples cited above. The Mamaku-Ohakuri eruptions were two of eight caldera-forming eruptions that occurred over a $\sim 100 \mathrm{kyr}$ period within an area comparable in size to the mapped HRT caldera and generated $\sim 3,000 \mathrm{~km}^{3}$ of material (Fig. 6.3: Houghton et al. 1995; Gravley et al. 2016). These eruptions emanated from six distinct calderas and the ignimbrite flare-up is interpreted to be related to regional rifting and elevated mantle flux acting on the TVZ. The comparable nature of the HRT magmatic complex in terms of total caldera collapse area and erupted volumes (Fig. 6.3), but contrasting timescale (i.e. eight eruptions within $\sim 100 \mathrm{kyr}$ in the TVZ compared to $\sim 600$ ka between caldera-forming eruptions at Yellowstone), is striking and suggest that the cyclical eruption history in the YPVF may be the result of regional forces rather than due to internal triggers (e.g. overpressure; Christiansen 2001; Gregg et al. 2015). Although the TVZ and YPVF are both in rifting environments, the lower current extension rates in the latter ( $\sim 2 \mathrm{~mm} / \mathrm{yr}$ compared to $\sim 10 \mathrm{~mm} / \mathrm{yr})$, thicker lithosphere and presence of a mantle plume (Houghton et al. 1995; Smith et al. 2009; Wilson and Rowland 2016) arguably modulate the contrasting nature of eruptive cyclicity in both volcanic provinces.

\subsubsection{Comparisons with other silicic caldera-forming eruptions}

Studies on the deposits of explosive, crystal-poor silicic eruptions show a large range in magmatic system configuration and eruption behaviour (Table 6.1). Diversity is evident within some systems in glass compositions (e.g. Toba: Westgate et al. 2013), single clast 


\begin{tabular}{|c|c|c|c|c|c|}
\hline Eruption & $\begin{array}{l}\text { Eruption style and } \\
\text { chronology }\end{array}$ & $\begin{array}{l}\text { Fall deposit chemical } \\
\text { composition }\end{array}$ & $\begin{array}{l}\text { Ignimbrite chemical } \\
\text { composition }\end{array}$ & $\begin{array}{l}\text { Role/presence of } \\
\text { mafic magma on the } \\
\text { silicic system }\end{array}$ & $\begin{array}{l}\text { Nature of magmatic } \\
\text { system }\end{array}$ \\
\hline $\begin{array}{l}\text { Crater Lake, Mt. } \\
\text { Mazama (Bacon } \\
\text { 1983; Bacon and } \\
\text { Druitt 1988; Suzuki- } \\
\text { Kamata et al. 1993). }\end{array}$ & $\begin{array}{l}\text { Continuous eruption of } \\
\sim 50 \mathrm{~km}^{3} \text { with initial fall } \\
\text { activity transitioning } \\
\text { into widespread } \\
\text { ignimbrite deposition. }\end{array}$ & $\begin{array}{l}\text { Homogenous } \\
\text { rhyodacite fall deposit } \\
\text { from a single vent. }\end{array}$ & $\begin{array}{l}\text { Zoned ignimbrite deposition } \\
\text { from a widened single vent } \\
\text { (pre-caldera collapse) } \\
\text { transitioning to multiple vents } \\
\text { along ring fractures (following } \\
\text { caldera collapse). }\end{array}$ & $\begin{array}{l}\text { Subordinate andesite } \\
\text { and cumulate scoriae in } \\
\text { the upper parts of the } \\
\text { ignimbrite and rarely in } \\
\text { the fall deposit. }\end{array}$ & $\begin{array}{l}\text { Single, melt-dominant } \\
\text { body, homogeneous } \\
\text { melt compositions but } \\
\text { variation in crystal } \\
\text { contents, underlain by } \\
\text { andesitic melts and } \\
\text { cumulates. }\end{array}$ \\
\hline $\begin{array}{l}\text { Oruanui, Taupo } \\
\text { Volcanic Zone } \\
\text { (Wilson 2001; Wilson } \\
\text { et al. 2006; Allan et } \\
\text { al. 2012, 2013, 2017). }\end{array}$ & $\begin{array}{l}\text { Eruption of } \sim 530 \mathrm{~km}^{3} \text { in } \\
10 \text { eruptive phases with } \\
\text { coeval fall and } \\
\text { ignimbrite deposition. } \\
\text { Three initial fall deposits } \\
\text { show evidence for time } \\
\text { breaks and deposition } \\
\text { over up to a year. }\end{array}$ & $\begin{array}{l}\text { Heterogenous fall } \\
\text { deposit, modulated by } \\
\text { tectonic forces, and } \\
\text { involving syn-eruptive } \\
10-15 \mathrm{~km} \text { lateral } \\
\text { transport of distinctive } \\
\text { magma, 'foreign' to the } \\
\text { main magmatic system. }\end{array}$ & $\begin{array}{l}\text { Compositional variation (low } \\
\text { to high-silica rhyolite) uniform } \\
\text { at each stratigraphic level. }\end{array}$ & $\begin{array}{l}\text { Mafic enclaves defining } \\
\text { two compositional } \\
\text { trends: one tholeiitic, } \\
\text { one calc-alkaline. }\end{array}$ & $\begin{array}{l}\text { Single, thermally and } \\
\text { chemically } \\
\text { homogenous melt- } \\
\text { dominant body } \\
\text { extracted from crystal } \\
\text { mush zone in }<2,000 \\
\text { years. Subordinate, co- } \\
\text { erupted low-silica } \\
\text { rhyolite body. }\end{array}$ \\
\hline $\begin{array}{l}\text { Mamaku-Ohakuri, } \\
\text { Taupo Volcanic Zone } \\
\text { (Gravley et al. 2007; } \\
\text { Bégué et al. 2014). }\end{array}$ & $\begin{array}{l}\text { Paired eruptions from } \\
\text { adjacent calderas ( 30 } \\
\mathrm{km} \text { apart) erupting a } \\
\text { cumulative }>245 \mathrm{~km}^{3} \text {. } \\
\text { Interfingering of } \\
\text { deposits from both } \\
\text { sources. }\end{array}$ & $\begin{array}{l}\text { Homogenous Ohakuri } \\
\text { fall deposit. }\end{array}$ & $\begin{array}{l}\text { Compositionally } \\
\text { heterogenous, with clustered } \\
\text { single clast and glass } \\
\text { compositions. Ignimbrite } \\
\text { deposition initiated following } \\
\text { change in local stress field } \\
\text { following fall deposition. }\end{array}$ & No evidence. & $\begin{array}{l}\text { Five magma bodies } \\
\text { juxtaposed in the crust } \\
\text { and generated from a } \\
\text { common, } \\
\text { heterogeneous crystal } \\
\text { mush zone. }\end{array}$ \\
\hline $\begin{array}{l}\text { Kidnappers-Rocky } \\
\text { Hill, Taupo Volcanic } \\
\text { Zone (Cooper et al. } \\
2012,2016,2017 \text { ) }\end{array}$ & $\begin{array}{l}\text { Closely spaced eruptions } \\
\text { (time gap of years- } \\
\text { decades) from the same } \\
\text { source region. } \\
\text { Kidnappers fall and } \\
\text { subsequent ignimbrite }\end{array}$ & $\begin{array}{l}\text { Systematic tapping of } \\
\text { three homogeneous } \\
\text { melt-dominant bodies, } \\
\text { representing two } \\
\text { independent magmatic } \\
\text { systems. }\end{array}$ & $\begin{array}{l}\text { Ignimbrite deposition } \\
\text { coincidental with wholesale } \\
\text { caldera collapse. Evacuation } \\
\text { of three magma bodies, } \\
\text { representing the two } \\
\text { magmatic systems present in }\end{array}$ & $\begin{array}{l}\text { Mixing of small-volume } \\
\text { rhyolitic magma with } \\
\text { more primitive mafic } \\
\text { melt. }\end{array}$ & $\begin{array}{l}\text { Two laterally adjacent } \\
\text { magmatic systems } \\
\text { remain independent } \\
\text { throughout the } \\
\text { eruption. Systems } \\
\text { generate three }\end{array}$ \\
\hline
\end{tabular}




\begin{tabular}{|c|c|c|c|c|c|}
\hline \multicolumn{6}{|l|}{ Table 6.1 continued } \\
\hline & $\begin{array}{l}\left.\text { (total } \sim 1200 \mathrm{~km}^{3}\right) \\
\text { deposition followed by } \\
\text { Rocky Hill ignimbrite } \\
\left(\sim 200 \mathrm{~km}^{3}\right) .\end{array}$ & & $\begin{array}{l}\text { the fall deposit. Rocky Hill } \\
\text { ignimbrite represents } \\
\text { rejuvenation of the same } \\
\text { magmatic systems. }\end{array}$ & & $\begin{array}{l}\text { discrete } \\
\text { heterogeneous melt- } \\
\text { dominant bodies } \\
\text { (Kidnappers fall- } \\
\text { ignimbrite) and } \\
\text { regenerate in } 10-20 \\
\text { years with formation } \\
\text { of two homogenous } \\
\text { melt-dominant bodies } \\
\text { (Rocky Hill ignimbrite). }\end{array}$ \\
\hline $\begin{array}{l}\text { Averno } 2 \text { and } \\
\text { Solftara eruptions, } \\
\text { Campi Flegrei } \\
\text { (Pistolesi et al. 2016) }\end{array}$ & $\begin{array}{l}\text { Simultaneous eruptions } \\
\text { from multiple vents } 5.4 \\
\mathrm{~km} \text { apart. Fall deposition } \\
\text { with minor pyroclastic } \\
\text { density currents due to } \\
\text { ash column collapse. } \\
\text { Total eruptive volume of } \\
\sim 0.1 \mathrm{~km}^{3} \text {. }\end{array}$ & $\begin{array}{l}\text { Clustered } \\
\text { compositions. }\end{array}$ & $\begin{array}{l}\text { Only minor pyroclastic density } \\
\text { current deposition. }\end{array}$ & No evidence. & $\begin{array}{l}\text { Discrete melt- } \\
\text { dominant bodies from } \\
\text { different shallow } \\
\text { portions of common } \\
\text { magmatic system. }\end{array}$ \\
\hline $\begin{array}{l}\text { Bishop Tuff, Long } \\
\text { Valley (Wilson and } \\
\text { Hildreth 1997; } \\
\text { Hildreth and Wilson } \\
\text { 2007; Chamberlain et } \\
\text { al. 2014a, 2014b, } \\
\text { 2015) }\end{array}$ & $\begin{array}{l}\text { Short-lived (six days) } \\
\text { eruption of }>600 \mathrm{~km}^{3} \text {, } \\
\text { comprising nine phases } \\
\text { of coeval fall and } \\
\text { ignimbrite deposition. }\end{array}$ & $\begin{array}{l}\text { Continuum of trace } \\
\text { element glass } \\
\text { compositions with } \\
\text { broadly uniform major } \\
\text { element compositions. }\end{array}$ & $\begin{array}{l}\text { Continuum of glass } \\
\text { compositions. }\end{array}$ & No evidence. & $\begin{array}{l}\text { Single, zoned magma } \\
\text { body formed over } \sim 80 \\
\text { kyr with intrusion of } \\
\text { less-evolved melt } \\
\text { (>500 years) prior to } \\
\text { eruption. }\end{array}$ \\
\hline $\begin{array}{l}\text { Rattlesnake Tuff, } \\
\text { Oregon (Streck and } \\
\text { Grunder 1997, 1999, } \\
\text { 2008) }\end{array}$ & $\begin{array}{l}\text { Single cooling unit } \\
\text { comprising } \sim 280 \mathrm{~km}^{3} \\
\text { magma. }\end{array}$ & $\begin{array}{l}\text { Rare basal fallout, } \\
\text { homogeneous. }\end{array}$ & $\begin{array}{l}\text { Compositionally zoned } \\
\text { ignimbrite contains pumice } \\
\text { and glass shards that cluster } \\
\text { into five, physically-distinct } \\
\text { chemical groups, formed } \\
\text { through varying degrees of } \\
\text { fractionation of a common } \\
\text { parent. }\end{array}$ & $\begin{array}{l}\text { Quenched mafic } \\
\text { inclusions found at the } \\
\text { top of the ignimbrite as } \\
\text { well as dacitic pumices } \\
\text { (mix of mafic and } \\
\text { rhyolitic melts). }\end{array}$ & $\begin{array}{l}\text { Single compositionally } \\
\text { and density stratified } \\
\text { magma chamber. }\end{array}$ \\
\hline
\end{tabular}




\begin{tabular}{|c|c|c|c|c|c|}
\hline $\begin{array}{l}\text { Youngest Toba Tuff } \\
\text { (Chesner 1998, 2012; } \\
\text { Westgate et al. 2013) }\end{array}$ & $\begin{array}{l}\text { Eruption of } \sim 2800 \mathrm{~km}^{3} \\
\text { magma in a few weeks } \\
\text { from ring fractures } \\
\text { during caldera collapse. }\end{array}$ & No evidence. & $\begin{array}{l}\text { Pumice and fiamme range } \\
\text { from high-silica rhyolite to } \\
\text { dacite. Composition varies } \\
\text { systematically with crystal } \\
\text { content. Co-ignimbrite ash } \\
\text { uniformly high-silica rhyolite } \\
\text { but forms four distinct } \\
\text { compositional clusters. No } \\
\text { geographical or stratigraphic } \\
\text { separation of compositional } \\
\text { variation. }\end{array}$ & No evidence. & $\begin{array}{l}\text { Compositionally zoned } \\
\text { melt-dominant body, } \\
\text { with increasing crystal } \\
\text { content towards the } \\
\text { base. }\end{array}$ \\
\hline $\begin{array}{l}\text { Huckleberry Ridge } \\
\text { Tuff (Christiansen } \\
\text { 2001; Myers et al. } \\
\text { 2016; Wilson et al. } \\
\text { in prep; this study) }\end{array}$ & $\begin{array}{l}\text { Prolonged eruption } \\
\text { of } \sim 2,500 \mathrm{~km}^{3} \text {. } \\
\text { Initial fall deposits } \\
\text { show evidence for } \\
\text { episodic eruption } \\
\text { onset. Weeks- } \\
\text { months time break } \\
\text { between ignimbrite } \\
\text { members A and B, } \\
\text { then a years-decades } \\
\text { hiatus between } \\
\text { ignimbrite members } \\
\text { B and C. }\end{array}$ & $\begin{array}{l}\text { Earliest initial fall } \\
\text { deposit result of } \\
\text { simultaneous } \\
\text { tapping of three } \\
\text { distinct, laterally- } \\
\text { adjacent melt- } \\
\text { dominant bodies } \\
\text { reflecting two } \\
\text { magmatic lineages. }\end{array}$ & $\begin{array}{l}\text { Ignimbrite member A } \\
\text { reflects evacuation of } \\
\text { multiple melt-dominant } \\
\text { bodies reflecting two } \\
\text { magmatic systems } \\
\text { (systems } 1 \text { and } 2 \text { ) active } \\
\text { during initial fall } \\
\text { deposition. Member B } \\
\text { indicates a hiatus in } \\
\text { activity of system } 2 \text { and } \\
\text { mixing within system } 1 . \\
\text { Member } C \text { involves the } \\
\text { regeneration of magmatic } \\
\text { system } 2 \text { and appearance } \\
\text { of two new magmatic } \\
\text { systems ( } 3 \text { and } 4 \text { ), both } \\
\text { with crust-like isotopic } \\
\text { signatures. Magmatic } \\
\text { system } 1 \text { is absent from } \\
\text { member C. }\end{array}$ & $\begin{array}{l}\text { Present as dense } \\
\text { enclaves (member } \\
\text { A) and mingled } \\
\text { scoria (member B) } \\
\text { with compositions } \\
\text { similar to lava flows } \\
\text { to the west but } \\
\text { distinct from } \\
\text { Yellowstone olivine } \\
\text { tholeiites. No direct } \\
\text { presence of the } \\
\text { latter but system } 4 \\
\text { related to olivine } \\
\text { tholeiitic mafic root } \\
\text { zone. Up } \\
\text { temperature } \\
\text { geochemical signals } \\
\text { also hint to its } \\
\text { thermal role. }\end{array}$ & $\begin{array}{l}\text { Comprised four } \\
\text { magmatic systems } \\
\text { which were } \\
\text { episodically active } \\
\text { throughout the } \\
\text { eruption. At least } \\
\text { three of these } \\
\text { contained multiple } \\
\text { melt-dominant } \\
\text { bodies. }\end{array}$ \\
\hline
\end{tabular}


appearance/composition (e.g. Rattlesnake Tuff: Streck and Grunder 1997) and/or mineral assemblage (e.g. Oruanui: Allan et al. 2012, 2017; Kidnappers/Rocky Hill: Cooper et al. 2012, 2016). These diversities (or lack thereof) has been related to evacuation of single (e.g. Streck and Grunder 1997; Bishop Tuff: Hildreth and Wilson 2007; Chamberlain et al. 2015; Crater Lake: Bacon 1983; Bacon and Druitt 1988) to multiple magma bodies (e.g. Cooper et al. 2012, 2016, 2017; Mamaku-Ohakuri: Bégué et al. 2014). However, despite broadly similar mineral assemblages within all juvenile material, the HRT shows a remarkable geochemical diversity that is broadly related to clast appearance. The presence of four magmatic systems, with distinct elemental and/or isotopic characteristics, with at least three of these containing multiple melt-dominant bodies, make the HRT unique in crystal-poor silicic eruptions (Table 6.1). The diversity of compositions, the complexity of the overall magmatic complex and the temporal variations within a single eruption are unprecedented, and is comparable in size to multiple eruptions from a single silicic volcanic province (cf. Gravley et al. 2016). Although there is much more still to discover, this overview of the HRT breaks new ground in extending the complexity possible in large silicic magmatic systems.

\subsection{Future work}

Although this work has been able to shed new light on the remarkable compositional complexities in the HRT, many unanswered questions remain. Some of these are due to limitations regarding the field geology, or model constraints, and others are avenues for further work regarding the HRT.

\subsubsection{Limitations to the current data set}

As the HRT represents the first explosive eruption known from the YPVF, significant faulting, uplift and erosion, and burial and concealment of the tuff has occurred. This has limited this study in several ways.

First, there is limited information available on volcanism that occurred prior to the HRT in the area beneath and immediately around what became the HRT caldera. Only one rhyolitic (Snake River Butte) and one basaltic (Junction Butte Basalt) eruptive episodes are documented (Christiansen 2001). No lava flows of comparable composition to the HRT mafics 
occur, despite indications that root zones related to mafic suites 1 and 2 were contemporaneously active. Only the latter reached the surface as far as is known.

Second, evidence constraining the relative positions of the various magmatic systems and foci of eruption/caldera collapse is limited. Identification of vent positions of the initial fall deposits, which could constrain the locations of magmatic systems 1 and 2, is obscured by lack of exposure. Analysis of lithic fragments has been used in other caldera-forming eruptions to constrain vent positions and caldera collapse (e.g. Hildreth and Mahood 1986; Suzuki-Kamata et al. 1993), but as the HRT is lithic poor (CJN Wilson, pers comm) a similar approach here is not applicable. Christiansen (2001) proposed three separate foci of caldera collapse, one for each ignimbrite member. Three foci are also plausible, based on the evidence presented in this thesis, with individual foci for magmatic systems 1 and 2 and a combined focus of collapse for systems 3 and 4. However, erosion and concealment have masked foci of caldera collapse, or the location of the ring fracture(s), and hence source regions for the four magmatic systems.

Third, it is unclear what volume of tuff is concealed under younger deposits. As intracaldera fill is typically inferred to be of subequal volume to outflow sheets (e.g. Lipman 2000), determination of the thickness of HRT intracaldera fill could significantly alter the Christiansen (2001) $\sim 2,500 \mathrm{~km}^{3}$ estimate for eruption volume. In addition, mapping of the intra-caldera fill would provide evidence for foci of subsidence and collapse and hence, potentially, source areas of magmatic systems (e.g. Lipman 2000).

Better constraints on magmatic system positions would allow spatial reconstruction of the magmatic complex and inferences regarding external factors and their control on the eruption progression. As magmatic systems 3 and 4 show evidence for significant involvement of Archean country rocks, these systems plausibly were situated away from the focus of either contemporaneous or previous (i.e. Absaroka) magmatism. Furthermore, young episodes of volcanism at Yellowstone show aligned vent positions (Christiansen 2001), inferred to represent a control by regional stress fields. If a similar identification of vent positions was possible with the HRT, this would allow inference regarding the stress field present at the onset of Yellowstone volcanism and its control on the HRT eruption.

Another challenge associated with significant erosion and concealment is the reduction in suitable sampling locations. This study has focused on the sampling of single clasts, and of these glassy samples were particularly sought after. Suitable materials for sampling of pumice 
were only found (by CJN Wilson) at a limited number of localities exposing non-welded, vitric tuff and these were fully utilised. Samples from these and other localities exhibit remarkable compositional variations (Chapters 4 and 5), but whether the juvenile clast suite sampled provides a volumetrically representative snapshot of all material erupted, or whether preservation is biased towards some magmatic systems/compositions is not known. However, in the silicic compositions, analysed fiamme from devitrified host tuff show comparable compositional ranges to the glassy clasts that were focused on. To test whether this range is also present in pumice-/fiamme-poor, devitrified parts of the HRT would have to be tested through crystal compositions, which could then be compared to data from single pumices/fiamme. This approach could also be applied to other ignimbrites in Yellowstone (e.g. the Lava Creek Tuff), and also to the Snake River Plain ignimbrites where pumice or fiamme are unusually sparse (Branney et al. 2008).

\subsubsection{Constraining mixing end members}

The radiogenic (i.e. crustal) isotopic compositions of products in member $\mathrm{C}$ from magmatic systems 3 and 4 mean that significant incorporation of country rock is an inescapable process when discussing petrogenesis of these systems. Similarly radiogenic isotopic signatures of whole rock or crystals from the HRT and Arbon Valley Tuff (Snake River Plain) have been linked to $\sim 40-60 \%$ assimilation of Archean crustal material (Hildreth et al. 1991; Drew et al. 2013; Wotzlaw et al. 2015). However, these models utilised limited isotopic systems and had little trace elemental compositional data. Although there is a range of crustal and xenolith elemental and isotopic data available (e.g. Leeman et al. 1985; Wooden and Mueller 1988; Meen and Eggler 1989; Frost et al. 2006), none reported would fit the $\mathrm{Pb}$ isotopic requirements of a mixing end-member for the member $\mathrm{C}$ magmatic systems, notably the unradiogenic ${ }^{208} \mathrm{~Pb} /{ }^{204} \mathrm{~Pb}$. Furthermore, although pyroxene-rich cumulates have been described from the Snake River Plain (Leeman et al. 1985), there is a lack of elemental compositional data associated with these xenoliths. Therefore, there is an absence of

literature data yielding plausible crustal end members for magmatic systems 3 and 4 . As a result, mixing models lack meaning, as choices for assimilant compositions could be arbitrary and not be representative of the range of compositions (e.g. choosing an average crustal xenolith isotopic composition when ${ }^{87} \mathrm{Sr} /{ }^{86} \mathrm{Sr}$ varies by 0.128 : Watts et al. 2010). Better controls on the crustal lithologies and their end member compositions would allow much 
greater constraint on the role of different components in rhyolite petrogenesis in the HRT and other Yellowstone silicic products.

\subsubsection{Geobarometric constraints on melt-dominant body storage}

The spatial relationship between individual melt-dominant bodies is important in reconstructing the configuration of the large-scale HRT magmatic complex. Multiple meltdominant bodies are commonly assumed to be vertically stacked (e.g. Cashman and Giordano 2014; Cashman et al. 2017) but pressure estimates from some large silicic deposits indicate this is not always the case (e.g. Cooper et al. 2012, 2016). Myers et al. (2016) highlighted the overlapping pressures and lack of a systematic relationship between melt inclusion composition and entrapment depth in the early HRT fall deposits. This feature, combined with pressure estimates derived from major element glass compositions in the basal ignimbrite is more consistent with the melt-dominant bodies being laterally separated. However, the accuracy and precision of these estimates is strongly dependent on the quality of input data (e.g. Wilke et al. 2017). Significant analytical variability associated with glass compositional data are reflected in large uncertainties in pressure estimates (e.g. Chamberlain et al. 2015). Therefore, investigation of glassy (where available) melt inclusions from all ignimbrite members and investigation of their volatile contents to yield storage pressure estimates would be immensely valuable. Particularly of note would be whether member C meltdominant bodies, including those associated with the rejuvenated magmatic system 2 , were stored at similar depths to either each other or to the member A and B bodies.

\subsubsection{Detailed study of the crystal cargo}

Documentation of the compositions of the main crystal phases (sanidine, plagioclase, pyroxene and olivine) undertaken here has provided further evidence with which to distinguish magmatic systems. Broad textural categorisation has also been undertaken on feldspar and pyroxene crystals. However, important insights into the development of magmatic systems can be attained through detailed textural and compositional study of multiple crystal phases (e.g. Bachmann et al. 2002; Chamberlain et al. 2015; Allan et al. 2017). Features particularly of note in the HRT include the presence of carbonate-cemented feldspars, 'plutonic-textured' feldspars containing intergrowths and exsolution features, anti- 
rapakivi textures in feldspars, and cores and inclusions of pigeonite within augite crystals. Whether parts or all of these crystals represent phenocrysts (grown in the melt in which they were found), antecrysts (related to the magmatic system) or xenocrysts (unrelated to the magmatic system: after Charlier et al. 2005) is important in providing insights into the evolution of the magmatic systems. As remelted and/or remobilised cumulates are inferred to represent an important component in the petrogenesis of the magmatic suites (Chapter 5), investigation of 'plutonic' feldspars may provide valuable constraint on end member components not currently documented. Related to this, elemental and particularly isotopic compositions of crystals can yield important insights into the chemical evolution of magmatic suites, and the timing and nature of any crustal assimilation (e.g. Charlier et al. 2008; Wolff and Ramos 2014; Wotzlaw et al. 2015). This would not only be of interest for magmatic systems 3 and 4 in member $C$, where country rock contamination is evident, but also for members $A$ and $B$ where the crustal isotopic signature is more muted.

In addition, the complex, and occasionally decoupled behaviour of $\mathrm{P}_{2} \mathrm{O}_{5}$ and LREE (e.g. La) within the HRT data set suggests a role for apatite and/or chevkinite in magma evolution. Chevkinite has previously been documented in the HRT but its crystallisation conditions are poorly constrained (Macdonald and Belkin 2002; Vazquez et al. 2014). Investigating the relationship between apatite and chevkinite crystallisation in the HRT may shed light on magmatic evolution and stability conditions of both phases. Another puzzling feature is the common exsolution features shown by one or more crystals in Fe-Ti oxide pairs. As Fe-Ti oxides are inferred to rapidly equilibrate (e.g. Evans et al. 2016), it is unusual that exsolution should be present. Further investigation to identify any oxide pairs that are not exsolved, and use these to further constrain pre-eruptive temperatures, and to interpret the causes and implications of oxide exsolution would be beneficial.

In the HRT juvenile clasts, crystal aggregates are commonly present, comprising feldspar, pyroxene, olivine and Fe-Ti oxides. Similar aggregates have been observed in other eruption deposits from the Snake River Plain (Ellis et al. 2014) and interpreted to be fragments of crystal mush material entrained into the melt-dominant body. The petrogenetic models proposed in this study, involving partial melting of cumulates coupled with fractional crystallisation, require the presence of a crystal-rich mush. Further investigation of these crystal aggregates to see whether a similar interpretation to that of Ellis et al. (2014) applies 
to the HRT would provide useful insights into the crystalline residue associated with the meltdominant bodies in Yellowstone magmatism.

Fuller characterisation of the crystal cargo in the HRT could also provide the framework for a broader study of later Yellowstone volcanism. The caldera associated with the $1.3 \mathrm{Ma}$ Mesa Falls Tuff together with younger rhyolite domes sits within the HRT caldera (Christiansen 2001; Stelten et al. 2018). Although Mesa Falls Tuff sanidines have isotopic compositions distinct from HRT member B sanidines (Ellis et al. 2017), a full crystal-specific investigation of the post-HRT tuff and local rhyolite domes could reveal the response of the magmatic system(s) after the HRT supereruption, similar to the study of Barker et al. (2015). Post-caldera volcanism at Yellowstone shows sharp changes in isotopic compositions (Hildreth et al. 1984; Bindeman and Valley 2001) but whether that is mirrored in the crystal cargo has not been fully explored.

\subsubsection{Constraints on timescales of syn-eruptive processes}

This study provides evidence for the rapid development and mixing and mingling of meltdominant bodies and highlights the diversity of timescales associated with silicic magmatic systems and their eruptions. The geologically short time gaps between each of the three ignimbrite members (Wilson 2009; Wilson et al. in prep) are associated with significant changes within the HRT magmatic complex, i.e. mixing and reorganisation of magmatic system 1 (between members $A$ and B), and rejuvenation of system 2 plus melt-dominant body formation within systems 3 and 4 (between members B and C). Although quartz growth rates have been used to provide quantitative estimates of timescales of melt-dominant body formation, published growth rates vary by two orders of magnitude (e.g. Swanson and Fenn 1986 versus Gualda et al. 2012). Although applicable diffusion coefficients are also variable, timescales of melt-dominant body formation (Druitt et al. 2012; Allan et al. 2013), magma system rejuvenation (Cooper et al. 2017) and influx of less-evolved magma (Chamberlain et al. 2014b), all processes evident in the HRT materials, have been estimated and constrained using diffusion chronometry. The presence of bright, Ba-rich rims on sanidines in suite A2 clasts and pumices in member B could be used to constrain pre-eruptive timescales of magma body invigoration. Furthermore, the presence of contrasting core and rim compositions in clasts from the rejuvenated magmatic system 2 and the newly-formed systems 3 and 4 in member $\mathrm{C}$ provide the opportunity to constrain the timescale of formation of these bodies. 
Comparison between the two would indicate whether reorganisation of the magmatic system(s) prior to member $\mathrm{C}$ occurred on similar timescales to the break inferred from field evidence (cf. Cooper et al. 2017) and was a uniform or piecemeal process. This would have significant implications for the post-eruption hazard assessment of large silicic magmatic systems i.e. determining whether an eruptive cycle is complete.

In summary, this thesis demonstrates the value of a detailed, systematic, stratigraphicallyconstrained geochemical investigation into the deposits of large, silicic, caldera-forming eruption using multiple macro- and micro-analytical techniques. Such depth and breadth of observation and interpretation would simply not be possible from a uni-dimensional approach to a limited sample suite. 


\section{References}

Aguirre-Díaz GJ (2001) Recurrent magma mingling in successive ignimbrites from Amealco caldera, central Mexico. Bull Volcanol 63:238-251

Allan ASR, Wilson CJN, Millet M-A, Wysoczanski RJ (2012) The invisible hand: tectonic triggering of a rhyolitic supereruption, Geology 40:563-56

Allan ASR, Morgan DJ, Wilson CJN, Millet M-A (2013) From mush to eruption in centuries: assembly of the super-sized Oruanui magma body. Contrib Mineral Petrol 166:143164

Allan ASR, Barker SJ, Millet M-A, Morgan DJ, Rooyakkers SM, Schipper CI, Wilson CJN (2017) A cascade of magmatic events during the assembly and eruption of a super-sized magma body, Contrib Mineral Petrol 172:49

Almeev RR, Bolte T, Nash BP, Holtz F, Erdmann M, Cathey HE (2012) High-temperature low $\mathrm{H}_{2} \mathrm{O}$ silicic magmas of the Yellowstone hotspot: an experimental study of rhyolite from the Bruneau-Jarbridge eruptive center, central Snake River Plain, USA. J Petrol $53: 1837-1866$

Anderson AT, Davis AM, Lu F (2000) Evolution of Bishop Tuff rhyolitic magma based on melt and magnetite inclusions and zoned phenocrysts. J Petrol 41:449-473

Armstrong RL, Leeman WP, Malde HE (1975) K-Ar dating Quaternary and Neogene volcanic rocks of the Snake River Plain, Idaho. Am J Sci 275:225-251

Bachmann O, Bergantz GW (2004) On the origin of crystal-poor rhyolites: extracted from batholithic crystal mushes. J Petrol 45:1565-1582

Bachmann O, Bergantz GW (2008) Deciphering magma chamber dynamics from styles of compositional zoning in large silicic ash flow sheets. Rev Mineral Geochem 69:651-674

Bachmann O, Huber C (2016) Silicic magma reservoirs in the Earth's crust. Am Mineral 101:2377-2404

Bachmann O, Dungan MA, Lipman PW (2002) The Fish Canyon magma body, San Juan volcanic field, Colorado: rejuvenation and eruption of an upper-crustal batholith. J Petrol 43:1469-1503

Bachmann O, Deering CD, Lipman PW, Plummer C (2014) Building zoned ignimbrites by recycling silicic cumulates: insight from the $1,000 \mathrm{~km}^{3}$ Carpenter Ridge Tuff, CO. Contrib Mineral Petrol 167:1025 
Bacon CR (1983) Eruptive history of Mount Mazama and Crater Lake caldera, Cascade Range, USA. J Volcanol Geotherm Res 18:57-115

Bacon CR, Druitt TH (1988) Compositional evolution of the zoned calcalkaline magma chamber of Mount Mazama, Crater Lake, Oregon. Contrib Mineral Petrol 98:224-256

Bacon CR, Metz J (1984) Magmatic inclusions in rhyolites, contaminated basalts and compositional zonation beneath the Coso volcanic field, California. Contrib Mineral Petrol 85:346-365

Barker SJ, Wilson CJN, Smith EGC, Charlier BLA, Wooden JL, Hiess J, Ireland TR (2014) Postsupereruption magmatic reconstruction of Taupo volcano (New Zealand), as reflected in zircon ages and trace elements. J Petrol 55:1511-1533

Barker SJ, Wilson CJN, Allan ASR, Schipper CI (2015) Fine-scale temporal recovery, reconstruction and evolution of a post-supereruption magmatic system. Contrib Mineral Petrol 170:5

Barker SJ, Wilson CJN, Morgan DJ, Rowland JV (2016) Rapid priming, accumulation and recharge of magma driving recent eruptions at a hyperactive caldera volcano. Geology 44:323-326

Befus KS, Gardner JE (2016) Magma storage and evolution of the most recent effusive and explosive eruptions from Yellowstone Caldera. Contrib Mineral Petrol 171:30

Bégué F, Deering CD, Gravely DM, Kennedy BM, Chambefort I, Gualda GAR, Bachmann O (2014) Extraction storage and eruption of multiple isolated magma batches in the paired Mamaku and Ohakuri eruption, Taupo Volcanic Zone, New Zealand. J Petrol 55:1653-1684

Berndt J, Koepke J, Holtz F (2005) An experimental investigation of the influence of water and oxygen fugacity on differentiation of MORB at $200 \mathrm{MPa}$. J Petrol 46:135-167

Best MG, Gromme S, Deino AL, Christiansen EH, Hart GL, Tingey DG (2013) The 36-18 Ma Central Nevada ignimbrite field and calderas, Great Basin, USA: multicyclic supereruptions. Geosphere 9:1562-1636

Bindeman IN, Simakin AG (2014) Rhyolites-hard to produce, but easy to recycle and sequester: integrating microgeochemical observations and numerical models. Geosphere 10:930-957

Bindeman IN, Valley JW (2001) Low- $\delta^{18}$ O rhyolites from Yellowstone: magmatic evolution based on analyses of zircons and individual phenocrysts. J Petrol 42:1491-1517 
Bindeman IN, Fu B, Kita NT, Valley JW (2008) Origin and evolution of silicic magmatism at Yellowstone based on ion microprobe analysis of isotopically zoned zircons. J Petrol 49:163-193

Birck JL (1986) Precision K-Rb-Sr isotopic analysis: application to Rb-Sr chronology. Chem Geol $56: 73-83$

Blake S (1984) Volatile oversaturation during the evolution of silicic magma chambers as an eruption trigger. J Geophys Res 89:8237-8244

Blundy JD, Wood BJ (1991) Crystal-chemical controls on the partitioning of Sr and Ba between plagioclase feldspar, silicate melts and hydrothermal solutions. Geochim Cosmochim Acta 55 193-209

Boehnke P, Watson EB, Trail D, Harrison TM, Schmitt AK (2013) Zircon saturation re-revisited. Chem Geol 351:324-334

Bolte T, Holtz F, Almeev R, Nash B (2015) The Blacktail Creek Tuff: an analytical and experimental study of rhyolites from the Heise volcanic field, Yellowstone hotspot system. Contrib Mineral Petrol 169:15

Bonnichsen B, Leeman WP, Honjo N, McIntosh WC, Godchaux MM (2008) Miocene silicic volcanism in southwestern Idaho: geochronology, geochemistry, and evolution of the central Snake River Plain. Bull Volcanol 70:315-342

Bouvier A, Vervoort JD, Patchett PJ (2008) The Lu-Hf and Sm-Nd isotopic composition of CHUR: constraints from unequilibrated chondrites and implications for the bulk composition of terrestrial planets. Earth Planet Sci Lett 273:48-57

Brady D (2012) Supervolcano: Yellowstone's fury. CBC (video file). Retrieved from https://vimeocom/53341234. Accessed 08/01/2018

Branney MJ, Bonnichsen B, Andrews GDM, Ellis B, Barry TL, McCurry M (2008) 'Snake River (SR)-type' volcanism at the Yellowstone hotspot track: distinctive products from unusual high-temperature silicic super-eruptions. Bull Volcanol 70:293-314

Brey GP, Köhler T (1990) Geothermobarometry in four-phase Iherzolites II. New thermobarometers, and practical assessment of existing thermobarometers. J Petrol $31: 1353-1378$

Brophy JG (1991) Composition gaps, critical crystallinity, and fractional crystallization in orogenic (calc-alkaline) magmatic systems. Contrib Mineral Petrol 109:173-182 
Brown SJA, Wilson CJN, Cole JW, Wooden J (1998) The Whakamaru group ignimbrites, Taupo Volcanic Zone, New Zealand: evidence for reverse tapping of a zoned silicic magmatic system. J Volcanol Geotherm Res 84:1-37

Brueseke ME, Downey AC, Dodd ZC, Hart WK, Adams DC, Benowitz JA (2018) The leading wisps of Yellowstone: post-ca $5 \mathrm{Ma}$ extension-related magmatism in the upper Wind River Basin, Wyoming (USA) associated with the Yellowstone hotspot tectonic parabola. Geosphere 14:74-94

Burgisser A, Bergantz GW (2011) A rapid mechanism to remobilize and homogenize highly crystalline magma bodies. Nature 471:212-215

Bursik MI, Renshaw C, McCalpin J, Berry M (2003) A volcanotectonic cascade: activation of range front faulting and eruptions by dike intrusion, Mono Basin-Long Valley caldera, California. J Geophys Res 108:2393

Campbell IH, Taylor SR (1983) No water, no granites-no oceans, no continents. Geophys Res Lett 10:1061-1064

Caricchi L, Annen C, Blundy J, Simpson G, Pinel V (2014) Frequency and magnitude of volcanic eruptions controlled by magma injection and buoyancy. Nature Geosci 7:126-130

Carpenter PK (2008) Electron-probe microanalysis (EPMA): an overview for beginners and a status report for experts. Microsc Microanal 14:1150-1151

Cas RAF, Wright HMN, Folkes CB, Lesti C, Porreca M, Giordano G, Viramonte JG (2011) The flow dynamics of an extremely large volume pyroclastic flow, the 2.08-Ma Cerro Galan Ignimbrite, NW Argentina, and comparison with other flow types. Bull Volcanol 73:1583-1609

Cashman KV, Giordano G (2014) Calderas and magma reservoirs. J Volcanol Geotherm Res 288:28-45

Cashman KV, Sparks RSJ, Blundy JD (2017) Vertically extensive and unstable magmatic systems: a unified view of igneous processes. Science 355:eaag3055

Cathey HE, Nash BP (2004) The Cougar Point Tuff: implications for thermomechanical zonation and longevity of high-temperature, large-volume silicic magmas of the Miocene Yellowstone hotspot. J Petrol 45:27-58

Chadwick RA (1970) Belts of eruptive centers in the Absaroka-Gallatin Volcanic Province, Wyoming-Montana. Geol Soc Am Bull 81:267-274 
Chamberlain KJ, Wilson CJN, Wooden JL, Charlier BLA, Ireland TR (2014a) New perspectives on the Bishop Tuff from zircon textures ages and trace elements. J Petrol 55:395-426

Chamberlain KJ, Morgan DJ, Wilson CJN (2014b) Timescales of mixing and mobilisation in the Bishop Tuff magma body: perspectives from diffusion chronometry. Contrib Mineral Petrol 168:1034

Chamberlain KJ, Wilson CJN, Wallace PJ, Millet M-A (2015) Micro-analytical perspectives on the Bishop Tuff and its magma chamber. J Petrol 56:605-640

Charlier BLA, Wilson CJN, Lowenstern JB, Blake S, Van Calsteren PW, Davidson JP (2005) Magma generation at a large hyperactive silicic volcano (Taupo, New Zealand) revealed by U-Th and U-Pb systematics in zircons. J Petrol 46:3-32

Charlier BLA, Ginibre C, Morgan D, Nowell GM, Pearson DG, Davidson JP, Ottley CJ (2006) Methods for the microsampling and high-precision analysis of strontium and rubidium isotopes at single crystal scale for petrological and geochronological applications. Chem Geol 232:114-133

Charlier BLA, Wilson CJN, Davidson JP (2008) Rapid open-system assembly of a large silicic magma body: time resolved evidence from cored plagioclase crystals in the Oruanui eruption deposits, New Zealand. Contrib Mineral Petrol 156:799-813

Charlier BLA, Wilson CJN, Mortimer N (2010) Evidence from zircon U-Pb age spectra for crustal structure and felsic magma genesis at Taupo volcano, New Zealand. Geology 38:915918

Chesner CA (1998) Petrogenesis of the Toba tuffs, Sumatra, Indonesia. J Petrol 39:397-438

Chesner CA (2012) The Toba caldera complex. Quat Int 258:5-18

Christiansen EH (2005) Contrasting processes in silicic magma chambers: evidence from very large volume ignimbrites. Geol Mag 142:669-681

Christiansen EH, McCurry M (2008) Contrasting origins of Cenozoic silicic volcanic rocks from the western Cordillera of the United States. Bull Volcanol 70:251-267

Christiansen RL (1979) Cooling units and composite sheets in relation to caldera structure. In: Chapin CE, Elston WE (eds) Ash-flow tuffs. Geol Soc Am Spec Pap 180:29-42

Christiansen RL (2001) The Quaternary and Pliocene Yellowstone Plateau volcanic field of Wyoming, Idaho and Montana. US Geol Surv Prof Pap 729-G

Christiansen RL, Blank Jr HR (1972) Volcanic stratigraphy of the Quaternary rhyolite plateau in Yellowstone National Park. US Geol Surv Prof Pap 729-B 
Christiansen RL, Yeats RS (1992) Post-Laramide geology of the US Cordilleran region, in Burchfiel BC, Lipman PW, Zoback ML (eds) The Cordilleran Orogen: conterminous US. Boulder, Colorado, Geological Society of America, The Geology of North America G3:261-406

Christiansen RL, Lowenstern JB, Smith RB, Heasler H, Morgan LA, Nathenson M, Mastin LG, Muffler LP, Robinson JE (2007) Preliminary assessment of volcanic and hydrothermal hazards in Yellowstone National Park and vicinity. US Geol Surv Open File Rep 20071071:1-94

Coble MA, Mahood GA (2012) Initial impingement of the Yellowstone plume located by widespread silicic volcanism contemporaneous with Columbia River flood basalts. Geology 40:655-658

Coble MA, Mahood GA (2015) Geology of the High Rock caldera complex, northwest Nevada, and implications for intense rhyolitic volcanism associated with flood basalt magmatism and the initiation of the Snake River Plain-Yellowstone trend. Geosphere $12: 58-113$

Colón DP, Bindeman IN, Wotzlaw J-F, Christiansen EH, Stern RA (2018) Origins and evolution of rhyolitic magmas in the central Snake River Plain: insights from coupled highprecision geochronology, oxygen isotope, and hafnium isotope analyses of zircon. Contrib Mineral Petrol 173:11

Cook KH (2003) Role of continents in driving the Hadley Cells. J Atmos Sci 60:957-976

Cooper GF, Wilson CJN (2014) Development, mobilisation and eruption of a large crystal-rich rhyolite: the Ongatiti ignimbrite, New Zealand. Lithos 198-199:38-57

Cooper GF, Wilson CJN, Millet M-A, Baker JA, Smith EGC (2012) Systematic tapping of independent magma chambers during the 1 Ma Kidnappers supereruption. Earth Planet Sci Lett 313-314:23-33

Cooper GF, Wilson CJN, Millet M-A, Baker JA (2016) Generation and rejuvenation of a supervolcanic magmatic system: a case study from Mangakino volcanic centre, New Zealand. J Petrol 57:1135-1170

Cooper GF, Morgan DJ, Wilson CJN (2017) Rapid assembly and rejuvenation of a large silicic magmatic system: insights from mineral diffusive profiles in the Kidnappers and Rocky Hill deposits, New Zealand. Earth Planet Sci Lett 473:1-13 
Croux C, Filzmoser P, Oliveira M (2007) Algorithms for Projection-Pursuit robust principal component analysis. Chemometr Intell Lab Syst 87:218-225

Davidson JP, Morgan DJ, Charlier BLA, Harlou R, Hora JM (2007) Microsampling and isotopic analysis of igneous rocks: implications for the study of magmatic systems. Ann Rev Earth Planet Sci Lett 35:273-311

Deering CD, Bachmann O, Vogel TA (2011) The Ammonia Tanks Tuff: erupting a melt-rich cap and its remobilized crystal cumulate. Earth Planet Sci Lett 310:518-525

Degruyter W, Huber C (2014) A model for eruption frequency of upper crustal silicic magma chambers. Earth Planet Sci Lett 403:117-130

DePaolo DJ, Wasserburg GJ (1976) Nd isotopic variations and petrogenetic models. Geophys Res Lett 3 249-252

de Silva S, Gregg PM (2014) Thermomechanical feedbacks in magmatic systems: implications for growth, longevity, and evolution of large caldera-forming magma reservoirs and their supereruptions. J Volcanol Geotherm Res 282:77-91

Doe BR, Leeman WP, Christiansen RL, Hedge CE (1982) Lead and strontium isotopes and related trace elements as genetic tracers in the upper Cenozoic rhyolite-basalt association of the Yellowstone Plateau volcanic field. J Geophys Res 87:4785-4806

Drew DL, Bindeman IN, Watts KE, Schmitt AK, Fu B, McCurry M (2013) Crustal-scale recycling in caldera complexes and rift zones along the Yellowstone hotspot track: $\mathrm{O}$ and $\mathrm{Hf}$ isotopic evidence in diverse zircons from voluminous rhyolites of the Picabo volcanic field, Idaho. Earth Planet Sci Lett 381:63-77

Drew DL, Bindeman IN, Loewen MW, Wallace PJ (2016) Initiation of large-volume silicic centres in the Yellowstone hotspot track: insights from $\mathrm{H}_{2} \mathrm{O}$ - and F-rich quartz-hosted rhyolitic melt inclusions in the Arbon Valley Tuff of the Snake River Plain. Contrib Mineral Petrol 171:10

Druitt TH, Costa F, Deloule E, Dungan M, Scaillet B (2012) Decadal to monthly timescales of magma transfer and reservoir growth at a caldera volcano. Nature 482:77-80

Eggins SM, Shelley JMG (2002) Compositional heterogeneity in MIST SRM 610-619 glasses. Geostand News 26:269-286

Eggins SM, Woodhead JD, Kinsley LPJ, Mortimer GE, Sylvester P, McCulloch MT, Hergt JM, Handler MR (1997) A simple method for the precise determination of $\geq 40$ trace 
elements in geological samples by ICPMS using enriched isotope internal standardisation. Chem Geol 134:311-326

Elkins LT, Grove TL (1990) Ternary feldspar experiments and thermodynamic models. Am Mineral 75:544-559

Ellis BS, Wolff JA (2012) Complex storage of rhyolite in the central Snake River Plain. J Volcanol Geotherm Res 211-212:1-11

Ellis BS, Mark DF, Pritchard CJ, Wolff JA (2012) Temporal dissection of the Huckleberry Ridge Tuff using the ${ }^{40} \mathrm{Ar} /{ }^{39} \mathrm{Ar}$ dating technique. Quat Geochron 9:34-41

Ellis BS, Wolff JA, Boroughs S, Mark DF, Starkel WA, Bonnichsen B (2013) Rhyolite volcanism of the central Snake River Plain: a review. Bull Volcanol 75:745

Ellis BS, Bachmann O, Wolff JA (2014) Cumulate fragments in silicic ignimbrites: the case of the Snake River Plain. Geology 42:431-434

Ellis BS, Mark DF, Troch J, Bachmann O, Guillong M, Kent AJR, von Quadt A (2017) Split-grain ${ }^{40} \mathrm{Ar} /{ }^{39} \mathrm{Ar}$ dating: integrating temporal and geochemical data from crystal cargoes. Chem Geol 457:15-23

Ersoy Y, Helvaci C (2010) FC-AFC-FCA and mixing modeler: a Microsoft ${ }^{\circledR}$ Excel $^{\circledR}$ spreadsheet program for modeling geochemical differentiation of magma by crystal fractionation, crustal assimilation and mixing Comput Geosci 36:383-390

Evans BW, Hildreth W, Bachmann O, Scaillet B (2016) In defense of magnetite-ilmenite thermometry in the Bishop Tuff and its implication for gradients in silicic magma reservoirs. Am Mineral 101:469-482

Farrell J, Smith RB, Husen S, Diehl T (2014) Tomography from 26 years of seismicity revealing the spatial extent of the Yellowstone crustal magma reservoir extends well beyond the Yellowstone caldera. Geophys Res Lett 41:3068-3073

Feeley TC (2003) Origin and tectonic implications of across-strike geochemical variations in the Eocene Absaroka volcanic province, United States. J Geol 111:329-346

Filzmoser P, Fritz H, Kalcher K (2014) pcaPP: Robust PCA by projection pursuit. R package version 1.9-60. https://CRAN.R-project.org/package=pcaPP

Folkes CB, de Silva SL, Wright HM, Cas RAF (2011) Geochemical homogeneity of a long-lived large silicic system; evidence from the Cerro Galán caldera, NW Argentina. Bull Volcanol 73:1455-1486 
Fraley C, Raftery AE, Murphy TB, Scrucca L (2012) mclust Version 4 for R: normal mixture modeling for model-based clustering, classification, and density estimation. Technical Report No. 597, Department of Statistics, University of Washington, Seattle

Fridrich CJ, Mahood GA (1987) Compositional layers in the zoned magma chamber of the Grizzly Peak Tuff. Geology 15:299-303

Frost CD, Frost BR, Kirkwood R, Chamberlain KR (2006) The tonalite-trondhjemitegranodiorite (TTG) to granodiorite-granite (GG) transition in the late Archean plutonic rocks of the central Wyoming province. Can J Earth Sci 43:1419-1444

Geist DJ, Sims EN, Hughes SS, McCurry M (2002) Open-system evolution of a single episode of Snake River Plain magmatism. In: Link PK, Mink LL (eds) Geology, Hydrogeology and Environmental Remediation: Idaho National Engineering and Environmental Laboratory, Eastern Snake River Plain, Idaho. Geol Soc Am Spec Pap 353:193-204

Gerstenberger H, Haase G (1996) A highly effective emitter substance for mass spectrometric $\mathrm{Pb}$ isotope ratio determinations. Chem Geol 136:309-312

Girard G, Stix J (2009) Magma recharge and crystal mush rejuvenation associated with early post-collapse Upper Basin Member rhyolites, Yellowstone caldera, Wyoming. J Petrol $50: 2095-2125$

Girard G, Stix J (2010) Rapid extraction of discrete magma batches from a large differentiating magma chamber: the Central Plateau Member rhyolites, Yellowstone caldera, Wyoming. Contrib Mineral Petrol 160:441-465

Gladney ES, Roelandts I (1990) 1988 compilation of elemental concentration data for CCRMP reference rock samples SY-2, SY-3 and MRG-1. Geostand News 14:373-458

Glazner AF (2014) Magmatic life at low Reynolds number. Geology 42:935-938

Gravley DM, Wilson CJN, Leonard GS, Cole JW (2007) Double trouble: paired ignimbrite eruptions and collateral subsidence in the Taupo Volcanic Zone, New Zealand. Geol Soc Am Bull 119:18-30

Gravley DM, Deering CD, Leonard GS, Rowland JV (2016) Ignimbrite flare-ups and their drivers: a New Zealand perspective. Earth-Sci Rev 162:65-82

Green TH, Adam J (2003) Experimentally-determined trace element characteristics of aqueous fluid from partially dehydrated mafic oceanic crust at $30 \mathrm{GPa} 650-700{ }^{\circ} \mathrm{C}$. Eur J Mineral 15:815-830 
Green TH, Blundy JD, Adam J, Yaxley GM (2000) SIMS determination of trace element partition coefficients between garnet, clinopyroxene and hydrous basaltic liquids at 2-75 GPa and $1080-1200^{\circ} \mathrm{C}$. Lithos $53: 165-187$

Gregg PM, de Silva SL, Grosfils EB, Parmigiani JP (2012) Catastrophic caldera-forming eruptions: thermomechanics and implications for eruption triggering and maximum caldera dimensions on Earth. J Volcanol Geotherm Res 241-242:1-12

Gregg PM, Grosfils EB, de Silva SL (2015) Catastrophic caldera-forming eruptions II: the subordinate role of magma buoyancy as an eruption trigger. J Volcanol Geotherm Res 305:100-113

Gualda GAR, Ghiorso MS (2013) The Bishop Tuff giant magma body: an alternative to the Standard Model. Contrib Mineral Petrol 166:755-775.

Gualda GAR, Pamukcu AS, Ghiorso MS, Anderson AT Jr, Sutton SR, Rivers ML (2012) Timescales of quartz crystallization and the longevity of the Bishop giant magma body. PLoS ONE 7:e37492

Gudmundsson A (2012) Magma chambers: formation, local stresses, excess pressures and compartments. J Volcanol Geotherm Res 237-238:19-41

Guillong M, Hametner K, Reusser E, Wilson SA, Günther D (2005) Preliminary characterisation of new glass reference materials (GSA-1G, GSC-1G, GSD-1G and GSE-1G) by laserablation-inductively coupled plasma-mass spectrometry using $193 \mathrm{~nm}, 213 \mathrm{~nm}$ and 266 nm wavelengths. Geostand News 29:315-331

Hanan BB, Shervais JW, Vetter SK (2008) Yellowstone plume-continental lithosphere interaction beneath the Snake River Plain. Geology 36:51-54

Hart SR (1984) A large-scale isotope anomaly in the Southern Hemisphere mantle. Nature 309:753-757

Hayden LA, Manning CE (2011) Rutile solubility in supercritical $\mathrm{NaAlSi}_{3} \mathrm{O}_{8}-\mathrm{H}_{2} \mathrm{O}$ fluids. Chem Geol 284:74-81

Hedenquist JW, Lowenstern JB (1994) The role of magmas in the formation of hydrothermal ore deposits. Nature 370:519-527

Hier-Majumder S, Tauzin B (2017) Pervasive upper mantle melting beneath the western US. Earth Planet Sci Lett 463:25-35

Hildreth W (1981) Gradients in silicic magma chambers: implications for lithospheric magmatism. J Geophys Res 86:10153-10192 
Hildreth W (2004) Volcanological perspectives on Long Valley Mammoth Mountain and Mono Craters: several contiguous but discrete systems. J Volcanol Geotherm Res 136:169198

Hildreth W, Fierstein J (2012) The Novarupta-Katmai eruption of 1912-largest eruption of the twentieth century: centennial perspectives. US Geol Surv Prof Pap 1791:1-259 Hildreth W, Mahood GA (1986) Ring-fracture eruption of the Bishop Tuff. Geol Soc Am Bull 97:396-403

Hildreth W, Wilson CJN (2007) Compositional zoning of the Bishop Tuff. J Petrol 48:951-999

Hildreth W, Christiansen RL, O'Neill JR (1984) Catastrophic isotopic modification of rhyolitic magma at times of caldera subsidence Yellowstone Plateau volcanic field. J Geophys Res 90:8339-8369

Hildreth W, Halliday AN, Christiansen RL (1991) Isotopic and chemical evidence concerning the genesis and contamination of basaltic and rhyolitic magma beneath the Yellowstone Plateau volcanic field. J Petrol 32:63-138

Hildreth W, Fierstein J, Calvert A (2017) Early post-caldera rhyolite and structural resurgence at Long Valley caldera, California. J Volcanol Geotherm Res 335:1-34

Hirschmann MM (2000) Mantle solidus: experimental constraints and the effects of peridotite composition. Geochem Geophys Geosys 1:200GC000070

Hoernle K, Tilton G, Le Bas MJ, Duggen S, Garbe-Schönberg D (2002) Geochemistry of oceanic carbonatites compared with continental carbonatites: mantle recycling of oceanic crustal carbonate. Contrib Mineral Petrol 142:520-542

Hofmann AW (1988) Chemical differentiation of the Earth: the relationship between mantle continental crust and oceanic crust. Earth Planet Sci Lett 90:297-314

Hofmann AW (1997) Mantle geochemistry: the message from oceanic volcanism. Nature $385: 219-229$

Horwitz EP, Chiarizia R, Dietz ML, Diamond H, Nelson DM (1993) Separation and preconcentration of actinides from acidic media by extraction chromatography. Anal Chim Acta 281:361-372

Hosaka M, Miyata T, Sunagawa I (1995) Growth and morphology of quartz crystals synthesized above the transition temperature. J Cryst Growth 152:300-306 
Houghton BF, Wilson CJN, McWilliams MO, Lanphere MA, Weaver SD, Briggs RM, Pringle MS (1995) Chronology and dynamics of a large silicic magmatic system: central Taupo Volcanic Zone, New Zealand. Geology 23:13-16

Hu Z, Zhang W, Liu Y, Chen H, Gasching RM, Zong K, Li M, Gao G, Hu S (2013) Rapid bulk rock decomposition by ammonium fluoride $\left(\mathrm{NH}_{4} \mathrm{~F}\right)$ in open vessels at an elevated digestion temperature. Chem Geol 355:144-152

Huang H-H, Lin F-C, Schmandt B, Farrell J, Smith RB, Tsai VC (2015) The Yellowstone magmatic system from the mantle plume to the upper crust. Science 348:773-776

Huber C, Bachmann O, Dufek J (2011) Thermo-mechanical reactivation of locked crystal mushes: melting induced internal fracturing and assimilation processes in magmas. Earth Planet Sci Lett 304:443-454

Huber C, Bachmann O, Dufek J (2012) Crystal-poor versus crystal-rich ignimbrites: a competition between stirring and reactivation. Geology 40:115-118

Humphreys ED (1995) Post-Laramide removal of the Farallon slab, western United States. Geology 23:987-990

Humphreys ED, Dueker KG, Schutt DL, Smith RB (2000) Beneath Yellowstone: evaluation plume and nonplume models using teleseismic images of the upper mantle. GSA Today 10:1-7

Humphreys MCS, Kearns SL, Blundy JD (2006) SIMS investigation of electron-beam damage to hydrous rhyolitic glasses: implications for melt inclusion analysis. Am Mineral 91:667679

Hurwitz S, Lowenstern JB (2014) Dynamics of the Yellowstone hydrothermal system. Rev Geophys 51:375-411

Imai N, Terashima S, Itoh S, Ando A (1995) 1994 compilation of analytical data for minor and trace elements in seventeen GSJ geochemical reference samples, "Igneous rock series". Geostand News 19:135-213

Ingamells CO (1980) Microprobe column. Geostand News 4:139

Ingamells CO (1983) Microprobe column. Geostand News 7:243

Iwahashi GS (2010) Physical and compositional implications for the evolution of Spencer-High Point volcanic field, Idaho. 165 p MSc thesis Idaho State University, Pocatello

Izett GA, Wilcox RE (1982) Map showing localities and inferred distributions of the Huckleberry Ridge, Mesa Falls, and Lava Creek ash beds (Pearlette family ash beds) of 
Pliocene and Pleistocene age in the western United States and southern Canada. USGS Misc Geol Investig Map I-1325, scale 1:4,000,000

Jackson DA (1993) Stopping rules in principal component analysis: A comparison of heuristical and statistical approaches. Ecology 74:2204-2214

James DE, Fouch MJ, Carlson RW, Roth JB (2011) Slab fragmentation, edge flow and the origin of the Yellowstone hotspot track. Earth Planet Sci Lett 311:124-135

Jarosewich E, Nelen JA, Norberg JA (1980) Reference samples for electron microprobe analysis. Geostand News 4:43-47

Jaupart C, Tait S (1995) Dynamics of differentiation in magma reservoirs. J Geophys Res 100:17615-17636

Jellinek AM, DePaolo DJ (2003) A model for the origin of large silicic magma chambers: precursors of caldera-forming eruptions. Bull Volcanol 65:363-381

Jicha BR, Singer BS, Sobol P (2016) Re-evaluation of the ages of ${ }^{40} \mathrm{Ar} /{ }^{39} \mathrm{Ar}$ sanidine standards and supereruptions in the western US using a Noblesse multi-colector mass spectrometer. Chem Geol 431:54-66

Jochum KP, Weis U, Kuzmin D, Yang Q, Raczek I, Jacob DE, Stracke A, Birbaum K, Frick DA, Günther D, Enzweiler J (2011) Determination of reference values for NIST SRM 610617 glasses following ISO guidelines. Geostand Geoanal Res 35:397-429

Jochum KP, Weis U, Schwager B, Stoll B, Wilson SA, Haug GH, Andreae MO, Enzweiler J (2016) Reference values following ISO guidelines for frequently requested rock reference materials. Geostand Geoanal Res 40:333-350

Kaneko K, Kamata H, Koyaguchi T, Yoshikawa M, Furukawa K (2007) Repeated large-scale eruptions from a single compositionally stratified magma chamber: an example from Aso volcano, Southwest Japan. J Volcanol Geotherm Res 167:160-180

Kennedy BM, Lynch MA, Reynolds JH, Smith SP (1985) Intensive sampling of noble gases in fluids at Yellowstone: I. Early overview of the data; regional patterns. Geochim Cosmochim Acta 49:1251-1261

Kuntz MA, Champion DE, Spiker EC, Lefebvre RH, McBroome LA (1982) The Great Rift and the evolution of the Craters of the Moon lava field, Idaho. In: Bonnichsen B, Breckenridge RM (eds) Cenozoic geology of Idaho. Idaho Bureau Mines Geology Bull 26:423-437 
Kuntz MA, Champion DE, Spiker EC, Lefebvre RH (1986) Contrasting magma types and steadystate volume-predictable basaltic volcanism along the Great Rift, Idaho. Geol Soc Am Bull 97:579-594

Kuntz MA, Covington HR, Schorr $\amalg$ (1992) An overview of basaltic volcanism of the eastern Snake River Plain, Idaho. In: Link PK, Kuntz MA, Platt LB (eds) Regional geology of eastern Idaho and western Wyoming. Geol Soc Am Mem 179:227-268

Lake ET, Farmer GL (2015) Oligo-Miocene mafic intrusions of the San Juan Volcanic Field, southwestern Colorado, and their relationship to voluminous, caldera-forming eruptions. Geochim Cosmochim Acta 157:86-108

Laporte D, Provost A (1994) The equilibrium crystal shape of silicates: implications for the grain-scale distribution of partial melts. Eos 75:364

Le Bas MJ, Streckeisen AL (1991) The IUGS systematics of igneous rocks. J Geol Soc Lond $148: 825-833$

Lee C-TA, Bachmann O (2014) How important is the role of crystal fractionation in making intermediate magmas? Insights from $\mathrm{Zr}$ and $\mathrm{P}$ systematics. Earth Planet Sci Lett $393: 266-274$

Leeman WP (1974) Part I: petrology of basaltic lavas from the Snake River Plain, Idaho and Part II: experimental determination of partitioning of divalent cations between olivine and basaltic liquid. 337 p PhD thesis University of Oregon, Eugene

Leeman WP, Manton WI (1971) Strontium isotopic composition of basaltic lavas from the Snake River Plain, southern Idaho. Earth Planet Sci Lett 11:420-434

Leeman WP, Vitaliano CJ, Prinz M (1976) Evolved lavas from the Snake River Plain: Craters of the Moon National Monument, Idaho. Contrib Mineral Petrol 56:35-60

Leeman WP, Menzies MA, Matty DJ, Embree GF (1985) Strontium, neodymium and lead isotopic compositions of deep crustal xenoliths from the Snake River Plain: evidence for Archean basement. Earth Planet Sci Lett 75:354-368

Leeman WP, Schutt DL, Hughes SS (2009) Thermal structure beneath the Snake River Plain: implications for the Yellowstone hotspot. J Volcanol Geotherm Res 188:57-67

Lipman PW (2000) Central San Juan caldera cluster: regional volcanic framework. Geol Soc Am Spec Pap 346:9-69

Lipman PW, Bachmann O (2015) Ignimbrites to batholiths: integrating perspectives from geological, geophysical, and geochronological data. Geosphere 11:705-743 
Loewen MW, Bindeman IN (2015) Oxygen isotope and trace element evidence for three-stage petrogenesis of the youngest episode (260-79 ka) of Yellowstone rhyolitic volcanism. Contrib Mineral Petrol 170:39

Loewen MW, Bindeman IN (2016) Oxygen isotope thermometry reveals high magmatic temperatures and short residence times in Yellowstone and other hot-dry rhyolites compared to cold-wet systems. Am Mineral 101:1222-1227

Loewen MW, Kent AJR (2012) Sources of elemental fractionation and uncertainty during the analysis of semi-volatile metals in silicate glasses using LA-ICP-MS. J Anal Atom Spectrom 27:1502-1508

Louvel M, Sanchez-Valle C, Malfait WJ, Testemale D, Hazemann J-L (2013) Zr complexation in high pressure fluids and silicate melts and implications for the mobilization of HFSE in subduction zones. Geochim Cosmochim Acta 104:281-299

Louvel M, Sanchez-Valle C, Malfait WJ, Cardon H, Testemale D, Hazemann J-L (2014) Constraints on the mobilization of $\mathrm{Zr}$ in magmatic-hydrothermal processes in subduction zones from in situ fluid-melt partitioning experiments. Am Mineral 99:1616-1625

Lowe DR, Tice MM (2004) Geologic evidence for Archean atmospheric and climatic evolution: fluctuating levels of $\mathrm{CO}_{2}, \mathrm{CH}_{4}$, and $\mathrm{O}_{2}$ with an overriding tectonic control. Geology 32:493-496

Lowenstern JB, Hurwitz S (2008) Monitoring a supervolcano in repose: heat and volatile flux at the Yellowstone caldera. Elements 4:35-40

Lowenstern JB, Smith RB, Hill DP (2006) Monitoring super-volcanoes: geophysical and geochemical signals at Yellowstone and other large caldera systems. Phil Trans R Soc Lond A364:2055-2072

Lowenstern JB, Evans WC, Bergfeld D, Hunt AG (2014) Prodigious degassing of a billion years of accumulated radiogenic helium at Yellowstone. Nature 506:355-358

Lowenstern JB, Bergfeld D, Evans WC, Hunt AG (2015) Origins of geothermal gases at Yellowstone. J Volcanol Geotherm Res 302:87-101

Lu F, Anderson AT, Davis AM (1992) Melt inclusions and crystal-liquid separation in rhyolitic magma of the Bishop Tuff. Contrib Mineral Petrol 110:113-120

Ludwig KR (2008) Isoplot/Ex version 3.7. A geochronological toolkit for Microsoft Excel. Berkely Geochronological Centre, Special Publication 4 
Lundstrom CC, Glazner AF (2016) Silicic magmatism and the volcanic-plutonic connection. Elements 12:91-96

Macdonald R, Belkin HE (2002) Compositional variation in minerals of the chevkinite group. Min Mag 66:1075-1098

Mahood GA (1990) Second reply to comment of RSJ Sparks, HE Huppert and CJN Wilson on

"Evidence for long residence times of rhyolitic magma in the Long Valley magmatic system: the isotopic record in the precaldera lavas of Glass Mountain". Earth Planet Sci Lett 99:395-399

Mahood GA, Gilbert CM, Carmichael ISE (1985) Peralkaline and metaluminous mixed-liquid ignimbrites of the Guadalajara region, Mexico. J Volcanol Geotherm Res 25:259-271 Malfait WJ, Seifert R, Petitgirard S, Perrillat J-P, Mezouar M, Ota T, Nakamura E, Lerch P, Sanchez-Valle C (2014) Supervolcano eruptions driven by melt buoyancy in large silicic magma chambers. Nature Geosci 7:122-125

Manley CR (1996) Morphology and maturation of melt inclusions in quartz phenocrysts from the Badlands rhyolite lava flow, southwestern Idaho. Am Mineral 81:158-168

Manning CE, Wilke M, Schmidt C, Cauzid J (2008) Rutile solubility in albite- $\mathrm{H}_{2} \mathrm{O}$ and $\mathrm{Na}_{2} \mathrm{Si}_{3} \mathrm{O}_{7}-$ $\mathrm{H}_{2} \mathrm{O}$ at high temperatures and pressures by in-situ synchrotron radiation micro-XRF. Earth Planet Sci Lett 272:730-737

Marsh BD (1981) On the crystallinity, probability of occurrence, and rheology of lava and magma. Contrib Mineral Petrol 78:85-98

Marsh BD (1988) Crystal capture, sorting and retention in convecting magma. Geol Soc Am Bull 100:1720-1737

Martin D, Nokes R (1988) Crystal settling in a vigorously convecting magma chamber. Nature $332: 534-536$

Mason BG, Pyle DM, Oppenheimer C (2004) The size and frequency of the largest explosive eruptions on Earth. Bull Volcanol 66:735-748

Masotta M, Mollo S, Gaeta M, Freda C (2016) Melt extraction in mush zones: the case of crystal-rich enclaves at the Sabatini Volcanic District (central Italy). Lithos 248251:288-292

Matthews NE, Vazquez JA, Calvert AT (2015) Age of the Lava Creek supereruption and magma chamber assembly at Yellowstone based on ${ }^{40} \mathrm{Ar} /{ }^{39} \mathrm{Ar}$ and U-Pb dating of sanidine and zircon crystals. Geochem Geophys Geosyst 16:2508-2528 
McCulloch MT, Gamble JA (1991) Geochemical and geodynamical constraints on subduction zone magmatism. Earth Planet Sci Lett 102:358-374

McCurry M, Rodgers DW (2009) Mass transfer along the Yellowstone hotspot track I: petrologic constraints on the volume of mantle-derived magma. J Volcanol Geotherm Res 188:86-98

McCurry M, Hayden KP, Morse LH, Mertzman S (2008) Genesis of post-hotspot A-type rhyolite of the Eastern Snake River Plain volcanic field by extreme fractional crystallization of olivine tholeiite. Bull Volcanol 70:361-383

McDonough WF, Sun S-s (1995) The composition of the Earth. Chem Geol 120:223-253

McGee LE, Smith IEM, Millet M-A, Handley HK, Lindsay JM (2013) Asthenospheric control of melting processes in a monogenetic basaltic system: a case study of the Auckland volcanic field, New Zealand. J Petrol 54:2125-2153

Meen JK, Eggler DH (1989) Chemical and isotopic compositions of Absaroka granitoids, southwestern Montana. Contrib Mineral Petrol 102:462-477

Menzies MA, Leeman WP, Hawkesworth CJ (1984) Geochemical and isotopic evidence for the origin of continental flood basalts with particular reference to the Snake River Plain, Idaho, USA. Phil Trans R Soc Lond A310:643-660

Miller CF, Mittlefehldt DW (1984) Extreme fractionation in felsic magma chambers: a product of liquid-state diffusion or fractional crystallization? Earth Planet Sci Lett 68:151-158

Miller CF, Wark DA (eds) (2008) Supervolcanoes. Elements 4:11-49

Mirnejad H, Bell K (2006) Origin and source evolution of the Leucite Hills lamproites: evidence from Sr-Nd-Pb-O isotopic compositions J Petrol 47:2463-2489

Mueller UA, Grunsky EC (2016) Multivariate spatial analysis of lake sediment geochemical data: Melville Peninsula, Nunavut, Canada. Applied Geochemistry 75:247-262

Myers ML, Wallace PJ, Wilson CJN, Morter BK, Swallow EJ (2016) Prolonged ascent and episodic venting of discrete magma batches at the onset of the Huckleberry Ridge supereruption, Yellowstone. Earth Planet Sci Lett 451:285-297

Nairn IA, Kohn BP (1973) Relation of the Earthquake Flat Breccia to the Rotoiti Breccia, central North Island, New Zealand. NZ J Geol Geophys 16:269-279

Nairn IA, Kobayashi T, Nakagawa M (1998) The 10 ka multiple vent pyroclastic eruption sequence at Tongariro Volcanic Centre, Taupo Volcanic Zone, New Zealand: part 1. Eruptive processes during regional extension. J Volcanol Geotherm Res 86:19-44 
Nash BP, Perkins ME, Christensen JN, Lee D-C, Halliday AN (2006) The Yellowstone hotpot in space and time: Nd and $\mathrm{Hf}$ isotopes in silicic magmas. Earth Planet Sci Lett 247:143156

Olin PH, Wolff JA (2010) Rare earth and high field strength element partitioning between ironrich clinopyroxenes and felsic liquids. Contrib Mineral Petrol 160:761-775

Oversby VM (1975) Lead isotopic systematics and ages of Archaean acid intrusives in the Kalgoorlie-Norseman area, Western Australia. Geochim Cosmochim Acta 39:11071125

Pamukcu AS, Gualda GAR, Bégué F, Gravley DM (2015) Melt inclusion shapes: timekeepers of short-lived giant magma bodies. Geology 43:947-950

Parmigiani A, Huber C, Bachmann O (2014) Mush microphysics and the reactivation of crystalrich magma reservoirs. J Geophys Res 119:6308-6322

Parsons I (1978) Feldspars and fluids in cooling plutons. Mineral Mag 42:1-17

Parsons T (1995) The Basin and Range province. In: Olsen KH (ed) Continental rifts: evolution, structure, tectonics. Developments in Geotectonics 25:277-324

Perkins ME, Nash BP (2002) Explosive silicic volcanism of the Yellowstone hotspot: the ash fall tuff record. Geol Soc Am Bull 114:367-381

Perkins ME, Nash WP, Brown FH, Fleck RJ (1995) Fallout tuffs of Trapper Creek, Idaho-a record of Miocene explosive volcanism in the Snake River Plain volcanic province. Geol Soc Am Bull 107:1484-1506

Pierce KL, Morgan LA, (1992) The track of the Yellowstone hot spot: volcanism, faulting, and uplift. In: Link PK, Kuntz MA, Platt LB (eds) Regional geology of eastern Idaho and western Wyoming. Geol Soc Am Mem 179:1-53

Pierce KL, Morgan LA (2009) Is the track of the Yellowstone hotspot driven by a deep mantle plume? - Review of volcanism, faulting, and uplift in light of new data. J Volcanol Geotherm Res 188:1-25

Pin C, Zalduegui JFS (1997) Sequential separation of light rare-earth elements, thorium and uranium by miniaturized extraction chromatography: application to isotopic analyses of silicate rocks. Anal Chim Acta 339:79-89

Pin C, Gannoun A, Dupont A (2014) Rapid simultaneous separation of Sr, Pb and Nd by extraction chromatography prior to isotope ratios determination by TIMS and MC-ICPMS. J Anal Atom Spectrom 29:1858-1870 
Pistolesi M, Isaia R, Marianelli P, Bertagnini A, Fourmentraux C, Albert PG, Tomlinson EL, Menzies MA, Rosi M, Sbrana A (2016) Simultaneous eruptions from multiple vents at Campi Flegrei (Italy) highlight new eruption processes at calderas. Geology 44:487-490

Pistone M, Arzilli F, Dobson KJ, Cordonnier B, Reusser E, Ulmer P, Marone F, Whittington F, Mancini L, Fife JL, Blundy JD (2015) Gas-driven filter pressing in magmas: insights into in-situ melt segregation from crystal mushes. Geology 43:699-702

Poldervaart A, Hess HH (1951) Pyroxenes in the crystallization of basaltic magma. J Geol 59:472-489

Potter KE, Shervais JW, Christiansen EH, Vetter SK (2018) Evidence for cyclical fractional crystallization, recharge, and assimilation in basalts of the Kimama drill core, central Snake River Plain, Idaho: 5.5-million-years of petrogenesis in a mid-crustal sill complex. Front Earth Sci 6:10

Price RC, Gamble JA, Smith IEM, Stewart RB, Eggins S, Wright IC (2005) An integrated model for the temporal evolution of andesites and rhyolites and crustal development in New Zealand's North Island. J Volcanol Geotherm Res 140:1-24

Pritchard CJ, Larson PB, Spell TL, Tarbert KD (2016) Eruption-triggered mixing of extra-caldera basalt and rhyolite complexes along the East Gallatin-Washburn fault zone, Yellowstone National Park, WY, USA. Lithos 175-176:163-177

Puskas CM, Smith RB, Meertens CM, Chang WL (2007) Crustal deformation of the Yellowstone-Snake River Plain volcano-tectonic system: campaign and continuous GPS observations, 1987-2004. J Geophys Res 112:B03401

Putirka KD (2008) Thermometers and barometers for volcanic systems. Rev Mineral Geochem 69:61-120

Putirka KD, Kuntz MA, Unruh DM, Vaid N (2009) Magma evolution and ascent at the Craters of the Moon and neighboring volcanic fields, southern Idaho, USA: implications for the evolution of polygenetic and monogenetic volcanic fields. J Petrol 50:1639-1665

R Development Core Team (2016) R: A language and environment for statistical computing R Foundation for Statistical Computing Vienna, Austria. URL https://wwwR-projectorg/

Ramsey MH, Potts PJ, Webb PC, Watkins P, Watson JS, Coles BJ (1995) An objective assessment of analytical method precision: comparison of ICP-AES and XRF for the analysis of silicate rocks. Chem Geol 124:1-19 
Rasoazanamparany C, Widom E, Valentine GA, Smith EI, Cortés JA, Kuentz D, Johnsen R (2015)

Origin of chemical and isotopic heterogeneity in a mafic monogenetic volcanic field: a case study of the Lunar Crater Volcanic Field, Nevada. Chem Geol 397:76-93

Reid MR (1995) Processes of mantle enrichment and magmatic differentiation in the eastern Snake River Plain: Th isotope evidence Earth Planet Sci Lett 131:239-254

Reid MR (2008) How long does it take to supersize an eruption? Elements 4:23-28

Ren M (2004) Partitioning of Sr, Ba, Rb, Y, and LREE between alkali feldspar and peraluminous silicic magma. Am Mineral 89:1290-1303

Reubi O, Blundy J (2008) Assimilation of plutonic roots, formation of high-K 'exotic melt inclusions and genesis of andesitic magmas at Volcán de Colima, Mexico. J Petrol 49:2221-2243

Reynolds RL (1977) Paleomagnetism of welded tuffs of the Yellowstone group. J Geophys Res 82:3677-3693

Rivera TA, Schmitz MD, Crowley JL, Storey M (2014) Rapid magma evolution constrained by zircon petrochronology and ${ }^{40} \mathrm{Ar} /{ }^{39} \mathrm{Ar}$ sanidine ages for the Huckleberry Ridge Tuff, Yellowstone, USA. Geology 42:643-646

Rivera TA, Schmitz MD, Jicha BR, Crowley JL (2016) Zircon petrochronology and ${ }^{40} \mathrm{Ar} /{ }^{39} \mathrm{Ar}$ sanidine dates for the Mesa Falls Tuff: crystal-scale records of magmatic evolution and the short lifespan of a large Yellowstone magma chamber. J Petrol 57:1677-1704

Rivera TA, Darata R, Lippert PC, Jicha BR, Schmitz MD (2017) The duration of a Yellowstone super-eruption cycle and implications for the age of the Olduvai subchron. Earth Planet Sci Lett 479:377-386

Roberge J, Wallace PJ, Kent AJR (2013) Magmatic processes in the Bishop Tuff rhyolitic magma based on trace elements in melt inclusions and pumice matrix glass. Contrib Mineral Petrol 165:237-257

Roche O, Druitt TH (2001) Onset of caldera collapse during ignimbrite eruptions. Earth Planet Sci Lett 191:191-202

Rosenberg CL, Handy MR (2005) Experimental deformation of partially melted granite revisited: implications for the continental crust. J Metamorph Geol 23:19-28

Rosenberg MD (2017) Volcanic and tectonic perspectives on the age and evolution of the Wairakei-Tauhara geothermal system. PhD thesis, Victoria University of Wellington, New Zealand 
Rosi M, Vezzoli L, Aleotti P, De Censi M (1996) Interaction between caldera collapse and eruptive dynamics during the Campanian Ignimbrite eruption, Phlegraean Fields, Italy. Bull Volcanol 57:541-554

Rosman KJR, Taylor PDP (1998) Isotopic compositions of the elements 1997. Pure Appl Chem 70:217-235

Rowe MC, Wolff JA, Gardner JN, Ramos FC, Teasdale R, Heikoop CE (2007) Development of a continental volcanic field: petrogenesis of pre-caldera intermediate and silicic rocks and origin of the Bandelier magmas, Jemez Mountains (New Mexico USA). J Petrol 48:2063-2091

Rowland JV, Wilson CJN, Gravley DM (2010) Spatial and temporal variations in magmaassisted rifting, Taupo Volcanic Zone, New Zealand. J Volcanol Geotherm Res 190:89108

Rubatto D, Hermann J (2003) Zircon formation during fluid circulation in eclogites (Monviso Western Alps): implications for $\mathrm{Zr}$ and $\mathrm{Hf}$ budget in subduction zones. Geochim Cosmochim Acta 67:2173-2187

Sampson DE, Cameron KL (1987) The geochemistry of the Inyo volcanic chain: multiple magma systems in the Long Valley region, eastern California. J Geophys Res 92:1040310421

Scaillet B, Holtz F, Pichavant M (1998) Phase equilibrium constraints on the viscosity of silicic magmas 1. Volcanic-plutonic connection. J Geophys Res 103:27257-27266

Schmandt B, Humphreys E (2010) Complex subduction and small-scale convection revealed by body-wave tomography of the western United States upper mantle. Earth Planet Sci Lett 297:435-445

Schmandt B, Humphreys E (2011) Seismically imaged relict slab from the 55 Ma Siletzia accretion to the northwest United States. Geology 39:175-178

Schmandt B, Dueker K, Humphreys E, Hansen S (2012) Hot mantle upwelling across the 660 beneath Yellowstone. Earth Planet Sci Lett 331-332:224-236

Schuraytz BC, Vogel TA, Younker LW (1989) Evidence for dynamic withdrawal from a layered magma body: the Topopah Spring Tuff, southwestern Nevada. J Geophys Res 94:59255942

Self S (2006) The effects and consequences of very large explosive volcanic eruptions. Phil Trans R Soc Lond A364:2073-2097 
Shane P, Martin SB, Smith VC, Beggs KF, Darragh MB, Cole JW, Nairn IA (2007) Multiple rhyolite magmas and basalt injection in the 17.7 ka Rerewhakaaitu eruption episode from Tarawera volcanic complex, New Zealand. J Volcanol Geotherm Res 164:1-26

Shane P, Nairn IA, Smith VC, Darragh M, Beggs K, Cole JW (2008) Silicic recharge of multiple rhyolite magmas by basaltic intrusion during the 22.6 ka Okareka eruption episode, New Zealand. Lithos 103:527-549

Singer BS, Jicha BR, Condon DJ, Macho AS, Hoffman KA, Dierkhising J, Brown MC, Feinberg JM, Kidane T (2014) Precise ages of the Réunion event and Huckleberry Ridge excursion: episodic clustering of geomagnetic instabilities and the dynamics of flow within the outer core. Earth Planet Sci Lett 405:25-38

Singer BS, Costa F, Herrin JS, Hildreth W, Fierstein J (2016) The timing of compositionallyzoned magma reservoirs and mafic 'priming' weeks before the 1912 NovaruptaKatmai rhyolite eruption. Earth Planet Sci Lett 451:125-137

Sisson TW, Bacon CR (1999) Gas-driven filter pressing in magmas. Geology 27:613-616

Sisson TW, Ratajeski K, Hankins WB, Glazner AF (2005) Voluminous granitic magmas from common basaltic sources. Contrib Mineral Petrol 148:635-661

Smith RB, Braile LW (1994) The Yellowstone hotspot. J Volcanol Geotherm Res 61:121-187

Smith RB, Jordan M, Steinberger B, Puskas CM, Farrell J, Waite GP, Husen S, Chang W-L, O'Connell R (2009) Geodynamics of the Yellowstone hotspot and mantle plume: seismic and GPS imaging, kinematics and mantle flow. J Volcanol Geotherm Res $188: 26-56$

Smith RL (1979) Ash-flow magmatism. In: Chapin CE, Elston WE, (eds) Ash-flow tuffs. Geol Soc Am Spec Pap 180:5-27

Sparks RSJ, Sigurdsson H, Wilson L (1977) Magma mixing: a mechanism for triggering acid explosive eruptions. Nature 267:315-318

Sparks RSJ, Huppert HE, Turner JS (1984) The fluid dynamics of evolving magma chambers. Phil Trans R Soc Lond A310:511-534

Sparks RSJ, Bursik MI, Carey SN, Gilbert JS, Glaze LS, Sigurdsson H, Woods AW (1997) Volcanic Plumes. John Wiley, Chichester, UK, $574 \mathrm{p}$

Sparks RSJ, Self S, Grattan J, Oppenheimer C, Pyle D, Raymer H (2005) Super-eruptions: global effects and future threats. Report of the Geological Society of London Working Group, London. The Geological Society, 24 pp 
Stelten ME, Cooper KM, Vazquez JA, Calvert AT, Glessner JG (2015) Mechanisms and timescales of generating eruptible rhyolitic magmas at Yellowstone caldera from zircon and sanidine geochronology and geochemistry. J Petrol 56:1607-1642

Stelten ME, Cooper KM, Wimpenny JB, Vazquez JA, Zin Q-Z (2017) The role of mantle-derived magmas in the isotopic evolution of Yellowstone's magmatic system. Geochem Geophys Geosyst 18:1350-1365

Stelten ME, Champion DE, Kuntz MA (2018) The timing and origin of pre- and post-caldera volcanism associated with the Mesa Falls Tuff, Yellowstone Plateau volcanic field. J Volcanol Geotherm Res 350:47-60

Streck MJ (2014) Evaluation of crystal mush extraction models to explain crystal-poor rhyolites. J Volcanol Geotherm Res 284:79-94

Streck MJ, Grunder AL (1997) Compositional gradients and gaps in high-silica rhyolites of the Rattlesnake Tuff, Oregon. J Petrol 38:133-163

Streck ML, Grunder AL (1999) Enrichment of basalt and mixing of dacite in the rootzone of a large rhyolitic chamber: inclusions and pumices from the Rattlesnake Tuff, Oregon. Contrib Mineral Petrol 136:193-212

Streck MJ, Grunder AL (2008) Phenocryst-poor rhyolites of bimodal tholeiitic provinces: the Rattlesnake Tuff and implications for mush extraction models. Bull Volcanol 70:385401

Strelow FWE, von Toerien FS (1966) Separation of Lead(II) from Bismuth(III), Thallium(III), Cadmium(II), Mercury(II), Gold(III), Platinum(IV), Palladium(II), and other elements by anion exchange chromatography. Anal Chim Acta 38:545-548

Sun C, Graff M, Liang Y (2017) Trace element partitioning between plagioclase and silicate melt: the importance of temperature and plagioclase composition with implications for terrestrial and lunar magmatism. Geochim Cosmochim Acta 206:273-295

Sun S-s, McDonough WF (1989) Chemical and isotopic systematics of oceanic basalts: implications for mantle composition and processes. Geol Soc Lond Spec Pub 42:313345

Sutton AN, Blake S, Wilson CJN (1995) An outline geochemistry of rhyolite eruptives from Taupo volcanic centre, New Zealand. J Volcanol Geotherm Res 68:153-175 
Suzuki-Kamata K, Kamata H, Bacon CR (1993) Evolution of the caldera-forming eruption at Crater Lake, Oregon, indicated by component analysis of lithic fragments. J Geophys Res 98:14059-14074

Swallow EJ, Wilson CJN, Charlier BLA, Gamble JA (2018a) Mafic inputs into the rhyolitic magma system of the 2.08 Ma Huckleberry Ridge eruption, Yellowstone. Am Mineral 103:757775

Swallow EJ, Wilson CJN, Myers ML, Wallace PJ, Collins KS, Smith EGC (2018b) Evacuation of multiple magma bodies and the onset of caldera collapse in a supereruption, captured in glass and mineral compositions. Contrib Mineral Petrol 173:33

Swanson SE, Fenn PM (1986) Quartz crystallization in igneous rocks. Am Mineral 71:331-342

Szymanowski D, Ellis BS. Bachmann O. Guillong M. Phillips WM (2015) Bridging basalts and rhyolites in the Yellowstone-Snake River Plain volcanic province: the elusive intermediate step. Earth Planet Sci Lett 415:80-89

Tarasewicz J, White RS, Woods AW, Brandsdóttir B, Gudmundsson MT (2012) Magma mobilization by downward-propagating decompression of the Eyjafjallajökull volcanic plumbing system. Geophys Res Lett 39:L19309

Thirlwall MF (1991) Long-term reproducibility of multicollector $\mathrm{Sr}$ and $\mathrm{Nd}$ isotope ratio analysis. Chem Geol 94:85-104

Thirlwall MF (2000) Inter-laboratory and other errors in Pb isotope analyses investigated using a ${ }^{207} \mathrm{~Pb}-{ }^{204} \mathrm{~Pb}$ double spike. Chem Geol 163:299-322

Thompson RN (1975) Primary basalts and magma genesis II. Snake River Plain, Idaho, USA. Contrib Mineral Petrol 52:213-232

Till CB, Vazquez JA, Boyce JW (2015) Months between rejuvenation and volcanic eruption at Yellowstone caldera, Wyoming. Geology 43:695-698

Tilley CE, Thompson RN (1970) Melting and crystallization relations of the Snake River basalts of southern Idaho, USA. Earth Planet Sci Lett 8:79-92

Todt W, Cliff RA, Hanser A, Hofmann AW (1996) Evaluation of a ${ }^{202} \mathrm{~Pb}-{ }^{205} \mathrm{~Pb}$ double spike for high-precision lead isotope analysis. In: Basu A, Hart S (eds) Earth Processes: reading the Isotopic Code 95 p 429-437 Geophys Mono Am Geophys Union, Washington DC

Tramontano S, Gualda GAR, Ghiorso MS (2017) Internal triggering of volcanic eruptions: tracking overpressure regimes for giant magma bodies. Earth Planet Sci Lett 472:142151 
Troch J, Ellis BS, Mark DF, Bindeman IN, Kent AJR, Guillong M, Bachmann O (2017) Rhyolite generation prior to a supereruption: insights from the Island Park-Mount Jackson rhyolite series. J Petrol 58:29-52

Troch J, Ellis BS, Harris C, Ulmer P, Bachmann O (2018) The effect of prior hydrothermal alteration on the melting behaviour during rhyolite formation in Yellowstone, and its importance in the generation of low- $\delta{ }^{18} \mathrm{O}$ magmas. Earth Planet Sci Lett 481:338-349

Tsay A, Zajacz Z, Sanchez-Valle C (2014) Efficient mobilization and fractionation of rare-earth elements by aqueous fluids upon slab dehydration. Earth Planet Sci Lett 398:101-112

Valet, J-P, Fournier A (2016) Deciphering records of geomagnetic reversals. Rev Geophys $54: 410-446$

Vazquez JA, Kyriazis SF, Reid MR, Sehler RC, Ramos FC (2009) Thermomechanical evolution of young rhyolites at Yellowstone: evidence for a cooling but periodically replenished postcaldera magma reservoir. J Volcanol Geotherm Res 188:186-196

Vazquez JA, Velasco NO, Schmitt AK, Bleick HA, Stelten ME (2014) ${ }^{238} \mathrm{U}-{ }^{230}$ Th dating of chevkinite in high-silica rhyolites from La Primavera and Yellowstone calderas. Chem Geol 390:109-118

Vogel TA, Ryerson FJ, Noble DC, Younker LW (1987) Limits to magma mixing based on chemistry and mineralogy of pumice fragments erupted from a chemically zoned magma body. J Geol 95:659-670

Vogel TA, Eichelberger JC, Younker LW, Schuraytz BC, Horkowitz HW, Stockman HW, Westrich HR (1989) Petrology and emplacement dynamics of intrusive and extrusive rhyolites of Obsidian Dome, Inyo Craters volcanic chain, eastern California. J Geophys Res 94:17937-17956

Walker GPL (1972) Crystal concentration in ignimbrites. Contrib Mineral Petrol 36:135-146

Wallace PJ, Anderson AT, Davis AM (1999) Gradients in $\mathrm{H}_{2} \mathrm{O} \mathrm{CO}_{2}$ and exsolved gas in a largevolume silicic magma system: interpreting the record preserved in melt inclusions from the Bishop Tuff. J Geophys Res 104:20097-20122

Wark DA, Hildreth W, Spear FS, Cherniak DJ, Watson EB (2007) Pre-eruption recharge of the Bishop magma system. Geology 35:235-238

Waters LE, Lange RA (2015) An updated calibration of the plagioclase-liquid hygrometerthermometer applicable to basalts through rhyolites. Am Mineral 100:2172-2184 
Watkins JM, Gardner JE, Befus KS (2017) Nonequilibrium degassing, regassing and vapour fluxing in magmatic feeder systems. Geology 45:183-186

Watson EB, Harrison TM (1983) Zircon saturation revisited: temperature and composition effects in a variety of crustal magma types. Earth Planet Sci Lett 64:295-304

Watts KE, Leeman WP, Bindeman IN, Larson PB (2010) Supereruptions of the Snake River Plain: two-stage derivation of low- $\delta^{18} O$ rhyolites from normal- $\delta^{18} O$ crust as constrained by Archean xenoliths. Geology 38:503-506

Watts KE, Bindeman IN, Schmitt AK (2012) Crystal scale anatomy of a dying supervolcano: an isotope and geochronology study of individual phenocrysts from voluminous rhyolites of the Yellowstone caldera. Contrib Mineral Petrol 164:45-67

Watts KE, John DA, Colgan JP, Henry CD, Bindeman IN, Schmitt AK (2016) Probing the volcanicplutonic connection and the genesis of crystal-rich rhyolite in a deeply dissected supervolcano in the Nevada Great Basin: source of the late Eocene Caetano Tuff. J Petrol 57:1599-1644

Werner C, Brantley S (2003) $\mathrm{CO}_{2}$ emissions from the Yellowstone volcanic system. Geochem Geophys Geosyst 4:1061

Westgate JA, Pearce NJG, Perkins WT, Preece SJ, Chesner CA, Muhammad RF (2013) Tephrochronology of the Toba Tuffs: four primary glass populations define the 75-ka Youngest Toba Tuff, northern Sumatra, Indonesia. J Quat Sci 28:772-776

Whitaker ML, Nekvasil H, Lindsley DH, McCurry M (2008) Can crystallization of olivine tholeiite give rise to potassic rhyolites?-an experimental investigation. Bull Volcanol 70:417434

Wilcox RE (1944) Rhyolite-basalt complex on Gardiner River, Yellowstone Park, Wyoming. Geol Soc Am Bull 55:1047-1080

Wilke M, Schmidt C, Dubrail J, Appel K, Borchert M, Kvashnina K, Manning CE (2012) Zircon solubility and zirconium complexation in $\mathrm{H}_{2} \mathrm{O}+\mathrm{Na}_{2} \mathrm{O}+\mathrm{SiO}_{2} \pm \mathrm{Al}_{2} \mathrm{O}_{3}$ fluids at high pressure and temperature. Earth Planet Sci Lett 349-350:15-25

Wilke S, Holtz F, Neave DA, Almeev R (2017) The effect of anorthite and water on quartzfeldspar cotectic compositions in the rhyolitic system and implications for geobarometry. J Petrol 58:789-818

Wilson CJN (1993) Stratigraphy, chronology, styles and dynamics of late Quaternary eruptions from Taupo volcano, New Zealand. Phil Trans R Soc Lond A343:205-306 
Wilson CJN (2001) The 26.5 ka Oruanui eruption, New Zealand: an introduction and overview. J Volcanol Geotherm Res 112:133-174

Wilson CJN (2008) Supereruptions and supervolcanoes: processes and products. Elements $4: 29-34$

Wilson CJN (2009) Physical volcanology of the Huckleberry Ridge Tuff. Eos Trans AGU 90(52) Fall Meet Suppl Abstract V23C-2085

Wilson CJN, Charlier BLA (2009) Rapid rates of magma generation at contemporaneous magma systems, Taupo volcano, New Zealand: insights from U-Th model-age spectra in zircons. J Petrol 50:875-907

Wilson CJN, Charlier BLA (2016) The life and times of silicic volcanic systems. Elements 12:103108

Wilson CJN, Hildreth W (1997) The Bishop Tuff: new insights from eruptive stratigraphy. J Geol 105:407-439

Wilson CJN, Rowland JV (2016) The volcanic, magmatic and tectonic setting of the Taupo Volcanic Zone, New Zealand, reviewed from a geothermal perspective. Geothermics 59:168-187

Wilson CJN, Blake S, Charlier BLA, Sutton AN (2006) The 26.5 ka Oruanui eruption, Taupo volcano, New Zealand: development characteristics and evacuation of a large rhyolitic magma body. J Petrol 47:35-69

Wilson CJN, Gravley DM, Leonard GS, Rowland JV (2009) Volcanism in the central Taupo Volcanic Zone, New Zealand: tempo, styles and controls. In: Thordarson T, Self S, Larsen G, Rowland SK, Hoskuldsson A, (eds) Studies in Volcanology: The Legacy of George Walker. Spec Publ IAVCEI 2:225-247

Wilson CJN, Stelten ME, Lowenstern JB (2018) Contrasting perspectives on the Lava Creek Tuff eruption, Yellowstone, from new U-Pb and ${ }^{40} \mathrm{Ar} /{ }^{39} \mathrm{Ar}$ age determinations. Bull Volcanol $80: 53$

Wilson L, Sparks RSJ, Walker GPL (1980) Explosive volcanic eruptions-IV. The control of magma properties and conduit geometry on eruption column behaviour. Geophys J R Astron Soc 63:117-148

Wolff JA (2017) On the syenite-trachyte problem. Geology 45:1067-1070 
Wolff JA, Ramos FC (2014) Processes in caldera-forming high-silica rhyolite magma: Rb-Sr and $\mathrm{Pb}$ isotope systematics of the Otowi member of the Bandelier Tuff, Valles caldera, New Mexico, USA. J Petrol 55:345-375

Wolff JA, Ellis BS, Ramos FC, Starkel WA, Boroughs S, Olin PH, Bachmann O (2015) Remelting of cumulates as a process for producing chemical zoning in silicic tuffs: a comparison of cool, wet and hot, dry rhyolitic magma systems. Lithos 236-237:275-286

Wooden JL, Mueller PA (1988) Pb, Sr, and Nd isotopic compositions of a suite of Late Archean, igneous rocks, eastern Beartooth Mountains: implications for crust-mantle evolution. Earth Planet Sci Lett 87:59-72

Wotzlaw J-F, Bindeman IN, Stern RA, D’Abzac F-X, Schaltegger U (2015) Rapid heterogeneous assembly of multiple magma reservoirs prior to Yellowstone supereruptions. Sci Rep $5: 14026$

Yuan HY, Dueker K (2005) Teleseismic P-wave tomogram of the Yellowstone plume. Geophys Res Lett 32:L07304

Zhou Q, Liu L, Hu J (2018) Western US volcanism due to intruding oceanic mantle driven by ancient Farallon slabs. Nature Geosci 11:70-76

Zindler A, Hart S (1986) Chemical geodynamics. Ann Rev Earth Planet Sci 14:493-571 


\section{S3. Supplementary material for Chapter 3}

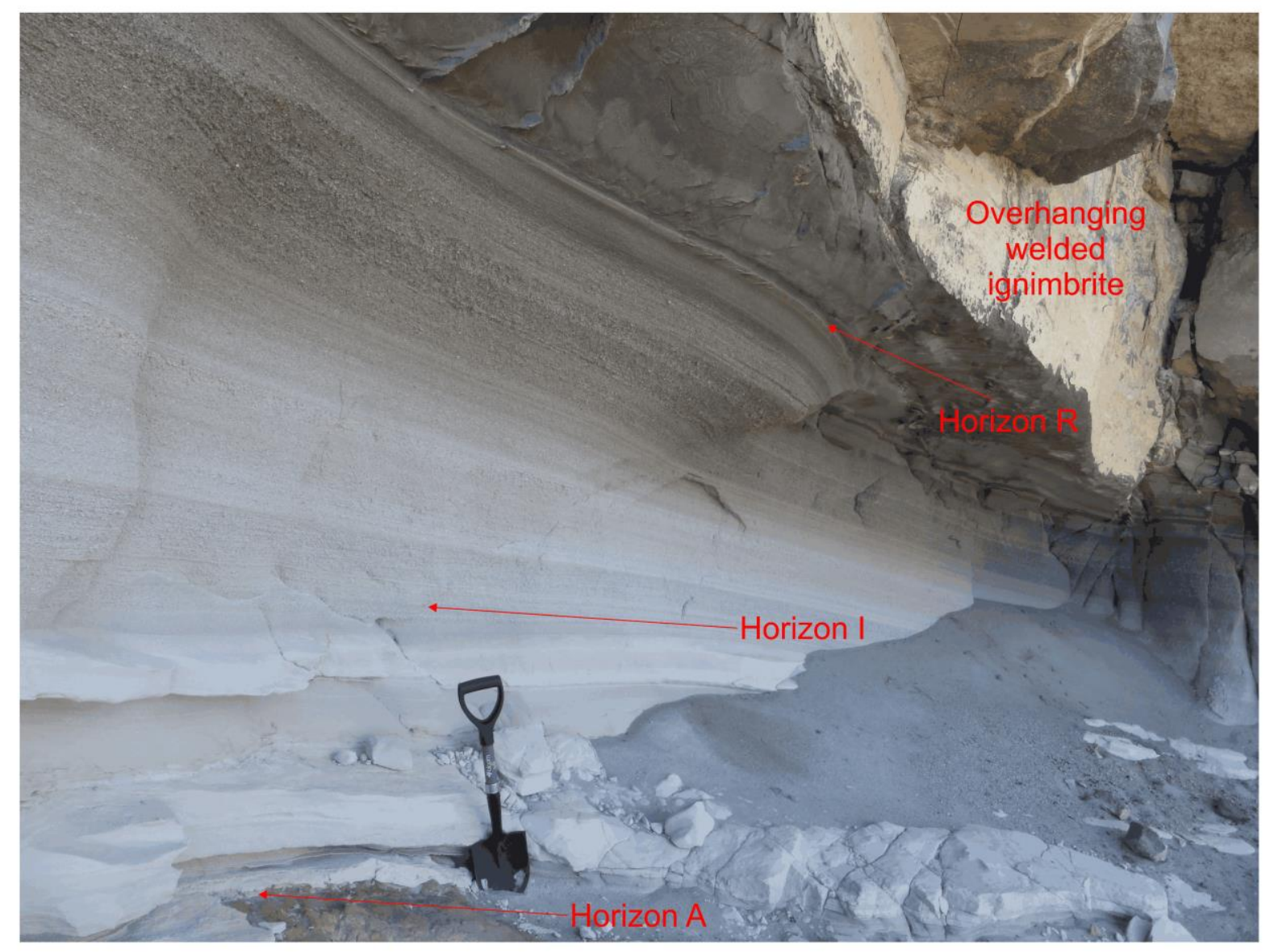

Figure S3.1: Photograph of the initial fall deposit of the Huckleberry Ridge Tuff (HRT) at the location sampled on the western rim of Mt. Everts near Mammoth, Wyoming. Selected sampled horizons are identified for reference (see Fig. 3.8 in Chapter 3). The upper third of the fall deposits has been fused by the overlying welded ignimbrite and is darkened through microlite growth. Pumices present are $<1 \mathrm{~cm}$ and so glass shards, along with crystals, were sampled from each horizon. 
Fall deposit:

- Horizon $\mathrm{H} \quad$ Horizon J

- Horizon Q * Horizon R

Basal ignimbrite:

$\diamond$ Mt Everts

$\triangle$ Jackson Hole $(\mathrm{U})$

$\triangle$ Swan Valley $(U)$

I Fall deposit plagioclase

(391/396)

I I Fall deposit alkali

- feldspar (1289/1290)

$\square$ Fall deposit alkali feldspar (160/164)

$\square$ Fall deposit plagioclase $(65 / 77)$

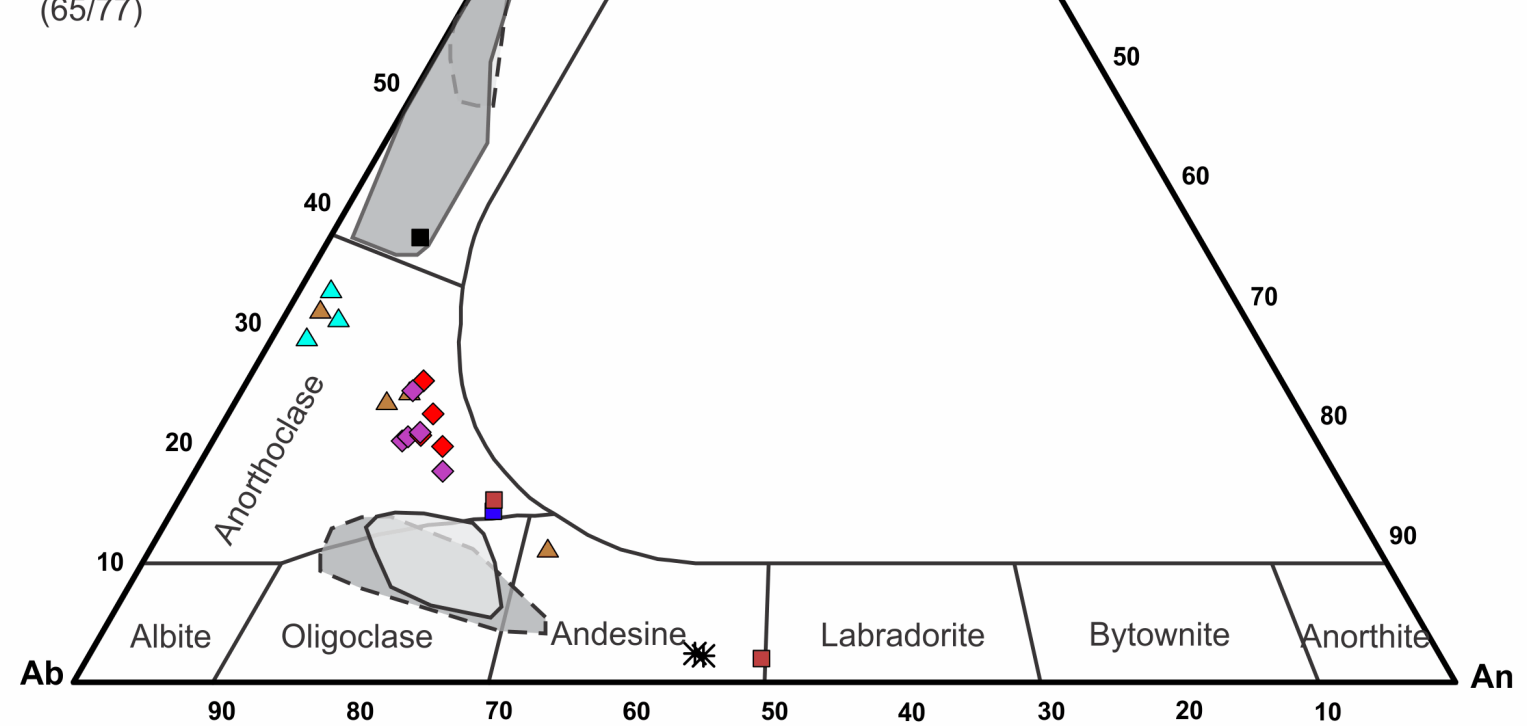

Figure S3.2: Ternary plot of feldspar compositions showing the compositional ranges of sanidine and plagioclase in the initial fall deposits and basal parts of ignimbrite member $A$ in the Huckleberry Ridge Tuff. Individual symbols show those analyses that differ from the dominant compositions (indicated by the grey fields, with the number of analyses included and the total number of analyses). Basal ignimbrite feldspar analyses show some scatter into anorthoclase compositions indicating incorporation of crystals from a more diverse range of sources. Labelled fields show conventional compositional classification. 

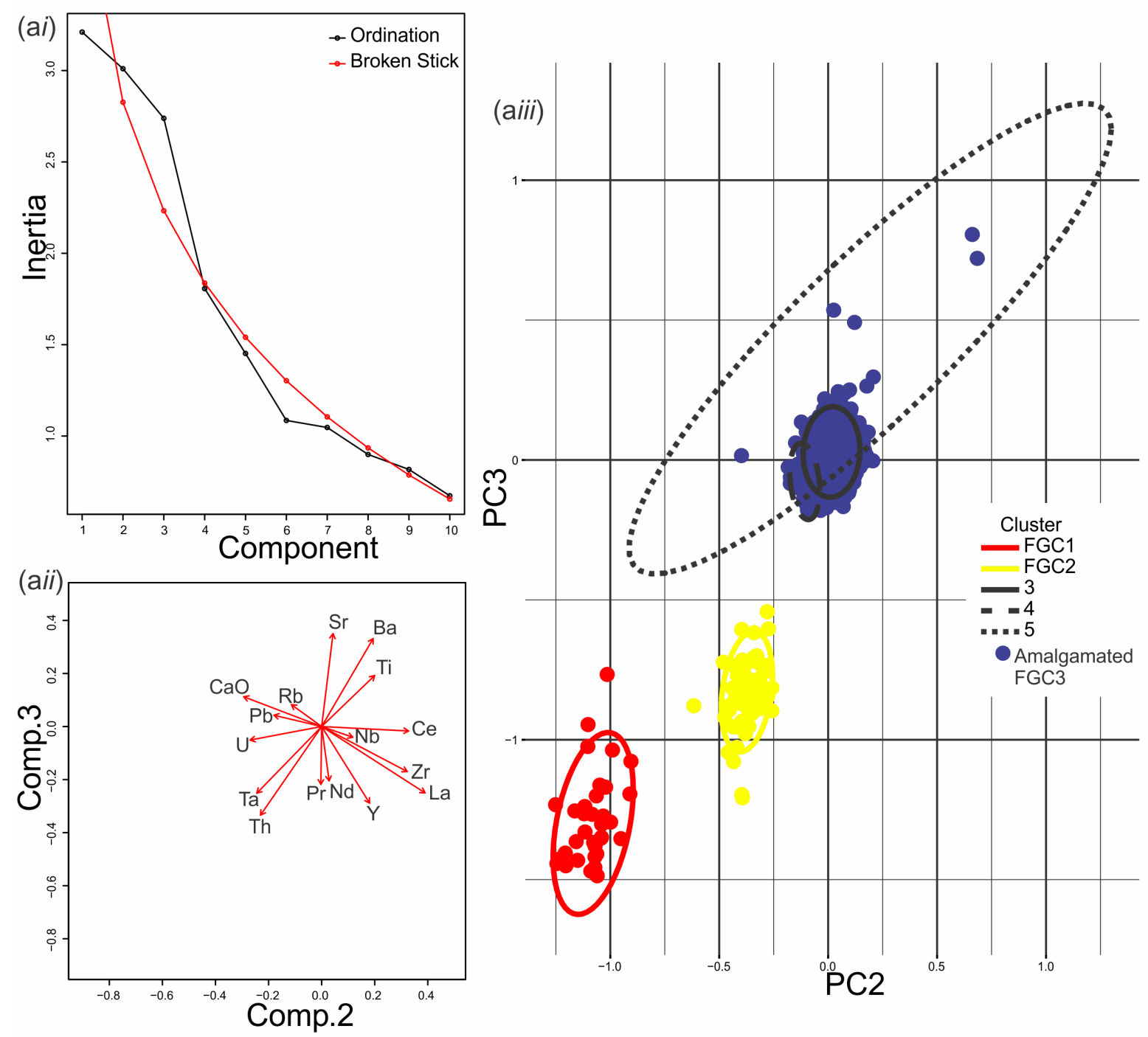

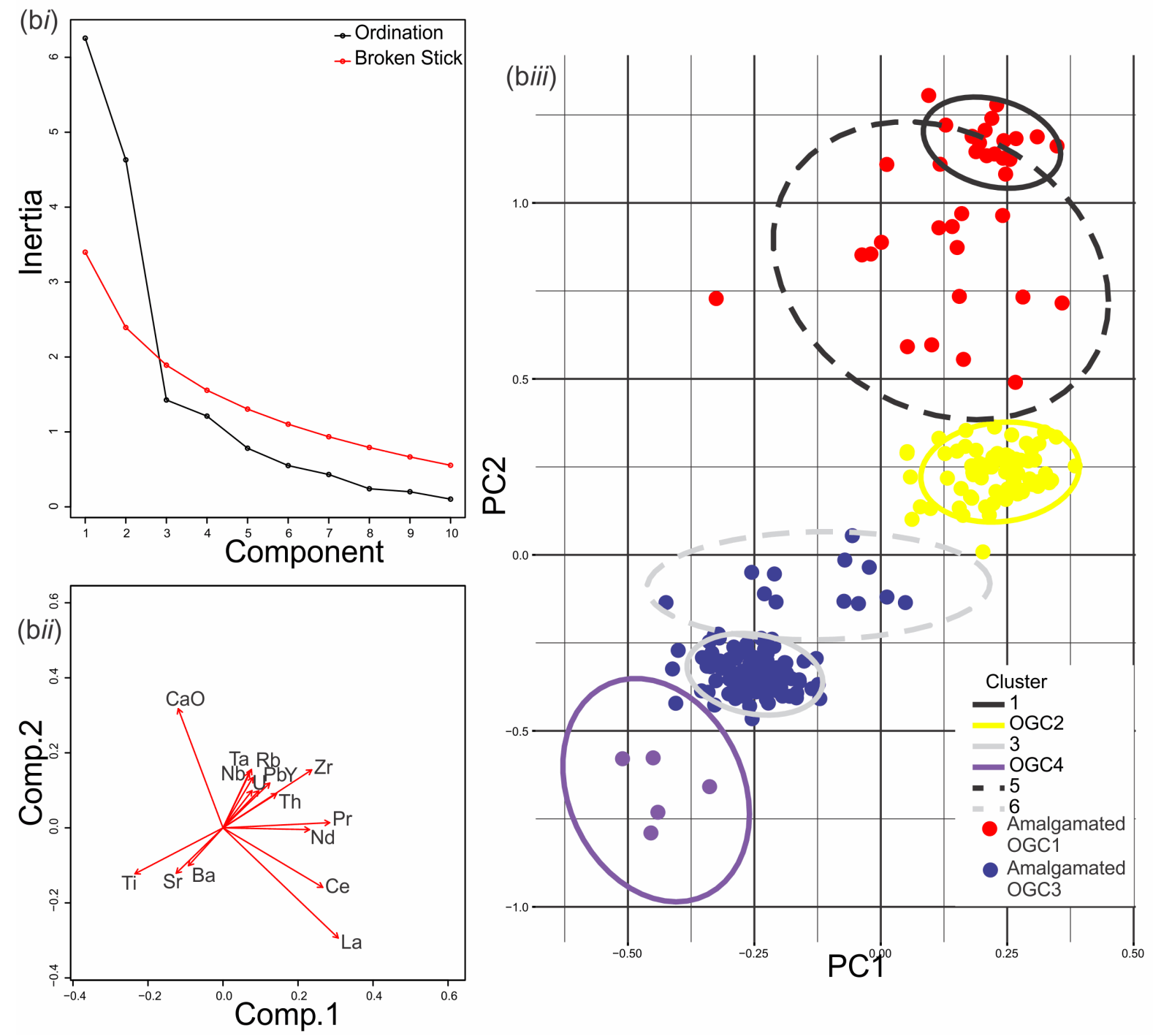

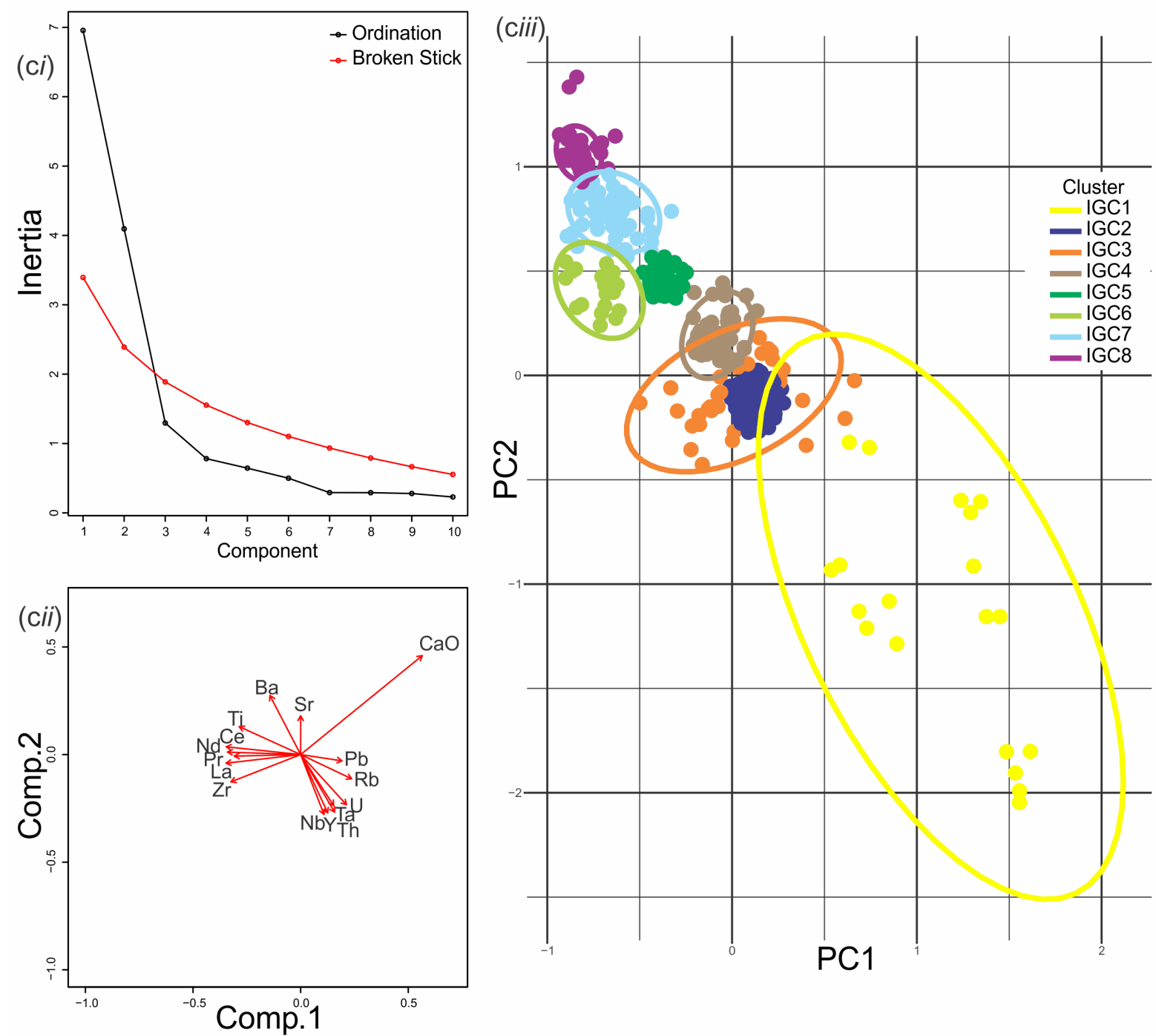

Figure S3.3: Broken stick models (i), principal component analysis (PCA) biplots (ii) and Bayesian mixture-modelling cluster analysis (MMCA) plots (iii) generated by $R^{\otimes}(R$ Development Core Team 2016) for (a) glass shards and (b) obsidian juvenile pyroclasts in the fall deposit and (c) glass in the basal ignimbrite. All three PCA plots show at least two principal components, which are strongly controlled by crystallisation of the mineral assemblage including sanidine and chevkinite, as shown by the PCA eigenvectors (ii). PCs 1-3 in the fall deposit glass analysis represent $47 \%$ of the variance $(17 \%, 16 \%$ and $14 \%$, respectively; PC1 not shown here but used in the MMCA), PCs $1+2$ represent $68 \%$ of the variance in the fall deposit obsidian analysis (39\% and 29\%, respectively) and 69\% in the basal ignimbrite glass (43\% and $25 \%$, respectively). The overlapping nature of the three MMCA derived clusters in the fall deposit glass (aiii) is used to amalgamate these into one cluster, FGC3. This is also the case with the obsidian glass analyses: two clusters, 1 and 5, are amalgamated to form OGC1, and 3 and 6 combined to form OGC3. 


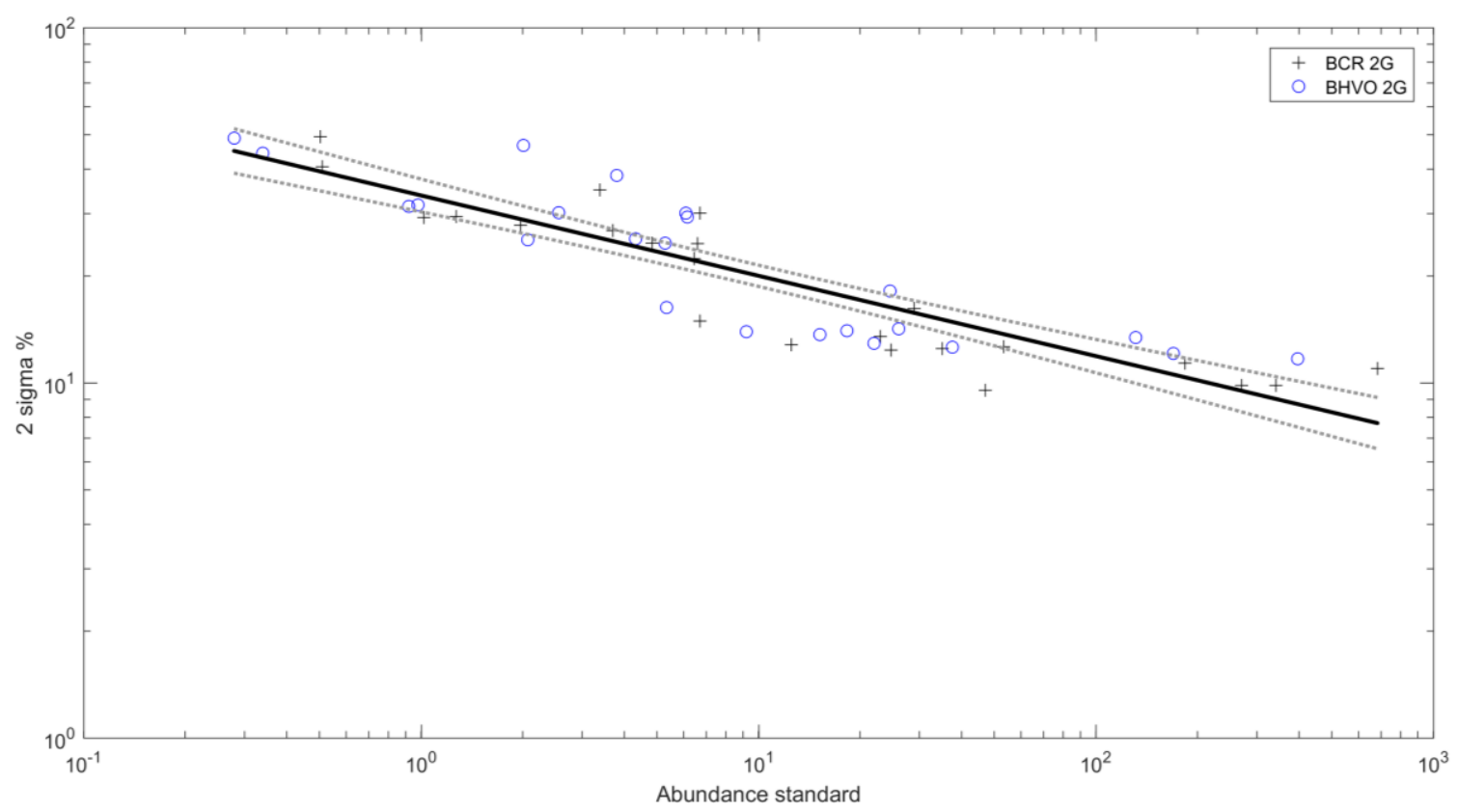

Figure S3.4: $\log (2 s d \%$ or sigma\%) v. $\log$ (abundance) for the 23 elements identified in the supplementary text from the two glass secondary standards analysed by LA-ICP-MS. The thick black line is a simple regression of the data. It is evident that the values of the two standards are similarly scattered about the regression line. The dashed grey lines represent the 95\% confidence intervals for the regression. 


\begin{tabular}{|c|c|c|c|c|c|}
\hline Locality & $\begin{array}{l}\text { UTM } \\
\text { easting }\end{array}$ & $\begin{array}{l}\text { UTM } \\
\text { northing }\end{array}$ & Unit & Nature of material & Notes \\
\hline Mount Everts & 526522 & 4979967 & $\mathrm{HRT}(\mathrm{A})$ & Dense welded vitric material & Dense welded vitrophyre from $\sim 50 \mathrm{~cm}$ above basal contact \\
\hline Tom Miner Basin & 498846 & 4997273 & $\mathrm{HRT}(\mathrm{A})$ & Non-welded material & Basal non-welded zone in ignimbrite (no fall deposit - rests directly on soil) \\
\hline S Madison River (L) & 454054 & 4968320 & $\mathrm{HRT}(\mathrm{A})$ & Welded vitric material & Crosses the fall-flow contact \\
\hline S Madison River (U) & 451590 & 4971553 & $\mathrm{HRT}(\mathrm{A})$ & Poorly welded vitric material & Sample from base of HRT(A) over fused fall material \\
\hline Hebgen Lake & 480506 & 4961367 & $\mathrm{HRT}(\mathrm{A})$ & Dense welded vitric material & Densely welded vitrophyre near base of ignimbrite \\
\hline Porcupine Creek (L) & 481142 & 5006593 & $\mathrm{HRT}(\mathrm{A})$ & Non-welded material & Top part of lower flow unit \\
\hline Porcupine Creek (U) & 481142 & 5006593 & $\mathrm{HRT}(\mathrm{A})$ & Non-welded material & Base of upper flow unit \\
\hline Swan Valley (L) & 472776 & 4811374 & $\mathrm{HRT}(\mathrm{A})$ & Non-welded material & Basal non-welded zone in lower ignimbrite flow unit, over fall deposit \\
\hline Swan Valley (U) & 478847 & 4805471 & $\mathrm{HRT}(\mathrm{A})$ & $\begin{array}{l}\text { Incipiently sintered vitric } \\
\text { material }\end{array}$ & Basal non-welded zone in upper ignimbrite flow unit \\
\hline Ririe Dam & 443498 & 4820050 & $\mathrm{HRT}(\mathrm{A})$ & Non-welded material & Basal non-welded zone in ignimbrite (no fall deposit - rests directly on soil) \\
\hline Taylor Creek Road (L) & 477827 & 4991060 & $\mathrm{HRT}(\mathrm{A})$ & Non-welded material & Basal non-welded zone in ignimbrite, over fall deposit \\
\hline Taylor Creek Road (U) & 477847 & 4993468 & $\operatorname{HRT}(\mathrm{A})$ & Non-welded material & $\begin{array}{l}\text { Basal non-welded zone in ignimbrite, } 5-10 \mathrm{~cm} \text { above contact with fall } \\
\text { deposit }\end{array}$ \\
\hline Black Butte & 492023 & 4989114 & $\mathrm{HRT}(\mathrm{A})$ & Non-welded material & Basal non-welded zone in ignimbrite (no fall deposit - rests directly on soil) \\
\hline Teton Pass Highway & 495465 & 4821653 & $\mathrm{HRT}(\mathrm{A})$ & Non-welded material & Basal non-welded zone in ignimbrite (no fall deposit - rests directly on soil) \\
\hline Jackson Hole (L) & 534888 & 4854704 & $\mathrm{HRT}(\mathrm{A})$ & Sintered vitric material & Sintered ignimbrite, $0-8 \mathrm{~cm}$ above basal contact of ignimbrite \\
\hline Jackson Hole (U) & 534888 & 4854704 & $\mathrm{HRT}(\mathrm{A})$ & Dense welded vitric material & Ignimbrite, $25-0 \mathrm{~cm}$ above basal contact \\
\hline N Madison River & 446509 & 4987677 & $\operatorname{HRT}(\mathrm{A})$ & $\begin{array}{l}\text { Incipiently sintered vitric } \\
\text { material }\end{array}$ & Basal non-welded zone in ignimbrite (no fall deposit - rests directly on soil) \\
\hline Flagg Ranch & 528468 & 4883064 & $\mathrm{HRT}(\mathrm{A})$ & Non-welded material & Non-welded vitric ignimbrite just below onset of sintering \\
\hline Sawtell Road & 468582 & 4930226 & $\mathrm{HRT}(\mathrm{A})$ & Dense welded vitric material & Densely welded vitrophyre near base of ignimbrite \\
\hline Cress Ck & 442013 & 4834090 & $\mathrm{HRT}(\mathrm{A})$ & Non-welded material & Basal non-welded zone in ignimbrite (no fall deposit - rests directly on soil) \\
\hline Table Rock Cyn Road & 453857 & 4829304 & $\mathrm{HRT}(\mathrm{A})$ & Non-welded material & Basal non-welded zone in ignimbrite (basal contact not exposed) \\
\hline Teton River (L) & 463122 & 4865166 & $\mathrm{HRT}(\mathrm{A})$ & Non-welded material & Non welded, inverted base to HRT ignimbrite; obsidian kernels from fiamme \\
\hline Teton River (U) & 458439 & 4863208 & $\mathrm{HRT}(\mathrm{A})$ & Non-welded material & $25-35 \mathrm{~cm}$ above base of ignimbrite \\
\hline
\end{tabular}




\section{Supplementary information}

Principal component analysis was run using $R^{\circledR}$ ( $R$ Development Core Team 2016) for fall deposit glass shards, fall deposit obsidian pyroclasts and basal ignimbrite glass independently. A robust sparse PCA (Croux et al. 2007; Filzmoser et al. 2014) was run on centred log-ratio transformed data (Mueller and Grunsky 2016 and references therein). Principal components were compared to a broken stick distribution to determine the number of significant components (Jackson 1993). Only significant components were then used in a Bayesian mixture-modellng cluster analysis (Fraley et al. 2012) and their assignment probabilities used to determine horizon or location proportions.

As our measured compositional variation is greater than the range of standards used in this study (Figs. 3.4, 3.5 in Chapter 3; Electronic Appendix 3.1), we have used the relationship between elemental abundance in the standards and analytical variation to propagate analytical uncertainties to the extrema of our measured compositional range. Uncertainties in the measured abundance of sample constituent elements have been determined from repeated measurements $(\sim 80)$ of glass standards BCR-2G and BHVO-2G by LA-ICP-MS. The repeated measurements of the standards resulted in estimates for each measured element of standard deviation of the abundance expressed as a percentage of the abundance.

For 23 selected elements with atomic numbers $>30$ ( $\mathrm{Ga}, \mathrm{Rb}, \mathrm{Sr}, \mathrm{Y}, \mathrm{Zr}, \mathrm{Nb}, \mathrm{Mo}, \mathrm{Ba}$, La, $\mathrm{Ce}, \mathrm{Pr}, \mathrm{Nd}, \mathrm{Sm}, \mathrm{Eu}, \mathrm{Gd}, \mathrm{Tb}, \mathrm{Dy}, \mathrm{Ho}, \mathrm{Er}, \mathrm{Tm}, \mathrm{Yb}, \mathrm{Lu}, \mathrm{Hf}$ ), figure S3.4 shows the percentage uncertainty ( $2 \mathrm{sd} \%$ or $2 \sigma \%)$ plotted against measured abundance for the two standards. The $2 \sigma \%$ values are not independent of abundance, but fall as abundance increases. A simple regression has been fitted to $\log (2 \sigma \%) v$. $\log ($ abundance), yielding:

$$
\log (2 \sigma \%)=3.52( \pm 0.10,2 \sigma)-0.226( \pm 0.035,2 \sigma) \log (\text { abundance })
$$

from which the uncertainties of sample constituent elements can be determined from their measured abundances.

The uncertainties in the abundance ratios of selected elements have been determined from 5000 Monte Carlo simulations. For each required ratio, values of the element abundance have been simulated using the $2 \sigma \%$ uncertainty estimates to scale 5000 standard Gaussian variates. Twice the standard deviations of the resulting 5000 ratios yields a $2 \sigma$ (or 2 sd) uncertainty for the ratio. 
S4. Supplementary material for Chapter 4 
Table S4.1: Table documenting samples analysed in this study for each mafic suite listed in Table 4.1 in Chapter 4.

\begin{tabular}{|c|c|c|c|}
\hline Sample type & Sample ID & $\begin{array}{c}\text { Locality (UTM zone 12), } \\
\text { easting, northing }\end{array}$ & Host HRT member or eruptive unit \\
\hline \multirow{14}{*}{$\begin{array}{l}\text { Suite 1: dense } \\
\text { mafics }\end{array}$} & YP122 & 456848,4877524 & (A) \\
\hline & YP243 & 454137,4890366 & (A) \\
\hline & YP244 & 454137,4890366 & (A) \\
\hline & YP246 & 454137,4890366 & (A) \\
\hline & YP248 & 454137,4890366 & (A) \\
\hline & YP381 & 464771,4884027 & (A) \\
\hline & YP382 & 464771,4884027 & (A) \\
\hline & YP383 & 464771,4884027 & (A) \\
\hline & YP384 & 464646,4884097 & (A) \\
\hline & YP385 & 464646,4884097 & (A) \\
\hline & YP447 & 464646,4884097 & (A) \\
\hline & YP448 & 464771,4884027 & (A) \\
\hline & YP449 & 464771,4884027 & (A) \\
\hline & YP242 & 452598,4889036 & (B) \\
\hline \multirow{7}{*}{ Suite 1: scoria } & YP185 & 476874,4887036 & $(\mathrm{~A})$ \\
\hline & YP188 & 476874,4887036 & (A) \\
\hline & YP071BLACK & 451507,4864635 & (B) \\
\hline & YP071RED & 451507,4864635 & (B) \\
\hline & YP266SCORIA & 451394,4864614 & (B) \\
\hline & YP334B & 451507,4864635 & (B) \\
\hline & YP083SCORIA & 451507,4864635 & (B) \\
\hline \multirow{12}{*}{ Suite 2} & YR289 & 471761,4878361 & Falls River Basalt \\
\hline & YR291 & 476651,4885380 & Warm River Basalt \\
\hline & YR292 & 548102,4972327 & Basalt of the Narrows (topmost lava) \\
\hline & YR294 & 548397,4974082 & Junction Butte Basalt (Junction Butte) \\
\hline & YR296 & 536172,4978238 & Undine Falls Basalt (Gardiner River) \\
\hline & YR297 & 530622,4977997 & $\begin{array}{l}\text { Junction Butte Basalt (north of Blacktail } \\
\text { Deer ponds) }\end{array}$ \\
\hline & YR300 & 511629,4943650 & Madison Basalt (Madison Junction) \\
\hline & YR302 & 468222,4915236 & Gerrit Basalt (Henrys Fork river) \\
\hline & YR303 & 455860,4903130 & Snake River Basalt \\
\hline & YR307 & 474598,4892348 & Gerrit Basalt \\
\hline & YR327 & 458439,4863208 & $\begin{array}{c}\text { Junction Butte Basalt (beneath HRT in } \\
\text { diapirically upheaved rocks) }\end{array}$ \\
\hline & YR362 & 547838,4975353 & Junction Butte Basalt (Tower Creek) \\
\hline \multirow{7}{*}{ Suite 3} & YR304 & 455497,4901523 & High Point scoria cone \\
\hline & YR305 & 455510,4901472 & High Point scoria cone \\
\hline & YR418 & 448232,4905177 & Un-named scoria cone \\
\hline & YR420 & 448232,4905177 & Un-named scoria cone \\
\hline & YR421 & 445780,4904771 & Fogg Bute \\
\hline & YR422 & 444627,4904086 & Crystal Butte \\
\hline & YR425 & 434543,4905055 & Blacks Knoll \\
\hline
\end{tabular}




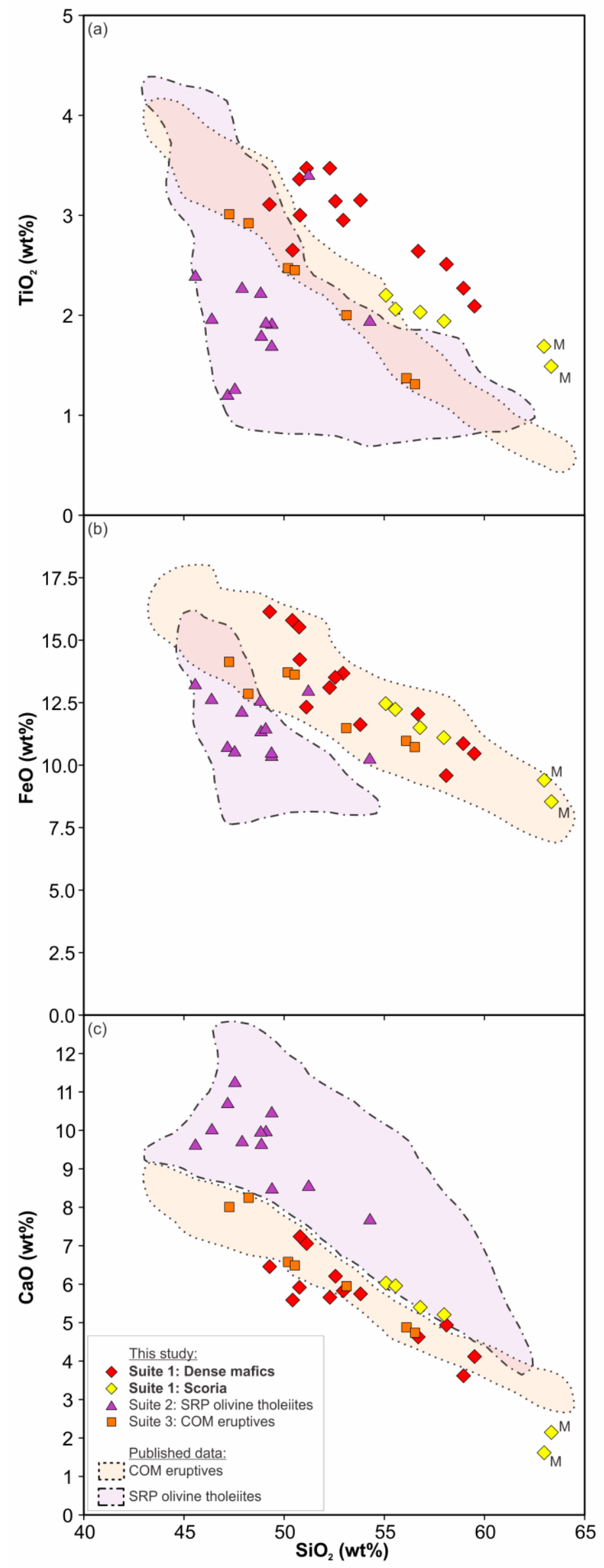

Figure S4.1: $\mathrm{SiO}_{2}$ vs. (a) $\mathrm{TiO}_{2}$, (b) $\mathrm{FeO}$ and (c) $\mathrm{CaO}$ for the three suites analysed in this study and relevant fields of published data (see text in Chapter 4 for sources of published data). Plots show elevated $\mathrm{TiO}_{2}$ and $\mathrm{FeO}$, and lower $\mathrm{CaO}$ in suites 1 and 3 relative to Suite 2. Suite 1 is distinct by its higher $\mathrm{TiO}_{2}$ compared to all suites and published data from COM eruptives. $2 \mathrm{sd}$ uncertainties are smaller than the symbol size. 


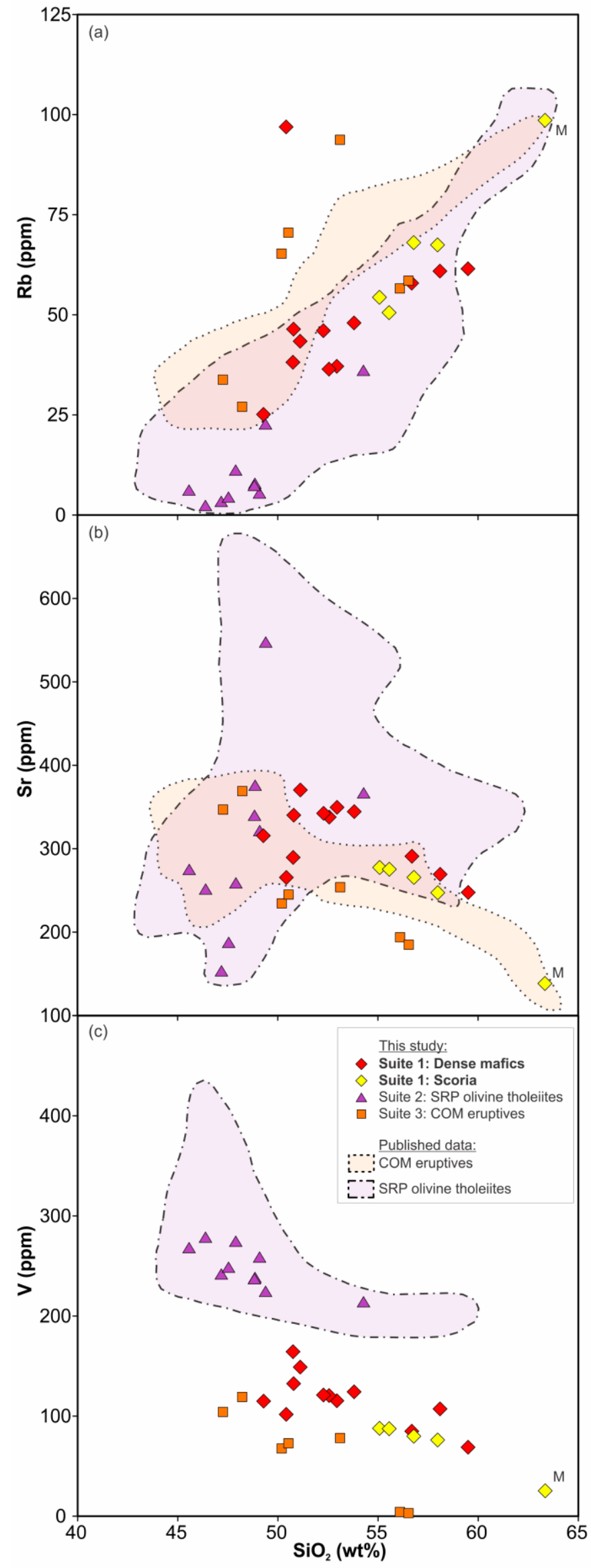

Figure S4.2: $\mathrm{SiO}_{2}$ vs. (a) $\mathrm{Rb}$, (b) $\mathrm{Sr}$ and (c) $V$ for the suites analysed in this study and relevant fields of published data (see text in Chapter 4 for sources of published data). Plots show higher $\mathrm{Rb}$ in suites 1 and 3 compared to Suite 2 for a given value of $\mathrm{SiO}_{2}$ but $\mathrm{Sr}$ is comparable between the different suites. Suite 2 is enriched in V. 2sd uncertainties are smaller than the symbol size. 


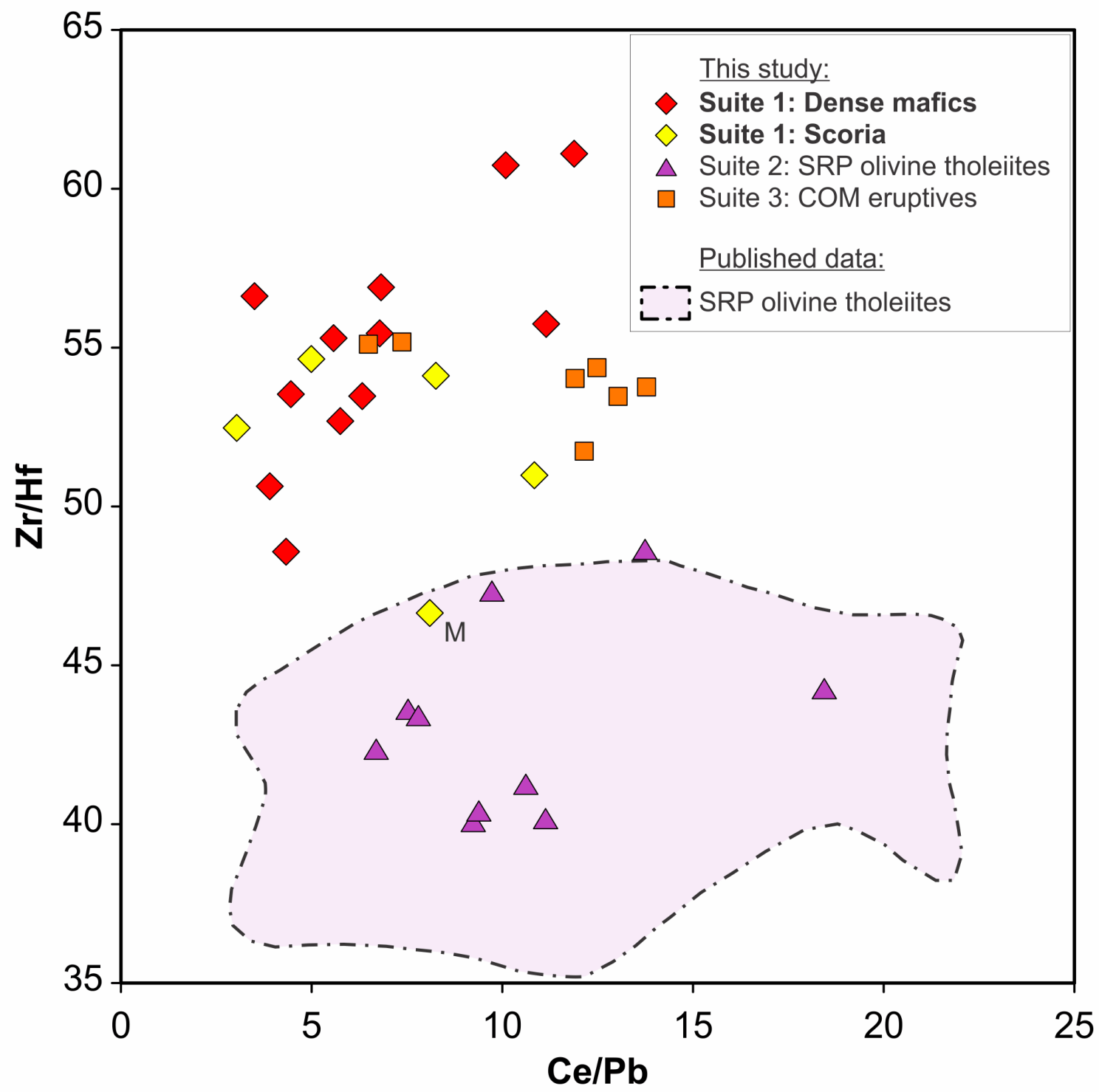

Figure S4.3: $\mathrm{Ce} / \mathrm{Pb}$ vs. $\mathrm{Zr} / \mathrm{Hf}$ for the suites analysed in this study and relevant fields of published data (see text in Chapter 4 for sources of published data). Due to the similar partition coefficients between both elements in each ratio, ratios should be uniform. Although $\mathrm{Ce} / \mathrm{Pb}$ ratios are similar for all suites, suite 1 and 3 samples show elevated $\mathrm{Zr} / \mathrm{Hf}$ ratios. 


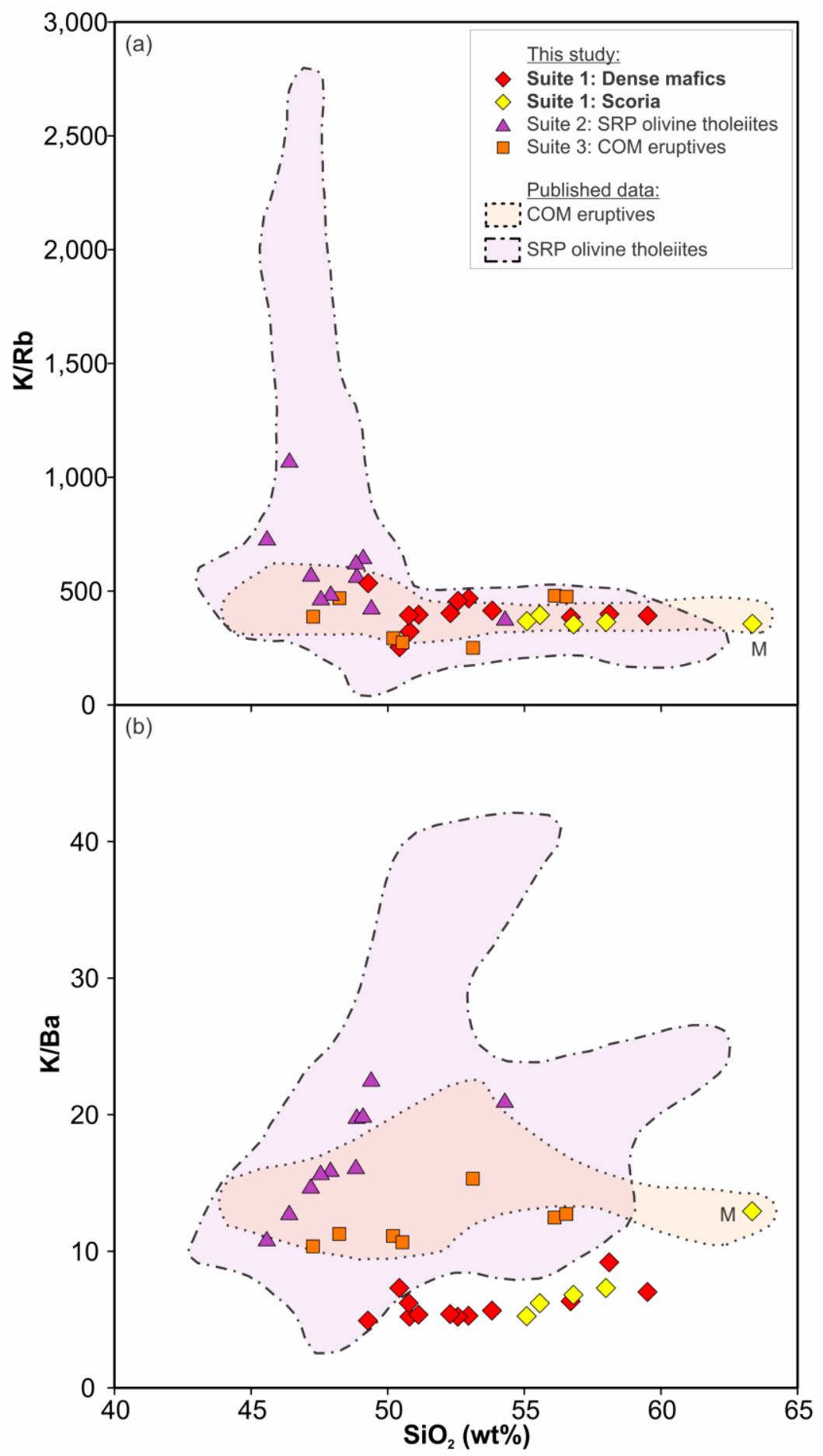

Figure S4.4: $\mathrm{SiO}_{2}$ plotted against (a) $\mathrm{K} / \mathrm{Rb}$ and (b) $\mathrm{K} / \mathrm{Ba}$ values for all the suites in this study and fields from published data (see text in Chapter 4 for sources). Ratios would ratios would likely strongly increase and decrease, respectively, with crustal contamination. The uniformity or weakly positive slopes in suite 1 samples indicates the inter- and intra- suite variation is not controlled by crustal contamination. 
(a)
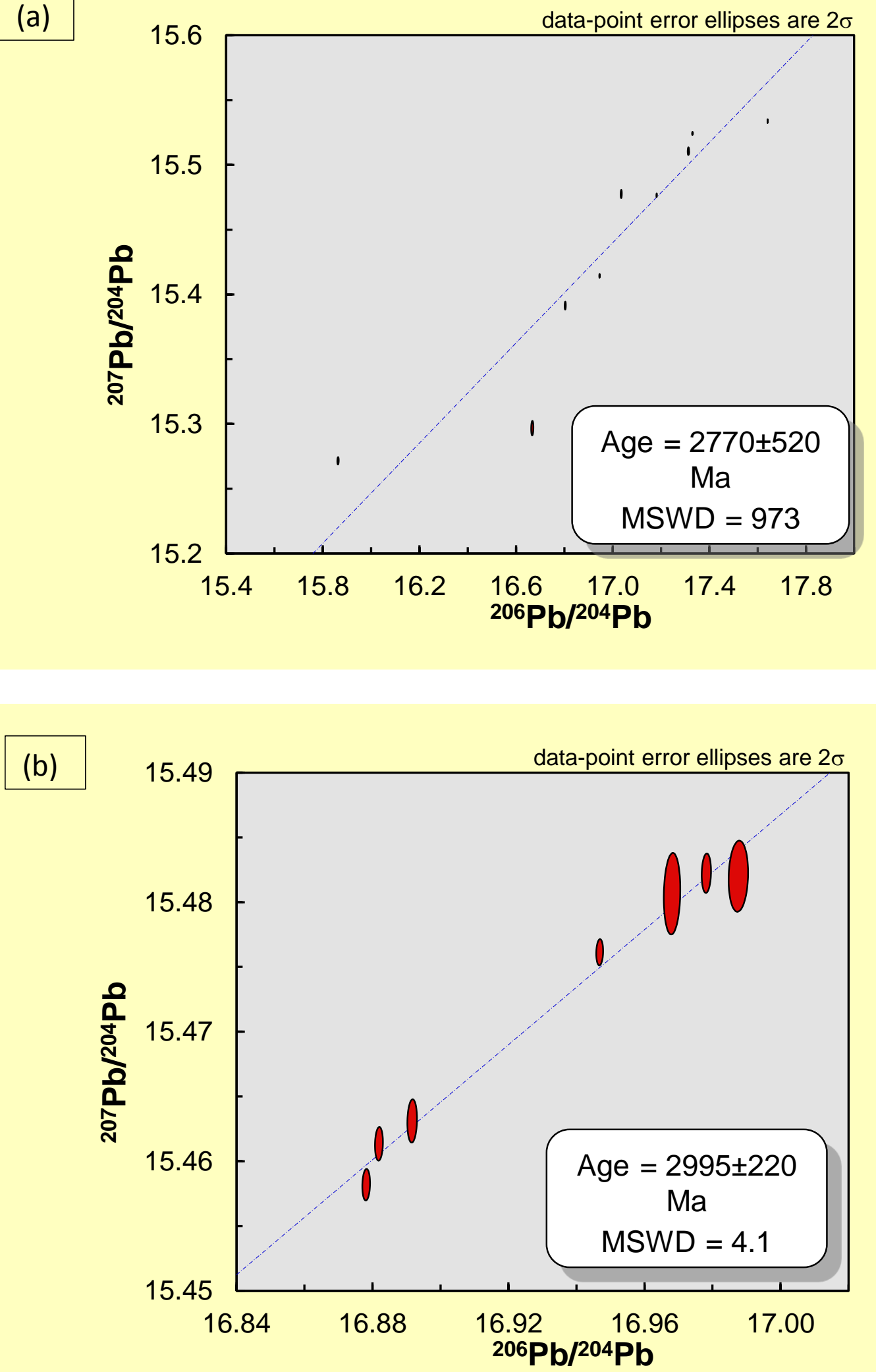
(c)

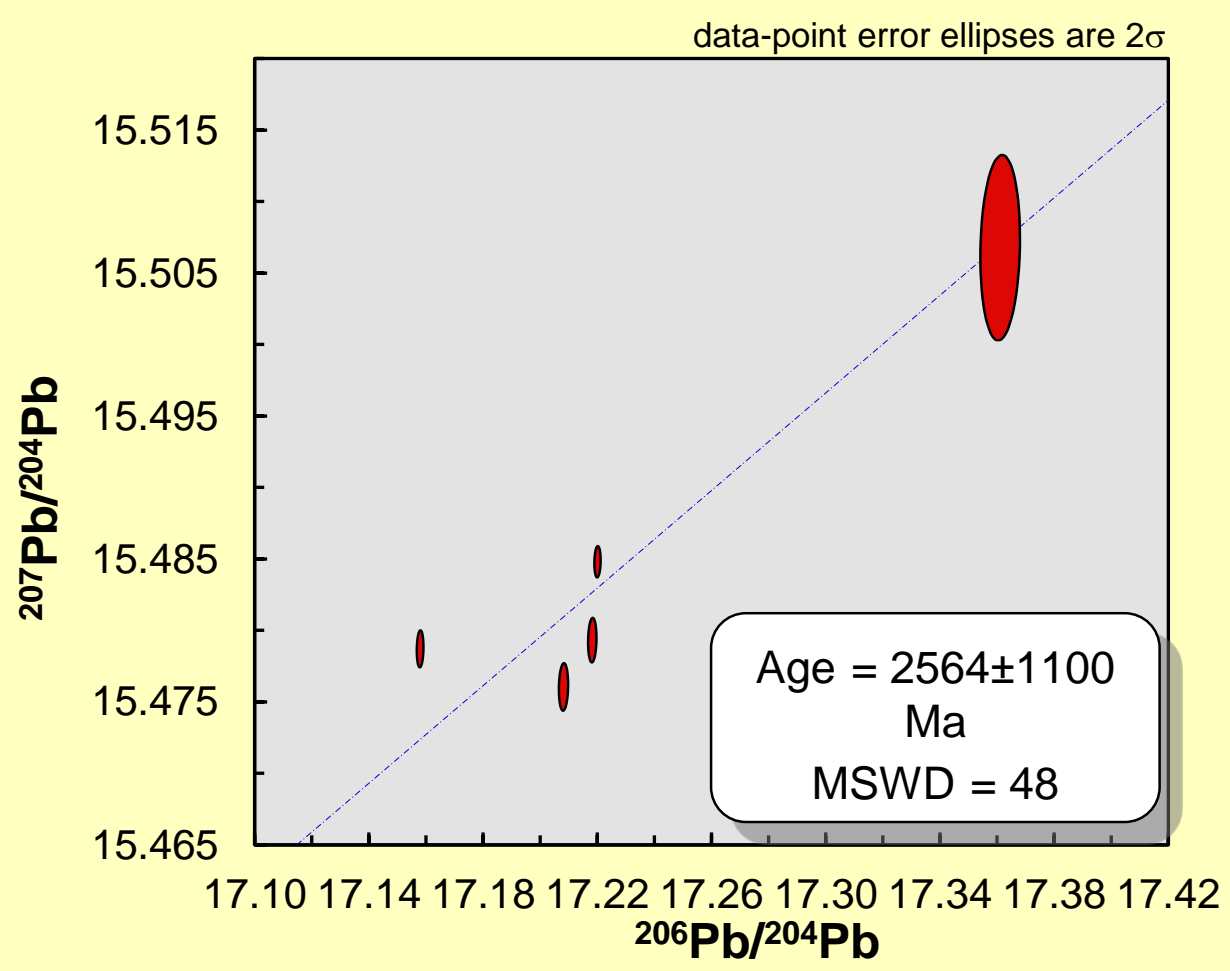

Figure S4.5: Pb-Pb isochrons generated using Isoplot (Ludwig 2008) for (a) Suite 2 samples (olivine tholeiites), (b) Suite 1 HRT mafics (minus YP122) and (c) Suite 3 Craters of the Moon samples. Ellipses represent 2se errors. 


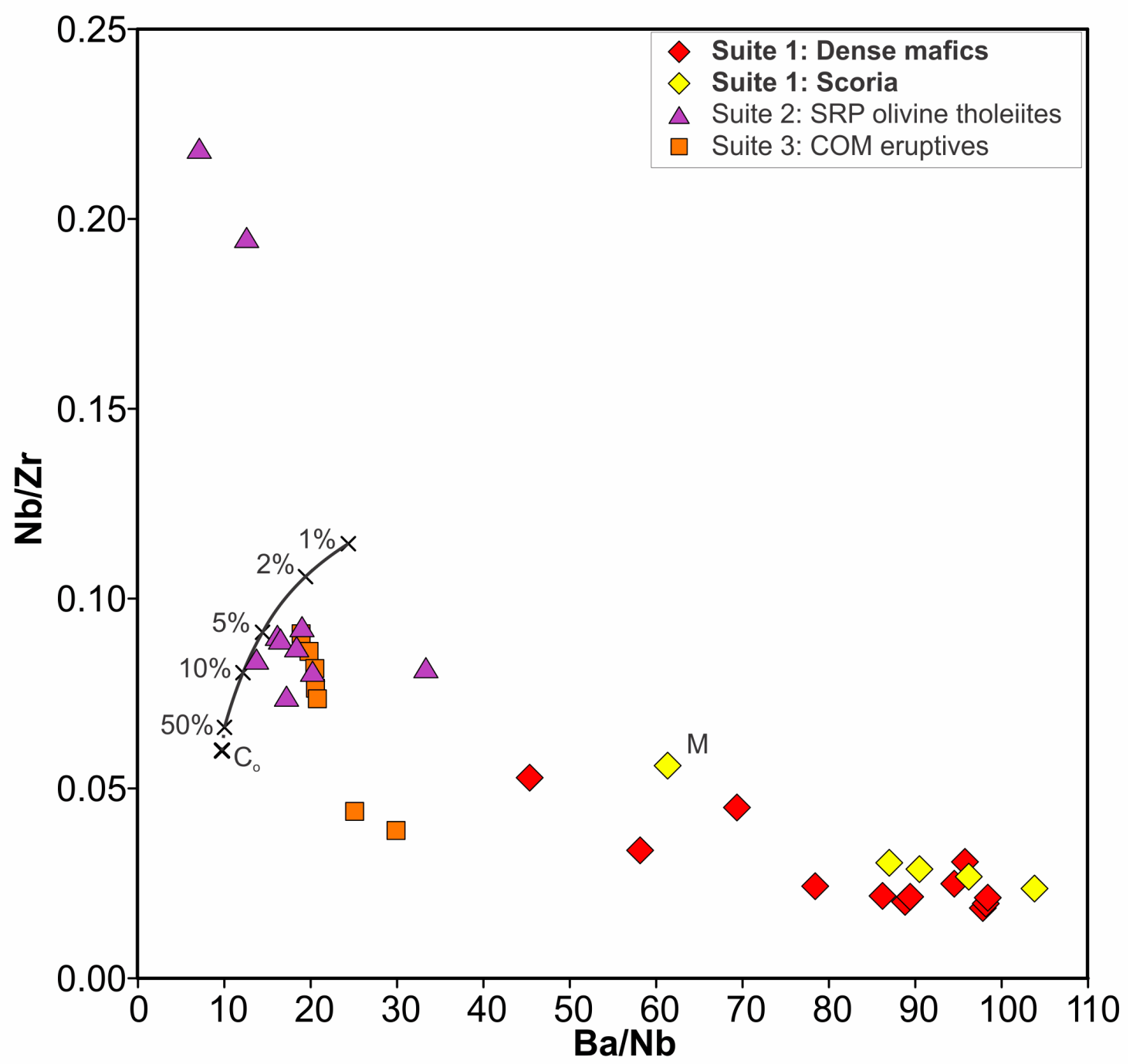

Figure S4.6: $\mathrm{Ba} / \mathrm{Nb}$ vs. $\mathrm{Nb} / \mathrm{Zr}$ for all suites in this study. Incompatible element ratios are sensitive to variations in the degree of partial melting of a common source. Curved line explores changes in the ratios with different degrees of partial melting of a primitive mantle source with composition $C_{0}$ (McDonough and Sun 1989). Partition coefficients of $0.01,0.04$ and 0.08 for $D_{B a}, D_{N b}$ and $D_{z r}$ respectively (Hofmann 1988). Although the absolute values are approximates, the relative compatibilities are the controlling factor on the trends. The trends show that it is unlikely the different suites can be explained through different degrees of partial melting of a common source zone. Batch melting was modelled using the equation:

$$
\frac{C_{L}}{C_{O}}=\frac{1}{\bar{D}(1-F)+F}
$$

where $C_{L}$ and $C_{O}$ are the liquid and original concentrations respectively, $F$ is the fraction of melt [melt/(melt+rock)] and $\bar{D}$ is the bulk elemental distribution coefficient. 


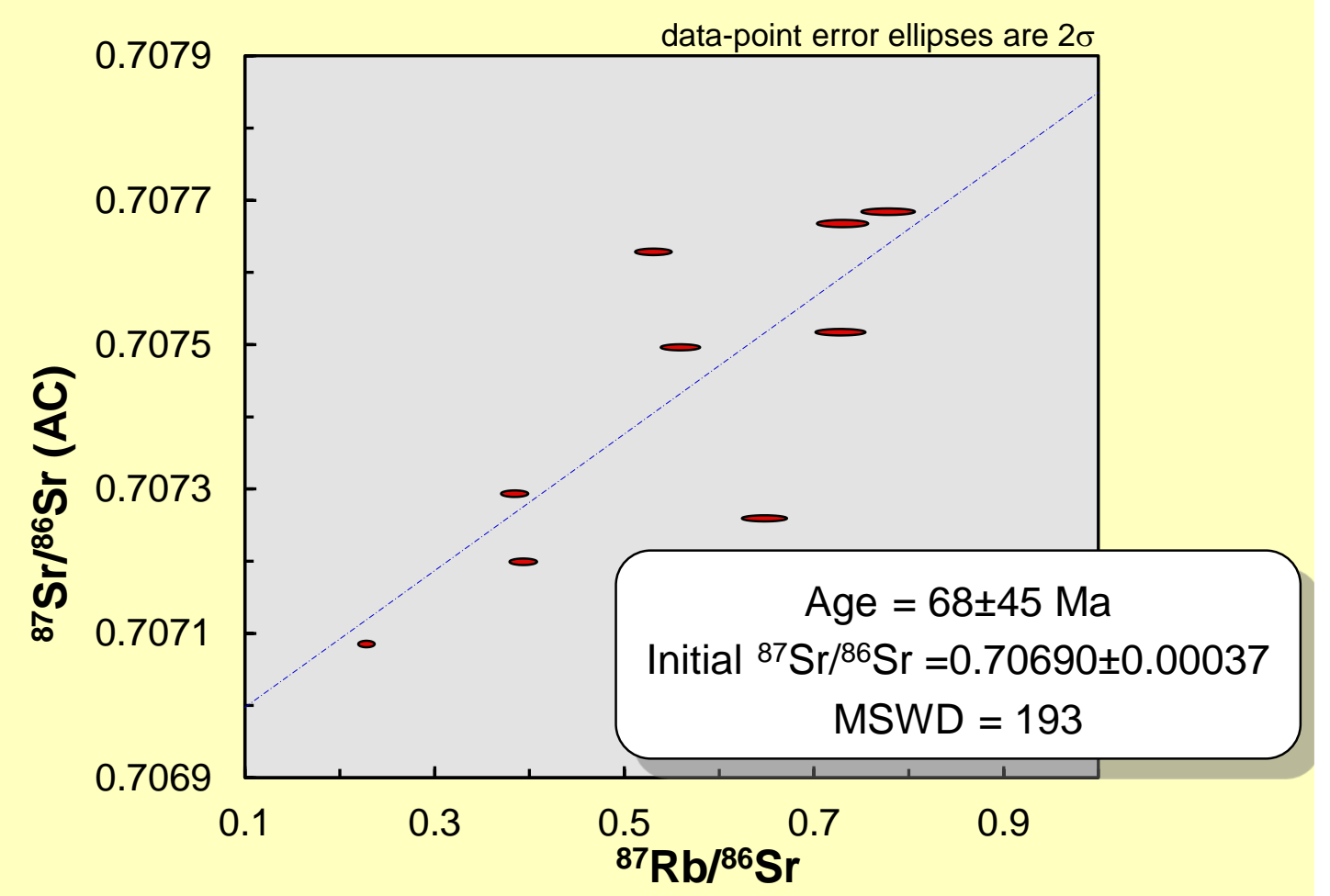

Figure S4.7: Sr isotope isochron generated using Isoplot (Ludwig 2008) for the HRT mafics suite. Ratios were age-corrected using an age of $2.08 \mathrm{Ma}$ (Rivera et al. 2014; Wotzlaw et al. 2015). Ellipses represent 2 se $\left({ }^{87} \mathrm{Sr} /{ }^{86} \mathrm{Sr}\right)$ and $3 \%\left({ }^{87} \mathrm{Rb} /{ }^{86} \mathrm{Sr}\right)$ errors. The imprecise late Cretaceous age coincides with widespread volcanism in the western US (Christiansen and Yeats 1992) and is consistent with the young metasomatic event inferred in the Absaroka volcanic province by Feeley (2003) and from Wyoming lamproites by Mirnejad and Bell (2006). The ${ }^{87} \mathrm{Sr} /{ }^{86} \mathrm{Sr}$ o value of 0.7069 is similar to the focus of Yellowstone-Snake River Plain basalts (McCurry and Rodgers 2009). 


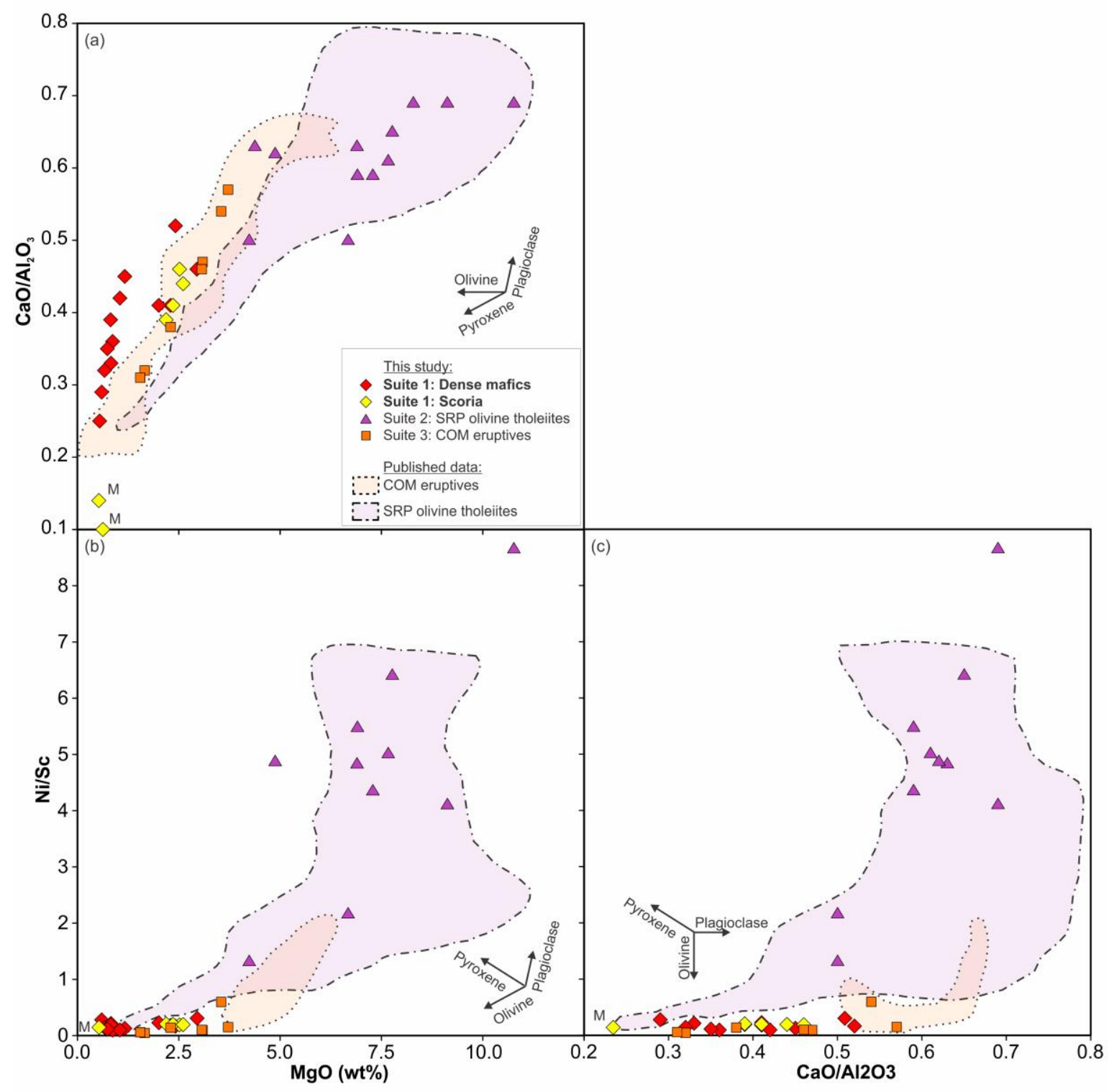

Figure S4.8: Plots showing the relationship between $\mathrm{MgO}, \mathrm{CaO} / \mathrm{Al}_{2} \mathrm{O}_{3}$ and $\mathrm{Ni} / \mathrm{Sc}$, showing intra-suite variation (see text in Chapter 4 for sources of published data). Arrows indicate the trend of melt evolution as a result of crystallisation of the three principal phases in comparable rocks. These plots indicate that Suite 2 variation is compatible with olivine and pyroxene crystallisation whereas the trends in suites 1 and 3 suggest a lesser role for olivine. 


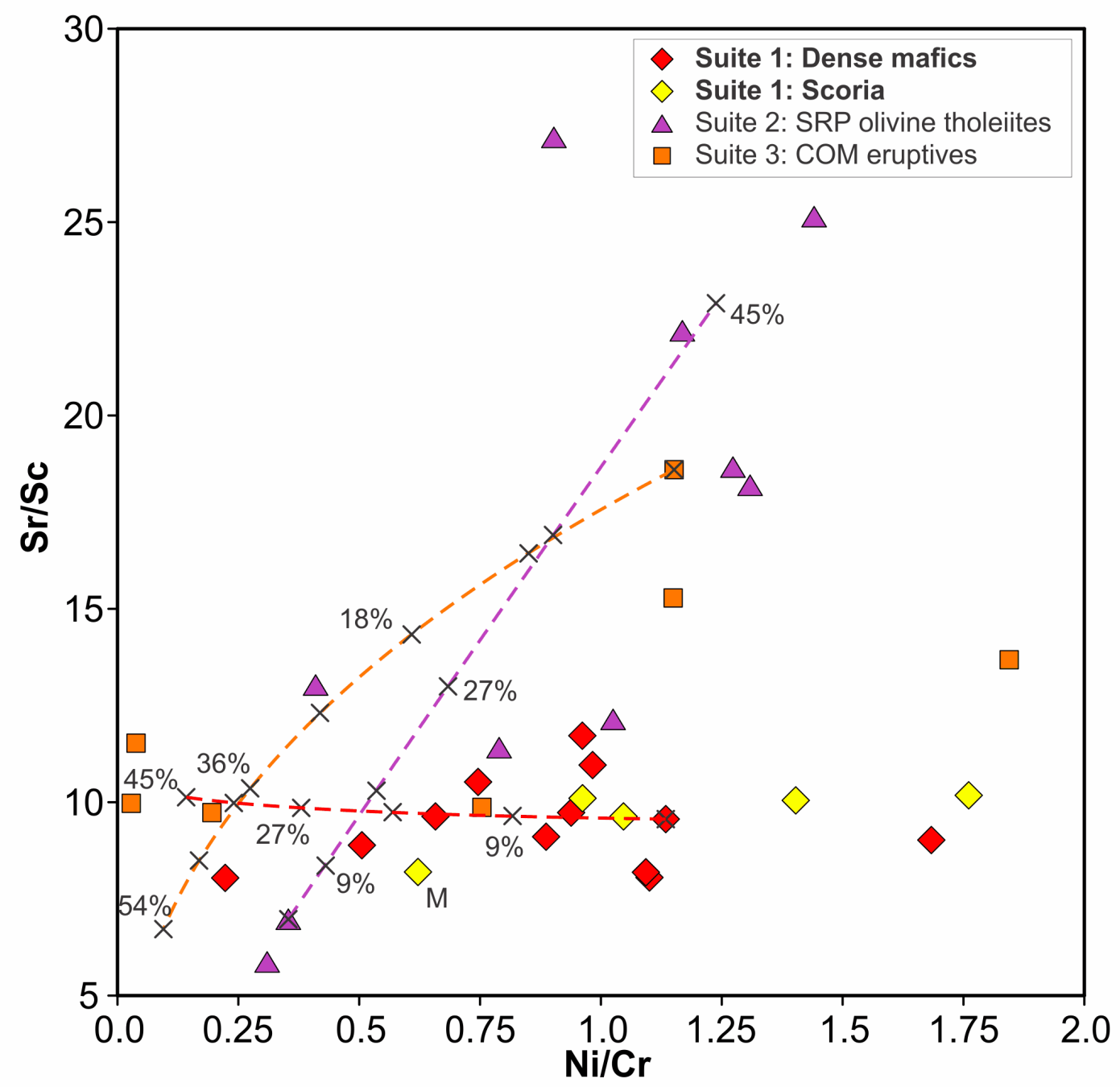

Figure S4.9: $\mathrm{Ni} / \mathrm{Cr}$ vs. Sr/Sc ratios for the samples analysed in this study. Red, purple and orange dashed lines show modelled fractional crystallisation trends for Suite 1 (YP122 as a starting composition, crystallising $45 \%$ plagioclase, $30 \%$ olivine and $25 \%$ clinopyroxene), Suite 2 (YR291 as starting composition, crystallising assemblage of $60 \%$ clinopyroxene, $35 \%$ olivine, $5 \%$ plagioclase) and Suite 3 (YR422 as starting composition, crystallising assemblage of $80 \%$ plagioclase, $15 \%$ olivine, $5 \%$ clinopyroxene), respectively, (see Chapter 4 for details). Modelling was done using the modeler from Ersoy and Helvaci (2010). Black crosses represent 9\% increments of crystallisation. The positive correlation in Suite 2 samples is consistent with a clinopyroxene-olivine dominated crystallizing assemblage in contrast to a decrease in $\mathrm{Sr} / \mathrm{Sc}$ with fractionation in suite 3 samples, consistent with a plagioclase-dominant assemblage due to the compatible nature Sc and Sr in clinopyroxene and plagioclase, respectively. The uniform $\mathrm{Sr} / \mathrm{Sc}$ with decreasing $\mathrm{Ni} / \mathrm{Cr}$ is consistent with a more balanced assemblage. 


\section{Isotope methodologies}

Separation of $\mathrm{Sr}, \mathrm{Nd}$ and $\mathrm{Pb}$ were achieved through extraction chromatography based on the method of Pin et al. (2014). Two aliquots of rock powder, one for Sr and $\mathrm{Nd}$, and one for $\mathrm{Pb}$ (containing $\geq 300 \mathrm{ng} \mathrm{Pb}$ ) of rock powder were digested in pre-cleaned Savillex screw-topped Teflon beakers using a combination of $\mathrm{HF}, \mathrm{HNO}_{3}$ and $\mathrm{HCl}$. The $\mathrm{Sr}$ and $\mathrm{Nd}$ digested sample was taken up in $6 \mathrm{M} \mathrm{HNO}_{3}$ ready to pass through cleaned columns loaded with pre-cleaned SrSpec resin. The Sr-Spec resin was pre-conditioned with $\sim 0.5 \mathrm{ml} 9 \mathrm{M} \mathrm{HNO}$. The sample was loaded and then washed sequentially with 100,200 , and $3 \times 1000 \mu \mathrm{l} 9 \mathrm{M} \mathrm{HNO}_{3}$ to remove $\mathrm{Ba}$ and other unwanted elements. The wash was collected for further separation to extract $\mathrm{Nd}$. $2 \mathrm{ml} 0.05 \mathrm{M} \mathrm{HNO}_{3}$ was then passed through the Sr-Spec column to collect the Sr.

The dried $\mathrm{Nd}$ fraction was taken up with $1 \mathrm{ml}$ of $1 \mathrm{M} \mathrm{HNO}_{3}$ containing $50 \mathrm{mg} \mathrm{ml}^{-1}$ ascorbic acid $\left(\mathrm{C}_{6} \mathrm{H}_{8} \mathrm{O}_{6}\right)$ in order to reduce the $\mathrm{Fe}_{(I I I)}$ present. This nitric and ascorbic solution was previously passed through a TRU-Spec column in order to reduce the $\mathrm{Nd}$ procedural blank. When the sample solution turned pale-yellow the solution was ready to pass through the columns.

The TRU-Spec columns were pre-conditioned with $0.25 \mathrm{ml}$ of the $\mathrm{HNO}_{3}$-ascorbic solution before addition of the sample solution. Then 50,100, 200 and $2 \times 1000 \mu \mathrm{l}$ of $1 \mathrm{M}$ $\mathrm{HNO}_{3}$ was passed through the column to remove all unwanted elements. Then the LREE, Th and $\mathrm{U}$ fraction was removed and collected through addition of $2 \times 1 \mathrm{ml}$ of $0.05 \mathrm{HNO}_{3}$. This eluted fraction was then dried and taken up with $300 \mu \mathrm{l} 0.25 \mathrm{M} \mathrm{HCl}$ and put through the LNSpec column. The lanthanides were sequentially eluted through further addition of $0.25 \mathrm{M}$ $\mathrm{HCl}$. Column calibrations were undertaken to identify the $\mathrm{Nd}$ fraction and to minimise $\mathrm{Ce}$ and Pr overlap. This specified collection after the addition of $8 \mathrm{ml} 0.25 \mathrm{M} \mathrm{HCl}$ and collection for a further $4 \mathrm{ml}$. This fraction was free of Sm.

The dried $\mathrm{Pb}$ digestion was taken up in $0.5 \mathrm{ml} 1 \mathrm{M} \mathrm{HBr}$. This was passed through AG1$\mathrm{X} 8$ anion resin. The pre-cleaned resin was further cleaned by passing alternating MQ water and $6 \mathrm{M} \mathrm{HCl}$ through the resin twice. Any residual $\mathrm{HCl}$ was then washed out through the passing of $\sim 2.5 \mathrm{ml} \mathrm{MQ}$ through the resin. The resin was then pre-conditioned with $0.5 \mathrm{ml}$ $1 \mathrm{M} \mathrm{HBr}$ before the sample was loaded. The sample was then eluted with two passes of 0.5 $\mathrm{ml} 1 \mathrm{M} \mathrm{HBr}$. Pb was then collected with two $0.5 \mathrm{ml}$ washes of $6 \mathrm{M} \mathrm{HCl}$. This entire process was repeated. Prior to drying, $\sim 0.1 \mathrm{ml}$ conc. $\mathrm{HNO}_{3}$ was added to the collected solution to ensure the evaporation of all remaining $\mathrm{Br}$. 
Isotope analyses were run on a ThermoFisher Triton Thermal Ionisation Mass spectrometer (TIMS) at the Open University, UK and Victoria University of Wellington, New Zealand on the same instrument.

The dried $\mathrm{Sr}$ fraction was dissolved in concentrated $\mathrm{HNO}_{3}$ with a ratio of $\sim 1 \mu$ to $1000 \mathrm{ng} \mathrm{Sr} .0 .7 \mu \mathrm{l}$ of pre-cleaned $\mathrm{TaF}_{2}$ activator (as in Charlier et al. 2006) was loaded onto a single Re filament. Before the activator had dried, $1 \mu$ of the sample was added to ensure the load was mixed on the filament. Filaments were heated sufficiently $\left(1450-1500^{\circ} \mathrm{C}\right)$ to generate $\sim 50 \mathrm{mV}{ }^{84} \mathrm{Sr}$. 240 ratios were measured in blocks of 10 . A peak-centre and tune was automated at the beginning of every 10 blocks.

The dried $\mathrm{Nd}$ fraction was taken up in 1-2 $\mu \mathrm{l}$ conc. $\mathrm{HCl}$ until dissolved. 200-800 ng of the sample was loaded onto a double Re filament following the addition, and drying, of $1 \mu l$ $\mathrm{H}_{3} \mathrm{PO}_{4}$ loading solution. A further $1 \mu$ l of loading solution was added following evaporation of the sample solution and then dried.

$\mathrm{Nd}$ was run using a double filament assembly with an evaporation filament (containing the sample) and a hotter ionisation filament $\left(1650-1800^{\circ} \mathrm{C}\right)$ to generate $2-8 \mathrm{~V}$ ${ }^{142} \mathrm{Nd}$ depending on the size of the sample. 270 ratios were analysed in blocks with a peakcentre and tune completed prior to every 10 blocks. Time-corrected mass dependent fractionation of the ${ }^{143} \mathrm{Nd} /{ }^{144} \mathrm{Nd}$ ratios was corrected for using an exponential law and normalisation to ${ }^{146} \mathrm{Nd} /{ }^{144} \mathrm{Nd}=0.7219$.

The dried $\mathrm{Pb}$ fraction was taken up in $2 \mu \mathrm{H}_{3} \mathrm{PO}_{4}$-silica gel mix (Gerstenberger and Haase 1996). Half was loaded onto a single Re filament and run naturally for 180 ratios (integration time of $8.389 \mathrm{~s}$ ). The remaining aliquot was then mixed outside of the beaker with a ${ }^{207} \mathrm{~Pb} /{ }^{204} \mathrm{~Pb}$ spike (Thirlwall 2000). Spiked aliquots were then loaded onto single $\mathrm{Re}$ filaments and analysed for 120 ratios under the same conditions. The data was then deconvolved to determine the isotopic ratios. 
S5. Supplementary material for Chapter 5 


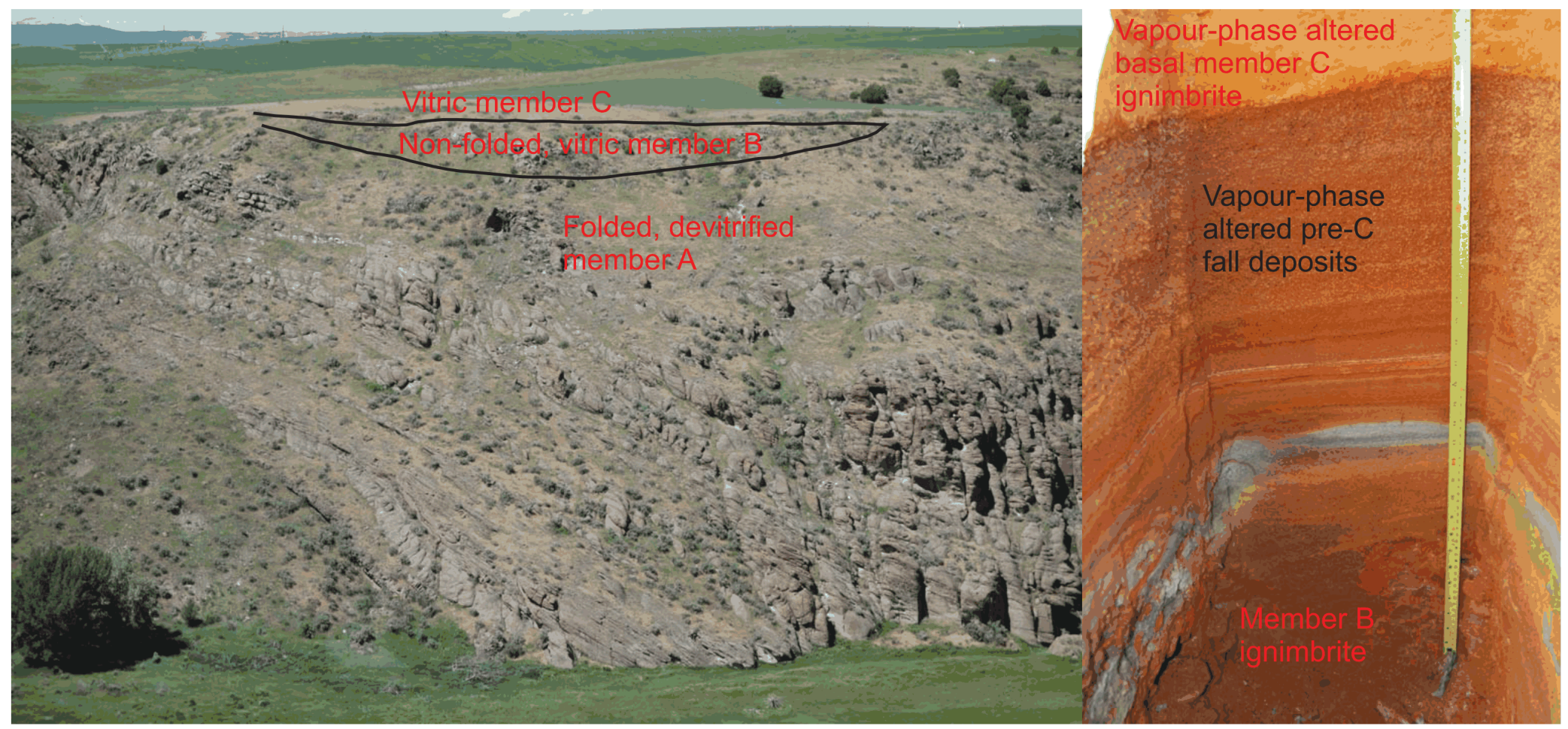

Figure S5.1: Photographs showing evidence for time breaks within the HRT eruption. Images and text from CJN Wilson (pers comm). Left: true right bank of the Teton River showing folded and devitrified member A ignimbrite at the base of the cliff. Member B is non-folded and vitric, indicating member A had deformed and begun to cool prior to deposition of member B, suggesting a time gap of months. Right: photo of a pit dug through the pre-C fall deposits down to the contact with the upper member B ignimbrite. Despite a welding break between members B and C (observed at other localities), pre-C fall deposits and the base of member $C$ ignimbrite are vapour-phase altered. This indicates ignimbrite member $B$ (and $A$ ) were still fumarolically degassing when member $\mathrm{C}$ (and fall deposits) were emplaced, constraining the time gap to years-decades. 


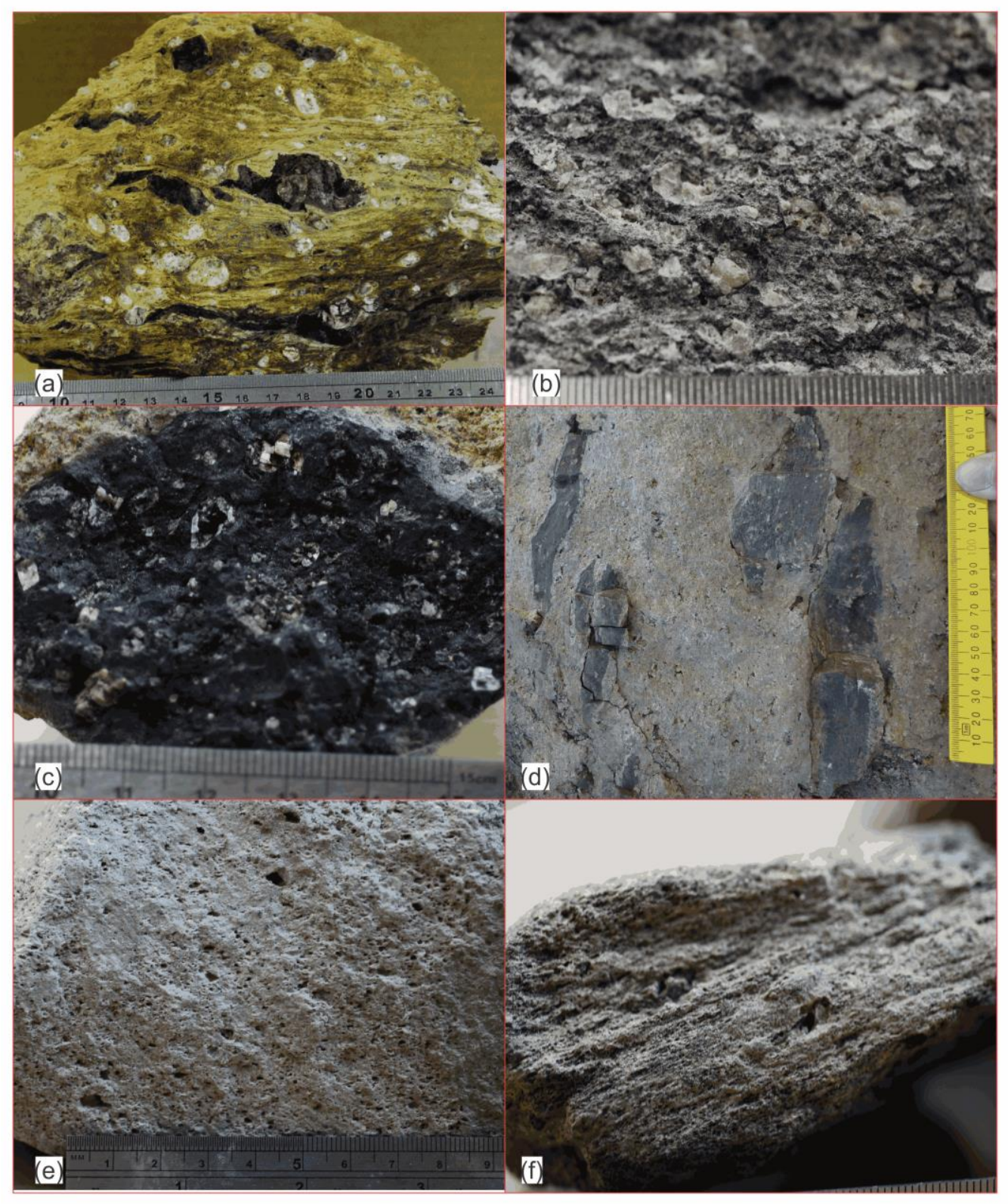

Figure S5.2: Photographs showing representative of clasts types samples in this study. (a) Scoriabearing J4-type clast YP071 from member B containing $\mathrm{cm}$-size lenses of scoria within a crystal rich, fibrous silicic pumice similar to J1-type samples. (b) J2-type sample YP251 from member A exhibiting a characteristic crystal-rich, dense texture with darkened groundmass glass. (c) J3-type sample YP191 from member A showing coarse euhedral feldspars within blackened groundmass glass. (d) Outcrop photograph of J5-type clasts within member C ignimbrite. Variable morphology is found within these clasts from equant to elongate. Samples are characteristically non-vesicular, crystal-poor and devitrified. Photography courtesy of CJN Wilson. (e) Rounded, crystal-poor pumice (YP133) characteristic of J7-type pumices from locality 332 in member C. (f) Characteristic pumice (YP088, not analysed in this study) of J8-type samples with an elongate morphology and an extremely vesicular, fibrous, crystal-poor texture. 


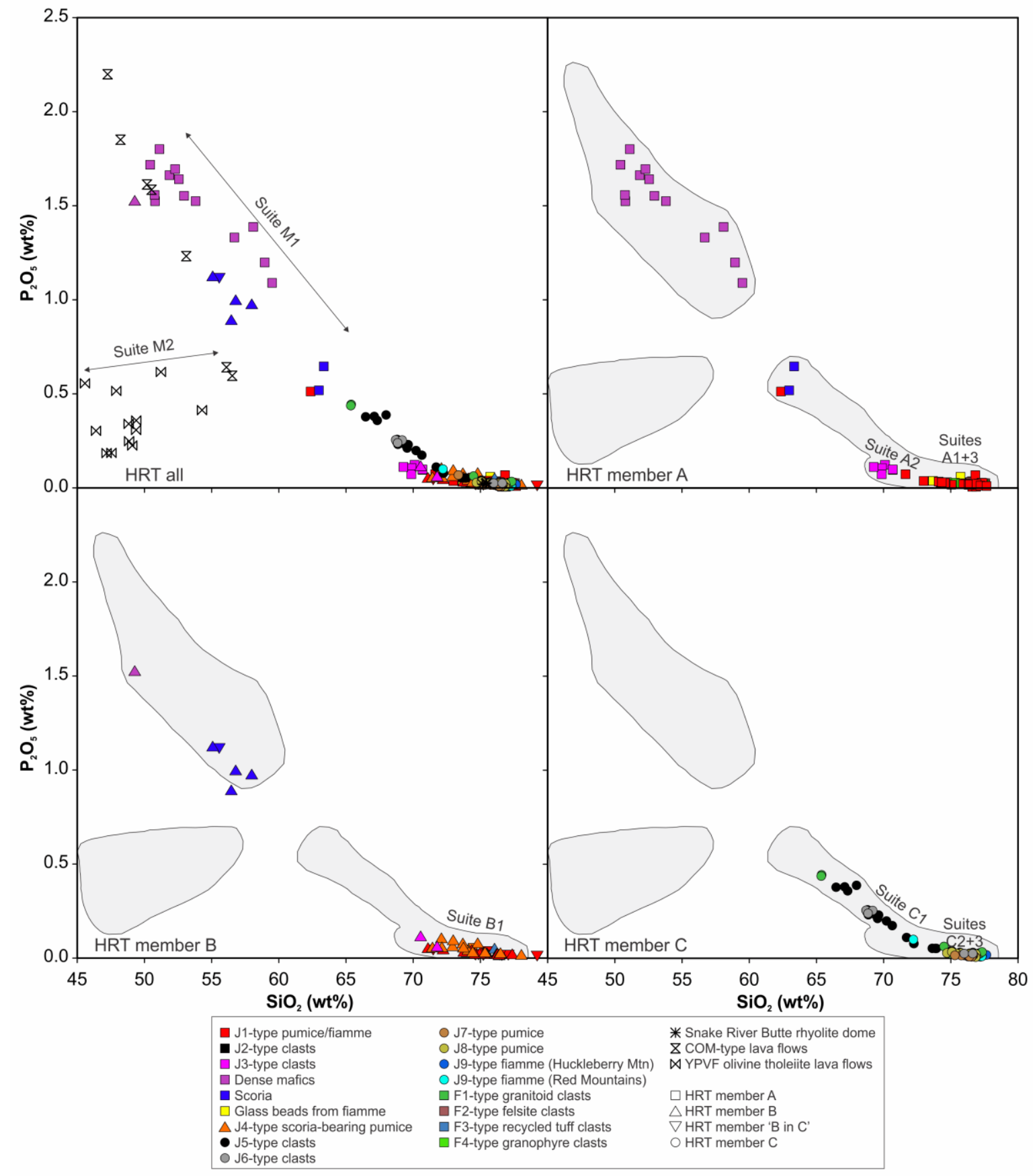

Figure S5.3: $\mathrm{SiO}_{2}$ vs. $\mathrm{P}_{2} \mathrm{O}_{5}$ for samples analysed in this study for the entire HRT (and relevant regional eruptives) and individual members. A compositional gap between suites $A 1$ and $A 2$ is infilled in member B (suite B1). See Fig. 5.3 in Chapter 5 for symbol and suite details. Suite C1 is elevated in $\mathrm{P}_{2} \mathrm{O}_{5}$ relative to the other suites. Compositional fields (grey shaded regions) from the entire HRT are copied across to plots for individual members for comparison. Analytical 2 sd precisions are smaller than the symbol size. 


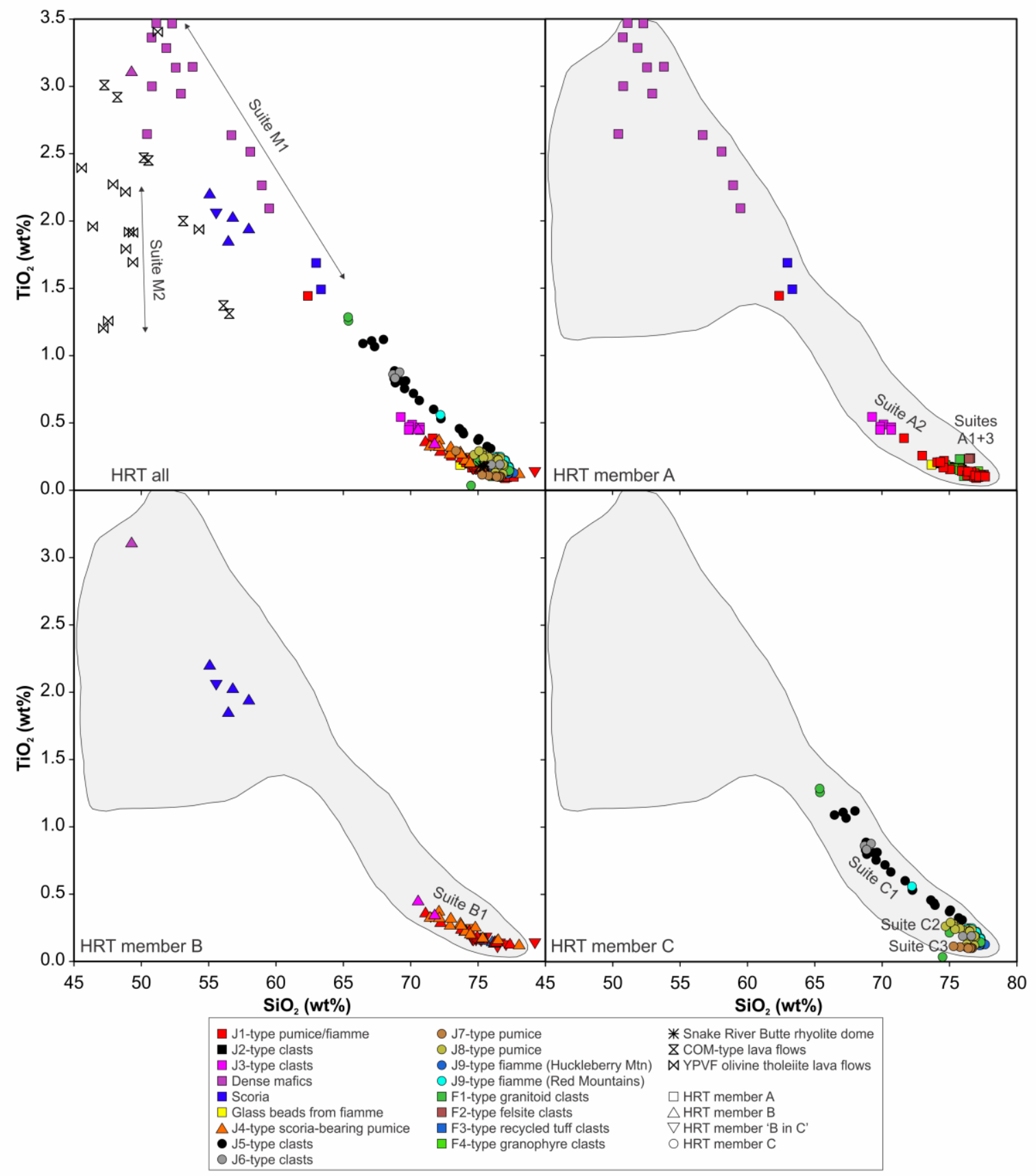

Figure S5.4: $\mathrm{SiO}_{2}$ vs. $\mathrm{TiO}_{2}$ for samples analysed in this study for the entire HRT (and relevant regional eruptives) and individual members. A compositional gap between suites A1 and A2 is infilled in member B (suite B1). Three sub-parallel compositional suites are apparent in member $C$, with the most Ti-rich suite (C1) projecting towards more Ti-rich mafic compositions. See Fig. 5.3 in Chapter 5 for symbol and suite details. Compositional fields (grey shaded regions) from the entire HRT are copied across to plots for individual members for comparison. Analytical 2sd precisions are smaller than the symbol size. 


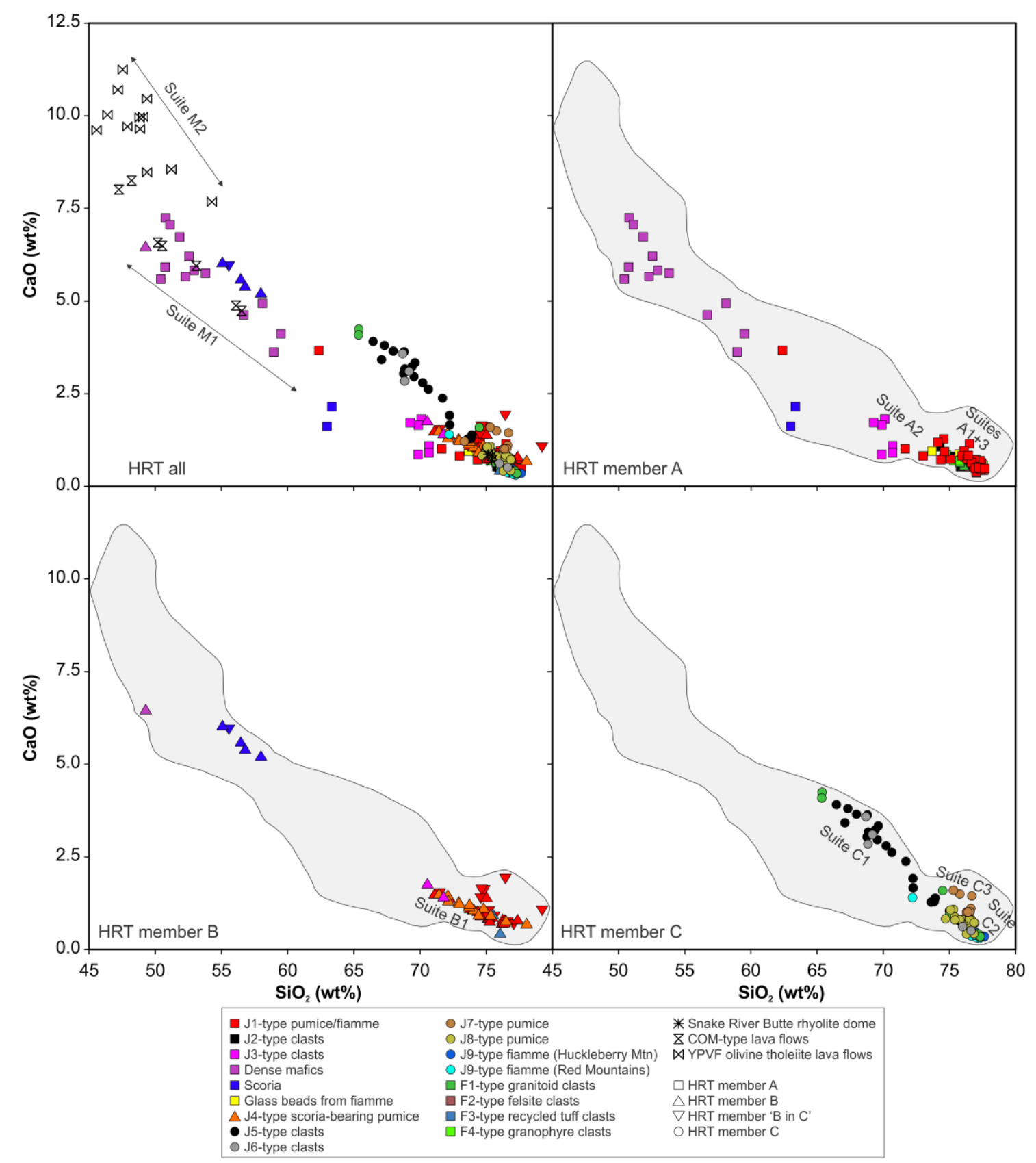

Figure S5.5: $\mathrm{SiO}_{2}$ vs. $\mathrm{CaO}$ for samples analysed in this study for the entire HRT (and relevant regional eruptives) and individual members. Member $\mathrm{A}$ and $\mathrm{B}$ suites are depleted in $\mathrm{CaO}$ relative to $\mathrm{C} 1$, the latter of which trends back towards more Ca-rich olivine tholeiitic compositions. See Fig. 5.3 in Chapter 5 for symbol and suite details. Compositional fields (grey shaded regions) from the entire HRT are copied across to plots for individual members for comparison. Analytical 2 sd precisions are smaller than the symbol size. 


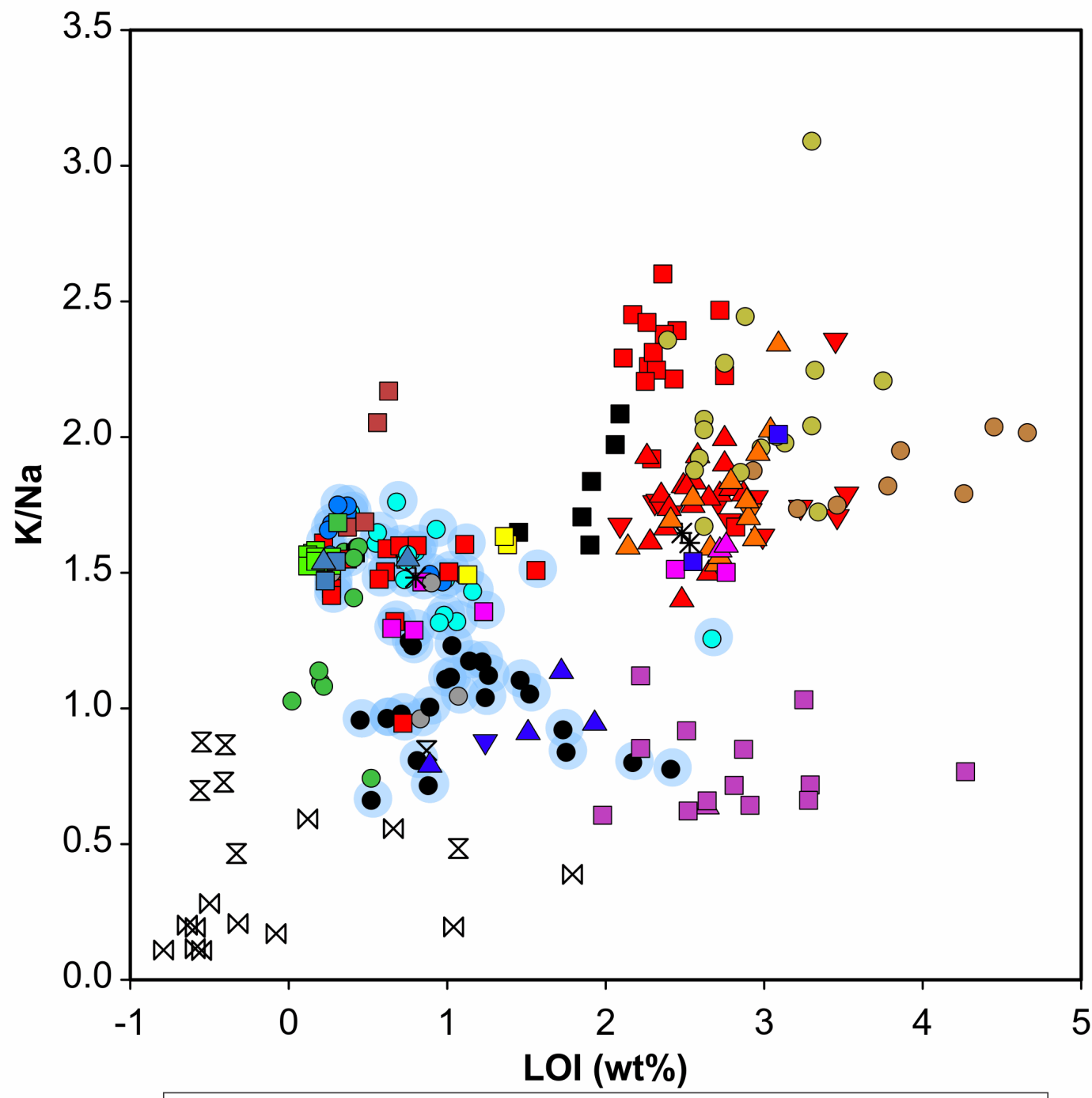

\begin{tabular}{|ll|}
\hline$\square$ J1-type pumice/fiamme & $\square$ F1-type granitoid clasts \\
J2-type clasts & $\square$ F2-type felsite clasts \\
$\square$ J3-type clasts & $\square$ F3-type recycled tuff clasts \\
$\square$ Dense mafics & $\square$ F4-type granophyre clasts \\
$\square$ Scoria & * Snake River Butte rhyolite dome \\
$\square$ Glass beads from fiamme & Z COM-type lava flows \\
$\triangle$ J4-type scoria-bearing pumice & $\bowtie$ YPVF olivine tholeiite lava flows \\
J5-type clasts & \\
O J6-type clasts & $\square$ HRT member A \\
O J7-type pumice & $\triangle$ HRT member B \\
O J8-type pumice & $\nabla$ HRT member 'B in C' \\
O J9-type fiamme (Huckleberry Mtn) & O HRT member C \\
O J9-type fiamme (Red Mountains) & \\
\hline
\end{tabular}

Figure S5.6: Single clast loss on ignition (LOI) vs. K/Na for samples analysed in this study for the entire HRT (and relevant regional eruptives). Devitrified juvenile clasts are highlighted in blue. There is no clear relationship between $\mathrm{LOI}$ and $\mathrm{K} / \mathrm{Na}$, whereas the latter would be expected to increase with hydration if alkali mobility (especially Na loss) were important (Hildreth and Wilson 2007). Although broadly higher LOI values are seen in glassy pumices, there is overlapping $\mathrm{K} / \mathrm{Na}$ values between different juvenile clast types. See Fig. 5.3 in Chapter 5 for symbol and colour details. 


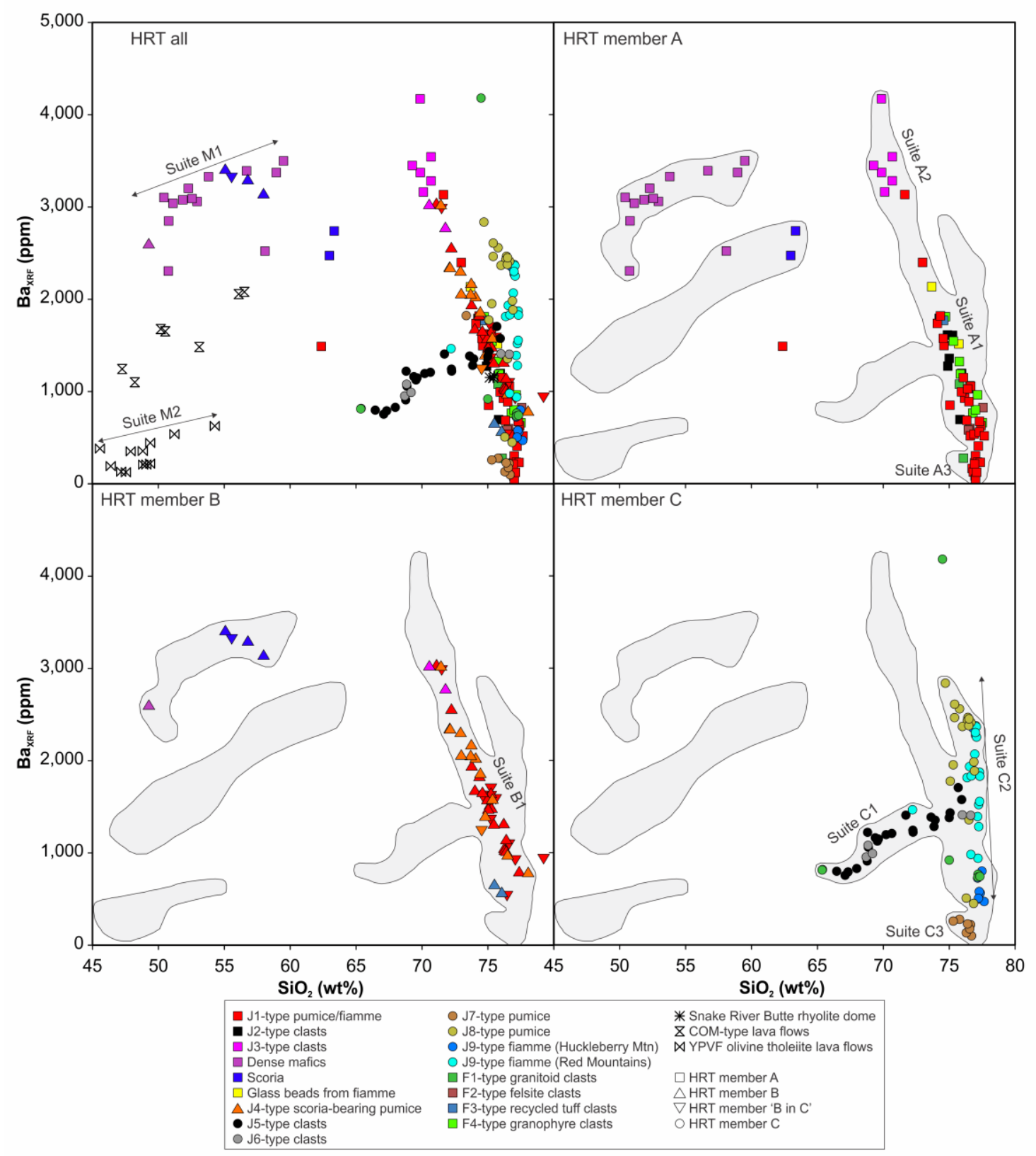

Figure S5.7: $\mathrm{SiO}_{2}$ vs. BaxRF for samples analysed in this study for the entire HRT (and relevant regional eruptives) and individual members. Suite A3 is distinguished from suite A1 in trace elements (low $\left.\mathrm{Ba}_{\mathrm{XRF}}\right)$ and is comparable to suite $\mathrm{C} 3$. Suites $\mathrm{A} 1-3$ and $\mathrm{C} 2$ and $\mathrm{C} 3$ trend back towards high $\mathrm{Ba}$ compositions typical of suite M1 mafic compositions, whereas suite $\mathrm{C} 1$ trends back towards suite M2 olivine tholeiite lava flows. See Fig. 5.3 in Chapter 5 for symbol and suite details. Compositional fields (grey shaded regions) from the entire HRT are copied across to plots for individual members for comparison. Analytical 2sd precisions are smaller than the symbol size. 


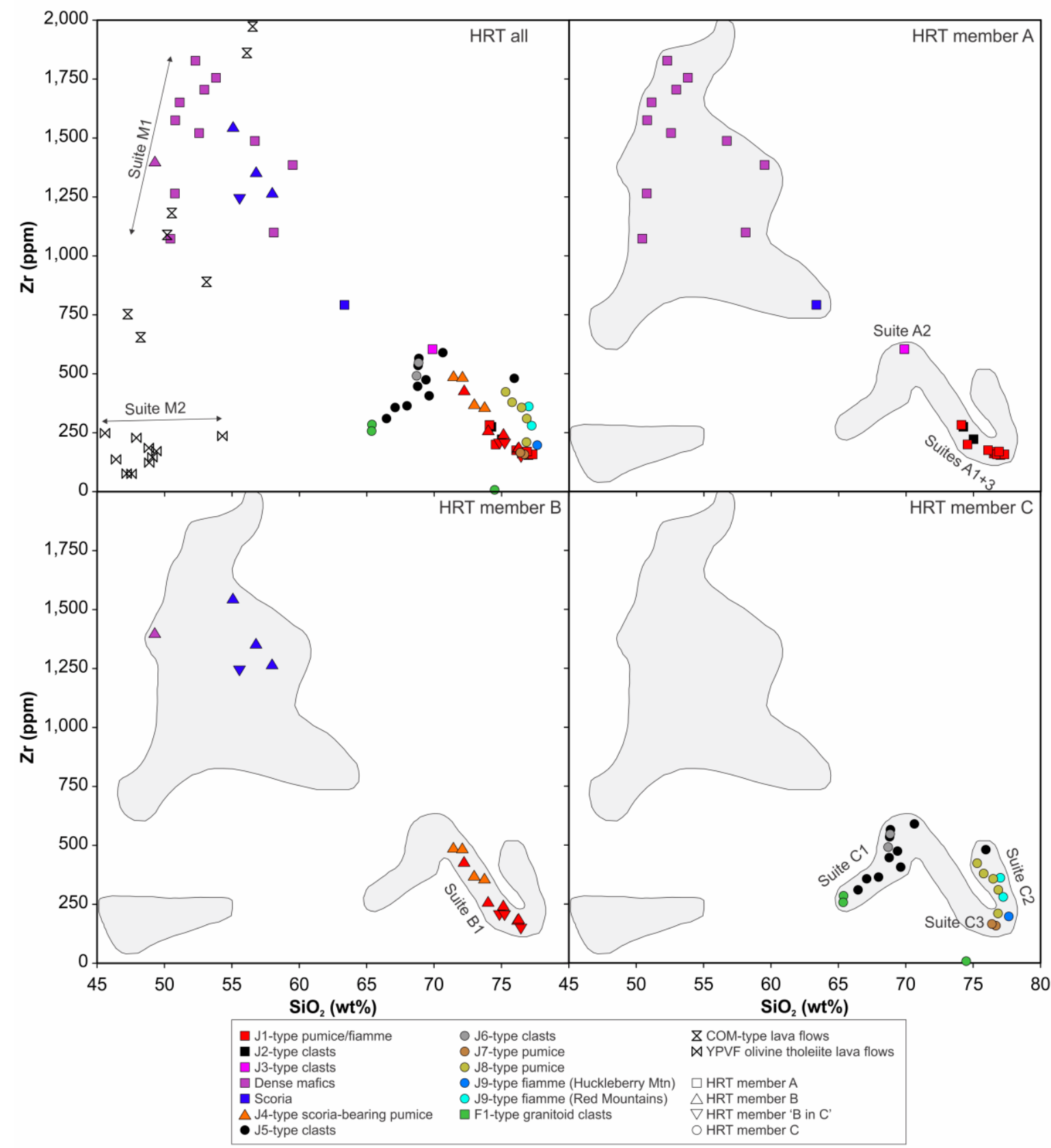

Figure S5.8: $\mathrm{SiO}_{2}$ vs. $\mathrm{Zr}$ for samples analysed in this study for the entire HRT (and relevant regional eruptives) and individual members. The compositional gap observed between suites A1 and A2 is infilled by suite $\mathrm{B} 1$. All silicic suites, except $\mathrm{C} 1$, show a negative correlation between $\mathrm{SiO}_{2}$ and $\mathrm{Zr}$, indicative of zircon crystallisation. Suites $A 1-3$ and $C 2$ and $C 3$ trend back towards high $\mathrm{Zr}$ compositions typical of suite M1 mafic compositions, whereas suite $\mathrm{C} 1$ trends back towards suite M2 olivine tholeiite lava flows. See Fig. 5.3 in Chapter 5 for symbol and suite details. Compositional fields (grey shaded regions) from the entire HRT are copied across to plots for individual members for comparison. Analytical 2sd precisions are smaller than the symbol size. 


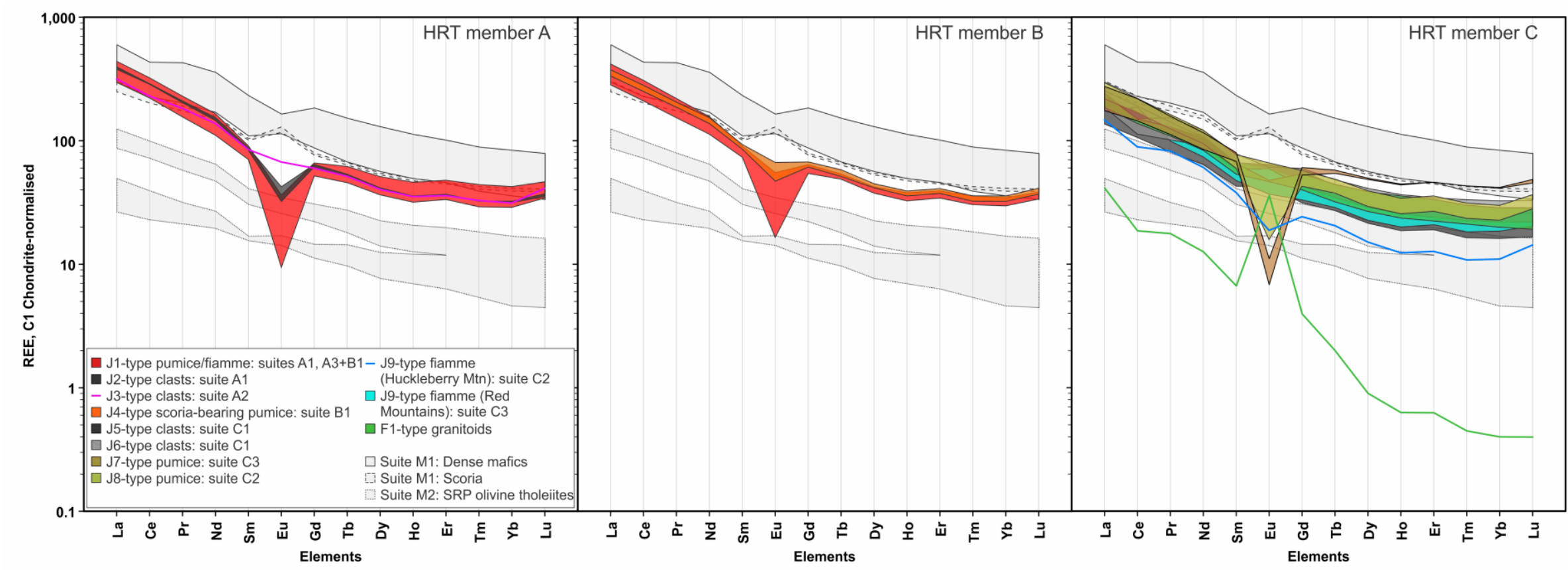

Figure S5.9: $C 1$ chondrite-normalised rare earth-element (REE) plot for samples from members $A, B$ and $C$ of the HRT. Suites A1 and A3 show a negative Eu anomaly in contrast to suite $A 2$. This Eu anomaly gap is infilled in member $B$, predominantly by J4-type scoria-bearing pumices. Member $C$ suites show flatter REE patterns with variable Eu anomalies, with the greatest negative anomalies observed in suite C3 samples. F1-type granitoid YR275 (green line) shows a depleted REE pattern with a positive Eu anomaly. Compositional fields (grey shaded regions) of mafic suites 1 and 2 copied from Swallow et al. (2018a, Chapter 4: suites M1 and M2) for comparison. See Fig. 5.3 in main paper for symbol and suite details. Normalising values from McDonough and Sun (1995). 


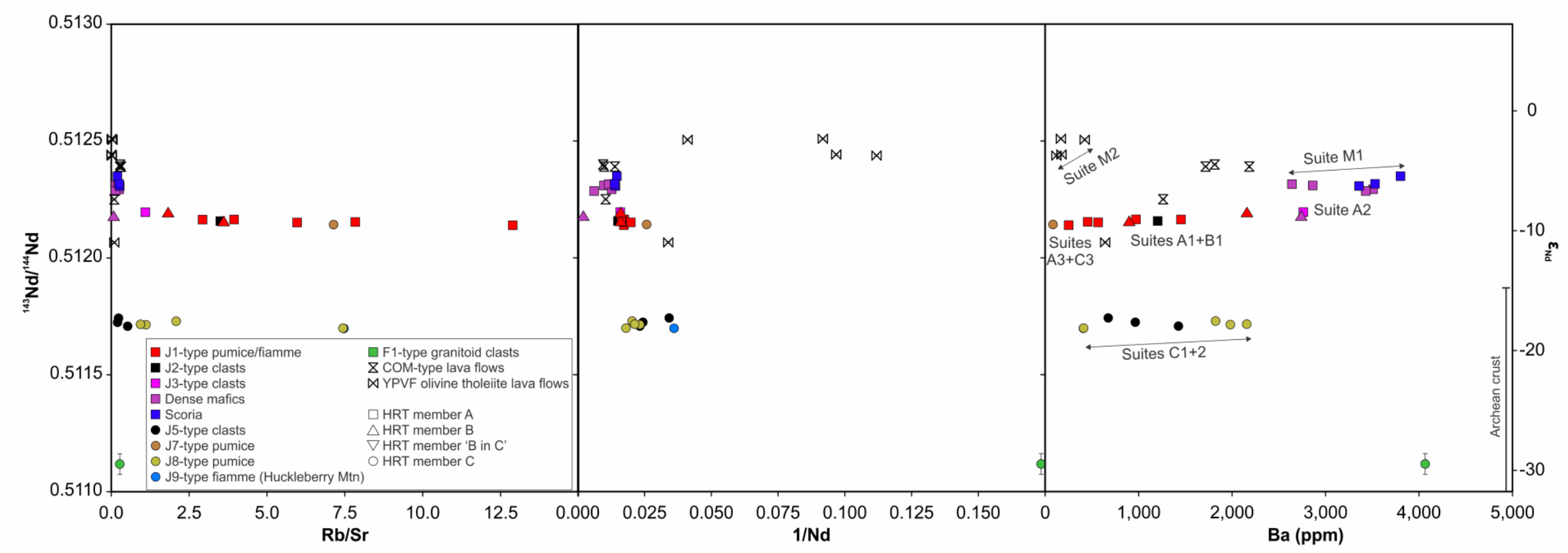

Figure S5.10: ${ }^{143} \mathrm{Nd} /{ }^{144} \mathrm{Nd}$ vs indices of magmatic evolution for single clast samples from the HRT and relevant regional eruptives. Members $A$ and $B$ compositions lie at the unradiogenic end of mafic suites. Isotopic compositions show no significant change with evolution (e.g. increasing Rb/Sr, decreasing Ba: cf. Sr isotopes [Fig. 5.12 in Chapter 5]). Suite C3 samples are comparable to their suite A3 comparators. Suites C1 and C2 are remarkably less radiogenic but similarly show flat trends with degrees of evolution. See Fig. 5.3 in Chapter 5 for symbol and suite details. Individual 2se analytical uncertainties are smaller than symbol size unless shown. 


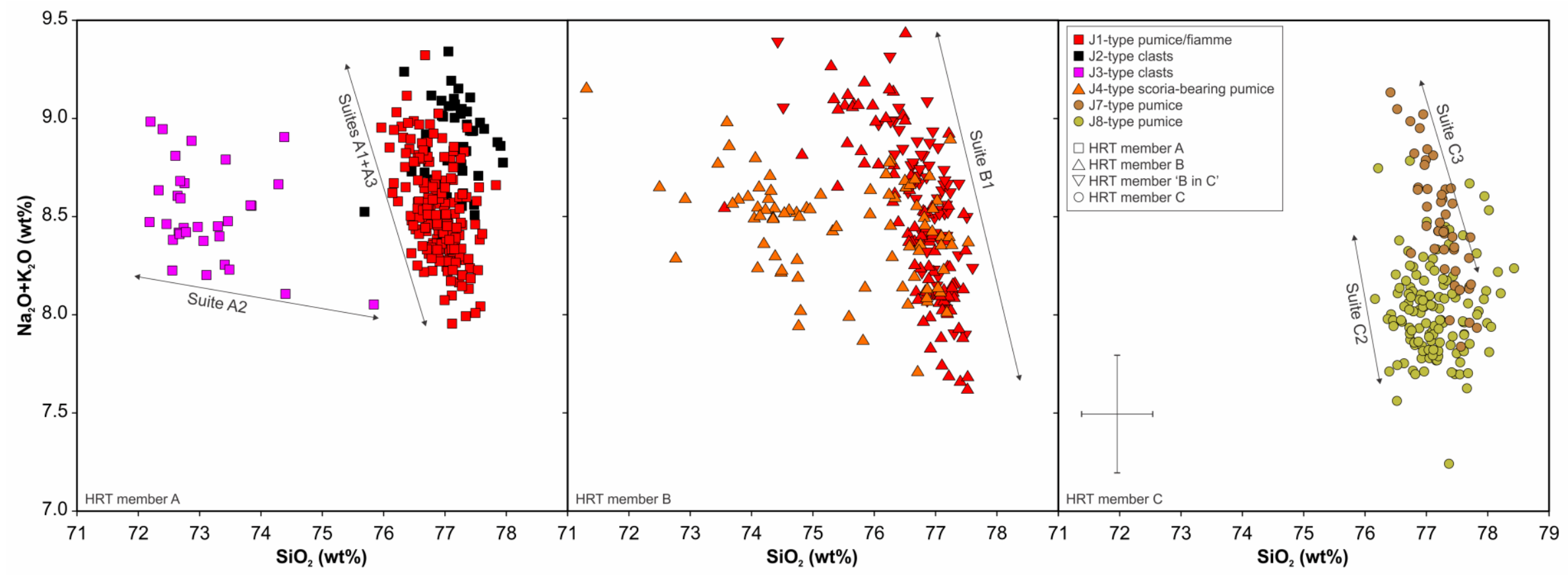

Figure S5.11: Groundmass glass $\mathrm{SiO}_{2}$ vs total alkalis $\left(\mathrm{Na}_{2} \mathrm{O}+\mathrm{K}_{2} \mathrm{O}\right)$ for samples from members $\mathrm{A}, \mathrm{B}$ and $\mathrm{C}$ of the HRT. Groundmass glass major element compositions are high-silica rhyolite, are tightly clustered and relatively homogeneous (cf. trace element compositions: Figs. 5.14, 5.15 in Chapter 5). Exceptions to this are J2-type samples, which may have experienced some excessive secondary hydration, and lower-SiO ${ }_{2}$ suite $\mathrm{A} 2$ and $\mathrm{J} 4$-type $5 c 0$ iabearing pumices. See Fig. 5.3 in Chapter 5 for symbol and suite details. Cross at the bottom left of the member C plot shows 2 sd analytical precisions. 


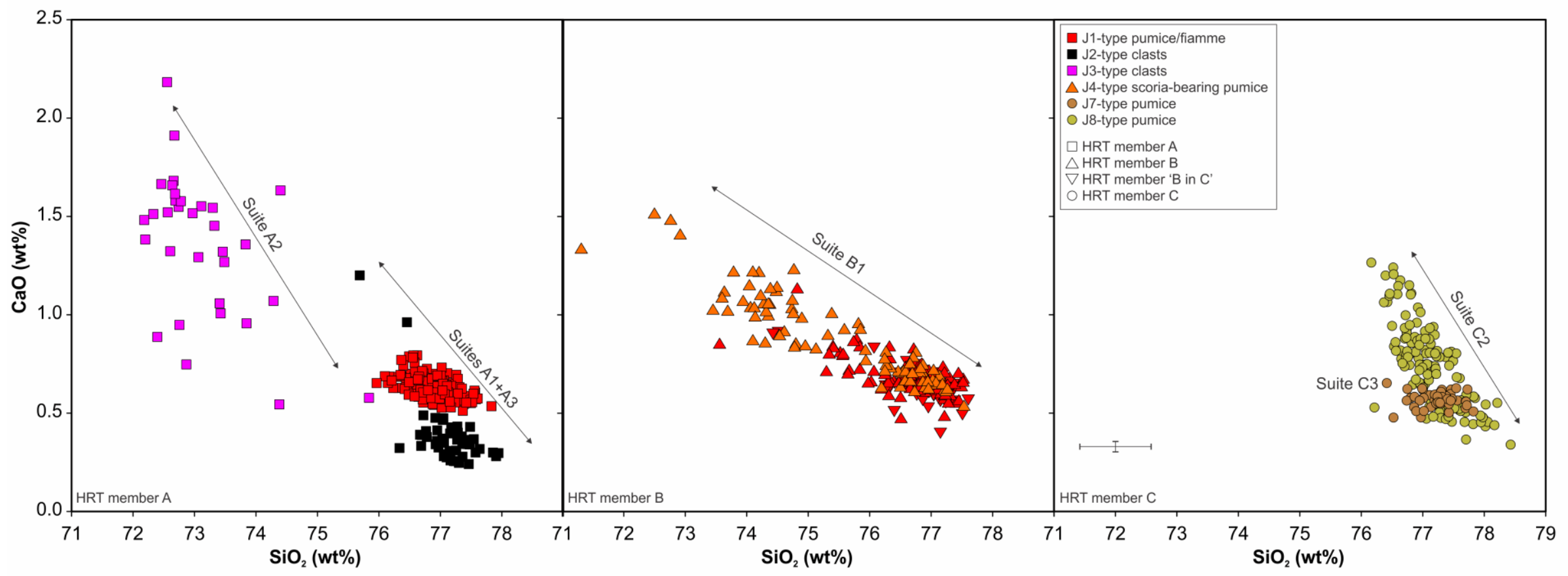

Figure S5.12: Groundmass glass $\mathrm{SiO}_{2}$ vs $\mathrm{CaO}$ for samples from members A, B and C of the HRT. Groundmass glass major element compositions are highsilica rhyolite, are tightly clustered and relatively homogeneous (c.f. trace element compositions: Figs. 5.14, 5.15 in Chapter 5). Lower CaO glass from J2type samples may reflect excessive secondary hydration. Suite $\mathrm{A} 2$ and J4-type scoria-bearing pumices extend to lower-SiO $\mathrm{O}_{2}$ contents. Suite $\mathrm{C} 2$ groundmass glass extends to higher $\mathrm{CaO}$ than suite C3. See Fig. 5.3 in Chapter 5 for symbol and suite details. Cross at the bottom left of the member C plot shows 2 sd analytical precisions. 


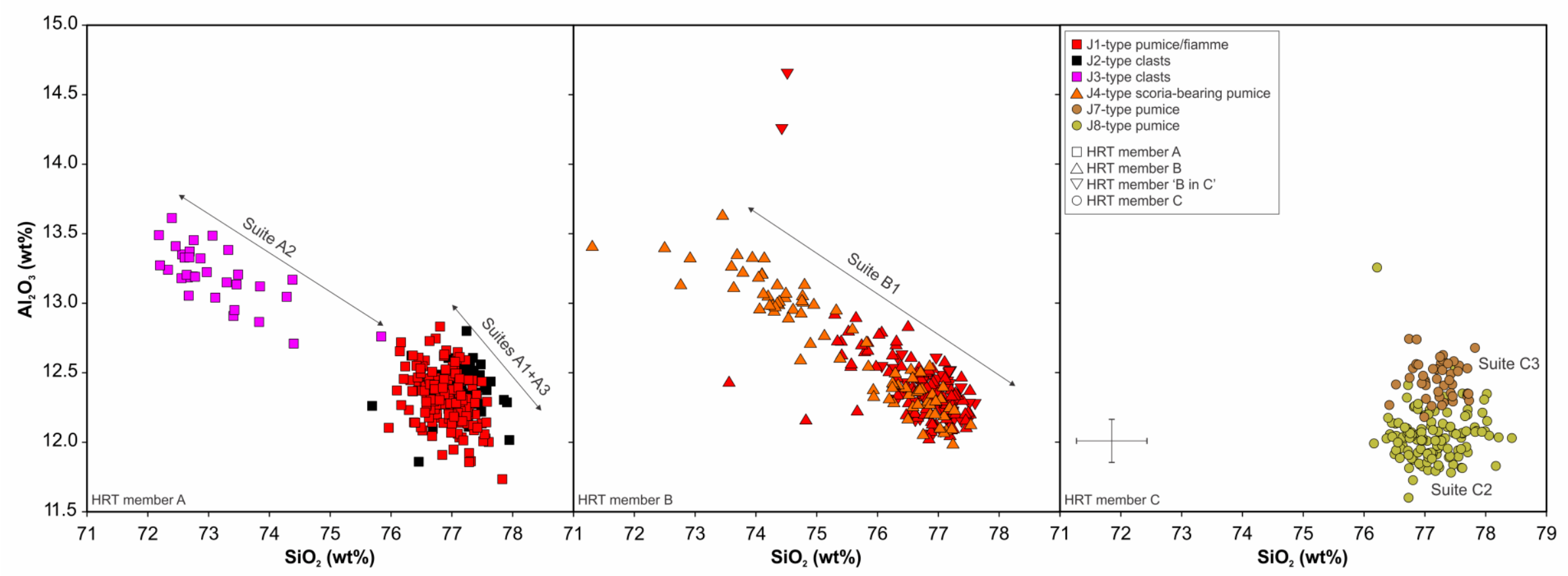

Figure S5.13: Groundmass glass $\mathrm{SiO}_{2}$ vs $\mathrm{Al}_{2} \mathrm{O}_{3}$ for samples from members $\mathrm{A}, \mathrm{B}$ and $\mathrm{C}$ of the HRT. Groundmass glass major element compositions are highsilica rhyolite, are tightly clustered and relatively homogeneous (c.f. trace element compositions Figs. 5.14 and 5.15). Suite A2 and J4-type scoria-bearing pumices extend to lower-SiO ${ }_{2}$ contents. Suite $\mathrm{C} 3$ groundmass glass is offset to higher $\mathrm{Al}_{2} \mathrm{O}_{3}$ than suite $\mathrm{C} 2$. See Fig. 5.3 in Chapter 5 for symbol and suite details. Cross at the bottom left of the member $\mathrm{C}$ plot shows 2 sd analytical precisions. 


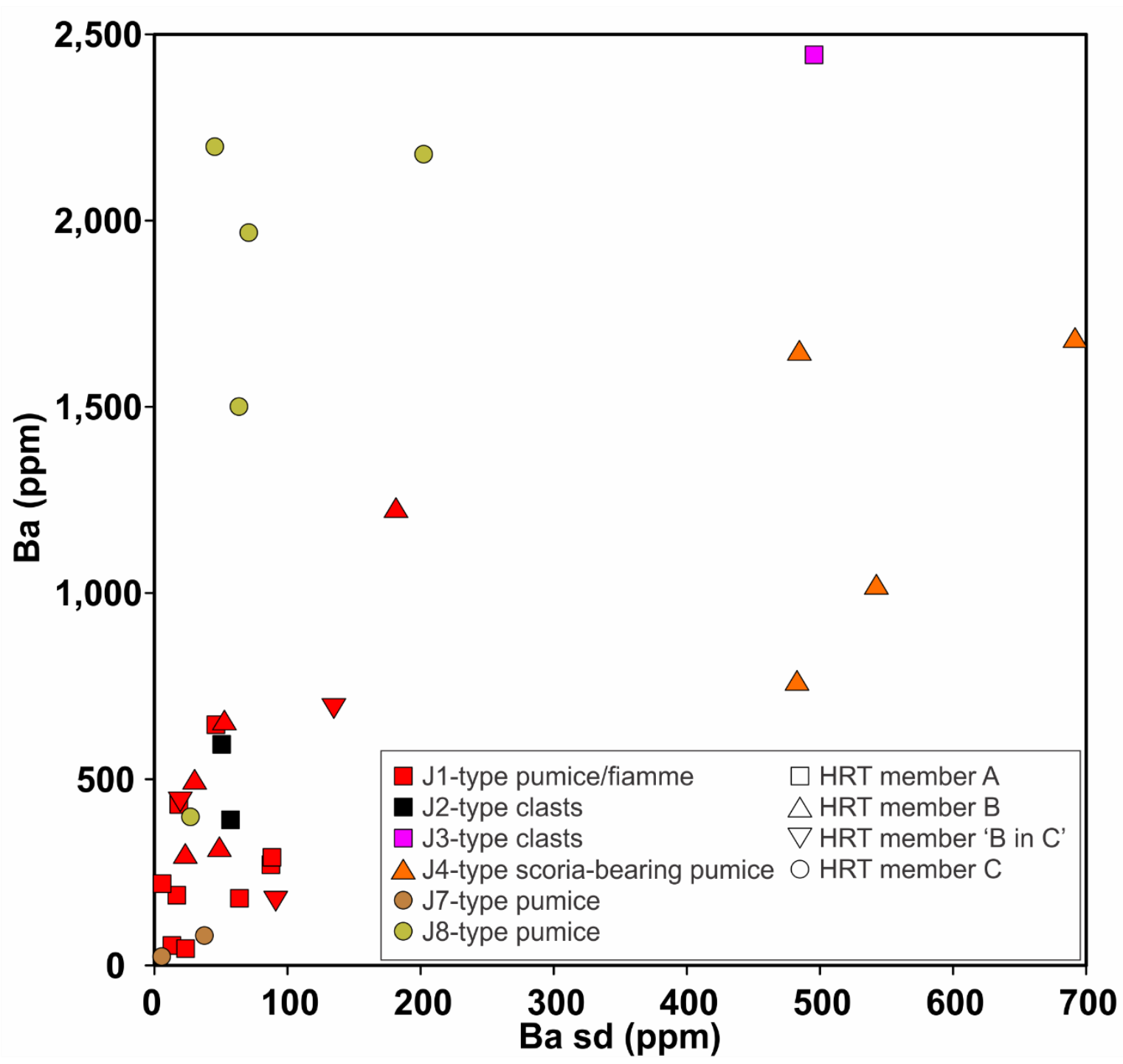

Figure S5.14: Average groundmass glass Ba concentrations from a single sample and standard deviation (sd) of the glass population for samples from the HRT. Groundmass glass from samples in member A are typically more homogeneous than pumices in member B of similar average $\mathrm{Ba}$ composition, particularly in higher Ba pumices and J4-type scoria bearing clasts. See Fig. 5.3 in Chapter 5 for symbol details. 2sd analytical precisions are smaller than symbol size. 


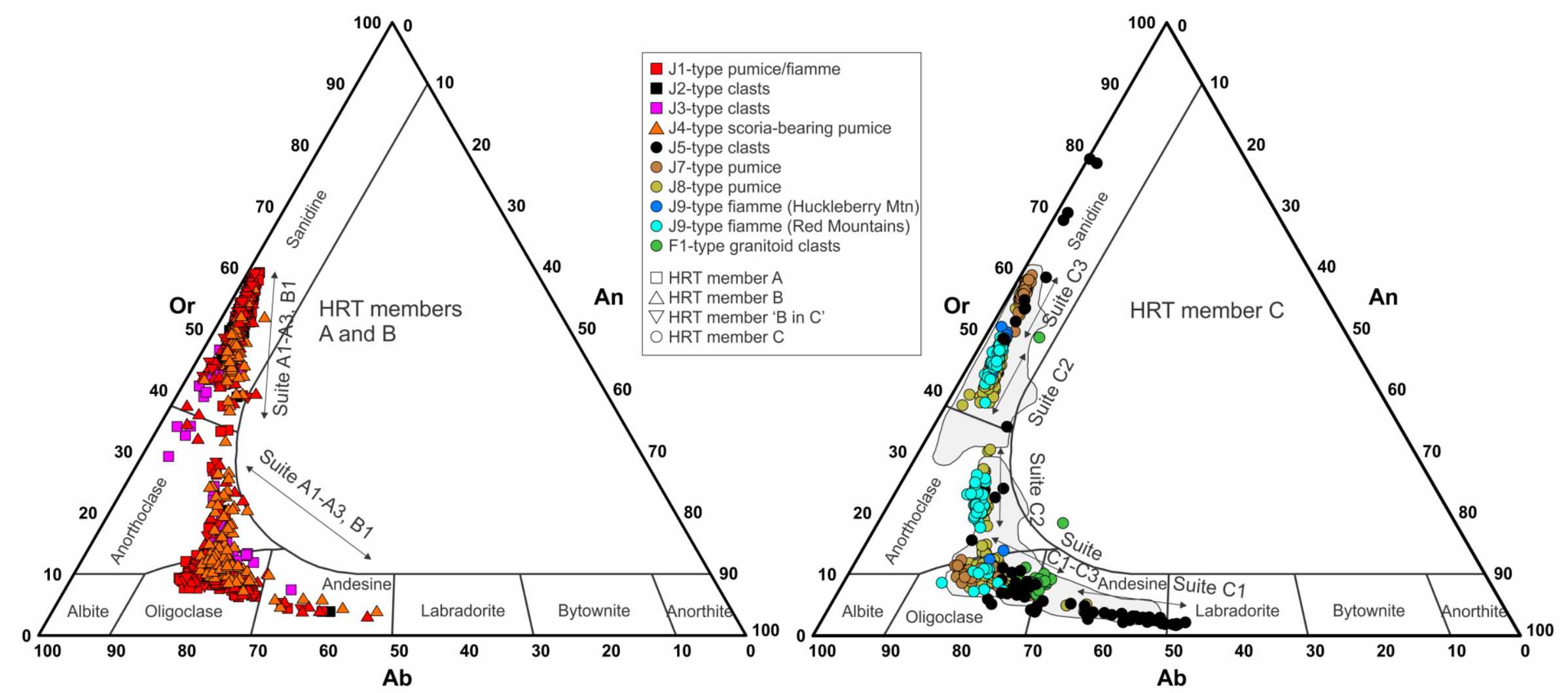

Figure S5.15: Ternary diagrams showing feldspar compositions for crystals from members A, B and C of the HRT. Left: all analyses from members A and B of the HRT. Potassium-rich feldspars are dominantly sanidine whereas plagioclase compositions are dominantly oligoclase. Both feldspars exhibit a trend to anorthoclase compositions. Right: all analyses from member $\mathrm{C}$ of the HRT. Compositions are more clustered, separated by suite type, than members A and B. Suite C1 compositions trend towards more An-rich plagioclase compositions. See Fig. 5.3 in Chapter 5 for symbol and suite details. Compositional fields from members A and B (grey shaded regions) are copied across for reference. Compositional fields show commonly used classifications. 


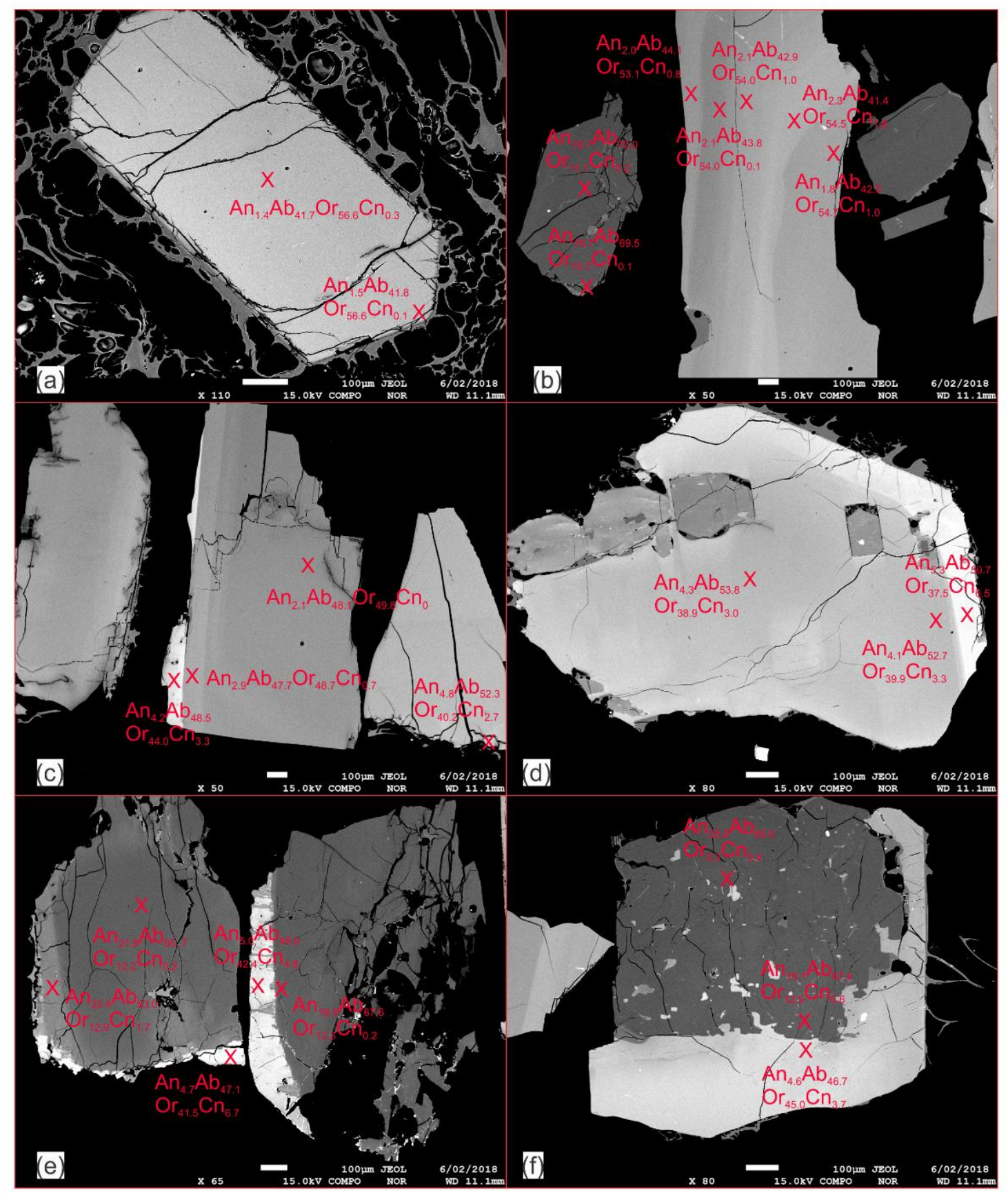

Figure S5.16: Backscattered electron images of representative feldspar textures found in the HRT and compositional data from EPMA. (a) Homogenous sanidine crystal from YP416 (member A J1type) and typical of suite A3 and C3 sanidines. (b) Plagioclase and sanidine crystals from YP023 (member B J1-type) show the contrast between homogeneous plagioclase (found in all suites) and zoned sanidines characteristic of suites A1 and B1. (c) Sanidines from YP191 (member A J3-type) showing textural diversity in suite A2 samples. High Ba rims on sanidines are present, as are homogenous crystals. (d) Ba-rich rim characteristic of sanidines from suite C2 (YP282: J8-type). (e), (f) Anti-rapakivi feldspars present in suite A2 (YP191: J3-type) and suite B1 (YP056: J4-type), respectively, with a plagioclase interior and Ba-rich sanidine overgrowth. 


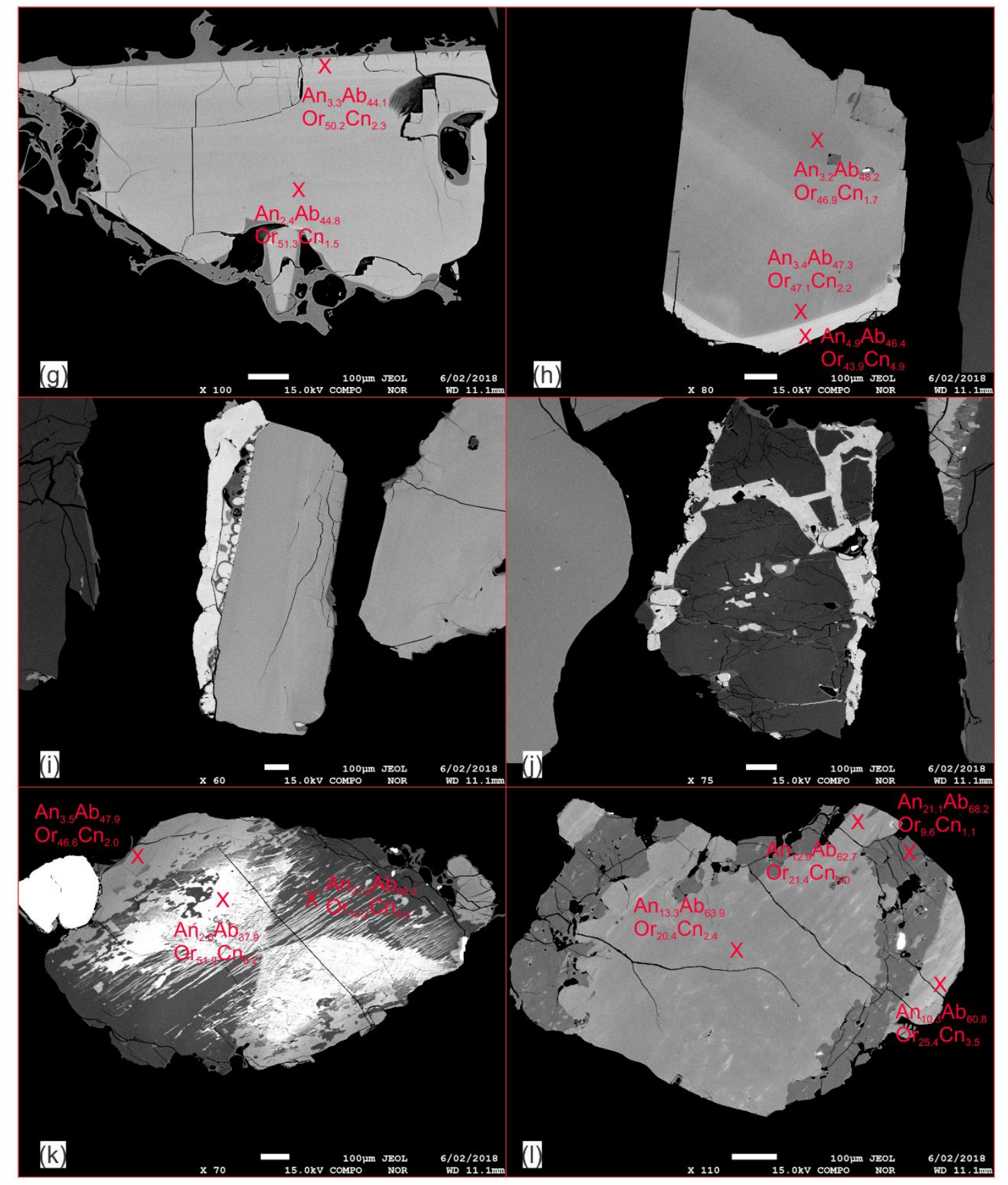

Figure S5.16 continued: (g), (h) Bright, high-Ba rims found in suite B1 J4-type scoria bearing pumices (YP056 and YP061, respectively). (i), (j) Carbonate-cemented sanidine (YP307: J1-type) and plagioclase (YP414: J1-type) crystals in member A. (k), (I) 'Plutonic-textured' feldspars present in J4type (YP071: member B) and J8-type (YP282: J8-type) marked by feldspar intergrowths and dissolution textures (e.g. corroded cores). 


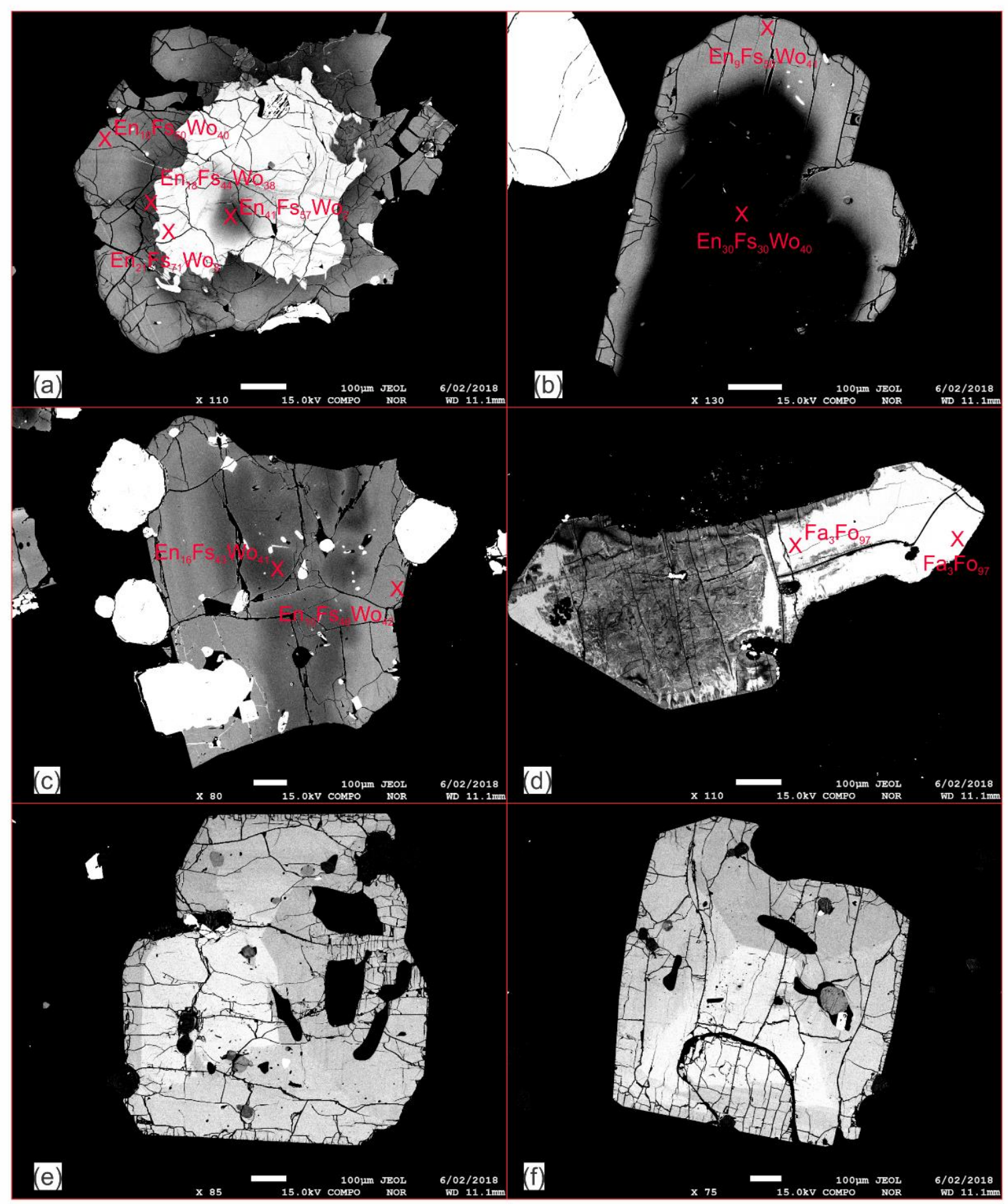

Figure S5.17: Backscattered electron images of representative ferromagnesian mineral textures found in the HRT and compositional data from EPMA. (a) Bright pigeonite core within a augite crystal from YP140 (a member 'B in C' J1-type, suite B1). (b) Dark Mg-rich augite core within lighter Fe-rich augitic rim from YP414 (member A J1-type, suite A1). (c) Zoned augite crystal from YP363 (member A J1-type, suite A1). Oscillatory zoned crystals are also present. (d) Altered olivine crystal with bright, homogeneous unaltered regions and darker oxidised domains, the latter commonly found around rims and along fractures (YP562: member C J9-type, suite C2). (e), (f) Chevkinite crystals in YP255 (member A J1-type, suite A3). 


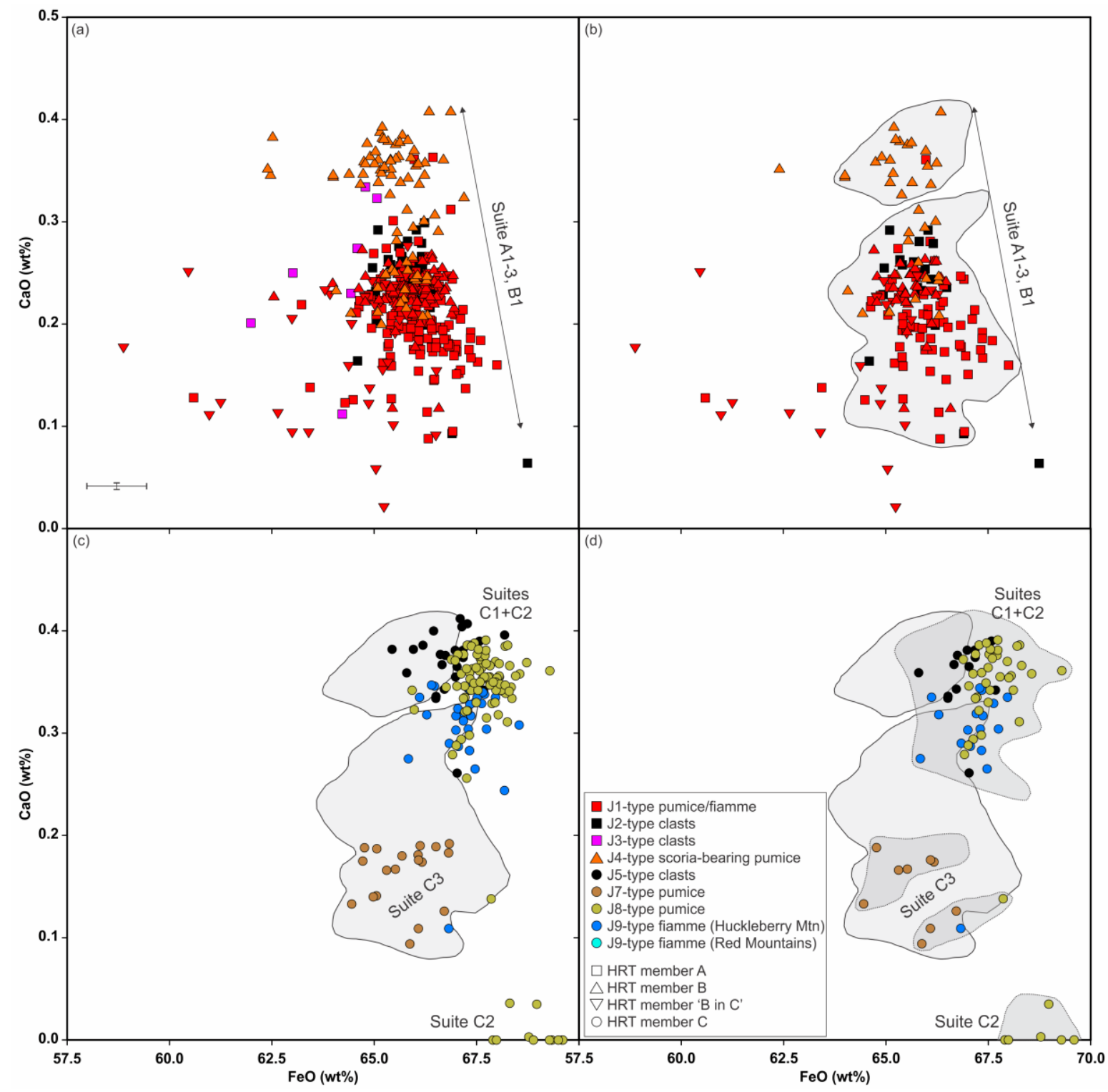

Figure S5.18: $\mathrm{FeO}$ vs $\mathrm{CaO}$ for olivine compositions of crystals from the HRT. (a) All analyses from members A and B. A broad bimodality is present with a Ca-rich cluster dominated by crystals from J4-type scoria-bearing pumices. (b) Rim compositions of crystals from members A and B. Rim compositions encompass the same compositional range as interior domains. Compositional fields from (a) copied across for comparison. (c) All analyses from member C of the HRT. Suite C3 compositions cluster within the field of member A and B olivines. Suites C1 and C2 crystals are predominantly Ca-rich and offset to higher FeO members A and B. Compositional fields from (a) copied for reference. (d) Rim analyses from member C ignimbrite. A similar pattern is observed to that from all analyses. Compositional fields from (a) and (c) copied across for comparison. See Fig. 5.3 in Chapter 5 for symbol and suite details. Cross in bottom left corner of (a) represents 2 sd analytical precisions. 


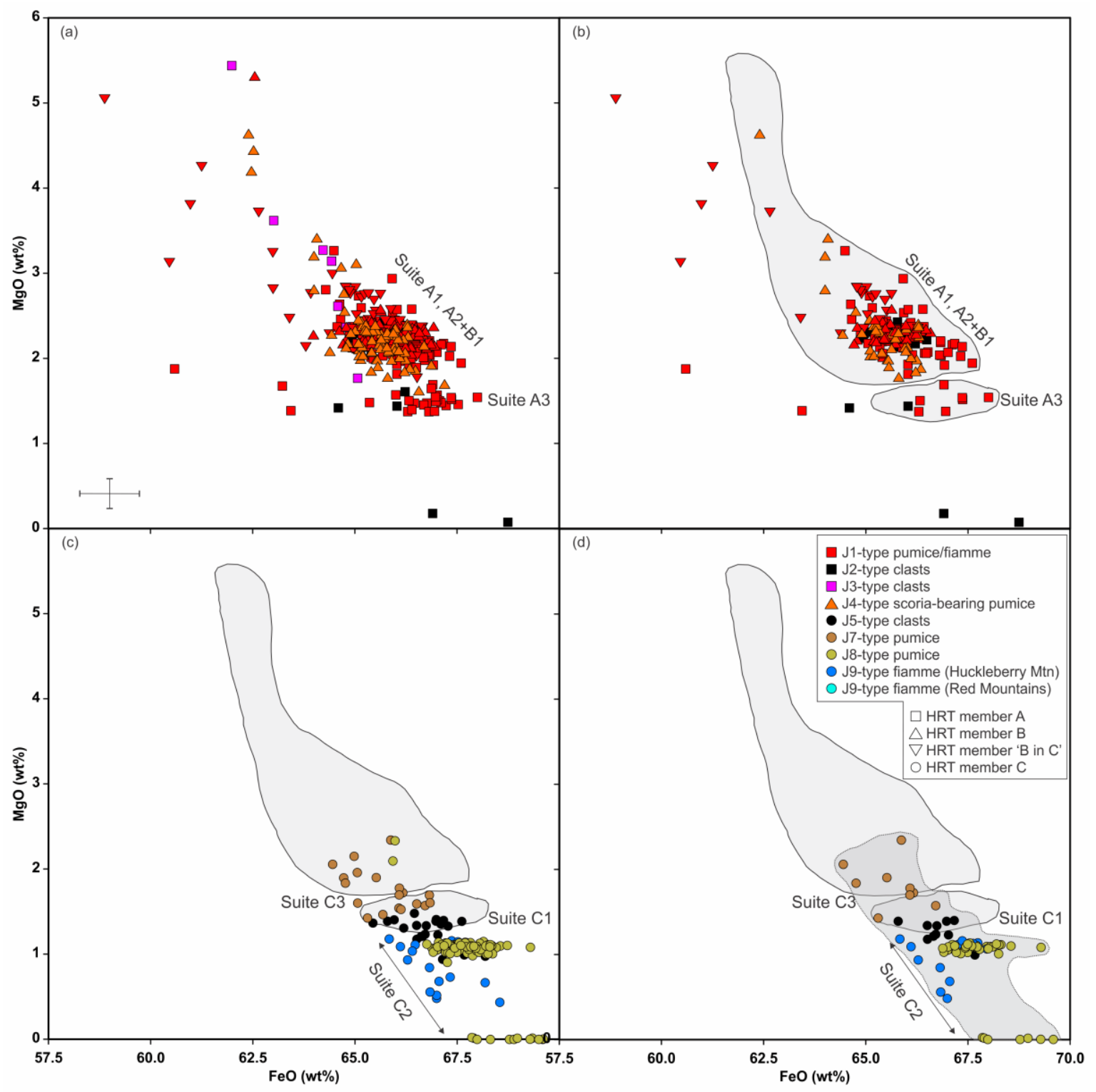

Figure S5.19: $\mathrm{FeO}$ vs $\mathrm{MgO}$ for olivine compositions of crystals from the HRT. (a) All analyses from members $\mathrm{A}$ and $\mathrm{B}$. A broad bimodality is present with a lower $\mathrm{MgO}$ group dominated by suite $\mathrm{A} 3$ crystals. (b) Rim compositions of crystals from members A and B. Rim compositions exhibit a comparable range and pattern to all analyses, consistent with the homogeneous appearance of HRT olivines. Compositional fields from (a) copied across for comparison. (c) All analyses from member C of the HRT. Clustering is evident, based on suite type. Suite C3 olivines are similar in composition to their comparable suite $\mathrm{A} 3$ crystals. Suites $\mathrm{C} 1$ and $\mathrm{C} 2$ crystals are offset to lower $\mathrm{MgO}$ with a cluster of suite C2 olivines MgO-free. Compositional fields from (a) copied for reference. (d) Rim analyses from member $\mathrm{C}$ ignimbrite. A similar pattern is observed to that from all analyses. Compositional fields from (a) and (c) copied across for comparison. See Fig. 5.3 in Chapter 5 for symbol and suite details. Cross in bottom left corner of (a) represents 2 sd analytical precisions. 


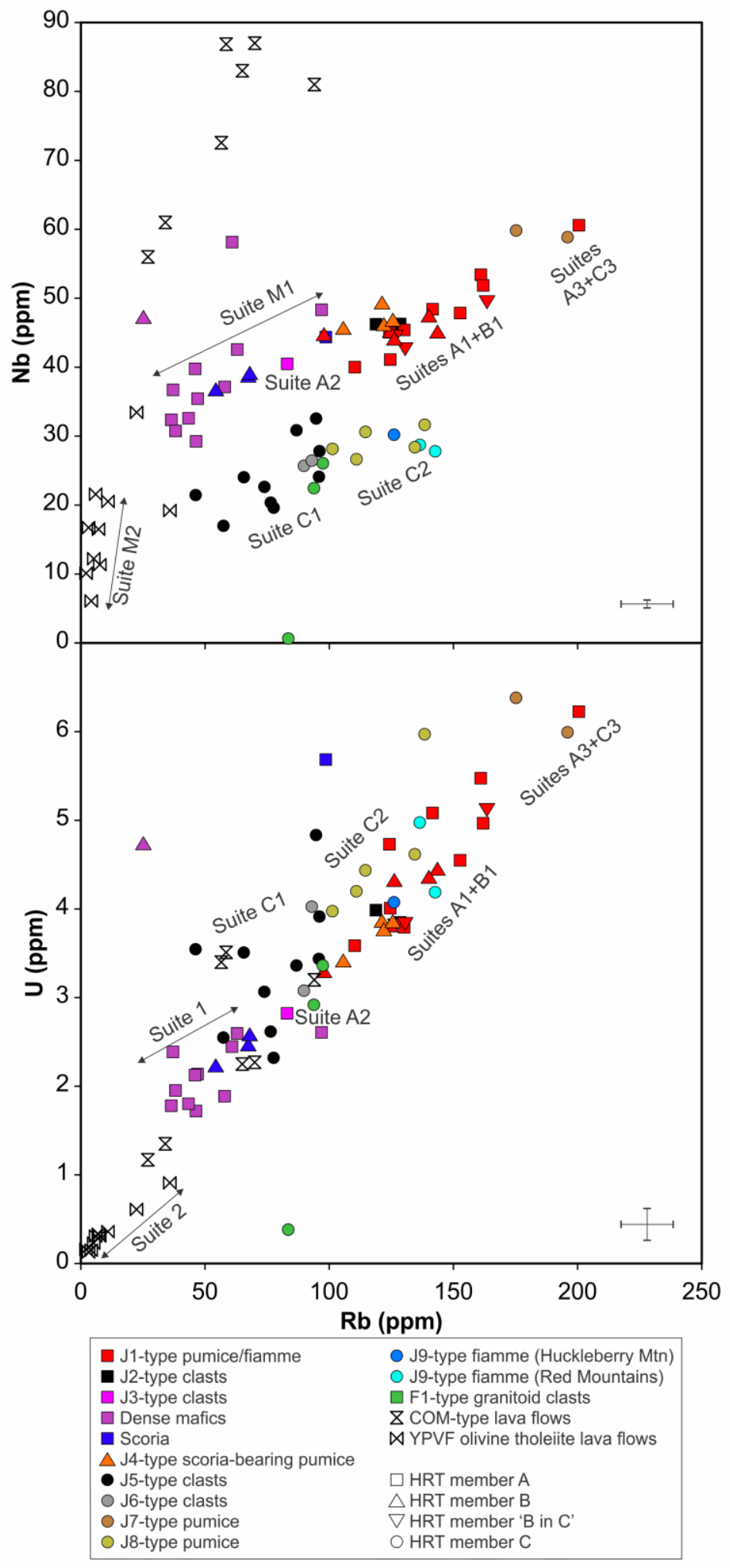

Figure S5.20: $\mathrm{Rb}$ vs $\mathrm{Nb}$ (top) and $\mathrm{U}$ (bottom) for samples analysed in this study for the entire HRT and relevant regional eruptives. Despite the major element compositional gaps (Figs. 5.3-5.5 in Chapter 5, Figs. S5.2-S5.4), incompatible trace elements are continuous between suite 1 and suites A1-3. See Fig. 5.3 in Chapter 5 for symbol and suite details. Crosses in the bottom right corner of the plots show analytical 2sd precisions. 


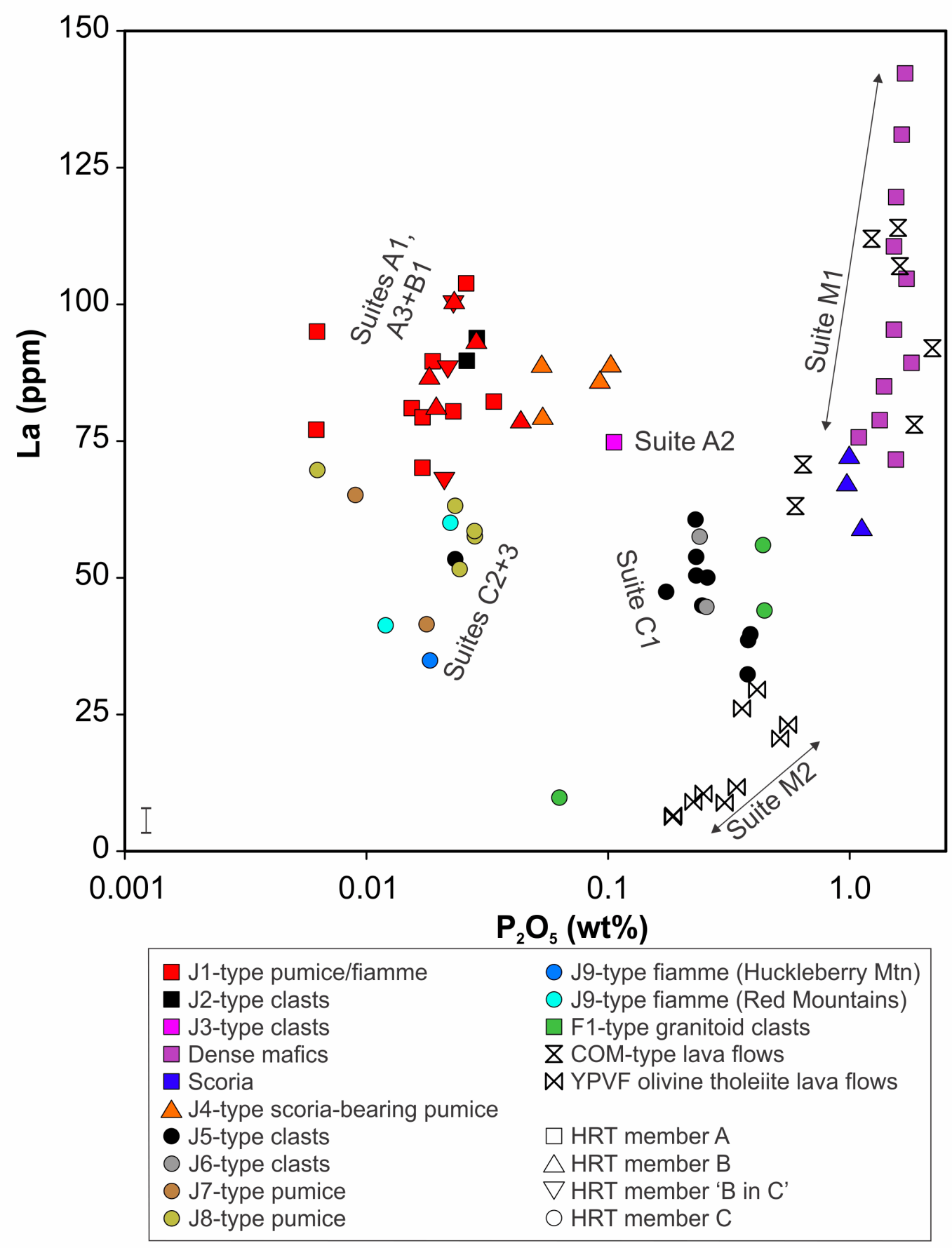

Figure S5.21: $\mathrm{P}_{2} \mathrm{O}_{5}$ vs La for samples analysed in this study for the entire HRT and relevant regional eruptives (excluding HRT mafic samples YP188 and YP242). $\mathrm{P}_{2} \mathrm{O}_{5}$ and La show a coupled decrease in Suite $\mathrm{M} 1$, indicative of apatite fractionation. Although $\mathrm{P}_{2} \mathrm{O}_{5}$ contents continue to decrease, $\mathrm{La}$ concentrations become decoupled and increase between suite $A 2$ and suites $A 1, A 3$ and $B 1$. Behaviour between the two elements is broadly coupled within suites $A 1, A 3$ and $B 1$, possibly indicating minor chevkinite fractionation. See Fig. 5.3 in Chapter 5 for symbol and suite details. Bar in bottom left corner indicates analytical 2sd precisions for La concentrations. 2sd analytical precisions for $\mathrm{P}_{2} \mathrm{O}_{5}$ measurements are smaller than symbol size. 


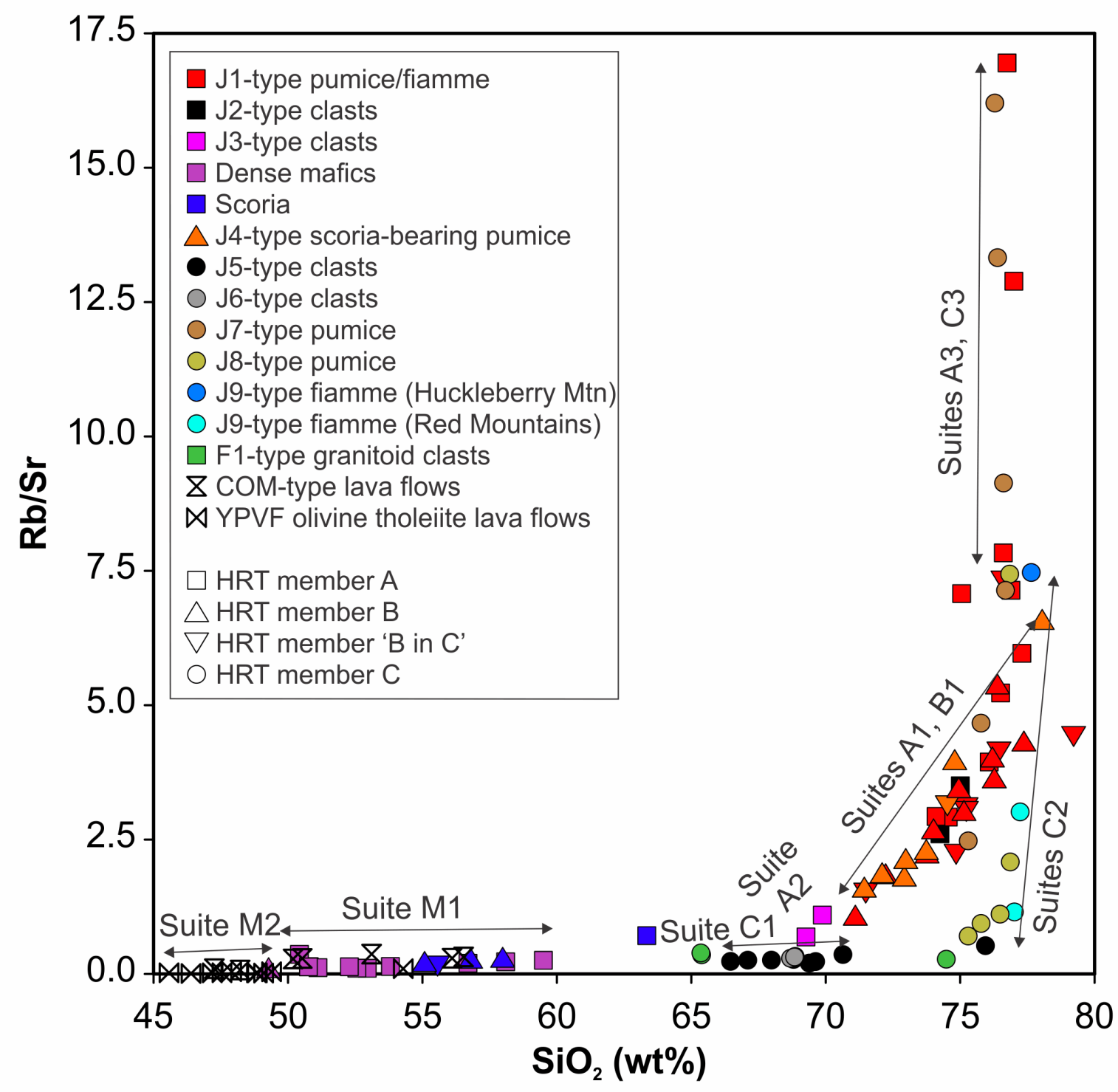

Figure S5.22: $\mathrm{SiO}_{2}$ vs $\mathrm{Rb} / \mathrm{Sr}$ for samples analysed in this study for the entire HRT and relevant regional eruptives (excluding HRT mafic samples YP188 and YP242). Of the suites that show a large compositional range, suites $\mathrm{A} 1$ and $\mathrm{C} 2$ exhibit curved trends with increasing $\mathrm{Rb} / \mathrm{Sr}$ with $\mathrm{SiO}_{2}$, indicative of fractional crystallisation. In contrast, J4-type scoria bearing-samples in suite B1 show a straight trend, typical of magma mixing. See Fig. 5.3 in Chapter 5 for symbol and suite details. 2 sd analytical precisions are smaller than symbol size. 


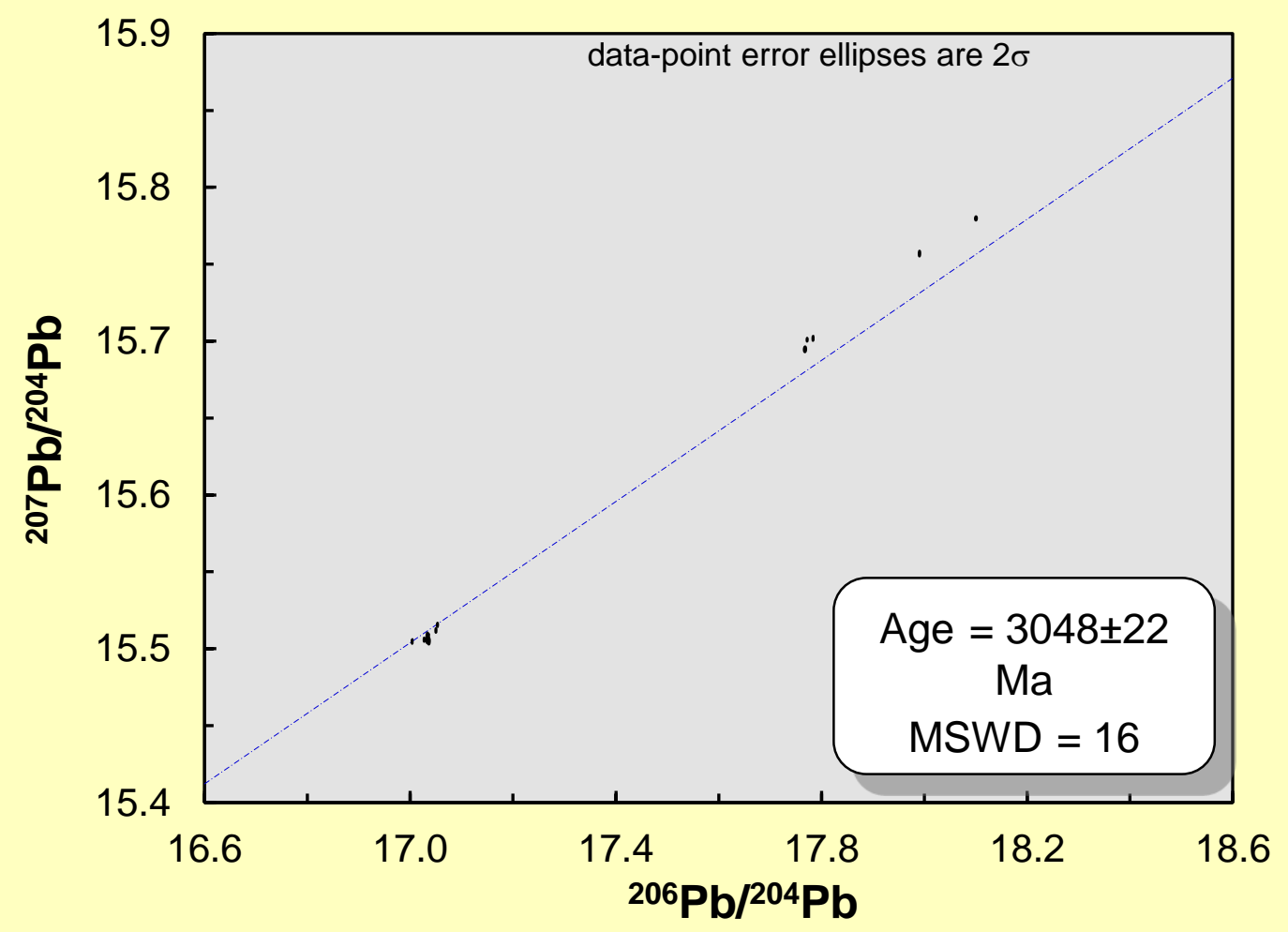

Figure S5.23: $\mathrm{Pb}-\mathrm{Pb}$ isochron generated by Isoplot (Ludwig 2008) for silicic pumice/fiamme from all members of the HRT yielding an apparent age of $3.05 \mathrm{Ga}$. Ellipses are 2 se. 


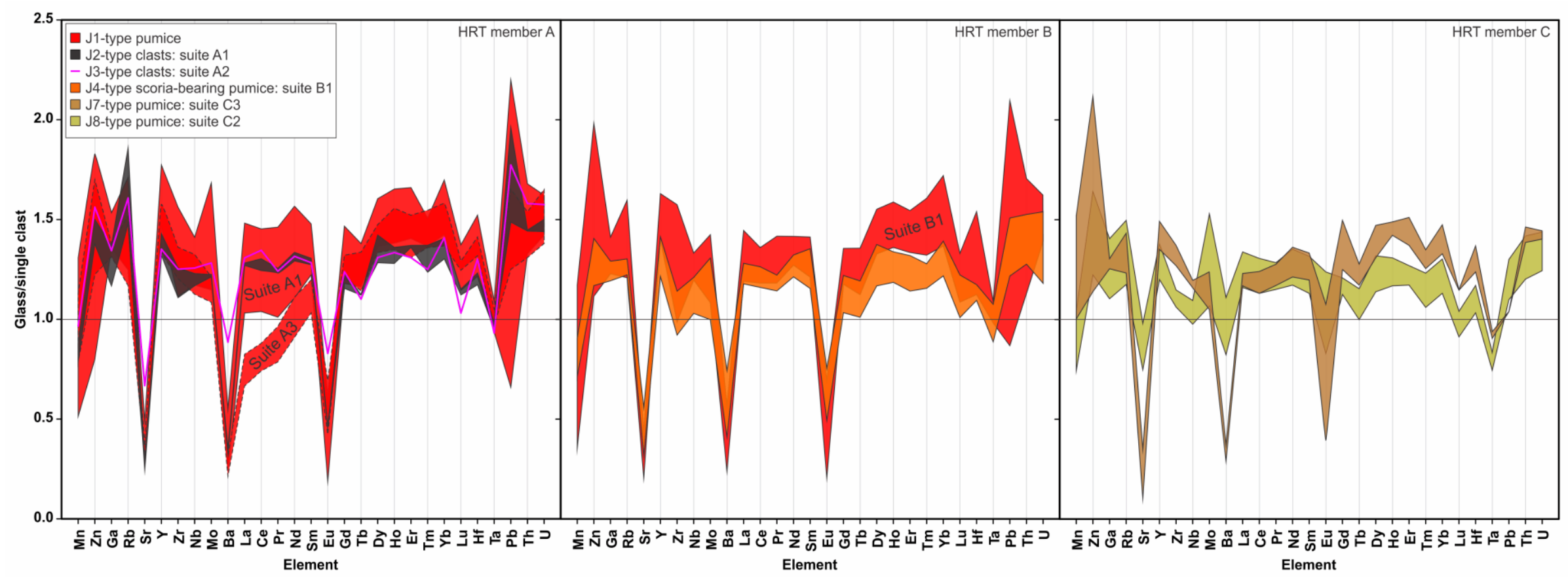

Figure S5.24: A multi-element diagram for glassy pumices from each member of the HRT showing the elemental ratio between the average groundmass glass concentration and the single clast composition. Glass is enriched (glass/single clast $>1$ ) is incompatible elements. Groundmass glass from suite A3 samples is depleted in LREE (glass/single clast $<1$ ) indicating minor chevkinite fractionation. In contrast, comparable compositional suite C3 pumices have LREE-enriched groundmass glass (glass/single clast >1) precluding significant chevkinite fractionation. See Fig. 5.3 in Chapter 5 for symbol and suite details. 


\section{Supplementary material and electronic appendices references}

Boehnke P, Watson EB, Trail D, Harrison TM, Schmitt AK (2013) Zircon saturation rerevisited. Chem Geol 351:324-334

Charlier BLA, Ginibre C, Morgan D, Nowell GM, Pearson DG, Davidson JP, Ottley CJ (2006) Methods for the microsampling and high-precision analysis of strontium and rubidium isotopes at single crystal scale for petrological and geochronological applications. Chem Geology 232:114-133

Christiansen RL, Yeats RS (1992) Post-Laramide geology of the US Cordilleran region, in Burchfiel BC, Lipman PW, Zoback ML (eds) The Cordilleran Orogen: conterminous US. Boulder, Colarado, Geological Society of America, The Geology of North America G3:261-406

Croux C, Filzmoser P, Oliveira M (2007) Algorithms for Projection-Pursuit robust principal component analysis. Chemometr Intell Lab Syst 87:218-225

Elkins LT, Grove TL (1990) Ternary feldspar experiments and thermodynamic models. Am Mineral 75:544-559

Ersoy Y, Helvaci C (2010) FC-AFC-FCA and mixing modeler: a Microsoft ${ }^{\circledR}$ Excel $^{\odot}$ spreadsheet program for modeling geochemical differentiation of magma by crystal fractionation, crustal assimilation and mixing Comput Geosci 36:383-390

Feeley TC (2003) Origin and tectonic implications of across-strike geochemical variations in the Eocene Absaroka volcanic province, United States. J Geology 111:329-346

Filzmoser P, Fritz H, Kalcher K (2014) pcaPP: Robust PCA by projection pursuit. R package version 1.9-60. https://CRAN.R-project.org/package=pcaPP

Fraley C, Raftery AE, Murphy TB, Scrucca L (2012) mclust Version 4 for R: normal mixture modeling for model-based clustering, classification, and density estimation. Technical Report No. 597, Department of Statistics, University of Washington, Seattle

Gerstenberger H, Haase G (1996) A highly effective emitter substance for mass spectrometric $\mathrm{Pb}$ isotope ratio determinations. Chem Geology 136:309-312

Hildreth W, Wilson CJN (2007) Compositional zoning of the Bishop Tuff. J Petrol 48:951-999 Hofmann AW (1988) Chemical differentiation of the Earth: the relationship between mantle continental crust and oceanic crust. Earth Planet Sci Lett 90:297-314 
Ingamells CO (1980) Microprobe column. Geostand Anal Res 4:139

Ingamells CO (1983) Microprobe column. Geostand News 7:243

Jackson DA (1993) Stopping rules in principal component analysis: A comparison of heuristical and statistical approaches. Ecology 74:2204-2214

Jarosewich E, Nelen JA, Norberg JA (1980) Reference samples for electron microprobe analysis. Geostand Newsl 4:43-47

Jochum KP, Weis U, Schwager B, Stoll B, Wilson SA, Haug GH, Andreae MO, Enzweiler J (2016) Reference values following ISO guidelines for frequently requested rock reference materials. Geostand Geoanal Res 40:333-350

Ludwig KR (2008) Isoplot/Ex version 3.7. A geochronological toolkit for Microsoft Excel. Berkely Geochronological Centre, Special Publication 4

McCurry M, Rodgers DW (2009) Mass transfer along the Yellowstone hotspot track I: petrologic constraints on the volume of mantle-derived magma. J Volcanol Geotherm Res 188:86-98

McDonough WF, Sun S-s (1995) The composition of the Earth. Chem Geology 120:223-253 Mirnejad H, Bell K (2006) Origin and source evolution of the Leucite Hills lamproites: evidence from Sr-Nd-Pb-O isotopic compositions J Petrol 47:2463-2489 Mueller UA, Grunsky EC (2016) Multivariate spatial analysis of lake sediment geochemical data: Melville Peninsula, Nunavut, Canada. Applied Geochemistry 75:247-262

Pin C, Gannoun A, Dupont A (2014) Rapid simultaneous separation of Sr, Pb and Nd by extraction chromatography prior to isotope ratios determination by TIMS and MCICP-MS. J Anal Atom Spectrom 29:1858-1870

R Development Core Team (2016) R: A language and environment for statistical computing R Foundation for Statistical Computing Vienna, Austria. URL https://wwwR-projectorg/

Rivera TA, Schmitz MD, Crowley JL, Storey M (2014) Rapid magma evolution constrained by zircon petrochronology and ${ }^{40} \mathrm{Ar} /{ }^{39} \mathrm{Ar}$ sanidine ages for the Huckleberry Ridge Tuff, Yellowstone, USA. Geology 42:643-646

Thirlwall MF (2000) Inter-laboratory and other errors in Pb isotope analyses investigated using a ${ }^{207} \mathrm{~Pb}-{ }^{204} \mathrm{~Pb}$ double spike. Chem Geol 163:299-322

Waters LE, Lange RA (2015) An updated calibration of the plagioclase-liquid hygrometerthermometer applicable to basalts through rhyolites. Am Mineral 100:2172-2184 
Watson EB, Harrison TM (1983) Zircon saturation revisited: temperature and composition effects in a variety of crustal magma types. Earth Planet Sci Lett 64:295-304

Wotzlaw J-F, Bindeman IN, Stern RA, D'Abzac F-X, Schaltegger U (2015) Rapid heterogeneous assembly of multiple magma reservoirs prior to Yellowstone supereruptions. Sci Rep 5:14026 